\title{
Diversity, composition, and biogeography of trees in tropical mountain forests of Sulawesi, Indonesia
}

\author{
DISSERTATION \\ zur Erlangung des mathematisch-naturwissenschaftlichen Doktorgrades \\ Doctor rerum naturalium \\ der Georg-August-Universität Göttingen \\ im Promotionsprogramm Biologie \\ der Georg August University School of Science (GAUSS)
}

vorgelegt von

Fabian Brambach

aus Halle (Saale)

Göttingen, 2019 


\section{Betreuungsausschuss}

Prof. Dr. Christoph Leuschner

Pflanzenökologie und Ökosystemforschung, Georg-August-Universität Göttingen

PD Dr. Heike Culmsee

Pflanzenökologie und Ökosystemforschung, Georg-August-Universität Göttingen

\section{Mitglieder der Prüfungskommission}

Prof. Dr. Christoph Leuschner (Referent)

Pflanzenökologie und Ökosystemforschung, Georg-August-Universität Göttingen

PD Dr. Heike Culmsee (Korreferentin)

Pflanzenökologie und Ökosystemforschung, Georg-August-Universität Göttingen

Prof. Dr. Erwin Bergmeier

Vegetationsanalyse und Phytodiversität, Georg-August-Universität Göttingen

Prof. Dr. Holger Kreft

Biodiversität, Makroökologie und Biogeographie, Georg-August-Universität Göttingen

Prof. Dr. Hermann Behling

Palynologie und Klimadynamik, Georg-August-Universität Göttingen

Prof. Dr. Dirk Hölscher

Waldbau und Waldökologie der Tropen, Georg-August-Universität Göttingen

\section{Tag der mündlichen Prüfung}

25. Juni 2019 
I should describe it rather as an intense interest in the mere variety of living things, the variety that catches the eye of the observer even among those which are very much alike, but which are soon found to differ in several distinct characters [...] we became travellers, collectors, and observers, in some of the richest and most interesting portions of the earth; and we thus had forced upon our attention all the strange phenomena of local and geographical distribution

Alfred Russel Wallace 


\section{Contents}

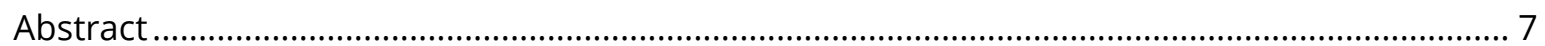

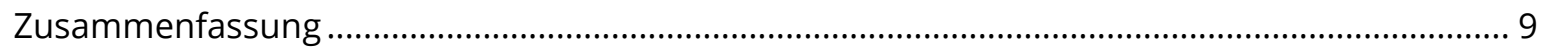

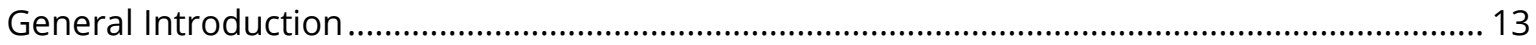

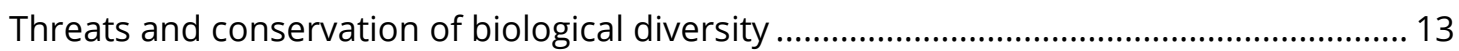

Tropical hinterland regions as frontiers of biodiversity research .......................................... 14

Sulawesi - an understudied tropical region ....................................................................... 15

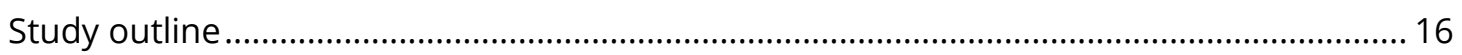

1 Magnolia sulawesiana described, and a key to the species of Magnolia

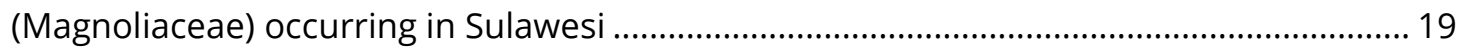

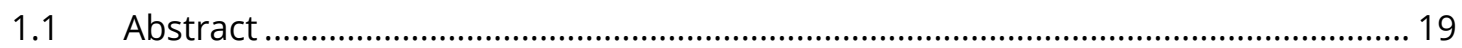

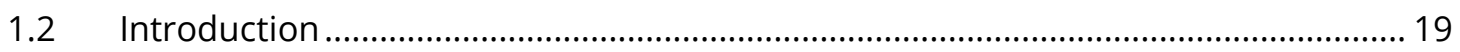

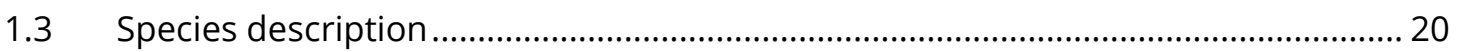

1.4 Keys to species of Magnolia subsection Elmerrillia (section Michelia) ...................... 24

1.5 Key to the species of Magnolia occurring in Sulawesi ................................................ 25

2 Elaeocarpus firdausii(Elaeocarpaceae), a new species from tropical mountain forests

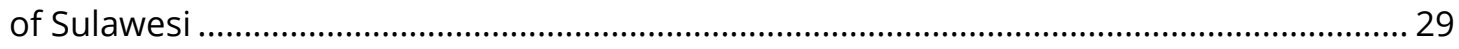

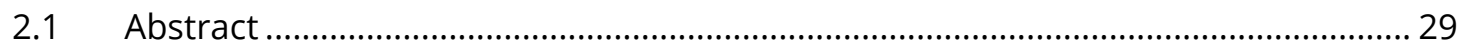

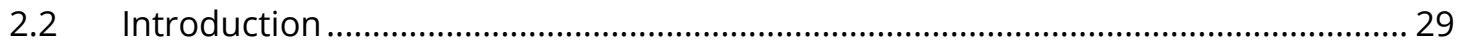

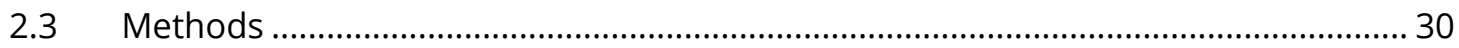

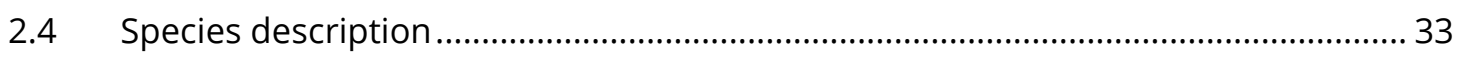

3 Five new species of Syzygium (Myrtaceae) from Sulawesi, Indonesia .................................... 41

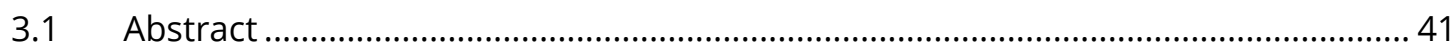

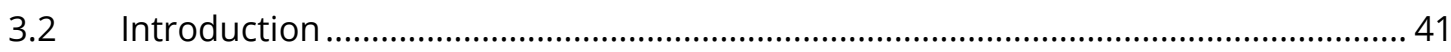

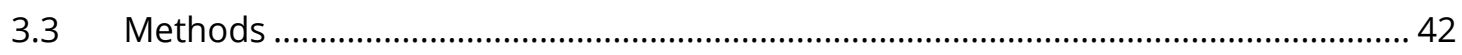

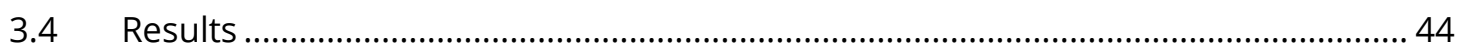

4 Diversity, endemism, and composition of tropical mountain forest communities in Sulawesi, Indonesia, in relation to elevation and soil properties........................................... 69

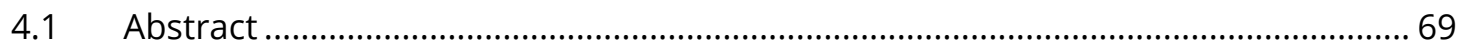

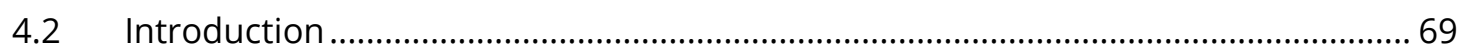

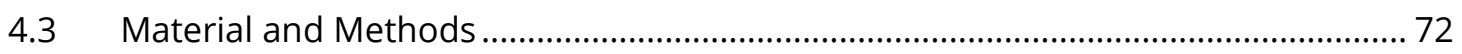

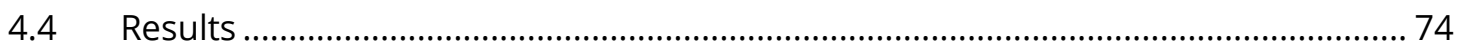

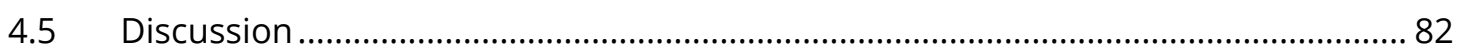

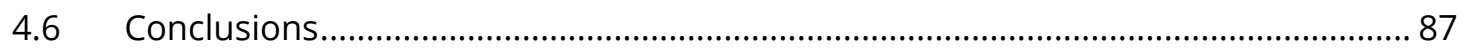

5 Predominant colonization of Malesian mountains by Australian tree lineages................... 89

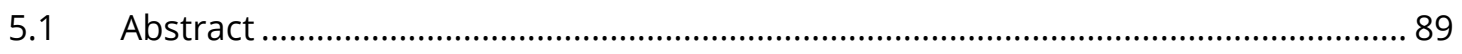

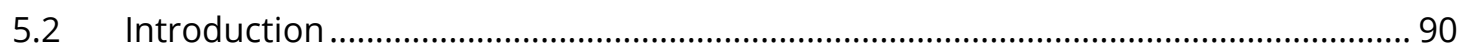

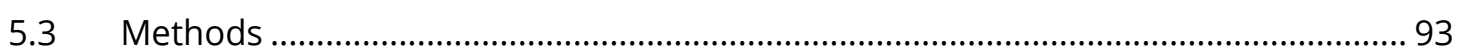

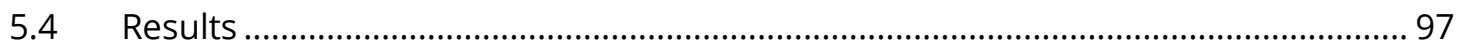

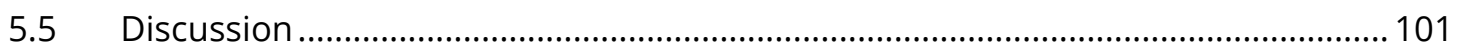




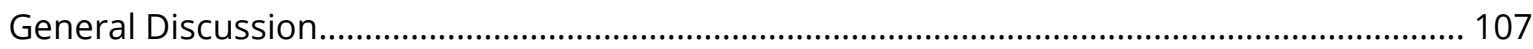

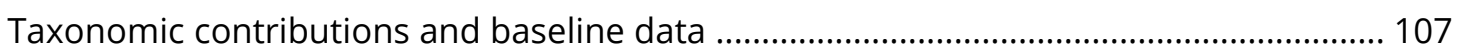

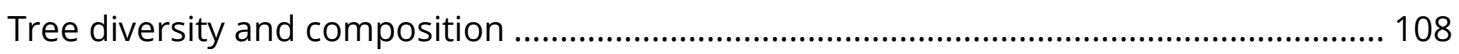

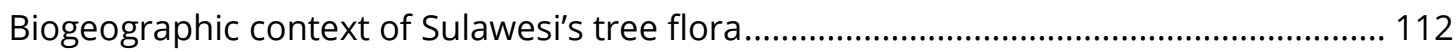

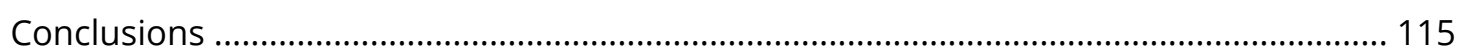

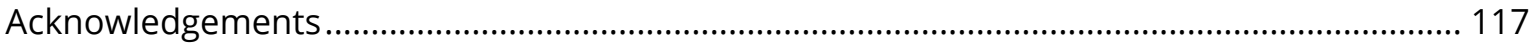

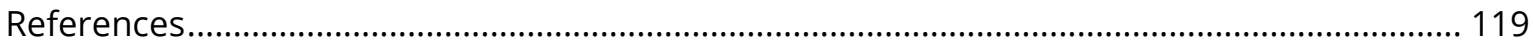

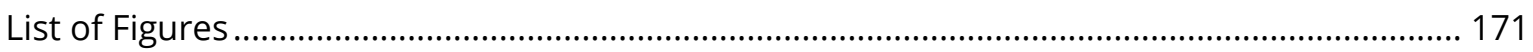

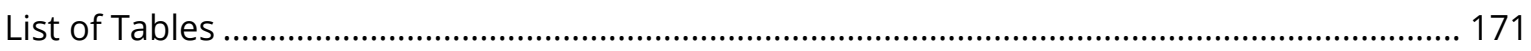

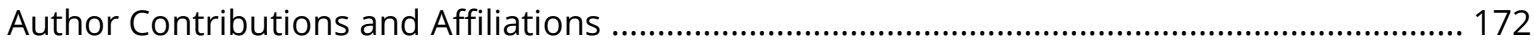

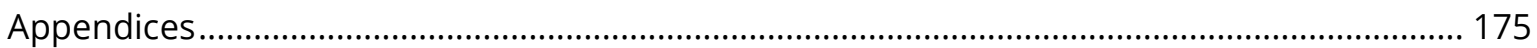

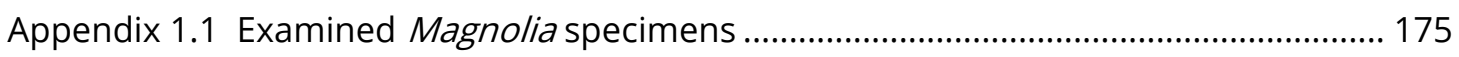

Appendix 4.1 Detailed description of methods .................................................................... 177

Appendix 4.2 Taxonomy and species identification ...................................................... 182

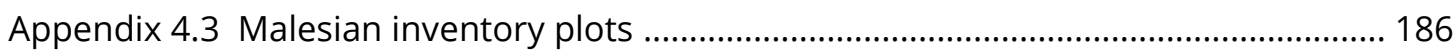

Appendix 4.4 Environmental parameters ....................................................................... 188

Appendix 4.5 List of all species and their abundances in inventory plots ........................ 189

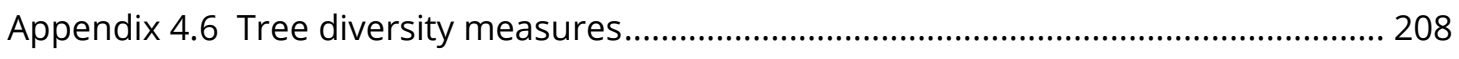

Appendix 4.7 Environmental factors influencing community composition ...................... 210

Appendix 4.8 Family Importance Values for 13 inventory plots ....................................... 212

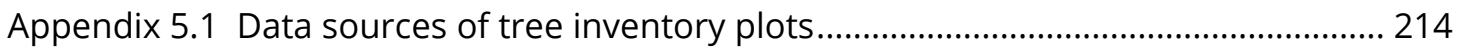

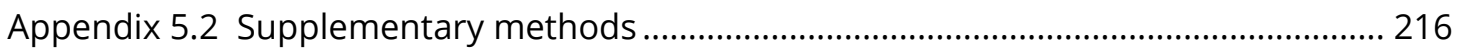

Appendix 5.3 Tree species with assigned geographic origin ............................................... 252 



\section{Abstract}

Human activities are increasingly threatening the integrity of Earth's ecosystems. For successful conservation measures, one necessary prerequisite is an adequate level of understanding about the ecosystems and their constituting organisms. Currently, however, there are considerable deficits in our knowledge about which and how many species exist (Linnean shortfall), where these species are distributed geographically (Wallacean shortfall) and ecologically (Hutchinsonian shortfall), how abundant they are (Prestonian shortfall), and their evolutionary histories (Darwinian shortfall), among others. Many methods are available to fill these existing knowledge gaps but one of the undoubtedly crucial approaches is work on the ground in tropical hinterland regions, where high levels of biodiversity, important knowledge gaps, and often imminent threats to natural habitats coincide. One example for such a hinterland region is the Indonesian island of Sulawesi in the centre of the Malesian archipelago, whose large portions of relatively undisturbed tropical mountain forests harbour a rich and biogeographically unique, yet poorly known flora. With his thesis, I aim to contribute to a better understanding of the ecology of Sulawesi's tropical mountain forest and its tree flora in relation to environmental factors and evolutionary history. To do so, I conducted extensive plot-based field work in the Lore Lindu National Park in Central Sulawesi, putting special emphasis on rigorous species identification. In the different chapters, I address the specific knowledge gaps or shortfalls outlined above.

In an attempt to deal with the Linnean shortfall, I describe seven new endemic tree species from Sulawesi (Chapters 1-3), including information of their distribution, ecology, and conservation status. The species descriptions furthermore provide the necessary foundation for analyses carried out in later chapters. Chapter 1 contains the description of Magnolia sulawesiana (Magnoliaceae), a new Magnolia species from upper montane forests of Sulawesi, as well as an identification key for all ten species of the genus native to the island. Another montane species, Elaeocarpus firdausii (Elaeocarpaceae) of the species-rich and predominantly Australasian genus Elaeocarpus, is described in Chapter 2. In the third chapter, I propose five new species of Syzygium (Myrtaceae), one of the largest genera of woody plants worldwide. Although the genus is widespread, diverse, and often dominant, the taxonomy of Syzygium in Sulawesi is largely unresolved and taxonomic work on the genus is urgently needed. The newly proposed species are Syzygium balgooyi, Syzygium contiguum, Syzygium devogelii, Syzygium eymae, and Syzygium galanthum.

In Chapter 4, I investigate patterns of tree species diversity, endemism, and composition along gradients of elevation and soil properties. I show that species diversity in Sulawesi at the plot level is similar to other Malesian regions and that it monotonically declines with elevation. Over $25 \%$ of the recorded tree species are new occurrence-records for (Central-) Sulawesi or undescribed species, highlighting how underexplored the region is. Levels of endemism found in this study clearly exceed estimates from previous studies, especially in high-elevation forests. The forest communities are mostly determined by elevation and can be grouped into three 
floristically distinct elevational belts whereas soil characteristics play only a minor role. I take a closer look at understorey trees species, a guild that is often neglected in standard forest or biodiversity inventories and highlight the important contribution of these understorey tree species to local species diversity.

Given Sulawesi's geographical position and geological history, the island's tree flora needs to be viewed in a wider spatial and temporal context that includes Asia and Australia. I therefore widen the scope in Chapter 5 to address the Darwinian shortfall, which is defined as the lack of knowledge about the evolutionary history of Malesian tree species. The central part of Malesia only formed in the last $23 \mathrm{My}$ and in that timespan, plants have colonized Malesia from Asia and Australia in a process termed the Malesian Floristic Interchange. I used my dataset from Central Sulawesi and published studies from other Malesia subregions and inferred the geographical origin of the tree lineages in the dataset based on phylogenetic and fossil information. I then related the relative abundance of Asian versus Australian trees per plot to environmental parameters to show that the colonization success of tree lineages in Malesia is strongly determined by habitat. The results showed a higher proportion of Australian tree species and individuals at higher elevations, over ultramafic bedrock, and east of Wallace's line. The trend is stronger for tree individuals than for species meaning that montane forests and those on poor soils in Malesia are mainly dominated by Australian tree-lineages. These patterns are a consequence of the climatic and biogeographical history of Malesia and indicate that environmental similarities between source and sink habitats have largely determined the colonization success during the Malesian floristic interchange.

In conclusion, I show that the rain forests of Sulawesi harbour a species-rich and unique tree flora, characterized by high proportions of small understorey trees and endemic species, many of which remain to be discovered and formally described. The biogeographical history changes from sub-montane communities dominated by Asian tree lineages to upper montane forests composed of mainly Australian lineages and many endemics. Although less-diverse than lowland rain forests, these upper montane communities therefore have high conservation values. At the same time, they remain among the least-studied ecosystems in Malesia. While with this thesis I hope to have bridged some knowledge gaps regarding Sulawesi's trees and forests, repeated biodiversity inventories including phylogenetic and trait-based approaches will be indispensable to improve our baseline knowledge about plant diversity patterns in Sulawesi. 


\section{Zusammenfassung}

Menschliche Aktivitäten bedrohen zunehmend die Unversehrtheit der Ökosysteme auf der Erde. Eine wichtige Voraussetzung für erfolgreiche Naturschutzmaßnahmen ist ein angemessenes Verständnis der einzelnen Ökosysteme und der sie ausmachenden Organismen. Bisher bestehen jedoch beträchtliche Wissenslücken, unter anderem darüber wie viele Arten existieren und wie diese heißen (Linnéisches Defizit), wie diese Arten geographisch (Wallaceisches Defizit) und ökologisch (Hutchinsonisches Defizit) verbreitet sind und wie häufig die Arten sind (Prestonisches Defizit) sowie über ihre evolutionäre Geschichte (Darwinisches Defizit). Zahlreiche Methoden stehen zur Verfügung um diese Wissenslücken zu füllen; ein zweifellos entscheidender Ansatz ist Feldforschung in tropischen Hinterlandregionen, wo reiche Biodiversität, große Wissenslücken, und oft auch unmittelbar bevorstehende Bedrohungen der natürlichen Habitate zusammenfallen. Die indonesische Insel Sulawesi im Zentrum des malesichen Archipels ist ein Besipiel für solche Hinterlandregionen. Ihre großen und relativ ungestörten tropischen Bergwaldgebiete beherbergen eine reiche und biogeographisch einzigartige, gleichzeitig aber schlecht erforschte Flora. Mit dieser Dissertation beabsichtige ich zu einem besseren Verständnis über die Ökologie von Sulawesi's tropischen Bergwäldern und ihrer Baumflora im Kontext von Umweltfaktoren und evolutionärer Geschichte beizutragen. Dafür habe ich umfangreiche plotbasierte Feldarbeiten im Lore Lindu Nationalpark in Zentralsulawesi durchgeführt und dabei besonderes Augenmerk auf die gründliche Bestimmung der gefundenen Baumarten gelegt. In den einzelnen Kapiteln befasse ich mich mit den oben genannten Wissenslücken oder Defiziten.

In den Kapiteln 1-3 versuche ich das Linnéische Defizit zu verringern indem ich sieben neue, für Sulawesi endemische Baumarten beschreibe und Information über deren Verbreitung, Ökologie und Gefährundsstatus beisteuere. Die Artbeschreibungen liefern darüber hinaus die notwendige Basis für die weiterführenden Analysen der späteren Kapitel. Kapitel 1 enthält die Beschreibugn von Magnolia sulawesiana (Magnoliaceae), eine neue Magnolienart aus den hochmontanen Bergwäldern Sulawesis, sowie einen Bestimmungsschlüssel für alle zehn Arten der Gattung, die auf der Insel vorkommen. Eine weitere montane Art, Elaeocarpus firdausii (Elaeocarpaceae) aus der artenreichen und hauptsächlich australasiatischen Gattung Elaeocarpus wird in Kapitel 2 beschrieben. Im dritten Kapitel, schlage ich fünf neue Arten der Gattung Syzygium (Myrtaceae) vor, einer der größten Gattungen holziger Pflanzen weltweit. Obwohl die Gattung weit verbreitet, artenreich und often ökologische dominant ist, bestehen beträchtliche Lücken in der Taxonomie von Syzygium auf Sulawesi; pflanzensystematische Arbeit ist daher dringend geboten. Die fünf neuen Arten sind Syzygium balgooyi, Syzygium contiguum, Syzygium devogelii, Syzygium eymae, and Syzygium galanthum.

In Kapitel 4 untersuche ich die Muster von Baumartendiversität, -endemismus und zusammensetzung entlang von ökologischen Gradienten (Meereshöhe und Bodeneigenschaften). Ich zeige, dass die Artenvielfalt in Sulawesi zumindest auf Plotebene der anderer Regionen in Malesien ähnlich ist und dass sie linear mit der Meereshöhe abnimmt. 
Über 25\% der gefundenen Baumarten sind Neufunde für (Zentral-) Sulawesi oder unbeschriebene Arten; ein klarer Hinweis auf die mangelnde botanische Kenntniss über die Region. Der in dieser Studie gefundene Anteil endemischer Arten ist deutlich höher als Schätzungen vorheriger Arbeiten, vor allem in den höher gelegenen Waldgesellschaften. Die Waldgeschellschaften werden vor allem durch die Meereshöhe bestimmt und können in drei floristisch-verschiedene Höhenzonen eingeteilt werden; Bodeneigenschaften spielen im Vergleich zu Meereshöhe eine untergeordnete Rolle. Ich lege besonderes Augenmerk auf kleine, im-Unterstand-wachsende Baumarten; eine Gruppe, die in den meisten forstlichen oder botanischen Inventuren vernachlässigt wird, und hebe den bedeutenden Beitrag dieser Gruppe zum lokalen Baumartenpool hervor.

Angesichts von Sulawesi's geographischer Lage und geologischer Geschichte muss die Baumflora der Insel in einem weiteren räumlichen und zeitlichen Kontext betrachtet werden, der Asien und Australien beinhaltet. Daher weite ich den Blickwinkel in Kapitel 5 und betrachte das Darwinische Defizit, das unzureichende Wissen über die Evolutionsgeschichte der Baumarten Malesiens. Der zentrale Teil Malesien entstand in den letzten 20-25 Millionen Jahren und erst seitdem haben Pflanzenarten Malesien von Asien und von Australien aus besiedelt. Dieser Vorgang wird malesischer floristischer Austausch (Malesian Floristic Interchange) genannt. Ich habe meine Daten aus Zentralsulawesi und solche von publizierten Studien aus anderen malesischen Gebieten verwendet und die geographische Herkunft der Abstammungslinien aller Bäume in dem vereinten Datensatz mithilfe von phylogenetischen Studien und Fossilfunden ermittelt. Anschließend habe ich die relative Abundanz der aus Asien bzw. Australien stammenden Bäume pro Plot mit Umweltfaktoren in Verbindung gesetzt um zu zeigen, dass der Besiedlungserfolg malesicher Bäume stark von den zur Verfügung stehenden Habitaten bestimmt wird. Die Ergebnisse zeigen einen höheren Anteil australischer Baumarten und -individuen mit steigender Meereshöhe, auf ultrabasichem Gestein, und östlich der Wallace-Linie. Der Zusammenhang ist für Individuen stärker ausgeprägt, so dass montane Wälder und solche auf ärmeren Böden in Malesien meist von aus-Australien-stammenden Baumarten dominiert werden. Diese Muster stehen im Zusammenhang mit der klimatischen und biogeographischen Geschichte Malesiens und zeigen, dass Ähnlichkeiten der Umweltfaktoren von Quellen- und Senkenhabitaten zu einem großen Teil den Besiedlungserfolg während des malesischen floristischen Austausches bestimmt haben.

Zusammengefasst zeige ich, dass die Regenwälder Sulawesis eine artenreiche und einzigartige Baumflora aufweisen, die durch einen hohen Anteil im-Waldesinneren-wachsender, kleinwüchsiger Arten und Endemiten geprägt ist, von denen viele noch nicht entdeckt und beschrieben worden. Submontane Waldgesellschaften warden von asiatischen Baumabstammungslinien dominiert während die hochmontane Wäldern vor allem aus Bäumen australischen Abstammungslinien und vieler endemischer Arten zusammengesetzt sind. Obwohl diese hochmontanen Waldgesellschaften weniger artenreich als Tieflandregenwälder sind, haben sie daher einen hohen Wert für den Naturschutz. Gleichzeitig 
gehören sie nach wie vor zu den am wenigsten erforschten Ökosystemen in Malesien. Ich hoffe, dass ich mit dieser Dissertation unsere Wissenslücken über Sulawesi's Bäume und Wäldern verkleinern konnte, weise aber darauf hin, das seine systematische Inventur der Pflanzenarten sowie ihrer funktionellen Merkmale und phylogenetischen Verwandschaftsverhältnisse unabdingbar ist um unser grundlegendes Verständnis über biologische Diversitätsmuster in Sulawesi zu verbessern. 



\section{General Introduction}

\section{Threats and conservation of biological diversity}

In the last century, human impact on the Earth has risen dramatically. There is increasing evidence that the effects of human activities are functioning at the same scale as geophysical forces and that these activities are driving the planet beyond planetary boundaries that have maintained stable conditions throughout the Holocene, i.e. the time in which human civilizations have developed (Steffen et al. 2011, Pachauri et al. 2015, Zalasiewicz et al. 2017). Now, in the Anthropocene, there is a real risk of passing planetary thresholds that would likely induce even more dramatic and potentially irreversible changes to Earth's biogeochemical cycles and ecosystems and severely affect human well-being (Rockström et al. 2009, Barnosky et al. 2012, Ripple et al. 2017, Steffen et al. 2018). Among the most important and threatened proposed planetary boundaries is biosphere integrity, the diversity of biological organisms and their functions, which ensures the continued functioning of ecosystems under changing conditions (Steffen et al. 2018). The present decline of biodiversity due to human activities occurs across taxa and biomes (May 2010, Maxwell et al. 2016, Ceballos et al. 2017, Lister and Garcia 2018, Sánchez-Bayo and Wyckhuys 2019). Analogous to other catastrophic periods of rapid biodiversity decline in Earth's history it has been termed the Earth's sixth mass extinction event (Barnosky et al. 2011, Pimm et al. 2014, de Vos et al. 2015, Ceballos et al. 2017). Major factors contributing to this decline are the large-scale destruction of natural habitats, extraction of resources, introduction of alien species, pollution, and climate change (Urban 2015, van Kleunen et al. 2015, Maxwell et al. 2016, Fadrique et al. 2018, Lister and Garcia 2018, Midolo et al. 2019, Sánchez-Bayo and Wyckhuys 2019).

To halt the biodiversity loss, the importance of conservation and sustainable use of existing species and ecosystems has long been acknowledged in multilateral treaties like the Convention on Biological Diversity or, more recently, the Aichi Biodiversity Targets. One of the difficulties to achieve those targets is the incomplete knowledge about biodiversity on Earth (Pimm et al. 2014). Even for a major relatively well-studied clade in the tree of life like the vascular plants, considerable knowledge gaps remain regarding the total number of plant species, their geographical distribution, population dynamics, and extinction threats (Brummitt et al. 2015, Meyer et al. 2015, Pimm and Joppa 2015, Pimm and Raven 2017). Large-scale efforts by the scientific community are underway to synthesize the scattered available information and make it publicly available in online databases (Kattge et al. 2011, Enquist et al. 2016, König et al. 2019, POWO 2019, The Plant List 2019, WCSP 2019, Weigelt et al. 2019, World Flora Online 2019). In addition, increasingly complex statistical models are able to deal with data gaps and still provide meaningful results about biodiversity patterns and species distributions (Kier et al. 2005, 2009, Raes et al. 2009, Jetz et al. 2012, Meyer et al. 2015, Keil and Chase 2019). Despite these efforts, real and problematic data gaps remain and these need to be tackled through interdisciplinary collaborations by taxonomists and plant ecologists (Gotelli 2004). For example, an estimated 
15\% of all plant species remains undescribed (Pimm and Raven 2017), calling for accelerated alpha-taxonomical work in herbaria (Bebber et al. 2010) and extensive field work, especially in underexplored regions (Wilson 2017).

\section{Tropical hinterland regions as frontiers of biodiversity research}

Plant diversity is not uniformly distributed across the globe. Most of it is concentrated in the tropics (Myers et al. 2000, Brummitt and Lughadha 2003, Kier et al. 2009, Pimm and Joppa 2015) and, in provides numerous essential contributions to the well-being of human populations from local to global levels (Díaz et al. 2018, Rasolofoson et al. 2018). At the same time, some of the biodiversity threats are also most severe in tropical regions due to rapid population growth and economic development (Sodhi et al. 2004, Maxwell et al. 2016, Nellemann et al. 2016, Ripple et al. 2017, Sánchez-Bayo and Wyckhuys 2019). Consequently, the majority of proposed global hotspots for the conservation of biodiversity are located in tropical regions (Myers et al. 2000). Unfortunately, biodiversity knowledge gaps are also most pronounced in the tropics. For example, most of the still undescribed plant species grow in tropical biodiversity hotspots (Joppa et al. 2011). More precisely, they are located in relatively inaccessible and therefore lessdisturbed tropical forests (Giam et al. 2012, Tyukavina et al. 2015). As these tropical hinterland regions are being fragmented and degraded (Potapov et al. 2017), a large portion of the species inhabiting them will disappear before being known to science (Pimm et al. 2014). Tropical mountain forests (TMF) are among these biodiverse, yet least known ecosystems in the tropics (Myers et al. 2000, Homeier et al. 2010, Takeuchi 2010, Hoorn et al. 2013, Merckx et al. 2015, Peters et al. 2016). Both climate and soil conditions change markedly along mountain slopes, making them preferred objects of research on the drivers of plant diversity (Ohsawa et al. 1985, Aiba and Kitayama 1999, Culmsee and Pitopang 2009, Homeier et al. 2010, Culmsee et al. 2011, Culmsee and Leuschner 2013, Merckx et al. 2015). The close proximity of different habitats and organismic communities along the environmental gradients result in high levels of beta diversity, so that TMF also constitute some of the botanically richest landscapes on earth and have exceptionally high conservation values (Aldrich et al. 1997, Brummitt and Lughadha 2003, Richter 2008, Merckx et al. 2015).

Knowledge gaps about earth's biodiversity have been classified in seven main shortfalls, related to taxonomy (Linnean shortfall), geographical distribution (Wallacean), abundance and population dynamics (Prestonian), evolutionary relationships (Darwinian), ecological functions (Raunkiæran), tolerances to abiotic conditions (Hutchinsonian), and biotic interactions (Eltonian; Hortal et al. 2015). All of these shortfalls apply to varying degrees to TMF. In fact, besides being hotspots of diversity, the latter are also hotspots of botanical knowledge gaps. Therefore, biodiversity field studies in underexplored TMF are needed to fill crucial knowledge gaps about plant diversity (Wilson 2017). 


\section{Sulawesi - an understudied tropical region}

Sulawesi, part of the island-nation Indonesia, is the world's $11^{\text {th }}$-largest island. It is located in the centre of the Indo-Australian Archipelago (Wallace 1863), usually referred to as Malesia in botanical research (Zollinger 1857, Raes and van Welzen 2009). The complex geological history of Sulawesi (Hall 2013, Nugraha and Hall 2017) has resulted in the islands particular shape, rugged topography (7\% of the island's area lie above $1500 \mathrm{~m}$; Culmsee and Leuschner 2013) and variety of different habitats. Since the initial studies of Alfred Russel Wallace (1869), Sulawesi has received attention by researchers because of its diverse fauna with a strong endemic element (e.g. Musser 1987, Michaux 2010, Stelbrink et al. 2012). The peculiar fauna reflects the island's position in the transition zone between Asian and Australian zoogeographical regions (Wallace 1876a, Kreft and Jetz 2013), called Wallacea. Wallacea, also including the Maluku Islands to the east and Lesser Sunda Islands (except Bali) to the south of Sulawesi, was included in the list of global biodiversity hotspots where conservation measures should be prioritized to minimize species loss (Myers et al. 2000). The hotspot is threatened by habitat loss due to mining activities and intensifying deforestation and Sulawesi is no exception (Hansen et al. 2013, Margono et al. 2014). However, Sulawesi still contains the largest tracts of relatively undisturbed forests in Wallacea, especially in mountain areas where access is more difficult (Cannon et al. 2007, Tyukavina et al. 2015).

While Sulawesi's fauna is reasonably well-known, botanical research has been lagging behind. Botanical exploration of the island started in the early $19^{\text {th }}$ century mostly in the Minahasa region at the tip of the northern peninsula (Koorders 1898, Koorders-Schumacher 1914) and the region around Makassar in the southwest (Reinwardt and de Vriese 1856, Teijsmann 1879). In the $20^{\text {th }}$ century, extensive collection trips all over Sulawesi were carried out by the Forest Research Institute ('Boschbouwproefstation') in Bogor (e.g. Bloembergen 1940, Eyma 1940) as well as others (Schlechter 1925, Kjellberg and Christensen 1933). Renewed interest in the 1970s lead to botanical expeditions in the central part of the island (Meijer 1983, Balgooy and Tantra 1986). Since then, several botanical expeditions by Herbarium Bogoriense, Kebun Raya Bogor, and international partner institutions have increased the number of collected specimens but only part of the material has been studied in detail (e.g. Powling et al. 2016). The first plot-based plant inventories were conducted by different botanists within the framework of the Indonesian-German interdisciplinary research project STORMA in the area of Lore Lindu National Park (LLNP) in Central Sulawesi (Pitopang et al. 2004, Kessler et al. 2005, Culmsee and Pitopang 2009, Cicuzza et al. 2010, Culmsee et al. 2011, Willinghöfer et al. 2011, Culmsee and Leuschner 2013), providing quantitative, spatially explicit data including species abundance and allowing more general conclusions about diversity patterns on the island. Nevertheless, Sulawesi remains one of the most underexplored tropical regions worldwide today resulting in insufficient knowledge about its flora (Vogel 1989, Cannon et al. 2007, Culmsee and Pitopang 2009, Culmsee et al. 2011) Particularly, there is still a lack of quantitative data including species' distributions, abundances and functions. Also, despite the large proportion of montane habitats 
in Sulawesi, there has never been a concerted effort to study the montane flora and vegetation as for example in Borneo (Beaman and Beaman 1990, Beaman et al. 1992, Kitayama 1992, 1992, Aiba and Kitayama 1999, Merckx et al. 2015) or New Guinea (Richards and Suryadi 2002, Richards 2007, Utteridge and Edwards 2009, Takeuchi 2010, Richards and Gamui 2011).

\section{Study outline}

With this thesis, I aim to contribute to a better ecological understanding of the TMF in Sulawesi by closing knowledge gaps about their tree species diversity, composition, endemism, and biogeographic context. The study builds on previous research on plant ecology and diversity in Central Sulawesi's Lore Lindu National Park (Keßler et al. 2002, Kessler et al. 2005, Culmsee 2008, Culmsee and Pitopang 2009, Culmsee et al. 2010a, Berg and Culmsee 2011, Culmsee et al. 2011) and is mainly based on field work using plot-based tree inventories. Other important methods used were the morphology-based identification of plant specimens with taxonomic literature and reference collections in herbaria and an extensive literature survey on the evolutionary history of Malesian tree species. Each of the five chapters of this thesis aims to bridge specific shortfalls of biodiversity knowledge, as defined by Hortal et al. (2015):

Chapters 1-3 tackle the Linnean shortfall, the insufficient taxonomic knowledge about Earth's species, by proposing and describing seven new tree species in three families from Sulawesi based on material collected during the plot-based tree inventories. Correct species identification provides the basis for analyses of different dimensions of biodiversity. While for some measures (e.g. taxonomic alpha diversity and species composition), naming of species is not a necessity, the usefulness of un- or incompletely named datasets is limited. Correctly assigned species names allow to connect the individuals of a study to the accumulated information of previous and future work, including data on distribution, ecology, traits, and biotic interactions while incorrect or missing identifications may distort found diversity patterns (Dexter et al. 2010, Baker et al. 2017). The description of new species may therefore be a necessary precursor to further research on ecology and biogeography, as presented in Chapters 4-5. In particular, in Chapter 1 I describe a species of Magnolia endemic to montane forest of Sulawesi and belonging to the relatively well-studied and economically important family Magnoliaceae. I also provide a field identification key to the ten Magnolia-species occurring on Sulawesi. Chapter 2 includes the description of the new species Elaeocarpus firdausii (Elaeocarpaceae), also endemic to high mountain forests. Chapter 3 deals with the extremely species-rich and often ecologically dominant genus Syzygium (>1200 species). Only about $15 \%$ of Syzygium species expected to occur in Sulawesi have been formally described (Syzygium Working Group et al. 2016). I propose five new species of Syzygium, all endemic to the island.

In Chapter 4, I deal with the Wallacean, Prestonian, and Hutchinsonian shortfalls, i.e. the inadequate knowledge about species' geographic distributions and abundances, and abiotic tolerances by investigating patterns of tree species diversity, composition, and endemism along 
gradients of elevation and soil properties in TMF of Central Sulawesi. I put special emphasis on understorey trees species, a guild that is often neglected in standard forest or biodiversity inventories. More than one quarter of the reported tree species present new occurrencerecords for (Central-) Sulawesi or undescribed species. I show that forest communities are mostly determined by elevation and can be grouped into three floristically distinct elevational belts whereas soil characteristics play only a minor role. Furthermore, I demonstrate that the diversity of tree communities in Sulawesi's forest harbour is comparable to that of other Malesian regions and that diversity declines with elevation while higher elevation forests contain higher proportions of endemic species. Lastly, I highlight the important contribution of understorey tree species to local species diversity.

In Chapter 5, I widen the scope beyond Sulawesi to address the Darwinian shortfall, the incomplete insight into the evolutionary history of species. Sulawesi belongs to Wallacea, the transition zone between the Asian flora to the west and the Australian flora in the southeast. The region was only formed in the last $23 \mathrm{My}$ as a result of the collision of the Asian and IndoAustralian tectonic plates and plants have colonized Wallacea since then from either of the two continents in a process termed the Malesian Floristic Interchange. As the rest of Malesia, Wallacea is considered to have a predominantly Asian flora, indicating asymmetric colonization, but this assumption is based on studies with coarse datasets that have mostly not taken into account species' abundances and differing environmental conditions. I combine my dataset from Central Sulawesi with other published studies along environmental gradients in Malesia and conduct an extensive literature review to infer the geographic origin of the lineages of all tree individuals in the combined dataset based on phylogenetic and fossil information. Afterwards, I relate the relative abundance of Asian versus Australian trees to environmental parameters and geographic location to show that proportionally more Australian tree species and individuals occur in Malesia (1) at higher elevations, (2) on sites over ultramafic parent material, and (3) closer to their source region Australia with a significant drop at Wallace's line. The trend is stronger for tree individuals than for species meaning that montane forests and those on poor soils in Malesia are mainly dominated by Australian tree-lineages. I discuss these pattern in the context of the climatic and biogeographic history of Malesia and highlight that environmental similarities between the source and sink habitats have largely determined the colonization success during the Malesian floristic exchange, a pattern that has also been suggested for the mixing of North and South American biotas during the Great American Biotic Interchange. 



\title{
1 Magnolia sulawesiana described, and a key to the species of Magnolia (Magnoliaceae) occurring in Sulawesi
}

\author{
Fabian Brambach, Hans P. Nooteboom, Heike Culmsee \\ Published in Blumea 58: 271-276 (13 Dec 2013), \\ https://doi.org/10.3767/000651913×676817
}

\subsection{Abstract}

Magnolia sulawesiana is described as new species and a modified key of Magnolia subsect. Elmerrillia is included. In addition, a new key of the eleven Magnolia species occurring in Sulawesi is provided based on vegetative characters for easy identification in the field.

\subsection{Introduction}

Currently, 36 species of Magnolia are known to occur in Malesia, 25 of which are endemic to the region (WCSP 2019). The family has been thoroughly studied in Malesia in comparison with many other tree families (Keng 1978a, Nooteboom 1985, 1987, 1988, Kim et al. 2001). Taxonomic and phylogenetic studies using both morphological (Keng 1978a, Figlar 2000, Li and Conran 2003) and molecular data (Shi et al. 2000, Azuma et al. 2001, Kim et al. 2001, Nie et al. 2008) have challenged traditional generic concepts and relationships and modified the positions and circumscriptions of many taxa within the subfamily Magnolioideae. As a result, former segregate genera like Manglietia, Michelia and Elmerrillia have been reduced to taxa at infrageneric level in broadened Magnolia (Figlar and Nooteboom 2004) reflecting phylogenetic relationships. The former genus Elmerrillia Dandy, which was initially reduced to a section of the genus Magnolia by Figlar (2000), is currently treated as a subsection in Magnolia section Michelia (L.) Baill., based largely on its morphological characters - flowers that usually arise terminally on brachyblasts as in Michelia sensu stricto -, but differs slightly by its sessile gynoecium and introrse anther dehiscence. However, recently both nuclear and cpDNA sequences have shown subsection Elmerrillia taxa to be embedded within the Michelia sensu stricto clade (Azuma et al. 2001, Kim et al. 2001, Nie et al. 2008) rather than forming a separate sub-clade. Thus, the subsectional status for this group is now in doubt.

Sulawesi is the largest island of the geologically complex insular region termed Wallacea. While levels of biodiversity and endemism are high (Myers et al. 2000), Sulawesi's flora remains poorly known and botanical collections are sparse compared to the other major Malesian islands (Frodin 2001). The results of recent intensive tree inventories for ecological studies in montane areas of Central Sulawesi have highlighted the deficiencies in the taxonomic and distribution data for Sulawesi (Culmsee and Pitopang 2009, Berg and Culmsee 2011, Culmsee et al. 2011). Due to their size, valuable timber and the potential use as ornamentals, Magnolias are likely to 
be well represented in botanical collections. However, only recently Magnolia utilis (Dandy) V.S.Kumar, a species otherwise known to occur in Continental Southeast Asia and Borneo, was recorded in Sulawesi's Southeast Peninsula for the first time (Wen \& Kartonegoro 10261, 10276; BO, US). In the course of our above-mentioned tree inventory studies in montane forests of Sulawesi, we now discovered a new Magnolia species of subsection Elmerrillia, which is - to our present knowledge - endemic to the island. Here, we describe the new species and place it in existing keys. In addition, we provide a new key of the eleven known Magnolia species of Sulawesi based on vegetative characters for easy identification in the field. For the construction of the keys, in addition to our own observations and specimens from Sulawesi, herbarium specimens were studied in the National Herbarium of the Netherlands $(L, U)$, Herbarium Bogoriense (BO) and Herbarium Celebense (CEB).

\subsection{Species description}

Magnolia sulawesiana Brambach, Noot. \& Culmsee, sp. nov.

\section{urn:Isid:ipni.org:names:77135717-1 Figures 1.1, 1.2}

Prope M. tsiampacca (L.) Figlar \& Noot. et M. platyphyllam (Merr.) Figlar \& Noot. subsectionis Elmerrillia (Dandy) Figlar \& Noot. speciebus ceteris in petioli sulco superiore tantum pilis villosis plus minusve persistentibus et folii pagina inferior in lineis angustis proxime iuxta costae utrinque laterem, gynoecio 8--12 carpellis differt. - Type: Brambach et al. 1334 (flowers; holo L 3 sheets; iso BO, CEB), Indonesia, Province of Central Sulawesi (Sulawesi Tengah), Poso Regency, Lore Tengah District, Lore Lindu National Park, Mount Dali (S 01.700 , E 120.150), 1950 m, 23 Jan 2012.

Evergreen trees of tropical montane rain forest, up to $35 \mathrm{~m}$ tall and $100 \mathrm{~cm}$ diameter. Barkgreybrown, fissured, lenticellate, of mealy texture, flaking off in large, irregular plates on older trees, inner bark yellow, turning orange upon contact with air.

Twigs monopodial, proleptic, glabrous, c. 2-3 mm in diameter in the distal internodes; slightly flattened, more so at the nodes, innovations glossy green (reddish brown when dry), soon becoming darker green (darker brown when dry), with dispersed, conspicuous white lenticels; bark on older twigs silver-grey with fine longitudinal cracks.

Stipules amplexicaul, free from the petioles, yellowish green (reddish brown when dry), glabrous, cigar-shaped, flattened and usually twisted, becoming up to $6 \mathrm{~cm}$ long, caducous, leaving white contrasting annular scars.

Leaves glabrous except for a line of brown (pale when dry), erect, villous hairs running through the adaxial petiole groove to about the middle of the abaxial side of the leaf blade on both sides of the midrib, conspicuous in young leaves, glabrescent but often some hairs persistent; spirally arranged, usually oblong, elliptic or (narrowly) obovate (rarely narrowly ovate), the midrib arching downwards, V-shaped in cross section (midrib usually distorted when dry), (5-)6-9(-11) by (2.5-)3-4.5(-6.5) cm, ratio (1.6-)1.9-2.2(-2.4), margin entire, revolute, not thickened; base 
rounded to obtuse (to acute), slightly asymmetric, apex rounded to obtuse (to acute), with a short triangular, usually contorted acumen (c. 1-3 mm); coriaceous shiny green above (pale greenish-brown to reddish-brown when dry), paler beneath, (darker, golden-brown to chestnut when dry); midrib flat and narrow above, round and strongly prominent beneath, yellowishgreen on both sides (concolorous with leaf blade above, chestnut and darker than leaf blade beneath when dry), running up to the very tip, there often forming a tiny, inconspicuous mucro; lateral veins (13-)15-18(-20) per side, not very conspicuous, diverging at moderate to wide angles, running straight, \pm parallel, rarely branching, intersecondary veins rarely present, irregularly looping near the margin, concolorous and slightly impressed above, the surface minutely bullate, contrasting darker green and not prominent beneath (concolorous and clearly prominent on both surfaces when dry); $3^{\text {rd }}$ order venation subscalariform to reticulate, not very distinct from the reticulate $4^{\text {th }}$ order venation, colour and prominence similar to lateral veins but slightly less prominent. Petioles (0.9-)1.1-1.7(-2.1) cm long, tapering towards the apex, concolorous with the young twigs, on the adaxial side a narrow groove with brown (pale when dry) hairs.

Flowers bisexual, glabrous, solitary, terminal on brachyblasts. Brachyblasts sylleptic in the axils of normal foliage leaves (or leaves vestigial); $40-55$ by $1-2 \mathrm{~mm}$ at anthesis, clavate, in colour and texture similar to young twigs; consisting of three internodes, the proximal two of which of \pm equal length, the distal one reduced, so the flower sessile; one spathaceous bract at each node, adnate to vestigial, inconspicuous petioles, outside concolorous with the brachyblast, withering yellowish-brown and splitting in two before being shed, inside golden brown when dry (not seen fresh). Tepals 12, free, spathulate, white (dry: chestnut), subequal, in two whorls: outer 3 similar, c. 20 by $7 \mathrm{~mm}$, inner 9 successively becoming narrower, innermost ones c. 18 by $3 \mathrm{~mm}$. Stamens c. 12 , filaments c. $1 \mathrm{~mm}$ long, anthers creamy-yellow (chestnut when dry), linear, bifacially flattened, arching inwards, c. $8 \mathrm{~mm}$ long, bisporangiate, introrse, opening by two longitudinal slits along their whole length, connective rounded to subacute, c. $0.5 \mathrm{~mm}$ long. Gynoecium sessile, covered by the stamens at anthesis, carpels $8-11$, spirally arranged on the receptacle, \pm ovoid, fresh green with white lenticels (dry: black), the styles minutely curved outwards.

Fruit irregular, 1-2.5 cm long, fruiting carpels concrescent in developing fruit, finally free, only 2-3 of them developing seeds, dehiscing along the dorsal suture, falcate midrib sometimes persistent. Seeds not seen.

\subsubsection{Additional specimens}

Brambach et al. 0109 (from same tree as type, flower buds and fruits; BO 2 sheets; CEB 2; GOET 2; K 2; L 2), Indonesia, Province of Central Sulawesi (Sulawesi Tengah), Poso Regency, Lore Tengah District, Lore Lindu National Park, Mount Dali (S 01.700, E 120.150), 1950 m, 27 - 31 Mar 2011.

Culmsee 2581 (flower buds and young fruits; CEB 2, GOET, L); Culmsee 2945(sterile; CEB, GOET); Culmsee 3153 (sterile; GOET); Culmsee 3154 (sterile; L), all from: Indonesia, Province of Central Sulawesi (Sulawesi Tengah), Sigi Regency, Nokilalaki District; Lore Lindu National Park, Mount

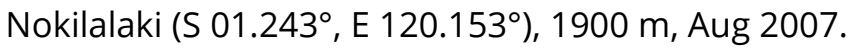




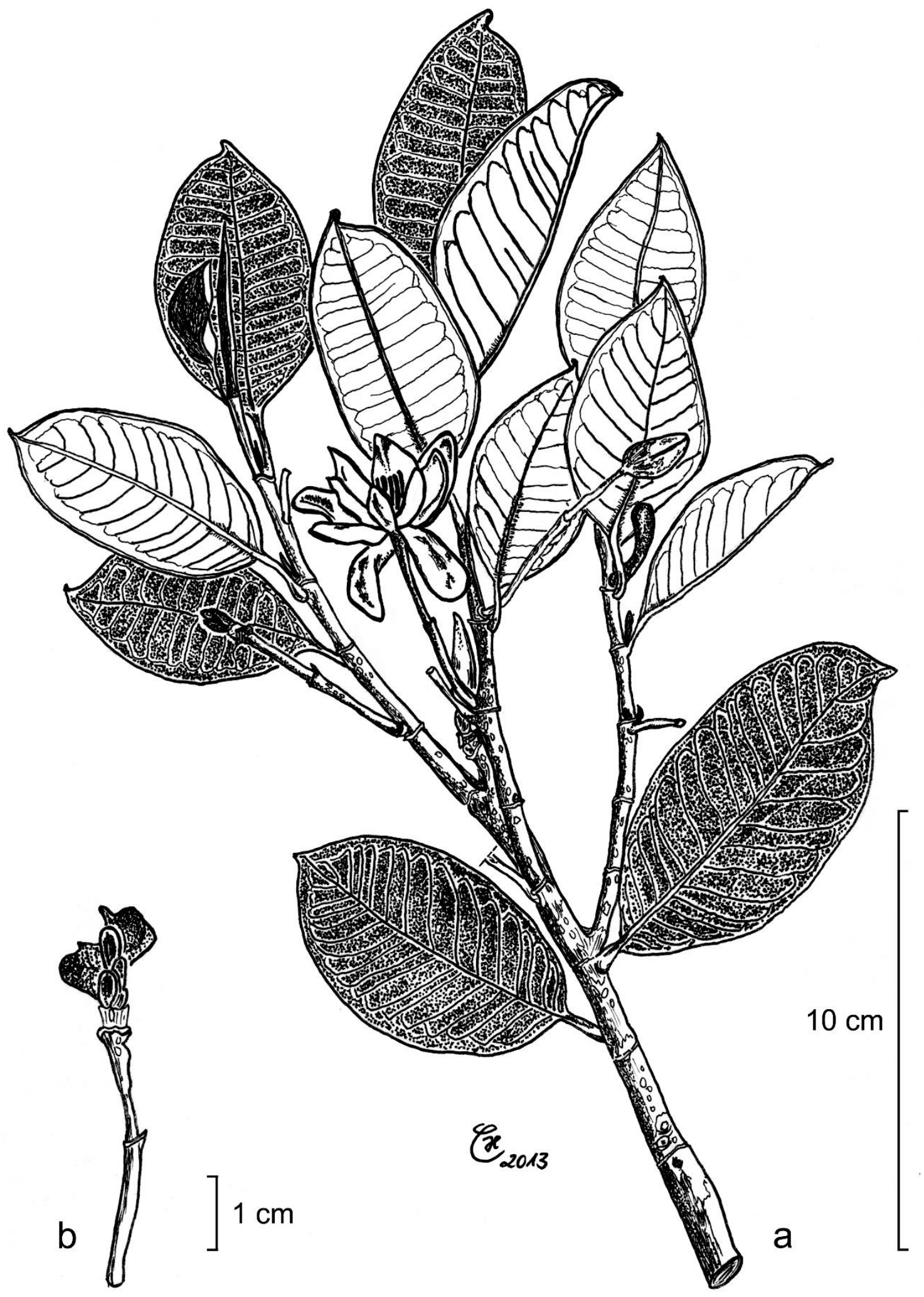

Figure 1.1 Magnolia sulawesiana Brambach, Noot. \& Culmsee. a. Leafy twig with flowers in four different development stages: flower buds (1st and 2nd to the right), open flower (middle) and young fruit after petals shed (left); b. ripe fruit (a. Brambach et al.1334, b. Brambach et al. 0109). 
Netherland Indies Forest Service (NIFS) bb 23355 (sterile; L, BO), Indonesia, Province of South Sulawesi (Sulawesi Selatan), Masamba Regency, Boschafdeeling Salotoradja, \pm 2200 m, 21 Oct 1937.

Sabir et al. B2 109 (sterile; CEB), Indonesia, Province of Central Sulawesi (Sulawesi Tengah), Sigi Regency, Nokilalaki District, Lore Lindu National Park, Mount Nokilalaki, 1600 m, Apr - May 2008.

\subsubsection{Distribution}

Endemic to Sulawesi according to the present state of knowledge; recorded from the central part of Sulawesi (Provinces of Central Sulawesi and South Sulawesi) between elevations of 1600-2200 m. In Lore Lindu National Park it has been found at two sites, Mount Nokilalaki (at 1600 and 1900 m a.s.I.) and Mount Dali (at 1950 m a.s.l.). The third collection site is located in the Regency of Masamba at 2200 m a.s.l. (exact location unknown). The known area of distribution spans a range of c. $100 \mathrm{~km}$ in $\mathrm{N}-\mathrm{S}$ direction (Figure 1.2).

Figure 1.2 Map of the known occurrences of Magnolia sulawesiana Brambach, Noot. \& Culmsee in the central part of Sulawesi. 1. Culmsee 2581, 2945, 3153, 3154; 2. Brambach et al. 0109, 1334; 3. NIFS bb 23355 (approximate location). Collection sites 1 and 2 are located within Lore Lindu National Park (bold black line). Grey areas indicate montane elevations $\geq 1500$ m a.s.l.

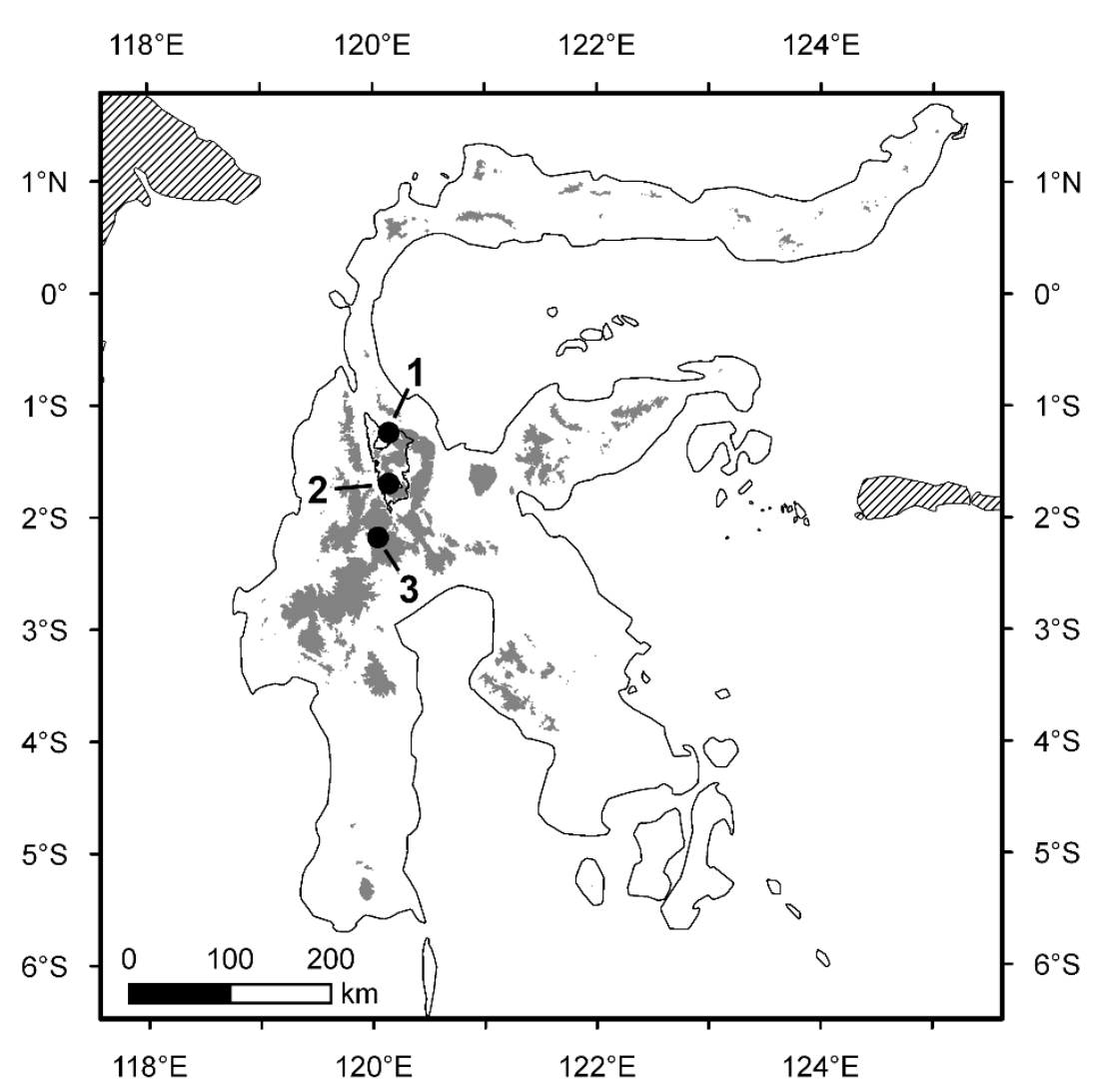

\subsubsection{Ecology}

Large, canopy forming trees of primary, ever-wet, montane forests growing on gently sloping ridges over granite-derived soils. At Mount Nokilalaki (1900 m a.s.l.), M. sulawesiana is codominant in a Fagaceae and Myrtaceae forest. At Mount Dali, it occurs together with M. carsonii Dandy ex Noot. var. carsonii (see below for discussion of infraspecific taxonomy). and M. liliifera (L.) Baill. var. liliifera in a forest dominated by Fagaceae, Myrtaceae and conifers. Flowering was observed in January, March and August; fruiting in March. 


\subsubsection{Conservation status}

The three collection localities of the species all lie within the mountain range of the central part of Sulawesi. Since the area is little explored botanically, and $M$. sulawesiana can be locally abundant (see Ecology), we expect the species to occur more widely within the mountain range. The land area of Sulawesi lying above $1500 \mathrm{~m}$ a.s.I. is ca. 13,600 km² (calculated in Quantum GIS Version 1.8.0 using SRTM data from Jarvis et al. 2008). Forest condition in these upland areas is so far mostly good to old-growth (Cannon et al. 2007), but pressure on the montane forests has increased during recent years where access was possible and is expected to intensify further. Based on these indications we propose a preliminary conservation assessment of Near Threatened (NT).

\subsubsection{Notes}

M. sulawesiana belongs to subsection Elmerrillia and is most similar to $M$. tsiampacca var. tsiampacca and M. platyphylla from that subsection. It differs from both species by its far fewer carpels (8-11 vs. > 20). It can also be distinguished from the sympatric $M$. tsiampacca var. tsiampacca by its usually smaller, oblong leaves which, as the rest of the tree, are completely glabrous except for the distinctive line of hairs that starts in the groove on the upper petiole side and continues on the lower surface of the leaf blade along a narrow line on each side of the midrib. The leaves of $M$. platyphylla are completely glabrous, much larger and do not have the close reticulation of $M$. sulawesiana. The species is also superficially similar to $M$. carsonii Dandy ex Noot. var. drymifolia Noot. of subsection Maingola because of its small, coriaceous, densely reticulate leaves. The former can be distinguished from the latter by the flowers with narrow white tepals on axillary brachyblasts (vs. terminal flowers with oblong tepals, the outer ones green, the inner ones yellow), its almost complete glabrousness, and the leaves with green lower surfaces (vs. glaucous) and more numerous lateral veins (13-20 vs. 6-12).

The sterile specimen NIFS bb 23355 (see Additional Specimens) was the only known record of M. carsonii var. drymifolia from Sulawesi. However, it is clearly a representative of $M$. sulawesiana. The distribution of the former taxon thus now remains restricted to Thailand, Sumatra, Borneo and possibly the Philippines (Palawan).

The name Magnolia vrieseana from inventory plot Nokilalaki (N1), published by Culmsee et al. (2011; Appendix species no. 33) is hereby corrected to Magnolia sulawesiana.

\subsection{Keys to species of Magnolia subsection Elmerrillia (section Michelia)}

The species can be accommodated in the key of Nooteboom (1988). Names were adapted according to Figlar \& Nooteboom (2004). 


\subsubsection{Key based on characters of flowers and fruits}

1. Tepals 12. Carpels concrescent during development, becoming free at dehiscence..........2

1. Tepals (12-)17. Carpels concrescent during development, remaining that way, forming a syncarp or becoming free at dehiscence.

2. Twigs and stipules hairy M. tsiampacca

2. Twigs and stipules glabrous......

3. Leaves large $(>20 \mathrm{~cm}$ long). Carpels $>20$. Plant completely glabrous. Philippines M. platyphylla

3. Leaves small ( $<12 \mathrm{~cm}$ long). Carpels $<12$. Plants with hairs in the adaxial petiole grooves and next to the midrib on the lower leaf surfaces. Sulawesi......

M. sulawesiana

4. Undersurface of leaves glaucous (sometimes a dense indumentum of adpressed hairs obscuring the glaucousness), hairy (in New Guinea sometimes glabrous: var. glaberrima). Fruiting carpels free, dorsally dehiscing. Borneo, Sulawesi, Maluku, New Guinea. M. tsiampacca

4. Undersurface of leaves not glaucous, glabrous or hairy. Fruiting carpels concrescent . .5

5. Twigs glabrous or yellowish villous, \pm soon glabrescent, rarely pubescent. Nerves in (1014-21 pairs. Sulawesi, Maluku. M. vrieseana

5. Twigs densely fulvously pubescent or tomentose, later glabrescent. Nerves in 20-24 pairs. Philippines (Mindanao).. M. pubescens

\subsubsection{Key based on fruit characters}

1. Carpels thickly concrescent, forming a syncarp, ripe carpels shedding their apical parts..2

1. Carpels thinly concrescent, becoming free when ripe and longitudinally dehiscing...........3

2. Young twigs and stipules glabrous or yellowish villous, \pm soon glabrescent, rarely pubescent. Nerves in (10-)14-21 pairs. Sulawesi, Maluku. M. vrieseana

2. Twigs densely fulvously pubescent or tomentose, later glabrescent. Nerves in 20-24 pairs. Philippines (Mindanao). M. pubescens

3. Carpels $<12$. Sulawesi. M. sulawesiana

3. Carpels $>20$. .4

4. Twigs and leaves glabrous. Brachyblast glabrous. Philippines. M. platyphylla

4. Twigs and leaves glabrous or hairy. Brachyblast hairy (except rarely in New Guinea: var. glaberrima). Borneo, Sulawesi, Maluku, New Guinea. .M. tsiampacca

\subsection{Key to the species of Magnolia occurring in Sulawesi}

The following key does not differentiate between the two varieties of $M$. carsonii found in Sulawesi, M. carsoniivar. carsonii and M. carsoniivar. phaulanta (Dandy ex Noot.) S.Kim \& Noot. As Nooteboom (1988) already pointed out, the two are very similar, possibly conspecific, and can only be differentiated by quantitative characters. The difference in leaf size (Kim et al. 2002) 
could not be confirmed for specimens from Sulawesi and Borneo present in the collections in $\mathrm{L}$ and BO, leaving slight differences in flower size (cluster of perianth and stamen scars 2-3 mm vs. c. $1 \mathrm{~mm}$ long) as the only separating character. We therefore prefer to treat all collections from Sulawesi as M. carsoniivar. carsonii.

M. angatensis is only known from one, sterile collection on Talaud Island (Lam 3121, L), midway between the north-eastern tip of Sulawesi and the Philippine island of Mindanao. Distinction between the many forms of $M$. liliifera and $M$. angatensis based on sterile material is nearly impossible. We do not treat the latter species separately in the key, because it would key out together with M. liliifera.

The key is mostly based on vegetative characters for easy identification in the field. Information on distribution (geography and elevation) is based on available material (from CEB, GOET, L and $U$ ). All species known to occur on the island of Sulawesi and surrounding minor islands (e.g. Kabaena, Buton, Sangihe and Talaud) as defined in Brummitt (2001) are included. It is intended to work for specimens from Sulawesi and may not cover intraspecific variation found on other Malesian islands. Leaf measurements are given for mature trees unless indicated otherwise; young trees and adventitious shoots may have larger leaves.

See Appendix 1.1 for complete binomials with author names.

1. Stipules adnate to the petiole. In older or fallen leaves visible by a scar on the upper side of the petiole.

1. Stipules free. Petioles without a scar on the upper side...................................................6

2. Young twigs, stipules and peduncles glabrous or with minute adpressed hairs (hardly visible with a handlens. Stipule scar about one third to half the length of the petiole. Leaves elliptic to obovate, 9-25 cm long, base cuneate. Flowers terminal on leafy twigs..

2. Young twigs, stipules and peduncles usually conspicuously hairy (rarely glabrous, but hairs sometimes lost). Stipule scar about half to the full length of the petiole. Flowers terminal on leafy twigs or on axillary short shoots.

3. Stipule scar clearly less than half the length of the petiole (rarely half the length). Twigs and stipules glabrous or with minute adpressed hairs (hardly visible with a handlens). Stipule scar $1 / 4$ to $1 / 3$ of the petiole length. Fruits ellipsoid or ovoid, only slightly longer than wide, Carpels opening first along the ventral suture. Widespread, 1000-1500 m M. sumatranavar. glauca

3. 3. Stipule scar 1/3 to half the petiole length. Fruits cylindrical, 2-3 times as long as broad. Carpels opening first along the dorsal suture. C- and SE-Sulawesi, rare, 800$1200 \mathrm{~m}$ M. utilis

4. Leaves c. 9-22 cm long, lanceolate, the widest part of the blade always beneath the middle. Petiole base not or only slightly thickened. Young twigs with numerous conspicuous white lenticels. Branching monopodial, internodes evenly spaced, flowers terminal on axillary short shoots. Cultivated, 0-1000 m.... M. champacavar. champaca 
4. Leaves c. 9-42 cm long, narrowly elliptic to elliptic (to oblanceolate), the widest part of the blade close to the middle or above it. Young twigs with few, dark, or no lenticels. Branching sympodial, internodes often conspicuously varying in length along twigs. Flowers terminal on normal leafy twigs. Occurring naturally, 0-2000 m. .5

5. Young twigs, stipules and underside of leaf blades woolly hairy, the hairs curled like pigs' tails, coming off in patches, usually \pm persistent on midrib and lateral veins of leaf undersurfaces. $\mathrm{N}$ peninsula of Sulawesi, once recorded at $150 \mathrm{~m}$. M. villosa

5. Young twigs, stipules and underside of leaf blades glabrous or silky hairy, the hairs, if present, adpressed and straight (sometimes mixed with minute curled hairs), persistent or not. Widespread and variable, 0-2000 m. ... liliifera var. liliifera

6. Young twigs and stipules hairy on the outside (or twigs glabrous, but then stipules at least hairy outside at the very tip. Most leaves $>15 \mathrm{~cm}$ long. Carpels $>40$ per flower. Widespread and common, 0-1300 m. .7

6. Young twigs and stipules completely glabrous on the outside. Most leaves $3-12 \mathrm{~cm}$ long. Carpels $<20$ per flower. Central part of Sulawesi, 750--2200 m. . .8

7. Leaves narrow oblong, narrow ovate or lanceolate (index 2.2-4.2). Leaf undersurface glaucous, densely adpressed hairy (sometimes hairs very small and hardly visible with a handlens). Young twigs and stipules usually with short ( $\leq 1 \mathrm{~mm}$ long), adpressed hairs. Mature fruits with free carpels, each carpel opening by a longitudinal slit. 0-1300 m M. tsiampacca var. tsiampacca

7. Leaves (ob-)ovate to elliptic (index 1.7-2.3, in juveniles often oblanceolate). Leaf undersurface not glaucous, glabrous, with scattered short hairs, or with long, curled hairs. Young twigs and stipules glabrous except for the stipule tip or with long (c. $2 \mathrm{~mm}$ ), yellow hairs. Mature fruits with carpels united, the outer parts breaking off in irregular masses. 0-1100 m. .M. vrieseana

8. Leaves completely glabrous, chartaceous to thin-coriaceous, lateral veins 8-15 per side. Young twigs with few or no lenticels. Flowers terminal on leafy twigs, appearing leafopposed due to sympodial vegetative growth. 1200-2000 m......... carsoniivar. carsonii

8. Leaves with a line of hairs in the adaxial petiole groove and on the leaf undersurface on both sides of the midrib (hairs lost in older leaves), otherwise glabrous, coriaceous, lateral veins 13-20 per side. Young twigs conspicuously lenticellate. Flowers on axillary brachyblasts (rarely terminal). 1600-2200 m.

M. sulawesiana 



\title{
2 Elaeocarpus firdausii (Elaeocarpaceae), a new species from tropical mountain forests of Sulawesi
}

\author{
Fabian Brambach, Mark J. E. Coode, Siria Biagioni, Heike Culmsee \\ Published in PhytoKeys 62:1-14 (25 Mar 2016), https://doi.org/10.3897/phytokeys.62.7548
}

\subsection{Abstract}

Based on ongoing ecological research in mountain forests of Sulawesi, a new species, Elaeocarpus firdausiiBrambach, Coode, Biagioni \& Culmsee, sp. nov. is described and illustrated from mossy forests at $>2000 \mathrm{~m}$ and information provided on the species' distribution, ecology and pollen morphology. Elaeocarpus firdausii is similar to E. Iuteolignum Coode but differs from the latter in having glabrous terminal buds, leaves with black gland dots, 4-merous, larger flowers, and more numerous stamens.

\subsection{Introduction}

Elaeocarpus is the largest genus of the Elaeocarpaceae, comprising approximately 350 species in the Old World tropics and subtropics (excluding mainland Africa), from Madagascar and Mauritius in the west, to Japan in the north, Australia and New Zealand in the south and Polynesia including Hawai'i in the east (Coode 2004, Baba 2013). The greatest number of species is found in the Malesian region and taxonomic work on these is currently under way.

Some progress has been made in understanding infrageneric groupings: Already in the early 20th century, Schlechter (1916) defined several sections for Papuasia, most of which still stand. Raymond Weibel worked on the whole genus, and made suggestions for sectional groupings, mostly in unpublished manuscripts at the Conservatoire in Geneva, copies of which have been put at the disposal of MC. In West Malesia (Sumatra, Peninsular Malaysia, Java, and Borneo), almost all species can be allotted to six major, morphologically defined groups. The "Polystachyus group" (Coode 1996c) is endemic to that area, while sect. Acronodia (Blume) Mast. (Coode 1996b) extends into the Lesser Sunda Islands. In Central and East Malesia, relationships are much less clear, although four of the groups from West Malesia are also represented here: sect. Elaeocarpus (Coode and Weibel 1994, Coode 1996a), sect. Ganitrus (Gaertn.) Brongn. \& Gris (Coode 2010), sect. Monocera Mast. (Coode 2001c, 2007, 2014), and sect. Coilopetalum Schltr. (Coode 1978, 2001a).

Coode (1995) published 10 new species for Sulawesi. In this paper he drew attention to the contrast between Sulawesi and neighbouring Borneo: In Sulawesi, fewer species of Elaeocarpus are present (c. 70 in Borneo vs. c. 35 in Sulawesi), but they belong to a greater number of groups 
( 6 in Borneo vs. $\geq 8$ in Sulawesi). In addition to the four widespread groups mentioned above, three more with a more Eastern distribution are found: sect. Dactylosphaera Schltr. (Coode 1978) , distributed from Sulawesi to New Guinea, sect. Fissipetalum Schltr. (Coode 1978, 2001b), from Sulawesi to Australia, and sect. Oreocarpus Schltr. (Coode 1978, 1984), which extends from the Philippines to Australia. Yet other species appear to be endemic, although their placement in any of the groups based on morphology has so far not been achieved. Coode (1995) suggested that some of these species from Sulawesi might be related to the Polystachyus group in Borneo.

Work on DNA samples at the Australian Tropical Herbarium (ATH), James Cook University in Cairns (e.g. Baba 2013), has established a molecular phylogenetic framework, within which, wellsupported species-level relationships are beginning to emerge (Darren Crayn, ATH, personal communication).

Many of the recently described Elaeocarpus species from Sulawesi grow in montane forests above c. 1500 m (Coode 1995, 1996a, 2001a). Lore Lindu National Park (LLNP) is the protected area covering the largest portion of montane environments on the island. It is located within the large, contiguous upland area that occupies most of the central part of Sulawesi roughly between the city of Palu and the central part of the Southern peninsula (Fig. 1). We will refer to this area as Central Sulawesi Mountains (CSM) throughout the manuscript.

Recent research on tree diversity and composition in LLNP (Culmsee and Pitopang 2009, Culmsee et al. 2011) has improved our knowledge of the flora and vegetation of Sulawesi's mountain forests. The continued research and new fieldwork in 2011-2012 have yielded material for 17 species of Elaeocarpus. One of them could not be assigned to any previously published species and is therefore proposed as new here.

\subsection{Methods}

\subsubsection{Morphological observations}

The relevant published identification keys for Elaeocarpus (Coode and Weibel 1994, Coode 1995, 1996a, 1996c, 2001a, 2001b, 2007) have been consulted, as well as herbarium collections of $\mathrm{B}, \mathrm{BO}, \mathrm{GOET}, \mathrm{K}$ and $\mathrm{L}$ (herbarium acronyms follow Thiers (continuously updated): http://sweetgum.nybg.org/science/ih/) and online databases of digitized herbarium specimens (JSTOR 2015, RBG Kew 2015, Wieringa 2015). We also recorded the character states of our specimens in a DELTA matrix (Dallwitz et al. 2010) for Elaeocarpus in Malesia developed and maintained by MC. Most specimens of Elaeocarpus from the Malesian region in $\mathrm{K}$ and $\mathrm{L}$ have been seen by $M C$ during his work on the genus over the last decades, so relatively few specimens remain unnamed. Our description is based solely on the material gathered during our (FB and HC) fieldwork in Central Sulawesi in 2011-2012, as no further matching specimens were found in herbaria. All our specimens were collected from permanently tagged trees in inventory plots. Duplicates of relevant specimens, including the type, were deposited in the 
Indonesian herbaria BO and CEB. All specimens seen by us for the description of the new species are marked with an exclamation mark in the present paper.

For the description, we boiled up flowers in dilute detergent for 5 minutes and dissected them afterwards. Dimensions were measured using a ruler with $0.5 \mathrm{~mm}$ accuracy. All colours and measures given refer to dried and pressed material unless stated otherwise. Photographs were taken in the field using a Canon EOS 500D camera with a Tamron AF 18-200mm f/6.2-38 lens.

Wood density (oven-dry mass per fresh volume) was determined from three wood cores extracted with increment borers and belonging to the specimens Brambach et al. 0721, 0973, and 2041, respectively. The samples' fresh volume was measured by Archimedes' principle and weight was noted from the same samples after oven-drying for $48 \mathrm{~h}$ at $105^{\circ} \mathrm{C}$.

\subsubsection{Pollen morphology}

One closed flower bud (from the specimen Brambach et al. 2041) was processed for the description of the pollen morphology. The pollen grains were treated following standard Erdtman's acetolysis method (Erdtman 1960, Faegri et al. 1989). The samples were mounted on permanent slides with Kaiser's glycerol gelatine and the slides were analysed under a Nikon Eclipse H550L photomicroscope at a magnification of 100×. Descriptions of the pollen grains were compiled following the terminology defined by Punt et al. (2007). The shape was described based on the measurements of the ratio between polar axis $(P)$ and equatorial diameter $(E)$ in equatorial view. Size values are based on a total of 10 grains measured, means are shown with minima and maxima in parentheses.

\subsubsection{Conservation Assessment}

With only three known collection localities (see "Distribution" below), a meaningful calculation of the extent of occurrence (EOO) and area of occupancy (AOO) (IUCN Standards and Petitions Subcommittee 2017) as basis for the conservation assessment is not feasible. We, therefore, attempted to estimate the extent and location of potential habitats for the proposed species based on its known habitat preferences. For that, we used the CGIAR digital elevation model (Jarvis et al. 2008) in QGIS (QGIS Development Team 2015) to quantify land areas in Sulawesi above the elevation threshold of $2000 \mathrm{~m}$. We defined this threshold based on our field observation of a marked and easily observable transition from mid-montane to upper montane (mossy) forest around this elevation. The proposed new species has so far only been recorded in upper montane forest at $>2000$ m elevation (see "Habitat" below). We then assessed the forest condition at elevations $\geq 2000 \mathrm{~m}$ using data from Cannon et al. (2007) and only used areas classified as "good" or "old-growth" by them for further analysis. As the proposed species has so far been recorded in the CSM and possibly the Eastern peninsula of Sulawesi, we also excluded all upper montane areas from the Northern and Southeastern peninsulas and the tip of the Southern peninsula (Figure 2.1). The resulting potential habitats were used for the calculation of the extent of occurrence $(E O O)$ and area of occupancy (AOO, grid cell size of $2 \times 2$ $\mathrm{km}$ ) following the recommendations of IUCN Standards and Petitions Subcommittee (2017). 


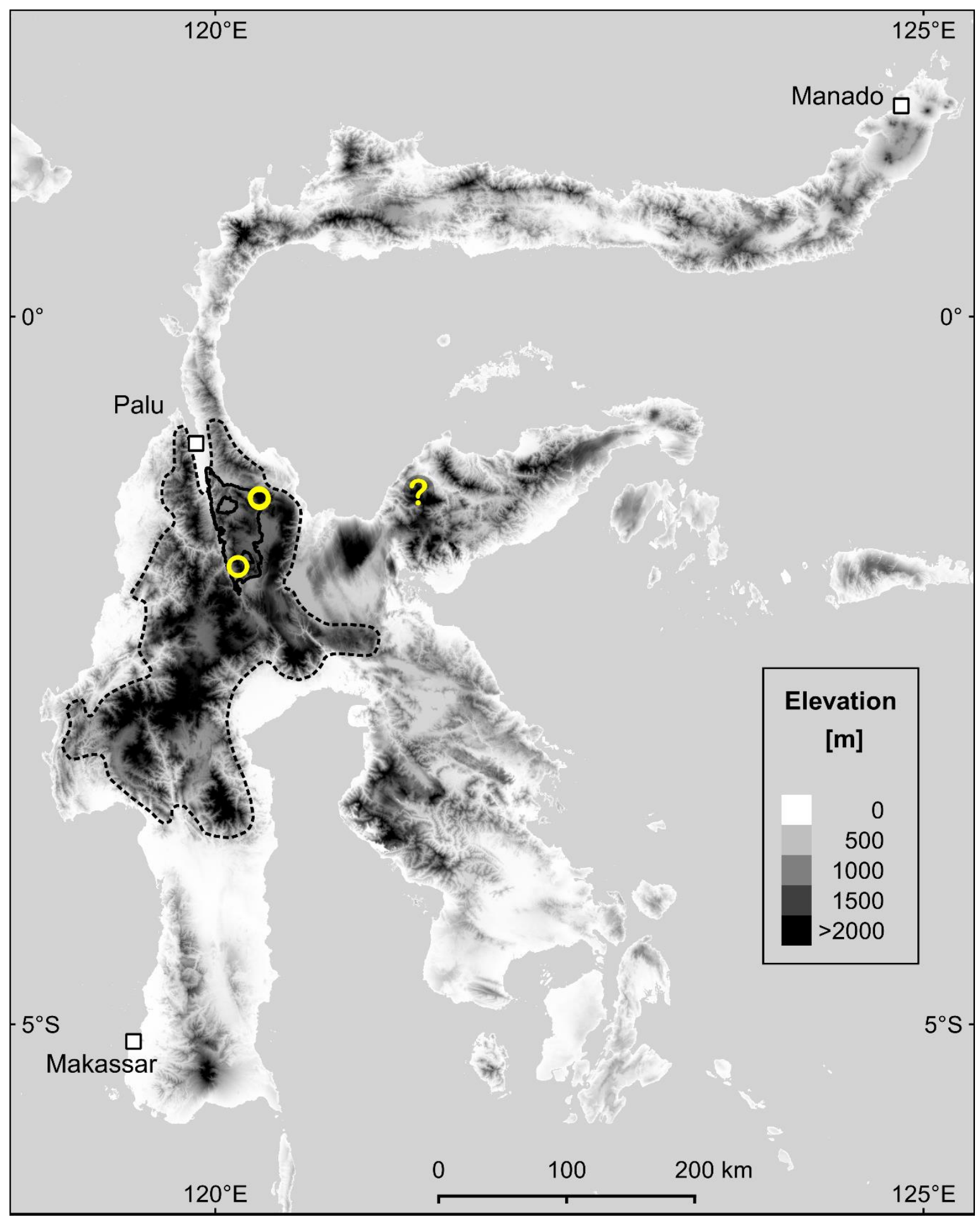

Figure 2.1 Map of known occurrences of Elaeocarpus firdausii in Sulawesi. Collecting localities are shown as yellow circles: Mt Rorekautimbu and Mt Malemo, both in Lore Lindu National Park (solid black line). The record on Mt Katopas on the Eastern peninsula (?) is based on a sighting without specimen. Most of the montane environments on the island are concentrated in the Central Sulawesi Mountains (CSM, dashed black line) stretching from near Palu into the Southern peninsula. Areas above $2000 \mathrm{~m}$ a.s.l. are shaded black. 


\subsection{Species description}

Elaeocarpus firdausii Brambach, Coode, Biagioni \& Culmsee, sp. nov.

urn:Isid:ipni.org:names:77153914-1 Figures 2.1, 2.2, 2.3, 2.4

\subsubsection{Diagnosis}

Similar to Elaeocarpus luteolignum Coode, but differing from that species in glabrous (vs minutely adpressed-hairy) terminal buds and young twigs, leaf blades with black gland dots (vs leaf blades without dots), 5-merous (vs 4-merous) flowers, larger flowers (e.g. sepals 5-8 $\times 1.5$ 2.5 vs $3-4 \times 1.5 \mathrm{~mm}$ ) and more numerous stamens (29-31 vs 20 ).

\subsubsection{Type}

INDONESIA. Central Sulawesi (Sulawesi Tengah): Lore Lindu National Park, Kabupaten Poso, Kecamatan Lore Utara, 7.7 km NNE of village Sedoa, Mt Rorekautimbu, tree-inventory plot "Bulu Torenali", 1¹7.2'S, 120¹8.7'E, 2350 m, 21-24 Apr 2012: Brambach F, Mangopo H, Firdaus, Faber M, Tiranda R 1953 (flowers; holotype: K, 2 sheets, [K000720760]!, [K000720898]!; isotypes: BO (BO 1926842)!, CEB, L [L.2055441]!).

\subsubsection{Description}

Trees 8-25 m tall, dbh $\leq 40 \mathrm{~cm}$, without buttresses or stilt roots, flowering when full-grown. Outer bark reddish brown, verrucose; inner bark pinkish with white streaks, granular, innermost layer yellow, easily detachable from wood, wood cream to white.

Twigs glabrous, strongly angulate at first, later terete, twig bark longitudinally cracking, forming a net-like pattern, with large conspicuous leaf scars and many prominent lenticels, gummyresinous where cut, $2.5-4.0 \mathrm{~mm}$ thick towards the tip, with gummy-resinous, glabrous terminal buds. Stipules caducous, linear-subulate to narrow-triangular, glabrous, often gummy, 1.5-5.0 mm long, tapering, entire.

Leaves spirally arranged, loosely to \pm tightly grouped towards twig tips in older trees, in juveniles often scattered, appearing in flushes, leaves of one flush \pm equal in size. Fresh leaves brownishred when young, later dark green with contrasting paler midrib above, much lighter green and with contrasting darker green venation and the sometimes red midrib beneath, dying red. Petioles 2-14 mm long, 1-3 mm thick, glabrous or almost so, sometimes verrucose when mature, often longitudinally finely striate, usually flat in apical third above, sometimes rounded or slightly channelled above, distinct from or merging into decurrent leaf base (variable within a specimen), pulvinous or not on both ends, without pegs at apex, sometimes with elongate glands at the junction of petiole and lamina-margin, geniculate. Blades chartaceous to coriaceous, mostly oblong-obovate, some oblong-elliptic or obovate, 2.1-4.0 times as long as wide, (5-) 6-13 $(-15.5) \times 1.5-5.0(-6.5) \mathrm{cm}$, acute to obtuse $\left(80-110^{\circ}\right)$ to rounded at apex, the very tip notched and with a (sometimes fused) pair of black glands, cuneate at base or tapering towards a broadly cuneate base (the larger leaves more narrowly cuneate), occasionally rounded, surface sometimes bullate, dull and glabrous above, glabrous or sometimes with 
some short adpressed hairs on the midrib beneath when young and then soon glabrescent, glabrous and not verrucose beneath when mature, with minute black gland dots on both sides. Midrib darker than lamina, prominent but widened and flattened towards base above, strongly prominent beneath, with 8-16 pairs of main lateral veins, diverging at $60-80^{\circ}$ from midrib, straight for most of their length or curved, breaking up 3/4 to 7/8 inside margin, looping forward and mostly joining up; usually with intermediate veins in between, \pm prominent and of same colour as or paler than lamina above and below, higher-order veins reticulate, obscure or \pm clear and raised above and below, of same colour as lamina, areoles squarish, $<2 \mathrm{~mm}$ across, domatia absent. Margins \pm entire to weakly glandular-serrate, sometimes less serrated in lower half, the teeth 2-11 $\mathrm{mm}$ apart, glands present regardless of serration, $0.5 \mathrm{~mm}$ long, spindle- or claw-shaped, sometimes elongate along margin, black.

Inflorescences in the axils of current leaves, solitary, racemose, \pm of same length as subtending leaf, 3-8 cm long, axis angular, 1.2-1.5 mm thick at about halfway, with sparse, short, straight hairs between adpressed and spreading, 5-9-flowered.

Flowers bisexual, 5-merous (once 6-petalled), spiral or almost whorled on inflorescence, bracts early caducous, not seen, pedicels 6-18 mm long and 0.5-1 mm thick in flower, bent downwards and thickened at apex, buds ovoid, acute at apex. Sepals 5-8 $\times 1.5-2.5 \mathrm{~mm}$, cream-coloured when fresh, not verrucose and \pm pale adpressed-sericeous outside, densely white-velutinous next to the margins inside, otherwise short-sericeous inside but glabrous in the basalmost 1.5 $\mathrm{mm}$, keeled inside for whole length. Petals thick and opaque, ivory-coloured on account of the hairs when fresh, oblong, parallel-sided almost to base, rounded to a narrow ( $1 \mathrm{~mm}$ wide) base, 6.5-7.5 mm long, 2.0-2.5 mm wide at widest point of limb, rounded at apex and divided into 912 narrow-triangular apical divisions $0.3-1.0 \mathrm{~mm}$ long, divisions unequal in length and grouped into lobes and acute at tip, not verrucose in dried material, densely white-sericeous outside, margins velvety or densely short-hairy throughout, densely short-hairy inside except for glabrous patch near base, with a low, narrow keel inside running for most of limb length, \pm flat at midpoint and flat at base, without any infolding of margins. Disk golden when fresh, \pm annular, 10-toothed, 0.5-0.8 mm high, densely covered with short, straight, golden hairs. Stamens 29-31, inserted in a \pm single ring between disk and ovary; filaments $0.6-1.8 \mathrm{~mm}$ long, straight to somewhat incurved tapering from base to apex, glabrous or with a few minute hairs; anthers 1.6-2.5 mm long, khaki when fresh, minutely hairy, with outer tooth clearly much longer than inner and with a beak 0.2-0.5 mm long, beak glabrous or with a few minute hairs without setae at tip. Ovary placed above the disk, shape clearly narrowed at base, $2.0-2.5 \mathrm{~mm}$ long, densely short- to medium-hairy, 2-3-locular; ovules 8-12 per locule; style 2.5-3.5 mm long, stout, tapering to a point, glabrous except for the very base.

Fruits unknown. 

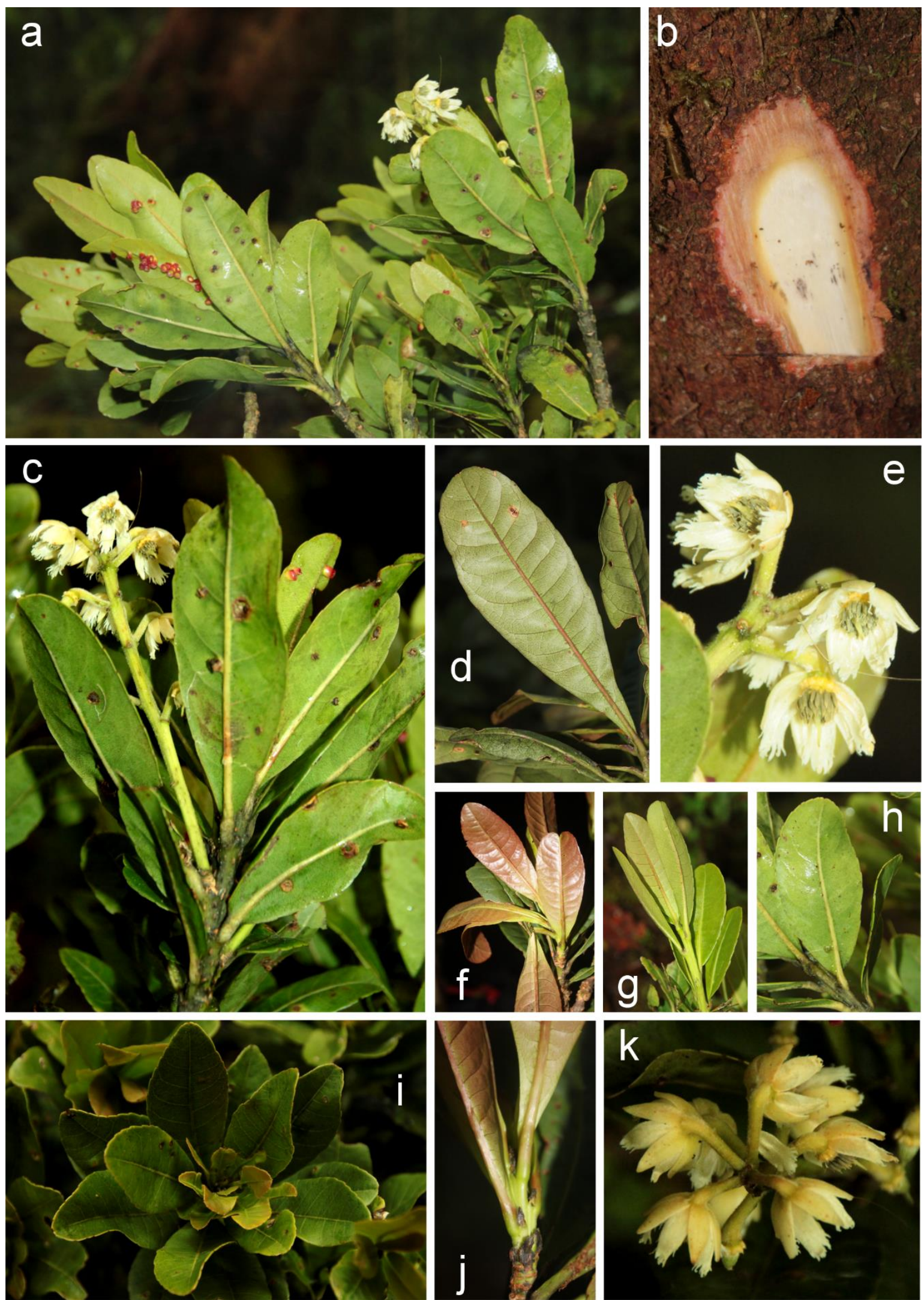

Figure 2.2 Elaeocarpus firdausii. a branch with leaves and flowers (note red leaf-galls); b bark slash; c branch apex with inflorescence; $d$ underside of mature leaf; e flowers with golden disc and grey anthers; $f$ reddish-brown young leaves; $g$ green young leaves; $h$ underside of mature leaf; $i$ clustered arrangement of leaves; j young twig with stipules; $\mathbf{k}$ flowers on apically bent pedicels. a, c, e, g-i and k from the type collection (Brambach et al. 1953); b, d, f and j from Brambach et al. 2041. 

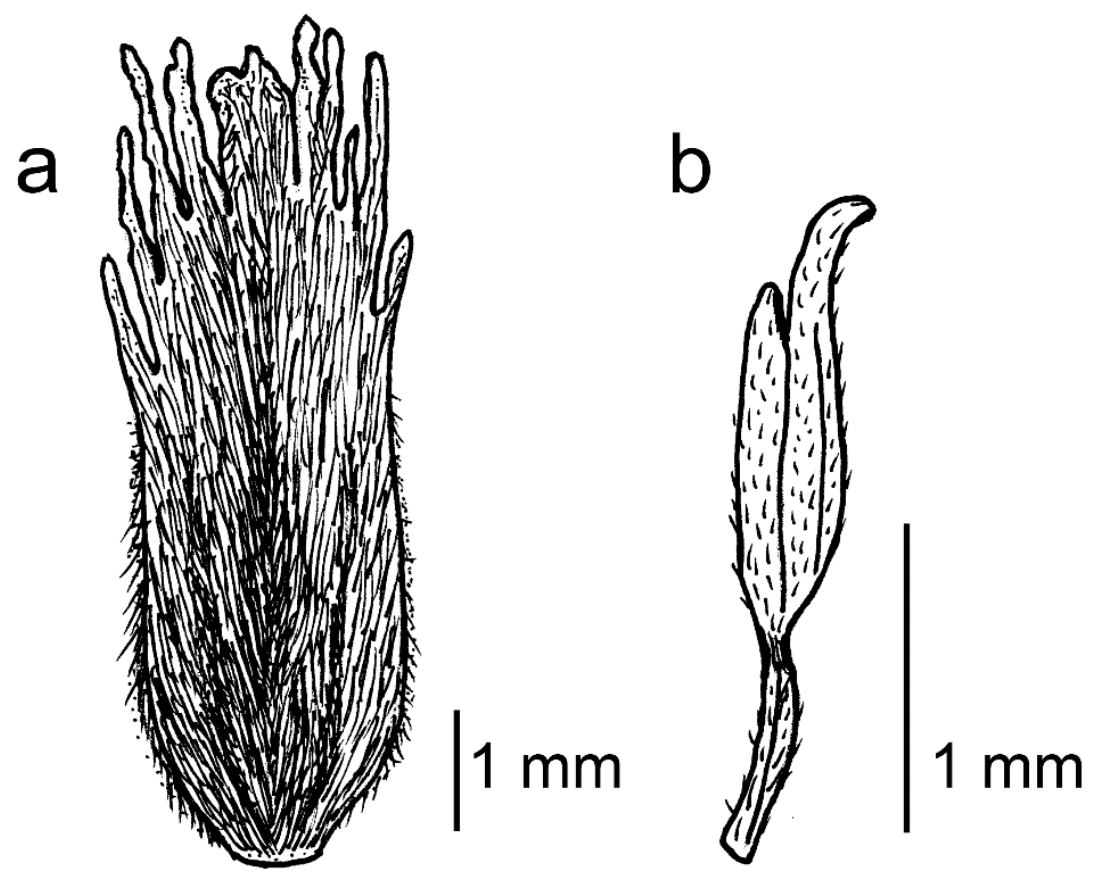

Figure 2.3 Flower details of Elaeocarpus firdausii. a petal with hairy outer surface and apical divisions; b stamen with clearly longer outer anther-tooth to the right. Drawing by Heike Culmsee from Brambach et al. 1953 (isotype, L!).

\subsubsection{Phenology}

Flowering was observed in April. No fruiting was observed.

\subsubsection{Pollen morphology and dimorphism}

The pollen of $E$. firdausii is dimorphic as two distinct morphological pollen grains were observed in the sample. The most common one is a 3-aperturate pollen grain, typical of the family Elaeocarpaceae (Coode 2004). The second, less common (4\%), type presents a 2-aperturate morphology and it is clearly distinguishable from the first (Figure 2.4). The two pollen types are described as follows:

3-colporate type (Figure 2.4a-b):

Prolate spheroidal to spheroidal pollen grains; outline in polar view (amb) rounded semi angular; psillate; P/E: 1.0 (0.9-1.1); polar axis (P): 12.2 (11.2-13.3) $\mu \mathrm{m}$; equatorial axis (E): 11.9 (10.4-13.1) $\mu \mathrm{m}$; apocolpium index 3-4 $\mu \mathrm{m}$. Colpi 7.1-11.2 × 1-2 $\mu \mathrm{m}$ long with indistinct ends. Endoaperture lalongate, c. $1 \mu \mathrm{m}$ in diameter. Exine c. $1 \mu \mathrm{m}$ thick, sexine as thick as nexine.

2-colporate type (Figure 2.4c):

Outline in polar view (amb) circular-elliptical; equatorial axis (E): $11.6(10.5-12.7) \mu m$. Remaining characteristics as the 3-colporate type.

So far, only one other case of pollen dimorphism has been documented for the genus Elaeocarpus (Huang 1972). In E. firdausii, the low percentage (ca. 4\%) of the 2-colporate type as compared to the 3-colporate suggests the former is an aberrant morphology, possibly associated with hybridism as reported in other species (e.g. Bhowmik and Datta 2012). 
Figure 2.4 Pollen of Elaeocarpus firdausii.

a)
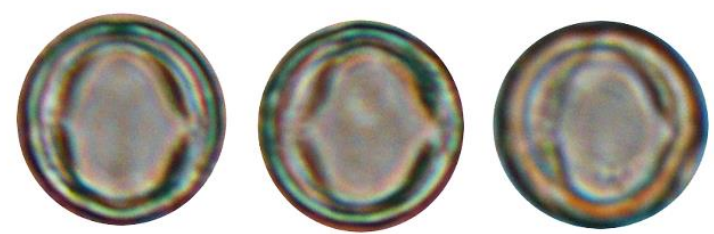

b)
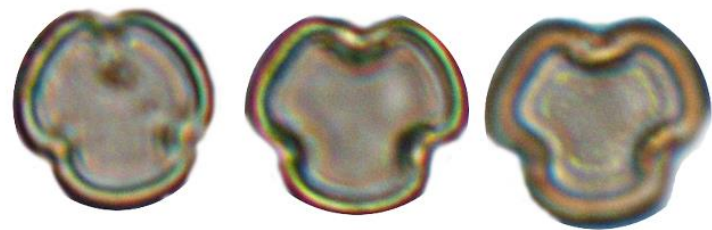

c)
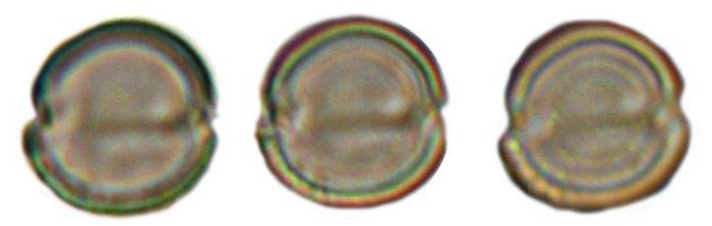

a the 3-colporate pollen type in equatorial view; b same in polar view; c the 2colporate pollen type in polar view.

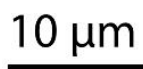

\subsubsection{Distribution}

Endemic to the central part of Sulawesi. The species is so far recorded with certainty from Mt Rorekautimbu and Mt Malemo at elevations from 2150 to 2400m (Figure 2.1). Both mountains are located within LLNP. During our ecological fieldwork, we recorded E. firdausii in all three inventory plots at $>2000 \mathrm{~m}$, although with rather few individuals at each site. Because of its apparent association with a distinct habitat (upper montane or mossy forest above c. 2000 m) and the general lack of information from montane habitats in Sulawesi, we consider it very likely that E. firdausii occurs in many of the upper montane forests of the CSM (Figure 2.1).

FB observed a sterile sapling matching all vegetative characters of E. firdausii on Mt Katopas, c.

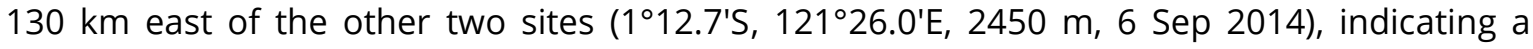
possible occurrence on Sulawesi's Eastern peninsula (Figure 2.1, question mark).

\subsubsection{Habitat}

Based on the morphological information available E. firdausii is a regular component of upper montane (mossy) forests, where its individuals can form part of the canopy. These forests occur from c. $2000 \mathrm{~m}$ upwards in the LLNP area and are easily distinguished because of the dominance of conifers (Podocarpaceae, mostly Dacrycarpus imbricatus (Blume) de Laub. and Phyllocladus hypophyllus Hook.f.). They have a thick layer of epiphytic mosses and ferns on trunks and branches of the trees, \pm abundant undergrowth, c. $20 \mathrm{~m}$ tall canopies with emergents reaching $>30 \mathrm{~m}$ and large amounts of dead wood. The soils are characterized by excess of moisture and heavy accumulation of organic matter. They were classified as Folic Gleysols, Folic Histosols and Folic Cambisols according to the WRB classification (IUSS Working Group WRB 2014). Dominant families besides conifers include Myrtaceae (e.g. Syzygium spp., Xanthomyrtus angustifolia A.J.Scott), Fagaceae (e.g. Lithocarpus havilandii (Stapf) Barnett), 
Paracryphiaceae (e.g. Quintinia apoensis (Elmer) Schltr.), and other Elaeocarpaceae (e.g. Elaeocarpus steupii Coode, E. teysmannii Koord. \& Valeton subsp. domatiferus Coode).

\subsubsection{Etymology}

The specific epithet honours our colleague Firdaus Dg. Matta (born 1984), formerly with Herbarium Celebense in Palu, Sulawesi, who collected the type specimen and contributed greatly to the success of our fieldwork with his skills in plant collection and identification.

\subsubsection{Conservation status}

Based on the locations of the estimated potential habitat for $E$. firdausii we calculated an EOO of $58534 \mathrm{~km}^{2}$ and an AOO of $5760 \mathrm{~km}^{2}$. The latter is presumably an overestimate as not all potentially suitable sites will necessarily be occupied by the species. Nevertheless, occurrence over a relatively wide range is plausible, given the large distance (c. $55 \mathrm{~km}$ ) between two of the collection sites. It is thus unlikely that either EOO or AOO will fall below the thresholds of criteria B1 or B2 for IUCN category VU (IUCN 2012). While deforestation is an ongoing threat to Sulawesi's forests, upper montane forests are usually less affected because of their remote locations and difficult access (Cannon et al. 2007). Hence, we do not consider habitat destruction or exploitation by humans as an imminent threat to population levels. Given (1) the uncertainties in the estimated $\mathrm{EOO}$ and $\mathrm{AOO}$ and (2) the recommendation to use a precautionary attitude in conservation assessments (IUCN Standards and Petitions Subcommittee 2017), we propose a preliminary extinction risk assessment of "Near Threatened" (NT) following the IUCN Red List Categories and Criteria (IUCN 2012).

\subsubsection{Notes}

Based on the morphological information available, E. firdausii is probably related to $E$. luteolignum, E. gambutanus Coode and E. linnaei Coode; this assemblage may be sister to the Polystachyus group from Western Malesia.

In addition to the morphological differences between E. firdausii and E. /uteolignum mentioned in the diagnosis above, according to our present knowledge there are differences in habitat preference: E. firdausii occurs in mossy forest at higher elevations while $E$. luteolignum is known from lower to mid-montane forest dominated by Fagaceae at 1200-1800 m (Coode 1995).

Both observations in the field and examination of dried specimens show that there are morphological differences between smaller understorey plants and mature canopy-forming individuals. The former have less-clustered, longer, thicker and relatively narrower leaves with more clearly bipulvinate petioles, less-rounded tips and more clearly serrate margins. We do not know whether these differences are related to age or rather to environmental factors, e.g. stronger radiation and transpiration in the canopy. Seedlings have even narrower leaves but the very short petioles are only swollen at the base. Conspicuous cup-shaped leaf galls or their presumed scars (Figure 2.2) were present in all collected specimens. All sepals and petals have a glabrous patch at the base of the otherwise hairy inner surface. These glabrous portions are 
apparently pressed against the 10-lobed disc before anthesis. Wood density, based on three specimens, varied from $0.45-0.56 \mathrm{~g} / \mathrm{cm}^{3}$.

\subsubsection{Specimens examined}

Accession numbers are given in parentheses, barcode numbers in square brackets. Barcodes of specimens in $K$ and $L$ link to specimen records in the respective databases (RBG Kew 2015, Wieringa 2015).

INDONESIA. Central Sulawesi (Sulawesi Tengah), Lore Lindu National Park:

Kabupaten Poso, Kecamatan Lore Utara, 8.7 km NNE of village Sedoa, Mt Rorekautimbu, treeinventory plot “Rorekautimbu”, 1¹6.7'S, 120¹8.6'E, $2400 \mathrm{~m}$ :

Brambach F, Mangopo H, Firdaus, Faber M, Tiranda R 0721 (18-30 Jul 2011, sterile, BO (BO 1926844)!, CEB, GOET [GOET014481]!, K [K000720899]!, L [L.2055437]!);

Culmsee H 2152 (Aug-Sep 2007, sterile, GOET [GOET014482]!).

Kab. Poso, Kec. Lore Utara, 7.7 km NNE of village Sedoa, Mt Rorekautimbu, tree-inventory plot "Bulu Torenali", 1¹7.2'S, 120¹8.7'E, 2350 m, 21-24 Apr 2012:

Brambach F, Mangopo H, Firdaus, Faber M, Tiranda R 2041 (flowers, BO (BO 1926843)!, CEB, GOET [GOET014478]!, K [K000720902]!, L [L.2055436]!);

Mangopo H, Firdaus, Brambach F 11 (seedling, L [L.2055440]!).

Kab. Sigi, Kec. Kulawi Selatan, 7.7 km ENE of village Moa, Mt Malemo, tree-inventory plot "Tutu Malemo", 145.9'S, 12009.6'E, 2150 m, 18-23 Oct 2011:

Brambach F, Mangopo H, Firdaus, Faber M, Tiranda R 0937 (sterile, CEB, GOET [GOET014480]!);

Brambach F, Mangopo H, Firdaus, Faber M, Tiranda R 0998 (sterile, CEB, K [K000720900]!, L [L.2055438]!),

Brambach F, Mangopo H, Firdaus, Faber M, Tiranda R 1026 (sterile, CEB, L [L.2055439]!),

Brambach F, Mangopo H, Firdaus, Faber M, Tiranda R 1028 (sterile, CEB, GOET [GOET014479]!, K [K000720901]!). 



\title{
3 Five new species of Syzygium (Myrtaceae) from Sulawesi, Indonesia
}

\author{
Fabian Brambach, James W. Byng, Heike Culmsee \\ Published in PhytoKeys 81: 47-78 (15 Jun 2017), \\ https://doi.org/10.3897/phytokeys.81.13488
}

\subsection{Abstract}

Following ongoing ecological research on the tree diversity of the Indonesian island of Sulawesi, we describe five new species of Syzygium. These are the first descriptions of Syzygium species from the island since Blume (1850, Jambosa celebica and J. cornifolia), highlighting the significant lack of taxonomic research on the genus for the region. The five species proposed as new are Syzygium balgooyi sp. nov., Syzygium contiguum sp. nov., Syzygium devogelii sp. nov., Syzygium eymae sp. nov., and Syzygium galanthum sp. nov. All species are illustrated and information on their distribution, ecology, and conservation status is given.

\subsection{Introduction}

The botanical diversity of the Indonesian island of Sulawesi is poorly known and remains one of the least studied in Southeast Asia (Vogel 1989, Cannon et al. 2007). The Checklist of woody plants of Sulawesi by Keßler et al. (2002), the most comprehensive taxonomic work for the island, highlighted how numerous taxonomic groups were in need of specialist systematic work. Myrtaceae and the largest genus in the family, Syzygium P.Browne ex Gaertner $(1788,166)$, were in particular emphasised because only four species of Syzygium were recorded in the checklist while approximately 350 un-named collections were listed. Several species now accepted as belonging to Syzygium were listed under other generic names in the checklist, such as Acmena de Candolle $(1828,262)$ and Eugenia Linnaeus $(1753,470)$, which further underscores the complex history of the genus.

Syzygium is the most species rich genus of woody plants in Southeast Asia with around 1000 species but little is known of the genus in Wallacea, the biogeographically important transition zone between the Asian and Australian continental areas. As in the other Wallacean regions, the Maluku Islands and Lesser Sunda Islands, the Syzygium species of Sulawesi have never been revised or monographed so there is no robust baseline data of which species occur in the region. The last Syzygium species to be described from Sulawesi were by Blume (1850) under the generic name Jambosa: J. celebica Blume and J. cornifolia Blume. The occurrence of other, mostly widespread species of Syzygium, have been noted over time and resulted in 14 species recorded from Sulawesi at present (WCSP 2019). This number is unrealistically low when considering Syzygium diversity in neighbouring regions: Java holds c. 60 species; Borneo, the Philippines, and New Guinea c. 200 species each (WCSP 2019). In fact, recent extensive 
examination of herbarium material suggests that Sulawesi harbours $>100$ species, the great majority of them yet unnamed (Syzygium Working Group et al. 2016).

Species of Syzygium are present in virtually all ecosystems of Sulawesi, and are often important components of the biological communities (Balgooy and Tantra 1986, Whitten et al. 1987, Milliken and Proctor 1999, Culmsee et al. 2010a), so the lack of taxonomic resolution presents a serious impediment for a better understanding of ecological processes as well as for conservation efforts on the island.

In 2006-2007 and 2011-2012, the University of Göttingen, Germany, and Tadulako University, Palu, Indonesia conducted ecological fieldwork campaigns in Lore Lindu National Park (LLNP), Central Sulawesi. Difficulties in the identification of Syzygium specimens collected during these surveys motivated us to take a closer look at the taxonomy of the genus. Fortunately, the area of LLNP had been visited before by other botanists (Bloembergen 1940, Meijer 1983, Balgooy and Tantra 1986), so good fertile collections for comparison were available in herbaria. Five species could not be matched with previously published taxa and are here proposed as new. This is the first time in > 165 years that species of Syzygium are described from Sulawesi.

\subsection{Methods}

\subsubsection{Morphological Observations}

The specimens collected during our ecological fieldwork in LLNP (HC, 2006-2007; HC and FB, 2011-2012) were the starting point for this study. Duplicates of relevant specimens, including types, were deposited in L and the Indonesian herbaria BO and CEB (herbarium acronyms follow Thiers, continuously updated: http://sweetgum.nybg.org/science/ih/). To identify our specimens, all Syzygium specimens from Sulawesi at A, B, BM, BO, E, GH, K, L, M and U were examined and all matching specimens sorted into morphospecies. We then attempted to identify our morphospecies using keys and floristic treatments from regions around Sulawesi: The Malay Peninsula (Henderson 1949), Borneo (Merrill and Perry 1939, Ashton 2011), Java (Amshoff 1963), the Philippines (Robinson 1909, Elmer 1914, Merrill 1915, 1921, 1951, Pelser et al. 2011), New Guinea (Diels 1922, 1924, Merrill and Perry 1942, Hartley and Perry 1973), and Australia (Hyland 1983). Because Syzygium is such a species-rich genus, we had to repeat this process several times to make sure we did not miss any species our specimens could be matched with. All specimens examined by us are marked with an exclamation mark. We recorded morphological characters of all cited specimens to produce the species descriptions using the package monographaR(Reginato 2016) in R (R Core Team 2016).

Photographs in the field were taken using a Canon EOS 500D camera with a Tamron AF 18$200 \mathrm{~mm}$ f/6.2-38 lens, for later photographs of dried material we used the same camera with a Tamron SP 90mm F/2.8 MACRO lens. Colours of dried specimens were compared to Munsell Soil-Color Charts (Munsell Color 2010) and colour names used accordingly. 
Wood density (oven-dry mass per fresh volume) was determined from wood cores extracted with increment borers. The samples' fresh volume was measured by Archimedes' principle and weight was noted from the same samples after oven-drying for $48 \mathrm{~h}$ at $105^{\circ} \mathrm{C}$.

For the descriptions, flowers and fruits were boiled in dilute detergent for 5 minutes and dissected thereafter. Dimensions were measured using a ruler with $0.5 \mathrm{~mm}$ accuracy. All colours and measures given refer to dried and pressed material unless otherwise stated. We measured the distance of intramarginal veins from leaf margin in the proximal 2/3 of the blade; it usually decreases towards the apex. Likewise, we measured the distance of secondary veins in the central $1 / 2$ of the leaf; it decreases near the base. Dimensions of flower buds are given including the anthopodium, those of the hypanthium excluding the anthopodium (if present).

\subsubsection{Terminology}

Terminology for organs in Syzygium has been varied and often confusing, with authors using different terms for the same structures or similar terms for different structures.

We here adopt the detailed concepts of Briggs and Johnson (1979) on inflorescence structure but use more common terms instead of their rather technical vocabulary: bract instead of pherophy/land bracteole instead of prophyll/ metaxyphy/l. We follow Briggs and Johnson (1979) in using the term anthopodium for the internode between the flower and its subtending bracteoles. This structure has been referred to as pseudopedicel (Schmid 1972) or pseudostalk(Henderson 1949), but Briggs and Johnson (1979) convincingly argued that it is indeed the last internode below the flower and coined the term anthopodium to avoid further confusion. The concept has been adopted by Hyland (1983) who, however, used the more common term pedicel. The anthopodium may be elongated or not; in the latter case the flowers are sessile, although they may appear stalked when arising from elongated higher-order axes of the inflorescence. Otherwise we follow the terminology of Beentje (2012) and Hyland (1983) except for using hypanthium instead of calyx tube.

\subsubsection{Presentation of data}

Since several specimens found in herbaria contained very limited information about the respective collecting localities, we interpreted the locality data of all specimens cited in this paper and translated it into a common format. The format contains approximate coordinates in WGS 84 (if not given on the label), the nearest village, and the administrative divisions in descending order: Province, Kabupaten (Kab., Regency), and Kecamatan (Kec., District).

Specimens collected in Sulawesi by the Forest Research Institute Buitenzorg (Bogor), also called Boschproefstation or Boschbouwproefstation (van Steenis-Kruseman and van Welzen 2014), often bear confusing information about the respective collectors. The original herbarium labels for these collections (usually deposited in $\mathrm{BO}$ ) give the actual collector with a personal collection number and in addition the institutional $b b$ - or Cel-number. Duplicate labels usually only contain the institutional number and either read Neth. Ind. For. Service or Boschproef station 
as collector. We cite these specimens as NIFS (Netherlands' Indies Forest Service) with the respective institutional number.

In the diagnoses, we give floral formulas for each species, following the format and recommendations of Prenner et al. (2010). Furthermore, we apply Appropriate Citation of Taxonomy (Seifert et al. 2008) throughout the manuscript.

Under Distribution and Habitat, we characterised the forest stands of the species which were found primarily in our (FB and $\mathrm{HC}$ ) inventory plots by mentioning the families with the five highest family importance values (FIV). The FIV is an objective measure of importance of a family in a stand taking into account the number of individuals, number of species, and basal area of that family and comparing them to the stand total (see Mori et al. 1983 for a detailed description of the method).

\subsubsection{Conservation Assessment}

We used GeoCAT (Bachman et al. 2011) to calculate the extent of occurrence (EOO) and area of occupancy (AOO) of each species as basis for the conservation assessments following the recommendations of IUCN Standards and Petitions Subcommittee (2017).

\subsection{Results}

All species here described are glabrous in all parts and possess flower characters placing them in the broadly defined Syzygium subg. Syzygium (Craven and Biffin 2010): anther sacs parallel and opening by longitudinal slits, placentation axile-median. The species of which we have seen fruiting material furthermore have seeds without intrusive tissue interlocking the cotyledons and free cotyledons, conforming with subgenus Syzygium as well. These characters are not mentioned again in the species descriptions.

\subsubsection{Syzygium balgooyi Brambach, Byng \& Culmsee, sp. nov.}

urn:Isid:ipni.org:names:60474721-2 Figures 3.1, 3.2, 3.8.

"Eugenia spec. BB" (Koorders 1898, 173, 459, Koorders-Schumacher 1914, 95).

„Myrtaceae sp. 10“ p.p. (Culmsee and Pitopang 2009, see also 2017 (Erratum), Culmsee et al. 2011).

\subsubsection{Diagnosis}

Syzygium balgooyi is characterised by long, elongate-clavate flowers, a character otherwise only known from the morphologically similar Syzygium schumannianum (Nied.) Diels $(1922,402)$ from New Guinea and the Maluku Islands. Syzygium balgooyi differs from that species by its smooth (vs prominently longitudinally ridged) hypanthium and fruit and by the hypanthium rim which remains entire after anthesis (vs apically splitting into 4 recurving lobes). Floral formula B1 Bt2 K4* C4* A ${ }^{*} \hat{G}(2)+V x^{\infty}$. 


\subsubsection{Type}

INDONESIA. South Sulawesi (Sulawesi Selatan), Kab. Luwu Timur, Kec. Nuha, Between Soroako and Nickel plant site, c. $2^{\circ} 33^{\prime} \mathrm{S}, 121^{\circ} 22^{\prime} \mathrm{E}, 500 \mathrm{~m}$, $10 \mathrm{Jul}$ 1979: van Balgooy 3956 (flowers; holotype L [L.2517558]! [spirit collection L 0771145] [wood sample L 0708624], isotype A [A01143212]!).

\subsubsection{Description}

Trees, up to $37 \mathrm{~m}$ tall, diameter at breast height $\leq 65 \mathrm{~cm}$, trunk straight, $\leq 20 \mathrm{~m}$ tall, often fluted and with buttresses $\leq 3 \mathrm{~m}$ tall and $1 \mathrm{~m}$ out. Outer bark pale brown to bright red, peeling off in small or large sheets, inner bark dark red, usually paler towards inside, sometimes with little watery red sap, wood very hard and heavy, sapwood cream, clearly separated from the dark reddish brown heartwood. Young branchlets 1-2 × 1.5-4 mm, strongly flattened, the flat sides usually with two lateral, rounded ridges leading to the petioles and one central ridge continuing into the next internode, often resinous when dry, epidermis green, drying dusky red to reddish black and usually smooth; becoming terete, bark drying red to dark reddish brown, finely flaking and with conspicuous flaking remnants of epidermis.

Leaves (sub-)opposite. Petioles 2-12 × 1-3.5 mm, flat and sometimes narrowly winged above, rounded or keeled beneath, drying reddish black and smooth. Blades (4-) 7-11.5 (-16) × (1.5-) 3-5 (-9) cm, ratio (1.2-) 1.8-2.7 (-5), (narrowly) elliptic, obovate, or oblanceolate, base cuneate and attenuate at the very base or obtuse to rounded, apex usually rounded or obtuse, sometimes emarginate or acute, margin slightly to strongly revolute; (thick-)coriaceous, purple, pink, or reddish when young, fresh to dark glossy green above, paler glossy green beneath, drying dull to shiny, often resinous after drying, reddish brown to reddish black above, reddish brown to very dusky red beneath. Midrib channelled above, prominent and rounded or keeled, drying reddish black and smooth beneath. Secondary vein pairs (9-) 11-14 (-16), 4-12 (-15) mm apart, \pm faint and lighter red than the lamina above, \pm prominent and darker than the lamina beneath; intersecondary veins present. Tertiary veins sup-parallel near the midrib, reticulate towards the margins, \pm faint above, faint or prominulous and darker than the lamina beneath. Inner intramarginal vein 1-5 mm from the leaf margin, \pm looping; outer intramarginal vein $<1$ $\mathrm{mm}$ from the leaf margin, often seemingly absent from leaf margin.

Inflorescences terminal and often in axils of distal leaf pair, rather dense panicles, 5-10 cm long, peduncles 1-6 cm long, axes subangular or rounded, flattened, resinous after drying. Bracts c. $3 \mathrm{~mm}$ long, linear, pellucid-dotted, caducous; bracteoles 2 per flower, sometimes seemingly 4 (by contraction of the ultimate inflorescence axes?), $1 \mathrm{~mm}$ long.

Flowers 5-15 per inflorescence, within the panicles in monads or clusters of 2-4, 4-merous, anthopodium absent, c. 20-30 mm in diameter at anthesis, mature buds 20-30 × 3-6 mm. Hypanthium 20-30 × 5-7 mm, elongate-clavate, yellowish green, drying smooth black, hypanthium rim $15 \mathrm{~mm}$ long, glandular inside. Calyx lobes c. $2 \times 2 \mathrm{~mm}$, claw- or hood-shaped. Petals c. $4 \times 3 \mathrm{~mm}, \pm$ obovate, pale green. Stamens c. 100, filaments $10-20 \mathrm{~mm}$ long, pale green, anthers c. 0.5-0.8 mm long, ellipsoid, yellow. Ovary bilocular, locules surrounded by spongy 
tissue, ovules c. 15-20 per locule, ascending, \pm arranged in 2 longitudinal rows. Style $25-35 \mathrm{~mm}$ long, pointed.

Fruits 1-2-seeded, 27-33 × 12-16 mm, ampulliform, yellowish green (immature?), drying black, smooth or slightly warty, pericarp c. $1 \mathrm{~mm}$ thick, leathery when fresh, \pm woody when dried, hypanthium rim 8-12 $\mathrm{mm}$ long, 4-5 $\mathrm{mm}$ in diameter.

Seeds 13-15 $\times$ 9-10 mm, ellipsoid, testa cartilaginous, attached to the pericarp, cotyledons free from the testa, \pm half-globose, minutely verrucose, facing surfaces undulate.

\subsubsection{Etymology}

The species is named after Max Michael Josephus van Balgooy (*1932), botanist and authority on Southeast Asian plant taxonomy, identification, and biogeography. He collected over 900 specimens during a Dutch-Indonesian expedition to Sulawesi in 1979, among them the type specimen of this species. We enjoyed the privilege of learning from Max during several stays at the herbarium in Leiden and receiving his help with the identification of our specimens collected in Central Sulawesi.

\subsubsection{Phenology}

Flowering specimens have been encountered throughout the year without any apparent association with geography or climate. Fruiting specimens have been recorded in May (de Voge/ 5413) and September (sight record by FB).

\subsubsection{Distribution and Habitat}

Syzygium balgooyi is restricted to Sulawesi and widespread across the island (Figure 3.2). The species occurs on a variety of geological substrates, namely volcanic rocks on the Northern Peninsula, acid plutonic rocks and schists in the Central Sulawesi Mountains (see Brambach et al. 2016 for definition), alluvial deposits at the base of the Southern Peninsula, and ultramafic rocks on the Eastern and Southeastern Peninsulas. According to the information on specimen labels it grows in primary forests, both virgin and disturbed, over a wide elevational range (c. 100-2000 m). There, it forms part of the canopy layer, sometimes co-dominant (Balgooy and Tantra 1986), but usually with scattered individuals (Culmsee et al. 2011, Brambach and Culmsee, unpublished).

\subsubsection{Conservation Status}

The AOO of $64 \mathrm{~km}^{2}$ would place Syzygium balgooyi in the category "Endangered" (EN), despite its wide distribution in Sulawesi (Figure 3.2) as reflected by the estimated EOO of $94451 \mathrm{~km}^{2}$. The species has been found in a wide variety of habitats, including montane forests at different elevations, with scattered individuals or even co-dominant at times (see Distribution and Habitat above). We have no reason to believe that it is scarce throughout its range. Rather, we argue that the small estimated $\mathrm{AOO}$ is an artefact due to the generally low collection rate in Sulawesi and the real geographic distribution does not meet criterion B for any of the "threatened" categories of IUCN (2012). However, although we lack real evidence about possible 
changes in population size over time, using the Global forest change website (Hansen et al. 2013), we detected deforestation activities at or near five of the 18 collection localities (28\%) of S. balgooyi. Given that the species is only recorded from old-growth forest habitats, we consider this a loss of suitable habitat, slightly below the 30\% threshold for the "Vulnerable" category. Notably, all deforestation took place in places with relatively easy access and at low elevations. Thus, given (1) the relatively large EOO of S. balgooyi, (2) its apparent wide ecological niche, (3) its frequency of occurrence, (3) the low collection rates in Sulawesi, and (4) the loss of suitable habitat, we propose a preliminary extinction risk assessment of "Near Threatened" (NT) following the IUCN Red List Categories and Criteria (IUCN 2012).

\subsubsection{Vernacular names}

Cenke hutan (= forest clove, Indonesian, de Vogel 2651), Jambu (general name for Syzygium, Indonesian, NIFS bb 33081), Rokobako (NIFS Cel./II-385), Tambeanitu (Bahasa Behoa, Brambach et al. 1047, 1083, 1290, 1316), Wawahuling (Bahasa Tondano, Koorders 18251, see Koorders $1898,173,459)$

\subsubsection{Notes}

Among Syzygium species of Sulawesi, S. balgooyican be recognised in the field by its tall stature (Figure 3.1a), the bright red bark that peels off in thin sheets (Figure 3.1d, g) and the rather thick, usually obovate or oblanceolate leaves with \pm rounded tips (Figure 3.1b-c, Figure 3.8a-e). Dry specimens are recognisable by the dark reddish-brown twigs bearing thick black flakes of the peeling epidermis and the very dark upper leaf surface with contrasting paler veins.

Leaf size and thickness are quite variable (Figure 3.8a-e), as can be expected for a species with such a wide ecological distribution. Small leaves are usually found at higher elevations, whereas thick leaves seem to be associated with ultramafic soils. While the extreme forms suggest that several distinct species are involved, when taking into account all the available material, intermediate states connecting the extremes appear. We therefore prefer to treat this as one species with the vegetative parts morphologically variable.

Team 2016) using the digital elevation model of Jarvis et al. (2008).

Syzygium balgooyi and S. schumannianum are difficult to separate in vegetative state. $S$. balgooyi usually has leaves with rounded, obtuse, emarginate, or acute tips, whereas they are shortly acuminate in S. schumannianum, but there are exceptions in both species. Flowers and fruits of the two species also share the same structure but there are two important differences which we consider sufficient to warrant specific separation: Firstly, as indicated by the original name Eugenia neurocalyx Schumann nom. illeg. (in Schumann and Hollrung 1889, 90), the outer surface of the hypanthium in S. schumannianum bears prominent "nerves", i.e. longitudinal ridges (Figure 3.11-m). These ridges are already visible in young flower buds and remain present until the fruiting stage. Single, very faint ridges may appear in flowering specimens of S. balgooyi (seen in de Vogel 2651) but in the bulk of the material at our disposition, flower buds, flowers, and fruits are completely smooth (Figure $3.1 \mathrm{j}-\mathrm{k}$ ). 

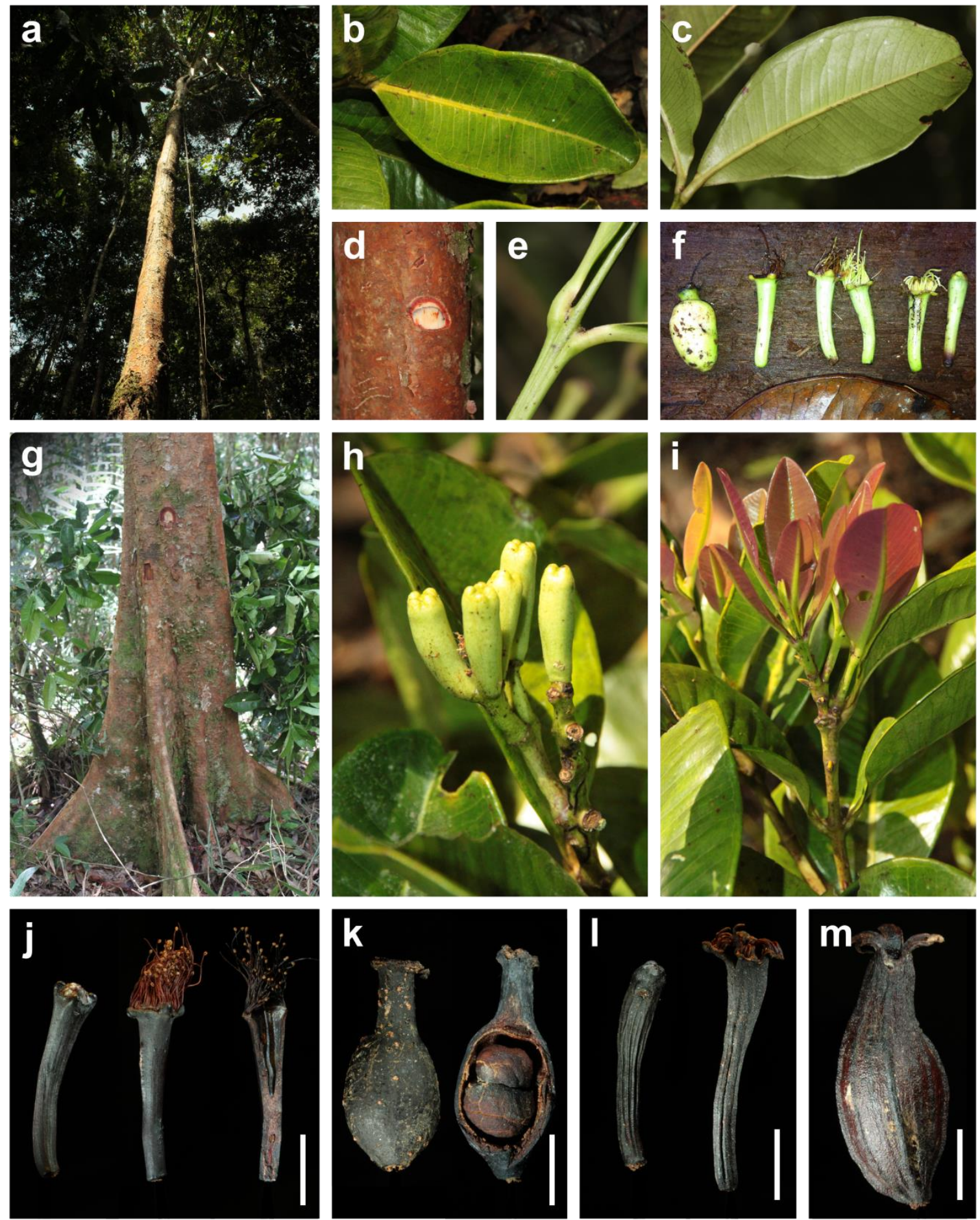

Figure 3.1 Morphological characters of Syzygium balgooyi and S. schumannianum. Syzygium balgooyi (ak): a c. 20 m tall trunk; b upper leaf surface; c lower leaf surface; d bark with slash; e ridged shoot apex with subopposite leaves; $\mathbf{f}$ flowers at different stages during anthesis and fruit; $\mathbf{g}$ trunk base with steep narrow buttresses; $\mathrm{h}$ inflorescence with flower buds; i shoot with young leaves; j dried flowers before and during anthesis and longitudinal section of flower; $\mathbf{k}$ dried fruit and longitudinal section of fruit showing two cotyledons. Syzygium schumannianum (I-m): I dried flowers before and during anthesis; $\mathrm{m}$ dried fruit. a-b and h-i Brambach et al. 1564; c Brambach et al. 0861, d-e Brambach et al. 0628; fighting on Mt Katopas by FB, g Brambach et al. 0889; j holotype van Balgooy 3956 [L.2517558]; k de Vogel 5413 [L.2517563]; I Wiakabu et al. LAE 50571 [L.2535534]; m Brass 13610 [L.2524420]. All scale bars $=1 \mathrm{~cm}$. 


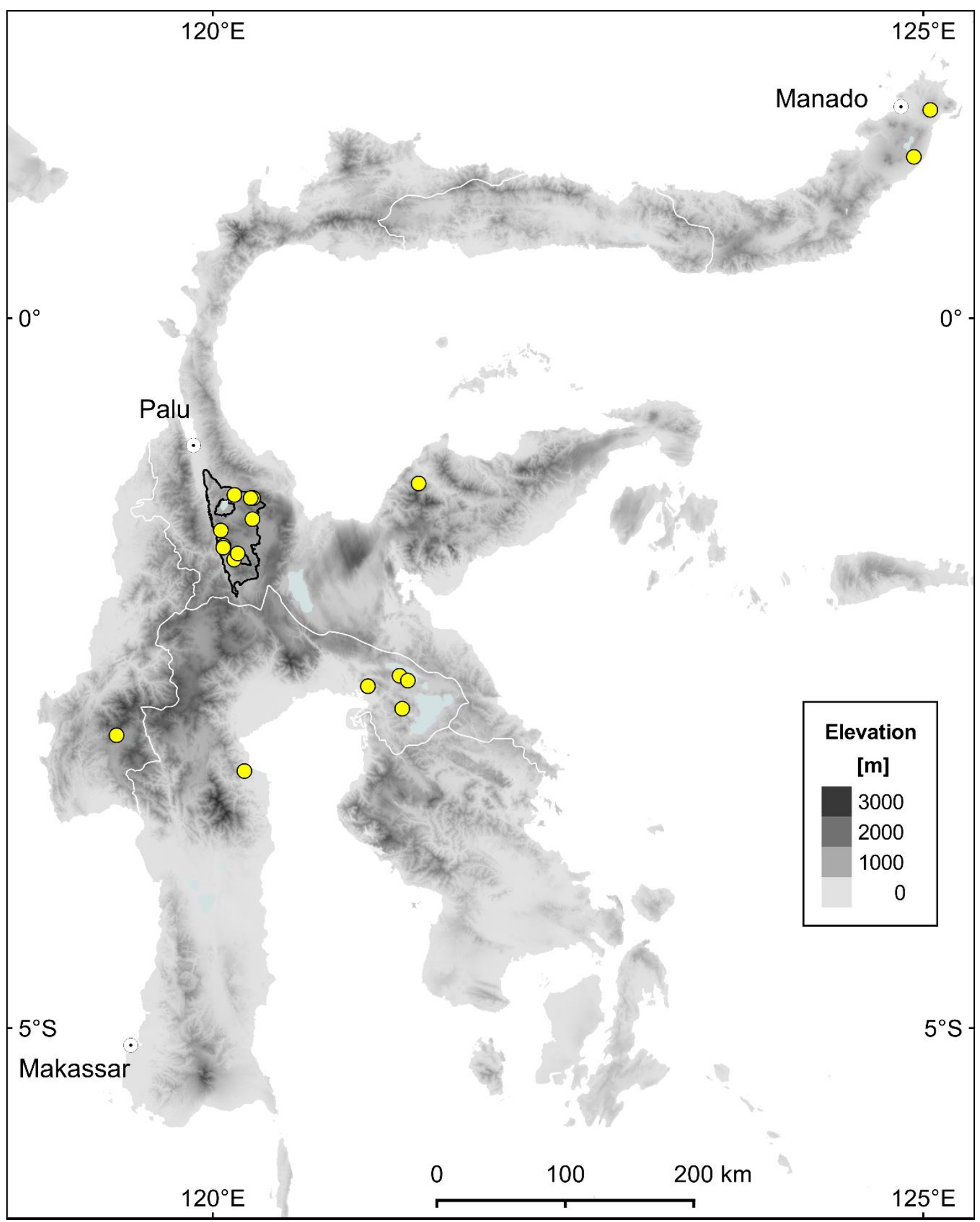

Figure 3.2 Distribution map of Syzygium balgooyi in Sulawesi. Collecting localities are shown as yellow dots; Lore Lindu National Park is indicated by a black line. Map created with QGIS (QGIS Development

Furthermore, in S. balgooyi the stamens are arranged in a ring along the upper margin of the hypanthium rim, which remains entire through the fruiting stage (Figure 3.1j-k). In $S$. schumannianum, the apical portion of the woody hypanthium rim splits into 4 outward-curving lobes and the stamens are arranged in a small area at the inside of each lobe near its tip (Figure 3.11-m, Schumann and Hollrung 1889, Merrill and Perry 1942). 
The wood of $S$. balgooyi is used for construction in North Sulawesi, but is not water-resistant (Koorders 1898, 173). Several collectors describe it as very hard and heavy. Mean wood density, as measured from 13 wood cores in LLNP was $0.74 \mathrm{~g} \mathrm{~cm}^{-1}$ ( \pm 0.05 SD).

\subsubsection{Additional Specimens Examined (Paratypes)}

INDONESIA. North Sulawesi (Sulawesi Utara):

Kab. Minahasa, Kec. Kakas, Old-growth forest Pinamorongan, c. $1^{\circ} 08^{\prime} \mathrm{N}, 124^{\circ} 56^{\prime} \mathrm{E}$ ("NoordCelebes, Residentie Menado, Pinamorongangebergte bij Kakas"), 500 m, 30 Jan 1895: Koorders 18251 (sterile; L [L.2517502]! [L.2535743]!).

Kota Bitung, Kec. Ranuwulu, southern part of Wiau Forest Reserve (Hutan Lindung G. Wiau), base of Mt Klabat, c. $1^{\circ} 28^{\prime} \mathrm{N}, 125^{\circ} 03^{\prime} \mathrm{E}, 400 \mathrm{~m}, 1$ Nov 1973: de Vogel EF 2651 (flowers; L [L.2535729]! [L.2535730]! [wood sample L 0204047]).

Central Sulawesi (Sulawesi Tengah), LLNP:

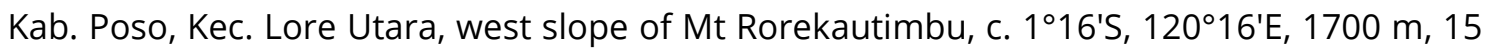
May 1979: van Balgooy MMJ 3371 (sterile; L [L.2535697]!).

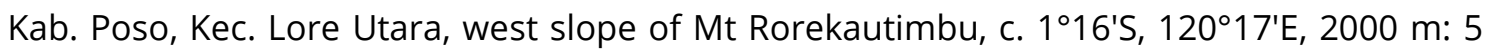
May 1979: Tantra IJM 1589 (sterile; L [L.2517457]!), \& 1592 (sterile; L [L.2535672]!); ibid. loco, 17 May 1979: de Vogel EF 5413 (fruits; BO [BO-1686561], K [K001024419]!, L [L.2517562]! [L.2517563]!, [wood sample L 0708565]).

Kab. Poso, Kec. Lore Utara, 4 km E of Wuasa, c. $200 \mathrm{~m}$ N of Rumuku waterfall, tree-inventory plot Torongkilo, $1^{\circ} 24.9^{\prime} \mathrm{S}, 120^{\circ} 16.7^{\prime} \mathrm{E}, 1450 \mathrm{~m}, 6 \mathrm{Mar} 2012$ : Brambach F, Mangopo H, Firdaus, Faber $M$, Tiranda R 1478 (sterile; BO [BO-1938440]!, CEB, L!) \& 1564 (flower buds; BO [BO1938441]!, CEB, K [K000993483]!) \& 1583 (sterile; GOET [GOET020022]!).

Kab. Poso, Kec. Lore Tengah, $9 \mathrm{~km}$ NW of Bariri, $100 \mathrm{~m}$ E of climate tower, tree-inventory plot Bariri NE, 139.4'S, $120^{\circ} 10.5^{\prime} \mathrm{E}, 1400 \mathrm{~m}$ : Jul 2007: Culmsee H y896 (sterile; CEB, L!); ibid. loco, 21 Aug 2011: Brambach F, Mangopo H, Firdaus, Faber M, Tiranda R 0861 (sterile; BO [BO1938438]!, CEB, GOET [GOET020025]!) \& 0889 (sterile; BO [BO-1938439]!, CEB, L!) \& 0907 (sterile; CEB, GOET [GOET020024]!, L!).

Kab. Poso, Kec. Lore Tengah, 9 km NW of Bariri, 80 m south of climate tower, tree-inventory plot Bariri S, 1³9.5'S, 120¹0.4'E, 1400 m, Jul 2007: Culmsee H 1459 (sterile; CEB, GOET [GOET020006]!) \& 1495 (sterile; BO [BO-1938457]!, CEB); ibid loco, Jul 2007: Culmsee H r808 (sterile; CEB, GOET [GOET020008]!).

Kab. Poso, Kec. Lore Tengah, 7 km WNW of Hanggira, E flank of Mt Dali, tree-inventory plot Pantakleabae, $1^{\circ} 42.0^{\prime} \mathrm{S}, 120^{\circ} 09.0^{\prime} \mathrm{E}, 1950 \mathrm{~m}$ : 3 Mar 2011: Culmsee H, Brambach F, Mangopo H, Firdaus, Faber M, Tiranda R r2162 (sterile; CEB, GOET [GOET020021]!) \& r2254 (sterile; BO [BO-1927087], CEB, GOET [GOET020023]!); ibid. loco, 30 Mar 2011: Brambach F, Mangopo H, Firdaus, Faber M, Tiranda R 0038 (sterile; BO [BO-1926965], CEB, GOET [GOET020027]!, K [K000993482]!, L!) \& 0058 (sterile; BO [BO-1926969]!, [BO-1926970]!, CEB, GOET [GOET020033]!) \& 0082 (sterile; BO [BO-1938382]!, CEB, GOET [GOET020030]!, L!) \& 0097 (sterile; CEB, GOET [GOET020029]!, L!); ibid. loco., 23 Jan 2012: Brambach F, Mangopo H, Firdaus, Faber M, Tiranda R 1333 (sterile; CEB, GOET [GOET020020]!, L!).

Kab. Sigi, Kec. Kulawi, 2.4 km ENE of Toro, NE edge of Pono Valley, tree-inventory plot Pono, $1^{\circ} 29.7^{\prime} \mathrm{S}, 120^{\circ} 03.4^{\prime} \mathrm{E}, 1050 \mathrm{~m}: 4$ Aug 2006: Culmsee 125 (sterile; BO [BO-1938456]!, CEB, L!) \& 
209 (sterile; CEB, K [K000993486]!); ibid. loco, Jul 2007: Culmsee r211 (sterile; CEB, GOET [GOET020009]!).

Kab. Sigi, Kec. Kulawi Selatan, 4 km E of Watukilo, following footpath to Mt Tokepangana,

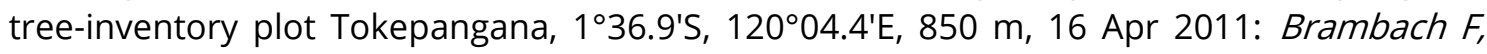
Mangopo H, Firdaus, Faber M, Tiranda R 0176 (sterile; BO [BO-1926967]!, CEB, GOET [GOET020028]!, L!) \& 0206 (sterile; BO [BO-1926968]!, CEB) \& 0283(sterile; BO [BO-1926973]! [BO-1926974]!, CEB, GOET [GOET020032]!, K [K000993481]!, L!) \& O319 (BO [BO-1926934]!, CEB) \& 0332 (BO [BO-1926966]!, CEB) \& 0363 (BO [BO-1926919]!, CEB).

Kab. Sigi, Kec. Kulawi Selatan, 4 km ENE of Watukilo, $400 \mathrm{~m} N$ of Mboe River, tree-inventory plot Rantena, 1³6.2'S, 12004.5'E, 700 m: 17 Jun 2011: Brambach F, Mangopo H, Firdaus, Faber M, Tiranda R 0466 (sterile; BO [BO-1938383]!, CEB, GOET [GOET020031]!); ibid. loco, 21 Jun 2011: Brambach F, Mangopo H, Firdaus, Faber M, Tiranda R 0628 (sterile; CEB, GOET [GOET020026]!, L!).

Kab. Sigi, Kec. Nokilalaki, 4.3 km SSW of Tongoa, NW flank of Mt Nokilalaki, ca. $400 \mathrm{~m}$ S of

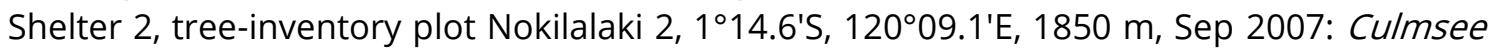
2923 (sterile; CEB, L) \& 3075 (sterile; BO [BO-1938463]!, CEB).

Kab. Sigi, Kec. Nokilalaki, 4.3 km SSW of Tongoa, NW flank of Mt Nokilalaki, ca. 500 m SSE of Shelter 2, tree-inventory plot Nokilalaki 1, 1¹4.7'S, 12009.2'E, 1900 m, Aug 2007: Culmsee 2636 (sterile; CEB, L!) \& 2641 (sterile; BO [BO-1938462]!, CEB, GOET [GOET020007]!) \& 2721 (sterile; CEB, K [K000993487]!).

Kab. Tojo Una-una, Kec. Ulubongka. N slope of Mt Katopas, $1^{\circ} 9.8^{\prime} \mathrm{S}, 11^{\circ} 26.9^{\prime} \mathrm{E}, 1100 \mathrm{~m}, 4$ Sep 2014: Sight record by F Brambach (photograph Figure 3.1f).

West Sulawesi (Sulawesi Barat):

Kab. Mamasa. Kec. Mamasa, near Osango c. 256'S, 119¹9'E ('Celebes en Ond. Boven Binoeang, ca. Osango"), c. 1500 m, 1 Jul 1939: Netherland's Indies Forest Service (NIFS) bb 28293 (sterile; L [L.2529832]!).

South Sulawesi (Sulawesi Selatan):

Kab. Luwu, Kec. Ponrang, near Kampung Tampa, c. 3¹1'S, 120 13'E ('Celebes en Ond. Palopo, Bakka, Kampoeng Tampa"), c. 100 m, 15 Sep 1941: NIFS bb 33081 (flowers; L [L.2535805]!).

Kab. Luwu Timur: Kec. Malili, Ussu, c. $2^{\circ} 36^{\prime} S, 12^{\circ} 06^{\prime}$ ("Selebes, Malili, Oesoe): c. 300 m, 13 Jul 1931: NIFS Cel./II-385 (flower buds; L [L.2535679]!); ibid. loco, c. 400 m, 19 Jun 1934: NIFS Cel./II-293 (sterile; L [L.2517541]!); ibid. loco, 100 m, 28 Mar 1941: NIFS bb 32595 (sterile; BO [BO-1304600], L [L.2517463]!).

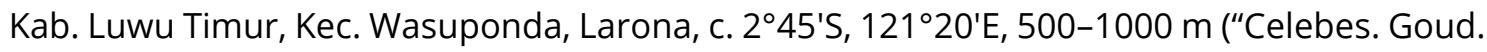
Celebes, Ond. afd. Malili, nabij La Rona"), n.d.: NIFS bb 1843(sterile; L [L.2535842]!) \& bb 1895 (sterile; L [L.2535843]!).

Kab. Luwu Timur, Kec. Nuha, Hills W of Soroako, c. $2^{\circ} 31^{\prime} S, 121^{\circ} 19^{\prime} E, 550$ m, 17 Jun 1979: van Balgooy MMJ 3767(old inflorescences; L [L.2535910]! [wood sample L 0708626]). 


\subsubsection{Syzygium contiguum Brambach, Byng \& Culmsee, sp. nov.}

\section{urn:Isid:ipni.org:names:60474722-2 Figures 3.3, 3.4, 3.8.}

“Myrtaceae sp. 9" (Culmsee and Pitopang 2009).

\subsubsection{Diagnosis}

Syzygium contiguum is a species of treelets with slender, angular young branchlets and (sub)sessile, chartaceous leaves with few (8-13), distinct secondary veins, two marginal veins, and conspicuous cordate bases; the basal lobes of opposed leaves often reach each other. The dense or lax paniculate inflorescences are terminal or arise from the upper leaf axils and bear small (5-6 × 3-4 mm in mature buds) pyriform flowers with numerous white stamens. The species is similar to Syzygium urdanetense (Elmer) Merrill $(1951,420)$ from the Philippines but differs from that species by angular (vs usually terete) young branchlets and inflorescence axes, by smaller (usually $9-14 \times 3.5-5$ vs $18-35 \times 6-11 \mathrm{~cm}$ ), chartaceous (vs coriaceous) leaves with shorter ( $0-1.5$ vs $3-5 \mathrm{~mm}$ ) petioles and fewer secondary vein pairs (8-13 vs 17-35), and by glanddotted (vs smooth) petals. It differs from Syzygium paucipunctatum (Koord. and Valeton) Merrill and Perry (Merrill and Perry 1939, 169) $(1939,169)$ from Sumatra, Java, and Borneo, in chartaceous (vs coriaceous), leaves with no or few gland dots (vs gland-dotted beneath) which dry dark reddish brown to very dusky red above and (dark) reddish brown beneath (vs. olivegreen above and brownish beneath) and shorter (5-6 vs c. $9 \mathrm{~mm}$ long) mature flower buds. Floral formula B1 Bt2 K4* $4^{*}{ }^{A} \infty * \hat{G}(2)+V x \sim 8$.

\subsubsection{Type}

INDONESIA. Central Sulawesi (Sulawesi Tengah), LLNP, Kab. Sigi, Kec. Kulawi, 2.4 km ENE of Toro, NW of Pono Valley, tree-inventory plot Pono, $1^{\circ} 29.7^{\prime} \mathrm{S}, 120^{\circ} 03.4^{\prime} \mathrm{E}, 1050 \mathrm{~m}$, Jul 2006: Culmsee $H$ 535 (flowers; holotype L[L.3962133]!, isotype CEB).

\subsubsection{Description}

Treelets, up to $10 \mathrm{~m}$ tall, diameter at breast height $\leq 11 \mathrm{~cm}$. Bark and wood not known. Young branchlets $0.5-1 \times 1-2 \mathrm{~mm}$, slender, rectangular in cross section, sometimes narrowly winged, epidermis drying dark reddish brown, smooth; soon becoming terete with 4 ridges and eventually terete, bark pale or yellowish brown with flaking remnants of epidermis; with (1-) 2 (-4) pairs of $\leq 2 \mathrm{~mm}$ long, caducous cataphylls near the base of the current flush.

Leaves opposite, (sub-)sessile. Petioles 0-1.5 $\times 1-2 \mathrm{~mm}$, absent or very short and stout, drying very dusky red. Blades (6.5-) 9-14 (-19) × (2.3-) 3.5-5 (-6.1) cm, ratio (1.9-) 2.5-3.2 (-3.6), narrowly elliptic or lanceolate, rarely oblanceolate, base distinctly cordate (or auriculate), basal lobes of opposed leaves often touching each other, apex (long-)acuminate or caudate, margin flat or sometimes minutely revolute; chartaceous, drying dull to satin, dark reddish brown to very dusky red above, (dark) reddish brown beneath; sometimes with scattered black gland dots. Midrib channelled above, prominent, rounded, and darker than the lamina beneath. Secondary vein pairs 8-12, (3-) 5-11 (-18) mm apart, slightly sunken or sometimes slightly 
prominent, rather inconspicuous above, very prominent and darker than the lamina beneath; some intersecondary veins usually present. Tertiary veins sub-parallel near the midrib to reticulate towards the margin, faint above, prominulous beneath. Inner intramarginal vein 3-7 $\mathrm{mm}$ from leaf margin, hardly looping; outer intramarginal vein $0.5-2 \mathrm{~mm}$ from leaf margin.

Inflorescences terminal and in the axils of 1-2 distal leaf-pairs, \pm lax panicles, (2.5-) 3.5-7.5 (11) $\mathrm{cm}$ long, peduncles $1-3.5 \mathrm{~cm}$ long, axes (sub-)angular, flattened. Bracts c. 0.5-2 (-7) mm long, lowermost foliaceous, caducous, others deltate, keeled, \pm persistent; bracteoles 2 per flower, 0.5-1 mm long, similar to bracts.

Flowers $\leq 40$ per inflorescence, within the panicles in monads or triads, 4-merous, anthopodium absent, c. $15 \mathrm{~mm}$ in diameter at anthesis, mature buds 5-6 × 3-4 mm. Hypanthium 4-5 × 3-5.5 $\mathrm{mm}$, obconical to infundibuliform, gland-dotted or \pm smooth, hypanthium rim $2 \mathrm{~mm}$ long. Calyx lobes $0.5-1 \times 1-2.5 \mathrm{~mm}$, deltate first, becoming broadly rounded and eventually splitting irregularly at anthesis. Petals 3-6 × 3-6 mm, pseudocalyptrate, orbicular, gland-dotted. Stamens c. 80-100, filaments 6-10 mm long, white, anthers c. $0.5 \mathrm{~mm}$ long, ellipsoid. Ovary bilocular, locules subtended by spongy tissue, ovules c. 8 per locule, spreading. Style 6-8 mm long, pointed.

Fruits 2-seeded, 1.1-1.3 x 1.8-1.9 cm, globose to oblate, drying smooth, pericarp c. $2 \mathrm{~mm}$ thick, hypanthium rim c. $5 \mathrm{~mm}$ in diameter.

Seeds 9-10 x 12-13 mm, half-moon shaped.

\subsubsection{Etymology}

The specific epithet refers to the leaf bases of opposing leaves which, due to their cordate shape and the short petioles, often approach or touch each other.

\subsubsection{Phenology}

In Central Sulawesi a slight dry season usually lasts from May to September or October. Flowering was observed during the wet and dry seasons: in July 2016, January/February 2007, July 2007 in Pono and in April 1975 on Mt Nokilalaki.

\section{Distribution and Habitat}

According to our present knowledge, the species is endemic to the province of Central Sulawesi. It has been recorded from only three localities in and around LLNP at 1000-1150 m elevation (Figure 3.4). Most of the specimens were collected in our (FB and $\mathrm{HC}$ ) inventory plot in Pono Valley near the western border of LLNP.

In the Pono inventory plot, the species was found in undisturbed submontane rainforest on flat terraces with Sideralic Cambisols (IUSS Working Group WRB 2014) developed from metamorphic rocks. The forest at Pono was dominated by Fagaceae, Lauraceae, Sapotaceae, Moraceae, and Rubiaceae species (families with top five FIV) and contained seven other species of Syzygium: S. acuminatissimum (Blume) de Candolle (1828, 261), S. balgooyi, S. galanthum, S. lineatum (DC.) Merrill and Perry (1938a, 109), S. phaeostictum Merrill and Perry (1942, 270), and two undetermined species (Brambach and Culmsee, unpublished). See Culmsee and Pitopang 
(2009) for more information on the floristics of the Pono valley plot. The collection locality of Widjaja EAW 3502 in the almost entirely deforested Napu valley suggests remnant riparian forest as habitat.
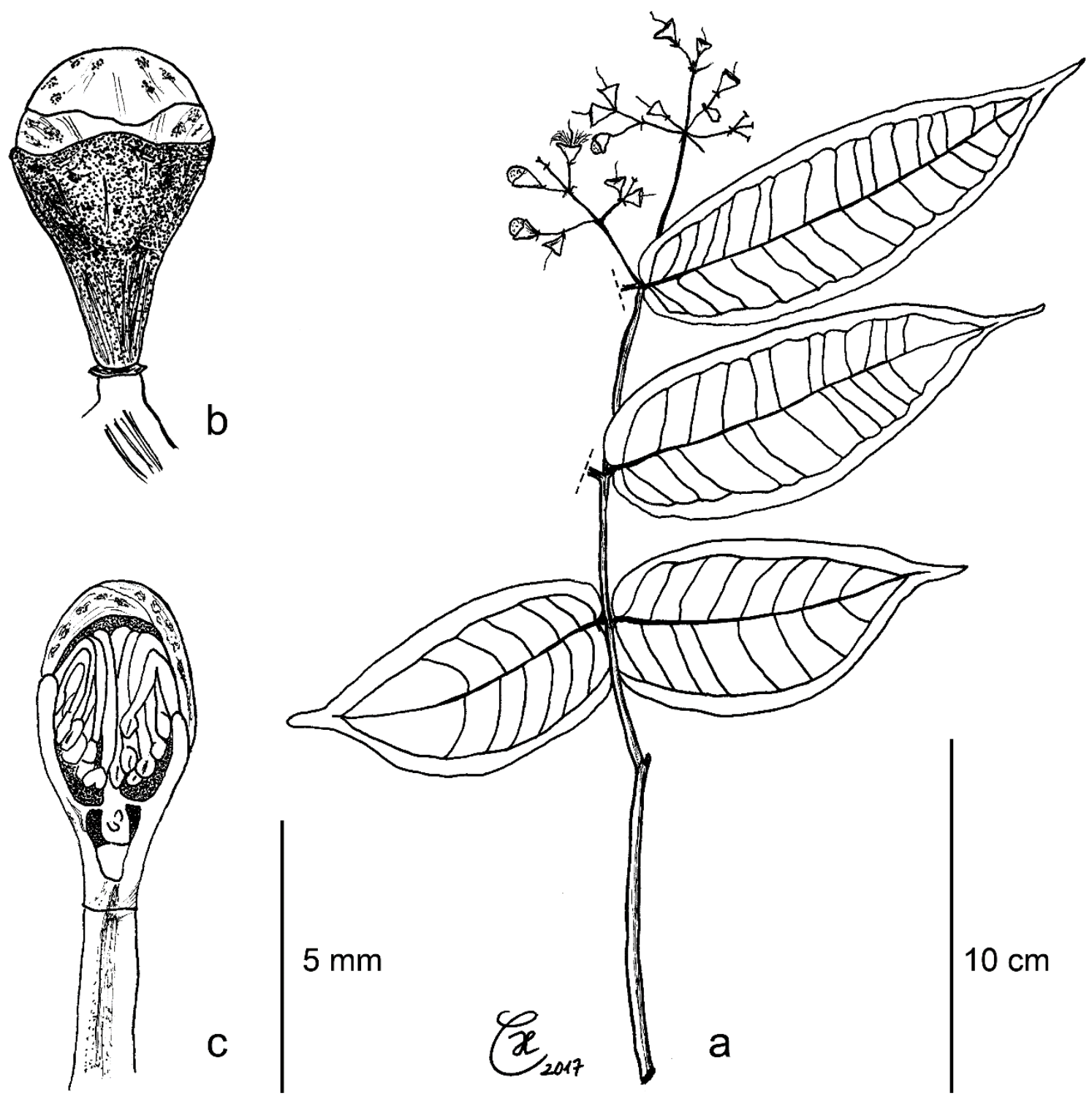

Figure 3.3 Syzygium contiguum: a leafy twig with flowers in different developmental stages; $\mathbf{b}$ flower bud with gland-dotted petals and shallow calyx lobes; c flower bud, longitudinal section. All from holotype Culmsee 535. 


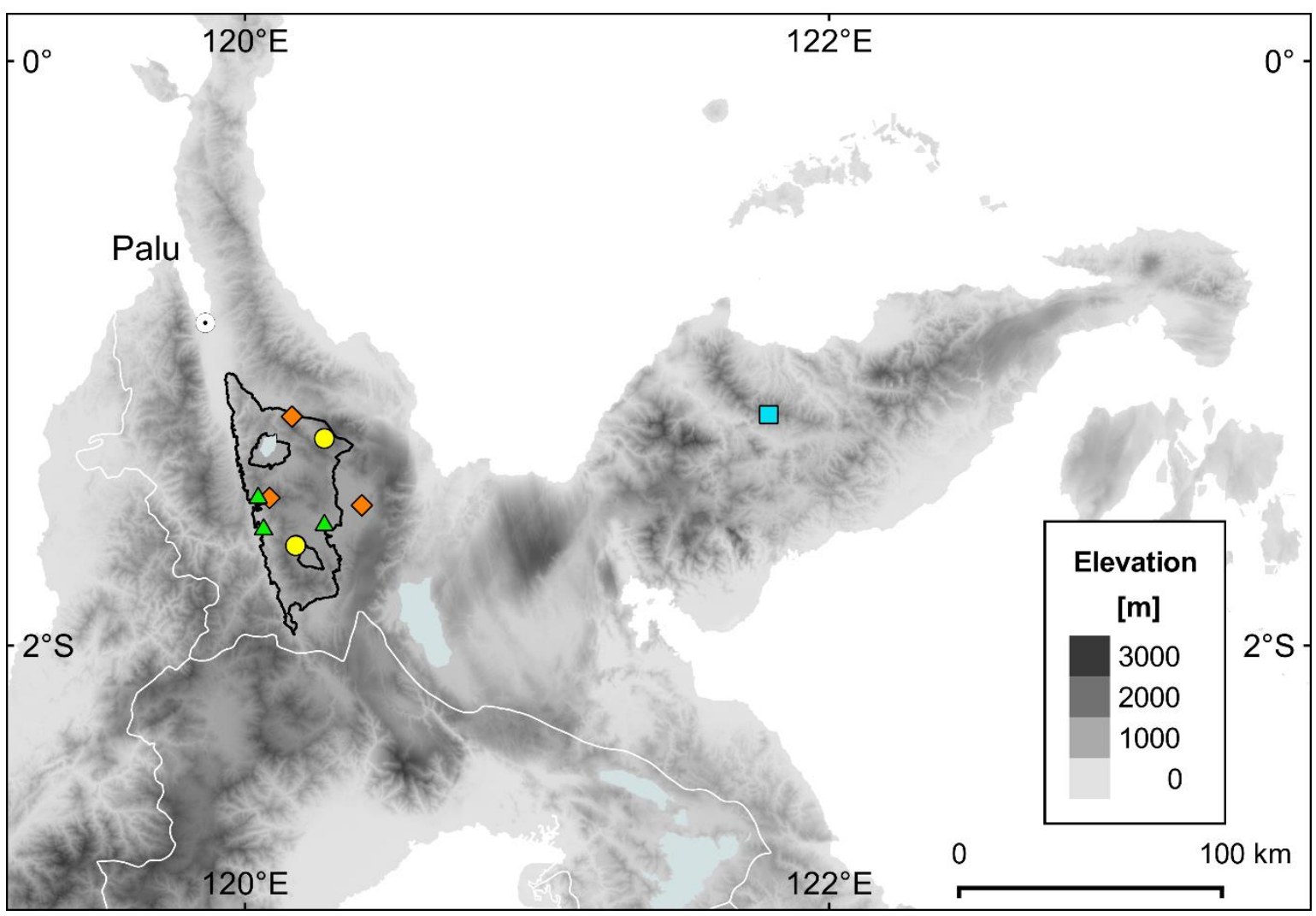

Figure 3.4 Distribution map of four species of Syzygium in Central Sulawesi: Syzygium contiguum (orange diamonds), S. devogelii (yellow dots), S. eymae (light blue square), and S. galanthum (green triangles). Lore Lindu National Park is indicated by a black line. Map created with QGIS (QGIS Development Team 2016) using the digital elevation model of Jarvis et al. (2008).

\subsubsection{Conservation Status}

Syzygium contiguum has a limited geographical distribution (estimated EOO $557 \mathrm{~km}^{2}$ ) and seems to be restricted to sub-montane forest within a narrow elevational belt. We assume that the estimated AOO of $12 \mathrm{~km}^{2}$ is unrealistically low, due to limited collection activities in Central Sulawesi. However, only the collection locality of Meijer 9572 seems to be covered by intact forest habitat. The other two localities are small forest fragments (Widjaja EAW 3502) and forest with recent deforestation activities in close proximity (Pono inventory plots, detected using the Global Forest Change website, Hansen et al. 2013), possibly related to the establishment of cocoa plantations (Aiyen Tjoa, Tadulako University, personal communication, June 2015). Given the apparent narrow geographical and elevational distribution and the recommendation to use a precautionary attitude in conservation assessments (IUCN Standards and Petitions Subcommittee 2017) we propose a preliminary extinction risk assessment of "Endangered" (EN B1ab(i,ii,iii)).

\subsubsection{Notes}

Syzygium urdanetense (as Eugenia urdanetensis, Elmer 1914, 2356), the species most similar to S. contiguum, was originally described from Mt Masay (previously Mt Urdaneta) on the southern Philippine island of Mindanao and is widespread throughout the Philippines (Merrill 1951, Pelser et al. 2011). The species is variable in vegetative characters such as leaf size, leaf base 
(usually rounded and only the very base cordate, but sometimes distinctly cordate) and branchlet shape (usually terete, but rarely subangular). In addition to the characters mentioned in the diagnosis, there are differences in the tertiary venation, the veins being \pm ladder-like and perpendicular to the midrib in $S$. urdanetense whereas in S. contiguum they are \pm parallel to the secondary veins near the midrib and become reticulate towards the leaf margin (Figure 3.8f). While with the available material, S. contiguum can be clearly distinguished from $S$. urdanetense on morphological grounds, we do not discard the possibility that future collections, especially from the northern peninsula of Sulawesi, will uncover populations with intermediate characters. If so, S. contiguum may eventually have to be sunk into an expanded S. urdanetense. In light of the almost complete lack of taxonomic resolution for Syzygium in Sulawesi, we nevertheless consider it advisable to propose $S$. contiguum as a distinct species.

Two fruiting specimens collected at low elevations (200-300 m) on Sulawesi's Southeast Peninsula, Prawiroatmodjo \& Maskuri 1231 [L.2517450] and 1957 [L.2517547], are morphologically similar to $S$. contiguum as defined above except for the leaf tips which are not long-acuminate. In the absence of flowering material, and because of the different habitat and distribution, we prefer not to include them here at present, but future additional collections may prove otherwise.

We choose Culmsee 535 as type specimen because it contains flowers in all stages of maturity although unfortunately, it was collected with only two duplicates (in CEB and L). Nevertheless, the more widely distributed paratypes collected by $\mathrm{HC}$ at the type locality all belong to the same population as the type.

\subsubsection{Additional Specimens Examined (Paratypes)}

INDONESIA. Central Sulawesi (Sulawesi Tengah), LLNP:

Kab. Poso, Kec. Nokilalaki, N slopes of Mt Nokilalaki. ("Celebes, central part, area of Mt. Nokilalaki, Loro Kalimata Reserve"), 1²13'S, 12008'E, \pm 1000 m, 24 Apr 1975: Meijer 9572 (flowers; L [L.2535817]!, US [US-2995269] photo!).

Kab. Poso, Kec. Lore Peore, Road to Napu from camp Dongi-dongi, 1³1.2'S, 120²2.4'E, 1127 m, 26 Dec 1988: Widjaja EA EAW 3502 (fruits; BO [BO-1917489]! [BO-1917490]!, K! , L).

Kab. Sigi, Kec. Kulawi, 2.4 km ENE of Toro, NW of Pono Valley, tree-inventory plot Pono, $1^{\circ} 29.7^{\prime} \mathrm{S}, 120^{\circ} 03.4^{\prime} \mathrm{E}, 1050 \mathrm{~m}$, Jul 2006: Culmsee H 284 (flowers; GOET [GOET020010]!).

Kab. Sigi, Kec. Kulawi, 2.4 km ENE of Toro, NW of Pono Valley, tree-inventory plot "Pono", $1^{\circ} 29.7^{\prime} \mathrm{S}, 120^{\circ} 03.4^{\prime} \mathrm{E}, 1050 \mathrm{~m}$, Jan 2007: Culmsee H y410(flower buds; BO [BO-1938450]! [BO1938451]!, CEB, GOET [GOET020012]!, K [K000993488]!, L!); ibid. loco, Jul 2007: Culmsee H r463(flower buds; BO [BO-1938464]!, CEB, GOET [GOET020011]!, K [K000993489]!, L!!) \& y503 (flower buds; CEB, GOET [GOET020013]!) \& y514 (flower buds; BO [BO-1938452]!, CEB) \& y581 (flower buds; CEB, L!) \& y582 (flower buds; CEB, K [K000993490]!) \& y592 (flower buds; BO [BO-1938453]! [BO-1938454]!, CEB) \& y595 (flower buds; CEB, GOET [GOET020014]!, L!). 


\subsubsection{Syzygium devogelii Brambach, Byng \& Culmsee, sp. nov.}

urn:Isid:ipni.org:names:60474723-2 Figures 3.4, 3.5, 3.8.

„Myrtaceae sp. 10" p.p. (Culmsee and Pitopang 2009, see also 2017 (Erratum)).

\subsubsection{Diagnosis}

Syzygium devogelii is a species of treelets characterised by slender, narrowly winged young branchlets, medium-sized narrowly elliptic leaves, straight and distinct secondary veins connected by an intramarginal vein impressed above and prominent beneath, small flowers ( 5 $\times 3 \mathrm{~mm}$ in bud) in terminal inflorescences that develop into rather large fruits (c. $20 \times 25 \mathrm{~mm}$ ), mature seeds lacking a testa, and cotyledons with echinate outer surfaces. The species is morphologically similar to Syzygium perspicuinervium (Merr.) Masamune $(1942,537)$ but differs from that species in smaller leaves with fewer secondary veins and in flowers with distinct calyx lobes (vs calyx calyptrate). It is furthermore similar to Syzygium valdevenosum (Duthie) Merrill and Perry $(1939,182)$ but differs in lateral veins which are impressed above (vs prominent), much smaller inflorescences, and smaller, obconical (vs infundibuliform) flowers. Floral formula

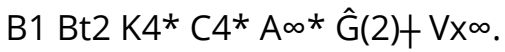

\subsubsection{Type}

INDONESIA. Central Sulawesi (Sulawesi Tengah), LLNP, Kab. Poso, Kec. Lore Utara, west slope of Mt Rorekautimbu, c. 1¹7.5'S 120¹6.3'E, 1350 m, 11 May 1979: de Vogel EF 5293 (fruits; holotype L [L.2535665]! [L.2535666]!; isotype K!).

\subsubsection{Description}

Trees, up to $13 \mathrm{~m}$ tall, diameter at breast height $\leq 13 \mathrm{~cm}$, trunk $\leq 7 \mathrm{~m}$ tall. Outer bark whitish to brown, mealy or peeling off in thin sheets, inner bark pale or dark red, wood cream-coloured. Young branchlets 1-2.5 $\times 2-3 \mathrm{~mm}, \pm$ flattened, angular or oblong in cross section with 4 narrow wings, epidermis dark red when young, drying reddish or yellowish brown, smooth; becoming rounded with 4 ridges, bark (yellowish) brown, peeling off in thin sheets.

Leaves (sub-)opposite. Petioles 7-16 × 1-3 mm, channelled above, rounded beneath, epidermis drying smooth or with transverse cracks. Blades (12.5-) 14-19 (-22.5) × (4-) 4.5-7 (-8.5) cm, ratio (2.1-) 2.6-3.3 (-4), narrowly elliptic (or lanceolate), base cuneate or obtuse, apex acuminate, margin revolute; chartaceous or coriaceous, red or pink when young, above, beneath, drying dull to satin, variable in colour from greyish brown and olive grey to very dusky red above, dull to satin and, dark reddish brown beneath; pellucid dots rather few, visible or not on both sides. Midrib channelled above, very prominent, rounded, smooth and drying darker than the lamina beneath. Secondary vein pairs (9-) 11-14 (-17), 5-22 mm apart, channelled or impressed above, prominent and drying darker than the lamina beneath, straight or slightly arching from the midrib; intersecondary veins sometimes present. Tertiary veins dense, \pm ladder-like and perpendicular to the midrib, faint above, prominulous beneath. Inner intramarginal vein 2-9 
$\mathrm{mm}$ from leaf margin, looping or not and prominent; outer intramarginal vein $0.5-1.5 \mathrm{~mm}$ from leaf margin, as prominent as tertiary venation.

Inflorescences terminal, dense metabotryoids, $2.5 \mathrm{~cm}$ long, peduncles $1 \mathrm{~cm}$ long, axes flattened, with 2 or 4 narrow wings, drying brown. Bracts c. $1.5 \mathrm{~mm}$ long, ovate, keeled, caducous; bracteoles 2 per flower, $1 \mathrm{~mm}$ long, similar to bracts.

Flowers c. 15 per inflorescence, within the inflorescence in triads, 4-merous, anthopodium absent, only known before anthesis, mature buds $5 \times 3 \mathrm{~mm}$. Hypanthium c. $4 \times 3 \mathrm{~mm}$, obconical, drying dark reddish brown, densely glandular-warty, hypanthium rim $2 \mathrm{~mm}$ long, glandular inside. Calyx lobes c. $1 \times 2 \mathrm{~mm}$, broadly rounded. Petals c. $3 \times 3 \mathrm{~mm}$, cucullate in bud. Stamens c. 100, filaments 2-3 mm long, anthers c. $0.4 \mathrm{~mm}$ long, ellipsoid. Ovary bilocular, surrounded by spongy tissue, ovules numerous per locule, ascending. Style 3-4 mm long, pointed.

Fruits 1 -seeded, c. $20 \times 25 \mathrm{~mm}$, irregularly depressed globose, laterally compressed, green, drying black and, smooth, pericarp \pm woody, $1 \mathrm{~mm}$ thick, hypanthium rim 1-2 mm long, 5-9 mm in diameter.

Seeds c. $15 \times 20 \mathrm{~mm}$, transverse ellipsoid, testa adhering to the pericarp, spongy inside and adhering to the outer surface of the cotyledons, cotyledons \pm half-globose, facing surfaces undulate, outer surfaces densely echinate, protuberances obscured by spongy testa tissue.

\subsubsection{Etymology}

The species is named after Eduard Ferdinand de Vogel (*1942). Ed de Vogel is a renowned authority on Malesian orchids, especially those from New Guinea. His contributions to the flora of Sulawesi are perhaps less well known: with almost 2000 specimens of excellent quality collected there in 1973-74 and 1979 - among them the type specimen of this species - he was one of the most prolific plant collectors on the island during the $20^{\text {th }}$ century.

\subsubsection{Phenology}

Flowering was recorded in August, fruiting in May.

\subsubsection{Distribution and Habitat}

Syzygium devogelii is endemic to the province of Central Sulawesi, currently known to occur in lower montane forest at two localities in LLNP from 1350-1400 m elevation (Figure 3.4). In the Bariri NE inventory plot, it was fairly common, growing on mid-slope terraces with Rhodic Ferralsols (IUSS Working Group WRB 2014) derived from acid plutonic rocks. The forest there was dominated by Fagaceae, Myrtaceae, Burseraceae, Lauraceae, and Elaeocarpaceae (families with top five FIV) and contained six other species of Syzygium: S. acuminatissimum, S. aff. baeuerlenii (F.Muell.) Craven and Biffin (in Craven et al. 2006, 135), S. lineatum, S. zeylanicum (L.) de Candolle $(1828,260)$, and two undetermined species (Brambach and Culmsee, unpublished). See Culmsee and Pitopang (2009) for more information on the floristics of the Bariri forest. 


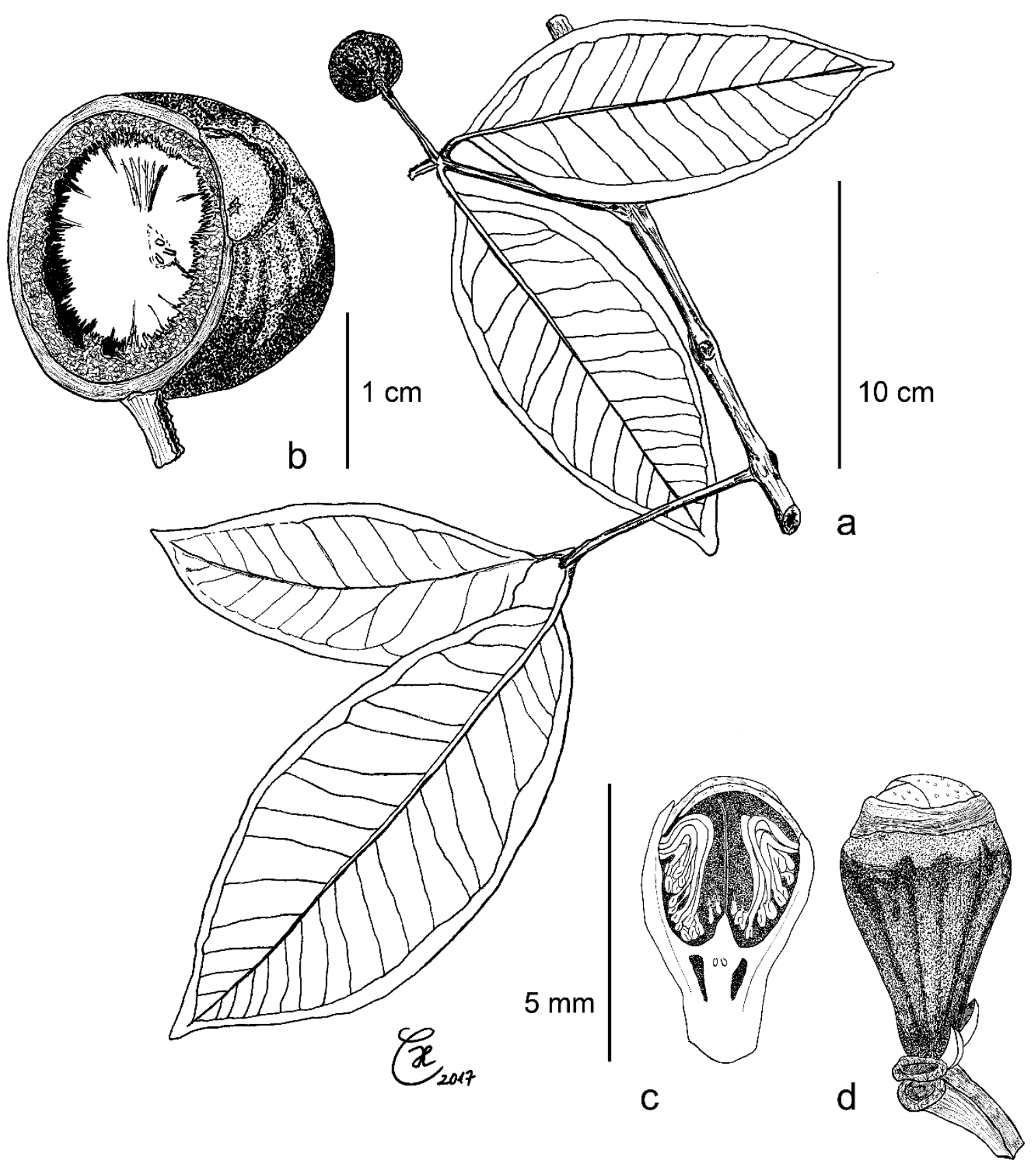

Figure 3.5 Syzygium devogelir: a leafy twig with fruit; b longitudinal section of ripe fruit with inner, flat side of cotyledon and echinate outer surface; c flower bud, longitudinal section; $d$ flower bud, exterior view. ab holotype de Voge/ 5293, c-d Culmsee 1564.

\subsubsection{Conservation status}

Syzygium devogelii has a limited geographical distribution and seems to be restricted to lower montane forest within a narrow elevational belt. Known from only two localities, the EOO and AOO cannot be estimated reliably for the species. Because of the low collection density in Central Sulawesi, we believe that the species is more widespread and common than it currently appears. Deforestation has been recorded close to the type locality (using the Global Forest Change website, Hansen et al. 2013). Given the apparent narrow geographical and elevational distribution, ongoing deforestation and the recommendation to use a precautionary attitude in 
conservation assessments (IUCN Standards and Petitions Subcommittee 2017), we propose a preliminary extinction risk assessment of "Endangered" (EN B1ab(i,ii,iii)).

\subsubsection{Notes}

Most species of Syzygium are reported to have cotyledons with rather smooth outer surfaces, unlike the peculiar echinate cotyledons of $S$. devogelii. We here interpret the tissue covering the outer surface of the cotyledons (Figure 3.5) and obscuring its protuberances as derived from the testa, as reported for the Australian species Syzygium bungadinnia (F.M.Bailey) Hyland $(1983,64)(1983,64)$, but closer examinations of fruit and seed structures are necessary to corroborate this interpretation.

Juvenile specimens of Syzygium balgooyi are similar to S. devogelii in their leaf shape, colour, and venation. In fact, both species were treated as one morphotype in Culmsee and Pitopang $(2009,2017)$. Besides the very different flowers, they can, however, be distinguished by the shape of the young branchlets: strongly flattened and with rounded ridges in S. balgooyi(Figure 3.1e) vs \pm flattened with 4 narrow wings in S. devogelii (Figure 3.5).

\subsubsection{Additional Specimens Examined (Paratypes)}

INDONESIA. Central Sulawesi (Sulawesi Tengah), LLNP, Kab. Poso, Kec. Lore Tengah:

$9 \mathrm{~km} \mathrm{NW}$ of Bariri, $100 \mathrm{~m}$ east of climate tower, tree-inventory plot Bariri NE, $1^{\circ} 39.4^{\prime} \mathrm{S}$, 120¹0.5'E, 1400 m, 9 Sep 2006: Culmsee H 1333 (sterile; BO [BO-1938455]!, CEB) \& 1378 (sterile; CEB, K [K000993491]!); ibid. loco, 18 Aug 2011: Brambach F, Mangopo H, Firdaus, Faber M, Tiranda R 0818 (sterile; BO [BO-1938442]!, CEB, GOET [GOET020015]!) \& 0845 (sterile; BO [BO-1938443]!, CEB, L!).

$9 \mathrm{~km} \mathrm{NW}$ of Bariri, $80 \mathrm{~m}$ south of climate tower, tree-inventory plot Bariri S, $1^{\circ} 39.5^{\prime} \mathrm{S}$, 120¹0.4'E, 1400 m, Jul 2006: Culmsee H 1252 (sterile; CEB, GOET [GOET020016]!) \& 1564 (flower buds; CEB, L!).

\subsubsection{Syzygium eymae Brambach, Byng \& Culmsee, sp. nov.}

\section{urn:Isid:ipni.org:names:60474724-2 Figures 3.4, 3.6, 3.8}

\subsubsection{Diagnosis}

Syzygium eymae is characterised by small (usually $2.3-4 \times 1.5-2.5 \mathrm{~cm}),($ sub-)sessile, leaves with thickly coriaceous, (broadly) elliptic or obovate blades, dense terminal inflorescences, and small, pyriform flowers with a calyptrate calyx that bears a minute apical opening and splits irregularly at anthesis. It differs from the morphologically similar Syzygium paradoxum (Merr.) Masamune $(1942,536)$ in angular young branchlets (vs terete), leaves without conspicuous gland dots (vs leaves conspicuously gland-dotted beneath), fewer pairs of secondary veins (5-7 vs 10-14), and smaller (5-6 $\times 3$ vs c. $12 \times 5 \mathrm{~mm}$ in mature buds), pyriform flowers without anthopodia (vs

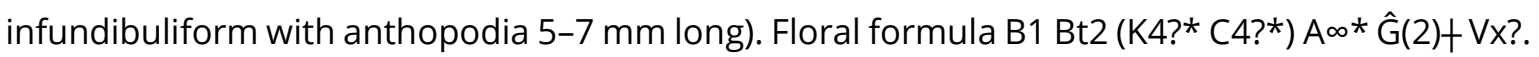




\subsubsection{Type}

INDONESIA. Central Sulawesi (Sulawesi Tengah), Kab. Tojo Una-Una, Border of Kec. Ulubongka and Kec. Ampana Tete, Mt Lumut, between summit and western secondary peak, c. $1^{\circ} 12.3^{\prime} \mathrm{S}$, $121^{\circ} 47.6^{\prime} E, \pm 2200$ m ("Selebes, Res. Menado. O.afd. Poso. G. Lóemoet, Pilaartop en W. bijtop. (summit)"), 5 Sep 1938: Eyma 3624 (flowers; holotype U [U.1439024]!; isotypes: BO [BO1679767]!, L [L.2535689]!).

\subsubsection{Description}

Trees, height, bark and wood unknown. Young branchlets slender, 0.5-1 × 1-2 mm, rectangular in cross section, ridges arising at the petioles and running downwards to next node, epidermis drying reddish black; remaining angular or becoming \pm terete, bark reddish brown and scaly; with 1-2 pairs of minute cataphylls near the base of the current flush.

Leaves opposite, (sub-)sessile. Petioles 0.5-2 $\times 1-1.5 \mathrm{~mm}$, absent or very short and stout, drying black. Blades (1.8-) 2.3-4 (-5.2) × (1.2-) 1.5-2.5 (-3.1) cm, ratio 1.3-2, (broadly) elliptic or (broadly) obovate, base obtuse or rounded, apex rounded, acute, or shortly acuminate, margin revolute; thickly coriaceous (c. $0.3 \mathrm{~mm}$ thick), dull, drying dark reddish grey to reddish black above, (very) dusky red beneath; without black gland dots. Midrib impressed above, prominent, rounded, and darker than the lamina beneath. Secondary vein pairs (4-) 5-7, 3-10 mm apart, channelled and inconspicuous above, (slightly) prominent and more reddish than the lamina beneath; intersecondary veins sometimes present. Tertiary veins reticulate, channelled above, indistinct beneath. Inner intramarginal vein 1-2 $\mathrm{mm}$ from leaf margin, looping; outer intramarginal vein not present.

Inflorescences terminal, 2-nodate metabotryoids, $\leq 3 \mathrm{~cm}$ long, peduncles $\leq 1 \mathrm{~cm}$ long, axes angular. Bracts c. 1-1.5 mm long, deltate, keeled, caducous; bracteoles 2 per flower, c. $1 \mathrm{~mm}$ long, similar to bracts.

Flowers $\leq 10$ per inflorescence, within the inflorescence in triads, anthopodium absent, mature buds 5-6 $\times 3 \mathrm{~mm}$. Hypanthium 4-5 × 4-5 mm, pyriform, smooth, hypanthium rim $1.5 \mathrm{~mm}$ long. Calyx lobes calyptrate with small apical opening, slightly lighter-coloured than hypanthium when dry, splitting irregularly at anthesis, caducous. Petals calyptrate, adhering to the calyx. Stamens c. 50, filaments 6-7 mm long, white, anthers c. $0.4 \mathrm{~mm}$ long, ellipsoid. Ovary bilocular, ovules several per locule, ascending. Style 6-7 mm long, pointed.

Fruits and seeds unknown.

\subsubsection{Etymology}

The species is named after Pierre Joseph Eyma (1903-1945), one of the early botanists to explore the mountainous regions of Central Sulawesi (Eyma 1940, 194, van Steenis-Kruseman and van Welzen 2014). Eyma collected many valuable specimens from high-elevation areas, including the type specimen of this species.

\subsubsection{Phenology}

The species was collected in flowering state in September 1938. 


\subsubsection{Distribution and Habitat}

S. eymae is endemic to the province of Central Sulawesi and currently only known from the type locality: Mt Lumut on Sulawesi `s eastern peninsula (Figure 3.4). No information on habitat is given on the label of the type specimen. Mt Lumut is made up of ultramafic rocks (Geological Research and Development Centre 1993) and upper montane (cloud) forest would be the expected vegetation type there at $2200 \mathrm{~m}$.

\subsubsection{Conservation Status}

With only the type specimen known, we consider S. eymae "Data Deficient" (DD) at present, following the IUCN Red List Categories and Criteria (IUCN 2012).

\subsubsection{Notes}

The species of tribe Syzygieae Wilson (in Wilson et al. 2005, 15) bearing a calyptrate calyx have mostly been treated under the genus Cleistocalyx Blume (1850, 84, see Merrill and Perry 1937). The calyptrate calyx is a relatively rare character, currently known to occur in only about 30 of the $>1200$ species of Syzygieae (Merrill and Perry 1937, Chantaranothai and Parnell 1993, Takeuchi 2002, Biffin et al. 2005, Craven and Biffin 2010). Its occurrence, however, is widely spread over the phylogenetic tree of the tribe; so Cleistocalyx is not monophyletic and has therefore been synonymised under an expanded Syzygium (Craven et al. 2006, Craven and Biffin 2010).

The flowers of Cleistocalyx are described as having "calyptrate calyces, the undivided, often more or less indurated upper parts of which fall as a lid", the lid often remaining attached at one side of the flower at early anthesis (Merrill and Perry 1937). In S. eymae, the calyx clearly has the form of a calyptra, but at anthesis it splits irregularly into four or five parts, starting with a minute $(<0.5 \mathrm{~mm}$ diam.) apical opening (Figure 3.6). One or several of the irregular segments may remain attached to the hypanthium rim shortly after anthesis before eventually being shed. The mode of dehiscence of the calyx thus seems to represent an intermediate condition between Cleistocalyx and classical Syzygium, similar to the situation in Syzygium apodophyllum (F.Muell.) Hyland $(1983,49)$ from Queensland, Australia.

Most species of Syzygium with calyptrate calyces are clearly different from S. eymae in their much larger leaves with more pairs of secondary veins. The few small-leaved species can all be easily distinguished: S. paradoxum from Borneo differs by the characters given in the diagnosis. S. pseudocalcicola Craven and Biffin (in Craven et al. 2006, 139) from the Philippines and $S$. canicortex Hyland $(1983,66)$ from Queensland have many, closely parallel secondary veins and caudate leaf apices, S. apodophyllum has ovate leaves with a long-acuminate apex and clavate flowers. Several specimens collected on Mt Rorekautimbu in LLNP at 2400 m (e.g. Brambach et al. 0768) may belong here. They are morphologically similar to the type specimen, but have longer petioles. Since we currently lack flowering material of these specimens and because of the large distance between the respective collection localities, we prefer to await more specimens before incorporating these collections in S. eymae. 


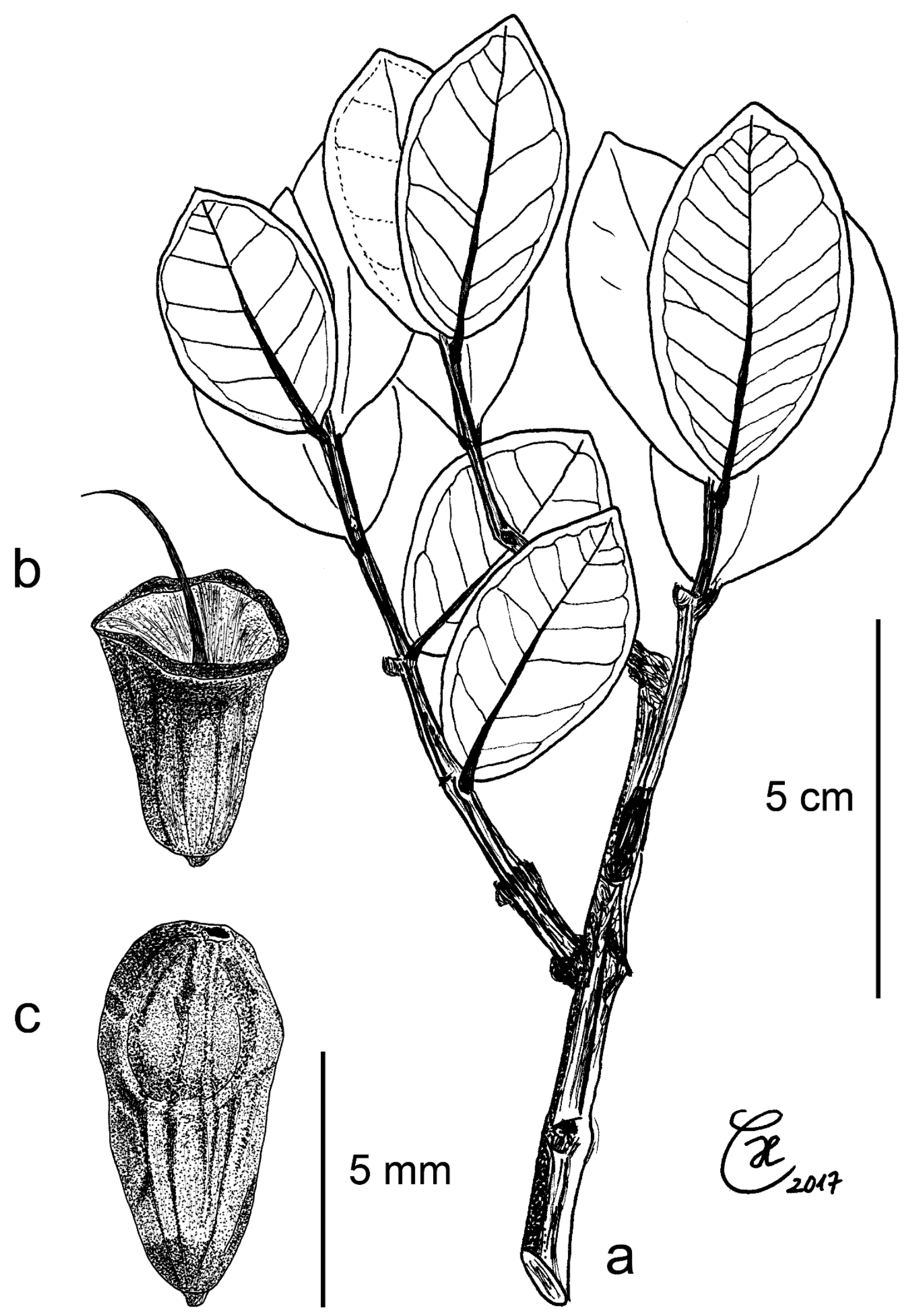

Figure 3.6 Syzygium eymae: a. leafy twig; b. flower after shedding of calyx and stamens; c. closed pyriform flower, calyptrate calyx with minute apical opening. All drawings from isotype (L) Eyma 3624. 


\title{
3.4.5 Syzygium galanthum Brambach, Byng \& Culmsee, sp. nov.
}

\author{
urn:Isid:ipni.org:names:60474725-2 Figures 3.4, 3.7, 3.8.
}

“Myrtaceae sp. 7" (Culmsee and Pitopang 2009)

\subsubsection{Diagnosis}

Syzygium galanthum is similar to Syzygium hylochare (Diels) Merrill and Perry $(1942,249)$ from New Guinea but differs from that species in larger leaves (usually 15-22 vs 8-14 cm long), more slender flowers with longer anthopodia (5-10 vs 3-5 $\mathrm{mm}$ ) and milky white petals (vs pink or red). It is also similar to the widely cultivated Syzygium malaccense (L.) Merrill and Perry (1938b, 215) but has subangular (vs clearly angular) and more slender branchlets (2-3 vs 6-8 $\mathrm{mm}$ in diameter), smaller, chartaceous leaves (vs coriaceous), more slender inflorescences, more slender flowers with longer anthopodia (5-10 mm vs 0-5 mm), hypanthia which dry reddish brown with many black glands (vs drying dark brown without conspicuous glands), and creamywhite petals (vs pink or red). Floral formula B1Bt2 K2:2+C4* $A \infty * \hat{G}(2)+V x^{\infty}$.

\subsubsection{Type}

INDONESIA. Central Sulawesi (Sulawesi Tengah): LLNP, Kab. Poso, Kec. Lore Tengah, 3.5 km NE of Rompo, following road to Katu for $3 \mathrm{~km}$, then following footpath $\mathrm{N}$ for $2 \mathrm{~km}$, tree-inventory plot Tarara, 1³5.3'S 120¹7.0'E, 1200 m, 29 Nov 2011: Brambach F, Mangopo H, Firdaus, Faber $M$, Tiranda R 1316 (flowers; holotype L[L.3962132]!; isotypes BO [BO-1938381]!, CEB, GOET [GOET020017]!, K [K000993484]!).

\subsubsection{Description}

Trees, up to $25 \mathrm{~m}$ tall, diameter at breast height $\leq 30 \mathrm{~cm}$, trunk straight, $\leq 15 \mathrm{~m}$ tall, with buttresses $0.4 \mathrm{~m}$ tall, sometimes with stilt roots. Outer bark bright- or rusty red, peeling off in thin sheets, inner bark pale or dark red, wood straw or cream-coloured. Young branchlets 1-2 $\times$ 2-3 mm, subangular, flattened, epidermis olive, drying reddish brown, striate; becoming \pm terete, bark (reddish) brown, striate or fissured, later peeling off in small thin sheets.

Leaves (sub-)opposite. Petioles 6-18 $\times 1-3 \mathrm{~mm}$, channelled above, rounded beneath, turning corky, pale brown, drying (reddish) brown. Blades (10-) 12-23 (-26) × (4-) 5.5-7.5 (-9) cm, ratio (1.7-) 2.5-3.2 (-3.5), (narrowly) elliptic or rarely oblanceolate, base acute, obtuse, or rounded, apex acuminate, acumen often recurved, margin flat or revolute; chartaceous, glossy green and often \pm bullate above, paler green beneath, drying dull and (greyish or olive) brown above, dull and (yellowish or greyish) brown beneath; pellucid dots scattered or numerous, usually visible on lower surface and sometimes also on upper surface. Midrib channelled above, prominent, rounded, drying pale or reddish brown, striate and with dark gland dots beneath. Secondary vein pairs (6-) 8-10 (-12), 7-25 mm apart, prominulous or not, concolorous with the lamina and usually inconspicuous above, prominent and concolorous with or more reddish than the lamina beneath; intersecondary veins present. Tertiary veins reticulate, lax, prominulous or not, concolorous with the lamina and usually inconspicuous above, prominent and concolorous with 
or more reddish than the lamina beneath. Inner intramarginal vein 3-8 $\mathrm{mm}$ from leaf margin, (strongly) looping; outer intramarginal vein 1-3 $\mathrm{mm}$ from leaf margin.

Inflorescences axillary on leafless portion of the twigs, often fascicled, lax, (sub-)sessile botryoids or monads, 3-5 cm long, peduncles absent or $\leq 1 \mathrm{~cm}$ long, axes angular, drying (reddish) brown with many black gland dots, turning corky at the base, often with conspicuous whitish blisters. Bracts c. $0.5 \mathrm{~mm}$ long, early caducous; bracteoles 2 per flower, similar to bracts. Flowers 1-8 per inflorescence, within the inflorescence in monads, 4-merous, only known before anthesis, mature buds 15-25 × 5-7 mm, anthopodium 5-10 (-14) mm long, slender. Hypanthium 7-11 × 5-7 mm, infundibuliform, pale green, drying dark reddish brown, wrinkled, densely black gland-dotted and with conspicuous whitish blisters, hypanthium rim $3 \mathrm{~mm}$ long. Calyx lobes $2 \times 3-5$ (outer) and 3-4 × 5-7 (inner) mm, broadly rounded with thin hyaline margins, greenish white, drying red, sparsely gland-dotted. Petals c. $8 \times 6 \mathrm{~mm}$, hood shaped before anthesis, milky white, drying yellowish red, faintly veined and densely pellucid-dotted. Stamens c. 100, filaments 4-10 mm long before anthesis, yellowish green, anthers c. $1 \mathrm{~mm}$ long, ovoid or ellipsoid, yellow. Ovary bilocular, locules surrounded by spongy tissue, ovules many per locule, ascending. Style $10 \mathrm{~mm}$ long before anthesis, pointed, green.

Fruits and seeds unknown.

\subsubsection{Etymology}

The species name derives from the Greek yáda (milk) and áv $\theta o \varsigma$ (flower) and refers to the petals' milky white colour (Figure $3.7 \mathrm{~g}$, j). The colour pattern of the flowers is furthermore similar to the one found in the amaryllidaceous genus Galanthus Linnaeus $(1753,288)$.

\subsubsection{Phenology}

The type specimen was collected with mature flower buds in late November, suggesting flowering in December.

\subsubsection{Distribution and Habitat}

Syzygium galanthum is currently only recorded from LLNP in the province of Central Sulawesi (Figure 3.4). There it occurs scattered in undisturbed submontane forest at three localities from 700-1200 m over Sideralic Cambisols and mollic Umbrisols derived from varied parent material. The forests at these localities were dominated by species of Fagaceae, Lauraceae, Moraceae, and Sapotaceae, among others.

\subsubsection{Conservation Status}

Syzygium galanthum has a limited geographical distribution (estimated EOO $140 \mathrm{~km}^{2}$ ) and seems to be restricted to submontane forest between 700 and $1200 \mathrm{~m}$. We assume that the estimated AOO of $12 \mathrm{~km}^{2}$ is unrealistically low, due to limited collection activities in Central Sulawesi. However, despite being inside the protected LLNP, recent deforestation activities have been detected near one of the collection sites (Pono inventory plot, detected using the Global Forest Change website, Hansen et al. 2013), possibly related to the establishment of cocoa 
plantations (Aiyen Tjoa, Tadulako University, personal communication June 2015). Given the ongoing deforestation activities in the species' narrow geographical range and the recommendation to use a precautionary attitude in conservation assessments (IUCN Standards and Petitions Subcommittee 2017) we propose a preliminary extinction risk assessment of "Endangered" (EN B1ab(i,ii,iii)).
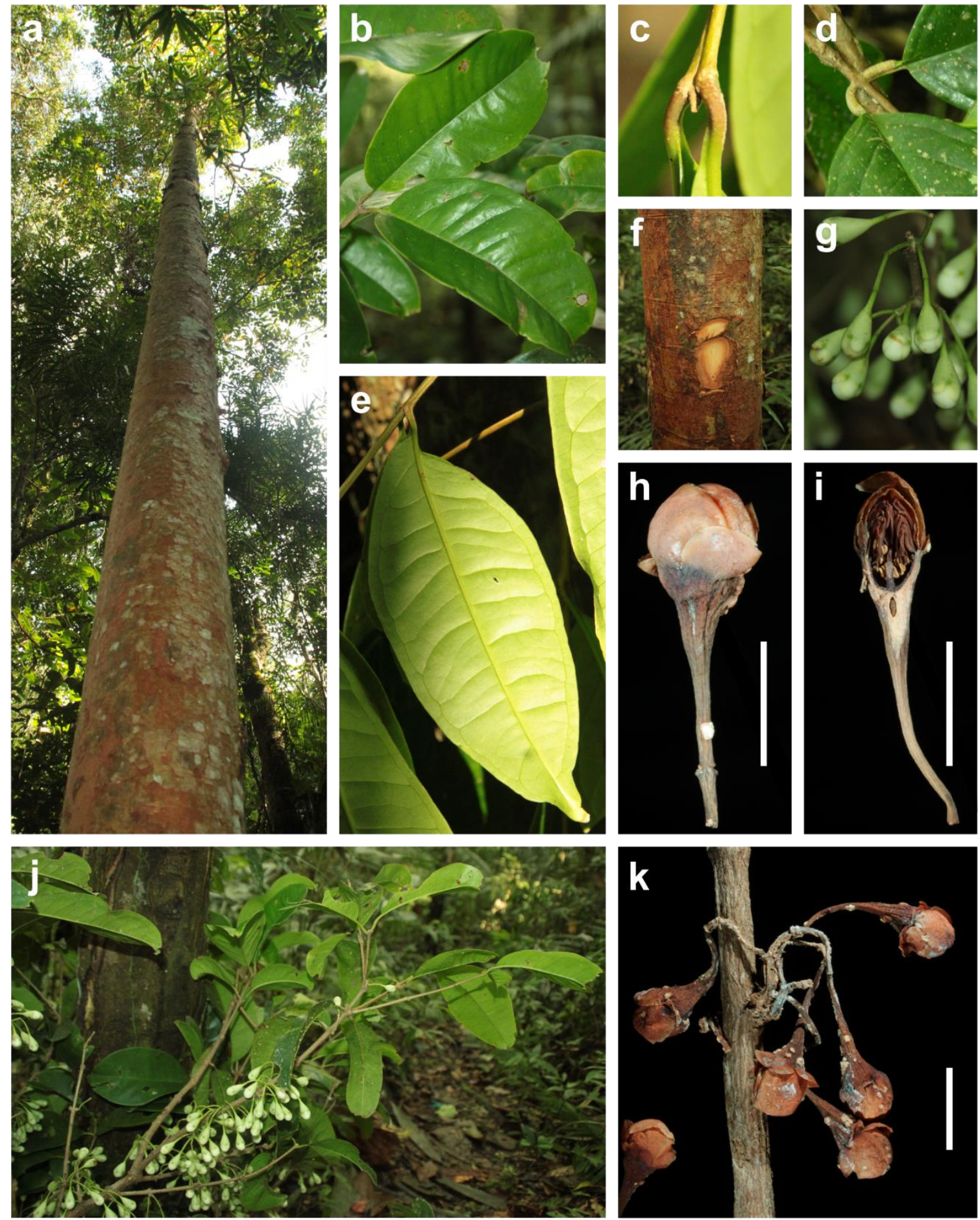

Figure 3.7 Morphological characters of Syzygium galanthum. a trunk, c. $15 \mathrm{~m}$ tall; b upper side of leaves; c branchlet tip with smooth younger petioles; $\mathbf{d}$ older corky petioles; e underside of leaf; $\mathbf{f}$ bark slash; $\mathbf{g}$ mature flower buds in fresh state; $h$ dried mature flower bud with apical part of inflorescence axis and white blister on the anthopodium; i longitudinal section of mature flower bud in dried state; $j$ branch with mature flower buds below the leaves; $\mathbf{k}$ detail of dried, fascicled inflorescences. $\mathbf{a}-\mathbf{b}$ and $\mathbf{f}-\mathbf{k}$ type collection Brambach et al. 1316; c and e Brambach et al. 1083; d Brambach et al. 1047. All scale bars $=1 \mathrm{~cm}$. 


\subsubsection{Vernacular name}

Tambeanitu (Bahasa Behoa, Brambach et al. 1316).

\subsubsection{Notes}

In the field, S. galanthum can be recognised by the leaves with corky petioles and rather few, \pm arching secondary veins. Similar corky petioles occur in S. peregrinum (Blume) Merrill and Perry $(1939,154)$ from Borneo and the Southern Philippines. A peculiarity is the presence of white blisters on the inflorescence axes and flowers of dried material (Figure 3.7h, k). These blisters were not observed in fresh state and must have appeared during the drying process.

It appears that there is a group of morphologically similar species in Malesia, all characterised by pale-drying leaves with rather few secondary veins, inflorescences below the leaves, and medium-sized to large, showy, infundibuliform flowers with short or long anthopodia and either white or red/pink petals and stamens: e.g. S. iliasii Ashton $(2011,222)$ from Borneo, $S$. galanthum and several unnamed collections from Sulawesi, S. hylochare, S. laqueatum Merrill and Perry $(1942,257)$, and S. phaeostictum from New Guinea and possibly the Maluku Islands, and the widely cultivated S. malaccense with unknown geographical origin. As can be seen from material in $\mathrm{L}$, the assignation of specimens to these species has not been consistent in the past and specific limits in the group need to be critically revised.

\subsubsection{Additional Specimens Examined (Paratypes)}

INDONESIA. Central Sulawesi (Sulawesi Tengah), LLNP:

Kab. Poso, Kec. Lore Tengah, $3.5 \mathrm{~km}$ NE of Rompo, following road to Katu for $3 \mathrm{~km}$, then following footpath $\mathrm{N}$ for $2 \mathrm{~km}$, tree-inventory plot Tarara, $1^{\circ} 35.3^{\prime} \mathrm{S} 120^{\circ} 17.0^{\prime} \mathrm{E}, 1200 \mathrm{~m}, 22$ Nov 2011: Brambach F, Mangopo H, Firdaus, Faber M, Tiranda R 1047 (sterile; BO [BO1938446]!, CEB, GOET [GOET020018]!) \& 1083 (sterile; BO [BO-1938445]!,CEB, L!) \& 1290 (sterile; BO [BO-1938444]!, CEB, K [K000993485]!).

Kab. Sigi, Kec. Kulawi, 2.4 km ENE of Toro, NE edge of Pono Valley, tree-inventory plot Pono, $1^{\circ} 29.7^{\prime} \mathrm{S}, 120^{\circ} 03.4^{\prime} \mathrm{E}, 1050 \mathrm{~m}, 16$ Aug 2006: Culmsee 537(sterile; CEB, K [K000993492]!) \& 890 (sterile; BO [BO-1938448]!, CEB); ibid. loco, Jul 2007: Culmsee r497(sterile; BO [BO-1938449]!, CEB, GOET [GOET020019]! , L!).

Kab. Sigi, Kec. Kulawi Selatan, 4 km ENE of Watukilo, 400 m N of Mboe River, tree-inventory plot Rantena, 1³6.2'S, $120^{\circ} 04.5^{\prime} \mathrm{E}, 700$ m, 17-26 Jun 2011: Brambach F, Mangopo H, Firdaus, Faber $M$, Tiranda R 0533 (sterile; BO [BO-1938447]!, CEB, L!). 


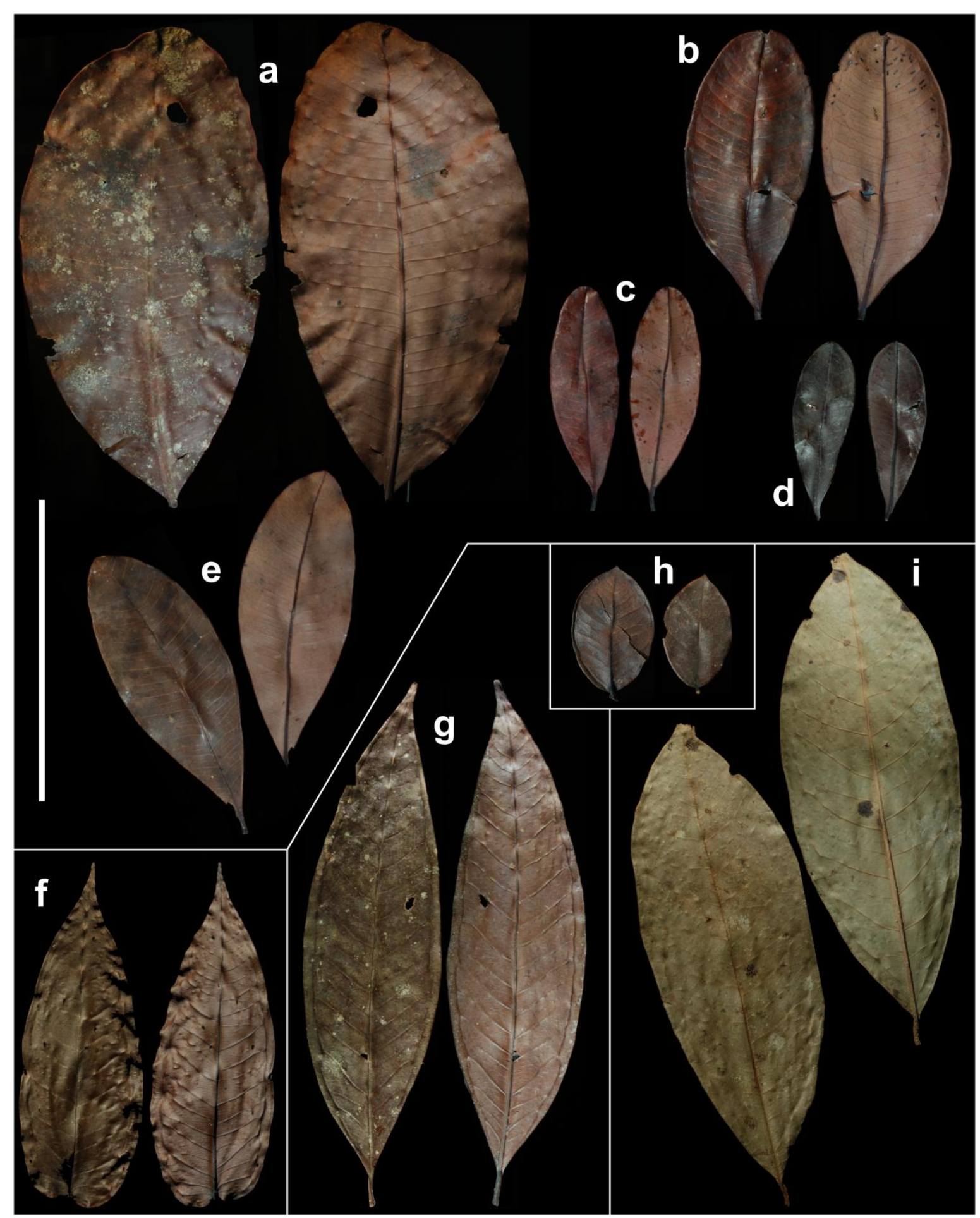

Figure 3.8 Leaves of all new species described. Variation of Syzygium balgooyi (a-e), S. contiguum (f), $S$. devogelii(g), S. eymae (h), and S. galanthum (i). a Brambach et al. 0283, b Brambach et al. 0681, c Brambach et al. 1333, d de Vogel 5413 [L.2517563], e Culmsee r2162, f Culmsee r463, g Brambach et al. 0818, h Eyma 3624 [L.2535689], i Brambach et al. 0533. Scale bar $=10 \mathrm{~cm}$, valid for all leaves. 


\title{
4 Diversity, endemism, and composition of tropical mountain forest communities in Sulawesi, Indonesia, in relation to elevation and soil properties
}

\author{
Fabian Brambach, Christoph Leuschner, Aiyen Tjoa, Heike Culmsee \\ Published in Perspectives in Plant Ecology, Evolution and Systematics 27: 68-79 (Aug 2017), \\ https://doi.org/10.1016/j.ppees.2017.06.003
}

\subsection{Abstract}

Explaining the diversity and distribution of tree taxa in the isolated tropical mountain forests (TMF) of the Malesian archipelago remains one of the great challenges of tropical biogeographical research. We investigated tree diversity, endemism and community composition in 13 plots of 0.24 ha between 700 and $2400 \mathrm{~m}$ in the TMF of Central Sulawesi's (Indonesia) highlands and related the patterns to gradients in elevation, climate and soil properties. Special attention was paid to understorey trees with stem diameters as low as $2 \mathrm{~cm}$, not exceeding 2/3 of stand canopy height. Based on extensive taxonomic work on the plots, we found that Sulawesi's TMF flora is with 27-78 species per 0.24 ha not species-poorer than that of other Malesian islands, and vascular plant endemism is higher (22\% of the species endemic to Sulawesi) than previously thought. Alpha diversity was mainly dependent on elevation and not soil factors (7 parameters tested). The alpha diversity of tree species, genera and families declined linearly with elevation, as did the number of species and genera per family, revealing higher phylogenetic clustering at lower elevations. Indicator Species Analysis and cluster analysis identified three main forest belts (sub-montane at c. 700-1400 m, lower montane at c. 1400-2000 m, upper montane at >c. $2000 \mathrm{~m}$ ), deviating from earlier zonation concepts by separating sub-montane (rich in taxa related to the lowlands) and lower montane communities (rich in Fagaceae and Myrtaceae). With $27-51 \%$ of all tree species in a plot never found in the upper canopy, our data suggest that the guild of true understorey tree species is species-rich (estimated at c. 130 species in our region), contradicting the hypothesis that Southeast Asian tropical forests with mass-flowering trees (here: Fagaceae) are particularly poor in understorey tree species. We conclude that the mountains of Sulawesi harbour remarkably species-rich, but still understudied, TMF with a unique tree flora rich in understorey trees, which are of high conservation priority.

\subsection{Introduction}

Tree species richness is not uniformly distributed across the tropics. In addition to differences at the continental scale (Barthlott et al. 2007, Slik et al. 2015), driven in part by the available species pool as a result of geological history (Parmentier et al. 2007), environmental factors like 
climate and soil properties (ter Steege et al. 2003, Koponen et al. 2004) and biological interactions (Noguchi et al. 2007) are important determinants of tree diversity patterns. Both climate and soil conditions change markedly along mountain slopes, making them preferred objects of research on the drivers of tree species diversity (Ohsawa et al. 1985, Aiba and Kitayama 1999, Culmsee and Pitopang 2009, Homeier et al. 2010, Culmsee et al. 2011, Culmsee and Leuschner 2013, Merckx et al. 2015). Due to the close proximity of different habitats and communities and resulting high beta diversity along the slope, tropical mountain forests (TMF) constitute one of the biologically richest landscapes on earth (Aldrich et al. 1997) and often contain a large number of endemic species (Merckx et al. 2015).

Along tropical mountain slopes, two principal patterns of plant alpha diversity change with elevation have been observed, a hump-shaped pattern, often found in herbs and ferns (Kessler 2000, Bhattarai and Vetaas 2003, Bhattarai et al. 2004, Willinghöfer et al. 2011, Dossa et al. 2013) and a monotonic decline with elevation, apparently prevalent in trees (Ohsawa et al. 1985, Aiba et al. 2002, Homeier et al. 2010, Culmsee and Leuschner 2013, Dossa et al. 2013). It has been argued that the latter pattern might be an artefact caused by incomplete sampling along the elevation gradient (Rahbek 1995, 2005), but studies on the complete vascular plant flora on the slope of Mount Kinabalu (Borneo) have confirmed the existence of both elevation patterns for the groups of ferns/herbs and trees (Grytnes and Beaman 2006). In Malesian TMF, where patterns of tree alpha diversity have been studied at the genus level (van Steenis 1935b, 1962, Culmsee and Leuschner 2013), a monotonic decline in taxonomic diversity was found as well. Here, the number of genera per family also decreased with elevation, reflecting phylogenetic clustering at lower elevations and overdispersion further upslope. It has been suggested that the diversity pattern of genera closely reflects that of species in Amazonian lowland forests and that therefore genus-level analyses are sufficient in many cases (Higgins and Ruokolainen 2004). However, the relationship between elevational patterns of species, genera, and family diversity of trees is so far unknown for Southeast Asian forests. We also lack information as to whether elevational patterns of species diversity differ between different phytogeographic regions in Southeast Asia. The geologically relatively young region of Wallacea, which includes Sulawesi, is generally assumed to harbour lower levels of biodiversity than the better-explored continental shelf area known as Sundaland to the west (Barthlott et al. 2007, Kier et al. 2009), but this may merely be an artefact caused by differences in land area (Roos et al. 2004).

Elevational gradients represent experiments of nature with respect to the response of plant communities to gradual environmental change (Körner 2007). In humid tropical mountains, the most influential abiotic factor that changes more or less monotonically with elevation is temperature. Temperature not only influences the physiology of the trees but also key ecosystem functions such as decomposition and mineralisation rates and the accumulation of soil organic matter (Letts et al. 2010). However, small-scale variation in topography on mountain slopes and related gradients in bedrock and soil properties are often overlaying the effects of the temperature decrease with elevation and they considerably increase habitat diversity in 
tropical mountains. For example, the extraordinarily high tree species richness in the TMF of the eastern slopes of the Ecuadorian Andes is in part the consequence of a high diversity of habitats on upper, mid and lower slope positions and variable slope aspects (Homeier et al. 2010). On Mount Kinabalu, Borneo, bedrock and thus soil chemical properties show a marked change along an elevation transect spanning about $2400 \mathrm{~m}$ (Kitayama and Aiba 2002). Although elevation was the most influential environmental correlate for the diversity and composition of tree communities in that elevational transect study, a significant proportion of the variation in tree diversity on Borneo was explained by soil properties (Slik et al. 2009). It appears that large differences in edaphic conditions, such as the contrast between soils on silicate, calcareous or ultramafic rocks, may in certain cases lead to larger differences in tree diversity and community structure than the elevation gradient itself (Aiba et al. 2015).

Since the first studies of Alfred Russel Wallace (1869), the strong endemic element in Sulawesi's fauna has been well recognised (e.g. Musser 1987, Michaux 2010, Stelbrink et al. 2012), while endemism in Sulawesi's flora has been thought to be less pronounced with estimates ranging from 12.3 to 14.2\% (van Balgooy 1987, Roos et al. 2004, van Welzen et al. 2011). If valid, this proportion would be much lower than for the neighbouring islands of Borneo, the Philippines and New Guinea (van Welzen and Slik 2009, Culmsee et al. 2011, van Welzen et al. 2011). However, reliable estimates of plant endemism are difficult to obtain for Sulawesi, mainly due to insufficient knowledge of the island's flora (Cannon 2001, Keßler et al. 2002, Culmsee et al. 2011). The presence of mountain ranges is an important factor which increases the number of endemic organisms. Unique biotas are also the main cause for the high conservation values of tropical mountains (Aldrich et al. 1997, Brummitt and Lughadha 2003, Brehm et al. 2005, Richter 2008). In the Malesian region, patterns of plant endemism in TMF have rarely been investigated (Raes et al. 2009, Merckx et al. 2015). On Sulawesi, which has 7\% of its total land surface area at montane elevations (> 1500 m; Culmsee and Leuschner 2013), tree inventories at mid- and upper montane elevations (Culmsee et al. 2011) found higher values (20\%) for endemic trees than those previously reported (see above) suggesting that endemism patterns in vascular plants at higher elevations of this island should be re-evaluated.

Many diversity analyses in tropical forests are incomplete because part of the understorey species is neglected due to the conventional stem diameter threshold of 10 or $7 \mathrm{~cm}$. However, this neglected guild of shade-tolerant, low-stature trees may significantly contribute to overall tree diversity and play an important role in canopy light interception, as it reduces transmission to very low levels. According to LaFrankie et al. (2006), the guild of understorey trees is less species-rich in Asian lowland rainforests than in Neotropical forests; this assumption needs verification by carefully collected field data.

We investigated tree diversity, endemism and community composition of natural forests along an elevational gradient from 700 to $2400 \mathrm{~m}$ in the highlands of Central Sulawesi and related the patterns to gradients in climate and soil properties. Special attention was laid on the inclusion of the understorey trees with stem diameters as low as $2 \mathrm{~cm}$. We expanded the data set of 
earlier work (Culmsee and Pitopang 2009, Culmsee et al. 2011, Culmsee and Leuschner 2013) to 13 intensive tree inventory plots, focused rigorously on correct species-level identification, and analysed endemism patterns in the woody flora in detail. The poor knowledge of the forest vegetation in this region required elaborating a basic forest community classification as a foundation for the analysis of diversity patterns. Specifically, we addressed the following questions:

1. How does tree alpha diversity at different taxonomic levels (species, genera, families) vary along environmental gradients (climate, soil)?

2. How does alpha diversity change along the elevation gradient in comparison with other mountain ridges in Malesia?

3. Does the diversity of endemic tree species change along the gradients?

4. How do beta diversity and community composition change along these environmental gradients?

5. Do true canopy and understorey species disperse differently along the climate and soil gradients?

\subsection{Material and Methods}

The study was carried out in Lore Lindu National Park (LLNP; Figure 4.1) in the central mountain range of Sulawesi, Indonesia, an area dominated by acid plutonic and metamorphic rocks and displaying a variety of soil types. The climate of the area is perhumid with most rainfall occurring during April-May and November-December and a slightly drier period from July to October. Drought stress can occur periodically in the intermontane valleys below $1500 \mathrm{~m}$ and at irregular intervals due to ENSO events (Wündsch et al. 2014). Seasonal temperature variation is minimal; mean annual temperature decreases by c. $5.2 \mathrm{~K}$ per $1000 \mathrm{~m}$ elevation from $23.0^{\circ} \mathrm{C}$ at $700 \mathrm{~m}$ to $14.1^{\circ} \mathrm{C}$ at $2400 \mathrm{~m}$ (Hijmans et al. 2005, WorldClim 2014). LLNP was created in 1999 and predominantly comprises rainforest from colline (c. $500 \mathrm{~m}$ a.s.l.) to upper-montane ( $2525 \mathrm{~m}$ a.s.l.) elevations (Cannon et al. 2007, Culmsee et al. 2010a) with a variety of forest types of high conservation value (Le Saout et al. 2013). With a size of c. $2215 \mathrm{~km}^{2}$ and $84 \%$ of its area at $>1000$ $\mathrm{m}$, it is the largest protected area of montane forest on Sulawesi. The parks' forests have been little affected by human activities until the end of the $19^{\text {th }}$ century, but since then, impact has steadily increased (Weber 2006, Biagioni et al. 2015b), in particular in the valleys. We selected thirteen study sites of primary forest in LLNP at elevations between 700 and $2400 \mathrm{~m}$ a.s.I. (Appendix 4.1, Table 1) and carried out tree inventories from February 2011 to April 2012.

At each site, we censused all trees with diameter at breast height ( $\mathrm{dbh}) \geq 10 \mathrm{~cm}$ ('large trees') in a rectangular plot of 0.24 ha size $(60 \mathrm{~m} \times 40 \mathrm{~m})$ and additionally all small trees (dbh $2-9.9 \mathrm{~cm}$ ) in subplots totalling 0.06 ha. All censused trees were permanently marked with a number, measured (dbh and height), and pre-identified in the field; we collected extensive herbarium specimens for species identification. Also, we dug four soil-pits per plot and extracted soil samples from the mineral topsoil $(0-10 \mathrm{~cm})$ and the ectorganic layer, measured in both horizons 
$\mathrm{pH}(\mathrm{KCl})$ and the concentration of plant macro nutrients $(\mathrm{C}, \mathrm{N}, \mathrm{Ca}, \mathrm{Mg}, \mathrm{K})$ and other cations ( $\mathrm{Na}$, $\mathrm{Al}, \mathrm{Fe}$, and $\mathrm{Mn}$ ), and calculated the cation exchange capacity (CEC) and the base saturation (i.e. the proportion of $\mathrm{Ca}, \mathrm{K}, \mathrm{Mg}$ and $\mathrm{Na}$ in $\mathrm{CEC}$ ). On all plots surveyed for the first time, we dug an additional pit to describe the soil profile and identify the soil type according to the WRB system (IUSS Working Group WRB 2014).
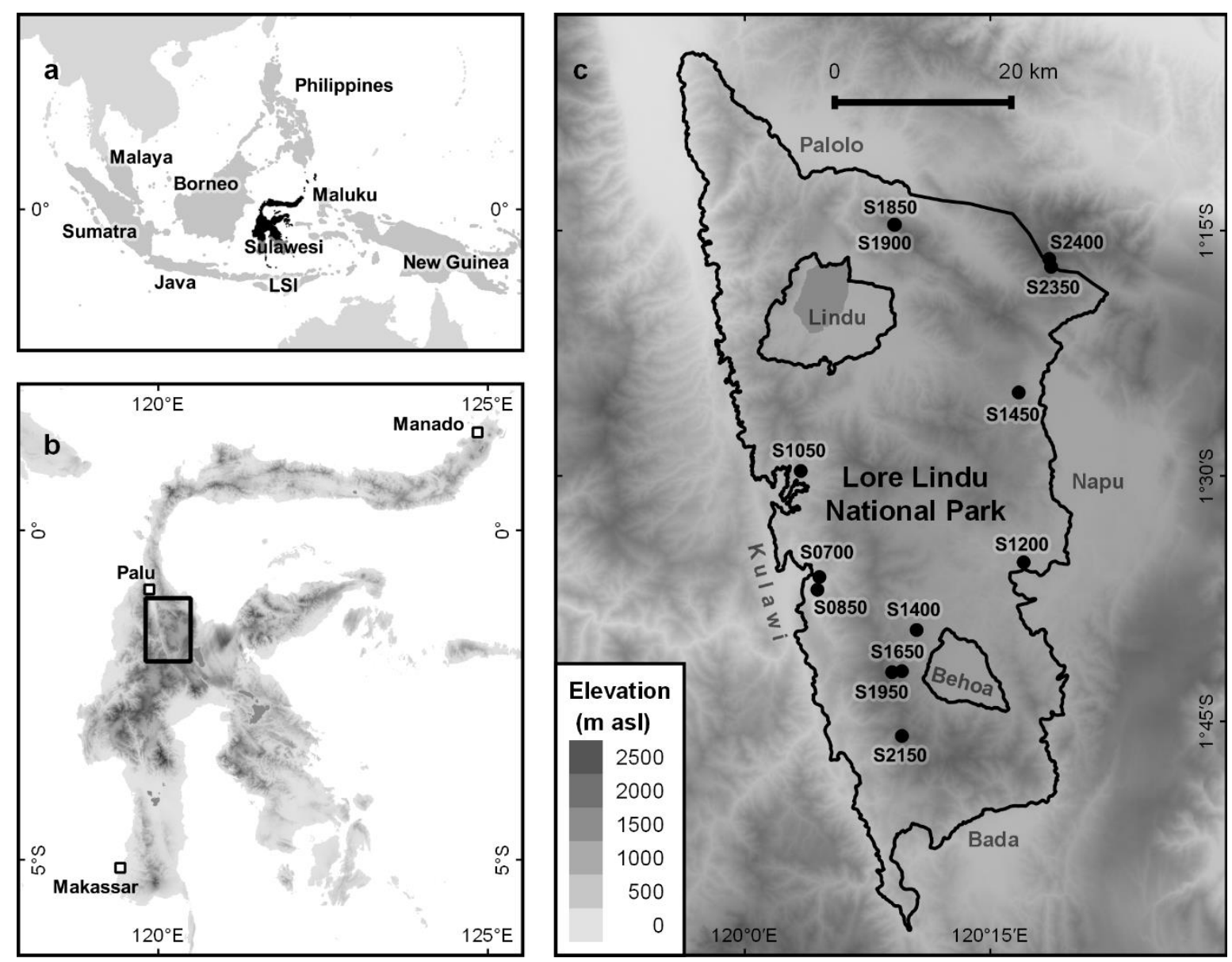

Figure 4.1 Location of study sites. a The island of Sulawesi (black) and its surrounding phytogeographical units within Malesia (dark grey, LSI = Lesser Sunda Islands). $\mathbf{b}$ The study area (rectangle) is located in the Central Sulawesi Mountains, south of the city of Palu. c Within the study area of Lore Lindu National Park (LLNP, black borderline), named after Lake Lindu (grey area) and bounded by four major valleys (grey names), 13 tree inventory plots were investigated; plot labels indicate elevation in $\mathrm{m}$ a.s.I. Created in QGIS (QGIS Development Team, 2016) using the digital elevation model from Jarvis et al. (2008).

Tree species identification was carried out by FB and HC from 2011-2014 based on the $>2000$ collected specimens and additional photographs taken in the field using taxonomic literature (Appendix 4.2) and the reference collections in the herbaria of BO, GOET, K and L (Thiers, continuously updated: http://sweetgum.nybg.org/science/ih/). In total, we surveyed 3852 individuals (2284 trees, 1568 small trees), of which 95.7\% were determined to species level. We recorded the distribution of each species (Appendix 4.2) to identify species endemic to the island of Sulawesi.

In each study plot, we performed analyses of diversity and composition for all trees ( $\mathrm{dbh} \geq 2$ $\mathrm{cm})$ and for the group of large trees $(\mathrm{dbh} \geq 10 \mathrm{~cm}$ ) separately. To estimate species alpha 
diversity, we calculated different measures: observed species richness ( $\left({ }^{0} \mathrm{D}_{\mathrm{obs}}\right)$ and effective number of species ( $\left({ }^{1} D_{\text {obs }}\right)$ as well as standardised species richness $\left({ }^{0} D_{210}\right)$ and effective number of species ( ${ }^{1} D_{210}$, primary diversity measure) using a rarefaction/extrapolation approach with a base sample size (BSS) of 210 (Jost 2006, Chao et al. 2014); analogous indices were calculated for genera and families. Then, we used the primary diversity measure as response variable in linear regression models with elevation and seven soil parameters as explaining variables and used backward selection to obtain the minimum adequate models. For the relative number of endemic species per plot, we ran logistic regression models (LRM) with plot elevation as explanatory variable. To compare the diversity data of our plots with those of other Malesian islands, we compiled a list of Malesian tree-inventory plots and calculated their diversity measures, here using a BSS of 90 (Appendix 4.3). Next, to search for patterns related to community composition, we calculated the modified Bray-Curtis dissimilarity index which takes into account unseen shared species between sites (Chao et al. 2005) for all pairs of plots and used the resulting matrix as dependent variable for a multivariate analysis of variance (MANOVA) with different environmental parameters as explanatory variables and a MonteCarlo permutation test with 500 permutations.

We also calculated the Family Importance Value (FIV; Mori et al. 1983) based on relative diversity, relative density and relative dominance of each family, to summarise the character of each plot's community composition. For the definition of elevational zones based on species composition, we performed a cluster analysis based on the modified Bray-Curtis dissimilarities between plots and an indicator species analysis (Dufrêne and Legendre 1997). Last, we assigned all species to one of two main tree guilds, canopy species or understorey species, using the maximum observed tree height in the plots and literature information on maximum tree height, if available. Species never exceeding 2/3 of canopy height in the plots were considered as understorey species, all others as canopy species. We computed the relative abundance of the guilds in a plot and calculated the respective mean values per elevational zone. For the 10 families with highest number of tree individuals, we ran LRM using plot elevation and guild as explanatory variables and relative abundance of the order as response variable and simplified the models stepwise. See Appendix 4.1 for detailed description of methods.

\subsection{Results}

\subsubsection{Environmental gradients along the slope}

Soils in the study region were generally acidic and nutrient-poor in the mineral soil as visible in the base saturation and $\mathrm{C} / \mathrm{N}$ ratio data (Appendix 4.4: Table 1). Soil properties related to carbon storage (organic layer thickness and the $\mathrm{C} / \mathrm{N}$ ratios of organic layer and mineral topsoil) increased with elevation indicating decreasing decomposition rates (Appendix 4.4: Table 1). Other parameters, i.e. the base cation concentration in the organic layer, the base saturation of the A-horizon, and the $\mathrm{pH}(\mathrm{KCl})$ value of organic layer and mineral topsoil showed no linear 
relation to elevation (Appendix 4.4: Table 2). The concentration of $\mathrm{Ca}, \mathrm{Mg}$ and $\mathrm{K}$ (base cations) varied largely among the plots (Appendix 4.4: Table 1).

At low and middle elevations up to c. $1700 \mathrm{~m}$, strongly weathered, mostly red, loamy soils with thin organic layers, classified as Ferralsols and Sideralic Cambisols (IUSS Working Group WRB, 2014) dominated. They were replaced by paler, sandy soils with well-developed A-horizons (Cambic Umbrisols) at c. 1800-2000 m. Frequent waterlogging and high accumulation of organic matter characterised the Gleysols and Histosols of the highest plots above c. $2000 \mathrm{~m}$ (Appendix 4.1, Table 1). Two plots (S1200 and S1450; Figure 4.1) fell outside this general pattern, having thick A-horizons, pale colours, and better nutrient supply despite occurring at rather low elevations (Appendix 4.1: Table 1, Appendix 4.4: Table 1).

\subsubsection{Richness of the tree flora and new species records}

We surveyed 3852 individuals (2284 large trees, 1568 small trees), which were assigned to 331 species (including morphospecies, henceforth referred to as "species", 282 in the group of large trees $\geq 10 \mathrm{~cm}$ dbh, 250 small trees $<10 \mathrm{~cm}$, Appendix 4.5) belonging to 166 genera (150 large trees, 131 small trees) in 78 families (74 large trees, 67 small trees). 201 species were present both as large trees and small trees, 81 only as large trees and 49 exclusively as small trees (Appendix 4.5). The most species-rich family was Lauraceae with 31 species, followed by Myrtaceae (27), Elaeocarpaceae, and Rubiaceae (16 each). Correspondingly, the most speciesrich genera were Syzygium (Myrtaceae, 25 species), Elaeocarpus (Elaeocarpaceae, 15), and Litsea (Lauraceae, 11). Twenty (6.0\%) hitherto undescribed tree species were collected, which now have been (Brambach et al., in press, 2016, 2013) or will be formally named and described. Furthermore, a large number of species was recorded for Sulawesi $(n=21 ; 6.3 \%)$ or the province of Central Sulawesi $(n=54 ; 16.3 \%)$ for the first time in the context of this study (Appendix 4.5).

\subsubsection{Alpha diversity patterns and their association with elevation and soil parameters}

Plot-level tree diversity (all trees of $\mathrm{dbh} \geq 2 \mathrm{~cm}$ ) varied from 27 to 78 species per 0.24 ha in the 13 plots. Species diversity declined monotonically with elevation, regardless of the diversity measure used ( ${ }^{0} D_{\text {obs, }}{ }^{1} D_{o b s},{ }^{0} D_{210},{ }^{1} D_{210}$; Figure 4.2a, Appendix 4.6: Table 1). However, some plots showed outliers with plots S0850 and S1850 having fewer and S1200 and S1450 more species than the neighbouring plots along the elevation gradient. The diversity of trees at higher taxonomic levels also declined monotonically with elevation, but the slopes were slightly (genera) or greatly (families) reduced (Figure 4.2b-c, Appendix 4.6: Table 1), reflecting higher numbers of species and genera per family at lower than at upper elevations. Alpha diversity patterns of large trees ( $d b h \geq 10 \mathrm{~cm}$ ) generally showed the same patterns as pooled data for all trees (Appendix 4.6: Figure 1, Table 2). 

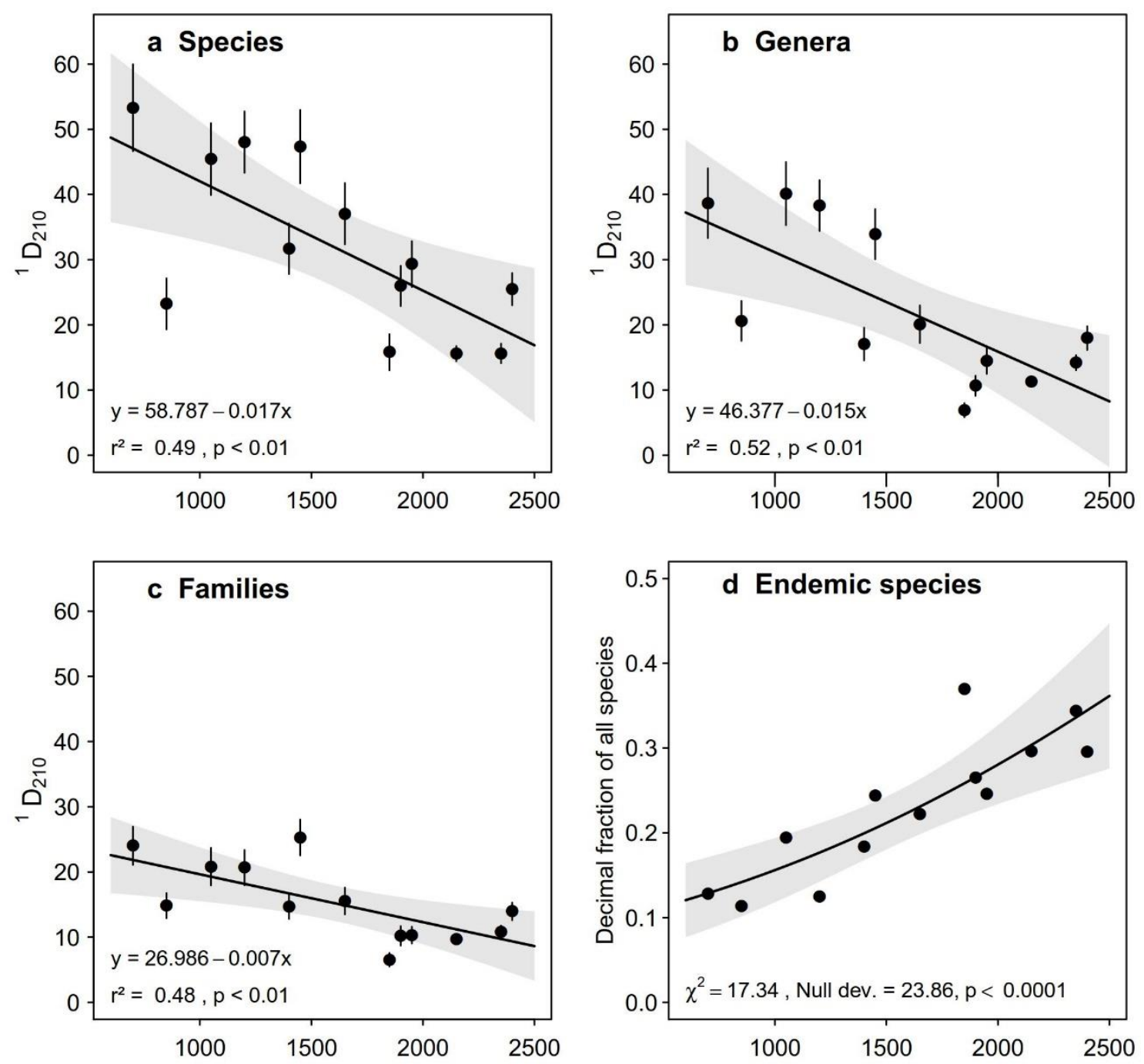

Elevation [m asl]

Figure 4.2 Changes in tree diversity at different taxonomic levels (a-c) and endemism (d) of all trees along the elevational gradient in Lore Lindu National Park. Tree diversity per plot $(0.24 \mathrm{ha})$ is the standardised number of taxa per 210 individuals $\left({ }^{1} D_{210}\right)$. Black lines are regression curves of linear regression models (a-c) and a logistic regression model with binomial error structure and logit link function (d). Grey areas represent the $95 \%$ confidence intervals of the models. Error bars show $95 \%$ confidence intervals of a rarefaction/extrapolation procedure using a bootstrap method with 500 replications. All data consider all trees with $\mathrm{dbh} \geq 2 \mathrm{~cm} ; \mathrm{n}=13$. See Appendix 4.1, Table 1 for plot details.

Of the seven soil parameters tested, the $\mathrm{pH}$ of the organic layer $\left(\mathrm{pH}_{\circ}\right)$ was the only one not correlated with elevation and having a significant effect on the diversity $\left({ }^{1} D_{210}\right)$ of all trees $(y=$ $-1.73+10.71 x, r^{2}=0.38, p<0.05$ for species; not significant for genera and families). However, at all tested taxonomic levels, the bivariate models with elevation as the only independent variable (Figure $4.2 \mathrm{a}-\mathrm{c}$ ) had higher explanatory power than any of the multiple models. The same pattern emerged when only the diversity $\left({ }^{1} D_{210}\right)$ of large trees was considered $(y=-8.05$ $+11.97 x, r^{2}=0.38, p<0.05$ for species; $y=-8.45+9.41 x, r^{2}=0.31, p<0.05$ for genera; not significant for families). Again, diversity was best explained by the bivariate model with elevation as only independent variable (Appendix 4.6, Figure 1a-c) 
The tree species richness in Sulawesi was comparable to that on other Malesian islands (Figure 4.3; Borneo, Java and the Philippines with 7-17 plots; Sumatra and the Maluku Islands represented by only one plot each). Alpha diversity monotonically decreased with elevation in all regions and the magnitude of decrease was also comparable among the islands (c. -12.5 effective species per $1000 \mathrm{~m}$ in Sulawesi vs. c. -16.5 on all islands). However, a strong positive effect of plot size on diversity is apparent when comparing ${ }^{1} D_{\text {obs }}$ of the assessed 51 Malesian plots (Appendix 4.3).

Figure 4.3 Species richness in 51 Malesian tree inventory plots in relation to elevation. Standardised number of species per 90 individuals ( $\left.{ }^{1} D_{90}\right)$ are shown. Closed circles represent plots from Sulawesi $(n=13)$, open circles those from other Malesian areas ( $n=38$ ); the size of circles is proportional to plot size (0.1 - $1.0 \mathrm{ha})$. The solid regression line is based on all plots ( $n=51$ ); error bars show 95\% confidence intervals of a rarefaction/ extrapolation procedure using a bootstrap method based on 500 replications. See Appendix 4.3 for plot details.

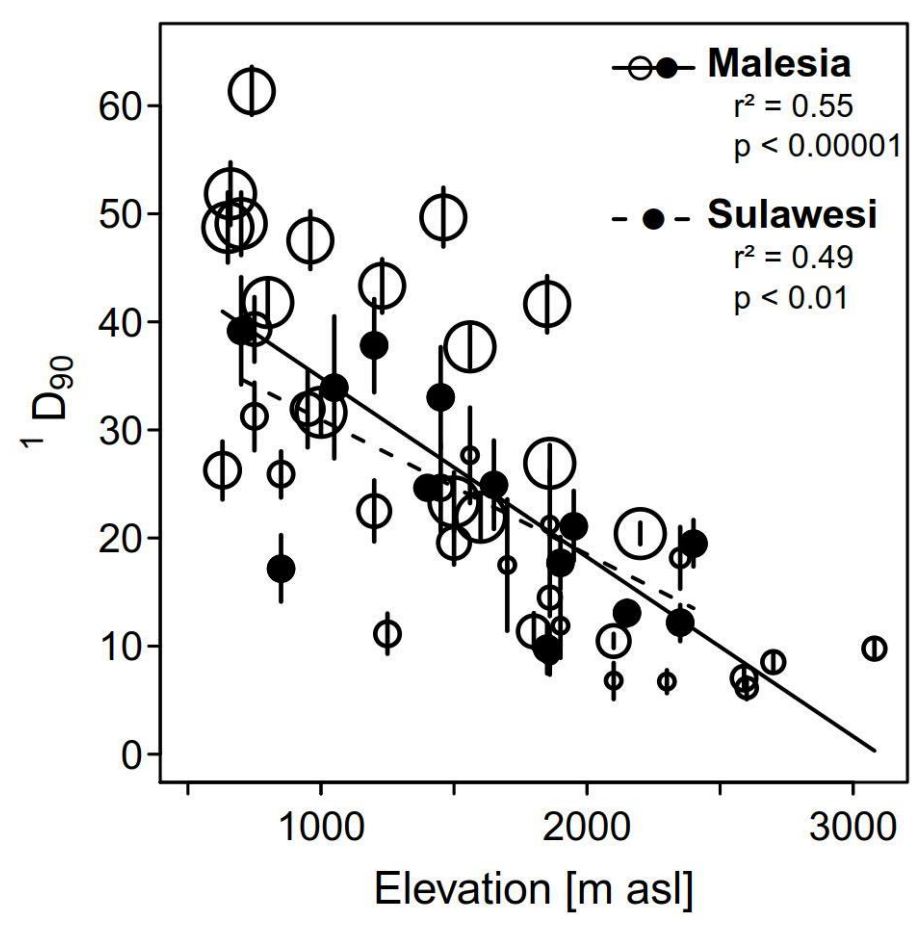

We found 73 endemic species (22.1\%) in total, 58 (20.6\%) among the trees $\geq 10 \mathrm{~cm}$ and an additional number of 15 species in the group of small trees. The Elaeocarpaceae (nine species of Elaeocarpus), Rubiaceae (eight species in six genera), Lauraceae (seven species in five genera) and Myrtaceae (seven species of Syzygium) were the most prominent families with endemic taxa. While the absolute number of endemic species per plot did not increase with elevation, the percentage contribution of endemics to total tree species richness significantly increased from c. $12 \%$ at $700 \mathrm{~m}$ to more than $30 \%$ at $2400 \mathrm{~m}$ a.s.l. (Figure $4.2 \mathrm{~d}$ ).

\subsubsection{Elevational change in community composition}

As for diversity, elevation had by far the largest influence on tree species composition of all investigated environmental parameters. According to a MANOVA based on the modified BrayCurtis dissimilarity, the floristic composition of the tree assemblages (only trees $\geq 10 \mathrm{~cm} \mathrm{dbh}$ ) was significantly influenced by elevation $\left(r^{2}=0.39 * *\right), \mathrm{pH}_{\circ}\left(r^{2}=0.10^{*}\right)$ and the interaction between them ( $r^{2}=0.19 * *$, residuals: $r^{2}=0.32$, see also ordination in Appendix 4.7: Figure 1$)$. A MANOVA based on the composition of all trees yielded similar results (elevation: $r^{2}=0.43^{* *}$, $\mathrm{pH}_{\mathrm{O}}: \mathrm{r}^{2}=0.10^{*}$, interaction: $\mathrm{r}^{2}=0.18^{* *}$, residuals: $\mathrm{r}^{2}=0.30$ ). The strong influence of elevation on community composition is also displayed by the marked turnover of dominant families (as expressed by their FIV) along the slope (Appendix 4.8). 

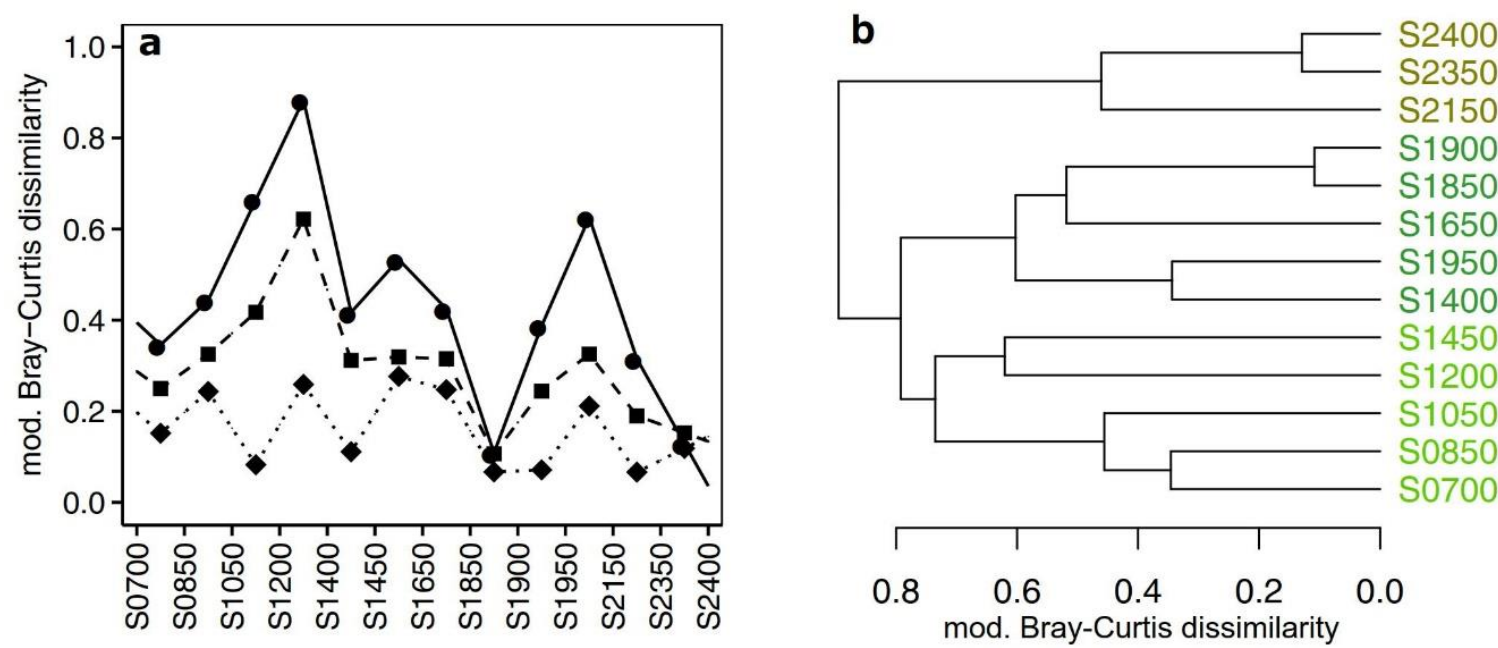

Figure 4.4 Floristic turnover of trees along the elevational gradient in Lore Lindu National Park. a Beta diversity, expressed as modified Bray-Curtis dissimilarity, between elevational 'adjacent' plots peaks around 1300 and $2000 \mathrm{~m}$. Diversity is shown at different taxonomic levels: species (circles, solid line), genera (squares, dashed line) and families (diamonds, dotted line). b Dendrogram showing clusters of tree assemblages (plots) related to elevation. Clustering based on modified Bray-Curtis dissimilarity using hierarchic agglomerative clustering with the average linkage method (UPGMA). The plots are grouped into three elevational zones: submontane, lower montane and upper montane, consistent with the three main resolved clusters. Data shown for large trees $(\mathrm{dbh} \geq 10 \mathrm{~cm})$. See Appendix 4.1, Table 1 for plot details.

The beta diversity patterns of species and genera along the slope, measured by modified BrayCurtis dissimilarity, showed major floristic turnovers at c. $1300 \mathrm{~m}$ and c. $2000 \mathrm{~m}$ elevation, pointing at well recognisable ecotones with marked floristic change at these elevations (Figure 4.4a). These ecotones were recognised for the group of all trees and the large trees $\geq 10 \mathrm{~cm}$. The cluster analysis (Figure 4.4b) and the NMDS (Appendix 4.7: Figure 1), both conducted for large trees, also recognised a clear division at c. $2000 \mathrm{~m}$, but further divided the remaining plots at about 1400 m, with plot S1450 more similar to lower-elevation sites and S1400 more to midelevation sites. Together, these results indicate three more or less distinct mountain forest belts in Central Sulawesi: (1) sub-montane forest (from < 700 to 1300-1450 m), (2) lower montane forest (from 1300-1450 to $2000 \mathrm{~m}$ ), and (3) upper montane forest (from 2000 to $2400 \mathrm{~m}$ ). While the sub-montane and upper montane forests were clearly distinguished and characterised by a unique set of indicator species in the large-tree group, the lower montane forest had a more transitional character and no indicator species at all (Table 4.1).

\subsubsection{Diversity and distribution of understorey tree species}

The dataset used for the analyses targeting understorey and canopy species contained 2187 individuals of 288 species, of which 689 individuals ( 133 species) belonged to the group of smallstature understorey species, and 1498 (155) to the canopy species. Hence, understorey trees provided less than a third (32\%) of the individuals, but almost half (46\%) of all tree species. At the plot level, between 27 and 51\% (mean: 42\%) of the tree species referred to the understorey guild. While the understorey trees displayed a similar diversity pattern along the elevation transect to the one observed in the canopy species (not shown), the floristic composition of the 
two guilds differed substantially. In several taxonomic groups, all taxa were confined either to the upper canopy layer (notably in the Fagales and Escalloniales (genus Polyosma)) or to the understorey (Gentianales with one exception, Arecales, and Cyatheales), irrespective of elevation. Other orders contained taxa with restriction to the upper canopy at certain elevations, e.g. as in the Mettenusiales (genus Platea) in the sub- and lower montane belt, in the Paracryphiales in the lower and upper montane belt, and in the Austrobaileyales (Trimenia papuana) only in the upper montane belt; all these orders occurred with only one or two species in the data set. In contrast, the Canellales ( Tasmannia piperita) were almost exclusively recorded in the understorey of the upper montane forests (Figure 4.5).

Table 4.1 Indicator tree species of three elevational zones in Lore Lindu National Park, Sulawesi, Indonesia. Data shown for large trees (dbh $\geq 10 \mathrm{~cm}$ ). See Appendix 4.5 for full names. Endemic species shaded grey.

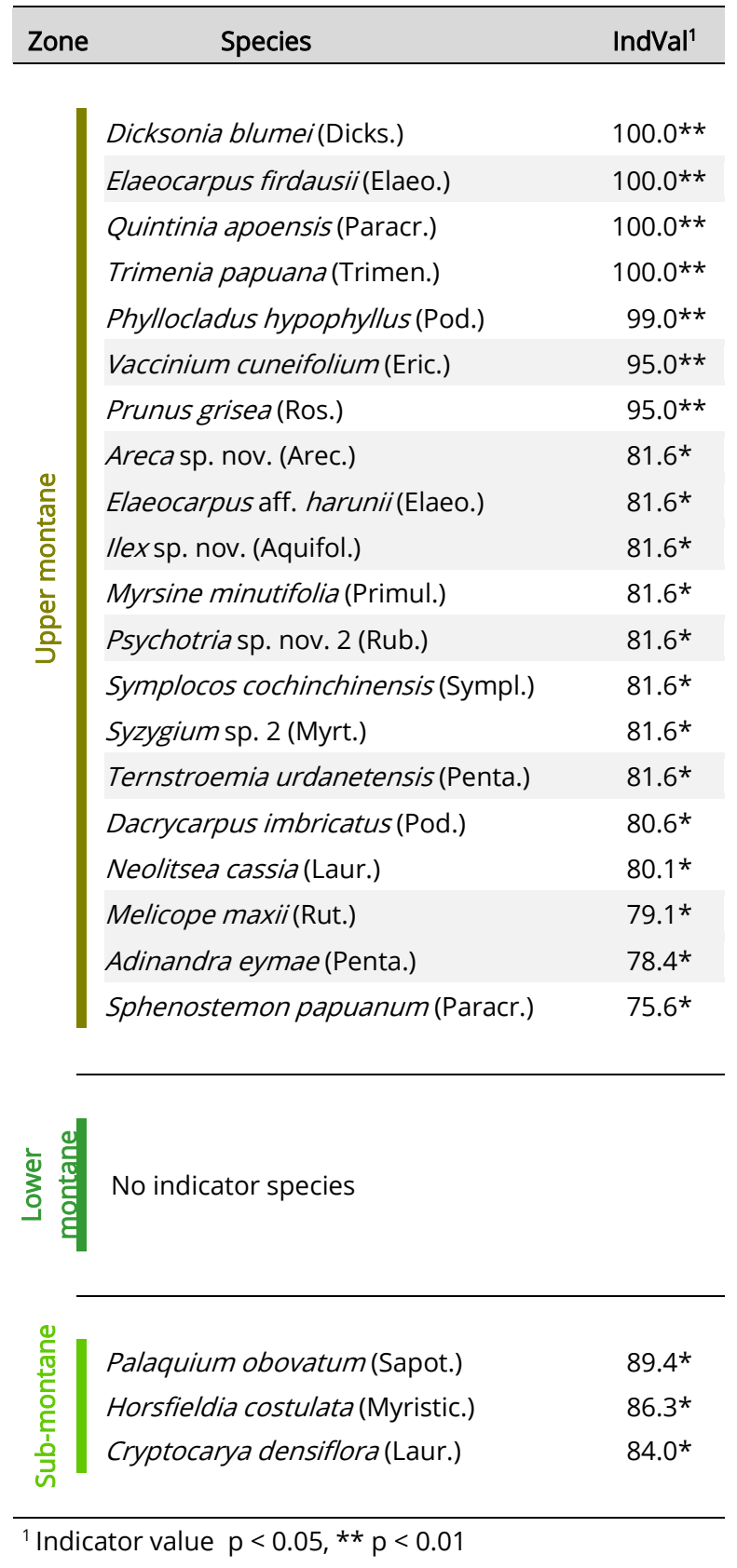


Most orders, however, contained species of both guilds (canopy species and understorey species), albeit with sometimes very different individual numbers. Four of the ten orders with highest individual numbers (Laurales, Magnoliales, Malpighiales, and Oxalidales) displayed no significant effect of guild affiliation on dominance in terms of present individuals; elevation was a more influential factor in the first three orders (Table 4.2, Figure 4.5). The number of individuals of the other six major orders was influenced by guild and elevation (Table 4.2), but the patterns varied individually: The number of species in the Sapindales dropped significantly with elevation with numbers of canopy species decreasing to a far greater extent than those of understorey species. The number of taxa in the Pinales (conifers), almost exclusively present as canopy species, rose exponentially with elevation reflecting their prominent role in the canopy of upper montane forests. Ericales remained relatively constant in the canopy, but increased strongly with elevation in the understorey, becoming the dominant order in the upper montane belt. Lastly, Myrtales, the most individual-rich order overall, were constantly present in rather small numbers in the understorey and increased in importance among the canopy species in the lower and upper montane zones (Table 4.2, Figure 4.5).

The resulting taxonomic structure of the understorey communities varied strongly between the altitudinal belts: The communities at sub-montane elevation consisted of 20 orders, with the species-rich orders Laurales (6.6\% $\pm 1.5 \%$ standard error of all individuals in a plot), Gentianales $(6.1 \pm 2.5 \%)$, Magnoliales $(3.9 \pm 3.1 \%)$, and Malpighiales $(4.0 \pm 0.6 \%)$ as the principal components. Lower montane plots harboured 16 orders containing understorey species; here, Ericales $(0.2 \pm$ $3.0 \%)$, Myrtales $(4.8 \pm 1.8 \%)$, Laurales $(3.1 \pm 1.3 \%)$, and Gentianales ( $2.9 \pm 1.2 \%)$ were most dominant. Only 15 orders of understorey species, dominated by Ericales (13.6 $\pm 0.6 \%)$ and Canellales (Tasmannia piperita, $6.8 \pm 3.8 \%$ ), occurred in the upper montane forests (Figure 4.5).

\begin{tabular}{llrrr}
\hline Order & Variable & p & \multicolumn{2}{c}{$\begin{array}{r}\text { Dev. explained } \\
\text { Var. }\end{array}$} \\
& & Model \\
\hline Myrtales (456) & Elevation & $0.090<$ & 0.06 & 0.57 \\
& Guild & 0.001 & 0.51 & \\
Ericales (291) & Elevation & 0.62 & 0.30 & 0.58 \\
& Guild & 0.046 & 0.14 & \\
& Interaction & 0.010 & 0.13 & \\
Fagales (211) & Elevation & 0.192 & 0.02 & 0.70 \\
& Guild & 0.994 & 0.68 & \\
Laurales (149) & Elevation & 0.006 & 0.28 & 0.28 \\
Sapindales (144) & Elevation & $<0.001$ & 0.36 & 0.69 \\
& Guild & $<0.001$ & 0.32 & \\
Pinales (114) & Elevation & $<0.001$ & 0.49 & 0.88 \\
& Guild & $<0.001$ & 0.39 & \\
Malpighiales (96) & Elevation & 0.002 & 0.41 & 0.41 \\
Gentianales (73) & Elevation & 0.024 & 0.09 & 0.64 \\
& Guild & 0.014 & 0.55 & \\
Oxalidales (69) & - & - & - & - \\
Magnoliales (67) & Elevation & 0.006 & 0.50 & 0.50 \\
\hline
\end{tabular}

Table 4.2 Factors influencing the dominance of important taxonomic orders in Lore Lindu National Park. Effects table of logistic regression models (LRM) for the ten most individual-rich orders showing how guild (nominal; canopy species vs understorey species) and elevation (continuous; 700 - 2400 $\mathrm{m}$ ) influence the relative number of each order's individuals per plot. Number of individuals per order in parentheses. Based on all trees with $\mathrm{dbh} \geq 2 \mathrm{~cm}$ in 13 inventory plots with 0.06 ha size each.

Dev. $=$ Deviance; Var. $=$ variable; Interaction = interaction effect Elevation:Guild 
Figure 4.5 Taxonomic groups of trees (phanerogam orders) in Sulawesi's Lore Lindu National Park mostly exhibit strong affinities with altitudinal belts and/or ecological guilds. The graph shows the mean percentage of tree individuals each order contributes to the communities in a given elevational zone: sub-montane (c. 700 to 1300-1450 m), lower montane (c. 1300-1450 to $2000 \mathrm{~m}$ ), and upper montane (c. 2000 $2400 \mathrm{~m}$ ). The percentage values are given separately for the two guilds (canopy species left, understorey species right). In each elevational zone, the percentages of all orders over both guilds add up to 100. Orders are arranged according to APG IV (The Angiosperm Phylogeny Group, 2016) and colour-coded according to major clades (legend at bottom left; bas. angiosp. = basal angiosperms, bas. superros. = basal superrosids). Based on inventory data including all trees with $\mathrm{dbh} \geq 2 \mathrm{~cm}$ in 13 inventory plots with plot size 0.06 ha. Error bars indicate one standard error.

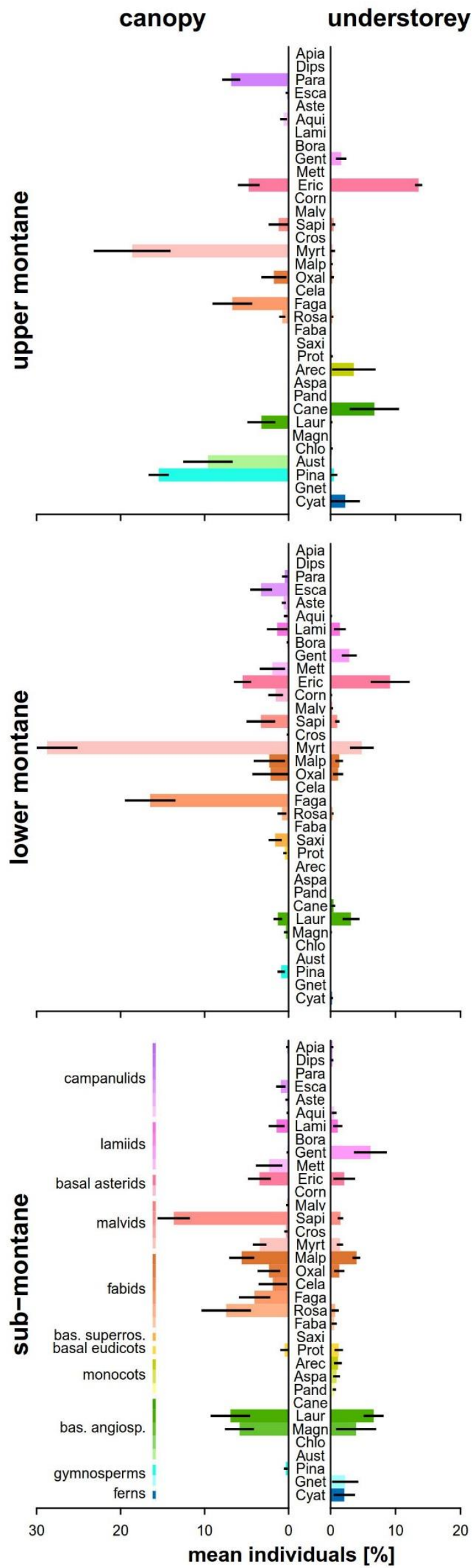




\subsection{Discussion}

\subsubsection{Factors controlling tree alpha diversity in Malesian TMF}

Although several studies have addressed altitudinal patterns of tree diversity in TMF (e.g. Aiba and Kitayama 1999, Aiba et al. 2005, Slik et al. 2009, Homeier et al. 2010, Culmsee and Leuschner 2013), no fully consistent picture about the abiotic and biotic factors causing these patterns has emerged yet. This is partly caused by different elevation ranges and altitudinal belts covered by the studies (Rahbek 1995), different latitudes and floristic regions sampled (Rahbek 2005, Culmsee and Leuschner 2013), and regional contrasts in the size and connectivity of the elevational zones considered (Ackerly 2003, Bertuzzo et al. 2016). Progress in our understanding is also hampered by the often insufficient knowledge about TMF floras. The latter is the case in the more remote regions of the Malesian Archipelago, where forest inventory plots with thorough species identification are very scarce and records of climatic and edaphic parameters along the slope are lacking.

Our study fills a knowledge gap for the mountains of Sulawesi, which are situated about halfway between the mountains of Sundaland and the Philippines in the northwest and New Guinea in the east. Based on the inventory of all trees with $\mathrm{dbh} \geq 2 \mathrm{~cm}$ in an elevation transect spanning $1700 \mathrm{~m}$, our data show that the taxonomic richness of trees decreases linearly with elevation at all taxonomic levels. The richness decline is similarly rapid at the species and genus levels, confirming the observation that the floristic patterns of tropical tree genera in the Amazon are closely related to those of the species (Higgins and Ruokolainen 2004) for Southeast Asian TMF at different elevations. That other mountain regions in Malesia showed steeper diversity declines with elevation than Sulawesi (see Figure 4.3) may partly be explained by the fact that, in the former regions, larger plots have often been investigated at lower elevations, leading to potentially inflated diversity scores there. Rarefaction/extrapolation can reduce the plot size effect and thus results in more comparable diversity scores $\left({ }^{0} D_{90},{ }^{1} D_{90}\right.$ values).

Even though we studied seven important soil parameters along the slope, we found that elevation is the single most important factor explaining the variance in alpha diversity and also species composition among the 15 studied stands, while edaphic factors were of marginal influence. Height above sea level explained almost $50 \%$ of the variation in tree species richness, suggesting that the linear decrease in tree alpha diversity is mainly driven by the temperature decrease. Elevation was also the main factor controlling tree species composition (Figure 4.4b, Appendix 4.6) and it explained the dominance of the ten most abundant plant orders along the slope (Table 4.2). This result is in line with a study from Borneo, where elevation was also the most influential correlate for gradients in tree diversity and community composition (Slik et al. 2009).

Temperature can act on plant communities through multiple pathways, either directly by influencing photosynthesis and respiration rates and thus the carbon balance, or indirectly via effects on decomposition and mineralisation rates, nutrient supply and organic matter 
accumulation on top of the soil. Widening $\mathrm{C} / \mathrm{N}$ ratios in the organic layer and the mineral topsoil with increasing elevation together with growing stores of organic material on top of the soil (Appendix 4.4) indicate that mineralisation rate and the availability of nitrogen (and likely of other nutrients) decrease with elevation in Sulawesi in a similar manner as it was found in other tropical mountains (e.g. Moser et al. 2011). This offers an alternative explanation for the observed alpha diversity decrease, independent of the direct effect of temperature reduction: reduced $\mathrm{N}$ availability might well exclude tree species of more fertile (and warmer) lowland habitats from colonising higher elevations due to a mechanism related to reduced nutrient supply. Other soil chemical properties such as soil acidity and the availability of base cations $(\mathrm{Ca}, \mathrm{Mg}, \mathrm{K})$ did not vary systematically with elevation in our transect and thus cannot explain the variation in diversity and species composition. This contrasts with the situation in e.g. Borneo, where Slik et al. (2009) found a significant part of the variation in diversity explained by soil characteristics such soil texture, carbon content, $\mathrm{pH}$, profile depth, soil drainage, and nutrient content. On Mt. Kinabalu on Borneo, Aiba \& Kitayama (1999) found a much lower tree diversity in TMF on ultrabasic rock compared to forests on non-ultrabasic substrates. This suggests that elevation (and temperature) effects on diversity can be secondary to soil chemistry effects, when the soil contains high concentrations of toxic elements or very unfavourable element ratios, as is the case with ultrabasic soils which are characterised by high Ni concentrations and high $\mathrm{Mg} / \mathrm{Ca}$ ratios (Proctor 2003). Such soils have the potential to limit tree productivity and they can thus function as effective environmental filters for colonizing tree species.

The study of Slik et al. (2009) in Borneo and our investigation in Sulawesi differ in that the former included a large number of lowland forests with dipterocarps, which have been found to vary in species richness largely dependent on soil chemistry or geology (Paoli et al. 2006). When elevation differences are small, diversity should depend on other factors than temperature, including soil chemistry and hydrology. Moreover, in the Sulawesi transect, geological variability was relatively low with acidic plutonic bedrocks dominating and only local occurrence of sedimentary and metamorphic rocks. However, even in regions of Malesia with much higher geological diversity, generic richness also correlated closely with elevation and not with soil parameters (Culmsee and Leuschner 2013). This is confirmed by our analysis of a sample of 51 Malesian plots on a wide range of bedrock types (Figure 4.3), where tree species diversity showed a relatively close relation to elevation as well $\left(r^{2}=0.55, p<0.00001\right)$.

\subsubsection{Speciation and endemism along the slope}

Lowland forests in South-east Asia have been found to contain a high number of species-rich genera, often with several closely related species co-occurring in a stand (Corlett and Primack 2011). We found a similar pattern in Syzygium, the most species-rich genus in our dataset and also the most species-rich woody genus worldwide (Syzygium Working Group et al. 2016). Syzygium and other diverse genera like Lithocarpus and Symplocos are most diverse at lower montane elevations in LLNP, occurring with up to 9 sympatric species (Appendix 4.5), suggesting recent radiations in Malesian TMF as reported for Begonia (Thomas et al. 2012) and 
Rhododendron (Schwery et al. 2015). However, most genera were present with only one to a few species in our Sulawesi data set, resulting in an overall species : genus ratio of 1.2-1.6 with maximum values at lower montane elevation (Appendix 4.6).

The linear decline with elevation of the number of species and genera per family (see Figure 4.2b-c, Appendix 4.7: Table 1) suggests that speciation rates have been higher at lower elevations, resulting in a larger number of closely related taxa and hence a marked phylogenetic clustering in the community structure of these forests compared to tree assemblages at higher elevations (Cavender-Bares et al. 2004, Culmsee and Leuschner 2013). To coexist successfully in a community, the microhabitats of sympatric taxa must be sufficiently different (Chave 2008), as was demonstrated for montane forests rich in Fagaceae in Thailand (Noguchi et al. 2007). Our floristic data suggest that density-dependent interactions should play a more prominent role at lower than higher elevations in the Malesian TMF (Ricklefs 2008), while physical constraints such as low temperatures and associated impairment of nutrient supply must be important environmental filtering processes at higher altitudes (Körner 2007, Culmsee and Leuschner 2013).

In their revision of the vascular flora for the Flora Malesiana project, van Welzen et al. (2011) found $14 \%$ endemic taxa for the island of Sulawesi. Our plot-level tree data show on average a much higher endemism rate (22\%) for this island. Endemism on the species level increased with elevation, both in upper canopy and understorey trees. Our higher endemism figures are in part a consequence of recent progress in our knowledge of Sulawesi's flora. However, it appears that endemism in the flora of this island has since long been underestimated, given that neighbouring islands, especially those that also possess high mountains, have higher endemism rates in general. For example, high endemism across multiple taxonomic groups was reported for Mount Kinabalu on Borneo (Merckx et al. 2015). This biodiversity hotspot of relatively recent origin (less than $10 \mathrm{Ma}$ old) has accumulated many neo-endemics in its mountain forests. The mountains of Central Sulawesi are even younger (ca. 5 Ma; Hall 2013), but despite the habitat's young age, most endemic plant taxa belong to old families (according to Davies et al. 2004) with a distribution centre in the Tropics, such as the Lauraceae (family age $100 \mathrm{Ma}$ ), Myrtaceae (81 Ma) and Rubiaceae (77 Ma), as predicted by Qian and Ricklefs (2016); only the Elaeocarpaceae with several endemics are a relatively young family (53 Ma).

\subsubsection{Elevational zonation of Malesian TMF}

Ashton (2014, fig. 4.10) summarised the forest zonation on major mountains in the wet Asian tropics by distinguishing four main altitudinal belts: lowland evergreen forest, lower montane forest, upper montane forest and sub-alpine forest. Our data suggest a major turnover in tree species composition around 1400-1450 m, i.e. between two vegetation zones that emerged from our data as a distinct sub-montane and lower montane belt. The forests at c. 700-1450 m altitude, which we termed sub-montane forest, represent a transition between lowland and lower montane forests which have also been recognized along other Asian mountain slope (Ohsawa 1993, Ashton 2003b). The sub-montane forests of Sulawesi are characterised by a 
number of indicator tree species of tropical families (cf. Table 4.1, Appendix 4.8) such as Sapotaceae and Myristicaceae, which are absent from the lower montane forest higher upslope. Similarly, sub-montane forests at $700 \mathrm{~m}$ on Mt Kinabalu (Borneo) also contain many lowland taxa and thereby differ from the forests in higher altitudinal belts (Aiba and Kitayama 1999).

The lower montane forests of Sulawesi at c. 1400-2000 m altitude lack any own indicator species, pointing to the transitional character of this belt between the sub-montane forests below that contain mostly true tropical taxa, and the upper montane zone above containing truly montane elements including many endemics. However, even though the lower montane forests do not contain a set of differentiating species, they are distinguished by the fact that Fagaceae and Myrtaceae dominate the stands both in terms of individuals and species numbers (see Appendices 4.5, 4.8). Myrtaceae may occur with up to nine species per plot and Fagaceae with up to five and, due to the relatively high wood density found in both families, the stands reach high biomasses, which exceed those of tropical montane forests in South America (Culmsee et al. 2010a).

The boundary between sub-montane and lower montane zone could not exactly be deduced from our data. The slightly different results on the floristic turnover along the slope (Figure 4.4a, Appendix 4.7: Figure 1) and of the cluster analysis indicated that, rather than a sharp boundary, there seems to be a gradual transition between the vegetation belts. In the cluster analysis, plot S1450 grouped with the sub-montane sites, while the lower-lying S1400 was more similar to the plots at 1600-2000 m. As Ashton (2003b) noted, boundaries between thermal elevation zones in tropical mountains are usually overlain by specific effects of local topography, exposition climate, and soil physics and chemistry. The plot S1450 is indeed peculiar for its elevation because tropical elements like Annonaceae and Sapotaceae are relatively abundant there (Appendices 4.5, 4.8). Due to its location in vicinity of the adjacent Napu valley (see Figure 4.1), the plot's regional climate may deviate somewhat from that of the other plots.

Upper montane forests, which were studied between $2150 \mathrm{~m}$ and the summits at about 2500 m, occur above c. 2000 m. In Sulawesi, they are largely dominated by the conifer family Podocarpaceae with Fagaceae, Myrtaceae, Elaeocarpaceae, Trimeniaceae, and Paracryphiaceae being co-dominant (Appendices 4.5, 4.8). These forests are more clearly distinguished from the lower montane forest belt by the occurrence of 21 indicator species, of which 10 were endemic to Sulawesi (Table 4.1). This is largely a consequence of the geographical isolation of high mountain peaks (Körner 2000), which may be colonized by species from lower elevations (Ackerly 2003), but which pose a strict environmental filter on possible invaders due to their specific climatic and edaphic conditions. This is supported by the argument that the higherorder taxa of high-elevation forests largely evolved specific adaptations for these conditions a long time ago (Qian and Ricklefs 2016). Podocarpaceae with their fleshy seed-receptacles are well suited for long-distance dispersal between these isolated mountain peaks (Keppel et al. 2011). 


\subsubsection{Floristic composition and diversity of the understorey}

Most of the data available for pan-tropical comparisons of forest structure and composition is based on samplings of mature trees with $\mathrm{dbh} \geq 10$ or $7 \mathrm{~cm}$. Much less is known about the freestanding woody plants of the understorey with stem diameter $<10 \mathrm{~cm}$, which typically dominate in numbers and may also be more species-rich than the large- and medium-sized trees (LaFrankie et al. 2006, Tchouto et al. 2006, Lü and Tang 2010). This group of woody plants includes the offspring of larger trees but it may also contain tree species with small stature at maturity and high shade tolerance throughout their life, which flower and reproduce in the lower strata of the forest. Species belonging to the latter group pursue a different strategy than the canopy trees, as they rarely receive full sunlight and are exposed to the specific microclimate of the forest interior for their entire lifespan. In our transect, 133 species belonged to this specialised guild, although we assume that the number of true understorey species must be slightly smaller, as several of these species (for which no maximum height is indicated in the literature) may occur in larger size outside of our plots. In fact, assignment of tree species to different categories of size at maturity may be biased in particular in the case of rare species and when the number of plots is limited as in our study.

Despite this uncertainty, our data suggest that, even though the guild of true understorey tree species represents only about a third of all individuals and contributes even less to tree biomass, it comprises almost half of the regional tree species flora in our study area. Forty-four species of this group (33\%) may represent endemics to Sulawesi. Furthermore, this group is quite diverse at the order and family level, including all tree fern and monocot families of the study region as well as several dicot families with well-recognized understorey trees (e.g. Chloranthaceae, Ericaceae, Gesneriaceae, Melastomataceae, Monimiaceae, Rubiaceae, and Winteraceae). Our data suggest that there is considerable species turnover in the understorey species along the slope, in a similar manner as is found in the upper canopy. Species of the orders Laurales and Gentianales were the most frequent understorey species of the submontane forest plots, while Ericales species gained in importance toward the upper montane plots. Species of Myrtales were present at all elevations in both the understorey and the upper canopy, possibly offering an explanation for their overall high species-richness in Sulawesi's TMF. Since forest height decreases and light penetration to the understorey tends to increase with elevation (e.g. Moser et al. 2008), it is likely that the understorey species of lower elevations are adapted to deeper shade than those at higher elevations and are in fact representing different tree functional types. Comparative physiological measurements are needed to characterize the ecology of tree species in the understorey guild at different elevations.

The few existing studies on tropical understorey trees have investigated only a limited number of lowland and lower montane forest stands across the Tropics. The available data suggested that true understorey tree species are much more frequent and diverse in neotropical forests, while the understorey of Southeast Asian forests to a high percentage consists of saplings of large- and medium-sized trees of the upper canopy with the obvious consequence that 
flowering and fruiting woody plants are much less common in the understorey of Asian tropical forests (Janzen 1977, LaFrankie et al. 2006, Corlett 2007). These authors hypothesized that the dominance of dipterocarps with periodic mass flowering may be responsible for the apparently striking difference. In support of this assumption, Lü and Tang (Lü and Tang 2010) found the understorey of non-dipterocarp forests in SW China to be mainly composed of trees with small and medium size at maturity, indicating that the absence of dipterocarps in Asian forests may result in a higher species diversity of understorey trees.

With 25 to $51 \%$ of all tree species in a plot never reaching the upper canopy, our data from nondipterocarp forests east of Wallace's line point to a considerable species richness in this guild, contradicting the hypothesis put forward by LaFrankie et al. (2006) that Southeast Asian forest understoreys are generally dominated by saplings of large canopy trees. However, we found no decrease in the relative species richness in this guild when moving upslope from sub-montane to lower montane elevation (c. 1300 - 1950 m), where Fagaceae, another family with periodic mass flowering, dominate. We expected that Dipterocarpaceae and Fagaceae should have a similar effect on the understorey trees. A possible explanation for the existence of a relatively species-rich true understorey vegetation in the forests with abundant Castanopsis and Lithocarpus in Central Sulawesi could be that the germination success of Fagaceae species after mass flowering is less in the cooler lower montane forests than that of Dipterocarpaceae species in the hot lowlands, or seed predator satiation is less effective in promoting the density of viable seeds in Fagaceae. Also, we observed that mature trees of Castanopsis usually secure their sustained survival by growing basal sprouts; hence they may be less reliant on offspring from generative reproduction. Finally, it is possible that dipterocarp saplings are generally reaching higher abundances in the understorey of the respective forests than tropical Fagaceae, as LaFrankie et al. (2006) found in Pasoh, Lambir and Palanan (Malaysia and Philippines) more than $50 \%$ of the plants in the smallest diameter class being dipterocarps, which is much higher than the frequency of Fagaceae offspring in our forests.

It is obvious that identifying true understorey tree species is not a trivial task, and percentages given for understorey species may be biased, as the definition of stature at maturity varies among studies; furthermore, low numbers of plots and individuals surveyed may lead to overestimation. A better criterion for identifying true understorey trees than a diameter threshold may be the observation of flowering of small-sized trees in the lower canopy. However, such information is at best available for a few permanently monitored tropical forest plots.

\subsection{Conclusions}

The tropical mountain forests of Central Sulawesi harbour a species-rich and unique tree flora, which contains more endemic species than previously thought. The understorey, as well, is surprisingly rich in species and genera, in apparent contrast with South-east Asian lowland forests dominated by dipterocarps. We present a delimitation of altitudinal forest zones based 
on species diversity, taxonomic composition and levels of endemism, distinguishing submontane, lower montane and upper montane forests, which does not fully match earlier zonation schemes. While soil properties may determine species composition and diversity in certain lowland forest regions, elevation is the main determinant of vegetation patterns in submontane to upper montane forests in the study region.

The unique species composition and relatively high endemism give the TMF of Sulawesi and other mountainous islands in the Malesian Archipelago high priority in conservation, even though their taxonomic diversity is smaller than that of lowland forests. The few existing data suggest that even different summits on the same island may harbour clearly recognizable and unique forest communities, which calls for concerted conservation action for the remaining lower montane and upper montane forests of this region. 


\title{
5 Predominant colonization of Malesian mountains by Australian tree lineages
}

\author{
Fabian Brambach, Christoph Leuschner, Aiyen Tjoa, Heike Culmsee \\ Published in Journal of Biogeography 46 (2019), https://doi.org/10.1111/JBI.13747
}

\subsection{Abstract}

Aim: Massive biota mixing due to plate-tectonic movement has shaped the biogeography of Malesia and during the colonization process, Asian plant lineages have presumably been more successful than their Australian counterparts. We aim to gain a deeper understanding of this colonization asymmetry and its underlying mechanisms by analyzing how species richness and abundance of Asian versus Australian tree lineages in three Malesian subregions change along environmental gradients. We hypothesize that differing environmental histories of Asia and Australia, and their relation to habitats in Malesia, have been important factors driving assembly patterns of the Malesian flora.

Location: Malesia, particularly Sundaland, the Philippines, and Wallacea.

Taxa studied: Seed plants (trees).

Methods: We compiled plot-level data of environmental variables and tree abundances from three Malesian subregions. For each species, we inferred its geographic ancestry (Asian or Australian) based on published phylogenetic studies and the fossil record. We used proportions of Australian versus Asian species and individuals per plot to test how they are related to environmental parameters and geographic position using logistic regression models.

Results: Proportionally more Australian (and fewer Asian) tree species and individuals occurred (1) at higher elevations, (2) on sites over ultramafic parent material, and (3) closer to their source region Australia with a significant increase of Australian elements east of Wallace's line. The trend was stronger for individuals than for species.

Main conclusions: Long-term environmental similarities between source and sink habitats have shaped the assembly of the Malesian flora: Tree lineages from tropical Southeast Asia predominantly colonized the Malesian lowlands and rich soils whereas trees from montane refuges in Australia were more successful in the newly emerging Malesian mountains and on poorer soils. The biogeographic patterns caused by the Malesian Floristic Interchange point to the importance of phylogenetic biome conservatism in biotic interchanges and resemble those resulting from the Great American Biotic Interchange in the Neotropics. 


\subsection{Introduction}

The distribution of terrestrial life on earth is spatially structured into biogeographic regions with more or less homogeneous biota, separated by biogeographic boundaries (Wallace 1876a, Cox 2001, Holt et al. 2012). Long-term geographic isolation has shaped the deepest boundaries between these regions (Ficetola et al. 2017) by limiting dispersal to and from other land masses, thus leading to the independent evolution of biotas (e.g. Madagascar, Australia) for millions of years. Rare but frequent long-distance dispersal events followed by successful establishment can lead to the exchange of organisms even between distant landmasses (Crisp et al. 2009). Events where landmasses approach each other due to sea-level changes and/or collision of moving tectonic plates are much less frequent than long-distance dispersal but cause massive biotic exchange with profound impacts on biotas (Vermeij 1991, Antonelli et al. 2018a). Examples include the collision of the Indian continent with Asia in the Eocene (Dutta et al. 2011, 20) and the repeated presence of the Bering Land Bridge between East Asia and North America during the Tertiary (Donoghue and Smith 2004, Graham 2018). Much more recently, transport of organisms by humans has been accelerating the mixing of biotas, causing massive environmental and economic impacts (van Kleunen et al. 2015). Understanding the patterns of past biotic exchanges and their underlying processes can help predict future impacts due to anthropogenic biotic interchange (Vermeij 1991, Heberling et al. 2017).

One of the best studied of such events was the successive establishment of the Central American land bridge (Montes et al. 2015, Graham 2018), which culminated in the Great American Biotic Interchange (GABl; Wallace 1876b, Marshall et al. 1982), the extensive mixing of South American and North American faunas and floras in the late Miocene to Pliocene. Much of our current understanding of tropical biotic exchange resulting from geologic processes stems from the intense study of the GABI. The past isolation of landmasses, availability of different habitats in space and time, and taxon-specific traits like dispersal capability have all had an influence on the interchange patterns, but their relative importance is debated (Simpson 1980, Marshall et al. 1982, Webb 2006, Woodburne 2010, Faurby and Svenning 2016). Furthermore, it remains unclear whether the mechanisms of biota mixing unravelled from the study of the GABI are of universal validity throughout the tropics or largely specific to the Neotropical realm.

Another striking example of geology-driven biota mixing in the tropics is the Indo-Australian or Malay Archipelago. This part of the Paleotropics encompasses the insular region between Asia and Australia (plus the Malay Peninsula) and is usually referred to as Malesia in botanical research (Zollinger 1857, Raes and van Welzen 2009). Similar to the situation in Central America before the closure of the Central American land bridge, the extensions of the Asian continent on the Sunda shelf and of the Australian continent on the Sahul shelf have never had a continuous land bridge connecting them. Today, they are separated by narrow stretches of ocean and the islands referred to as Wallacea (Hall 2017). Already in the Paleogene, when the continents were still far apart from each other, sporadic long-distance dispersal events by plants 
occurred from Asia to Australia and vice versa. However, biotic interchange, termed the Malesian Floristic Interchange (MFI) or Sahul-Sunda floristic exchange, sharply intensified in the Early Neogene when the two land masses approached each other and the Wallacean islands emerged in between (20-25 Ma; Lohman et al. 2011, Sniderman and Jordan 2011, Richardson et al. 2012, Crayn et al. 2015). Hence, we can generally assume that the species present today in Malesia belong to lineages that were present on either of the two continents before the Neogene but did not occur on both of them.

Today, the fauna of Malesia shows strong geographic structure and includes numerous taxa endemic to the region's diverse subregions. This pattern, known since the initial observations by Wallace (1860) and consistent with relatively low dispersal capabilities in many animal taxa, indicates dispersal filters from Asia to Australia and vice versa. The situation in plants, however, is different: Malesia is a well-defined floristic region, albeit with internal geographic structuring (Raes and van Welzen 2009, Culmsee and Leuschner 2013). Among the most diverse floras worldwide (Slik et al. 2015), the Malesian flora is furthermore said to be derived predominantly from Asian ancestors, indicating asymmetric colonization (Richardson et al. 2012). This assumption is mainly based on the fast-growing number of phylogeographic studies of single plant taxa (e.g. Thomas et al. 2012, Grudinski et al. 2014). These studies have proven highly valuable to understand the evolutionary history and biogeography of numerous Malesian taxa and have allowed insights into more general patterns of colonization (summarized in Crayn et al. 2015).

While the available information suggests that overall, Asian lineages dominate the Malesian flora today (e.g. Richardson et al. 2012), detailed phylogeographic studies are still lacking for many species-rich taxa and the mechanisms of the MFI are generally much less understood than those of its Neotropical counterpart GABI. In particular, the colonization patterns of plants since the onset of the MFI under different environmental conditions have not received sufficient attention (but see Yap et al. 2018). Earlier phytogeographic research has highlighted the abundance of Australian elements in certain Malesian forest habitats, such as in mountains and areas with ultramafic parent material (van Steenis 1935b). Attempts to quantify the contribution of plant lineages of different origins to habitat-wise floral assembly have so far been limited to case studies using few forest plots available on a regional level (Culmsee et al. 2011, Aiba et al. 2015). Furthermore, previous studies have predominantly used species richness as a measure for evolutionary success (e.g. Richardson et al. 2012) neglecting other quantitative measures like abundance or biomass due to lack of adequate data (but see Culmsee et al. 2010a). These other parameters are needed, however, to comprehensively describe patterns of colonization and dominance. Tropical mountain forests are well suited to study colonization processes in the distant geological past. They possess bioclimatic belts with a steep turnover in tree community composition (Körner et al. 2011), are typically less affected by anthropogenic disturbance and their tree floras are often more natural than those of remaining lowland forests (Cannon et al. 2007). 
Malesia and the MFI can serve as an independent model to test hypotheses resulting from decades of research on the GABI. If long isolation leads to lower competitiveness (Simpson 1980, Faurby and Svenning 2016), then Australian lineages should be less successful in the colonization of Malesia than their Asian counterparts, regardless of habitat suitability (in the following we speak of Asia and Australia instead of Sunda shelf and Sahul shelf, as Asian species dispersed into Malesia not only from Sundaland, but also via the Philippines (see van Steenis 1935a)). Alternatively, if colonization depends strongly on the available habitat (Cody et al. 2010, Woodburne 2010), colonization asymmetry will vary between habitats and relate to the environmental history of the source and sink regions. Trees with ancestors in continental Southeast Asia and Sundaland, where rainforest has been present since at least the mid-Eocene (Morley 2012, Hall 2013), may possess adaptations to hotter and moister climates than taxa from clades that originated on the Australian continent. The latter underwent strong aridification in the Neogene after its separation from Antarctica when mesic biomes remained confined to mountain areas along the eastern coast of Australia and in parts of New Guinea (Quarles van Ufford and Cloos 2005, Byrne et al. 2011, Sniderman and Jordan 2011, Kooyman et al. 2014). Furthermore, the large extent of nutrient-poor soils on the Australian continent could have favoured plant lineages adapted to these soils (van Steenis 1979, Hill 2004).

Dispersal filters such as stretches of ocean between suitable terrestrial habitats limit biotic exchange (Woodburne 2010, Bacon et al. 2015, Graham 2018). However, plants have comparatively high dispersal capabilities, so that the filter function of ocean barriers may be less-important to them than to many animal taxa, as exemplified by the relative commonness of long-distance dispersal in plants (Donoghue and Smith 2004, Sanmartín et al. 2004, Bacon et al. 2015). During the MFI, newly emerging islands in Wallacea likely facilitated stepping-stone dispersal, so that the occurrence of plant lineages in Malesia may be only weakly dependent on distance from their host region, i.e. the land masses of Asia and Australia, whereas suitable habitat may play a larger role.

In the present study, we attempt to close the knowledge gap about colonization asymmetry in the MFI. More specifically, we try to quantify the proportion of tree species and individuals with Asian versus Australian ancestry in Malesian forests by adopting a mixed approach. First, we compiled plot-level data of trees from the three major Malesian subregions and biodiversity hotspots Sundaland, the Philippines, and Wallacea, to establish a dataset with $>15800$ tree individuals of ca 1640 species from a wide phylogenetic range (ca 35\% of all vascular plant families containing trees). The dataset further contains information on species abundances and environmental variables for each plot. Second, we inferred the geographic ancestry (Asian or Australian) for each species by building on the wealth of phylogenetic information that has become available in the last three decades supplemented by relevant fossil records. This allows us to quantify for the first time the contribution of Asian versus Australian lineages to community composition in Malesian forests under different environmental conditions and to test the following hypotheses regarding biotic interchanges: 
1. The contribution of Asian versus Australian tree lineages to community composition in Malesian forests differs between habitats.

2. Asian lineages are more dominant in lowland rain forests, while Australian lineages strive better in mountains and on nutrient-poor soils.

3. Habitat, rather than distance to the source region (Asia or Australia), drives the differences in community composition.

\subsection{Methods}

\subsubsection{Malesian tree inventory data}

We compiled a dataset of 55 tree inventory plots (all trees with diameter at breast height $\geq 10$ $\mathrm{cm}$ ) in old-growth forests (Figure 5.1), including 42 plots from published studies and 13 plots of our own work on Sulawesi, Indonesia (Table 5.1, Appendix 5.1). We classified the western and central parts of Malesia covered by our dataset into three phytogeographical areas, Sundaland, the Philippines, and Wallacea, following the nomenclature of biodiversity hotspots of Myers et al. (2000). Sundaland was represented by plots in Sumatra $(n=1)$, Borneo $(n=19)$, and Java ( $n=$ 10) spanning an elevational gradient from $250-3080 \mathrm{~m}$ a.s.l., the Philippines by plots on four islands $(n=11)$ from $750-2200 \mathrm{~m}$, and Wallacea by two areas, each one in the subregions Sulawesi $(n=13)$ and Maluku Islands $(n=1)$ from $630-2400 \mathrm{~m}$. Plot size varied within and among the studies (0.1-1.0 ha; data sources in Appendix 5.1). We selected only such studies that provided species identification to genus or species level with a high taxonomic standard, including the deposition of voucher specimens in herbaria and a full list of the recorded species per plot with their abundances, i.e. the per-plot number of individuals per species.

\subsubsection{Assignment of biogeographic origin}

We checked the inventory lists of the original studies and excluded tree ferns (208 individuals from ten species) because we were not sure whether all original studies had included them in their inventories; we also removed non-tree taxa (24 individuals from four species). Then we combined the lists of species and their abundances from all plots (16 131 individuals in total) and standardized the plant names with the help of taxonomic literature and web tools (van Steenis et al. 1948-2019, Soepadmo et al. 1995-2014, IPNI 2015, The Plant List 2019, WCSP 2019). We pruned the original names to species level and manually corrected spelling errors. We removed cf.- and aff.-qualifiers but retained the following epithets unless the purportedly similar species did not occur naturally in the respective biogeographical region (in that case we used 'sp.'). We treated morphospecies as different species when they were clearly distinguished as such in the original sources (e.g. as sp.1, sp.2, etc., see Appendix 5.1). In addition, we assumed that morphospecies in the same genus but from different original studies represented different species. The total number of species in our dataset (see Appendix 5.3) is thus probably inflated and should be seen as an estimate. However, since our main results are based on calculated percentages on a plot basis, this possible bias does not affect our analyses. 
Table 5.1 Dataset of 55 tree inventory plots from 12 Malesian areas in the three phytogeographic regions of Sundaland, the Philippines, and Wallacea with physiographic information (geographic coordinates, distance from the Sahul Shelf, and elevation), geological substrate, plot sizes and numbers, and original sources. All data sources are listed in Appendix 5.1.

\begin{tabular}{|c|c|c|c|c|c|c|}
\hline Location & $\begin{array}{c}\text { Sahul } \\
\text { dist. (km) }\end{array}$ & Data source & $\begin{array}{l}\text { Parent } \\
\text { material }\end{array}$ & $\begin{array}{l}\text { Elevation } \\
\text { (m a.s.I.) }\end{array}$ & $\begin{array}{l}\text { Plot size } \\
\text { (ha) }\end{array}$ & $\begin{array}{l}\text { Plots } \\
\text { (n) }\end{array}$ \\
\hline \multicolumn{7}{|l|}{ Sundaland } \\
\hline $\begin{array}{l}\text { Batang Gadis NP, N Sumatra } \\
\left(\mathrm{N} 0.6^{\circ}, \mathrm{E} 99.5^{\circ}\right)\end{array}$ & 3050 & $\begin{array}{l}\text { Kartawinata et al. } \\
2004\end{array}$ & sedimentary & 660 & 1.00 & 1 \\
\hline $\begin{array}{l}\text { Batu Apoi NP, Brunei, Borneo } \\
\left(\mathrm{N} 4.5^{\circ}, \mathrm{E} 115.2^{\circ}\right)\end{array}$ & 1760 & Poulsen et al. 1996 & sedimentary & 250 & 1.00 & 1 \\
\hline $\begin{array}{l}\text { Apo Kayan FR, E Kalimantan, } \\
\left.\text { Borneo (N 2.7 } \text { E } 115.5^{\circ}\right)\end{array}$ & 1640 & Bratawinata 1986 & sedimentary & $740-1850$ & 0.80 & 5 \\
\hline \multirow[t]{3}{*}{$\begin{array}{l}\text { Mt Kinabalu, Sabah, Borneo } \\
\left(\mathrm{N} 6.1^{\circ}, \mathrm{E} 116.6^{\circ}\right)\end{array}$} & 1690 & Aiba et al. 2002 & $\begin{array}{l}\text { sedimentary } \\
\text { ultramafic }\end{array}$ & $\begin{array}{l}650-3080 \\
700-2700\end{array}$ & $\begin{array}{l}0.20-1.00 \\
0.20-1.00\end{array}$ & $\begin{array}{l}5 \\
3\end{array}$ \\
\hline & & Takyu et al. 2002 & $\begin{array}{l}\text { sedimentary } \\
\text { ultramafic }\end{array}$ & $\begin{array}{c}1560-1860 \\
1860\end{array}$ & $\begin{array}{l}0.10 \\
0.10\end{array}$ & $\begin{array}{l}2 \\
1\end{array}$ \\
\hline & & Kitayama 1995 & sedimentary & $2350-2600$ & $0.14-0.17$ & 2 \\
\hline $\begin{array}{l}\text { Mt. Wilis, E Java } \\
\left(\mathrm{S} 7.9^{\circ}, \mathrm{E} 111.8^{\circ}\right)\end{array}$ & 1410 & $\begin{array}{l}\text { Purwaningsih et al. } \\
2017\end{array}$ & volcanic & $1300-1500$ & 0.25 & 3 \\
\hline $\begin{array}{l}\text { Mt Gede-Pangrango } \\
\text { W Java } \\
\left(\mathrm{S} 6.8^{\circ}, \mathrm{E} 107.0^{\circ}\right)\end{array}$ & 1960 & $\begin{array}{l}\text { Helmi et al. } 2009 \\
\text { Meijer } 1959 \\
\text { Yamada } 1975 \\
\text { Yamada } 1977\end{array}$ & $\begin{array}{l}\text { volcanic } \\
\text { volcanic } \\
\text { volcanic } \\
\text { volcanic }\end{array}$ & $\begin{array}{c}800 \\
1500 \\
1600 \\
1700-2300\end{array}$ & $\begin{array}{l}1.00 \\
1.00 \\
1.00 \\
0.10\end{array}$ & $\begin{array}{l}1 \\
1 \\
1 \\
4\end{array}$ \\
\hline \multicolumn{7}{|l|}{ Philippines } \\
\hline $\begin{array}{l}\text { Mt Banahao, Luzon } \\
\left(\mathrm{N} 14.5^{\circ}, \mathrm{E} 121.5^{\circ}\right)\end{array}$ & 1980 & Aragones 1991 & volcanic & $750-2100$ & 0.42 & 6 \\
\hline $\begin{array}{l}\text { Mt Giting-Giting, Sibuyan } \\
\text { (N } 12.4^{\circ}, \text { E } 122.6^{\circ} \text { ) }\end{array}$ & 1730 & Proctor et al. 1998 & ultramafic & $770-1240$ & 0.25 & 3 \\
\hline $\begin{array}{l}\text { Mt Mandalagan, Negros } \\
\left(\mathrm{N} 10.7^{\circ}, \mathrm{E} 123.2^{\circ}\right)\end{array}$ & 1530 & Hamann et al. 1999 & volcanic & 1000 & 1.00 & 1 \\
\hline $\begin{array}{l}\text { Mt Kinasalapi, Mindanao } \\
\left(\mathrm{N} 8.0^{\circ}, \mathrm{E} 125.5^{\circ}\right)\end{array}$ & 1140 & $\begin{array}{l}\text { Pipoly \& Madulid } \\
1998\end{array}$ & volcanic & 2200 & 1.00 & 1 \\
\hline \multicolumn{7}{|l|}{ Wallacea } \\
\hline $\begin{array}{l}\text { Lore Lindu NP, Sulawesi } \\
\left(\mathrm{S} 1.5^{\circ}, \mathrm{E} 120.2^{\circ}\right)\end{array}$ & 1040 & Brambach et al. 2017 & acid plutonic & $700-2400$ & 0.24 & 13 \\
\hline $\begin{array}{l}\text { Tapayo, Halmahera, Maluku } \\
\text { Islands }\left(\mathrm{N} 0.8^{\circ}, \mathrm{E} 128.0^{\circ}\right)\end{array}$ & 330 & Whitmore et al. 1987 & sedimentary & 630 & 0.50 & 1 \\
\hline
\end{tabular}

FR = Forest Reserve, NP = National Park, Sahul dist. = Distance from Sahul Shelf

Assuming that each species or its ancestor was present in only one continent - Asia or Australia - before the intensification of the MFI in the early Neogene (Crayn et al. 2015), we separated the species into two groups: those with Asian ancestry (hereafter: Asian species) versus those with Australian origin (Australian species). To compile this information, we carried out an exhaustive literature search for phylogeographic studies (e.g. phylogenetic studies including direct reconstruction of ancestral areas), other dated and undated phylogenetic studies, relevant 
fossil data, and taxonomic literature, using in total ca 300 published sources (see references in Appendix 5.2 in the Supplementary Information). As most phylogenetic studies use incomplete taxon sampling, many of our species were not directly represented in the references. We therefore assumed that all species of a genus shared the same biogeographic ancestry (Asian or Australian) unless the results of studies indicated otherwise. In the latter cases (e.g. Macaranga, Ficus), we attempted to match our species to infrageneric clades, mostly based on systematic studies and morphological characters. Likewise, we attempted to assign species of polyphyletic genera to the correct clades in the phylogenetic studies. When phylogeographic studies were not available, we resorted to other phylogenetic sources. These often did not explicitly contain information on biogeographic history, but with the distribution of sampled species taken from floristic accounts and databases, we could usually infer the geographic ancestry nonetheless, especially when the phylogenies were dated. Tree individuals which could not be assigned to one of these ancestry groups were excluded from further analyses ( $n=245$ ). The majority of those ambiguous individuals belonged to morphospecies which did not have sufficient taxonomic resolution to infer their geographic origin, but we also included alien species here (eleven individuals in four species), as they do not convey any meaningful biogeographic information in the context or our study. The percentages of individuals with ambiguous ancestry per plot ranged from $0 \%$ to $11.8 \%$ (median $0 \%$, mean $1.3 \%$ ). Plots on ultramafic parent material contained a significantly higher proportion of individuals with unknown geographic origin than plots on other substrates (logistic regression model with quasibinomial error structure: $D^{2}=0.16, p<0.0001$ ), possibly highlighting the high number of insufficiently known endemics expected to occur there; the other variables did not have any significant effects (Appendix 5.2: Figure 1). Most of the trees that lack information on their geographic origin do so because of insufficient taxonomic resolution (i.e. completely unidentified or identified to family level only). We consider it unlikely that species with Australian ancestry are generally more difficult to identify than those from Asia or vice versa. Therefore, despite the unequal representation of trees with ambiguous geographic origin per plot, deleting these records prior to the main analyses is unlikely to add a significant bias to our results.

The final dataset contained 15886 individuals assigned to 1636 species and morphospecies. We were able to classify the majority of individuals (73\%) using phylogeographic studies or a combination of these with information on fossils. For most of the rest, we found dated (17\%) or undated phylogenies (9\%) without direct inference of geographic origin and combined these with information on the fossil record and/or distribution data to infer the respective ancestral regions from other sources. Only for the remaining $2 \%$ of individuals, we used fossil record and/or distribution data alone. Details regarding the methods, references and specifications of species' assignation to their geographic ancestry are summarized in Appendix S1. A list of all species with their respective inferred origin is given in Appendix S2. Finally, we calculated the proportion of Australian species per plot and the proportion of individuals belonging to these species (Australian individuals) per plot. The Australian and Asian proportions per plot amount to $100 \%$. 


\subsubsection{Data analysis}

To link the occurrence of Australian versus Asian lineages in Malesia to geography and environmental factors, we employed the per-plot proportions of Australian species and individuals as response variables in multiple logistic regression models (LRM) using the $\mathrm{g} / \mathrm{m}$ function in RStudio (RStudio Team 2016, based on R; R Core Team 2017).

To select suitable explanatory variables, we extracted plot elevation, geological parent material, and (approximate) geographic position from the original studies (). We followed two strategies to account for the geographic position: first, we calculated the distance of each plot to the nearest border of the Sahul Shelf (displayed in Figure 5.1a) using the ruler tool in QGIS (QGIS Development Team 2016). Second, we used the three phytogeographic regions Sundaland, the Philippines, and Wallacea to define the plots' regional affiliations.

We then tested for correlation between the environmental parameters elevation, parent material (geology), distance from the Sahul Shelf (Sahul distance) and phytogeographic region (phytoregion). Geology was strongly correlated with phytoregion (Chi ${ }^{2}$ test: $\mathrm{Chi}^{2}=62.5, \mathrm{p}<$ 0.00001 ) and with Sahul distance (Kruskal-Wallis test: $\mathrm{Chi}^{2}=31.5, \mathrm{p}<0.00001$ ). We explain this by the uneven distribution of different parent materials between the studied locations, e.g. volcanic material only occurred on Java, while acid plutonic rock was exclusively found on Sulawesi (Table 5.1). We therefore simplified the geology classification to have only two categories: ultramafic versus non-ultramafic. The resulting binary geology showed no significant correlation with phytoregion (Chi test: $\mathrm{Chi}^{2}=4.1, \mathrm{p}=0.13$ ) or Sahul distance (Kruskal-Wallis test: $\mathrm{Chi}^{2}=1.3, \mathrm{p}=0.25$ ) and was used for all further analyses. Phytoregion and Sahul distance were also highly correlated (Kruskal-Wallis test: $\mathrm{Chi}^{2}=34.5, \mathrm{p}<0.00001$ ), while elevation was independent of all other parameters. We decided to start the model selection with two separate models for each response variable, one employing elevation, geology and phytoregion (hereafter referred to as phytoregion model), the other using elevation, geology and Sahul distance (hereafter: distance model) as explanatory variables. Hence, we computed four different models: A phytoregion model for Australian species (model 1), a distance model for Australian species (model 2), a phytoregion model for Australian individuals (model 3), and a distance model for Australian individuals (model 4).

For the proportion of Australian species, we started with a full model with binomial error structure and logit link function containing all three explanatory variables and their interaction effects. Using the dredge function of the MuMIn package (Barton 2018), we then computed all possible nested models and sorted them according to their Bayesian information criterion (BIC) to select the best model. BIC penalizes model complexity more strongly than the commonly used Akaike information criterion (AIC). We chose BIC because we wanted to avoid multiple interaction effects, which would be difficult to interpret ecologically. We successively discarded all models with $\triangle \mathrm{BIC} \geq 2$ compared to the model with the lowest $\mathrm{BIC}$. Among the remaining ones, we discarded those with the most parameters. For both the phytoregion model and the distance model, the best model included all three independent variables but no interaction effects. For 
the proportion of Australian individuals, we employed a similar model selection process, but due to large data overdispersion, here we used the LRM with a quasi-binomial error structure and performed the model selection based on quasi-BIC (qBIC). The resulting best models also included all three independent variables without interaction effects. To test whether spatial autocorrelation between plots played a role beyond the tested parameters, we calculated Moran's I for the residuals of all four best models (models 1-4, see Table 2) using the Im.morantest function of the spdep package (Bivand et al. 2019). All models contained nonspatially correlated residuals (Moran's I = 0.45-0.60, $p=0.27-0.33$ ).

\subsection{Results}

\subsubsection{Biogeographical patterns in the Malesian subregions}

In the 12 analysed Malesian areas taken together, Asian lineages strongly dominated, representing $76 \%$ of all investigated tree species and $67 \%$ of all tree individuals. The dominance decreased from Sundaland in the west ( $80 \%$ of species, $69 \%$ of individuals) over the Philippines $(75 \%, 68 \%)$ to Wallacea in the east $(64 \%, 53 \%)$. Asian lineages were more dominant on sites over non-ultramafic ( $78 \%$ of species, $69 \%$ of individuals) than on those with ultramafic parent material $(65 \%, 54 \%)$.

Correspondingly, the mean per-plot percentage of Australian tree species was higher in Wallacea $(39 \%, n=14)$ than in the Philippines $(31 \%, n=11)$ and Sundaland $(30 \%, n=30)$. Similarly, Wallacean plots had the highest mean number of Australian individuals (43\%) compared to the Philippines (32\%) and Sundaland (34\%). Plots on ultramafic parent material on average had more Australian species $(43 \%, \mathrm{n}=7)$ and individuals $(51 \%)$ than non-ultramafic plots ( $31 \%$ of species and $34 \%$ of individuals, $n=48$ ).

\subsubsection{Environmental conditions driving biogeographical patterns}

Multiple logistic regression models (LRM) uncovered significant differences in the proportion of both Australian species and Australian individuals between the 55 plots from 12 Malesian areas in relation to all investigated environmental variables (Table 5.2). For the proportion of Australian species per plot, the model with elevation, parent material, and phytogeographic region as independent variables (model $1, \mathrm{D}^{2}$ adj $=0.71 * * *$ ) performed better than the one using elevation, parent material and distance from the Sahul shelf (model $2, D^{2}$ adj $=0.66^{\star \star *}$ ). In both models, plots at higher elevation had higher percentages of Australian species and this factor accounted for about half of the deviance. Australian species were also better represented on plots with ultramafic parent material compared to non-ultramafic localities but the explanatory power of the parent material was much lower $\left(D^{2}=0.12 * * *\right)$ compared to elevation. In the phytoregion model (model 1), phytoregion was the second most explanatory variable $\left(D^{2}{ }^{2}\right.$ dj $=$ 0.16). Here, Wallacean plots had significantly more Australian species than those from the 
Philippines and Sundaland. In the distance model (model 2), the explanatory power of distance to the Sahul shelf $\left(\mathrm{D}^{2}\right.$ adj $=0.08^{* *}$ ) was lower than that of parent material (Table 5.2, Figure $5.1 \mathrm{~b}$ d).

Table 5.2 Elevation, geology, and geographic position determine the proportion of tree species and individuals with Australian ancestry in Malesian forest plots. Results of multiple logistic regression models $(L R M)$ of the per-plot $(n=55)$ proportion of Australian tree species and individuals in 12 Malesian areas. Models include the independent environmental factors elevation, geology (ultramafic vs non-ultramafic) and geographic location. Geographic location (see Table 5.1) was included as the position in one of three phytoregions (Sundaland, the Philippines, and Wallacea; models 1 and 3) or the distance to the Sahul shelf (models 2 and 4). Error structure is binomial in models 1 and 2 and quasi-binomial due to overdispersion in models 3 and 4.

\begin{tabular}{|c|c|c|c|c|c|c|c|c|}
\hline & \multicolumn{8}{|c|}{ Proportion of } \\
\hline & \multicolumn{4}{|c|}{ Australian species plot ${ }^{-1}$} & \multicolumn{4}{|c|}{ Australian individuals plot ${ }^{-1}$} \\
\hline & & $\begin{array}{c}\text { Model } 1 \\
\text { (Phytoregion) }\end{array}$ & (Sar & $\begin{array}{l}\text { Model } 2 \\
\text { ul distance) }\end{array}$ & & $\begin{array}{l}\text { Model } 3 \\
\text { nytoregion) }\end{array}$ & & $\begin{array}{c}\text { Model } 4 \\
\text { Sahul distance) }\end{array}$ \\
\hline $\mathrm{BIC} / \mathrm{qBIC}$ & & 285.28 & & 298.48 & & 103.89 & & 105.63 \\
\hline$D^{2}{ }_{a d j}$ & & $0.71 * \star *$ & & $0.66 * * *$ & & $0.69 * * *$ & & $0.67 * * *$ \\
\hline Variable & $D^{2}$ & Coefficient & $D^{2}$ & Coefficient & $D^{2}$ & Coefficient & $D^{2}$ & Coefficient \\
\hline Elevation & 0.42 & $0.0007 * * *$ & 0.47 & $0.0007 * * *$ & 0.51 & $0.0010 * * *$ & 0.51 & $0.0009 * * *$ \\
\hline Geology (ultramafic) & 0.12 & $0.7133 * * *$ & 0.12 & $0.6625 * * *$ & 0.12 & $1.0595 * * *$ & 0.12 & $0.9942 * * *$ \\
\hline Sahul distance & - & - & 0.08 & $-0.0004 * * *$ & - & - & 0.06 & $-0.0006 * \star \star$ \\
\hline Phytoregion & 0.16 & & - & - & 0.06 & & - & - \\
\hline Sundaland & & -0.1814 & & & & -0.0065 & & \\
\hline Philippines & & 0 & & & & 0 & & \\
\hline Wallacea & & $0.4246 * *$ & & & & $0.7102 * *$ & & \\
\hline
\end{tabular}

$\mathrm{BIC}=$ Bayesian information criterion (models 1 and 2 ). $\mathrm{D}^{2}=$ proportion of deviance explained. $\mathrm{D}^{2}$ adj $=$ adjusted $\mathrm{D}^{2}$ (Guisan \& Zimmermann, 2000). qBIC = quasi-BIC based on a quasi-binomial error structure (models 3 and 4). Sahul distance $=$ Distance from Sahul Shelf. ${ }^{* *} p<0.01, * * * p<0.001$

For the proportion of Australian tree individuals in a plot, differences between phytoregion model (model 3, $\mathrm{D}^{2} \mathrm{adj}=0.69^{* \star *}$ ) and the distance model (model $4, \mathrm{D}^{2} \mathrm{adj}=0.67^{* \star *}$ ) were negligible. Again, elevation explained more than half of the deviance $\left(D^{2} \mathrm{adj}=0.54^{\star \star *}\right)$ with an increasing proportion of trees from Australian lineages towards higher elevations. The patterns of higher proportions of Australian trees in ultramafic than in non-ultramafic parent materials remained constant (models 3 and $4, D^{2}$ adj $=0.12^{* * *}$ ). Phytoregion (model 3 ) and the distance to the Sahul shelf (model 4) both explained a similar proportion of the respective model deviance, and in model 3, there was again a significant difference between the Wallacean plots with more and those from Sundaland and the Philippines with fewer Australian tree individuals (Table 5.2, Figure 5.1e-g). 

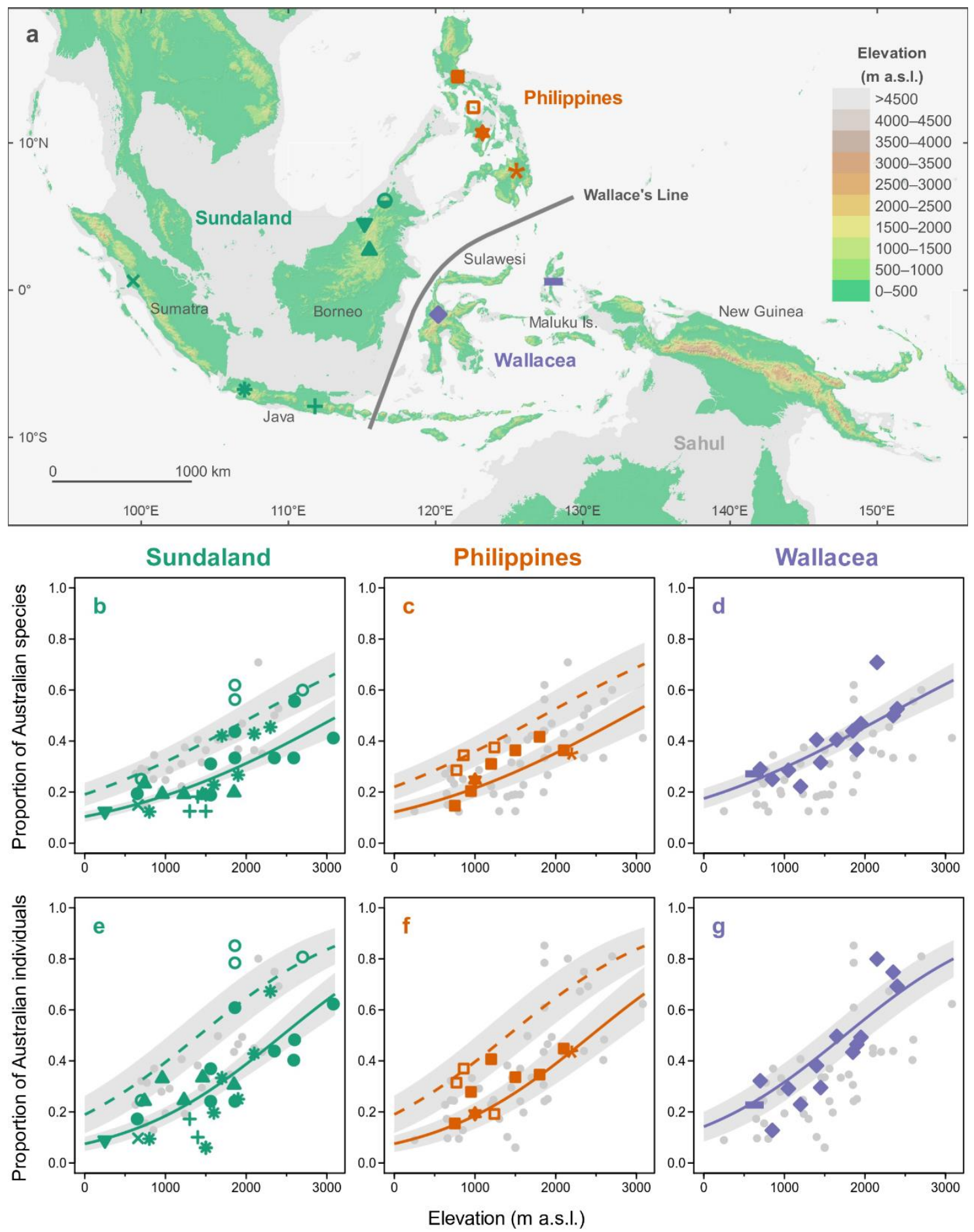

Figure 5.1 Diversity and abundance of Australian tree lineages in Malesian forest plots are higher at higher elevations, on ultramafic soils, and east of Wallace's line. Shown are the locations of 55 old-growth forest plots in 12 Malesian areas in the phytoregions Sundaland, the Philippines and Wallacea (a) and the perplot proportions of tree species (b-d) and individuals (e-g) with Australian ancestry in relation to elevation, parent material, and phytoregion. Regression lines show significant results based on multiple logistic regression models (model 1 for b-d, model 3 for e-g; see Table 5.2 for details). Symbols represent the 12 studied Malesian areas (a), each with 1-16 forest plots (b-g). Plots on non-ultramafic parent material are represented by closed symbols and continuous regression lines and plots on ultramafic parent material by open symbols and dashed regression lines (the Mt Kinabalu site in N Borneo contains plots with both types of parent material). Grey dots show plots of other phytoregions for comparison and light grey shadows indicate the $95 \% \mathrm{Cl}$ of the regression models. Map in WGS1984, Mercator projection, created with QGIS 3.4.9 showing shelf areas in grey (200-m bathymetric contours from Natural Earth: www.naturalearthdata.com). 
The patterns retrieved for the elevational distribution of Australian species and tree individuals were remarkably similar but the increase with elevation was stronger for individuals than species. Likewise, the increase of Australian individuals from non-ultramafic to ultramafic plots was larger than that of Australian species (Table 5.2, Figure 5.1b-g).

On non-ultramafic parent materials, our models predicted ca 35-55\% Australian species at an elevation of $2500 \mathrm{~m}$ in the three phytoregions (Figure $5.1 \mathrm{~b}-\mathrm{d}$ ), while the proportion of Australian individuals at the same elevation varied between 50 and 75\% (Figure 5.1e-g).

\subsubsection{Elevational tipping points}

On non-ultramafic substrates, the elevational tipping point with a 50\%-share of Australian species was reached at $2270 \mathrm{~m}$ in Wallacea (Figure 5.2a), but at $2890 \mathrm{~m}$ and $3150 \mathrm{~m}$ in the Philippines and Sundaland, respectively, according to model 1. On ultramafic soils, the $50 \%$ tipping points occurred at much lower elevations: $1850 \mathrm{~m}$ in the Philippines and $2110 \mathrm{~m}$ in Sundaland (Figure 5.2a).

In all areas, elevational tipping points with half of the individuals having Australian ancestry according to model 3 were much lower than those based on species, but patterns between phytoregions and parent materials were similar: the 50\%-individuals tipping point was reached at the lowest elevations on ultramafics (1410 $\mathrm{m}$ in the Philippines, 1420 in Sundaland) followed by non-ultramafic areas in Wallacea $(1750 \mathrm{~m})$, the Philippines $(2440 \mathrm{~m})$, and Sundaland (2450 m, Figure 5.2b).
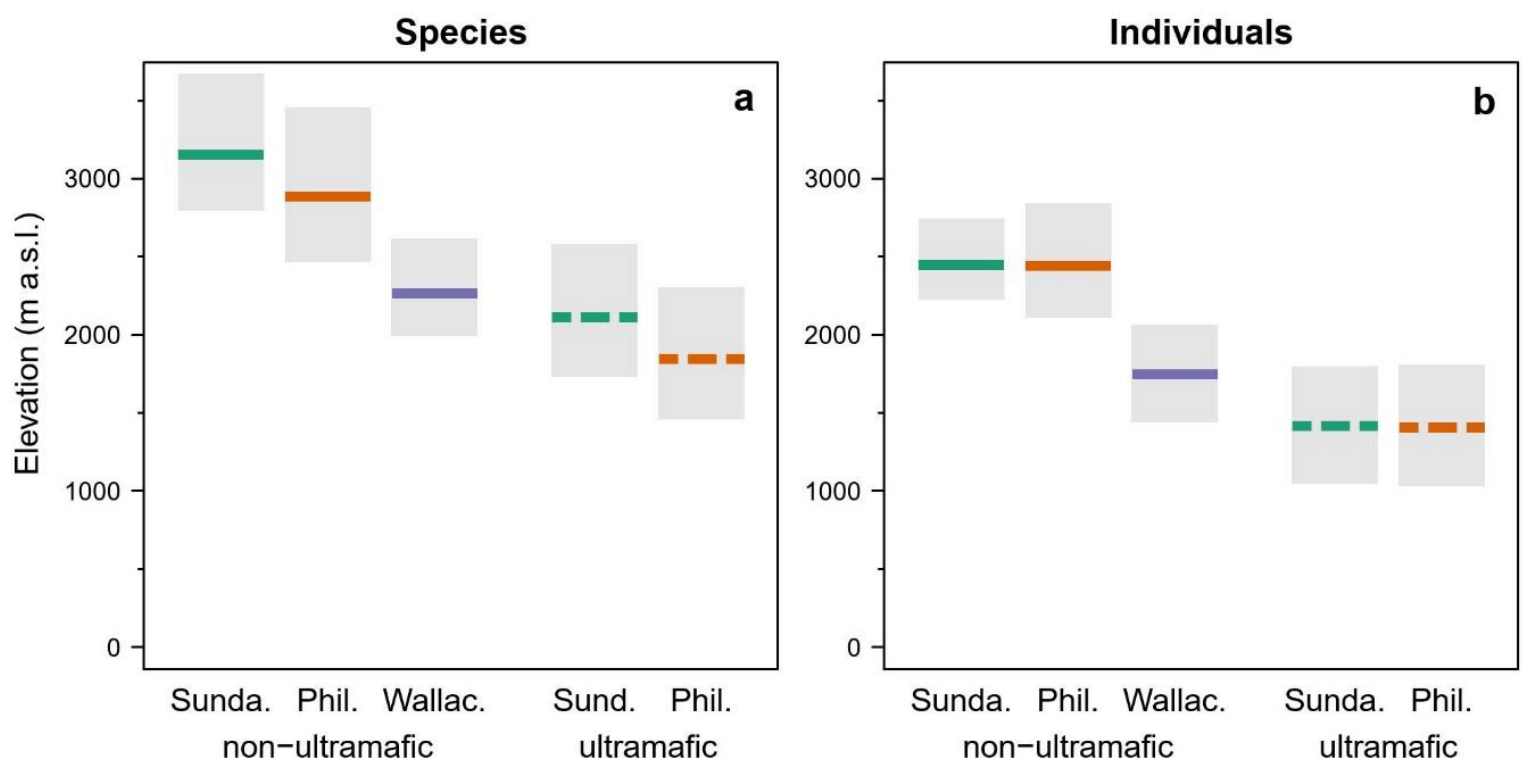

Figure 5.2 Elevational tipping points with a 50\%-share of Australian tree species showing the transition from Asian-dominated forests below the coloured lines to Australian-dominated forests above them. Data show the 50\%-tipping points for species (a) and individuals (b) in forests of the Malesian phytoregions Sundaland (Sunda.), the Philippines (Phil.), and Wallacea (Wallac.) on non-ultramafic (solid lines) and ultramafic (dashed lines) parent materials. Values from multiple logistic regression models with elevation, parent material, and phytoregion as independent variables (model 1 for a, model 3 for $b$; see Table 5.2 for details), based on 55 old-growth forest plots in 12 Malesian areas. Grey boxes correspond to the elevational range of the $95 \%-\mathrm{Cl}$ at a $50 \%$-proportion of Australian trees/individuals. 


\subsubsection{Dominant Australian taxa in Malesian forests}

Four taxa largely drove the proportion of Australian individuals: Myrtaceae, southern hemisphere conifers (Podocarpaceae and Araucariaceae), Polyosma (Escalloniaceae), and Elaeocarpus (Elaeocarpaceae) accounted for $70 \%$ of all recorded Australian individuals. They provided at least half of the individuals in $44(80 \%)$ and two-thirds or more in $28(51 \%)$ of all 55 plots. While Myrtaceae were present in most plots (although less so in Java), conifers attained high dominances at higher elevations and over ultramafic parent material. Elaeocarpus, on the other hand, was absent from ultramafic soils and rather poorly represented in the Philippines. Compared to the other subregions, Java stood out in the low percentages of Myrtaceae and conifers at higher elevations; instead Polyosma and Elaeocarpus were more dominant there (Figure 5.3).
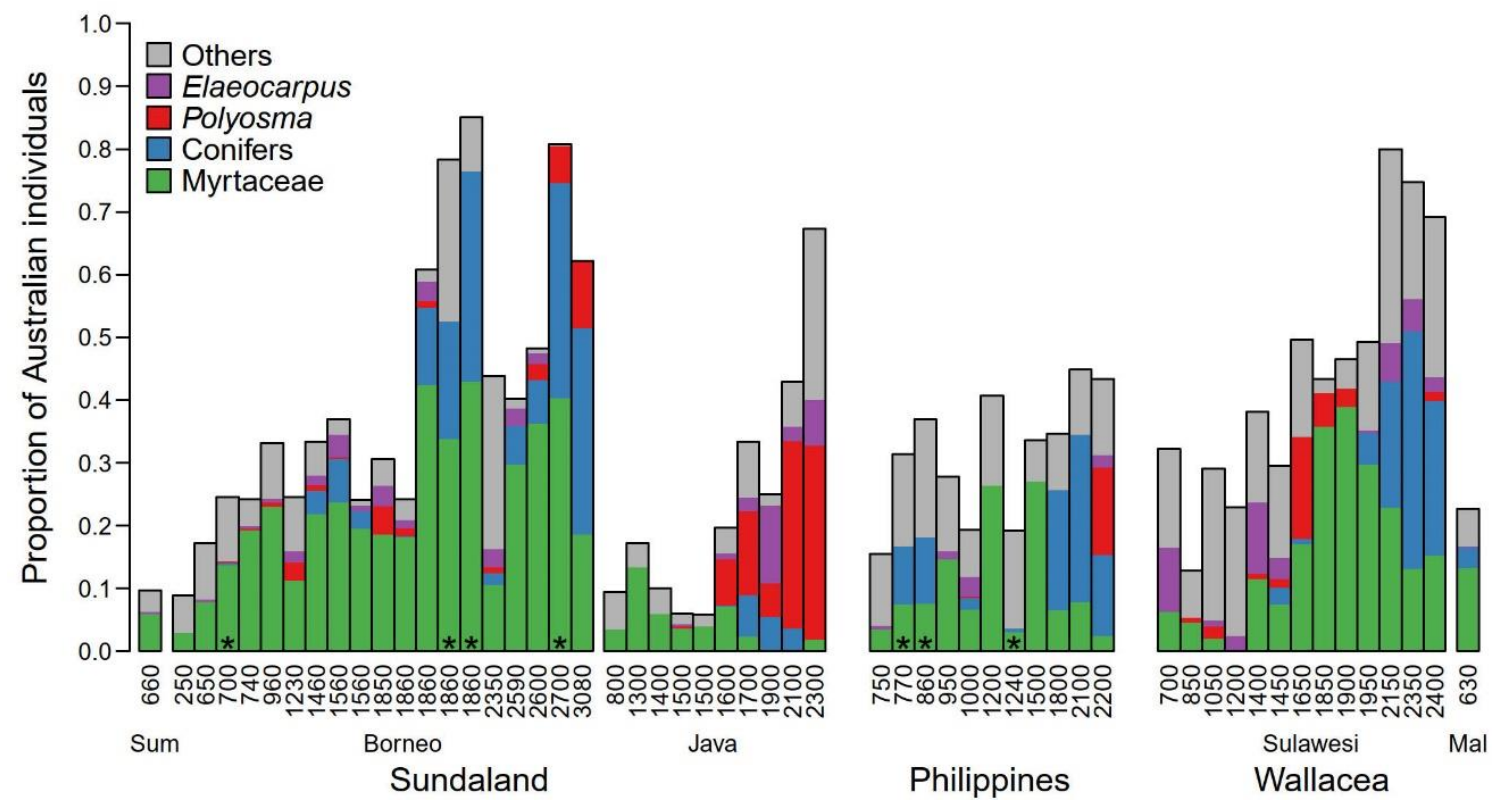

Figure 5.3 Four taxa drive the proportion of tree individuals with Australian ancestry in most of 55 Malesian forest plots. Plots are grouped by their geographic location and sorted by ascending elevation (m.a.s.l). Conifers include the Gondwanan families Podocarpaceae and Araucariaceae but not the Laurasian Taxaceae. Plots with ultramafic parent material are marked with an asterisk. Proportions of Australian and Asian trees per plot amount to 1. Sum = Sumatra, Mal = Maluku Islands.

\subsection{Discussion}

\subsubsection{Contrasting biogeographical patterns in Malesia}

Our results demonstrate that in Malesia proportionally more Australian (and conversely fewer Asian) tree species and individuals occur (1) at higher elevations, (2) in forests over ultramafic parent material, and (3) closer to their source region Australia with a significant increase east of Wallace's line, i.e. the boundary between Sundaland plus the Philippines and Wallacea. The trend is stronger for tree individuals than for species. Our estimates for the overall contribution of Asian species to the floras of Malesian subregions are generally lower than in previous 
studies, especially for Wallacea. This is unsurprising, since we focused on tree inventory plots along environmental gradients, giving more weight to azonal and less-diverse habitats like montane forests and those over ultramafic soils and less to lowland rain forest, the most widespread and diverse habitat. In contrast, previous results were based on flora treatments and checklists (Richardson et al. 2012), which rely on collected herbarium specimens. Especially in the underexplored areas of Wallacea, there may be a strong collection bias towards more accessible lowland sites (Cannon et al. 2007).

Due to lack of available data, we did not include plots from New Guinea in our study. However, previous studies have suggested that even in New Guinea and tropical northern Australia, Asian lineages contribute more to regional floras than their Australian counterparts (Richardson et al. 2012, Yap et al. 2018, 2018). Thus, the available information indicates that Asian lineages generally dominate the Malesian flora today. However, the picture changes, if one considers different habitats in a similar way has has been done in tropical northern Australia (Yap et al. 2018). Our results indicate that above a certain elevational tipping point, Australian lineages dominate Malesian forests. The exact elevation of the tipping point varied strongly (ca $1700 \mathrm{~m}$ elevation distance); it occurred at lower elevations on over ultramafic bedrock than over other parent materials. In Wallacea, east of Wallace's line, where only non-ultramafic sites were included, the proportions of Australian species and individuals per plot were comparable to those on ultramafic soils in the other two regions. The dominance of plants with Australian origin in montane areas and on poor soils in Malesia has long been acknowledged (Wallace 1869, van Steenis 1935b, Morley 1998, Culmsee et al. 2011, Culmsee and Leuschner 2013, Aiba et al. 2015) but here, we show for the first time that this pattern is consistent throughout western and central Malesia based on a large dataset of 55 plots including all major woody seed plant clades.

\subsubsection{Plate tectonics, climate, and the Malesian Floristic Interchange}

We used a dataset of tree inventory plots in three Malesian biodiversity hotspots in combination with the phylogeographic affinities of the present tree species from an extensive literature review to demonstrate that environmental conditions and - to a lesser degree - geographic position must have had a strong effect on biota mixing during the MFI. We explain patterns of contrasting colonization trajectories of Asian and Australian tree lineages in the context of the complex geologic and climatic history of Malesia and its adjacent regions Southeast Asia and Australia: Southeast Asia including Sundaland was assembled by the accretion of different continental fragments to the Asian plate in the Late Triassic and Cretaceous. Today, Sundaland consists of the Malay Peninsula and the islands Sumatra, Borneo, and Java, but only shallow seas over the continental Sunda Shelf separate these land areas. They formed a more or less continuous land mass connected to Eurasia during most of the Cenozoic and throughout that period, Sundaland remained near the equator (Hall 2013, 2017). Despite intervals of strong climatic oscillations, since the middle Eocene, tropical rain forests have covered parts of Sundaland, especially in what today is the island of Borneo. Hence, since the large-scale onset 
of the MFI ca $23 \mathrm{Ma}$, there has been a large source population of plants adapted to tropical rainforest habitats in Sundaland (Morley 2012, Hall 2013). On the other hand, Australia, together with the southern portion of present-day New Guinea, separated from Antarctica in the late Eocene to early Oligocene (40-33 Ma; Lawver et al. 2013) and started rafting north towards Asia. It also supported extensive tropical rain forest until the end of the separation at the EoceneOligocene-boundary when temperatures dropped, leading to a shift to temperate rain forests and widespread extinction of warm-adapted lineages. After ca $10 \mathrm{My}$ of isolation, the Australian plate started to collide with the Southeast Asian plate and island arcs from several Pacific plates around the Oligocene-Miocene boundary (ca 25-20 Ma). The exact geological processes involved were complex both in time and space but, together, caused extensive uplifting at the northern margin of the Sahul Shelf in what is today New Guinea, and shaped the young islands comprising Wallacea (Sulawesi, Maluku Islands, Lesser Sunda Islands) including some of the largest areas of ultramafic bedrock worldwide (Hall 2013, 2017, Galey et al. 2017). At the same time, temperatures rose again and moist tropical habitats expanded in Australia until the midMiocene climatic optimum. Global cooling since the mid-Miocene (ca $14 \mathrm{Ma}$ ) was offset in Australia by the continued rafting towards the equator, at least in the north, but intensive aridification occurred leading to an overall contraction of mesic biomes, which remained mostly in montane refugial areas along the eastern coast of the continent (Martin 2006, Byrne et al. 2011, Bryant and Krosch 2016) and in eastern New Guinea, where mountains had been present since the early Oligocene (Quarles van Ufford and Cloos 2005, Martin 2006, 200, Macphail 2007, Byrne et al. 2011, Bryant and Krosch 2016).

The emergence of Wallacea greatly reduced the distances of open sea between Asia and Australia and coincided with the dramatic intensification of the MFI (Crayn et al. 2015) likely due to the facilitation of, facilitating stepping-stone dispersal between the continents (van Welzen et al. 2011, Richardson et al. 2012). The dominance of plants with Asian ancestors observed today in most of Malesia derives from the high colonization success of these lineages in the newly emerging nutrient-rich and moist tropical habitats. The colonization success can be explained by the large and diverse source populations adapted to similar climatic and edaphic conditions that existed in Sundaland. Conversely, the Australian wet tropics have been a sink for Southeast Asian rain forest plants migrating through Malesia (Sniderman and Jordan 2011, Yap et al. 2018). Because the Australian flora had suffered widespread extinction of typical tropical rain forest taxa before the intensification of the $\mathrm{MFI}$, source populations for the colonization of Malesian lowlands were probably small, when rain forest habitats expanded in the early Miocene (Byrne et al. 2011, Sniderman and Jordan 2011, Richardson et al. 2012).

Nevertheless, our results show that some Australian lineages were highly successful in colonizing Malesia from the east, especially in azonal habitats with poor soils including ultramafics and on mountains. Taxa adapted to poor soils and/or colder upland habitats were widely present in Australia at the onset of the MFI (van Steenis 1979, Hill 2004, Bryant and Krosch 2016) and were presumably able to colonize the newly emerging extensive ultramafic 
areas in New Guinea and Wallacea in due time (Galey et al. 2017). Malesian mountain building has mainly occurred in the last 10 My but the highest ranges like the New Guinea Highlands, Central Sulawesi Mountains, Barisan Mountains in Sumatra, or Mt. Kinabalu in Borneo were only formed in the Plio-Pleistocene (Baldwin et al. 2012, Hall 2013, Merckx et al. 2015, Nugraha and Hall 2017). As montane habitats in Malesia were formed and aridification intensified in Australia, species spread from refugia along the eastern Australian coast and in already existing mountain ranges of New Gunea to the large montane areas in New Guinea, Wallacea, and Sundaland (Morley 1998, Hill 2004, Sniderman and Jordan 2011, Kooyman et al. 2014). This scenario is consistent with the retrieved recent timing of disjunction between Australian and Malesian montane taxa for most lineages we assessed, including the dominant Australian lineages in Malesia today (see below and Appendix 5.2). The late influx of Australian plants to Malesian mountains had a profound impact, essentially providing today's dominant components of the tree assemblages there (Figure 5.1 e-g, 5.3).

\subsubsection{Dominant Australian taxa differ in their history and ecology}

Four taxa mostly drove the dominance of Australian elements in montane and ultramafic areas: Myrtaceae, southern-hemisphere conifers (Podocarpaceae and Araucariaceae), Polyosma (Escalloniaceae), and Elaeocarpus (Elaeocarpaceae). The myrtle genus Syzygium started to diversify in the mid-Oligocene in eastern Australia, presumably in the prevalent temperate rain forests there, and dispersed into Malesia at least four times between 12.4 and $6.8 \mathrm{Ma}$. The genus underwent a spectacular radiation, possibly linked to the innovation of fleshy fruits (Biffin et al. 2010). Today it is the most species-rich genus of Malesian trees, occurring in a variety of moist forest ecosystems, especially dominant on nutrient-poor soils and in montane areas (Aiba et al. 2015). Elaeocarpus shows a similar spatial and temporal pattern of diversification (crown age ca $30 \mathrm{Ma}$, dispersal into Malesia ca $14 \mathrm{Ma}$; Crayn et al. 2006) and is widespread geographically and ecologically in Malesia. In contrast, southern conifers are old Gondwanan lineages that, however, mostly reached Wallacea and Sundaland only in the Plio-Pleistocene and remained largely confined to upland areas (Morley 1998, Kooyman et al. 2014). Notably, conifers with Asian affinities (Pinaceae) were common in mountains of Borneo until the Miocene, but Podocarpaceae apparently replaced them afterwards (Muller 1966). In upper montane forest throughout Malesia, podocarps are often extremely dominant, although not particularly species-rich (Aiba et al. 2015, Brambach et al. 2017). An exception is Java with its seasonal climate, where far fewer of the particularly drought-sensitive southern conifers occur (van Welzen et al. 2011). Instead, Polyosma and Elaeocarpus as well as Asian lineages like Fagaceae and Ericales dominate Javanese montane forests (Figure 5.3).

\subsubsection{Habitat-suitability is more important than distance}

We found evidence that Asian species predominantly colonized lowland habitats and medium to rich soils during the MFI, while Australian species were more successful in the colonization of montane areas and poorer (ultramafic) soils. This pattern across Malesia, one of the major 
tropical regions of the world, is remarkable given the region's large extension and archipelagic nature.

Geographic distance from the source regions (Asia and Australia) only had a minor influence on the colonization success compared to habitat. This influence was best explained using Malesian subregions as categorical variables, indicating a non-linear relationship (Table 5.2).

Newly emerging tropical lowland habitats in Malesia were predominantly colonized by lineages from Sundaland, where similar ecological conditions prevailed and large source populations existed (Richardson et al. 2012, Zobel 2016). The nature of habitats containing the lineages that came to colonize Malesian mountains and nutrient-poor soils, is more obscure because of the complex plate-tectonic and climatic history of Australia since the Oligocene that caused recurrent expansions and contractions of different forest types. Nevertheless, there are indications that moist habitats were mostly present in colder upland areas, a least since the middle Miocene (Martin 2006, Byrne et al. 2011, Bryant and Krosch 2016), providing the nearest source population of plants adapted to Malesian mountain habitats.

We therefore interpret the colonization pattern found here in the light of similar ecological conditions between source and sink areas, Sundaland as a source area for lowland Malesia on the one hand and Australia as a source area for montane Malesia on the other. This likely points to the importance of phylogenetic biome conservatism (Crisp et al. 2009, Crisp and Cook 2012), i.e. the tendency of lineages to retain their ancestral ecology over long time spans and continental scales, in the assembly of the Malesian vegetation (Grudinski et al. 2014, Kooyman et al. 2014). Notably, Asian immigrants have also been relatively successful in the colonization of tropical lowland habitats in northern Australia but not in temperate habitats further south due to environmental filtering (Yap et al. 2018). However, speciation events including biome shifts between montane and lowland forest and vice versa must have occurred in numerous clades, as indicated by species-rich genera spanning wide environmental gradients today like Syzygium, Lithocarpus (Fagaceae), Litsea (Lauraceae), Elaeocarpus, and Symplocos (Symplocaceae). Biome shifts between tropical lowland and montane forests have received relatively little attention, possibly due to the blurred boundaries and close spatial interconnectedness between the two (Donoghue and Edwards 2014, Antonelli et al. 2018b). Nevertheless, tropical mountain areas with their close proximity of widely differing habitats are known to be cradles of diversity with strong species turnover along the elevational gradient, facilitating speciation and associated niche evolution (Merckx et al. 2015, Sanín et al. 2016). The dynamic history of Malesia since the onset of the MFI together with two ecologically and geographically different source regions may thus have contributed to the exceptionally high plant diversity in Malesia today (Slik et al. 2015). Malesian montane forests, while less speciesrich than their lowland counterparts, today harbour many survivors of dramatic extinction events in Australia during the Tertiary (Kooyman et al. 2014) as well as elements of originally tropical Asian families. Their unique evolutionary history and associated higher phylogenetic 
diversity (Slik et al. 2009, Culmsee and Leuschner 2013) attest to their exceptional conservation value.

\subsubsection{Patterns resembling the Great American Biotic Interchange}

The patterns uncovered in this study allow the assessment of several hypotheses regarding biota mixing that have been postulated based on studies of the GABI, the mixing of North American and South American biotas during the Neogene and Quaternary. Malesia presents an independent model system, which has similarities to the Neotropics but also shows some differences. In both regions, tectonic movement and climatic changes have led to the mixing of biotas between Gondwanan fragments that had long been isolated before (Australia and South America) and Laurasian regions, which had repeatedly been connected to each other during the Tertiary (Eurasia and North America; Donoghue and Smith 2004, Lawver et al. 2013). No land bridge connects Asia and Australia, which is similar to the situation before the closure of the CALB in the Americas, but the absence of a land connection is less important to plants, which have relatively high dispersal capabilities compared to many animal groups (Sanmartín et al. 2004, Bacon et al. 2015). More importantly, before the GABI began, the largest source population of lowland rainforest plants was located in the Amazon basin, i.e. on the formerly isolated continent of South America. In contrast, Australia, had not only undergone a $10 \mathrm{My}$ long isolation before the onset of the MFI, but also large-scale extinction of rainforest plants due to continent-wide cooling and aridification (Byrne et al. 2011), while large tropical rainforests persisted in Sundaland. The dominance of Australian plants in Malesian mountain habitats today adds to the growing evidence against the isolation hypothesis (Cody et al. 2010, Bacon et al. 2015, Antonelli et al. 2018b), which states that biotas are less successful in events of biotic interchange after long isolation due to lower competitiveness or higher susceptibility to predators (Simpson 1980, Faurby and Svenning 2016). Instead, our results are in line with studies that have highlighted the importance of habitat similarities between source and sink areas during the GABI and, hence, phylogenetic biome conservatism in biotic interchanges. During the MFI, tropical Asian tree lineages spread through Malesia to tropical Australia in a similar manner as Amazonian lineages colonized tropical Central America. Conversely, Australian plants, adapted to upland habitats, had great colonization success in Malesian mountains as Nearctic lineages had in the Andes (Cody et al. 2010, Woodburne 2010, Bacon et al. 2015, Antonelli et al. 2018b, Graham 2018). While our results have to be viewed with caution due to the persisting lack of data from a key area, New Guinea, the congruence of scenarios from the MFI and the GABI shown here provide support to the idea that patterns and mechanisms that have been found through decades of studying the GABI are not specific to the Neotropics but have more universal validity. 


\section{General Discussion}

\section{Taxonomic contributions and baseline data}

With my thesis, I close some of the knowledge gaps about the little-known tropical mountain forests (TMF) of Sulawesi regarding the Linnean, Wallacean, Prestonian, Hutchinsonian, and Darwinian shortfalls (Hortal et al. 2015). I contribute to a better taxonomic knowledge about the tree flora of the island by rigorous species identification and the discovery of new species. Seven species in three different families are already described and published (Chapters 1-3) while for thirteen other species in eight families the description is in progress or planned. In recent years, the flora of Sulawesi has become the focus of a small number of dedicated taxonomists from different academic institutions in- and outside of Indonesia. Their efforts are mostly targeting species-rich taxa of herbs like Begonia (Doorenbos 2000, Hoover et al. 2004, Hughes 2006, Thomas and Hughes 2008, Girmansyah et al. 2009, Thomas et al. 2009a, 2009b, 2011, 2018, Wiriadinata 2013, Lin et al. 2017, Ardi et al. 2018) and Zingiberaceae (Poulsen 2012, Ardi and Ardiyani 2016, Ardiyani et al. 2017, de Boer et al. 2018, Poulsen et al. 2018, Trimanto and Hapsari 2018) or climbers and shrubs like Gesneriaceaea (Hilliard and Burtt 2002b, 2002a, Atkins 2003, Mendum 2003, Mendum and Atkins 2003, Mendum et al. 2006, Middleton and Scott 2008, Kartonegoro 2012, Atkins et al. 2013, Bone and Atkins 2013, Kartonegoro and Potter 2014, Kartonegoro et al. 2018) and Apocynaceae subfamily Asclepiadoideae (Kleijn and van Donkelaar 2001, Rodda and Omlor 2013, Rodda 2016, Rodda and Simonsson Juhonewe 2016). Much less attention has been directed to trees (e.g. Coode 1995, 2001a, 2007, Bramley 2012, Kiew 2016) although many species-rich and ecologically important tree families in Sulawesi are in urgent need of taxonomic revision (Arifiani 2001, Keßler et al. 2002, Ng 2005b, Syzygium Working Group et al. 2016). Funding for alpha-taxonomical work is not keeping pace to speed up the discovery of new species before they become extinct (Wägele et al. 2011, Pimm and Raven 2017). Hence, the discovery of new species by researchers from other disciplines, including plant ecologists, becomes more important and can even improve species descriptions through live examination of the plants in the field. The 'accidental' species discoveries in the context of this thesis thus complement the more targeted work by the taxonomists mentioned above.

Besides the detection of undescribed species, in my thesis I present a large number of new occurrence records, i.e. range extensions of known tree species. Almost one quarter of the tree species encountered had previously not been recorded from Sulawesi or the province of Central Sulawesi. Importantly, the records include spatially explicit abundances for each species, which can be related to environmental variables measured in the field (Chapter 4) or derived from models (e.g. Fan et al. 2013, Hengl et al. 2017, Karger et al. 2017) and be used to inform species distribution models (Raes et al. 2009). For these means, the occurrence records need to possess high data quality, i.e. be correctly identified and vouchered by herbarium specimens to enable re-identification as species concepts change. Species identification in a megadiverse and generally insufficiently known flora like that of Malesia is a challenging and time-consuming 
task. In my thesis, I put much emphasis on correct species identification, including collaboration with taxonomic specialists from major international herbaria (Chapters 1-3) to provide this kind of high-quality data. The tree-inventory data have been included in collaborative databases like Forestplots.net (Lopez-Gonzalez et al. 2011) and filled critical gaps for research projects investigating global patterns of tree diversity (Slik et al. 2018). Especially for large-scale analyses that use aggregated datasets, data quality of the original studies is critical, as potential errors are unlikely to be detected.

\section{Tree diversity and composition}

Beyond the localized provision of baseline data and detection of new species, I explored more general patterns of tree diversity along environmental gradients (Chapter 4). I show that species diversity of trees in Sulawesi is mostly controlled by elevation while soil parameters have only a marginal importance. The diversity declined monotonically with elevation from 700 to 2500 $\mathrm{m}$. This pattern has been repeatedly found in other TMF from all major tropical regions (Aiba and Kitayama 1999, Aiba et al. 2005, Raes et al. 2009, Homeier et al. 2010, Peters et al. 2016) and had also been reported for Sulawesi, but based on a fewer study sites (Culmsee and Pitopang 2009, Culmsee et al. 2011) and less-complete species identification.

Height above sea level explained almost 50\% of the variation in tree species richness, while seven important soil parameters had only marginal influence. This result is generally in line with a study from Borneo, where elevation was also the most influential correlate for gradients in tree diversity (Slik et al., 2009). However, in the latter study, which included mostly lowland and lower montane sites, soil characteristics also explained a significant portion of tree diversity. Dipterocarps, the main structural components of Sundaland lowland forests have been shown to vary in species richness largely dependent on soil chemistry or geology (Paoli et al., 2006). When elevation differences are small, diversity should depend on other factors than elevation, including soil chemistry and hydrology. On the other hand, the transect studied for this thesis, had only low geological variability, with most sites dominated by acid plutonic bedrocks. Sulawesi is one of the geologically most complex and diverse islands on Earth (Hall and Wilson 2000); it would therefore highly desirable to cover this geological diversity (e.g. volcanic, ultramafic, and limestone areas) in future studies to unravel the interplay between topographic and soil characteristics on tree diversity. Nevertheless, diversity in geologically diverse regions of Malesia at the genus level were shown to be correlated closely with elevation and not with soil parameters (Culmsee and Leuschner 2013). My comparison of 51 Malesian plots along a wide range of bedrock types, where tree species diversity showed a relatively close and highly significant relation to elevation, extends this pattern to species-level diversity.

Elevation drives site conditions for plants through different pathways. Temperature decrease and differences in cloud cover are closely correlated with elevation and can act on plant communities directly by influencing photosynthesis and respiration rates and thus the carbon balance (Malhi et al. 2017). However, there are also indirect effects mediated by soil 
characteristics such as decomposition and mineralisation rates, nutrient supply and organic matter accumulation. With increasing elevation, I found widening $\mathrm{C} / \mathrm{N}$ ratios in the organic layer and the mineral topsoil as well as growing stocks of organic matter in the organic layer, indicating that mineralisation rate and the availability of nitrogen decrease with elevation in Sulawesi in a similar manner as it was found in other tropical mountains (e.g. Moser et al., 2011). In addition to temperature reduction and increased cloud cover with elevation, the reduced $\mathrm{N}$ availability might also exclude tree species of more fertile (and warmer) lowland habitats from colonising higher elevations because of lower nutrient supply. On mount Kinabalu, where ultramafic and non-ultramafic bedrock occurs in close proximity, tree diversity is much lower in TMF on soils derived from ultramafic material (Aiba and Kitayama 1999). This suggests that elevation effects on diversity can be secondary to soil chemistry effects, in cases where concentrations of toxic elements are and high element ratios unfavourable, as in ultrabasic soils which are characterised by high $\mathrm{Ni}$ concentrations and high $\mathrm{Mg} / \mathrm{Ca}$ ratios (Proctor, 2003). Ultramafic soils are widespread in central and eastern Malesia with one of the largest areas of ultramafic bedrock occurring in Sulawesi's eastern and southeastern peninsulas (Galey et al. 2017). Comparative studies along an elevational gradient on ultramafics in Sulawesi would therefore be of great interest to elucidate to what degree unfavourable soils can act as environmental filters for colonizing tree species and how this filter mechanism interacts with elevation.

Regardless of the exact environmental factors driving tree species richness, previous studies have suggested that Sulawesi and other parts of Wallacea harbour a less-diverse flora compared to the Greater Sunda Islands to the west and New Guinea to the east (Barthlott et al. 2007, Kier et al. 2009). The results of this thesis, based on rigorous sampling and species identification, do not confirm that assumption, as levels of species diversity did not differ significantly between Sulawesi and other Malesian areas, at least at the level of forest communities between 700 and 2400 m elevation. While large islands like New Guinea, Borneo, and Sumatra are overall richer due to area effects (Roos et al. 2004), the supposedly more diverse floras of the Philippines and Java are likely to be artefacts of the greater attention botanists have given these areas (Merrill 1923a, 1923b, Backer and Bakhuizen van den Brink Jr. $1963 c, 1965 b, 1968)$ as compared to Sulawesi. The high number of new occurrence records in Sulawesi of my thesis supports this claim.

I also found a considerably higher rate of endemic tree species for Sulawesi (22\% in my dataset) than the previously reported numbers of 12-14\% (van Balgooy 1987, Roos et al. 2004, van Welzen and Slik 2009, van Welzen et al. 2011). Again, this discrepancy can be explained by the incomplete botanical knowledge of Sulawesi. While species diversity decreased with elevation, the number of endemic species remained constant throughout the elevational transect of Lore Lindu National Park, resulting in a relative increase in endemic species towards higher elevations. Historically, most botanical explorations in Sulawesi have focused on easily accessible areas while higher elevations have - with few exceptions - been neglected, resulting 
in underestimations of the endemic element of Sulawesi's flora. High levels of endemism in mountain areas are a globally consistent pattern (Steinbauer et al. 2016) and have been found in other Malesian islands, especially those that also possess high mountains which have been botanically explored. For example, Mt Kinabalu on Borneo has been a centre of speciation resulting in numerous endemic species across many different plant and animal taxa during its uplift in the last 10 My (Merckx et al. 2015). Mt Kinabalu's geological history is no exception in Malesia: all major mountain areas are the result of the recent collision of the Indo-Australian, Eurasian, and several Pacific plates and were created in the last $10 \mathrm{My}$, with major uplifts only in the Plio-Pleistocene (Hall and Wilson 2000, Hall 2013, Nugraha and Hall 2017). Because of the similar geological history, processes of speciation should also have been similar among Malesian mountains, resulting in comparable levels of endemism and overall species richness. In contrast to Borneo, Sulawesi possesses a much higher area of TMF and this area is spread over all parts of the island, but only a small fraction of this TMF has been explored. Taxonomic research from single taxa has shown that there are many narrow endemics restricted to only one mountain range or even only one peak (Coode 1995, Atkins 2003, Bone and Atkins 2013), suggesting that large parts of the endemic flora of Sulawesi's TMF are yet to be found.

Again, correct species identification is crucial here. As endemic species are usually less known than widespread ones, they are often more difficult to identify (or even undescribed). Hence, endemic species will tend to be overrepresented in the individuals which are often only identified to morphospecies in many ecological studies in tropical forests. The pattern of a linear increase of endemism among trees with elevation retrieved in my analyses only became apparent after identification was complete. At an earlier stage, with ca. 75\% of all individuals identified (and many endemic species from higher elevations still missing), I retrieved a humpshaped relationship with highest endemism rates at medium elevations (results not shown), i.e. an incorrect pattern because of incomplete data. As patterns of endemism are important for conservation efforts (Myers et al. 2000, Kier et al. 2009), such incorrectly retrieved patterns can have detrimental effects on efficient conservation planning. Extensive additional sampling of isolated mountain areas with rigorous identification - and description of new - species will therefore be necessary to fully appreciate the contribution of endemic species to Sulawesi's flora and hence the conservation value of Sulawesi's TMF.

While detailed knowledge of plant species distribution patterns in Sulawesi is still missing, spatially coarser information about the vegetation can also inform information efforts (Cannon et al. 2007). I found that elevation was the main factor controlling tree species composition, including the dominance of the ten most abundant plant orders along the slope, and that there are major turnovers in tree species composition around $1500 \mathrm{~m}$ and around $2000 \mathrm{~m}$. Vegetation belts between these ecotones in Lore Lindu National Park can be classified based on floristics: Submontane forest $(700$ - ca. $1500 \mathrm{~m}$ ) contains a high number of elements from tropical lowland forest, as in other tropical mountains (Aiba and Kitayama 1999, Ashton 2014) and indicated by the indicator species from the families Sapotaceae, and Myristicaceae. Lower 
montane forest (ca. 1500-2000m) does not have any indicator species, but is distinguished by the dominance of Fagaceae and Myrtaceae in terms of individuals and species numbers, resulting in high biomass compared to montane forests in other regions without these families (Culmsee et al. 2010a). Upper montane forest, occurring above c. $2000 \mathrm{~m}$, is dominated by the conifer family Podocarpaceae and contains numerous indicator species, mostly of families with Australian biogeographic affinities (Myrtaceae, Elaeocarpaceae, Trimeniaceae, and Paracryphiaceae). The exact elevational boundary between the sub- and the lower montane forest zones is difficult to define. This is partly because both zones themselves have a transitional character from tropical lowland elements on one hand to more temperate ones on the other. Also, the elevational boundary is mediated by other factors including topography and soil characteristics, resulting in a transition rather than a sharp boundary (Ashton 2003a). While the latter is also true for the boundary between lower and upper montane forest, the floristic transition there is much sharper as indicated by the high number of indicator species. Despite these caveats, tropical mountain forests can be classified into elevational zones that are relatively easy to recognize based on few indicator species or the dominance of well-known tree families. This classification can serve to inform conservation efforts in the absence of more detailed floristic knowledge (Cannon et al. 2007).

Upper montane forest, is clearly distinguished from the forest types further downslope in terms of floristics and soil characteristics. In addition, levels of cloud cover and structural parameters are also known to distinguish these forest communities (Ashton 2014). The unique environmental conditions and flora of upper montane forests suggest that because of phylogenetic niche conservatism (Wiens et al. 2010), enrichment through immigration and establishment from plants further downslope plays a limited role, although it does occur (Merckx et al. 2015). Indeed, the studied upper montane forest communities in Sulawesi are mostly dominated by taxa with southern temperate affinities (Kooyman et al. 2014). Detailed data about dispersal syndromes in Sulawesi's upper montane forests are lacking, but the dominance of taxa with small fleshy, likely bird-dispersed, propagules such as Podocarpaceae, Myrtaceae, Elaeocarpus, Quintinia, and Trimenia points to the importance of long-distance dispersal between mountain tops. Due to the stronger geographic isolation, as compared to lower-elevation forests, sporadic long-distance dispersal and subsequent establishment in upper montane forests is then likely to be followed by speciation, resulting in high levels of endemism (Steinbauer et al. 2016) as observed in this study.

Most tree inventories are based on samplings of mature trees with $\mathrm{dbh} \geq 10 \mathrm{~cm}$. Much less is known about the free-standing woody plants of the understorey with stem diameter $<10 \mathrm{~cm}$, which typically dominate in numbers and may also be more species-rich than the large- and medium-sized trees (LaFrankie et al. 2006, Lü and Tang 2010). These smaller trees comprise juveniles of large canopy trees but also mature individuals of a different guild, that of species which are adapted to the shady forest interior throughout their life cycle and never reach the canopy. In Chapter 4, I show that although these understorey tree species contribute relatively 
little to total biomass and number of individuals, they comprise almost half of the regional tree species flora. And a much higher proportion of them is endemic to Sulawesi, as compared to canopy species. This neglected group shows considerable turnover along the elevational gradient, both at species level and that of higher taxa. Previous studies have suggested that true understorey tree species are more frequent and diverse in neotropical forests, while the understorey of Southeast Asian forests to a high percentage consists of saplings of large- and medium-sized trees of the upper canopy, resulting in lower availability of fruits and flowers in the understorey (Janzen 1977, LaFrankie et al. 2006, Corlett 2007). These studies invoked the mass fruiting of Dipterocarpaceae, the dominant family in Sundaland lowland forests, as an explanation for this phenomenon. It was later shown that in Asian forests, which are not dominated by dipterocarps, indeed trees with small and medium size at maturity dominated the understorey (Lü and Tang 2010). Notably, at lower montane elevations in Sulawesi, where another mass-fruiting family, Fagaceae, was dominant, understorey diversity remained high. My results from forests each of Wallace's line rich in true understorey tree species thus contribute to a more nuanced view of Southeast Asian forests in terms of understorey composition.

\section{Biogeographic context of Sulawesi's tree flora}

Regardless of scale, patterns of tree diversity and composition are shaped by a combination of environmental factors and the available species pool, i.e. the combined evolutionary history of the constituting species (Keil and Chase 2019). After investigating the effects of present environmental factors in Chapter 4, I therefore investigated how tree lineages with different geographic origins, i.e. evolutionary histories have colonized Sulawesi and adjacent Malesian islands in Chapter 5. Investigating the evolutionary history is an attempt to diminish the Darwinian shortfall for this little known tropical biodiversity hotspot. As the other islands in Wallacea, Sulawesi is geologically young, having been shaped in the last ca. 25 My and all plant life present today on the island must have colonized it during that time span in a process called the Malesian Floristic Interchange (MFl; Richardson et al. 2012) or Sahul-Sunda floristic exchange (Crayn et al. 2015). Because of its position in the is located in the centre of Malesia, halfway between Asia and Australia, the biogeographical history of Sulawesi's tree flora is closely linked to that of other Malesian areas. Therefore, I expanded the scope of Chapter 5 beyond Sulawesi to include the three Malesian biodiversity hotspots Sundaland, the Philippines, and Wallacea.

Previous research has indicated that at the island scale, the majority of the Malesian flora originated in Asia (Sniderman and Jordan 2011, Richardson et al. 2012, Crayn et al. 2015). In this thesis, I confirm this overall pattern but also reveal strong differences depending on habitat. Using a dataset of tree inventory plots in combination with phylogeographic data on the present tree species, I show that the environmental conditions and - to a lesser degree - geographic position have had a strong effect on biota mixing during the MFI. More specifically, 
proportionally more Australian (and conversely fewer Asian) tree species and individuals occur (1) at higher elevations, (2) on sites over ultramafic parent material, and (3) closer to their source region Australia with a significant drop at Wallace's line, i.e. the boundary between Wallacea and Sundaland plus the Philippines. The trend is stronger for tree individuals than for species, resulting in forest communities dominated by Australian trees above elevational tipping points, which however differ between regions and depending on the parent material. Several previous researchers have acknowledged the dominance of plants with Australian origin in montane areas and on poor soils in Malesia (Aiba et al., 2015; Culmsee \& Leuschner, 2013; Culmsee et al., 2011; Morley, 1998; van Steenis, 1935b; Wallace, 1869) but in this thesis, I show for the first time that this pattern is consistent throughout Malesia based on a large dataset including all major woody plant clades.

This pattern across Malesia, one of the major tropical regions of the world is remarkable given the region's large extension and archipelagic nature. It is consistent with a scenario, in which plant lineages adapted to tropical lowland rainforest conditions were present in large numbers in Southeast Asia including Sundaland before the onset of the MFI (Morley 1998, 2001) and were therefore most successful in colonizing the newly emerging lowland habitats in Central and East Malesia during the MFI. The Australian flora on the other hand suffered widespread extinction of typical rainforest taxa due to continent-wide cooling and drying since the beginning of the Oligocene. Most Australian plant lineages around the Oligocene-Miocene boundary (ca. $23 \mathrm{Ma}$ ) were probably adapted to either arid or moist and cool upland habitats as well as to the widespread poor soils in Australia (Hill 2004, Martin 2006, Byrne et al. 2011, Bryant and Krosch 2016). When Wallacea emerged and the MFI started, Australian lineages were apparently highly successful in colonizing newly established habitats with similar environmental conditions as their ancestral habitats: poor soils and moist upland sites (Byrne et al. 2011, Sniderman and Jordan 2011, Richardson et al. 2012). Mountain building in Malesia has mainly occurred in the last 10 My but the highest ranges like the New Guinea Highlands, Central Sulawesi Mountains, or Mt. Kinabalu were only formed in the Plio-Pleistocene (Hall 2013, Merckx et al. 2015, Nugraha and Hall 2017). As montane habitats in Malesia were formed and aridification intensified in Australia, species spread from refugia along the eastern Australian coast to the large montane areas in New Guinea and further west into Wallacea and Sundaland. Indeed, most Australian lineages common in Malesian mountains today have diversified in the last $10 \mathrm{My}$, as indicated by the literature review of phylogenetic studies. This late influx of Australian plants to Malesian mountains has had a profound impact, essentially providing today's dominant components of the unique tree assemblages there. Interestingly, few taxa disproportionally to this dominance of Australian elements in Malesian mountains: Myrtaceae, southern-hemisphere conifers, Polyosma and Elaeocarpus. Interestingly, the overwhelming majority of species in these four taxa have small, fleshy, and often showy propagules fit to be dispersed by birds and possibly bats. Dispersal is an important yet understudied factor (Pannell 2018) to understand the biogeographical history of the archipelagic region Malesia. Wallace's line has been shown to be an - albeit permeable - dispersal filter for many lowland taxa originating in Sundaland 
(Nauheimer et al. 2012, Thomas et al. 2012, Grudinski et al. 2014). It has, however much less importance for montane plant lineages which are relatively homogeneous throughout Sundaland, the Philippines, and Wallacea (Culmsee and Leuschner 2013), and mostly originated in Australia as shown here. This pattern makes sense, when dispersal is taken into account: Australian lineages, which were able to leave Sahul (Australia and New Guinea) by crossing the stretches of sea separating the Wallacean islands by bird-facilitated dispersal, would also be able to continue into Sundaland. For Australian lineages, the strongest dispersal filter should therefore not be Wallace's, but Lydekker's line, the boundary of the Sahul Shelf. To answer these questions and gain a better understanding about how dispersal limitations shaped the Malesian flora, it would be highly desirable to compile dispersal-related plant traits and incorporate additional plot data along environmental gradients in New Guinea and Australia.

However, my results suggest that biogeographical patterns in the Malesian flora were not primarily influenced by processes related to dispersal limitations, but rather by the availability of suitable habitat, i.e. similar environmental conditions between the source- and sink regions during the floristic interchange. This is reflected in the dominance of southern temperate lineages in upper montane forests of Sulawesi (see above) and likely points to the importance of phylogenetic biome conservatism in the assembly of the Malesian vegetation (Crisp et al. 2009). It also shows that not only present environmental conditions affect the assembly of plant communities but also past environmental conditions that have shaped the available species pool at different temporal scales. Despite the importance of phylogenetic biome conservatism that is reflected in my results, there are also clear indications that some biome shifts (Donoghue and Edwards 2014) must have occurred and that these have had considerable consequences. This is indicated by species-rich genera spanning wide environmental gradients in Malesia today. Biome shifts between tropical lowland and montane forest communities at different elevations have received relatively little attention, possibly they are often difficult to separate clearly and occur close together (Antonelli et al. 2018b). This is unfortunate, since tropical mountain areas with their close proximity of widely differing habitats are known to be cradles of diversity with strong species-turnover along the elevational gradient, facilitating speciation and associated niche evolution (Merckx et al. 2015, Sanín et al. 2016). Malesia's exceptionally diverse flora has been assembled over at least the last 25 My by a complex interplay of migration, speciation, and extinction that is closely associated with the regions dynamic geological history. To unravel the exact processes at play and their relative contributions, clearly more detailed phylogeographic studies of species-rich and ecologically variable taxa which originated in Australia, such as Syzygium and Elaeocarpus are needed. These studies should ideally include reconstructions of ancestral habitats to model niche evolution. Regardless of these continuing knowledge gaps, it is clear that Malesian montane forests, while less speciesrich than their lowland counterparts, have a unique evolutionary history and associated higher phylogenetic diversity and hence exceptional conservation values (Culmsee and Leuschner 2013). 


\section{Conclusions}

The TMF of Central Sulawesi harbour a species-rich and unique tree flora, with high proportions of endemic species, surprisingly important contributions by small understorey species, and a unique biogeographical history with a transition from dominance of Asian to Australian elements with increasing elevation. These properties give the TMF of Sulawesi and other mountainous islands in the Malesian Archipelago high priority in conservation, even though their taxonomic diversity is smaller than that of lowland forests. The few existing data suggest that even different summits on the same island may harbour unique forest communities full of endemic species. Large knowledge gaps regarding all shortfalls of biodiversity knowledge remain about the flora and vegetation of Sulawesi. The gaps are more pronounced in some geographical areas, e.g. the eastern and southeastern peninsulas and the western part of the northern peninsula, but also in some forest habitats like those on ultramafic parent material and limestone or the few remaining swamp areas. Repeated biodiversity inventories in these especially underexplored areas will be necessary to improve our baseline knowledge about plant diversity patterns in Sulawesi. In the last decade, several botanical expeditions have collected numerous plant specimens from tropical hinterland forests in Sulawesi. This is an encouraging sign but needs to be matched with a concerted effort of research on biodiversity and ecology including phylogenetic and functional approaches to overcome the continuing lack of knowledge. 



\section{Acknowledgements}

Over the long time that it has taken me a long time to finish this dissertation, naturally a lot of people have greatly helped me and I feel tremendously grateful for all the help and support I have received from them. I would not have been able to complete this thesis without them.

Heike Culmsee and Christoph Leuschner have provided the topic of research and guided me through it with a lot of dedication, competence, and goodwill. Naturally, there have also been some moments of disagreement between my supervisors and me but I am grateful for these as they have taught me valuable lessons for the future. I would like to thank Heike and Christoph profoundly for all their guidance, their patience - which I have certainly stretched - and their ongoing support.

Fieldwork in the beautiful forests of Lore Lindu National Park in Sulawesi was one of the best experiences of my life and a long-held dream coming true. It wouldn't have been such a stunning time without my colleagues Hardianto Mangopo, Firdaus Dg. Matta, Rickson Tiranda, and Matthias Faber. Besides them, numerous people from the villages of Toro, Watukilo, Moa, Sedoa, Wuasa, Rompo, and Bariri have contributed to the fieldwork by giving our team shelter, carrying equipment with incredible endurance and skill, running the logistics, lighting campfires in the most adverse conditions, and helping with the actual research. Also, in the long nights in our field camps, they shared their stories, culture and languages and I am deeply thankful for these exchanges. Among these many local helpers, I would like to especially mention Papa Nano, James, and Papa Putra. In Palu, Dewi Ramadhaani and Ilfianti Kasmudin greatly helped with data analysis and all kinds of bureaucratic and logistic issues and I want to thank them for their support. Ibu Aiyen Tjoa went out of her way to solve any kind of problem that appeared during the time of fieldwork. I would like to apologize to her for not having been more prudent and avoided certain situations and thank her from my heart for all her support and guidance. I also thank the Lore Lindu National Park authorities for allowing me access to the national park and RISTEKDIKTI for granting research (08/EXT/SIP/FRP/SM/I/2012) and collection permits (035/5IP/FRP/II/2011). My fieldwork in Indonesia and herbarium work in the Netherlands and UK was funded by the German Research Foundation (DFG) and my PhD studies by a scholarship of Evangelisches Studienwerk Villigst e.V. (850738). I gratefully acknowledge both funders as well as the support by the Open Access Publication Funds of the University of Göttingen. Prof. Ina Kersten provided guidance and support shortly before the submission of this thesis and I am also most thankful for it.

I spent a considerable portion of the time for this thesis with the identification of species. For that endeavour, I consider myself very fortunate to have had the opportunity to learn from Max van Balgooy (L) and Tim Utteridge (K); both of whom also helped greatly with the identification of difficult taxa. Numerous other specialists provided help with their taxa, for which I am very thankful: Mark Coode (K/E; Elaeocarpaceae), Willem de Wilde (L; Myristicaceae), Peter van Welzen (L; Euphorbiaceae, Phyllanthaceae), Frits Adema (L; Fabaceae, Sapindaceae), Marcus 
Lehnert (STU; tree ferns), Hannah Atkins (E; Gesneriaceae), Deby Arifiani (BO; Lauraceae), Ruth Kiew (KEP; Oleaceae), Aljos Farjon (K; conifers), Peter Wilkie (E; Sapotaceae). I am also thankful for the curators of the herbaria A, B, BM, BO, E, HBG, K, KY, L, M, U and US who allowed me access to their collections, provided loans, or helped searching for specimens. Special thanks go to Nicolien Sol and Roxali Bijmoer ( $L$ ) for enduring all my requests and inquiries with great patience and making sure the type specimens ended up where they were supposed to.

Over the time, many researchers have helped and inspired me with discussions, questions, advice, and their knowledge. It is impossible to mention all but I would like to thank at least Peter Schad (TUM) for his great help with the soil classification of my inventory plots in Sulawesi, Darren Crayn, Ingrid M. Angel-Benavides, and Gunnar Keppel who provided valuable inspiration and input for Chapter 5, Siria Biagioni for her enthusiasm and our discussions about past and present vegetation and human influence on Sulawesi all the reviewers who improved the manuscripts of my published papers, and Jürgen Homeier for countless discussions about all possible aspects of tropical mountain forests. Also, I would like to thank Gertraud Mühlbauer who - probably without knowing it - sparked my interest for ecology and evolution during her biology classes in my last two years of high school.

My friends in Sulawesi made the time I lived there an unforgettable memory and were always there for any kind of problem, work-related or other. I have enjoyed their great hospitality again and again, last in October of 2018, shortly after the devastating earthquake and tsunami and am deeply moved and humbled by their strength, courage and continuing hospitality. Thank you Ira, Anna, Alex, Sisi, Ain, Witly, Atok, Firdaus, Kiki, Dewi, Shita, Anty, Arul, Agil, Nining, and Papa Nano. Also to Tante, Micky, Iris, Nina, Andreas, and the whole Purni crew. To all my close my friends, I am thankful for motivating or distracting me, or simply being there during the more difficult phases of the thesis writing. Without Laura, Stefan, and Jürgen, the long office nights wouldn't have been half as enjoyable, and I am glad that I could share the place with Maude, even if it was only for a short time. Tante Yasmin, I am thankful for your kindness and support, you know of course how all this is. Sadie, thank you for all the conversations, I always felt energized afterwards. My colleagues at the Biodiversity, Macroecology and Biogeography group of Göttingen University made me feel part of the group right from the start a year ago; I am thankful for all the good discussions, inspiring athmosphere, and you nice people there. In the last two years or so, Paula, Armin, Vera, and Merle have lent tremendous amounts of support whenever I needed it. I hope I can pay that back some time. Thanks also to Sara for being the perfect host and company to write up the last parts of this thesis. Lilibeth, Stefan, Aldi, Nina, Peppi, Carito, Sebas, and most of all Sophie have accompanied me (almost) since the start of my PhD studies and through many ups and downs. I hope you know how much I love you and how happy I am to have you!

My deepest thanks go to my parents, my sister, and my brothers for the values they have taught me, for encouraging me to travel far and learn things, and for their unconditional love and support always. I would never have finished this without you. 


\section{References}

Ackerly DD (2003) Community Assembly, Niche Conservatism, and Adaptive Evolution in Changing Environments. International Journal of Plant Sciences 164: S165-S184. https://doi.org/10.1086/368401

Adema F (2001) Millettia and Pongamia (Leguminosae-Papilionoideae) in Malesia. In: Saw LG, Chua LSL, Khoo KC (Eds), Taxonomy: the cornerstone of biodiversity: proceedings of the Fourth International Flora Malesiana Symposium, 1998. Forest Research Institute Malaysia, Kuala Lumpur, Malaysia, 41-50.

Adema F, Leenhouts PW, van Welzen PC (1994) Sapindaceae. Flora Malesiana, Series I 11: 419768.

Adiwibowo S (2005) Dongi-dongi - Culmination of a multi-dimensional ecological crisis: A political ecology perspective. PhD thesis. Universität Kassel Available from: https://www.deutsche-digitale-

bibliothek.de/binary/FG2VXODCJ2MQ6RUJ7PENNZ5YD7KEQOVO/full/1.pdf (February 25, 2015).

Aiba S-I, Kitayama K (1999) Structure, composition and species diversity in an altitude-substrate matrix of rain forest tree communities on Mount Kinabalu, Borneo. Plant Ecology 140: 139-157. https://doi.org/10.1023/A:1009710618040

Aiba S-I, Kitayama K, Repin R (2002) Species composition and species-area relationships of trees in nine permanent plots in altitudinal sequences on different geological substrates of Mount Kinabalu. Sabah Parks Nature Journal 5: 7-69.

Aiba S-I, Takyu M, Kitayama K (2005) Dynamics, productivity and species richness of tropical rainforests along elevational and edaphic gradients on Mount Kinabalu, Borneo. Ecological Research 20: 279-286. https://doi.org/10.1007/s11284-005-0043-z

Aiba S-I, Sawada Y, Takyu M, Seino T, Kitayama K, Repin R (2015) Structure, floristics and diversity of tropical montane rain forests over ultramafic soils on Mount Kinabalu (Borneo) compared with those on non-ultramafic soils. Australian Journal of Botany 63: 191-203. https://doi.org/10.1071/BT14238

Aldrich M, Billington C, Edwards M, Laidlaw R (1997) Tropical montane cloud forests: an urgent priority for conservation. World Conservation Monitoring Centre. Available from: http://www.unep-wcmc-apps.org/resources/publications/bulletin_2/text.htm (April 15, 2015).

Alejandro GJD, Magdaleno CMM, Pacia JAT, Paraguison LD, Quiogue KKC, Wong AED, Yayen KMR, Arriola AH (2014) Generic affiliations of Canthium species placed under Pyrostria group B sensu Bridson (Vanguerieae, Rubiaceae) inferred from morphology and molecular data. Botanical Studies 55: 65. https://doi.org/10.1186/s40529-014-0065-3

Alford MH (2005) Systematic studies in Flacourtiaceae. PhD thesis. Cornell University Available from:

https://www.researchgate.net/publication/34724623_Systematic_studies_in_Flacourtiace ae.

Ali SJ, Robbrecht E (1991) Remarks on the tropical Asian and Australian taxa included in Diplospora or Tricalysia (Rubiaceae - Ixoroideae - Gardenieae). Blumea - Biodiversity, Evolution and Biogeography of Plants 35: 279-305.

Amshoff GJH (1945) Myrtaceae (in C.A. Backer: Notes on the Flora of Java, II). Blumea 5: 495502.

Amshoff GJH (1963) Myrtaceae. In: Flora of Java (Spermatophytes only). Vol. I. N.V. P. Noordhoff, Groningen, The Netherlands, 333-351.

Andrews S (2002) Aquifoliaceae. In: Soepadmo E, Saw LG, Chung RCK (Eds), Tree Flora of Sabah and Sarawak. Forest Research Institute Malaysia (FRIM), Sabah Forestry Department, and Sarawak Forestry Department, Kuala Lumpur, 1-27. 
Antonelli A, Zizka A, Carvalho FA, Scharn R, Bacon CD, Silvestro D, Condamine FL (2018a) Amazonia is the primary source of Neotropical biodiversity. Proceedings of the National Academy of Sciences 115: 6034-6039. https://doi.org/10.1073/pnas.1713819115

Antonelli A, Kissling WD, Flantua SGA, Bermúdez MA, Mulch A, Muellner-Riehl AN, Kreft H, Linder HP, Badgley C, Fjeldså J, Fritz SA, Rahbek C, Herman F, Hooghiemstra H, Hoorn C (2018b) Geological and climatic influences on mountain biodiversity. Nature Geoscience 11: 718725. https://doi.org/10.1038/s41561-018-0236-z

Appelhans MS, Wen J (2016) On the identity of Blanco's Cissus frutescens and its correct name in Melicope (Rutaceae) with neotypification of Cissus arborea Blanco. PhytoKeys 58: 8185. https://doi.org/10.3897/phytokeys.58.5847

Appelhans MS, Wen J, Wagner WL (2014) A molecular phylogeny of Acronychia, Euodia, Melicope and relatives (Rutaceae) reveals polyphyletic genera and key innovations for species richness. Molecular Phylogenetics and Evolution 79: 54-68. https://doi.org/10.1016/j.ympev.2014.06.014

Appelhans MS, Keßler PJA, Smets E, Razafimandimbison SG, Janssens SB (2012) Age and historical biogeography of the pantropically distributed Spathelioideae (Rutaceae, Sapindales). Journal of Biogeography 39: 1235-1250. https://doi.org/10.1111/j.13652699.2012.02686.x

Appelhans MS, Reichelt N, Groppo M, Paetzold C, Wen J (2018) Phylogeny and biogeography of the pantropical genus Zanthoxylum and its closest relatives in the proto-Rutaceae group (Rutaceae). Molecular Phylogenetics and Evolution 126: 31-44. https://doi.org/10.1016/j.ympev.2018.04.013

Aragones EG Jr (1991) Vegetation-soil pattern along altitudinal gradient in the western slopes of Mt. Banahaw, Luzon, Philippines: I. The forest communities and changes in forest composition with altitude. Sylvatrop: Technical Journal for Philippine Ecosystems and Natural Ressources 1: 15-45.

Ardi WH, Ardiyani M (2016) Two new species of Alpinia (Zingiberaceae) from Sulawesi, Indonesia. Reinwardtia 14: 311-316. https://doi.org/10.14203/reinwardtia.v14i2.1677

Ardi WH, Chikmawati T, Witono JR, Thomas DC (2018) A synopsis of Begonia (Begoniaceae) of Southeastern Sulawesi including four new species. Phytotaxa 381: 27-50. https://doi.org/10.11646/phytotaxa.381.1.7

Ardiyani M, Newman MF, Poulsen, A.D. (2017) A new species of Zingiber (Zingiberaceae) east of Wallace's Line. Gardens' Bulletin, Singapore 69: 189-199. https://doi.org/10.26492/gbs69(2).2017-04

Arifiani D (2001) Taxonomic revision of Endiandra (Lauraceae) in Borneo. Blumea - Biodiversity, Evolution and Biogeography of Plants 46: 99-124.

Ashton PS (2003a) Dipterocarpaceae. In: Kubitzki K, Bayer C (Eds), Flowering Plants Dicotyledons: Malvales, Capparales and Non-betalain Caryophyllales. The Families and Genera of Vascular Plants, vol. 5. Springer, Berlin, Heidelberg, 182-197. https://doi.org/10.1007/978-3-662-07255-4_20

Ashton PS (2003b) Floristic zonation of tree communities on wet tropical mountains revisited. Perspectives in Plant Ecology, Evolution and Systematics 6: 87-104. https://doi.org/10.1078/1433-8319-00044

Ashton PS (2011) Myrtaceae s.I. In: Soepadmo E, Saw LG, Chung RCK, Kiew R (Eds), Tree Flora of Sabah and Sarawak. Vol. 7. Forest Research Institute Malaysia (FRIM), Sabah Forestry Department, and Sarawak Forestry Department, Selangor, Malaysia, 87-330.

Ashton PS (2014) On the Forests of Tropical Asia: Lest the Memory Fade. Royal Botanic Gardens, Kew, Richmond, U.K., 670 pp. Available from: http://www.press.uchicago.edu/ucp/books/book/distributed/O/bo19092051.html.

Atkins HJ (2003) The Gesneriaceae of Sulawesi II: Seven new species of Cyrtandra. Edinburgh Journal of Botany 60: 305-322. https://doi.org/10.1017/S096042860300026X 
Atkins HJ, Bramley GLC, Clark JR (2013) Current Knowledge and Future Directions in the Taxonomy of Cyrtandra (Gesneriaceae), with a New Estimate of Species Number. Selbyana 31: 157-165.

Azuma H, García-Franco JG, Rico-Gray V, Thien LB (2001) Molecular phylogeny of the Magnoliaceae: the biogeography of tropical and temperate disjunctions. American Journal of Botany 88: 2275-2285. https://doi.org/10.2307/3558389

Baba Y (2013) Evolution, systematics and taxonomy of Elaeocarpus (Elaeocarpaceae) in Australasia. PhD thesis. James Cook University Available from: http://researchonline.jcu.edu.au/38321/.

Bachman S, Moat J, Hill A, de la Torre J, Scott B (2011) GeoCAT: Geospatial Conservation Assessment Tool. Available from: http://geocat.kew.org/ (December 9, 2016).

Backer CA (1951) Myricaceae. Flora Malesiana, Series I 4: 276-279.

Backer CA, Bakhuizen van den Brink Jr. RC (1963a) Clusiaceae. In: Flora of Java (Spermatophytes only). N.V. P. Noordhoff, Groningen - The Netherlands, 383-388.

Backer CA, Bakhuizen van den Brink Jr. RC (1963b) Escalloniaceae. In: Flora of Java (Spermatophytes only). N.V. P. Noordhoff, Groningen - The Netherlands, 506-508.

Backer CA, Bakhuizen van den Brink Jr. RC (1963c) 1 Flora of Java (Spermatophytes only). Vol. 1. N.V. P. Noordhoff, under the auspices of the Rijksherbarium, Leyden, Groningen - The Netherlands, $648 \mathrm{pp}$.

Backer CA, Bakhuizen van den Brink Jr. RC (1965a) Aquifoliaceae. In: Flora of Java (Spermatophytes only). N.V. P. Noordhoff, Groningen - The Netherlands, 51-52.

Backer CA, Bakhuizen van den Brink Jr. RC (1965b) 2 Flora of Java (Spermatophytes only). Vol. 2. N.V. P. Noordhoff, under the auspices of the Rijksherbarium, Leyden, Groningen - The Netherlands, $640 \mathrm{pp}$.

Backer CA, Bakhuizen van den Brink Jr. RC (1968) 3 Flora of Java (Spermatophytes only). Vol. 3. N.V. P. Noordhoff, under the auspices of the Rijksherbarium, Leyden, Groningen - The Netherlands, $761 \mathrm{pp}$.

Bacon CD, Simmons MP, Archer RH, Zhao L-C, Andriantiana J (2016) Biogeography of the Malagasy Celastraceae: Multiple independent origins followed by widespread dispersal of genera from Madagascar. Molecular Phylogenetics and Evolution 94, Part A: 365-382. https://doi.org/10.1016/j.ympev.2015.09.013

Bacon CD, Silvestro D, Jaramillo C, Smith BT, Chakrabarty P, Antonelli A (2015) Biological evidence supports an early and complex emergence of the Isthmus of Panama. Proceedings of the National Academy of Sciences 112: 6110-6115. https://doi.org/10.1073/pnas.1423853112

Bailey IW, Nast CG, Smith AC (1943) The Family Himantandraceae. Journal of the Arnold Arboretum 24: 190-206.

Baker TR, Pennington RT, Dexter KG, Fine PVA, Fortune-Hopkins H, Honorio EN, HuamantupaChuquimaco I, Klitgård BB, Lewis GP, de Lima HC, Ashton PS, Baraloto C, Davies S, Donoghue MJ, Kaye M, Kress WJ, Lehmann CER, Monteagudo A, Phillips OL, Vasquez R (2017) Maximising Synergy among Tropical Plant Systematists, Ecologists, and Evolutionary Biologists. Trends in Ecology \& Evolution 32: 258-267. https://doi.org/10.1016/j.tree.2017.01.007

Baker WJ, Couvreur TLP (2013) Global biogeography and diversification of palms sheds light on the evolution of tropical lineages. I. Historical biogeography. Journal of Biogeography 40: 274-285. https://doi.org/10.1111/j.1365-2699.2012.02795.x

Bakhuizen van den Brink RC (1933) Enumeration of Malayan Ebenaceae. The Gardens' bulletin, Straits Settlements 7: 161-189.

Bakhuizen van den Brink RC (1936) Revisio Ebenacearum Malayensium. Bulletin du Jardin Botanique Buitenzorg, Série III 15: 1-515.

Bakker K, van Steenis CGGJ (1957) Pittosporaceae. Flora Malesiana, Series I 5: 345-362. 
Baldwin SL, Fitzgerald PG, Webb LE (2012) Tectonics of the New Guinea Region. Annual Review of Earth and Planetary Sciences 40: 495-520. https://doi.org/10.1146/annurev-earth040809-152540

van Balgooy MMJ (1987) A plant geographical analysis of Sulawesi. In: Biogeographical evolution of the Malay Archipelago. Oxford Biogeography Series. Clarendon Press, Oxford, UK, 94102.

van Balgooy MMJ (1997) Malesian Seed Plants, Volume 1: Spot Characters: An Aid for Identification of Families and Genera. National Herbarium of the Netherlands, Leiden, The Netherlands, 154 pp. Available from: http://www.repository.naturalis.nl/record/533510.

van Balgooy MMJ (1998) Malesian Seed Plants, Volume 2: Portraits of Tree Families. National Herbarium of the Netherlands, Leiden, The Netherlands, 307 pp. Available from: http://www.repository.naturalis.nl/record/533512.

van Balgooy MMJ (2010) An updated survey of Malesian seed plants families. Reinwardtia 13: 171-181. https://doi.org/10.14203/reinwardtia.v13i2.2138

Balgooy MMJ van, Tantra IGM (1986) The Vegetation in Two Areas in Sulawesi, Indonesia. Buletin Penelitian Hutan (Forest Reseach Bulletin) Edisi khusus/Special edition: 1-61.

Bardon L, Sothers C, Prance GT, Malé P-JG, Xi Z, Davis CC, Murienne J, García-Villacorta R, Coissac E, Lavergne S, Chave J (2016) Unraveling the biogeographical history of Chrysobalanaceae from plastid genomes. American Journal of Botany 103: 1089-1102. https://doi.org/10.3732/ajb.1500463

Barker NP, Weston PH, Rutschmann F, Sauquet H (2007) Molecular dating of the "Gondwanan" plant family Proteaceae is only partially congruent with the timing of the break-up of Gondwana. Journal of Biogeography 34: 2012-2027. https://doi.org/10.1111/j.13652699.2007.01749.x

Barker WR (1980) Taxonomic revisions in Theaceae in Papuasia. 1. Gordonia, Ternstroemia, Adinandra and Archboldiodendron. Australian Systematic Botany 3: 1-60. https://doi.org/10.1071/BRU9800001

Barnosky AD, Matzke N, Tomiya S, Wogan GOU, Swartz B, Quental TB, Marshall C, McGuire JL, Lindsey EL, Maguire KC, Mersey B, Ferrer EA (2011) Has the Earth's sixth mass extinction already arrived? Nature 471: 51-57. https://doi.org/10.1038/nature09678

Barnosky AD, Hadly EA, Bascompte J, Berlow EL, Brown JH, Fortelius M, Getz WM, Harte J, Hastings A, Marquet PA, Martinez ND, Mooers A, Roopnarine P, Vermeij G, Williams JW, Gillespie R, Kitzes J, Marshall C, Matzke N, Mindell DP, Revilla E, Smith AB (2012) Approaching a state shift in Earth's biosphere. Nature 486: 52-58. https://doi.org/10.1038/nature11018

Barrabé L, Buerki S, Mouly A, Davis AP, Munzinger J, Maggia L (2012) Delimitation of the genus Margaritopsis (Rubiaceae) in the Asian, Australasian and Pacific region, based on molecular phylogenetic inference and morphology. Taxon 61: 1251-1268.

Barthlott W, Hostert A, Kier G, Küper W, Kreft H, Mutke J, Rafiqpoor MD, Sommer JH (2007) Geographic Patterns of Vascular Plant Diversity at Continental to Global Scales (Geographische Muster der Gefäßpflanzenvielfalt im kontinentalen und globalen Maßstab). Erdkunde 61: 305-315.

Bartish IV, Antonelli A, Richardson JE, Swenson U (2011) Vicariance or long-distance dispersal: historical biogeography of the pantropical subfamily Chrysophylloideae (Sapotaceae). Journal of Biogeography 38: 177-190. https://doi.org/10.1111/j.1365-2699.2010.02389.x

Bartoń K (2018) MuMIn: Multi-Model Inference. Available from: https://CRAN.Rproject.org/package=MuMIn (March 12, 2018).

Bayer C, Kubitzki K (2003) Malvaceae. In: Kubitzki K, Bayer C (Eds), Flowering Plants Dicotyledons: Malvales, Capparales and Non-betalain Caryophyllales. The Families and Genera of Vascular Plants, vol. 5. Springer, Berlin, Heidelberg, 225-311. https://doi.org/10.1007/978-3-662-07255-4_28 
Beaman JH, Beaman RS (1990) Diversity and distribution patterns in the flora of Mount Kinabalu. In: Baas P, Kalkman K, Geesink R (Eds), The Plant Diversity of Malesia. Springer Netherlands, 147-160. Available from: http://link.springer.com/chapter/10.1007/978-94009-2107-8_14 (August 26, 2015).

Beaman RS, Beaman JH, Parris BS, Wood JJ, Anderson C (1992) The Plants of Mount Kinabalu. Parts 1-5. Natural History Publishing (Borneo) in association with Royal Botanic Gardens, Kew, Kota Kinabalu, Malaysia - Richmond, UK.

Bean AR (1992) The genus Leptospermum Forst. et Forst. f. (Myrtaceae) in Northern Australia and Malesia. Austrobaileya 3: 643-659.

Beaulieu JM, Tank DC, Donoghue MJ (2013) A Southern Hemisphere origin for campanulid angiosperms, with traces of the break-up of Gondwana. BMC Evolutionary Biology 13: 80. https://doi.org/10.1186/1471-2148-13-80

Bebber DP, Carine MA, Wood JRI, Wortley AH, Harris DJ, Prance GT, Davidse G, Paige J, Pennington TD, Robson NKB, Scotland RW (2010) Herbaria are a major frontier for species discovery. Proceedings of the National Academy of Sciences 107: 22169-22171. https://doi.org/10.1073/pnas.1011841108

Beentje H (2012) The Kew Plant Glossary: an illustrated dictionary of plant terms. With illustrations by Juliet Williamson. Revised edition. Royal Botanic Gardens, Kew, Richmond, Surrey, U.K., 164 pp.

Bell CD, Soltis DE, Soltis PS (2010) The age and diversification of the angiosperms re-revisited. American Journal of Botany 97: 1296-1303. https://doi.org/10.3732/ajb.0900346

Bello MA, Rudall PJ, Hawkins JA (2012) Combined phylogenetic analyses reveal interfamilial relationships and patterns of floral evolution in the eudicot order Fabales. Cladistics 28: 393-421. https://doi.org/10.1111/j.1096-0031.2012.00392.x

Berg CC (2012) Seven new Malesian species of Ficus (Moraceae). Blumea - Biodiversity, Evolution and Biogeography of Plants 57: 147-157. https://doi.org/10.3767/000651912X657585

Berg CC, Corner EJH (2005) Moraceae: Ficeae. Flora Malesiana, Series I 17: 1-702.

Berg CC, Culmsee H (2011) Ficus schwarzii redefined and two new species of Ficus (Moraceae) from Sulawesi (Indonesia) described. Blumea - Biodiversity, Evolution and Biogeography of Plants 56: 265-269. https://doi.org/10.3767/000651911X617869

Berg CC, Corner EJH, Jarrett FM (2006) Moraceae: Genera other than Ficus. Flora Malesiana, Series | 17: 1-146.

Berger BA, Kriebel R, Spalink D, Sytsma KJ (2016) Divergence times, historical biogeography, and shifts in speciation rates of Myrtales. Molecular Phylogenetics and Evolution 95: 116-136. https://doi.org/10.1016/j.ympev.2015.10.001

Berhaman A (1995) Clethraceae. In: Soepadmo E, Wong KM (Eds), Tree Flora of Sabah and Sarawak. Forest Research Institute Malaysia (FRIM), Sabah Forestry Department, and Sarawak Forestry Department, Kuala Lumpur, 181-186.

Bertuzzo E, Carrara F, Mari L, Altermatt F, Rodriguez-Iturbe I, Rinaldo A (2016) Geomorphic controls on elevational gradients of species richness. Proceedings of the National Academy of Sciences 113: 1737-1742. https://doi.org/10.1073/pnas.1518922113

Besnard G, Rubio de Casas R, Christin P-A, Vargas P (2009) Phylogenetics of Olea (Oleaceae) based on plastid and nuclear ribosomal DNA sequences: Tertiary climatic shifts and lineage differentiation times. Annals of Botany 104: 143-160. https://doi.org/10.1093/aob/mcp105

van Beusekom CF (1971) Revision of Meliosma (Sabiaceae), section Lorenzanea excepted, living and fossil, geography and phylogeny. Blumea - Biodiversity, Evolution and Biogeography of Plants 19: 355-529.

van Beusekom CF, van de Water ThPM (1984) Sabiaceae. Flora Malesiana, Series I 10: 679-715. Bhattarai KR, Vetaas OR (2003) Variation in plant species richness of different life forms along a subtropical elevation gradient in the Himalayas, east Nepal. Global Ecology and Biogeography 12: 327-340. https://doi.org/10.1046/j.1466-822X.2003.00044.x 
Bhattarai KR, Vetaas OR, Grytnes JA (2004) Fern species richness along a central Himalayan elevational gradient, Nepal. Journal of Biogeography 31: 389-400. https://doi.org/10.1046/j.0305-0270.2003.01013.x

Bhowmik S, Datta BK (2012) Pollen Dimorphism of Several Members of Nymphaeaceae and Nelumbonaceae: An Index of Geographical and Ecological Variation. Notulae Scientia Biologicae 4: 38-44. https://doi.org/10.15835/nsb.4.3.7689

Biagioni S, Wündsch M, Haberzettl T, Behling H (2015a) Assessing resilience/sensitivity of tropical mountain rainforests towards climate variability of the last 1500 years: The longterm perspective at Lake Kalimpaa (Sulawesi, Indonesia). Review of Palaeobotany and Palynology 213: 42-53. https://doi.org/10.1016/j.revpalbo.2014.11.005

Biagioni S, Haberzettl T, Wang L-C, St-Onge G, Behling H (2015b) Unravelling the past 1,000 years of history of human-climate-landscape interactions at the Lindu plain, Sulawesi, Indonesia. Vegetation History and Archaeobotany: 1-17. https://doi.org/10.1007/s00334015-0523-1

Biffin E, Conran JG, Lowe AJ (2011) Podocarp Evolution: A Molecular Phylogenetic Perspective. In: Turner BL, Cernusak L (Eds), Ecology of the Podocarpaceae in Tropical Forests. Smithsonian Contributions to Botany, Vol. 95. Smithsonian Institution Scholarly Press, Washington, D.C., 1-20.

Biffin E, Craven LA, Tuiwawa M, Crisp MD, Gadek PA (2005) South Pacific Cleistocalyx Transferred to Syzygium (Myrtaceae). Blumea - Biodiversity, Evolution and Biogeography of Plants 50: 383-388. https://doi.org/10.3767/000651905X623058

Biffin E, Lucas EJ, Craven LA, Ribeiro da Costa I, Harrington MG, Crisp MD (2010) Evolution of exceptional species richness among lineages of fleshy-fruited Myrtaceae. Annals of Botany 106: 79-93. https://doi.org/10.1093/aob/mcq088

Bissiengou P (2014) Systematics, evolution and historical biogeography of the family Ochnaceae with emphasis on the genus Campylospermum. Wageningen Univ.

Bittrich V (2014) Trigoniaceae. In: Kubitzki K (Ed), Flowering Plants - Eudicots: Malpighiales. The Families and Genera of Vascular Plants, vol. 11. Springer, Berlin, Heidelberg, 297-301. https://doi.org/10.1007/978-3-642-39417-1_24

Bivand R, Altman M, Anselin L, Assunção R, Berke O, Bernat A, Blanchet G, Blankmeyer E, Carvalho M, Christensen B, Chun Y, Dormann C, Dray S, Gómez-Rubio V, Gubri M, Halbersma R, Krainski E, Legendre P, Lewin-Koh N, Li A, Li H, Ma J, Mallik A, Millo G, Mueller W, Ono H, Peres-Neto P, Piras G, Reder M, Tiefelsdorf M, Westerholt R, Yu D (2019) spdep: Spatial Dependence: Weighting Schemes, Statistics and Models. Available from: https://CRAN.R-project.org/package=spdep (July 29, 2019).

Bloembergen S (1940) Verslag van een exploratie-tocht naar Midden-Celebes (Lindoe-meer en Goenoeng Ngilalaki ten Zuiden van Paloe) in Juli 1939. Tectona 33: 377-418.

Bloembergen S (1948) Aceraceae. Flora Malesiana, Series I 4: 3-4.

Blume CL (1850) Ord. Myrtaceae. In: Museum Botanicum Lugduno-Batavum. Tom. I, No. 6-8. E.J. Brill, Leiden, The Netherlands, 83-109, 113-125. Available from: http://biodiversitylibrary.org/page/48976315.

Bodegom S, Veldkamp JF (2001) Revision of the pseudo-stipular species of Medinilla (Melastomataceae). Blumea - Biodiversity, Evolution and Biogeography of Plants 46: 527567.

de Boer H, Newman M, Poulsen AD, Droop AJ, Fér T, Hiên LTT, Hlavatá K, Lamxay V, Richardson JE, Steffen K, Leong-Škorničková J (2018) Convergent morphology in Alpinieae (Zingiberaceae): Recircumscribing Amomum as a monophyletic genus. Taxon 67: 6-36. https://doi.org/10.12705/671.2

Bone RE, Atkins HJ (2013) Four new species of Cyrtandra (Gesneriaceae) from the Latimojong Mountains, South Sulawesi. Edinburgh Journal of Botany 70: 455-468. https://doi.org/10.1017/S0960428613000152 
Bouchenak-Khelladi Y, Maurin O, Hurter J, van der Bank M (2010) The evolutionary history and biogeography of Mimosoideae (Leguminosae): An emphasis on African acacias. Molecular Phylogenetics and Evolution 57: 495-508. https://doi.org/10.1016/j.ympev.2010.07.019

Bradford JC, Barnes RW (2001) Phylogenetics and Classification of Cunoniaceae (Oxalidales) Using Chloroplast DNA Sequences and Morphology. Systematic Botany 26: 354-385. https://doi.org/10.1043/0363-6445-26.2.354

Bradford JC, Hopkins HCF, Barnes RW (2004) Cunoniaceae. In: Kubitzki K (Ed), Flowering Plants Dicotyledons: Celastrales, Oxalidales, Rosales, Cornales, Ericales. The Families and Genera of Vascular Plants, Volume 6. Springer, Berlin, Heidelberg, 91-111. https://doi.org/10.1007/978-3-662-07257-8_11

Brambach F, Leuschner C, Tjoa A, Culmsee H (2017) Diversity, endemism, and composition of tropical mountain forest communities in Sulawesi, Indonesia, in relation to elevation and soil properties. Perspectives in Plant Ecology, Evolution and Systematics 27: 68-79. https://doi.org/10.1016/j.ppees.2017.06.003

Bramley GLC (2012) Three new species of Callicarpa (Lamiaceae) from Sulawesi. Kew Bulletin 67: 213-223. https://doi.org/10.1007/s12225-012-9359-3

Bratawinata AA (1986) Bestandesgliederung eines Bergregenwaldes in Ostkalimantan / Indonesia nach floristischen und strukturellen Merkmalen. PhD thesis. Georg-AugustUniversität Göttingen

Bray JR, Curtis JT (1957) An Ordination of the Upland Forest Communities of Southern Wisconsin. Ecological Monographs 27: 325-349. https://doi.org/10.2307/1942268

Brehm G, Pitkin LM, Hilt N, Fiedler K (2005) Montane Andean rain forests are a global diversity hotspot of geometrid moths. Journal of Biogeography 32: 1621-1627. https://doi.org/10.1111/j.1365-2699.2005.01304.x

Bremekamp CEB (1937) The Malaysian species of the genus Ixora (Rub.). Bulletin du Jardin Botanique Buitenzorg, Série III 14: 197-367.

Bremekamp CEB (1940a) A preliminary account of the Philippine species of Urophyllum Wall., Pleiocarpidia K. Sch. and Praravinia Korth. (Rub.). Journal of the Arnold Arboretum 21: 3247.

Bremekamp CEB (1940b) On Urophyllum Wall. (Rubiaceae) and its nearest allies. Mededelingen van het Botanisch Museum en Herbarium van de Rijksuniversiteit te Utrecht 76: 171-197.

Bremekamp CEB (1940c) The genus Praravinia Korth. (Rubiaceae) in Borneo and Celebes. Mededelingen van het Botanisch Museum en Herbarium van de Rijksuniversiteit te Utrecht 78: 237-278.

Bridson DM (1985) The Reinstatement of Psydrax (Rubiaceae, subfam. Cinchonoideae Tribe Vanguerieae) and a Revision of the African Species. Kew Bulletin 40: 687-725. https://doi.org/10.2307/4109853

Bridson DM (1987) Studies in African Rubiaceae: Vanguerieae: A New Circumscription of Pyrostria and a New Subgenus, Canthium subgen. Bullockia. Kew Bulletin 42: 611-639. https://doi.org/10.2307/4110068

Briggs BG, Johnson LAS (1979) Evolution in the Myrtaceae - Evidence from inflorescence structure. Proceedings of the Linnean Society of New South Wales 102: 157-256.

Brown GK, Murphy DJ, Ladiges PY (2011) Relationships of the Australo-Malesian genus Paraserianthes (Mimosoideae: Leguminosae) identifies the sister group of Acacia sensu stricto and two biogeographical tracks. Cladistics 27: 380-390. https://doi.org/10.1111/j.1096-0031.2011.00349.x

Brummitt NA, Lughadha EN (2003) Biodiversity: Where's Hot and Where's Not. Conservation Biology 17: 1442-1448. https://doi.org/10.1046/j.1523-1739.2003.02344.x

Brummitt NA, Bachman SP, Griffiths-Lee J, Lutz M, Moat JF, Farjon A, Donaldson JS, Hilton-Taylor C, Meagher TR, Albuquerque S, Aletrari E, Andrews AK, Atchison G, Baloch E, Barlozzini B, Brunazzi A, Carretero J, Celesti M, Chadburn H, Cianfoni E, Cockel C, Coldwell V, Concetti B, Contu S, Crook V, Dyson P, Gardiner L, Ghanim N, Greene H, Groom A, Harker R, 
Hopkins D, Khela S, Lakeman-Fraser P, Lindon H, Lockwood H, Loftus C, Lombrici D, LopezPoveda L, Lyon J, Malcolm-Tompkins P, McGregor K, Moreno L, Murray L, Nazar K, Power E, Tuijtelaars MQ, Salter R, Segrott R, Thacker H, Thomas LJ, Tingvoll S, Watkinson G, Wojtaszekova K, Lughadha EMN (2015) Green Plants in the Red: A Baseline Global Assessment for the IUCN Sampled Red List Index for Plants. PLOS ONE 10: e0135152. https://doi.org/10.1371/journal.pone.0135152

Brummitt RK, Pando F, Hollis S, Brummitt NA (2001) 2 World geographical scheme for recording plant distributions. 2nd ed. International Working Group on Taxonomic Databases for Plant Sciences (TDWG), Hunt Institute for Botanical Documentation, Carnegie Mellon University, Pittsburgh, 137 pp. Available from: http://grassworld.myspecies.info/sites/grassworld.myspecies.info/files/tdwg_geo2.pdf (May 17, 2015).

Bruneau A, Mercure M, Lewis GP, Herendeen PS (2008) Phylogenetic patterns and diversification in the caesalpinioid legumes. Botany 86: 697-718. https://doi.org/10.1139/B08-058

Bruneau A, Klitgaard BB, Prenner G, Fougère-Danezan M, Tucker SC (2014) Floral Evolution in the Detarieae (Leguminosae): Phylogenetic Evidence for Labile Floral Development in an Early-Diverging Legume Lineage. International Journal of Plant Sciences 175: 392-417. https://doi.org/10.1086/675574

Brunken U, Muellner AN (2012) A New Tribal Classification of Grewioideae (Malvaceae) Based on Morphological and Molecular Phylogenetic Evidence. Systematic Botany 37: 699-711. https://doi.org/10.1600/036364412X648670

Bryant LM, Krosch MN (2016) Lines in the land: a review of evidence for eastern Australia's major biogeographical barriers to closed forest taxa. Biological Journal of the Linnean Society 119: 238-264. https://doi.org/10.1111/bij.12821

Buerki S, Forest F, Alvarez N, Nylander JAA, Arrigo N, Sanmartín I (2011) An evaluation of new parsimony-based versus parametric inference methods in biogeography: a case study using the globally distributed plant family Sapindaceae. Journal of Biogeography 38: 531550. https://doi.org/10.1111/j.1365-2699.2010.02432.x

Buerki S, Forest F, Callmander MW, Lowry II PP, Devey DS, Munzinger J (2012) Phylogenetic inference of New Caledonian lineages of Sapindaceae: Molecular evidence requires a reassessment of generic circumscriptions. Taxon 61: 109-119.

Byng JW, Bernardini B, Christenhusz MJM, Chase MW (2016) Systematics of Irvingiaceae and Ixonanthaceae (Malpighiales): phylogenetic analysis based on three plastid DNA loci. Phytotaxa 260: 157-166. https://doi.org/10.11646/phytotaxa.260.2.5

Byrne M, Steane DA, Joseph L, Yeates DK, Jordan GJ, Crayn D, Aplin K, Cantrill DJ, Cook LG, Crisp MD, Keogh JS, Melville J, Moritz C, Porch N, Sniderman JMK, Sunnucks P, Weston PH (2011) Decline of a biome: evolution, contraction, fragmentation, extinction and invasion of the Australian mesic zone biota. Journal of Biogeography 38: 1635-1656. https://doi.org/10.1111/j.1365-2699.2011.02535.x

Cai L, Xi Z, Peterson K, Rushworth C, Beaulieu J, Davis CC (2016) Phylogeny of Elatinaceae and the Tropical Gondwanan Origin of the Centroplacaceae (Malpighiaceae, Elatinaceae) Clade. Wong WO (Ed). PLOS ONE 11: e0161881. https://doi.org/10.1371/journal.pone.0161881

Campbell CS, Evans RC, Morgan DR, Dickinson TA, Arsenault MP (2007) Phylogeny of subtribe Pyrinae (formerly the Maloideae, Rosaceae): Limited resolution of a complex evolutionary history. Plant Systematics and Evolution 266: 119-145. https://doi.org/10.1007/s00606007-0545-y

Campbell-Gasis EJF (1995) Juglandaceae. In: Soepadmo E, Wong KM (Eds), Tree Flora of Sabah and Sarawak. Forest Research Institute Malaysia (FRIM), Sabah Forestry Department, and Sarawak Forestry Department, Kuala Lumpur, 233-244.

Camus A (1952) Les Chênes: Monographie du Genre Quercus. Tome III. Paul Lechevalier, Paris, 1-1314 pp. 
Candolle AP de (1828) Prodromus systematis naturalis regni vegetabilis 3. Treuttel \& Würtz, Paris. Available from: http://biodiversitylibrary.org/page/152793.

Cannon CH (2001) The vegetation of Lore Lindu National Park, Central Sulawesi, Indonesia. The Nature Conservancy, Palu, Indonesia. Final Report, 26pp. Available from: http://www.faculty.biol.ttu.edu/cannon/pdfs/TNC_final_report.pdf.

Cannon CH, Manos PS (2003) Phylogeography of the Southeast Asian stone oaks (Lithocarpus). Journal of Biogeography 30: 211-226. https://doi.org/10.1046/j.1365-2699.2003.00829.x

Cannon CH, Summers M, Harting JR, Keßler PJA (2007) Developing Conservation Priorities Based on Forest Type, Condition, and Threats in a Poorly Known Ecoregion: Sulawesi, Indonesia. Biotropica 39: 747-759. https://doi.org/10.1111/j.1744-7429.2007.00323.x

Capitaine ML (1910) Ilex celebensis L. C.: Aquifoliacée nouvelle de I'Insulinde. Bulletin de la Société Botanique de France 57: 234-236.

Cardoso D, Harris DJ, Wieringa JJ, São-Mateus WMB, Batalha-Filho H, Torke BM, Prenner G, Queiroz LP de (2017) A molecular-dated phylogeny and biogeography of the monotypic legume genus Haplormosia, a missing African branch of the otherwise AmericanAustralian Brongniartieae clade. Molecular Phylogenetics and Evolution 107: 431-442. https://doi.org/10.1016/j.ympev.2016.12.012

Carter RJ (2011) Diversification of the Malvales, Sterculioideae and Brachychiton. PhD thesis. Australian National University Available from: http://hdl.handle.net/1885/109374 (November 6, 2017).

Cavender-Bares J, Ackerly DD, Baum DA, Bazzaz FA, Renner AESS (2004) Phylogenetic Overdispersion in Floridian Oak Communities. The American Naturalist 163: 823-843. https://doi.org/10.1086/386375

Ceballos G, Ehrlich PR, Dirzo R (2017) Biological annihilation via the ongoing sixth mass extinction signaled by vertebrate population losses and declines. Proceedings of the National Academy of Sciences 114: E6089-E6096. https://doi.org/10.1073/pnas.1704949114

Cervantes A, Fuentes S, Gutiérrez J, Magallón S, Borsch T (2016) Successive arrivals since the Miocene shaped the diversity of the Caribbean Acalyphoideae (Euphorbiaceae). Journal of Biogeography 43: 1773-1785. https://doi.org/10.1111/jbi.12790

Chai PPK, Yii PC (2002) Sapotaceae. In: Soepadmo E, Saw LG, Chung RCK (Eds), Tree Flora of Sabah and Sarawak. Forest Research Institute Malaysia (FRIM), Sabah Forestry Department, and Sarawak Forestry Department, Kuala Lumpur, 203-345.

Chanderbali AS, van der Werff H, Renner SS (2001) Phylogeny and Historical Biogeography of Lauraceae: Evidence from the Chloroplast and Nuclear Genomes. Annals of the Missouri Botanical Garden 88: 104-134. https://doi.org/10.2307/2666133

Chandler GT, Plunkett GM, Pinney SM, Cayzer LW, Gemmill CEC (2007) Molecular and morphological agreement in Pittosporaceae: phylogenetic analysis with nuclear ITS and plastid trnL-trnF sequence data. Australian Systematic Botany 20: 390-401. https://doi.org/10.1071/SB07004

Chantaranothai P, Parnell J (1993) New Taxa and Combinations in Cleistocalyx and Syzygium (Myrtaceae) in Thailand. Kew Bulletin 48: 589-610. https://doi.org/10.2307/4118723

Chao A, Chazdon RL, Colwell RK, Shen T-J (2005) A new statistical approach for assessing similarity of species composition with incidence and abundance data. Ecology Letters 8: 148-159. https://doi.org/10.1111/j.1461-0248.2004.00707.x

Chao A, Gotelli NJ, Hsieh TC, Sander EL, Ma KH, Colwell RK, Ellison AM (2014) Rarefaction and extrapolation with Hill numbers: a framework for sampling and estimation in species diversity studies. Ecological Monographs 84: 45-67. https://doi.org/10.1890/13-0133.1

Chase MW, Zmarzty S, Lledó MD, Wurdack KJ, Swensen SM, Fay MF (2002) When in Doubt, Put It in Flacourtiaceae: A Molecular Phylogenetic Analysis Based on Plastid rbcL DNA Sequences. Kew Bulletin 57: 141-181. https://doi.org/10.2307/4110825 
Chave J (2008) Spatial variation in tree species composition across tropical forests: pattern and process. In: Carson WP, Schnitzer SA (Eds), Tropical forest community ecology. WileyBlackwell, Chichester, UK, 11-30. Available from: http://wolfweb.unr.edu/ Idyer/classes/396/chave.pdf (January 16, 2017).

Chen J, Tan HTW, Wong KM (2015) A revision of Timonius (Rubiaceae) in Kinabalu Park, Borneo, with notes on typification and species distinction. Plant Ecology and Evolution 148: 420430. https://doi.org/10.5091/plecevo.2015.1073

Chen Z-D, Yang T, Lin L, Lu L-M, Li H-L, Sun M, Liu B, Chen M, Niu Y-T, Ye J-F, Cao Z-Y, Liu H-M, Wang X-M, Wang W, Zhang J-B, Meng Z, Cao W, Li J-H, Wu S-D, Zhao H-L, Liu Z-J, Du Z-Y, Wang Q-F, Guo J, Tan X-X, Su J-X, Zhang L-J, Yang L-L, Liao Y-Y, Li M-H, Zhang G-Q, Chung S-W, Zhang J, Xiang K-L, Li R-Q, Soltis DE, Soltis PS, Zhou S-L, Ran J-H, Wang X-Q, Jin X-H, Chen Y-S, Gao T-G, Li J-H, Zhang S-Z, Lu A-M, China Phylogeny Consortium (2016) Tree of life for the genera of Chinese vascular plants. Journal of Systematics and Evolution 54: 277-306. https://doi.org/10.1111/jse.12219

Chin S-W, Shaw J, Haberle R, Wen J, Potter D (2014) Diversification of almonds, peaches, plums and cherries - Molecular systematics and biogeographic history of Prunus (Rosaceae). Molecular Phylogenetics and Evolution 76: 34-48. https://doi.org/10.1016/j.ympev.2014.02.024

Christenhusz MJM, Reveal J, Farjon A, Gardner MF, Mill RR, Chase MW (2011) A new classification and linear sequence of extant gymnosperms. Phytotaxa 19: 55-70. https://doi.org/10.11646/phytotaxa.19.1.3

Cicuzza D, Kessler M, Pitopang R, Tjitrosoedirdjo SS, Gradstein SR (2010) Terrestrial herb communities of tropical submontane and tropical montane forests in Central Sulawesi, Indonesia. In: Tscharntke T, Leuschner C, Veldkamp E, Faust H, Guhardja E, Bidin A (Eds), Tropical Rainforests and Agroforests under Global Change. Environmental Science and Engineering. Springer Berlin Heidelberg, 377-390. Available from: http://dx.doi.org/10.1007/978-3-642-00493-3_17.

Clayton JW, Soltis PS, Soltis DE (2009) Recent Long-Distance Dispersal Overshadows Ancient Biogeographical Patterns in a Pantropical Angiosperm Family (Simaroubaceae, Sapindales). Systematic Biology 58: 395-410. https://doi.org/10.1093/sysbio/syp041

Cody S, Richardson JE, Rull V, Ellis C, Pennington RT (2010) The Great American Biotic Interchange revisited. Ecography 33: 326-332. https://doi.org/10.1111/j.16000587.2010.06327.x

Conn BJ (1980) A taxonomic revision of Geniostoma subg. Geniostoma (Loganiaceae). Blumea Biodiversity, Evolution and Biogeography of Plants 26: 245-364.

Coode MJE (1978) A Conspectus of Elaeocarpaceae in Papuasia. Brunonia 1: 131-302. https://doi.org/10.1071/BRU9780131

Coode MJE (1983) A Conspectus of Sloanea (Elaeocarpaceae) in the Old World. Kew Bulletin 38: 347-27. https://doi.org/10.2307/4107835

Coode MJE (1984) Elaeocarpus in Australia and New Zealand. Kew Bulletin 39: 509-20. https://doi.org/10.2307/4108594

Coode MJE (1995) Elaeocarpus in the Flora Malesiana area: E. kraengensis and ten new species from Sulawesi. Kew Bulletin 50: 267-294. https://doi.org/10.2307/4110631

Coode MJE (1996a) Elaeocarpus for Flora Malesiana: notes, new taxa and combinations in sect. Elaeocarpus: 2. Kew Bulletin 51: 83-101. https://doi.org/10.2307/4118746

Coode MJE (1996b) Elaeocarpus for Flora Malesiana: notes, new taxa and combinations in the Acronodia group. Kew Bulletin 51: 267-300. https://doi.org/10.2307/4119324

Coode MJE (1996c) Elaeocarpus for Flora Malesiana: the "Polystachyus group." Kew Bulletin 51: 649-666. https://doi.org/10.2307/4119720

Coode MJE (1998) Elaeocarpus for Flora Malesiana: Notes, New Taxa, Names and Combinations for Borneo. Kew Bulletin 53: 83-128. https://doi.org/10.2307/4110455 
Coode MJE (2001a) Elaeocarpus for Flora Malesiana: the Coilopetalum group in Sulawesi \& Maluku. Kew Bulletin 56: 837-874. https://doi.org/10.2307/4119298

Coode MJE (2001b) Elaeocarpus for Flora Malesiana: the Fissipetalum group in central Malesia. Kew Bulletin 56: 461-463. https://doi.org/10.2307/4110966

Coode MJE (2001c) Elaeocarpus for Flora Malesiana: the Verticellatae subgroup of the Monocera group and a new Philippine species. Kew Bulletin 56: 885-901. https://doi.org/10.2307/4119300

Coode MJE (2004) Elaeocarpaceae. In: Kubitzki K (Ed), Flowering Plants - Dicotyledons: Celastrales, Oxalidales, Rosales, Cornales, Ericales. The Families and Genera of Vascular Plants, vol. 6. Springer, Berlin, Heidelberg, 135-144. Available from: http://link.springer.com/chapter/10.1007/978-3-662-07257-8_18.

Coode MJE (2007) Elaeocarpaceae for Flora Malesiana: new information on Elaeocarpus from Borneo and Sulawesi. Kew Bulletin 62: 329-331.

Coode MJE (2010) Elaeocarpus for Flora Malesiana: new taxa and understanding in the Ganitrus group. Kew Bulletin 65: 355-399. https://doi.org/10.1007/s12225-010-9223-2

Coode MJE (2014) Elaeocarpus for Flora Malesiana: the Monocera group in western Malesia. Kew Bulletin 69: 1-16. https://doi.org/10.1007/s12225-014-9487-z

Coode MJE, Weibel R (1994) Elaeocarpus for Flora Malesiana: notes, new taxa and combinations in sect. Elaeocarpus: 1. Kew Bulletin 49: 235-259. https://doi.org/10.2307/4110262

Corlett RT (2007) What's so special about Asian tropical forests? Current Science 93: 1551-1557.

Corlett RT, Primack RB (2011) Tropical Rain Forests: An Ecological and Biogeographical Comparison. 2nd edition. John Wiley \& Sons, Ltd, Chichester, UK. Available from: http://doi.wiley.com/10.1002/9781444392296.

Couvreur TLP, Maas PJM, Meinke S, Johnson DM, Keßler PJA (2012) Keys to the genera of Annonaceae. Botanical Journal of the Linnean Society 169: 74-83. https://doi.org/10.1111/j.1095-8339.2012.01230.x

Cox B (2001) The biogeographic regions reconsidered. Journal of Biogeography 28: 511-523. https://doi.org/10.1046/j.1365-2699.2001.00566.x

Craven LA, Biffin E (2010) An infrageneric classification of Syzygium (Myrtaceae). Blumea Biodiversity, Evolution and Biogeography of Plants 55: 94-99. https://doi.org/10.3767/000651910X499303

Craven LA, Biffin E, Ashton PS (2006) Acmena, Acmenosperma, Cleistocalyx, Piliocalyx and Waterhousea Formally Transferred to Syzygium (Myrtaceae). Blumea - Biodiversity, Evolution and Biogeography of Plants 51: 131-142. https://doi.org/10.3767/000651906X622382

Craven LA, Sunarti S, Mudiana D, Yulistyarini T, Wardani M (2003) Identification Key to the Indigeneous Indonesian Genera of Myrtaceae. Floribunda 2: 89-94.

Crayn DM, Rossetto M, Maynard DJ (2006) Molecular phylogeny and dating reveals an OligoMiocene radiation of dry-adapted shrubs (former Tremandraceae) from rainforest tree progenitors (Elaeocarpaceae) in Australia. American Journal of Botany 93: 1328-1342. https://doi.org/10.3732/ajb.93.9.1328

Crayn DM, Costion C, Harrington MG (2015) The Sahul-Sunda floristic exchange: dated molecular phylogenies document Cenozoic intercontinental dispersal dynamics. Journal of Biogeography 42: 11-24. https://doi.org/10.1111/jbi.12405

Crisp MD, Cook LG (2012) Phylogenetic niche conservatism: what are the underlying evolutionary and ecological causes? New Phytologist 196: 681-694. https://doi.org/10.1111/j.1469-8137.2012.04298.x

Crisp MD, Arroyo MTK, Cook LG, Gandolfo MA, Jordan GJ, McGlone MS, Weston PH, Westoby M, Wilf P, Linder HP (2009) Phylogenetic biome conservatism on a global scale. Nature 458: 754-756. https://doi.org/10.1038/nature07764

Cruaud A, Rønsted N, Chantarasuwan B, Chou LS, Clement WL, Couloux A, Cousins B, Genson G, Harrison RD, Hanson PE, Hossaert-Mckey M, Jabbour-Zahab R, Jousselin E, Kerdelhué 
C, Kjellberg F, Lopez-Vaamonde C, Peebles J, Peng Y-Q, Pereira RAS, Schramm T, Ubaidillah R, Noort S van, Weiblen GD, Yang D-R, Yodpinyanee A, Libeskind-Hadas R, Cook JM, Rasplus J-Y, Savolainen V (2012) An Extreme Case of Plant-Insect Codiversification: Figs and Fig-Pollinating Wasps. Systematic Biology: sys068. https://doi.org/10.1093/sysbio/sys068

Culmsee H (2008) Dysoxylum quadrangulatum, and notes on Meliaceae in Sulawesi. Blumea Biodiversity, Evolution and Biogeography of Plants 53: 602-606. https://doi.org/10.3767/000651908X607530

Culmsee $\mathrm{H}$, Pitopang R (2009) Tree diversity in sub-montane and lower montane primary rain forests in Central Sulawesi. Blumea - Biodiversity, Evolution and Biogeography of Plants 54: 119-123. https://doi.org/10.3767/000651909X475473

Culmsee H, Leuschner C (2013) Consistent patterns of elevational change in tree taxonomic and phylogenetic diversity across Malesian mountain forests. Journal of Biogeography 40: 1997-2010. https://doi.org/10.1111/jbi.12138

Culmsee H, Pitopang R (2017) Erratum: Tree diversity in sub-montane and lower montane primary rain forests in Central Sulawesi. Blumea - Biodiversity, Evolution and Biogeography of Plants 62: 6. https://doi.org/10.3767/000651917X694813

Culmsee H, Leuschner C, Moser G, Pitopang R (2010a) Forest aboveground biomass along an elevational transect in Sulawesi, Indonesia, and the role of Fagaceae in tropical montane rain forests. Journal of Biogeography 37: 960-974. https://doi.org/10.1111/j.13652699.2009.02269.x

Culmsee H, Leuschner Ch, Moser G, Pitopang R (2010b) Forest aboveground biomass along an elevational transect in Sulawesi, Indonesia, and the role of Fagaceae in tropical montane rain forests. Journal of Biogeography 37: 960-974. https://doi.org/10.1111/j.13652699.2009.02269.x

Culmsee H, Pitopang R, Mangopo H, Sabir S (2011) Tree diversity and phytogeographical patterns of tropical high mountain rain forests in Central Sulawesi, Indonesia. Biodiversity and Conservation 20: 1103-1123. https://doi.org/10.1007/s10531-011-0019-y

Dallwitz MJ, Paine TA, Zurcher EJ (2010) User's guide to the DELTA system: a general system for processing taxonomic descriptions. 4th edition. Available from: http://deltaintkey.com/www/uguide.htm.

Daly DC, Harley MM, Martínez-Habibe MC, Weeks A (2010) Burseraceae. In: Kubitzki K (Ed), Flowering Plants - Eudicots: Sapindales, Cucurbitales, Myrtaceae. The Families and Genera of Vascular Plants, vol. 10. Springer, Berlin, Heidelberg, 76-104. https://doi.org/10.1007/978-3-642-14397-7_7

Darwin SP (2010) A Taxonomic Revision of Timonius Subgen. Pseudobobea (Valeton) S. P. Darwin (Rubiaceae). Candollea 65: 217-240. https://doi.org/10.15553/c2010v652a5

Davies TJ, Barraclough TG, Chase MW, Soltis PS, Soltis DE, Savolainen V (2004) Darwin's abominable mystery: Insights from a supertree of the angiosperms. Proceedings of the National Academy of Sciences 101: 1904-1909. https://doi.org/10.1073/pnas.0308127100

Davis AP, Bridson DM (2004) A Taxonomic Revision of the Genus Amaracarpus (Rubiaceae, Psychotrieae). Blumea - Biodiversity, Evolution and Biogeography of Plants 49: 25-68. https://doi.org/10.3767/000651904X486188

Davis CC, Webb CO, Wurdack KJ, Jaramillo CA, Donoghue MJ (2005) Explosive Radiation of Malpighiales Supports a Mid-Cretaceous Origin of Modern Tropical Rain Forests. The American Naturalist 165: E36-E65. https://doi.org/10.1086/428296

De Cáceres M, Jansen F (2015) indicspecies: Relationship Between Species and Groups of Sites. R package. . en. Available from: https://sites.google.com/site/miqueldecaceres/software.

De Cáceres M, Legendre P, Moretti M (2010) Improving indicator species analysis by combining groups of sites. Oikos 119: 1674-1684. https://doi.org/10.1111/j.1600-0706.2010.18334.x

Dechert G (2003) Nutrient dynamics and their control in land use systems of forest margins in Central Sulawesi, Indonesia. PhD thesis. Georg-August-Universität Göttingen Available 
from:

https://ediss.uni-goettingen.de/handle/11858/00-1735-0000-0006-AE63-4

(February 25, 2015).

Dexter KG, Pennington TD, Cunningham CW (2010) Using DNA to assess errors in tropical tree identifications: How often are ecologists wrong and when does it matter? Ecological Monographs 80: 267-286. https://doi.org/10.1890/09-0267.1

Díaz S, Pascual U, Stenseke M, Martín-López B, Watson RT, Molnár Z, Hill R, Chan KMA, Baste IA, Brauman KA, Polasky S, Church A, Lonsdale $M$, Larigauderie A, Leadley PW, van Oudenhoven APE, van der Plaat F, Schröter $M$, Lavorel $S$, Aumeeruddy-Thomas $Y$, Bukvareva E, Davies K, Demissew S, Erpul G, Failler P, Guerra CA, Hewitt CL, Keune H, Lindley S, Shirayama Y (2018) Assessing nature's contributions to people. Science 359: 270-272. https://doi.org/10.1126/science.aap8826

Diels L (1922) Die Myrtaceen von Papuasien. Lauterbach C (Ed). Botanische Jahrbücher für Systematik, Pflanzengeschichte und Pflanzengeographie 57: 356-426.

Diels L (1924) Myrtaceae. In: de Beaufort LF, Pulle AA, Rutten L (Eds), Nova Guinea. Résultats des expéditions scientifiques à la Nouvelle Guineée. E.J. Brill, Leiden, The Netherlands, 85-96.

Djarwaningsih T (2004) Revision of Pimelodendron (Euphorbiaceae) in Malesia. Blumea Biodiversity, Evolution and Biogeography of Plants 49: 407-423. https://doi.org/10.3767/000651904X484342

Donoghue MJ, Smith SA (2004) Patterns in the assembly of temperate forests around the Northern Hemisphere. Philosophical Transactions of the Royal Society B: Biological Sciences 359: 1633-1644. https://doi.org/10.1098/rstb.2004.1538

Donoghue MJ, Edwards EJ (2014) Biome Shifts and Niche Evolution in Plants. Annual Review of Ecology, Evolution, and Systematics 45: 547-572. https://doi.org/10.1146/annurevecolsys-120213-091905

Doorenbos J (2000) Begonia siccacaudata (Begoniaceae). A new species from Sulawesi. Blumea - Biodiversity, Evolution and Biogeography of Plants 45: 399-402.

Dossa GGO, Paudel E, Fujinuma J, Yu H, Chutipong W, Zhang Y, Paz S, Harrison RD (2013) Factors Determining Forest Diversity and Biomass on a Tropical Volcano, Mt. Rinjani, Lombok, Indonesia. PLoS ONE 8: e67720. https://doi.org/10.1371/journal.pone.0067720

Douglas N, Spellenberg R (2010) A new tribal classification of Nyctaginaceae. Taxon 59: 905-910.

Doust AN, Drinnan AN (2004) Floral development and molecular phylogeny support the generic status of Tasmannia (Winteraceae). American Journal of Botany 91: 321-331. https://doi.org/10.3732/ajb.91.3.321

Doyle JA, Manchester SR, Sauquet H (2008) A Seed Related to Myristicaceae in the Early Eocene of Southern England. Systematic Botany 33: 636-646. https://doi.org/10.1600/036364408786500217

Doyle JA, Sauquet H, Scharaschkin T, Le Thomas A (2004) Phylogeny, Molecular and Fossil Dating, and Biogeographic History of Annonaceae and Myristicaceae (Magnoliales). International Journal of Plant Sciences 165: S55-S67. https://doi.org/10.1086/421068

Dransfield J (1988) Pigafetta. Principes 42: 34-40.

Dransfield J, Uhl NW, Asmussen CB, Baker WJ, Harley M, Lewis C (2008) Genera Palmarum: The evolution and classification of palms. Royal Botanic Gardens, Kew, Richmond, U.K., 732 pp.

Dressler S, Bayer C (2004) Actinidiaceae. In: Kubitzki K (Ed), Flowering Plants - Dicotyledons: Celastrales, Oxalidales, Rosales, Cornales, Ericales. The Families and Genera of Vascular Plants, vol. 6. Springer, Berlin, Heidelberg, 14-19. https://doi.org/10.1007/978-3-66207257-8_3

Duangjai S, Samuel R, Munzinger J, Forest F, Wallnöfer B, Barfuss MHJ, Fischer G, Chase MW (2009) A multi-locus plastid phylogenetic analysis of the pantropical genus Diospyros (Ebenaceae), with an emphasis on the radiation and biogeographic origins of the New Caledonian endemic species. Molecular Phylogenetics and Evolution 52: 602-620. https://doi.org/10.1016/j.ympev.2009.04.021 
Dufrêne M, Legendre P (1997) Species assemblages and indicator species: the need for a flexible asymmetrical approach. Ecological Monographs 67: 345-366. https://doi.org/10.1890/0012-9615(1997)067[0345:SAAIST]2.0.CO;2

Dutta S, Tripathi SM, Mallick M, Mathews RP, Greenwood PF, Rao MR, Summons RE (2011) Eocene out-of-India dispersal of Asian dipterocarps. Review of Palaeobotany and Palynology 166: 63-68. https://doi.org/10.1016/j.revpalbo.2011.05.002

Elmer ADE (1914) Myrtaceae from Mount Urdaneta. Leaflets of Philippine Botany 7: 2343-2358. Endress PK (1993a) Hamamelidaceae. In: Kubitzki K, Rohwer JG, Bittrich V (Eds), Flowering Plants - Dicotyledons: Magnoliid, Hamamelid and Caryophyllid Families. The Families and Genera of Vascular Plants, vol. 2. Springer, Berlin, Heidelberg, 322-331. https://doi.org/10.1007/978-3-662-02899-5_37

Endress PK (1993b) Himantandraceae. In: Kubitzki K, Rohwer JG, Bittrich V (Eds), Flowering Plants - Dicotyledons: Magnoliid, Hamamelid and Caryophyllid Families. The Families and Genera of Vascular Plants, vol. 2. Springer, Berlin, Heidelberg, 338-341. https://doi.org/10.1007/978-3-662-02899-5_40

Enquist BJ, Condit R, Peet RK, Schildhauer M, Thiers BM (2016) Cyberinfrastructure for an integrated botanical information network to investigate the ecological impacts of global climate change on plant biodiversity. PeerJ Inc. https://doi.org/10.7287/peerj.preprints.2615v2

Erdtman G (1960) The acetolysis method. A revised description. Svensk Botanisk Tidskrift 54: 561-564.

Escapa IH, Catalano SA (2013) Phylogenetic Analysis of Araucariaceae: Integrating Molecules, Morphology, and Fossils. International Journal of Plant Sciences 174: 1153-1170. https://doi.org/10.1086/672369

Esser H-J (1997) A revision of Omalanthus (Euphorbiaceae) in Malesia. Blumea - Biodiversity, Evolution and Biogeography of Plants 42: 421-466.

Esser H-J (1999) A partial revision of the Hippomaneae (Euphorbiaceae) in Malesia. Blumea Biodiversity, Evolution and Biogeography of Plants 44: 149-215.

Eurlings MCM, Gravendeel B (2005) TrnL-trnF sequence data imply paraphyly of Aquilaria and Gyrinops (Thymelaeaceae) and provide new perspectives for agarwood identification. Plant Systematics and Evolution 254: 1-12. https://doi.org/10.1007/s00606-005-0312-x

Eyma PJ (1940) Bergtochten en Zuid- en Centraal Celebes. Nederlandsch-Indische Vereeniging voor Bergsport - Mededeelingen 17: 14-19.

Fadrique B, Báez S, Duque Á, Malizia A, Blundo C, Carilla J, Osinaga-Acosta O, Malizia L, Silman M, Farfán-Ríos W, Malhi Y, Young KR, C FC, Homeier J, Peralvo M, Pinto E, Jadan O, Aguirre $\mathrm{N}$, Aguirre Z, Feeley KJ (2018) Widespread but heterogeneous responses of Andean forests to climate change. Nature 564: 207-212. https://doi.org/10.1038/s41586-018-0715-9

Faegri K, Kaland PE, Krzywinski K (1989) Textbook of Pollen Analysis. 4th ed. Wiley, Chichester (UK), $328 \mathrm{pp}$.

Fan Y, Li H, Miguez-Macho G (2013) Global Patterns of Groundwater Table Depth. Science 339: 940-943. https://doi.org/10.1126/science.1229881

FAO (2006) Guidelines for soil description. 4th ed. FAO, Rome, $97 \mathrm{pp}$. Available from: http://www.fao.org/publications/card/en/c/903943c7-f56a-521a-8d32-459e7e0cdae9 (March 17, 2015).

Farjon A (2010) 1 \& 2 A handbook of the world's conifers. Brill, Leiden - Boston, 1115 pp.

Faurby S, Svenning J-C (2016) The asymmetry in the Great American Biotic Interchange in mammals is consistent with differential susceptibility to mammalian predation. Global Ecology and Biogeography 25: 1443-1453. https://doi.org/10.1111/geb.12504

Federman S, Dornburg A, Downie A, Richard AF, Daly DC, Donoghue MJ (2015) The biogeographic origin of a radiation of trees in Madagascar: implications for the assembly of a tropical forest biome. BMC Evolutionary Biology 15: 216. https://doi.org/10.1186/s12862-015-0483-1 
Feng C-M, Manchester SR, Xiang Q-Y (Jenny) (2009) Phylogeny and biogeography of Alangiaceae (Cornales) inferred from DNA sequences, morphology, and fossils. Molecular Phylogenetics and Evolution 51: 201-214. https://doi.org/10.1016/j.ympev.2009.01.017

Feng X, Tang B, Kodrul TM, Jin J (2013) Winged fruits and associated leaves of Shorea (Dipterocarpaceae) from the Late Eocene of South China and their phytogeographic and paleoclimatic implications. American Journal of Botany 100: 574-581. https://doi.org/10.3732/ajb.1200397

Ficetola GF, Mazel F, Thuiller W (2017) Global determinants of zoogeographical boundaries. Nature Ecology \& Evolution 1: 0089. https://doi.org/10.1038/s41559-017-0089

Figlar RB (2000) Proleptic branch initiation in Michelia and Magnolia sub-genus Yulania provides basis for combinations in subfamily Magnolioideae. In: Liu YH, Fan HM, Chen ZY, Wy QG, Zeng WG (Eds), Proceedings of the International Symposium on the family Magnoliaceae, May 18-22, 1998, Guangzhou, China. Science Press, Beijing, 14-25.

Figlar RB, Nooteboom HP (2004) Notes on Magnoliaceae IV. Blumea - Biodiversity, Evolution and Biogeography of Plants 49: 87-100. https://doi.org/10.3767/000651904X486214

Fior S, Ola Karis P, Anderberg AA (2003) Phylogeny, Taxonomy, and Systematic Position of Clethra (Clethraceae, Ericales) with Notes on Biogeography: Evidence from Plastid and Nuclear DNA Sequences. International Journal of Plant Sciences 164: 997-1006. https://doi.org/10.1086/378655

Forest F, Chase MW, Persson C, Crane PR, Hawkins JA (2007) The Role of Biotic and Abiotic Factors in Evolution of Ant Dispersal in the Milkwort Family (Polygalaceae). Evolution 61: 1675-1694. https://doi.org/10.1111/j.1558-5646.2007.00138.x

Fortune Hopkins HC, Hoogland RD (2002) Cunoniaceae. Flora Malesiana, Series I 16: 53-165.

Fossilworks (2016) http://fossilworks.org. Available from: http://fossilworks.org (January 10, 2017).

Foster CSP, Ho SYW, Conn BJ, Henwood MJ (2014) Molecular systematics and biogeography of Logania R.Br. (Loganiaceae). Molecular Phylogenetics and Evolution 78: 324-333. https://doi.org/10.1016/j.ympev.2014.06.001

Fougère-Danezan M, Herendeen PS, Maumont S, Bruneau A (2010) Morphological evolution in the variable resin-producing Detarieae (Fabaceae): do morphological characters retain a phylogenetic signal? Annals of Botany 105: 311-325. https://doi.org/10.1093/aob/mcp280

Frasier CL (2008) Evolution and systematics of the angiosperm order Gentianales with an indepth focus on Loganiaceae and its species-rich and toxic genus Strychnos. PhD thesis. The State University of New Jersey Available from: https://rucore.libraries.rutgers.edu/rutgers-lib/24550/PDF/1/.

Fritsch PW, Morton CM, Chen T, Meldrum C (2001) Phylogeny and Biogeography of the Styracaceae. International Journal of Plant Sciences 162: S95-S116. https://doi.org/10.1086/323418

Fritsch PW, Manchester SR, Stone RD, Cruz BC, Almeda F (2015) Northern Hemisphere origins of the amphi-Pacific tropical plant family Symplocaceae. Journal of Biogeography 42: 891901. https://doi.org/10.1111/jbi.12442

Fritsch PW, Lu L, Bush CM, Cruz BC, Kron KA, Li D-Z (2011) Phylogenetic Analysis of the Wintergreen Group (Ericaceae) Based on Six Genic Regions. Systematic Botany 36: 9901003. https://doi.org/10.1600/036364411X604994

Frodin DG (2001) Floras in retrospect and for the future. Plant talk: news and views on plant conservation worldwide 24: 36-39.

Gaertner J (1788) De Fructibus et Seminibus Plantarum. [1] Accedunt Seminum Centuriae Quinque Priores. Cum Tabulis Aeneis LXXIX. Tübingen, CLXXXII +1-385, 79 pl. pp. Available from: http://reader.digitalesammlungen.de/en/fs1/object/display/bsb10229639_00007.html.

Galey ML, van der Ent A, Iqbal MCM, Rajakaruna N (2017) Ultramafic geoecology of South and Southeast Asia. Botanical Studies 58: 18. https://doi.org/10.1186/s40529-017-0167-9 
Gallaher T, Callmander MW, Buerki S, Keeley SC (2015) A long distance dispersal hypothesis for the Pandanaceae and the origins of the Pandanus tectorius complex. Molecular Phylogenetics and Evolution 83: 20-32. https://doi.org/10.1016/j.ympev.2014.11.002

GBIF (2015) Global Biodiversity Information Facility - Free and Open Access to Biodiversity Data. Global Biodiversity Information Facility - Free and Open Access to Biodiversity Data. Available from: http://www.gbif.org/ (May 5, 2015).

Geological Research and Development Centre (1993) 1:1M map containing the combined bedrock and superficial geology and age information covering the entire Indonesian Archipelago. Available from: http://portal.onegeology.org/OnegeologyGlobal/.

Giam X, Scheffers BR, Sodhi NS, Wilcove DS, Ceballos G, Ehrlich PR (2012) Reservoirs of richness: least disturbed tropical forests are centres of undescribed species diversity. Proceedings of the Royal Society of London B: Biological Sciences 279: 67-76. https://doi.org/10.1098/rspb.2011.0433

Girmansyah D, Wiriadinata H, Thomas DC, Hoover WS (2009) Two new species and one new subspecies of Begonia (Begoniaceae) from Southeast Sulawesi, Sulawesi, Indonesia. Reinwardtia 13: 69-74. https://doi.org/10.14203/reinwardtia.v13i1.4

Gotelli NJ (2004) A taxonomic wish-list for community ecology. Philosophical Transactions of the Royal Society B: Biological Sciences 359: 585-597. https://doi.org/10.1098/rstb.2003.1443

Gottschling M, Hilger HH (2004) Characterisation of a Novel Fruit Type Found in Ehretia (Ehretiaceae, Boraginales). Blumea - Biodiversity, Evolution and Biogeography of Plants 49: 145-153. https://doi.org/10.3767/000651904X486250

Gottschling M, Weigend M, Hilger HH (2016) Ehretiaceae. In: Kadereit JW, Bittrich V (Eds), Flowering Plants - Eudicots: Aquifoliales, Boraginales, Bruniales, Dipsacales, Escalloniales, Garryales, Paracryphiales, Solanales (except Convolvulaceae), Icacinaceae, Metteniusaceae, Vahliaceae. The Families and Genera of Vascular Plants, vol. 14. Springer, Cham, 165-178. https://doi.org/10.1007/978-3-319-28534-4_12

Graham A (2006) Paleobotanical evidence and molecular data in reconstructing the historical phytogeography of Rhizophoraceae. Annals of the Missouri Botanical Garden 93: 325334. https://doi.org/10.3417/0026-6493(2006)93[325:PEAMDI]2.0.CO;2

Graham A (2018) Land bridges: ancient environments, plant migrations, and New World connections. The University of Chicago Press, Chicago, U.S.A., 288 pp.

Graham SA (2013) Fossil Records in the Lythraceae. The Botanical Review 79: 48-145. https://doi.org/10.1007/s12229-012-9116-1

Green PS (2002) A Revision of Olea L. (Oleaceae). Kew Bulletin 57: 91-140. https://doi.org/10.2307/4110824

Groppo M, Favaretto BSG, Silva Cl da, Jardim JG, Fiaschi P (2013) A New Species of Kuhlmanniodendron (Lindackerieae, Achariaceae) from Eastern Brazil and the Systematic Position of the Genus in Achariaceae. Systematic Botany 38: 162-171. https://doi.org/10.1600/036364413X662114

Grudinski M, Wanntorp L, Pannell CM, Muellner-Riehl AN (2014) West to east dispersal in a widespread animal-dispersed woody angiosperm genus (Aglaia, Meliaceae) across the Indo-Australian Archipelago. Journal of Biogeography 41: 1149-1159. https://doi.org/10.1111/jbi.12280

Grytnes JA, Beaman JH (2006) Elevational species richness patterns for vascular plants on Mount Kinabalu, Borneo. Journal of Biogeography 33: 1838-1849. https://doi.org/10.1111/j.1365-2699.2006.01554.x

Gunawan D (2006) Atmospheric variability in Sulawesi, Indonesia: regional atmospheric model results and observations. PhD thesis. Georg-August-Universität Göttingen Available from: http://ediss.uni-goettingen.de/bitstream/handle/11858/00-1735-0000-0006-B0F3-

4/gunawan.pdf?sequence $=1$. 
Guo W, Yu Y, Shen R, Liao W, Chin S, Potter D (2011) A phylogeny of Photinia sensu lato (Rosaceae) and related genera based on nrITS and cpDNA analysis. Plant Systematics and Evolution 291: 91-102. https://doi.org/10.1007/s00606-010-0368-0

Haegens RMAP (2000) Taxonomy, Phylogeny, and Biogeography of Baccaurea, Distichirhops, and Nothobaccaurea (Euphorbiaceae). Blumea, Supplement 12: 1-218.

Hall R (2012) Sundaland and Wallacea: geology, plate tectonics and palaeogeography. In: Gower DJ, Johnson KG, Richardson JE, Rosen BR, Rüber L, Williams ST (Eds), Biotic Evolution and Environmental Change in Southeast Asia. The Systematics Association Special Volume 82. Cambridge University Press, Cambridge, UK, 32-78.

Hall R (2013) The palaeogeography of Sundaland and Wallacea since the Late Jurassic. Journal of Limnology 72: 1-17. https://doi.org/10.4081/jlimnol.2013.s2.e1

Hall R (2017) Southeast Asia: New Views of the Geology of the Malay Archipelago. Annual Review of Earth and Planetary Sciences 45: 331-358. https://doi.org/10.1146/annurev-earth063016-020633

Hall R, Wilson MEJ (2000) Neogene sutures in eastern Indonesia. Journal of Asian Earth Sciences 18: 781-808. https://doi.org/10.1016/S1367-9120(00)00040-7

van der Ham RWJM (1977) A revision of Mischocarpus (Sapindaceae). Blumea - Biodiversity, Evolution and Biogeography of Plants 23: 251-288.

Hamann A, Barbon EB, Curio E, Madulid DA (1999) A botanical inventory of a submontane tropical rainforest on Negros Island, Philippines. Biodiversity and Conservation 8: 10171031. https://doi.org/10.1023/A:1008847704539

Hansen MC, Potapov PV, Moore R, Hancher M, Turubanova SA, Tyukavina A, Thau D, Stehman SV, Goetz SJ, Loveland TR, Kommareddy A, Egorov A, Chini L, Justice CO, Townshend JRG (2013) High-Resolution Global Maps of 21st-Century Forest Cover Change. Science 342: 850-853. https://doi.org/10.1126/science.1244693

Häring V, Köhler S, Gerold G (2005) Ergebnisse der Bodenkartierung Toro, Nopu (Sulawesi, Indonesien) im Rahmen des SFB552. Georg-August-Univesität Göttingen, Geographisches Institut, Göttingen, 40pp.

Harley RM, Atkins S, Budantsev AL, Cantino PD, Conn BJ, Grayer R, Harley MM, Kok R de, Krestovskaja T, Morales R, Paton AJ, Ryding O, Upson T (2004) Labiatae. In: Kadereit JW (Ed), Flowering Plants - Dicotyledons: Lamiales (except Acanthaceae including Avicenniaceae). The Families and Genera of Vascular Plants, vol. 7. Springer, Berlin, Heidelberg, 167-275. https://doi.org/10.1007/978-3-642-18617-2_11

Harrell Jr. FE (2015) Hmisc: Harrel miscellaneous. R package. . en. Available from: https://CRAN.R-project.org/package=Hmisc.

Harris AJ, Chen Y, Olsen RT, Lutz S, Wen J (2017a) On merging Acer sections Rubra and Hyptiocarpa: Molecular and morphological evidence. PhytoKeys 86: 9-42. https://doi.org/10.3897/phytokeys.86.13532

Harris AJ, Chen P-T, Xu X-W, Zhang J-Q, Yang X, Wen J (2017b) A molecular phylogeny of Staphyleaceae: Implications for generic delimitation and classical biogeographic disjunctions in the family. Journal of Systematics and Evolution 55: 124-141. https://doi.org/10.1111/jse.12236

Hartley TG (1974) A revision of the genus Acronychia (Rutaceae). Journal of the Arnold Arboretum 55: 525-567.

Hartley TG (1979) A revision of the genus Tetractomia (Rutaceae). Journal of the Arnold Arboretum 60: 127-153. https://doi.org/10.5962/bhl.part.12825

Hartley TG (1981) A Revision of the Genus Tetradium (Rutaceae). The Gardens' Bulletin, Singapore 34: 91-131.

Hartley TG (2000) On the Taxonomy and Biogeography of Euodia and Melicope (Rutaceae). Allertonia 8: 1-319.

Hartley TG, Perry LM (1973) A provisional key and enumeration of species of Syzygium (Myrtaceae) from Papuasia. Journal of the Arnold Arboretum 54: 160-227. 
Hartley TG, Craven LA (1977) A revision of the Papuasian species of Acmena (Myrtaceae). Journal of the Arnold Arboretum 58: 325-342.

Hauenschild F, Favre A, Michalak I, Muellner-Riehl AN (2018) The influence of the Gondwanan breakup on the biogeographic history of the ziziphoids (Rhamnaceae). Journal of Biogeography 45: 2669-2677. https://doi.org/10.1111/jbi.13448

Hayward J, Horton TR (2014) Phylogenetic trait conservation in the partner choice of a group of ectomycorrhizal trees. Molecular Ecology 23: 4886-4898. https://doi.org/10.1111/mec.12903

Heatubun CD, Dransfield J, Flynn T, Tjitrosoedirdjo SS, Mogea JP, Baker WJ (2012) A monograph of the betel nut palms (Areca: Arecaceae) of East Malesia. Botanical Journal of the Linnean Society 168: 147-173. https://doi.org/10.1111/j.1095-8339.2011.01199.x

Heberling JM, Jo I, Kozhevnikov A, Lee H, Fridley JD (2017) Biotic interchange in the Anthropocene: strong asymmetry in East Asian and eastern North American plant invasions. Global Ecology and Biogeography 26: 447-458. https://doi.org/10.1111/geb.12551

Heckenhauer J, Samuel R, Ashton PS, Turner B, Barfuss MHJ, Jang T-S, Temsch EM, Mccann J, Salim KA, Attanayake AMAS, Chase MW (2017) Phylogenetic analyses of plastid DNA suggest a different interpretation of morphological evolution than those used as the basis for previous classifications of Dipterocarpaceae (Malvales). Botanical Journal of the Linnean Society 185: 1-26. https://doi.org/10.1093/botlinnean/box044

Helmi N, Kartawinata K, Samsoedin I (2009) An undescribed lowland natural forest at Bodogol, the Gunung Gede Pangrango National Park, Cibodas Biosphere Reserve, West Jawa, Indonesia. Reinwardtia 13: 33-44.

Hembry DH, Kawakita A, Gurr NE, Schmaedick MA, Baldwin BG, Gillespie RG (2013) Noncongruent colonizations and diversification in a coevolving pollination mutualism on oceanic islands. Proceedings of the Royal Society of London B: Biological Sciences 280: 20130361. https://doi.org/10.1098/rspb.2013.0361

Henderson MR (1949) The genus Eugenia (Myrtaceae) in Malaya. The Gardens' Bulletin, Singapore 12: 1-293.

HengI T, Jesus JM de, Heuvelink GBM, Gonzalez MR, Kilibarda M, Blagotić A, Shangguan W, Wright MN, Geng X, Bauer-Marschallinger B, Guevara MA, Vargas R, MacMillan RA, Batjes NH, Leenaars JGB, Ribeiro E, Wheeler I, Mantel S, Kempen B (2017) SoilGrids250m: Global gridded soil information based on machine learning. PLOS ONE 12: e0169748. https://doi.org/10.1371/journal.pone.0169748

Henley D (2005) 201 Fertility, Food and Fever. Population, economy and environment in North and Central Sulawesi, 1600-1930. KITLV Press, Leiden, The Netherlands, 711 pp.

Herber BE (2003) Thymelaeaceae. In: Kubitzki K, Bayer C (Eds), Flowering Plants - Dicotyledons Malvales, Capparales and Non-betalain Caryophyllales. The Families and Genera of Vascular Plants, vol. 5. Springer, Berlin, Heidelberg, 373-396. https://doi.org/10.1007/9783-662-07255-4_28

Herbert J (2005) Systematics and biogeography of Myricaceae. PhD thesis. University of St Andrews Available from: http://hdl.handle.net/10023/2687 (February 24, 2017).

Hermann-Erlee MPM, van Royen P (1957) Revision of the Sapotaceae of the Malaysian area in a wider sense. IX. Pouteria Aublet. Blumea - Biodiversity, Evolution and Biogeography of Plants 8: 452-509.

Hermsen EJ (2013) A Review of the Fossil Record of the Genus Itea (Iteaceae, Saxifragales) with Comments on its Historical Biogeography. The Botanical Review 79: 1-47. https://doi.org/10.1007/s12229-012-9114-3

Hicks D (2006) The Racemose llex (Aquifoliaceae) of New Guinea. Kew Bulletin 61: 537-547.

Higgins MA, Ruokolainen K (2004) Rapid Tropical Forest Inventory: a Comparison of Techniques Based on Inventory Data from Western Amazonia. Conservation Biology 18: 799-811. https://doi.org/10.1111/j.1523-1739.2004.00235.x 
Hijmans RJ, Cameron SE, Parra JL, Jones PG, Jarvis A (2005) Very high resolution interpolated climate surfaces for global land areas. International Journal of Climatology 25: 1965-1978. https://doi.org/10.1002/joc.1276

Hill MO (1973) Diversity and Evenness: A Unifying Notation and Its Consequences. Ecology 54: 427-432. https://doi.org/10.2307/1934352

Hill RS (2004) Origins of the southeastern Australian vegetation. Philosophical Transactions of the Royal Society B: Biological Sciences 359: 1537-1549. https://doi.org/10.1098/rstb.2004.1526

Hilliard OM, Burtt BL (2002a) A new species of Agalmyla (Gesneriaceae) from Sulawesi. Edinburgh Journal of Botany 59: 323-324. https://doi.org/10.1017/S0960428602000148

Hilliard OM, Burtt BL (2002b) The genus Agalmyla (Gesneriaceae-Cyrtandroideae). Edinburgh Journal of Botany 59: 1-210. https://doi.org/10.1017/S096042860200001X

Holt BG, Lessard J-P, Borregaard MK, Fritz SA, Araújo MB, Dimitrov D, Fabre P-H, Graham CH, Graves GR, Jønsson KA, Nogués-Bravo D, Wang Z, Whittaker RJ, Fjeldså J, Rahbek C (2012) An Update of Wallace's Zoogeographic Regions of the World. Science: 1228282. https://doi.org/10.1126/science.1228282

Holttum RE (1963) Cyatheaceae. Flora Malesiana, Series II 1: 65-176.

Holzmeyer L, Duretto M, Crayn D, Hörandl E, Heslewood M, Jayanthan J, Appelhans MS (2015) Phylogeny of Acronychia (Rutaceae) and First Insights into Its Historical Biogeography and the Evolution of Fruit Characters. PLoS ONE 10: e0136296. https://doi.org/10.1371/journal.pone.0136296

Homeier J, Breckle S-W, Günter S, Rollenbeck RT, Leuschner C (2010) Tree Diversity, Forest Structure and Productivity along Altitudinal and Topographical Gradients in a SpeciesRich Ecuadorian Montane Rain Forest. Biotropica 42: 140-148. https://doi.org/10.1111/j.1744-7429.2009.00547.x

Hong-Wa C, Besnard G (2013) Intricate patterns of phylogenetic relationships in the olive family as inferred from multi-locus plastid and nuclear DNA sequence analyses: A close-up on Chionanthus and Noronhia (Oleaceae). Molecular Phylogenetics and Evolution 67: 367378. https://doi.org/10.1016/j.ympev.2013.02.003

Hoorn C, Mosbrugger V, Mulch A, Antonelli A (2013) Biodiversity from mountain building. Nature Geoscience 6: 154-154. https://doi.org/10.1038/ngeo1742

Hoover WS, Karegeannes C, Wiriadinata H, Hunter JM (2004) Notes on the geography of SouthEast Asian Begonia and species diversity in montane forests. Telopea 10: 749-764.

Horn JW (2007) Dilleniaceae. In: Kubitzki K (Ed), Flowering Plants - Eudicots: Berberidopsidales, Buxales, Crossosomatales, Fabales p.p., Geraniales, Gunnerales, Myrtales p.p., Proteales, Saxifragales, Vitales, Zygophyllales, Clusiaceae Alliance, Passifloraceae Alliance, Dilleniaceae, Huaceae, Picramniaceae, Sabiaceae. The Families and Genera of Vascular Plants, vol. 9. Springer, Berlin, Heidelberg, 132-154. https://doi.org/10.1007/978-3-54032219-1_17

Horn JW (2009) Phylogenetics of Dilleniaceae Using Sequence Data from Four Plastid Loci (rbcL, infA, rps4, rpl16 Intron). International Journal of Plant Sciences 170: 794-813. https://doi.org/10.1086/599239

Hortal J, de Bello F, Diniz-Filho JAF, Lewinsohn TM, Lobo JM, Ladle RJ (2015) Seven Shortfalls that Beset Large-Scale Knowledge of Biodiversity. Annual Review of Ecology, Evolution, and Systematics 46: 523-549. https://doi.org/10.1146/annurev-ecolsys-112414-054400

Hou D (1958) Rhizophoraceae. Flora Malesiana, Series I 5: 429-493.

Hou D (1960) Thymelaeaceae. Flora Malesiana, Series I 6: 1-48.

Hou D (1962) Celastraceae - I. Flora Malesiana, Series I 6: 227-291.

Hou D (1964) Celastraceae - II. Flora Malesiana, Series I 6: 389-421.

Hou D (1978) Anacardiaceae. Flora Malesiana, Series I 8: 395-548.

Hovenkamp PH, de Joncheere GJ (1988) Additions to the fern flora of Sulawesi. Blumea Biodiversity, Evolution and Biogeography of Plants 33: 395-409. 
Howard RA (1942) Studies of the Icacinaceae V. A revision of the genus Citronella D. Don. Contributions from the Gray Herbarium of Harvard University: 60-89.

Hsieh TC, Ma KH, Chao A (2014) iNEXT: iNterpolation and EXTrapolation for species diversity. R package. Available from: http://chao.stat.nthu.edu.tw/blog/software-download.

Hu CM (1999) New synonyms and combinations in Asiatic Ardisia (Myrsinaceae). Blumea Biodiversity, Evolution and Biogeography of Plants 44: 391-406.

Huang J-F, Li L, van der Werff H, Li H-W, Rohwer JG, Crayn DM, Meng H-H, van der Merwe M, Conran JG, Li J (2016) Origins and evolution of cinnamon and camphor: A phylogenetic and historical biogeographical analysis of the Cinnamomum group (Lauraceae). Molecular Phylogenetics and Evolution 96: 33-44. https://doi.org/10.1016/j.ympev.2015.12.007

Huang T-C (1972) Pollen flora of Taiwan. National Taiwan University, Botany Dept. Press, Taipei, $297 \mathrm{pp}$.

Hufford L (2004) Hydrangeaceae. In: Kubitzki K (Ed), Flowering Plants - Dicotyledons: Celastrales, Oxalidales, Rosales, Cornales, Ericales. The Families and Genera of Vascular Plants, vol. 6. Springer, Berlin, Heidelberg, 202-215. https://doi.org/10.1007/978-3-662-07257-8_22

Hughes M (2006) Four new species of Begonia (Begoniaceae) from Sulawesi. Edinburgh Journal of Botany 63: 191. https://doi.org/10.1017/S0960428606000588

Hyland BPM (1983) A Revision of Syzygium and Allied Genera (Myrtaceae) in Australia. Australian Journal of Botany Supplementary Series 13: 1-164. https://doi.org/10.1071/BT8309001

Ickert-Bond SM, Wen J (2006) Phylogeny and biogeography of Altingiaceae: Evidence from combined analysis of five non-coding chloroplast regions. Molecular Phylogenetics and Evolution 39: 512-528. https://doi.org/10.1016/j.ympev.2005.12.003

IPNI (2015) The International Plant Names Index. Published on the Internet. Available from: http://www.ipni.org/ipni/plantnamesearchpage.do (March 15, 2015).

IUCN (2012) IUCN Red List Categories and Criteria: Version 3.1. 2nd edition. IUCN, Gland, Switzerland and Cambridge, UK, iv +32 pp. Available from: http://www.iucnredlist.org/documents/redlist_cats_crit_en.pdf.

IUCN Standards and Petitions Subcommittee (2017) Guidelines for Using the IUCN Red List Categories and Criteria. Version 13. Prepared by the Standards and Petitions Subcommittee. IUCN, 108 pp. Available from: http://www.iucnredlist.org/documents/RedListGuidelines.pdf.

IUSS Working Group WRB (2014) World Reference Base for Soil Resources 2014. International soil classification system for naming soils and creating legends for soil maps. FAO, Rome, 181 pp. Available from: http://www.fao.org/3/a-i3794e.pdf.

Jackes BR (2009) Taxonomic revision of Australian Myrsinaceae: Ardisia Sw. and Tetrardisia Mez. Austrobaileya 8: 1-23.

Jacobs M (1960) Juglandaceae. Flora Malesiana, Series I 6: 143-154.

Jankalski S (2008) Subgenera and new combinations in Dracaena. Sansevieria 18: 17-21.

Janzen DH (1977) Promising Directions of Study in Tropical Animal-Plant Interactions. Annals of the Missouri Botanical Garden 64: 706-736. https://doi.org/10.2307/2395296

Jarvis A, Reuter HI, Nelson A, Guevara E (2008) Hole-filled SRTM for the globe, Version 4. Available from: http://srtm.csi.cgiar.org (November 5, 2015).

Jetz W, McPherson JM, Guralnick RP (2012) Integrating biodiversity distribution knowledge: toward a global map of life. Trends in Ecology \& Evolution 27: 151-159. https://doi.org/10.1016/j.tree.2011.09.007

Jian S, Soltis PS, Gitzendanner MA, Moore MJ, Li R, Hendry TA, Qiu Y-L, Dhingra A, Bell CD, Soltis DE, Savolainen V (2008) Resolving an Ancient, Rapid Radiation in Saxifragales. Systematic Biology 57: 38-57. https://doi.org/10.1080/10635150801888871

Joppa LN, Roberts DL, Myers N, Pimm SL (2011) Biodiversity hotspots house most undiscovered plant species. Proceedings of the National Academy of Sciences 108: 13171-13176. https://doi.org/10.1073/pnas.1109389108 
Jost L (2006) Entropy and diversity. Oikos 113: 363-375. https://doi.org/10.1111/j.2006.00301299.14714.x

JSTOR (2015) Global Plants on JSTOR. Available from: http://plants.jstor.org/ (December 15, 2015).

Julia S (2005) A synopsis of the genus Actinodaphne Nees (Lauraceae) in Sabah and Sarawak, Malaysia. Gardens' Bulletin, Singapore 57: 69-100.

Kainulainen K, Razafimandimbison SG, Bremer B (2013) Phylogenetic relationships and new tribal delimitations in subfamily Ixoroideae (Rubiaceae). Botanical Journal of the Linnean Society 173: 387-406. https://doi.org/10.1111/boj.12038

Kainulainen K, Razafimandimbison SG, Wikström N, Bremer B (2017) Island hopping, longdistance dispersal and species radiation in the Western Indian Ocean: historical biogeography of the Coffeeae alliance (Rubiaceae). Journal of Biogeography 44: 1966 1979. https://doi.org/10.1111/jbi.12981

Kalkman C (1954) Revision of the Burseraceae of the Malaysian area in a wider sense. Vla, VIIIX. Blumea - Biodiversity, Evolution and Biogeography of Plants 7: 495-552.

Kalkman C (1965) The Old World species of Prunus subg. Laurocerasus including those formerly referred to Pygeum. Blumea - Biodiversity, Evolution and Biogeography of Plants 13: 1174.

Kalkman C (1993) Rosaceae. Flora Malesiana, Series I 11: 227-351.

Karger DN, Linder HP, Kreft H, Böhner J, Kessler M, Zimmermann NE, Conrad O, Soria-Auza RW, Kawohl T (2017) Climatologies at high resolution for the earth's land surface areas. Scientific Data 4: sdata2017122. https://doi.org/10.1038/sdata.2017.122

Kartawinata K, Samsoedin I, Heriyanto M, Afriastini JJ (2004) A tree species inventory in a onehectare plot at the Batang Gadis National Park, North Sumatra, Indonesia. Reinwardtia 12: 145-157.

Kartonegoro A (2012) The Gesneriaceae of Sulawesi V: A new species of Rhynchoglossum and a new combination in Codonoboea. Edinburgh Journal of Botany 69: 357-361. https://doi.org/10.1017/S0960428612000157

Kartonegoro A, Potter D (2014) The Gesneriaceae of Sulawesi VI: The species from Mekongga Mts. with a new species of Cyrtandra described. Reinwardtia 14: 1-11.

Kartonegoro A, Bone RE, Atkins HJ (2018) Eleven new species of Cyrtandra (Gesneriaceae) from Sulawesi, Indonesia. Edinburgh Journal of Botany 75: 173-204. https://doi.org/10.1017/S0960428618000045

Kattge J, Díaz S, Lavorel S, Prentice IC, Leadley P, Bönisch G, Garnier E, Westoby M, Reich PB, Wright IJ, Cornelissen JHC, Violle C, Harrison SP, Van BODEGOM PM, Reichstein M, Enquist BJ, Soudzilovskaia NA, Ackerly DD, Anand M, Atkin O, Bahn M, Baker TR, Baldocchi D, Bekker R, Blanco CC, Blonder B, Bond WJ, Bradstock R, Bunker DE, Casanoves F, CavenderBares J, Chambers JQ, Chapin lii FS, Chave J, Coomes D, Cornwell WK, Craine JM, Dobrin BH, Duarte L, Durka W, Elser J, Esser G, Estiarte M, Fagan WF, Fang J, Fernández-Méndez $F$, Fidelis A, Finegan B, Flores O, Ford $H$, Frank D, Freschet GT, Fyllas NM, Gallagher RV, Green WA, Gutierrez AG, Hickler T, Higgins SI, Hodgson JG, Jalili A, Jansen S, Joly CA, Kerkhoff AJ, Kirkup D, Kitajima K, Kleyer M, Klotz S, Knops JMH, Kramer K, Kühn I, Kurokawa $H$, Laughlin D, Lee TD, Leishman M, Lens F, Lenz T, Lewis SL, Lloyd J, Llusià J, Louault F, Ma S, Mahecha MD, Manning P, Massad T, Medlyn BE, Messier J, Moles AT, Müller SC, Nadrowski K, Naeem S, Niinemets Ü, Nöllert S, Nüske A, Ogaya R, Oleksyn J, Onipchenko VG, Onoda Y, Ordoñez J, Overbeck G, Ozinga WA, Patiño S, Paula S, Pausas JG, Peñuelas J, Phillips OL, Pillar V, Poorter H, Poorter L, Poschlod P, Prinzing A, Proulx R, Rammig A, Reinsch S, Reu B, Sack L, Salgado-Negret B, Sardans J, Shiodera S, Shipley B, Siefert A, Sosinski E, Soussana J-F, Swaine E, Swenson N, Thompson K, Thornton P, Waldram M, Weiher E, White M, White S, Wright SJ, Yguel B, Zaehle S, Zanne AE, Wirth C (2011) TRY - a global database of plant traits. Global Change Biology 17: 2905-2935. https://doi.org/10.1111/j.1365-2486.2011.02451.x 
Keeley SC, Forsman ZH, Chan R (2007) A phylogeny of the "evil tribe" (Vernonieae: Compositae) reveals Old/New World long distance dispersal: Support from separate and combined congruent datasets (trnL-F, ndhF, ITS). Molecular Phylogenetics and Evolution 44: 89-103. https://doi.org/10.1016/j.ympev.2006.12.024

Keil P, Chase JM (2019) Global patterns and drivers of tree diversity integrated across a continuum of spatial grains. Nature Ecology \& Evolution 3: 390-399. https://doi.org/10.1038/s41559-019-0799-0

Keng H (1978a) The delimitation of the genus Magnolia (Magnoliaceae). The Gardens' Bulletin, Singapore 31: 127-131.

Keng H (1978b) The genus Phyllocladus (Phyllocladaceae). Journal of the Arnold Arboretum 59: 249-273.

Keng H (1984) Florae Malesianae Precursores - LVIII, Part Two. The Genus Gordonia (Theaceae) in Malesia. The Gardens' Bulletin, Singapore 37: 1-47.

Keng H (1990) The Genus Camellia (Theaceae) in Malesia. Florae Malesianae Precursores - LVIII, Part Three. The Gardens' Bulletin, Singapore 42: 65-69.

Keppel G, Prentis P, Biffin E, Hodgskiss P, Tuisese S, Tuiwawa MV, Lowe AJ (2011) Diversification history and hybridisation of Dacrydium (Podocarpaceae) in remote Oceania. Australian Journal of Botany 59: 262-273. https://doi.org/10.1071/BT10181

Kern DJ, van Steenis CGGJ (1951) Caprifoliaceae. Flora Malesiana, Series I 4: 175-194.

Kershaw P, Wagstaff B (2001) The Southern Conifer Family Araucariaceae: History, Status, and Value for Paleoenvironmental Reconstruction. Annual Review of Ecology and Systematics 32: 397-414. https://doi.org/10.1146/annurev.ecolsys.32.081501.114059

Kessler M (2000) Elevational gradients in species richness and endemism of selected plant groups in the central Bolivian Andes. Plant Ecology 149: 181-193. https://doi.org/10.1023/A:1026500710274

Kessler M, Keßler PJA, Gradstein SR, Bach K, Schmull M, Pitopang R (2005) Tree diversity in primary forest and different land use systems in Central Sulawesi, Indonesia. Biodiversity and Conservation 14: 547-560. https://doi.org/10.1007/s10531-004-3914-7

Keßler PJA (1993) Annonaceae. In: Kubitzki K, Rohwer JG, Bittrich V (Eds), Flowering Plants Dicotyledons: Magnoliid, Hamamelid and Caryophyllid Families. The Families and Genera of Vascular Plants, vol. 2. Springer, Berlin, Heidelberg, 93-129. https://doi.org/10.1007/978-3-662-02899-5_9

Keßler PJA (1995) Studies in the tribe Saccopetaleae (Annonaceae) - IV. Revision of the genus Alphonsea Hook. f. \& Thomson. Botanische Jahrbücher für Systematik, Pflanzengeschichte und Pflanzengeographie 118: 81-112.

Keßler PJA, Bos MM, Sierra Daza SEC, Kop A, Willemse LPM, Pitopang R, Gradstein SR (2002) Checklist of woody plants of Sulawesi, Indonesia. Blumea - Biodiversity, Evolution and Biogeography of Plants 23: 278. https://doi.org/10.1111/j.1756-1051.2003.tb00393.x

Khan MA, Spicer RA, Spicer TEV, Bera S (2017) Evidence for diversification of Calophyllum L. (Calophyllaceae) in the Neogene Siwalik forests of eastern Himalaya. Plant Systematics and Evolution 303: 371-386. https://doi.org/10.1007/s00606-016-1376-5

Kier G, Mutke J, Dinerstein E, Ricketts TH, Küper W, Kreft H, Barthlott W (2005) Global patterns of plant diversity and floristic knowledge. Journal of Biogeography 32: 1107-1116. https://doi.org/10.1111/j.1365-2699.2005.01272.x

Kier G, Kreft H, Lee TM, Jetz W, Ibisch PL, Nowicki C, Mutke J, Barthlott W (2009) A global assessment of endemism and species richness across island and mainland regions. Proceedings of the National Academy of Sciences 106: 9322-9327. https://doi.org/10.1073/pnas.0810306106

Kiew R (1978) Florae Malesianae Praecursores LVII. The Oleaceae of Malesia. I. The genus Ligustrum. Blumea - Biodiversity, Evolution and Biogeography of Plants 24: 143-149.

Kiew R (1998) Name changes for Malesian species of Chionanthus (Oleaceae). Blumea Biodiversity, Evolution and Biogeography of Plants 43: 471-477. 
Kiew R (2016) Chionanthus (Oleaceae) in Sulawesi, Indonesia, including three new species. Reinwardtia 14: 287-295. https://doi.org/10.14203/reinwardtia.v14i2.1672

Kim C, Deng T, Chase M, Zhang D-G, Nie Z-L, Sun H (2015) Generic phylogeny and character evolution in Urticeae (Urticaceae) inferred from nuclear and plastid DNA regions. Taxon 64: 65-78. https://doi.org/10.12705/641.20

Kim S, Park C-W, Kim Y-D, Suh Y (2001) Phylogenetic relationships in family Magnoliaceae inferred from ndhF sequences. American Journal of Botany 88: 717-728. https://doi.org/10.2307/2657073

Kim S, Nooteboom HP, Park C-W, Suh Y (2002) Taxonomic revision of Magnolia section Maingola (Magnoliaceae). Blumea - Biodiversity, Evolution and Biogeography of Plants 47: 319-339.

Kirleis W, Pillar VD, Behling H (2011) Human-environment interactions in mountain rainforests: archaeobotanical evidence from central Sulawesi, Indonesia. Vegetation History and Archaeobotany 20: 165-179. https://doi.org/10.1007/s00334-010-0272-0

Kitayama K (1992) An altitudinal transect study of the vegetation on Mount Kinabalu, Borneo. Vegetatio 102: 149-171. https://doi.org/10.1007/BF00044731

Kitayama K (1995) Biophysical Conditions of the Montane Cloud Forests of Mount Kinabalu, Sabah, Malaysia. In: Hamilton LS, Juvik JO, Scatena FN (Eds), Tropical Montane Cloud Forests. Ecological Studies. Springer US, New York, 183-197. https://doi.org/10.1007/9781-4612-2500-3_12

Kitayama K, Aiba S-I (2002) Ecosystem structure and productivity of tropical rain forests along altitudinal gradients with contrasting soil phosphorus pools on Mount Kinabalu, Borneo. Journal of Ecology 90: 37-51. https://doi.org/10.1046/j.0022-0477.2001.00634.x

Kjellberg G, Christensen C (1933) Pteridophyta von Celebes gesammelt von G. Kjellberg 1929. Botanische Jahrbücher für Systematik, Pflanzengeschichte und Pflanzengeographie 66: 39-70.

Kleijn D, van Donkelaar R (2001) Notes on the taxonomy and ecology of the genus Hoya (Asclepiadaceae) in Central Sulawesi. Blumea - Biodiversity, Evolution and Biogeography of Plants 46: 457-483.

van Kleunen M, Dawson W, Essl F, Pergl J, Winter M, Weber E, Kreft H, Weigelt P, Kartesz J, Nishino M, Antonova LA, Barcelona JF, Cabezas FJ, Cárdenas D, Cárdenas-Toro J, Castaño N, Chacón E, Chatelain C, Ebel AL, Figueiredo E, Fuentes N, Groom QJ, Henderson L, Inderjit, Kupriyanov A, Masciadri S, Meerman J, Morozova O, Moser D, Nickrent DL, Patzelt A, Pelser PB, Baptiste MP, Poopath M, Schulze M, Seebens H, Shu W, Thomas J, Velayos M, Wieringa JJ, Pyšek $P$ (2015) Global exchange and accumulation of non-native plants. Nature 525: 100-103. https://doi.org/10.1038/nature14910

Knopf P, Schulz C, Little DP, Stützel T, Stevenson DW (2012) Relationships within Podocarpaceae based on DNA sequence, anatomical, morphological, and biogeographical data. Cladistics 28: 271-299. https://doi.org/10.1111/j.1096-0031.2011.00381.x

Kobuski CE (1947) Studies in the Theaceae, XV. A Review of the genus Adinandra. Journal of the Arnold Arboretum 28: 1-98.

Kobuski CE (1953) Studies in the Theaceae, XXVII. Miscellaneous new species in Theaceae. Journal of the Arnold Arboretum 34: 125-137.

Kobuski CE (1961a) Studies in the Theaceae, XXXI: A new species of Adinandra from the Celebes. Journal of the Arnold Arboretum 42: 112-113.

Kobuski CE (1961b) Studies in the Theaceae, XXXII: A review of the genus Ternstroemia in the Philippine Islands. Journal of the Arnold Arboretum 42: 263-275.

Kobuski CE (1963) Studies in the Theaceae, XXXIV: Some Asiatic taxa of Ternstroemia. Journal of the Arnold Arboretum 44: 421-433.

Kochummen KM (1995) Burseraceae. In: Soepadmo E, Wong KM (Eds), Tree Flora of Sabah and Sarawak. Forest Research Institute Malaysia (FRIM), Sabah Forestry Department, and Sarawak Forestry Department, Kuala Lumpur, 45-100. 
Koecke AV, Muellner-Riehl AN, Pennington TD, Schorr G, Schnitzler J (2013) Niche evolution through time and across continents: The story of Neotropical Cedrela (Meliaceae). American Journal of Botany 100: 1800-1810. https://doi.org/10.3732/ajb.1300059

Koenen EJM (2011) Phylogenetic and biogeographic studies in Guareeae (Meliaceae: Melioideae). MSc thesis. University of Wageningen Available from: http://edepot.wur.nl/189376.

Koenen EJM, Clarkson JJ, Pennington TD, Chatrou LW (2015) Recently evolved diversity and convergent radiations of rainforest mahoganies (Meliaceae) shed new light on the origins of rainforest hyperdiversity. New Phytologist 207: 327-339. https://doi.org/10.1111/nph.13490

Kok R de (2008) The genus Vitex (Labiatae) in the Flora Malesiana region, excluding New Guinea. Kew Bulletin 63: 17. https://doi.org/10.1007/s12225-007-9013-7

König C, Weigelt P, Schrader J, Taylor A, Kattge J, Kreft H (2019) Biodiversity data integrationThe significance of data resolution and domain. Mace GM (Ed). PLOS Biology 17: e3000183. https://doi.org/10.1371/journal.pbio.3000183

Kool R (1980) A taxonomic revision of the genus Ixonanthes (Linaceae). Blumea - Biodiversity, Evolution and Biogeography of Plants 26: 191-204.

Kool R (1988) Ixonanthaceae. Flora Malesiana, Series I 10: 621-627.

Koorders SH (1898) Verslag eener botanische dienstreis door de Minahasa, tevens eerste overzicht der flora van N. O. Celebes uit een wetenschappelijk en praktisch oogpunt. G. Kolff \& Co., Batavia [Jakarta] - 's Gravenhage [Den Haag], xxvi + 716 pp. Available from: http://catalog.hathitrust.org/Record/001494565.

Koorders-Schumacher A (1914) Systematisches Verzeichnis der zum Herbar Koorders gehörenden, in Niederländisch-Ostindien, besonders in den Jahren 1888-1903 gesammelten Phanerogamen und Pteridophyten nach den OriginalEinsammlungsnotizen und Bestimmungs-Etiketten, unter der Leitung von Dr. S. H. Koorders: III, IV und V. Abteilung. Celebes, Lombok, allgemeine Bemerkungen und Register. Selbstverlag der Verfasserin, Buitenzorg [Bogor], 1-160 pp.

Kooyman RM, Wilf P, Barreda VD, Carpenter RJ, Jordan GJ, Sniderman JMK, Allen A, Brodribb TJ, Crayn D, Feild TS, Laffan SW, Lusk CH, Rossetto M, Weston PH (2014) Paleo-Antarctic rainforest into the modern Old World tropics: The rich past and threatened future of the "southern wet forest survivors." American Journal of Botany 101: 2121-2135. https://doi.org/10.3732/ajb.1400340

Koponen P, Nygren P, Sabatier D, Rousteau A, Saur E (2004) Tree species diversity and forest structure in relation to microtopography in a tropical freshwater swamp forest in French Guiana. Plant Ecology 173: 17-32. https://doi.org/10.1023/B:VEGE.0000026328.98628.b8

Korall P, Conant DS, Metzgar JS, Schneider H, Pryer KM (2007) A molecular phylogeny of scaly tree ferns (Cyatheaceae). American Journal of Botany 94: 873-886. https://doi.org/10.3732/ajb.94.5.873

Körner C (2000) Why are there global gradients in species richness? mountains might hold the answer. Trends in Ecology \& Evolution 15: 513-514. https://doi.org/10.1016/S0169$5347(00) 02004-8$

Körner C (2007) The use of "altitude" in ecological research. Trends in Ecology \& Evolution 22: 569-574. https://doi.org/10.1016/j.tree.2007.09.006

Körner C, Paulsen J, Spehn EM (2011) A definition of mountains and their bioclimatic belts for global comparisons of biodiversity data. Alpine Botany 121: 73. https://doi.org/10.1007/s00035-011-0094-4

Kostermans AJGH (1956) New and critical Malaysian plants IV. Reinwardtia 4: 1-40.

Kostermans AJGH (1962) The Asiatic Species of Persea Mill. (Lauraceae). Reinwardtia 6: 189-194. https://doi.org/10.14203/reinwardtia.v6i2.219

Kostermans AJGH (1968) Materials for a revision of Lauraceae I. Reinwardtia 7: 291-356. https://doi.org/10.14203/reinwardtia.v7i4.978 
Kostermans AJGH (1969) Materials for a revision of Lauraceae II. Reinwardtia 7: 451-536. https://doi.org/10.14203/reinwardtia.v7i5.947

Kostermans AJGH (1970) Materials for a revision of Lauraceae III. Reinwardtia 8: 21-196. https://doi.org/10.14203/reinwardtia.v8i1.2126

Kostermans AJGH (1973) A synopsis of Alseodaphne Nees (Lauraceae). Candollea 28: 93-136.

Kostermans AJGH (1977) Notes on Asiatic, Pacific, and Australian Diospyros. Blumea Biodiversity, Evolution and Biogeography of Plants 23: 449-474.

Kostermans AJGH (1982) The genus Carallia (Rhizophoraceae) in Ceylon. Plant Biology 31: 327329. https://doi.org/10.1111/j.1438-8677.1982.tb01639.x

Kostermans AJGH (1986) A Monograph of the Genus Cinnamomum Schaeff. (Lauraceae). Part. I. Ginkgoana 6: 1-171.

Kostermans AJGH (1988) Materials for a revision of Lauraceae V. Reinwardtia 10: 439-469. https://doi.org/10.14203/reinwardtia.v10i5.280

Kreft H, Jetz W (2013) Comment on "An Update of Wallace's Zoogeographic Regions of the World." Science 341: 343-343. https://doi.org/10.1126/science.1237471

Kubitzki K (2007a) Daphniphyllaceae. In: Kubitzki K (Ed), Flowering Plants - Eudicots: Berberidopsidales, Buxales, Crossosomatales, Fabales p.p., Geraniales, Gunnerales, Myrtales p.p., Proteales, Saxifragales, Vitales, Zygophyllales, Clusiaceae Alliance, Passifloraceae Alliance, Dilleniaceae, Huaceae, Picramniaceae, Sabiaceae. The Families and Genera of Vascular Plants, vol. 9. Springer, Berlin, Heidelberg, 127-128. https://doi.org/10.1007/978-3-540-32219-1_15

Kubitzki K (2007b) Iteaceae. In: Kubitzki K (Ed), Flowering Plants - Eudicots: Berberidopsidales, Buxales, Crossosomatales, Fabales p.p., Geraniales, Gunnerales, Myrtales p.p., Proteales, Saxifragales, Vitales, Zygophyllales, Clusiaceae Alliance, Passifloraceae Alliance, Dilleniaceae, Huaceae, Picramniaceae, Sabiaceae. The Families and Genera of Vascular Plants, vol. 9. Springer, Berlin, Heidelberg, 202-204. https://doi.org/10.1007/978-3-54032219-1_25

Kubitzki K (2014a) Ctenolophonaceae. In: Kubitzki K (Ed), Flowering Plants - Eudicots: Malpighiales. The Families and Genera of Vascular Plants, vol. 11. Springer, Berlin, Heidelberg, 29-31. https://doi.org/10.1007/978-3-642-39417-1_6

Kubitzki K (2014b) Ixonanthaceae. In: Kubitzki K (Ed), Flowering Plants - Eudicots: Malpighiales. The Families and Genera of Vascular Plants, vol. 11. Springer, Berlin, Heidelberg, 233-236. https://doi.org/10.1007/978-3-642-39417-1_15

Kulip J, Wong KM (1995) Simaroubaceae. In: Soepadmo E, Wong KM (Eds), Tree Flora of Sabah and Sarawak. Forest Research Institute Malaysia (FRIM), Sabah Forestry Department, and Sarawak Forestry Department, Kuala Lumpur, 421-442.

Kulju KKM, Sierra SEC, Draisma SGA, Samuel R, van Welzen PC (2007) Molecular phylogeny of Macaranga, Mallotus, and related genera (Euphorbiaceae s.s.): insights from plastid and nuclear DNA sequence data. American Journal of Botany 94: 1726-1743. https://doi.org/10.3732/ajb.94.10.1726

LaFrankie JV, Ashton PS, Chuyong GB, Co L, Condit R, Davies SJ, Foster R, Hubbell SP, Kenfack D, Lagunzad D, Losos EC, Nor NSMd, Tan S, Thomas DW, Valencia R, Villa G (2006) Contrasting Structure and Composition of the Understory in Species-Rich Tropical Rain Forests. Ecology 87: 2298-2305. https://doi.org/10.1890/00129658(2006)87[2298:CSACOT]2.0.CO;2

Lam HJ (1948) Sarcospermaceae. Flora Malesiana, Series I 4: 32-34.

Lam HJ, van Royen P (1952) Concise revision of the Sarcospermataceae. Blumea - Biodiversity, Evolution and Biogeography of Plants 7: 148-153.

Landis MJ, Matzke NJ, Moore BR, Huelsenbeck JP (2013) Bayesian Analysis of Biogeography when the Number of Areas is Large. Systematic Biology 62: 789-804. https://doi.org/10.1093/sysbio/syt040

de Laubenfels DJ (1988) Coniferales. Flora Malesiana, Series I 10: 337-453. 
de Laubenfels DJ (2015) New Sections and Species of Podocarpus Based on the Taxonomic Status of P. neriifolius (Podocarpaceae) in Tropical Asia. Novon: A Journal for Botanical Nomenclature 24: 133-152. https://doi.org/10.3417/2012091

Lauterbach C (1924) Die Guttiferen Papuasiens. Lauterbach C (Ed). Botanische Jahrbücher für Systematik, Pflanzengeschichte und Pflanzengeographie 58: 1-49.

Lawver LA, Gahagan LM, Dalziel IWD (2013) A Different Look at Gateways: Drake Passage and Australia/Antarctica. In: Anderson JB, Wellner JS (Eds), Tectonic, Climatic, and Cryospheric Evolution of the Antarctic Peninsula. American Geophysical Union (AGU), Washington, D.C., 5-33. https://doi.org/10.1029/2010SP001017

Le Saout S, Hoffmann M, Shi Y, Hughes A, Bernard C, Brooks TM, Bertzky B, Butchart SHM, Stuart SN, Badman T, Rodrigues ASL (2013) Protected Areas and Effective Biodiversity Conservation. Science 342: 803-805. https://doi.org/10.1126/science.1239268

Leenhouts PW (1957) Dichapetalaceae. Flora Malesiana, Series I 5: 305-316.

Leenhouts PW (1959) Revision of the Burseraceae of the Malaysian area in a wider sense. Xa. Canarium Stickm. Blumea - Biodiversity, Evolution and Biogeography of Plants 9: 275-475.

Leenhouts PW (1962) Loganiaceae. Flora Malesiana, Series I 6: 293-387.

Leenhouts PW (1981) A new Fagraea (Loganiaceae) from Celebes, Indonesia. Blumea Biodiversity, Evolution and Biogeography of Plants 27: 209-210.

Leenhouts PW, Kalkman C, Lam HJ (1956) Burseraceae. Flora Malesiana, Series I 5: 209-296.

Leitner D (2010) Auswirkungen von ENSO-Trockenperioden und Landnutzungspraktiken auf die Dynamik von C, N und P in einem tropischen Regenwald und in Agroforst-Systemen in Zentral-Sulawesi, Indonesien. PhD thesis. Georg-August-Universität Göttingen Available from: https://ediss.uni-goettingen.de/handle/11858/00-1735-0000-0006-B2E8-0 (February 25, 2015).

Lemmens RHMJ, Breteler FJ, Jongkind CCH (2004) Connaraceae. In: Kubitzki K (Ed), Flowering Plants - Dicotyledons: Celastrales, Oxalidales, Rosales, Cornales, Ericales. The Families and Genera of Vascular Plants, vol. 6. Springer, Berlin, Heidelberg, 74-81. https://doi.org/10.1007/978-3-662-07257-8_9

Leslie AB, Beaulieu JM, Rai HS, Crane PR, Donoghue MJ, Mathews S (2012) Hemisphere-scale differences in conifer evolutionary dynamics. Proceedings of the National Academy of Sciences 109: 16217-16221. https://doi.org/10.1073/pnas.1213621109

Letts MG, Mulligan M, Rincón-Romero ME, Bruijnzeel LA (2010) Environmental controls on photosynthetic rates of lower montane cloud forest vegetation in south-western Colombia. In: Bruijnzeel LA, Scatena NS, Hamilton LS (Eds), Tropical Montane Cloud Forests: Science for Conservation and Management. International Hydrology Series. Cambridge University Press, Cambridge, UK, 465-478. Available from: http://www.researchgate.net/profile/Matthew_Letts/publication/255821045_Environme ntal_controls_on_photosynthetic_rates_of_lower_montane_cloud_forest_vegetation_in_s outh-western_Colombia/links/00b7d520be98be3fad000000.pdf (January 13, 2016).

Levin G (2014) Putranjivaceae. In: Kubitzki K (Ed), Flowering Plants - Eudicots: Malpighiales. The Families and Genera of Vascular Plants, vol. 11. Springer, Berlin, Heidelberg, 273-276. https://doi.org/10.1007/978-3-642-39417-1_21

Li B, Cantino PD, Olmstead RG, Bramley GLC, Xiang C-L, Ma Z-H, Tan Y-H, Zhang D-X (2016) A large-scale chloroplast phylogeny of the Lamiaceae sheds new light on its subfamilial classification. Scientific Reports 6: 34343. https://doi.org/10.1038/srep34343

Li J (2008) Molecular Phylogenetics of Hamamelidaceae: Evidence from DNA Sequences of Nuclear and Chloroplast Genomes. In: Sharma AK, Sharma A (Eds), Plant Genome: Biodiversity and Evolution. Volume 1, Part E: Phanerogams - Angiosperms. Science Publishers, Enfield, NH, U.S.A., 227-250.

Li J, Conran JG (2003) Phylogenetic relationships in Magnoliaceae subfam. Magnolioideae: a morphological cladistic analysis. Plant Systematics and Evolution 242: 33-47. https://doi.org/10.1007/s00606-003-0055-5 
Li J, Alexander JH, Zhang D (2002) Paraphyletic Syringa (Oleaceae): Evidence from Sequences of Nuclear Ribosomal DNA ITS and ETS Regions. Systematic Botany 27: 592-597. https://doi.org/10.1043/0363-6445-27.3.592

Li J, Christophel DC, Conran JG, Li H-W (2004) Phylogenetic relationships within the "core" Laureae (Litsea complex, Lauraceae) inferred from sequences of the chloroplast gene matK and nuclear ribosomal DNA ITS regions. Plant Systematics and Evolution 246: 1934. https://doi.org/10.1007/s00606-003-0113-z

Li J, Goldman-Huertas B, DeYoung J, Alexander J (2012) Phylogenetics and Diversification of Syringa Inferred from Nuclear and Plastid DNA Sequences. Castanea 77: 82-88. https://doi.org/10.2179/11-016

Li J, Conran JG, Christophel DC, Li Z-M, Li L, Li H-W (2008) Phylogenetic Relationships of the Litsea Complex and Core Laureae (Lauraceae) Using ITS and ETS Sequences and Morphology. Annals of the Missouri Botanical Garden 95: 580-599. https://doi.org/10.3417/2006125.9504

Li L, Li J, Rohwer JG, Werff H van der, Wang Z-H, Li H-W (2011) Molecular phylogenetic analysis of the Persea group (Lauraceae) and its biogeographic implications on the evolution of tropical and subtropical Amphi-Pacific disjunctions. American Journal of Botany 98: 15201536. https://doi.org/10.3732/ajb.1100006

Li M-M, Li J-H, Del Tredici P, Corajod J, Fu C-X (2013) Phylogenetics and biogeography of Theaceae based on sequences of plastid genes. Journal of Systematics and Evolution 51: 396-404. https://doi.org/10.1111/jse.12017

Li R, Wen J (2014) Phylogeny and biogeography of Asian Schefflera (Araliaceae) based on nuclear and plastid DNA sequence data. Journal of Systematics and Evolution 52: 431-449. https://doi.org/10.1111/jse.12052

Li Y, Dressler S, Zhang D, Renner SS (2009) More Miocene Dispersal Between Africa and Asiathe Case of Bridelia (Phyllanthaceae). Systematic Botany 34: 521-529. https://doi.org/10.1600/036364409789271263

Lin C-W, Thomas DC, Ardi WH, Peng C-I (2017) Begonia ignita (sect. Petermannia, Begoniaceae), a new species with orange flowers from Sulawesi, Indonesia. Gardens' Bulletin, Singapore 69: 89-95. https://doi.org/10.3850/S2010098116000081

van der Linden BL (1960) Staphyleaceae. Flora Malesiana, Series I 6: 49-59.

Linnaeus C (1753) Species plantarum, exhibentes plantas rite cognitas ad genera relatas, cum differentiis specificis, nominibus trivialibus, synonymis selectis, locis natalibus, secundum systema sexuale digestas. Tomus I. Laurentius Salvius, Holmia [Stockholm], 560 pp. Available from: http://dx.doi.org/10.5962/bhl.title.669.

Lister BC, Garcia A (2018) Climate-driven declines in arthropod abundance restructure a rainforest food web. Proceedings of the National Academy of Sciences 115: E10397E10406. https://doi.org/10.1073/pnas.1722477115

Liu J, Möller M, Gao L-M, Zhang D-Q, Li D-Z (2011) DNA barcoding for the discrimination of Eurasian yews (Taxus L., Taxaceae) and the discovery of cryptic species. Molecular Ecology Resources 11: 89-100. https://doi.org/10.1111/j.1755-0998.2010.02907.x

Livshultz T, Middleton DJ, Endress ME, Williams JK (2007) Phylogeny of Apocynoideae and the APSA clade (Apocynaceae s.l.). Annals of the Missouri Botanical Garden 94: 324-359. https://doi.org/10.3417/0026-6493(2007)94[324:POAATA]2.0.CO;2

Loesener T (1901) Monographia Aquifoliacearum. Pars I. Nova Acta Academiae Caesareae Leopoldino-Carolinae Germanicae Naturae Curiosorum 78: 1-598, Plates I-XV.

Loesener T (1908) Monographia Aquifoliacearum. Pars II. Mit 11 Abbildungen im Text und 3 Karten. Nova Acta Academiae Caesareae Leopoldino-Carolinae Germanicae Naturae Curiosorum 89: 1-313.

Loesener T (1924) Die Aquifoliaceen Papuasiens. Lauterbach C (Ed). Botanische Jahrbücher für Systematik, Pflanzengeschichte und Pflanzengeographie 59: 80-83. 
Löfstrand SD, Krüger $\AA$, Razafimandimbison SG, Bremer B (2014) Phylogeny and Generic Delimitations in the Sister Tribes Hymenodictyeae and Naucleeae (Rubiaceae). Systematic Botany 39: 304-315. https://doi.org/10.1600/036364414X678116

Lohman DJ, Bruyn M de, Page T, Rintelen K von, Hall R, Ng PKL, Shih H-T, Carvalho GR, Rintelen T von (2011) Biogeography of the Indo-Australian Archipelago. Annual Review of Ecology, Evolution, and Systematics 42: 205-226. https://doi.org/10.1146/annurev-ecolsys102710-145001

Lopez-Gonzalez G, Lewis SL, Burkitt M, Phillips OL (2009) ForestPlots.net Database. www.forestplots.net. Available from: 02 April 2015.

Lopez-Gonzalez G, Lewis SL, Burkitt M, Phillips OL (2011) ForestPlots.net: a web application and research tool to manage and analyse tropical forest plot data. Journal of Vegetation Science 22: 610-613. https://doi.org/10.1111/j.1654-1103.2011.01312.x

Low YW (2013) Two New Species of Sulawesi Gardenia (Rubiaceae) and Notes on G. mutabilis. Systematic Botany 38: 235-241. https://doi.org/10.1600/036364413X661944

Lowry PP, Plunkett GM (2010) Recircumscription of Polyscias (Araliaceae) to include six related genera, with a new infrageneric classification and a synopsis of species. Plant Diversity and Evolution 128: 55-84. https://doi.org/10.1127/1869-6155/2010/0128-0003

Lu P-L, Morden CW (2014) Phylogenetic Relationships among Dracaenoid Genera (Asparagaceae: Nolinoideae) Inferred from Chloroplast DNA Loci. Systematic Botany 39: 90-104. https://doi.org/10.1600/036364414X678035

Lü X-T, Tang J-W (2010) Structure and composition of the understory treelets in a nondipterocarp forest of tropical Asia. Forest Ecology and Management 260: 565-572. https://doi.org/10.1016/j.foreco.2010.05.013

Luebert F, Cecchi L, Frohlich MW, Gottschling M, Guilliams CM, Hasenstab-Lehman KE, Hilger HH, Miller JS, Mittelbach M, Nazaire M, Nepi M, Nocentini D, Ober D, Olmstead RG, Selvi F, Simpson MG, Sutorý K, Valdés B, Walden GK, Weigend M (2016) Familial classification of the Boraginales. Taxon 65: 502-522. https://doi.org/10.12705/653.5

Mabberley DJ (1985) Florae Malesianae Praecursores LXVII. Meliaceae (Divers genera). Blumea - Biodiversity, Evolution and Biogeography of Plants 31: 129-152.

Mabberley DJ (2010) Meliaceae. In: Kubitzki K (Ed), Flowering Plants - Eudicots: Sapindales, Cucurbitales, Myrtaceae. The Families and Genera of Vascular Plants, vol. 10. Springer, Berlin, Heidelberg, 185-211. https://doi.org/10.1007/978-3-642-14397-7_13

Mabberley DJ, Pannell CM, Sing AM (1995) Meliaceae. Flora Malesiana, Series I 12: 1-388.

Macphail M (2007) "Palaeo" works (but will it here)? Palynology in the Australo-Papuan region. Consultant Palynological Services, Aranda, ACT, Australia. Palynological report prepared 25 October 2007 for Professor S. Donnellan, South Australian Museum, Adelaide, 47pp.

Magallón S, Gómez-Acevedo S, Sánchez-Reyes LL, Hernández-Hernández T (2015) A metacalibrated time-tree documents the early rise of flowering plant phylogenetic diversity. New Phytologist 207: 437-453. https://doi.org/10.1111/nph.13264

Malécot V, Lobreau-Callen D (2005) A survey of species assigned to the fossil pollen genus Anacolosidites. Grana 44: 314-336. https://doi.org/10.1080/00173130500477688

Malhi Y, Girardin CAJ, Goldsmith GR, Doughty CE, Salinas N, Metcalfe DB, Huasco WH, SilvaEspejo JE, Aguilla-Pasquell J del, Amézquita FF, Aragão LEOC, Guerrieri R, Ishida FY, Bahar NHA, Farfan-Rios W, Phillips OL, Meir P, Silman M (2017) The variation of productivity and its allocation along a tropical elevation gradient: a whole carbon budget perspective. New Phytologist 214: 1019-1032. https://doi.org/10.1111/nph.14189

Manchester SR (1989) Early history of the Juglandaceae. In: Ehrendorfer F (Ed), Woody plants evolution and distribution since the Tertiary. Springer, Vienna, 231-250. https://doi.org/10.1007/978-3-7091-3972-1_12

Manchester SR, Kvaček Z (2009) Fruits of Sloanea (Elaeocarpaceae) in the Paleogene of North America and Greenland. International Journal of Plant Sciences 170: 941-950. https://doi.org/10.1086/600148 
Manchester SR, Grímsson F, Zetter R (2015) Assessing the Fossil Record of Asterids in the Context of Our Current Phylogenetic Framework. Annals of the Missouri Botanical Garden 100: 329-363. https://doi.org/10.3417/2014033

Manen J-F, Boulter MC, Naciri-Graven Y (2002) The complex history of the genus llex L. (Aquifoliaceae): evidence from the comparison of plastid and nuclear DNA sequences and from fossil data. Plant Systematics and Evolution 235: 79-98. https://doi.org/10.1007/s00606-002-0225-x

Manns U, Bremer B (2010) Towards a better understanding of intertribal relationships and stable tribal delimitations within Cinchonoideae s.s. (Rubiaceae). Molecular Phylogenetics and Evolution 56: 21-39. https://doi.org/10.1016/j.ympev.2010.04.002

Manns U, Wikström N, Taylor CM, Bremer B (2012) Historical Biogeography of the Predominantly Neotropical Subfamily Cinchonoideae (Rubiaceae): Into or Out of America? International Journal of Plant Sciences 173: 261-286. https://doi.org/10.1086/663971

Manos PS, Stanford AM (2001) The Historical Biogeography of Fagaceae: Tracking the Tertiary History of Temperate and Subtropical Forests of the Northern Hemisphere. International Journal of Plant Sciences 162: S77-S93. https://doi.org/10.1086/323280

Margono BA, Potapov PV, Turubanova S, Stolle F, Hansen MC (2014) Primary forest cover loss in Indonesia over 2000-2012. Nature Climate Change 4: 730-735. https://doi.org/10.1038/nclimate2277

Markgraf DJ (1951) Gnetaceae. Flora Malesiana, Series I 4: 336-347.

Marshall LG, Webb SD, Sepkoski JJ, Raup DM (1982) Mammalian Evolution and the Great American Interchange. Science 1351-1357. https://doi.org/10.1126/science.215.4538.1351

Martin HA (1977) The history of Ilex (Aquifoliaceae) with special reference to Australia: Evidence from pollen. Australian Journal of Botany 25: 655-673. https://doi.org/10.1071/BT9770655

Martin HA (2006) Cenozoic climatic change and the development of the arid vegetation in Australia. Journal of Arid Environments 66: 533-563. https://doi.org/10.1016/j.jaridenv.2006.01.009

Masamune G (1942) Boruneo no kenka shokubutsu. Enumeratio phanerogamarum Bornearum. Taihoku Imperial University, Taihoku, Taiwan.

Massoni J, Forest F, Sauquet H (2014) Increased sampling of both genes and taxa improves resolution of phylogenetic relationships within Magnoliidae, a large and early-diverging clade of angiosperms. Molecular Phylogenetics and Evolution 70: 84-93. https://doi.org/10.1016/j.ympev.2013.09.010

Mast AR, Willis CL, Jones EH, Downs KM, Weston PH (2008) A smaller Macadamia from a more vagile tribe: inference of phylogenetic relationships, divergence times, and diaspore evolution in Macadamia and relatives (tribe Macadamieae; Proteaceae). American Journal of Botany 95: 843-870. https://doi.org/10.3732/ajb.0700006

Matthew KM (1976) A revision of the genus Mastixia (Cornaceae). Blumea - Biodiversity, Evolution and Biogeography of Plants 23: 51-93.

Matthew KM (1977) Cornaceae. Flora Malesiana, Series I 8: 85-97.

Maxwell JF, Veldkamp JF (1990a) Notes on the Astronieae (Melastomataceae) - I. Astrocalyx, Astronia. Blumea - Biodiversity, Evolution and Biogeography of Plants 35: 71-114.

Maxwell JF, Veldkamp JF (1990b) Notes on the Astronieae (Melastomataceae) - II. Astronidium, Beccarianthus. Blumea - Biodiversity, Evolution and Biogeography of Plants 35: 115-164.

Maxwell SL, Fuller RA, Brooks TM, Watson JEM (2016) Biodiversity: The ravages of guns, nets and bulldozers. Nature News 536: 143. https://doi.org/10.1038/536143a

May RM (2010) Ecological science and tomorrow's world. Philosophical Transactions of the Royal Society B: Biological Sciences 365: 41-47. https://doi.org/10.1098/rstb.2009.0164

McDonald JA, Ismail R. (1995) Macadamia erecta (Proteaceae), a New Species from Sulawesi. Harvard Papers in Botany 1: 7-10. 
Mehrotra RC, Shukla A, Srivastava G, Tivari RP (2014) Miocene Megaflora of Peninsular India: Present Status and Future Prospect. In: Tiwari RP (Ed), Indian Miocene: a geodynamic and chronologic framework for palaeobiota, sedimentary environments and palaeoclimates. Palaeontological Society of India, Lucknow, India, 273-281. Available from: http://www.academia.edu/download/34386785/MIOCENE_MEGAFLORA_OF_PENINSULA R_INDIA.pdf.

van der Meijden R (1988) Polygalaceae. Flora Malesiana, Series I 10: 455-539.

Meijer W (1959) Plantsociological Analysis of Montane Rainforest Near Tjibodas, West Java. Acta Botanica Neerlandica 8: 277-291. https://doi.org/10.1111/j.1438-8677.1959.tb00540.x

Meijer W (1983) Botanical Explorations in Celebes and Bali. Research Reports (National Geographic Society, Committee for Research and Exploration) 60: 583-605.

Mendum M (2003) The Gesneriaceae of Sulawesi III: Three new species of Aeschynanthus. Edinburgh Journal of Botany 60: 323-330. https://doi.org/10.1017/S0960428603000271

Mendum M, Atkins HJ (2003) The Gesneriaceae of Sulawesi I: An introduction. Edinburgh Journal of Botany 60: 299-304. https://doi.org/10.1017/S0960428603000258

Mendum M, Scott SM, Galloway LER (2006) The Gesneriaceae of Sulawesi IV: Two new species of Aeschynanthus. Edinburgh Journal of Botany 63: 67. https://doi.org/10.1017/S0960428606000345

Merckx VSFT, Kissling J, Hentrich H, Janssens SB, Mennes CB, Specht CD, Smets EF (2013) Phylogenetic relationships of the mycoheterotrophic genus Voyria and the implications for the biogeographic history of Gentianaceae. American Journal of Botany 100: 712-721. https://doi.org/10.3732/ajb.1200330

Merckx VSFT, Hendriks KP, Beentjes KK, Mennes CB, Becking LE, Peijnenburg KTCA, Afendy A, Arumugam N, de Boer $\mathrm{H}$, Biun A, Buang MM, Chen P-P, Chung AYC, Dow R, Feijen FAA, Feijen H, Soest CF, Geml J, Geurts R, Gravendeel B, Hovenkamp P, Imbun P, Ipor I, Janssens SB, Jocqué M, Kappes H, Khoo E, Koomen P, Lens F, Majapun RJ, Morgado LN, Neupane $S$, Nieser N, Pereira JT, Rahman H, Sabran S, Sawang A, Schwallier RM, Shim P-S, Smit H, Sol N, Spait M, Stech M, Stokvis F, Sugau JB, Suleiman M, Sumail S, Thomas DC, van Tol J, Tuh FYY, Yahya BE, Nais J, Repin R, Lakim M, Schilthuizen M (2015) Evolution of endemism on a young tropical mountain. Nature 524: 347-350. https://doi.org/10.1038/nature14949

Merrill ED (1915) New species of Eugenia. The Philippine Journal of Science, C. Botany 10: 207228.

Merrill ED (1921) New Philippine Myrtaceae. The Philippine Journal of Science 18: 289-308.

Merrill ED (1923a) 1-3 An enumeration of Philippine Flowering Plants. Department of Agriculture and Natural Resources, Bureau of Science, Manila.

Merrill ED (1923b) 2 An enumeration of Philippine Flowering Plants, Volume 2. Department of Agriculture and Natural Resources, Bureau of Science, Manila, 530 pp.

Merrill ED (1951) Readjustments in the Nomenclature of Philippine Eugenia Species. The Philippine Journal of Science 79: 351-430.

Merrill ED, Perry LM (1937) Reinstatement and revision of Cleistocalyx Blume (including Acicalyptus A. Gray), a valid genus of the Myrtaceae. Journal of the Arnold Arboretum 18: 322-343.

Merrill ED, Perry LM (1938a) On the Indo-Chinese species of Syzygium Gaertner. Journal of the Arnold Arboretum 19: 99-116.

Merrill ED, Perry LM (1938b) The Myrtaceae of China. Journal of the Arnold Arboretum 19: 191 247.

Merrill ED, Perry LM (1939) The Myrtaceous genus Syzygium Gaertner in Borneo. Memoirs of the American Academy of Arts and Sciences 18: 135-202. https://doi.org/10.2307/25058505

Merrill ED, Perry LM (1942) Plantae Papuanae Archboldianae, IX. Journal of the Arnold Arboretum 23: 233-297. 
Meseguer AS, Lobo JM, Cornuault J, Beerling D, Ruhfel BR, Davis CC, Jousselin E, Sanmartín I (2018) Reconstructing deep-time palaeoclimate legacies in the clusioid Malpighiales unveils their role in the evolution and extinction of the boreotropical flora. Global Ecology and Biogeography 27: 616-628. https://doi.org/10.1111/geb.12724

Meyer C, Kreft H, Guralnick R, Jetz W (2015) Global priorities for an effective information basis of biodiversity distributions. Nature Communications 6: 8221. https://doi.org/10.1038/ncomms9221

Michaux B (2010) Biogeology of Wallacea: geotectonic models, areas of endemism, and natural biogeographical units. Biological Journal of the Linnean Society 101: 193-212. https://doi.org/10.1111/j.1095-8312.2010.01473.x

Middleton DJ (2007) Apocynaceae (subfamilies Rouvolfioideae and Apocynoideae). Flora Malesiana, Series I 18: 1-152.

Middleton DJ, Scott SM (2008) A new species of Agalmyla (Gesneriaceae) from Sulawesi. Edinburgh Journal of Botany 65: 49-52. https://doi.org/10.1017/S0960428608004988

Midolo G, Alkemade R, Schipper AM, Benítez-López A, Perring MP, Vries WD (2019) Impacts of nitrogen addition on plant species richness and abundance: A global meta-analysis. Global Ecology and Biogeography 28: 398-413. https://doi.org/10.1111/geb.12856

Milliken W, Proctor J (1999) Montane forest in the Dumoga Bone National Park, North Sulawesi. Edinburgh Journal of Botany 56: 449-458. https://doi.org/10.1017/S0960428600001372

Mogea JP (2002) Preliminary study on the palm flora of the Lore Lindu National Park, Central Sulawesi, Indonesia. Biotropica 18: 1-20.

Molina JE, Wen J, Struwe L (2013) Systematics and biogeography of the non-viny grape relative Leea (Vitaceae). Botanical Journal of the Linnean Society 171: 354-376. https://doi.org/10.1111/j.1095-8339.2012.01320.x

Mols JB, Keßler PJA (2000) Revision of the genus Phaeanthus (Annonaceae). Blumea Biodiversity, Evolution and Biogeography of Plants 45: 205-233.

Montes C, Cardona A, Jaramillo C, Pardo A, Silva JC, Valencia V, Ayala C, Pérez-Angel LC, Rodriguez-Parra LA, Ramirez V, Niño H (2015) Middle Miocene closure of the Central American Seaway. Science 348: 226-229. https://doi.org/10.1126/science.aaa2815

Mori SA, Boom BM, Carvalino AM de, Santos TS dos (1983) Ecological Importance of Myrtaceae in an Eastern Brazilian Wet Forest. Biotropica 15: 68-70. https://doi.org/10.2307/2388002

Mori SA, Tsou C-H, Wu C-C, Cronholm B, Anderberg AA (2007) Evolution of Lecythidaceae with an emphasis on the circumscription of neotropical genera: information from combined ndhF and trnL-F sequence data. American Journal of Botany 94: 289-301. https://doi.org/10.3732/ajb.94.3.289

Morley RJ (1998) Palynological evidence for Tertiary plant dispersals in the SE Asian region in relation to plate tectonics and climate. In: Hall R, Holloway JD (Eds), Biogeography and geological evolution of SE Asia. Backhuys, Leiden, The Netherlands, 417.

Morley RJ (2001) Tertiary history of the Malesian flora: A palynological perspective. In: Saw LG, Chua LSL, Khoo KC (Eds), Taxonomy: the cornerstone of biodiversity: proceedings of the Fourth International Flora Malesiana Symposium, 1998. Forest Research Institute Malaysia, Kuala Lumpur, Malaysia, 197-210.

Morley RJ (2012) A review of the Cenozoic palaeoclimate history of Southeast Asia. In: Gower DJ, Johnson KG, Richardson JE, Rosen BR, Rüber L, Williams ST (Eds), Biotic Evolution and Environmental Change in Southeast Asia. The Systematics Association Special Volume 82. Cambridge University Press, Cambridge, UK, 79-114.

Morokawa R (2014) Biogeography of ViWiTa clade and phylogeny of Willughbeieae (Apocynaceae, Rauvolfioideae). PhD thesis, Universidade Estadual de Campinas, Campinas, Brasil. Universidade Estadual de Campinas Available from: http://repositorio.unicamp.br/jspui/handle/REPOSIP/315277 (January 7, 2018).

Moser G, Röderstein M, Soethe N, Hertel D, Leuschner C (2008) Altitudinal Changes in Stand Structure and Biomass Allocation of Tropical Mountain Forests in Relation to Microclimate 
and Soil Chemistry. In: Beck E, Bendix J, Kottke I, Makeschin F, Mosandl R (Eds), Gradients in a Tropical Mountain Ecosystem of Ecuador. Ecological Studies. Springer, Berlin Heidelberg, 229-242. Available from: http://dx.doi.org/10.1007/978-3-540-73526-7_22.

Moser G, Leuschner C, Hertel D, Graefe S, Soethe N, lost S (2011) Elevation effects on the carbon budget of tropical mountain forests (S Ecuador): the role of the belowground compartment. Global Change Biology 17: 2211-2226. https://doi.org/10.1111/j.13652486.2010.02367.x

Motsi MC (2009) Origin and diversification of the Australasian genera Pimelea and Thecanthes (Thymelaeaceae). PhD thesis. University of Johannesburg Available from: https://ujcontent.uj.ac.za/vital/access/services/Download/uj:9709/CONTENT1.

Muellner AN, Savolainen V, Samuel R, Chase MW (2006) The mahogany family "out-of-Africa": Divergence time estimation, global biogeographic patterns inferred from plastid rbcL DNA sequences, extant, and fossil distribution of diversity. Molecular Phylogenetics and Evolution 40: 236-250. https://doi.org/10.1016/j.ympev.2006.03.001

Muellner-Riehl AN, Weeks A, Clayton JW, Buerki S, Nauheimer L, Chiang Y-C, Cody S, Pell SK (2016) Molecular phylogenetics and molecular clock dating of Sapindales based on plastid rbcL, atpB and trnL-trnF DNA sequences. Taxon 65: 1019-1036. https://doi.org/10.12705/655.5

Muller J (1966) Montane pollen from the Tertiary of NW. Borneo. Blumea - Biodiversity, Evolution and Biogeography of Plants 14: 231-235.

Munsell Color (2010) Munsell Soil-Color Charts. Munsell Color, Grand Rapids, U.S.A.

Musser GG (1987) The mammals of Sulawesi. In: Biogeographical evolution of the Malay Archipelago. Oxford Biogeography Series. Clarendon Press, Oxford, UK, 73-93.

Myers N, Mittermeier RA, Mittermeier CG, da Fonseca GAB, Kent J (2000) Biodiversity hotspots for conservation priorities. Nature 403: 853-858. https://doi.org/10.1038/35002501

Nauheimer L, Boyce PC, Renner SS (2012) Giant taro and its relatives: A phylogeny of the large genus Alocasia (Araceae) sheds light on Miocene floristic exchange in the Malesian region. Molecular Phylogenetics and Evolution 63: 43-51. https://doi.org/10.1016/j.ympev.2011.12.011

Nellemann C, Henriksen R, Kreilhuber A, Stewart D, Kotsovou M, Raxter P, Mrema E, Barrat S eds. (2016) The rise of environmental crime: a growing threat to natural resources, peace, development and security. United Nations Environment Programme, Nairobi, Kenya, 104 pp. Available from: https://www.grida.no/publications/344.

Ng FSP (2004) Ebenaceae. In: Soepadmo E, Saw LG, Chung RCK (Eds), Tree Flora of Sabah and Sarawak. Forest Research Institute Malaysia (FRIM), Sabah Forestry Department, and Sarawak Forestry Department, Kuala Lumpur, 29-100.

Ng FSP (2005a) Taxonomic notes on Bornean Cryptocarya R.Br. (Lauraceae). The Gardens' Bulletin, Singapore 57: 63-68.

Ng FSP (2005b) Taxonomic notes on Bornean Litsea, Lindera, Neolitsea and Iteadaphne (Lauraceae). Gardens' Bulletin, Singapore 57: 217-246.

Nickrent DL, Malécot V, Vidal-Russell R, Der JP (2010) A revised classification of Santalales. Taxon 59: 538-558.

Nicolas AN, Plunkett GM (2014) Diversification Times and Biogeographic Patterns in Apiales. The Botanical Review 80: 30-58. https://doi.org/10.1007/s12229-014-9132-4

Nie Z-L, Wen J, Azuma H, Qiu Y-L, Sun H, Meng Y, Sun W-B, Zimmer EA (2008) Phylogenetic and biogeographic complexity of Magnoliaceae in the Northern Hemisphere inferred from three nuclear data sets. Molecular Phylogenetics and Evolution 48: 1027-1040. https://doi.org/10.1016/j.ympev.2008.06.004

Nielsen IC (1992) Mimosaceae (Leguminosae-Mimosoideae). Flora Malesiana, Series I 11: 1-226. Nielsen IC, Baretta-Kuipers T, Guinet P (1984) The genus Archidendron (Leguminosae Mimosoideae). Nordic Journal of Botany 4: 770-770. https://doi.org/10.1111/j.17561051.1984.tb02008.x 
Nishida S (2008) Taxonomic revision of Beilschmiedia (Lauraceae) in Borneo. Blumea Biodiversity, Evolution and Biogeography of Plants 53: 345-383.

Noguchi H, Itoh A, Mizuno T, Sri-ngernyuang K, Kanzaki M, Teejuntuk S, Sungpalee W, Hara M, Ohkubo T, Sahunalu P, Dhanmmanonda P, Yamakura T (2007) Habitat divergence in sympatric Fagaceae tree species of a tropical montane forest in northern Thailand. Journal of Tropical Ecology 23: 549-558. https://doi.org/10.1017/S0266467407004403

Noorsiha A (1995) Aceraceae. In: Soepadmo E, Wong KM (Eds), Tree Flora of Sabah and Sarawak. Forest Research Institute Malaysia (FRIM), Sabah Forestry Department, and Sarawak Forestry Department, Kuala Lumpur, 1-4.

Nooteboom HP (1962) Simaroubaceae. Flora Malesiana, Series I 6: 193-226.

Nooteboom HP (1975) Revision of the Symplocaceae of the Old World, New Caledonia excepted. Universitaire Pers Leiden, Leiden, The Netherlands, 335 pp.

Nooteboom HP (1977) Symplocaceae. Flora Malesiana, Series I 8: 205-274.

Nooteboom HP (1985) Notes on Magnoliaceae with a revision of Pachylarnax and Elmerrillia and the Malesian species of Manglietia and Michelia. Blumea - Biodiversity, Evolution and Biogeography of Plants 31: 65-121.

Nooteboom HP (1987) Notes on Magnoliaceae II. Revision of Magnolia sections Maingola (Malesian species), Aromadendron, and Blumiana. Blumea - Biodiversity, Evolution and Biogeography of Plants 32: 343-382.

Nooteboom HP (1988) Magnoliaceae. Flora Malesiana, Series I 10: 561-605.

Nooteboom HP (2011) How did Mangolias (Magnoliaceae: Magnolioideae) reach Tropical Asia? The Gardens' Bulletin, Singapore 63: 299-306.

Nugraha AMS, Hall R (2017) Late Cenozoic palaeogeography of Sulawesi, Indonesia. Palaeogeography, Palaeoclimatology, Palaeoecology. https://doi.org/10.1016/j.palaeo.2017.10.033

Ohsawa M (1993) Latitudinal pattern of mountain vegetation zonation in southern and eastern Asia. Journal of Vegetation Science 4: 13-18. https://doi.org/10.2307/3235728

Ohsawa M, Nainggolan PHJ, Tanaka N, Anwar C (1985) Altitudinal zonation of forest vegetation on Mount Kerinci, Sumatra: with comparisons to zonation in the temperate region of east Asia. Journal of Tropical Ecology 1: 193-216. https://doi.org/10.1017/S0266467400000286

Oksanen J, Blanchet FG, Kindt R, Legendre P, Minchin PR, O'Hara RB, Simpson GL, Solymos P, Stevens $\mathrm{MHH}$, Wagner H (2016) vegan: Community Ecology Package. R package. . en. Available from: http://CRAN.R-project.org/package=vegan.

Olmstead RG, Zjhra ML, Lohmann LG, Grose SO, Eckert AJ (2009) A molecular phylogeny and classification of Bignoniaceae. American Journal of Botany 96: 1731-1743. https://doi.org/10.3732/ajb.0900004

Orel G, Wilson PG, Curry AS, Luu HT (2013) Two new species of Polyspora (Theaceae) from Vietnam and new combinations for some Asian species. Willdenowia - Annals of the Botanic Garden and Botanical Museum Berlin-Dahlem 43: 301-308. https://doi.org/10.3372/wi.43.43210

Ottens-Treurniet MAD, van Welzen PC (2016) A revision of the Malesian genus Blumeodendron (Euphorbiaceae). Blumea - Biodiversity, Evolution and Biogeography of Plants 61: 64-82. https://doi.org/10.3767/000651916X691547

Pachauri RK, Mayer L, Intergovernmental Panel on Climate Change eds. (2015) Climate change 2014: synthesis report. Intergovernmental Panel on Climate Change (IPCCC), Geneva, Switzerland, $151 \mathrm{pp}$.

Pannell CM (1992) Kew Bulletin Additional Series XVI A taxonomic monograph of the genus Aglaia Lour. (Meliaceae). H.M.S.O., London, 379 pp.

Pannell CM (2018) Reproductive biology, morphological taxonomy, biogeography and molecular phylogeny of Aglaia Lour. (Meliaceae): the monographic approach to a large genus of tropical trees. Sibbaldia: the Journal of Botanic Garden Horticulture 16: 87-97. 
Paoli GD, Curran LM, Zak DR (2006) Soil nutrients and beta diversity in the Bornean Dipterocarpaceae: evidence for niche partitioning by tropical rain forest trees. Journal of Ecology 94: 157-170. https://doi.org/10.1111/j.1365-2745.2005.01077.x

Parmentier I, Malhi Y, Senterre B, Whittaker RJ, Alonso A, Balinga MPB, Bakayoko A, Bongers F, Chatelain C, Comiskey JA, Cortay R, Kamdem M-ND, Doucet J-L, Gautier L, Hawthorne WD, Issembe YA, Kouamé FN, Kouka LA, Leal ME, Lejoly J, Lewis SL, Nusbaumer L, Parren MPE, Peh KS-H, Phillips OL, Sheil D, Sonké B, Sosef MSM, Sunderland TCH, Stropp J, Ter Steege H, Swaine MD, Tchouto MGP, Gemerden BSV, Van Valkenburg JLCH, Wöll H (2007) The odd man out? Might climate explain the lower tree a-diversity of African rain forests relative to Amazonian rain forests? Journal of Ecology 95: 1058-1071. https://doi.org/10.1111/j.1365-2745.2007.01273.x

Payens JPDW (1967) A monograph of the genus Barringtonia (Lecythidaceae). Blumea Biodiversity, Evolution and Biogeography of Plants 15: 157-263.

Pell SK, Mitchell JD, Miller AJ, Lobova TA (2010) Anacardiaceae. In: Kubitzki K (Ed), Flowering Plants - Eudicots: Sapindales, Cucurbitales, Myrtaceae. The Families and Genera of Vascular Plants, vol. 10. Springer, Berlin, Heidelberg, 7-50. https://doi.org/10.1007/978-3642-14397-7_3

Pelser PB, Barcelona JF, Nickrent DL (2011) Co's Digital Flora of the Philippines. Available from: http://www.philippineplants.org/ (May 18, 2015).

Pennington TD (2004) Sapotaceae. In: Kubitzki K (Ed), Flowering Plants - Dicotyledons: Celastrales, Oxalidales, Rosales, Cornales, Ericales. The Families and Genera of Vascular Plants, vol. 6. Springer, Berlin, Heidelberg, 390-421. https://doi.org/10.1007/978-3-66207257-8_41

Pereira JT (1995) Staphyleaceae. In: Soepadmo E, Wong KM (Eds), Tree Flora of Sabah and Sarawak. Forest Research Institute Malaysia (FRIM), Sabah Forestry Department, and Sarawak Forestry Department, Kuala Lumpur, 453-462.

Persson C (2001) Phylogenetic Relationships in Polygalaceae Based on Plastid DNA Sequences from the trnL-F Region. Taxon 50: 763-779. https://doi.org/10.2307/1223706

Peters MK, Hemp A, Appelhans T, Behler C, Classen A, Detsch F, Ensslin A, Ferger SW, Frederiksen SB, Gebert F, Haas M, Helbig-Bonitz M, Hemp C, Kindeketa WJ, Mwangomo E, Ngereza C, Otte I, Röder J, Rutten G, Costa DS, Tardanico J, Zancolli G, Deckert J, Eardley $C D$, Peters RS, Rödel M-O, Schleuning M, Ssymank A, Kakengi V, Zhang J, Böhning-Gaese K, Brandl R, Kalko EKV, Kleyer M, Nauss T, Tschapka M, Fischer M, Steffan-Dewenter I (2016) Predictors of elevational biodiversity gradients change from single taxa to the multi-taxa community level. Nature Communications 7: 13736. https://doi.org/10.1038/ncomms13736

Philipson WR (1977) A revision of the Malesian species of Arthrophyllum BI. (Arailaceae). The Gardens' Bulletin, Singapore 30: 299-312.

Philipson WR (1978) A synopsis of the Malesian species of Polyscias (Araliaceae). Blumea Biodiversity, Evolution and Biogeography of Plants 24: 169-172.

Philipson WR (1979) Araliaceae - I. Flora Malesiana, Series I 9: 1-105.

Philipson WR (1980) A revision of Levieria (Monimiaceae). Blumea - Biodiversity, Evolution and Biogeography of Plants 26: 373-385.

Philipson WR (1982) A synopsis of Matthaea (Monimiaceae). Blumea - Biodiversity, Evolution and Biogeography of Plants 28: 77-83.

Philipson WR (1984) A synopsis of the Malesian species of Steganthera (Monimiaceae). Blumea - Biodiversity, Evolution and Biogeography of Plants 29: 481-497.

Philipson WR (1985) A synopsis of the Malesian species of Kibara (Monimiaceae). Blumea Biodiversity, Evolution and Biogeography of Plants 30: 389-415.

Philipson WR (1986) Trimeniaceae. Flora Malesiana, Series I 10: 327-332. 
Pimm SL, Joppa LN (2015) How Many Plant Species are There, Where are They, and at What Rate are They Going Extinct? Annals of the Missouri Botanical Garden 100: 170-176. https://doi.org/10.3417/2012018

Pimm SL, Raven PH (2017) The Fate of the World's Plants. Trends in Ecology \& Evolution 32: 317320. https://doi.org/10.1016/j.tree.2017.02.014

Pimm SL, Jenkins CN, Abell R, Brooks TM, Gittleman JL, Joppa LN, Raven PH, Roberts CM, Sexton JO (2014) The biodiversity of species and their rates of extinction, distribution, and protection. Science 344: 1246752. https://doi.org/10.1126/science.1246752

Pipoly JohnJ III, Madulid DA (1998) Composition, structure and species richness of a submontane moist forest on Mt Kinasalapi, Mindanao, Philippines. In: Dallmeier F, Comiskey JA (Eds), Forest biodiversity research, monitoring and modelling: Conceptual background and Old World case studies. Man and Biosphere Series. UNESCO and The Parthenon Publishing Group, Paris, New York, 591-599.

Pitopang R, Keßler PJA, Gradstein SR, Guhardja E, Tjitrosudirdjo SS, Wiriadinata H (2004) Tree Composition in Secondary Forest of Lore Lindu National Park, Central Sulawesi, Indonesia. In: Gerold PDG, Fremerey PDM, Guhardja PDE (Eds), Land Use, Nature Conservation and the Stability of Rainforest Margins in Southeast Asia. Environmental Science. Springer Berlin Heidelberg, 269-279. Available from: http://link.springer.com/chapter/10.1007/978-3-662-08237-9_15 (February 25, 2015).

Plunkett GM, Lowry PP (2010) Paraphyly and polyphyly in Polyscias sensu lato: molecular evidence and the case for recircumscribing the "pinnate genera" of Araliaceae. Plant Diversity and Evolution 128: 23-54. https://doi.org/10.1127/1869-6155/2010/0128-0002

Potapov P, Hansen MC, Laestadius L, Turubanova S, Yaroshenko A, Thies C, Smith W, Zhuravleva I, Komarova A, Minnemeyer S, Esipova E (2017) The last frontiers of wilderness: Tracking loss of intact forest landscapes from 2000 to 2013. Science Advances 3: e1600821. https://doi.org/10.1126/sciadv.1600821

Potgieter MJ, Duno R (2016) Icacinaceae. In: Kadereit JW, Bittrich V (Eds), Flowering Plants Eudicots: Aquifoliales, Boraginales, Bruniales, Dipsacales, Escalloniales, Garryales, Paracryphiales, Solanales (except Convolvulaceae), Icacinaceae, Metteniusaceae, Vahliaceae. The Families and Genera of Vascular Plants, vol. 14. Springer, Cham, 239-256. https://doi.org/10.1007/978-3-319-28534-4_21

Poulsen AD (2012) Etlingera of Sulawesi. Natural History Publ, Malaysia, 278 pp.

Poulsen AD, Mathisen HB, Newman MF, Ardiyani M, Lofthus $\varnothing$, Bjorå CS (2018) Sulettaria: A new ginger genus disjunct from Elettaria cardamomum. Taxon 67: 725-738. https://doi.org/10.12705/674.3

Powell EA, Kron KA (2002) Hawaiian Blueberries and Their Relatives-A Phylogenetic Analysis of Vaccinium Sections Macropelma, Myrtillus, and Hemimyrtillus (Ericaceae). Systematic Botany 27: 768-779. https://doi.org/10.1043/0363-6445-27.4.768

Powling A, Phillips A, Pritchett R, Segar ST, Wheeler R, Mardiastuti A (2016) The vegetation of Lambusango Forest, Buton, Indonesia. Reinwardtia 14: 265-286. https://doi.org/10.14203/reinwardtia.v14i2.1671

POWO (2019) Plants of the World Online. Royal Botanic Gardens Kew. Available from: http://www.plantsoftheworldonline.org/ (February 12, 2019).

Prance GT (1989) Chrysobalanaceae. Flora Malesiana, Series I 10: 635-678.

Prance GT (1995) Chrysobalanaceae. In: Soepadmo E, Wong KM (Eds), Tree Flora of Sabah and Sarawak. Forest Research Institute Malaysia (FRIM), Sabah Forestry Department, and Sarawak Forestry Department, Kuala Lumpur, 155-180.

Prenner G, Bateman RM, Rudall PJ (2010) Floral formulae updated for routine inclusion in formal taxonomic descriptions. Taxon 59: 241-250.

Proctor J (2003) Vegetation and soil and plant chemistry on ultramafic rocks in the tropical Far East. Perspectives in Plant Ecology, Evolution and Systematics 6: 105-124. https://doi.org/10.1078/1433-8319-00045 
Proctor J, Argent GC, Madulid DA (1998) Forests of the ultramafic mount Giting-Giting, Sibuyan Island, the Philippines. Edinburgh Journal of Botany 55: 295-316. https://doi.org/10.1017/S0960428600002201

Punt W, Hoen PP, Blackmore S, Nilsson S, Le Thomas A (2007) Glossary of pollen and spore terminology. Review of Palaeobotany and Palynology 143: 1-81. https://doi.org/10.1016/j.revpalbo.2006.06.008

QGIS Development Team (2016) QGIS Geographic Information System. Version 2.18 - LaS Palmas de G.C. Open Source Geospatial Foundation Project. Available from: http://www.qgis.org (December 15, 2016).

Qian H, Ricklefs RE (2016) Out of the Tropical Lowlands: Latitude versus Elevation. Trends in Ecology \& Evolution 31: 738-741. https://doi.org/10.1016/j.tree.2016.07.012

Qin H, Boufford DE (2007) Rhizophoraceae. In: Wu Z-Y, Raven PH, Hong D-Y (Eds), Flora of China. Vol. 13 (Clusiaceae through Araliaceae). Science Press, Beijing, 295-299. Available from: http://www.efloras.org/florataxon.aspx?flora_id=2\&taxon_id=10767 (January 3, 2017).

Quarles van Ufford A, Cloos M (2005) Cenozoic tectonics of New Guinea. AAPG Bulletin 89: 119140. https://doi.org/10.1306/08300403073

Quiroga MP, Mathiasen P, Iglesias A, Mill RR, Premoli AC (2016) Molecular and fossil evidence disentangle the biogeographical history of Podocarpus, a key genus in plant geography. Journal of Biogeography 43: 372-383. https://doi.org/10.1111/jbi.12630

R Core Team (2015) R: A language and environment for statistical computing. R Foundation for Statistical Computing, Vienna, Austria. en. Available from: http://www.R-project.org/.

R Core Team (2016) R: A language and environment for statistical computing. Version 3.3.2 (Sincere Pumpkin Patch). R Foundation for Statistical Computing, Vienna, Austria. en. Available from: http://www.R-project.org/.

R Core Team (2017) R: A language and environment for statistical computing. R Foundation for Statistical Computing, Vienna, Austria. en. Available from: http://www.R-project.org/.

Raes N, van Welzen PC (2009) The demarcation and internal division of Flora Malesiana: 1857 present. Blumea - Biodiversity, Evolution and Biogeography of Plants 54: 6-8. https://doi.org/10.3767/000651909X475888

Raes N, Roos MC, Slik JWF, Van Loon EE, Steege H ter (2009) Botanical richness and endemicity patterns of Borneo derived from species distribution models. Ecography 32: 180-192. https://doi.org/10.1111/j.1600-0587.2009.05800.x

Rahbek C (1995) The elevational gradient of species richness: a uniform pattern? Ecography 18: 200-205. https://doi.org/10.1111/j.1600-0587.1995.tb00341.x

Rahbek C (2005) The role of spatial scale and the perception of large-scale species-richness patterns. Ecology Letters 8: 224-239. https://doi.org/10.1111/j.1461-0248.2004.00701.x

Rasolofoson RA, Hanauer MM, Pappinen A, Fisher B, Ricketts TH (2018) Impacts of forests on children's diet in rural areas across 27 developing countries. Science Advances 4: eaat2853. https://doi.org/10.1126/sciadv.aat2853

Razafimandimbison SG, Lantz H, Mouly A, Bremer B (2009) Evolutionary Trends, Major Lineages, and New Generic Limits in the Dioecious Group of the Tribe Vanguerieae (Rubiaceae): Insights into the Evolution of Functional Dioecy. Annals of the Missouri Botanical Garden 96: 161-181. https://doi.org/10.3417/2006191

Razafimandimbison SG, Kainulainen K, Wikström N, Bremer B (2017) Historical biogeography and phylogeny of the pantropical Psychotrieae alliance (Rubiaceae), with particular emphasis on the Western Indian Ocean Region. American Journal of Botany 104: 14071423. https://doi.org/10.3732/ajb.1700116

RBG Kew (2015) The Herbarium Catalogue, Royal Botanic Gardens, Kew. Published on the Internet. Available from: http://apps.kew.org/herbcat/gotoHomePage.do (December 15, 2015).

Reginato M (2016) monographaR: An R package to facilitate the production of plant taxonomic monographs. Brittonia 68: 212-216. https://doi.org/10.1007/s12228-015-9407-z 
Reinwardt CGC, de Vriese WH (1856) Plantae Indiae Batavae Orientalis quas, in itinere per insulas archipelagi Indici Javam, Amboinam, Celebem, Ternatam, aliasque, annis 18151821, exploravit Casp. Georg. Carol. Reinwardt. Brill, Leiden, The Netherlands, 1-160, Plate I-VIII pp. Available from: https://archive.org/details/bub_gb_OJE_AAAAYAAJ/.

Renner SS (2004) Bayesian analysis of combined chloroplast loci, using multiple calibrations, supports the recent arrival of Melastomataceae in Africa and Madagascar. American Journal of Botany 91: 1427-1435. https://doi.org/10.3732/ajb.91.9.1427

Renner SS, Strijk JS, Strasberg D, Thébaud C (2010) Biogeography of the Monimiaceae (Laurales): a role for East Gondwana and long-distance dispersal, but not West Gondwana. Journal of Biogeography 37: 1227-1238. https://doi.org/10.1111/j.1365-2699.2010.02319.x

Richards SJ, Suryadi S eds. (2002) 25 A biodiversity assessment of Yongsu - Cyclops Mountains and the Southern Mamberano Basin, Papua, Indonesia. Conservation International, Washington, D.C., $180 \quad$ pp. Available from: https://library.conservation.org/Published\%20Documents/2009/TerrRap25.pdf.

Richards SJ ed. (2007) 45 A rapid biodiversity assessment of the Kaijende Highlands, Enga Province, Papua New Guinea. Conservation International, Arlington, VA, USA, 96 pp. Available from: https://library.conservation.org/Published\%20Documents/2009/RAP45_PNG.pdf.

Richards SJ, Gamui BG eds. (2011) 60 Rapid Biological Assessment of the Nakanai Mountains and the upper Strickland Basin: surveying the biodiversity of Papua New Guinea's sublime karst environments. Conservation International, Arlington, VA, USA, 258 pp. Available from:

https://library.conservation.org/Published\%20Documents/RAP\%2060_PNG_full\%20repo rt_lores.pdf.

Richardson JE, Costion CM, Muellner AN (2012) The Malesian floristic interchange. In: Gower DJ, Johnson KG, Richardson JE, Rosen BR, Rüber L, Williams ST (Eds), Biotic Evolution and Environmental Change in Southeast Asia. The Systematics Association Special Volume 82. Cambridge University Press, Cambridge, UK, 138-163. Available from: https://doi.org/10.1017/CBO9780511735882.008.

Richardson JE, Whitlock BA, Meerow AW, Madriñán S (2015) The age of chocolate: a diversification history of Theobroma and Malvaceae. Evolutionary and Population Genetics 3: 120. https://doi.org/10.3389/fevo.2015.00120

Richardson JE, Bakar AM, Tosh J, Armstrong K, Smedmark J, Anderberg AA, Slik F, Wilkie P (2014) The influence of tectonics, sea-level changes and dispersal on migration and diversification of Isonandreae (Sapotaceae). Botanical Journal of the Linnean Society 174: 130-140. https://doi.org/10.1111/boj.12108

Richter M (2008) Tropical mountain forests - distribution and general features. In: Gradstein SR, Homeier J, Gansert D (Eds), The tropical mountain forest. Patterns and processes in a biodiversity hotspot. Biodiversity and ecology series. Universitätsverlag Göttingen, Göttingen, Germany, 7-24.

Ricketson JM, Pipoly JohnJ III (2003) Revision of Ardisia Subgenus Auriculardisia (Myrsinaceae). Annals of the Missouri Botanical Garden 90: 179-317. https://doi.org/10.2307/3298582

Ricklefs RE (2008) Disintegration of the Ecological Community. The American Naturalist 172: 741-750. https://doi.org/10.1086/593002

Ridsdale CE (1978) A revision of the tribe Naucleeae s.s. (Rubiaceae). Blumea - Biodiversity, Evolution and Biogeography of Plants 24: 307-366.

Ridsdale CE (1989) A revision of Neonauclea (Rubiaceae). Blumea - Biodiversity, Evolution and Biogeography of Plants 34: 177-275.

Riedl H (1997) Boraginaceae. Flora Malesiana, Series I 13: 43-144.

Ripple WJ, Wolf C, Newsome TM, Galetti M, Alamgir M, Crist E, Mahmoud MI, Laurance WF (2017) World Scientists' Warning to Humanity: A Second Notice. BioScience. https://doi.org/10.1093/biosci/bix125 
Robinson CB (1909) A preliminary revision of Philippine Myrtaceae. The Philippine Journal of Science, C. Botany 4: 331-407.

Robinson H (1999) Revisions in paleotropical Vernonieae (Asteraceae). Proceedings of the Biological Society of Washington 112: 220-247.

Robinson H, Keeley SC, Skvarla J], Chan R (2008) Studies on the Gymnantheminae (Vernonieae: Asteraceae) III: restoration of the genus Strobocalyx and the new genus Tarlmounia. Proceedings of the Biological Society of Washington 121: 19-33. https://doi.org/10.2988/07-21.1

Rockström J, Steffen W, Noone K, Persson Å, Chapin lii FS, Lambin EF, Lenton TM, Scheffer M, Folke C, Schellnhuber HJ, Nykvist B, de Wit CA, Hughes T, van der Leeuw S, Rodhe H, Sörlin S, Snyder PK, Costanza R, Svedin U, Falkenmark M, Karlberg L, Corell RW, Fabry VJ, Hansen J, Walker B, Liverman D, Richardson K, Crutzen P, Foley JA (2009) A safe operating space for humanity. Nature 461: 472-475. https://doi.org/10.1038/461472a

Rodda M (2016) Checklist and typification of Heterostemma (Apocynaceae, Asclepiadoideae, Ceropegieae). Phytotaxa 263: 1-17. https://doi.org/10.11646/phytotaxa.263.1.1

Rodda M, Omlor R (2013) The taxonomy of Oreosparte (Apocynaceae: Asclepiadoideae). Webbia 68: 91-95. https://doi.org/10.1080/00837792.2013.850898

Rodda M, Simonsson Juhonewe N (2016) Hoya isabelchanae Rodda \&amp; Simonsson, a new, showy species of Hoya R.Br. (Apocynaceae, Asclepiadoideae) with pomegranate red flowers from Sulawesi, Indonesia. PhytoKeys 68: 45-50. https://doi.org/10.3897/phytokeys.68.8803

Rodenburg WF (1971) A revision of the genus Trimenia (Trimeniaceae). Blumea - Biodiversity, Evolution and Biogeography of Plants 19: 3-15.

Rohwer JG (1993) Lauraceae. In: Kubitzki K, Rohwer JG, Bittrich V (Eds), Flowering Plants Dicotyledons: Magnoliid, Hamamelid and Caryophyllid Families. The Families and Genera of Vascular Plants, vol. 2. Springer, Berlin, Heidelberg, 366-391. https://doi.org/10.1007/978-3-662-02899-5_46

Rohwer JG, Moraes PLRD, Rudolph B, Werff HVD (2014) A phylogenetic analysis of the Cryptocarya group (Lauraceae), and relationships of Dahlgrenodendron, Sinopora, Triadodaphne, and Yasunia. Phytotaxa 158: 111-132. https://doi.org/10.11646/phytotaxa.158.2.1

Roos MC, Keßler PJA, Robbert Gradstein S, Baas P (2004) Species diversity and endemism of five major Malesian islands: diversity-area relationships. Journal of Biogeography 31: 18931908. https://doi.org/10.1111/j.1365-2699.2004.01154.x

van Royen P (1957) Revision of the Sapotaceae of the Malaysian area in a wider sense. VII. Planchonella Pierre. Blumea - Biodiversity, Evolution and Biogeography of Plants 8: 235445.

van Royen P (1960) Revision of the Sapotaceae of the Malaysian area in a wider sense. XXIII. Palaquium Blanco. Blumea - Biodiversity, Evolution and Biogeography of Plants 10: 432606.

van Royen P (1962) Sertulum Papuanum 6: Himantandraceae. Nova Guinea: contributions to the anthropology, botany, geology, and zoology of the Papuan region. Botany 9: 127-135.

RStudio Team (2015) RStudio: Integrated development environment for R. Version 0.99.491. RStudio, Inc., Boston, MA. en. Available from: http://www.rstudio.com (April 21, 2015).

RStudio Team (2016) RStudio: Integrated development environment for R. RStudio, Inc., Boston, U.S.A. en. Available from: http://www.rstudio.com (April 21, 2015).

Ruhfel BR, Bove CP, Philbrick CT, Davis CC (2016) Dispersal largely explains the Gondwanan distribution of the ancient tropical clusioid plant clade. American Journal of Botany 103: 1117-1128. https://doi.org/10.3732/ajb.1500537

Rutschmann F, Eriksson T, Schönenberger J, Conti E (2004) Did Crypteroniaceae Really Disperse Out of India? Molecular Dating Evidence from rbcL, ndhF, and rpl16 Intron Sequences. International Journal of Plant Sciences 165: S69-S83. https://doi.org/10.1086/383335 
Sagun VG, Levin GA, van Welzen PC (2010) Revision and phylogeny of Acalypha (Euphorbiaceae) in Malesia. Blumea - Biodiversity, Evolution and Biogeography of Plants 55: 21-60. https://doi.org/10.3767/000651910X499141

Samain M-S, Wanke S, Goetghebeur P (2010) Unraveling Extensive Paraphyly in the Genus Hydrangea s. I. with Implications for the Systematics of Tribe Hydrangeeae. Systematic Botany 35: 593-600. https://doi.org/10.1600/036364410792495827

Samarakoon T (2015) Phylogenetic Relationships of Samydaceae and Taxonomic Revision of the Species of Casearia in South-Central Asia. Dissertations 89. Available from: http://aquila.usm.edu/dissertations/89 (March 4, 2017).

Sánchez-Bayo F, Wyckhuys KAG (2019) Worldwide decline of the entomofauna: A review of its drivers. Biological Conservation 232: 8-27. https://doi.org/10.1016/j.biocon.2019.01.020

Sanín MJ, Kissling WD, Bacon CD, Borchsenius F, Galeano G, Svenning J-C, Olivera J, Ramírez R, Trénel P, Pintaud J-C (2016) The Neogene rise of the tropical Andes facilitated diversification of wax palms (Ceroxylon: Arecaceae) through geographical colonization and climatic niche separation. Botanical Journal of the Linnean Society 182: 303-317. https://doi.org/10.1111/boj.12419

Sanmartín I, Ronquist F, Cunningham C (2004) Southern Hemisphere Biogeography Inferred by Event-Based Models: Plant versus Animal Patterns. Systematic Biology 53: 216-243. https://doi.org/10.1080/10635150490423430

Sattarian A (2006) Contribution to the biosystematics of Celtis L. (Celtidaceae) with special emphasis on the African species. PhD thesis. Wageningen University Available from: http://library.wur.nl/WebQuery/wurpubs/fulltext/121819.

Saunders RMK (2002) The genus Goniothalamus (Annonaceae) in Sumatra. Botanical Journal of the Linnean Society 139: 225-254. https://doi.org/10.1046/j.1095-8339.2002.00061.x

Saunders RMK (2003) A synopsis of Goniothalamus species (Annonaceae) in Peninsular Malaysia, with a description of a new species. Botanical Journal of the Linnean Society 142: 321-339. https://doi.org/10.1046/j.1095-8339.2003.00177.x

Schaefer H, Heibl C, Renner SS (2009) Gourds afloat: a dated phylogeny reveals an Asian origin of the gourd family (Cucurbitaceae) and numerous oversea dispersal events. Proceedings of the Royal Society of London B: Biological Sciences 276: 843-851. https://doi.org/10.1098/rspb.2008.1447

Schlechter R (1914) Die Saxifragaceae Papuasiens. Lauterbach C (Ed). Botanische Jahrbücher für Systematik, Pflanzengeschichte und Pflanzengeographie 50: 118-138.

Schlechter R (1916) Die Elaeocarpaceen Papuasiens. Botanische Jahrbücher für Systematik, Pflanzengeschichte und Pflanzengeographie 54: 92-155.

Schlechter R (1925) Die Orchidaceen der Insel Celebes. Repertorium novarum specierum regni vegetabilis 21: 13-212. https://doi.org/10.1002/fedr.19250210802

Schmid R (1972) Floral anatomy of Myrtaceae I. Syzygium. Botanische Jahrbücher für Systematik, Pflanzengeschichte und Pflanzengeographie 92: 433-489.

Schot AM (1998) Biogeography of Aporosa (Euphorbiaceae): testing a phylogenetic hypothesis using geology and distribution patterns. In: Hall R, Holloway JD (Eds), Biogeography and Geological Evolution of SE Asia. Backhuys, Leiden, The Netherlands, 279-290. Available from: http://searg.rhul.ac.uk/searg_uploads/2016/01/Schot.pdf (March 15, 2017).

Schumann K, Hollrung M (1889) Die Flora von Kaiser Wilhelms Land. Asher \& Co., Berlin, V + 137 pp. Available from: http://nbn-resolving.de/urn:nbn:de:hebis:30:2-259142.

Schwery O, Onstein RE, Bouchenak-Khelladi Y, Xing Y, Carter RJ, Linder HP (2015) As old as the mountains: the radiations of the Ericaceae. New Phytologist 207: 355-367. https://doi.org/10.1111/nph.13234

Scott AJ (1979) A Revision of Xanthomyrtus (Myrtaceae). Kew Bulletin 33: 461-484. https://doi.org/10.2307/4110146 
Seifert KA, Crous PW, Frisvad JC (2008) Correcting the Impact Factors of Taxonomic Journals by Appropriate Citation of Taxonomy (ACT). Persoonia - Molecular Phylogeny and Evolution of Fungi 20: 105. https://doi.org/10.3767/003158508X324236

Shaw HKA (1972) Notes on Malesian and Other Asiatic Euphorbiaceae. Kew Bulletin 27: 3-93. https://doi.org/10.2307/4117873

Shaw HKA (1981) Notes on Asiatic, Malesian and Melanesian Euphorbiaceae. Kew Bulletin 36: 599-612. https://doi.org/10.2307/4117592

Shaw HKA (1982) The Euphorbiaceae of Central Malesia (Celebes, Moluccas. Lesser Sunda Is.). Kew Bulletin 37: 1-40. https://doi.org/10.2307/4114718

Shi S, Jin H, Zhong Y, He X, Huang Y, Tan F, Boufford DE (2000) Phylogenetic relationships of the Magnoliaceae inferred from cpDNA matK sequences. Theoretical and Applied Genetics 101: 925-930. https://doi.org/10.1007/s001220051563

Shukla A, Mehrotra RC, Spicer RA, Spicer TEV (2016) Aporosa Blume from the paleoequatorial rainforest of Bikaner, India: Its evolution and diversification in deep time. Review of Palaeobotany and Palynology 232: 14-21. https://doi.org/10.1016/j.revpalbo.2016.05.006

Sierra SEC, van Welzen PC (2005) A taxonomic Revision of Mallotus Section Mallotus (Euphorbiaceae) in Malesia. Blumea - Biodiversity, Evolution and Biogeography of Plants 50: 249-274.

Simmons MP, Cappa JJ (2013) Wilczekra, a New Genus of Celastraceae for a Disjunct Lineage of Euonymus. Systematic Botany 38: 148-153. https://doi.org/10.1600/036364413X661881

Simmons MP, Bacon CD, Cappa JJ, McKenna MJ (2012a) Phylogeny of Celastraceae Subfamilies Cassinoideae and Tripterygioideae Inferred from Morphological Characters and Nuclear and Plastid Loci. Systematic Botany 37: 456-467. https://doi.org/10.1600/036364412X635502

Simmons MP, McKenna MJ, Bacon CD, Yakobson K, Cappa JJ, Archer RH, Ford AJ (2012b) Phylogeny of Celastraceae tribe Euonymeae inferred from morphological characters and nuclear and plastid genes. Molecular Phylogenetics and Evolution 62: 9-20. https://doi.org/10.1016/j.ympev.2011.08.022

Simões AO, Livshultz T, Conti E, Endress ME (2007) Phylogeny and systematics of the Rauvolfioideae (Apocynaceae) based on molecular and morphological evidence. Annals of the Missouri Botanical Garden 94: 268-297. https://doi.org/10.3417/00266493(2007)94[268:PASOTR]2.0.CO;2

Simpson GG (1980) Splendid isolation: the curious history of South American mammals. Yale University Press, New Haven, U.S.A., ix, 266 pp.

Sleumer H (1954) Flacourtiaceae. Flora Malesiana, Series I 5: 1-106.

Sleumer H (1955) Proteaceae. Flora Malesiana, Series I 5: 147-206.

Sleumer H (1961) Florae Malesianae Precursores XXVIII. The genus Vaccinium in Malaysia.

Blumea - Biodiversity, Evolution and Biogeography of Plants 11: 9-112.

Sleumer H (1966) Ericaceae. Flora Malesiana, Series I 6: 469-914.

Sleumer H (1971a) Clethraceae. Flora Malesiana, Series I 7: 139-150.

Sleumer H (1971b) Icacinaceae. Flora Malesiana, Series I 7: 1-87.

Sleumer H (1980) A taxonomic account of the Olacaceae of Asia, Malesia, and the adjacent areas. Blumea 26: 145-168.

Sleumer H (1988a) A revision of the genus Ardisia Sw. (Myrsinaceae) in New Guinea. Blumea Biodiversity, Evolution and Biogeography of Plants 33: 115-140.

Sleumer H (1988b) The genera Discocalyx Mez, Fittingia Mez, Loheria Merr. and Tapeinosperma Hook.f. (Myrsinaceae) in New Guinea. Blumea - Biodiversity, Evolution and Biogeography of Plants 33: 81-107.

Slik JWF (2009) Plants of Southeast Asia. Plants of Southeast Asia. Available from: http://www.asianplant.net (May 18, 2015).

Slik JWF, Raes N, Aiba S-I, Brearley FQ, Cannon CH, Meijaard E, Nagamasu H, Nilus R, Paoli G, Poulsen AD, Sheil D, Suzuki E, Van Valkenburg JLCH, Webb CO, Wilkie P, Wulffraat S (2009) 
Environmental correlates for tropical tree diversity and distribution patterns in Borneo. Diversity and Distributions 15: 523-532. https://doi.org/10.1111/j.14724642.2009.00557.x

SlikJWF, Arroyo-Rodríguez V, Aiba S-I, Alvarez-Loayza P, Alves LF, Ashton PS, Balvanera P, Bastian $M L$, Bellingham PJ, Berg E van den, Bernacci L, Bispo P da C, Blanc L, Böhning-Gaese $K$, Boeckx P, Bongers F, Boyle B, Bradford M, Brearley FQ, Hockemba MB-N, Bunyavejchewin S, Matos DCL, Castillo-Santiago M, Catharino ELM, Chai S-L, Chen Y, Colwell RK, Robin CL, Clark C, Clark DB, Clark DA, Culmsee H, Damas K, Dattaraja HS, Dauby G, Davidar P, DeWalt SJ, Doucet J-L, Duque A, Durigan G, Eichhorn KAO, Eisenlohr PV, Eler E, Ewango C, Farwig N, Feeley KJ, Ferreira L, Field R, Filho AT de O, Fletcher C, Forshed O, Franco G, Fredriksson G, Gillespie T, Gillet J-F, Amarnath G, Griffith DM, Grogan J, Gunatilleke N, Harris D, Harrison R, Hector A, Homeier J, Imai N, Itoh A, Jansen PA, Joly CA, Jong BHJ de, Kartawinata K, Kearsley E, Kelly DL, Kenfack D, Kessler M, Kitayama K, Kooyman R, Larney E, Laumonier Y, Laurance S, Laurance WF, Lawes MJ, Amaral IL do, Letcher SG, Lindsell J, Lu X, Mansor A, Marjokorpi A, Martin EH, Meilby H, Melo FPL, Metcalfe DJ, Medjibe VP, Metzger JP, Millet J, Mohandass D, Montero JC, Valeriano M de M, Mugerwa B, Nagamasu $\mathrm{H}$, Nilus R, Ochoa-Gaona S, Onrizal, Page N, Parolin P, Parren M, Parthasarathy N, Paudel E, Permana A, Piedade MTF, Pitman NCA, Poorter L, Poulsen AD, Poulsen J, Powers J, Prasad RC, Puyravaud J-P, Razafimahaimodison J-C, Reitsma J, Santos JR dos, Spironello WR, Romero-Saltos H, Rovero F, Rozak AH, Ruokolainen K, Rutishauser E, Saiter F, Saner $P$, Santos BA, Santos F, Sarker SK, Satdichanh M, Schmitt CB, Schöngart J, Schulze M, Suganuma MS, Sheil D, Pinheiro E da S, Sist P, Stevart T, Sukumar R, Sun I-F, Sunderand T, Suresh HS, Suzuki E, Tabarelli M, Tang J, Targhetta N, Theilade I, Thomas DW, Tchouto P, Hurtado J, Valencia R, Valkenburg JLCH van, Do TV, Vasquez R, Verbeeck H, Adekunle V, Vieira SA, Webb CO, Whitfeld T, Wich SA, Williams J, Wittmann F, Wöll H, Yang X, Yao CYA, Yap SL, Yoneda T, Zahawi RA, Zakaria R, Zang R, Assis RL de, Luize BG, Venticinque EM (2015) An estimate of the number of tropical tree species. Proceedings of the National Academy of Sciences 112: 7472-7477. https://doi.org/10.1073/pnas.1423147112

Slik JWF, Franklin J, Arroyo-Rodríguez V, Field R, Aguilar S, Aguirre N, Ahumada J, Aiba S-I, Alves LF, K A, Avella A, Mora F, Aymard C. GA, Báez S, Balvanera P, Bastian ML, Bastin J-F, Bellingham PJ, van den Berg $E$, da Conceição Bispo P, Boeckx P, Boehning-Gaese K, Bongers F, Boyle B, Brambach F, Brearley FQ, Brown S, Chai S-L, Chazdon RL, Chen S, Chhang P, Chuyong G, Ewango C, Coronado IM, Cristóbal-Azkarate J, Culmsee H, Damas K, Dattaraja HS, Davidar P, DeWalt SJ, Din H, Drake DR, Duque A, Durigan G, Eichhorn K, Eler ES, Enoki T, Ensslin A, Fandohan AB, Farwig N, Feeley KJ, Fischer M, Forshed O, Garcia QS, Garkoti SC, Gillespie TW, Gillet J-F, Gonmadje C, Granzow-de la Cerda I, Griffith DM, Grogan J, Hakeem KR, Harris DJ, Harrison RD, Hector A, Hemp A, Homeier J, Hussain MS, Ibarra-Manríquez G, Hanum IF, Imai N, Jansen PA, Joly CA, Joseph S, Kartawinata K, Kearsley E, Kelly DL, Kessler M, Killeen TJ, Kooyman RM, Laumonier Y, Laurance SG, Laurance WF, Lawes MJ, Letcher SG, Lindsell J, Lovett J, Lozada J, Lu X, Lykke AM, Mahmud KB, Mahayani NPD, Mansor A, Marshall AR, Martin EH, Calderado Leal Matos D, Meave JA, Melo FPL, Mendoza ZHA, Metali F, Medjibe VP, Metzger JP, Metzker T, Mohandass D, Munguía-Rosas MA, Muñoz R, Nurtjahy E, de Oliveira EL, Onrizal, Parolin P, Parren M, Parthasarathy N, Paudel E, Perez R, Pérez-García EA, Pommer U, Poorter L, Qi L, Piedade MTF, Pinto JRR, Poulsen AD, Poulsen JR, Powers JS, Prasad RC, Puyravaud J-P, Rangel O, Reitsma J, Rocha DSB, Rolim S, Rovero F, Rozak A, Ruokolainen K, Rutishauser E, Rutten G, Mohd. Said MohdN, Saiter FZ, Saner P, Santos B, dos Santos JR, Sarker SK, Schmitt CB, Schoengart J, Schulze M, Sheil D, Sist P, Souza AF, Spironello WR, Sposito T, Steinmetz R, Stevart T, Suganuma MS, Sukri R, Sultana A, Sukumar R, Sunderland T, Supriyadi, Suresh HS, Suzuki E, Tabarelli M, Tang J, Tanner EVJ, Targhetta N, Theilade I, Thomas D, Timberlake $\mathrm{J}$, de Morisson Valeriano $M$, van Valkenburg J, Van Do T, Van Sam H, Vandermeer JH, Verbeeck H, Vetaas OR, Adekunle V, Vieira SA, Webb CO, Webb EL, Whitfeld T, Wich S, 
Williams J, Wiser S, Wittmann F, Yang X, Adou Yao CY, Yap SL, Zahawi RA, Zakaria R, Zang R (2018) Phylogenetic classification of the world's tropical forests. Proceedings of the National Academy of Sciences 115: 1837-1842. https://doi.org/10.1073/pnas.1714977115 Smedmark JEE, Eriksson T, Bremer B (2010) Divergence time uncertainty and historical biogeography reconstruction - an example from Urophylleae (Rubiaceae). Journal of Biogeography 37: 2260-2274. https://doi.org/10.1111/j.1365-2699.2010.02366.x

Smedmark JEE, Razafimandimbison SG, Wikström N, Bremer B (2014) Inferring geographic range evolution of a pantropical tribe in the coffee family (Lasiantheae, Rubiaceae) in the face of topological uncertainty. Molecular Phylogenetics and Evolution 70: 182-194. https://doi.org/10.1016/j.ympev.2013.09.007

Smith AC (1969) A Reconsideration of the Genus Tasmannia (Winteraceae). Taxon 18: 286-290. https://doi.org/10.2307/1218830

Sniderman JMK, Jordan GJ (2011) Extent and timing of floristic exchange between Australian and Asian rain forests. Journal of Biogeography 38: 1445-1455. https://doi.org/10.1111/j.1365-2699.2011.02519.x

Sodhi NS, Koh LP, Brook BW, Ng PKL (2004) Southeast Asian biodiversity: an impending disaster. Trends in Ecology \& Evolution 19: 654-660. https://doi.org/10.1016/j.tree.2004.09.006

Soejarto DD (1980) Revision of South American Saurauia (Actinidiaceae). Fieldiana. Botany. New Series 2: i-vii, 1-141.

Soepadmo E (1970) Florae Malesianae Praecursores XLIX. Malesian species of Lithocarpus BI. (Fagaceae). Reinwardtia 8: 197-308. https://doi.org/10.14203/reinwardtia.v8i1.953

Soepadmo E (1977) Ulmaceae. Flora Malesiana, Series I 8: 31-76.

Soepadmo E (2000) Fagaceae. In: Soepadmo E, Saw LG (Eds), Tree Flora of Sabah and Sarawak. Ampang Press Sdn. Bhd. for Forest Research Institute Malaysia (FRIM), Sabah Forestry Department, and Sarawak Forestry Department, Kuala Lumpur, 1-117.

Soepadmo E, van Steenis CGGJ (1972) Fagaceae. Flora Malesiana, Series I 7: 265-403.

Soepadmo E, Wong KM, Saw KM, Chung RCK, Kiew R (1995) 1-8 Tree Flora of Sabah and Sarawak. Forest Research Institute Malaysia (FRIM), Sabah Forestry Department, and Sarawak Forestry Department, Kuala Lumpur, Selangor.

Soh W-K, Parnell J (2015) A revision of Syzygium Gaertn. (Myrtaceae) in Indochina (Cambodia, Laos and Vietnam). Adansonia 37: 179-275. https://doi.org/10.5252/a2015n2a1

Sohmer SH (1988) The nonclimbing species of the genus Psychotria (Rubiaceae) in New Guinea and the Bismarck Archipelago. Bishop Museum Press, Honolulu, vi + 339 pp.

Sohmer SH, Davis AP (2007) The Genus Psychotria (Rubiaceae) in the Philippine Archipelago. Botanical Research Institute of Texas, Fort Worth, Texas. Available from: viii + 247.

Sothers CA, Prance GT (2014) Resurrection of Angelesia, a Southeast Asian genus of Chrysobalanaceae. Blumea - Biodiversity, Evolution and Biogeography of Plants 59: 103105. https://doi.org/10.3767/000651914X684880

Spriggs EL, Clement WL, Sweeney PW, Madriñán S, Edwards EJ, Donoghue MJ (2015) Temperate radiations and dying embers of a tropical past: the diversification of Viburnum. New Phytologist 207: 340-354. https://doi.org/10.1111/nph.13305

Ståhl B, Anderberg AA (2004) Myrsinaceae. In: Kubitzki K (Ed), Flowering Plants - Dicotyledons: Celastrales, Oxalidales, Rosales, Cornales, Ericales. The Families and Genera of Vascular Plants, vol. 6. Springer, Berlin, Heidelberg, 266-281. https://doi.org/10.1007/978-3-66207257-8_30

ter Steege H, Pitman N, Sabatier D, Castellanos H, Van Der Hout P, Daly DC, Silveira M, Phillips $O$, Vasquez R, Van Andel T, Duivenvoorden J, De Oliveira AA, Ek R, Lilwah R, Thomas R, Van Essen J, Baider C, Maas P, Mori S, Terborgh J, NúÑez Vargas P, Mogollón H, Morawetz W (2003) A spatial model of tree a-diversity and tree density for the Amazon. Biodiversity and Conservation 12: 2255-2277. https://doi.org/10.1023/A:1024593414624

van Steenis CGGJ (1935a) On the origin of the Malaysian mountain flora. Part 1. Facts and statement of the problem. Bulletin du Jardin Botanique Buitenzorg, Série III 13: 135-262. 
van Steenis CGGJ (1935b) On the origin of the Malaysian mountain flora. Part 2. Altitudinal zones, general considerations and renewed statement of the problem. Bulletin du Jardin Botanique Buitenzorg, Série III 13: 289-417.

van Steenis CGGJ (1949) Styracaceae. Flora Malesiana, Series I 4: 49-56.

van Steenis CGGJ (1962) The mountain flora of the Malaysian tropics. Endeavour 21: 183-194.

van Steenis CGGJ (1977) Bignoniaceae. Flora Malesiana, Series I 8: 114-186.

van Steenis CGGJ (1979) Plant-geography of east Malesia. Botanical Journal of the Linnean Society 79: 97-178. https://doi.org/10.1111/j.1095-8339.1979.tb01511.x

van Steenis CGGJ (1984) Floristic altitudinal zones in Malesia. Botanical Journal of the Linnean Society 89: 289-292. https://doi.org/10.1111/j.1095-8339.1984.tb02560.x

van Steenis CGGJ (1986) Sphenostemonaceae. Flora Malesiana, Series I 10: 145-149.

van Steenis CGGJ, de Wilde WJJO, Nooteboom HP, Kalkman C, Kirkup DW, Stevens PF, Saw LG (1948) 1-23 Flora Malesiana, being an illustrated account of the Malaysian Flora, including keys for determination, diagnostic descriptions, references to the literature, synonymy, and distribution, and notes on the ecology of its wild and commonly cultivated plants. Series I - Spermatophyta / Seed Plants. Noordhoff-Kolff N.V., Rijksherbarium / Hortus Botanicus Leiden, Nationaal Herbarium Nederlands, Naturalis Biodiversity Center, Lembaga IImu Pengetahuan Indonesia (LIPI), Jakarta, Leiden.

van Steenis-Kruseman MJ, van Welzen PC (2014) Cyclopaedia of Malesian Collectors. Available from: http://www.nationaalherbarium.nl/FMCollectors/ (August 20, 2016).

Steffen W, Persson A, Deutsch L, Zalasiewicz J, Williams M, Richardson K, Crumley C, Crutzen P, Folke C, Gordon L, Molina M, Ramanathan V, Rockström J, Scheffer M, Schellnhuber HJ, Svedin U (2011) The Anthropocene: From Global Change to Planetary Stewardship. AMBIO 40: 739. https://doi.org/10.1007/s13280-011-0185-x

Steffen W, Rockström J, Richardson K, Lenton TM, Folke C, Liverman D, Summerhayes CP, Barnosky AD, Cornell SE, Crucifix M, Donges JF, Fetzer I, Lade SJ, Scheffer M, Winkelmann R, Schellnhuber HJ (2018) Trajectories of the Earth System in the Anthropocene. Proceedings of the National Academy of Sciences: 201810141. https://doi.org/10.1073/pnas.1810141115

Steinbauer MJ, Field R, Grytnes J-A, Trigas P, Ah-Peng C, Attorre F, Birks HJB, Borges PAV, Cardoso P, Chou C-H, De Sanctis M, de Sequeira MM, Duarte MC, Elias RB, Fernández-Palacios JM, Gabriel R, Gereau RE, Gillespie RG, Greimler J, Harter DEV, Huang T-J, Irl SDH, Jeanmonod D, Jentsch A, Jump AS, Kueffer C, Nogué S, Otto R, Price J, Romeiras MM, Strasberg D, Stuessy T, Svenning J-C, Vetaas OR, Beierkuhnlein C (2016) Topography-driven isolation, speciation and a global increase of endemism with elevation. Global Ecology and Biogeography 25: 1097-1107. https://doi.org/10.1111/geb.12469

Stelbrink B, Albrecht C, Hall R, von Rintelen T (2012) The Biogeography of Sulawesi Revisited: Is There Evidence for a Vicariant Origin of Taxa on Wallace's "anomalous Island"? Evolution 66: 2252-2271. https://doi.org/10.1111/j.1558-5646.2012.01588.x

Stemmerik JF (1964) Florae Malesianae Precursores XXXVIII. Notes on Pisonia L. in the Old World (Nyctaginaceae). Blumea - Biodiversity, Evolution and Biogeography of Plants 12: 275284.

Stevens PF (1980) A revision of the Old World species of Calophyllum (Guttiferae). Journal of the Arnold Arboretum 61: 117-424.

Stevens PF (2007) Clusiaceae-Guttiferae. In: Kubitzki K (Ed), Flowering Plants - Eudicots: Berberidopsidales, Buxales, Crossosomatales, Fabales p.p., Geraniales, Gunnerales, Myrtales p.p., Proteales, Saxifragales, Vitales, Zygophyllales, Clusiaceae Alliance, Passifloraceae Alliance, Dilleniaceae, Huaceae, Picramniaceae, Sabiaceae. The Families and Genera of Vascular Plants, vol. 9. Springer, Berlin, Heidelberg, 48-66. https://doi.org/10.1007/978-3-540-32219-1_10 
Stevens PF (2017) Angiosperm Phylogeny Website. Version 14, July 2017. http://www.mobot.org/MOBOT/research/APweb/welcome.html. Available from: http://www.mobot.org/MOBOT/research/APweb/welcome.html (March 15, 2018).

Stevens PF, Dressler S, Weitzman AL (2004a) Theaceae. In: Kubitzki K (Ed), Flowering Plants Dicotyledons: Celastrales, Oxalidales, Rosales, Cornales, Ericales. The Families and Genera of Vascular Plants, vol. 6. Springer, Berlin, Heidelberg, 463-471. https://doi.org/10.1007/978-3-662-07257-8_49

Stevens PF, Luteyn J, Oliver EGH, Bell TL, Brown EA, Crowden RK, George AS, Jordan GJ, Ladd P, Lemson K, Mclean CB, Menadue Y, Pate JS, Stace HM, Weiller CM (2004b) Ericaceae. In: Kubitzki K (Ed), Flowering Plants - Dicotyledons: Celastrales, Oxalidales, Rosales, Cornales, Ericales. The Families and Genera of Vascular Plants, vol. 6. Springer, Berlin, Heidelberg, 145-194. https://doi.org/10.1007/978-3-662-07257-8_19

Stone BC (1974) Towards and improved infrageneric classification in Pandanus (Pandanaceae). Botanische Jahrbücher für Systematik, Pflanzengeschichte und Pflanzengeographie 94: 459-540.

Stone BC (1983a) Some new and critical Pandanus species of subgenus Acrostigma. I. Supplement to Revisio Pandanacearum. The Gardens' Bulletin, Singapore 36: 205-212.

Stone BC (1983b) Studies in the Malesian Pandanaceae, 19. New species of Freycinetia and Pandanus from Malesia and Southeast Asia. Journal of the Arnold Arboretum 64: 309324.

Stone BC (1989) New and Noteworthy Malesian Myrsinaceae, III. On the Genus Ardisia Sw. in Borneo. Proceedings of the Academy of Natural Sciences of Philadelphia 141: 263-306.

Stone BC (1990) Studies in Malesian Myrsinaceae, V. Additional New Species of Ardisia Sw. Proceedings of the Academy of Natural Sciences of Philadelphia 142: 21-58.

Stone RD (2014) The species-rich, paleotropical genus Memecylon (Melastomataceae): Molecular phylogenetics and revised infrageneric classification of the African species. Taxon 63: 539-561. https://doi.org/10.12705/633.10

Stoops E, van Welzen PC (2013) A revision of Ptychopyxis (Euphorbiaceae) in southeast Asia. Nordic Journal of Botany 31: 094-112. https://doi.org/10.1111/j.1756-1051.2012.01591.x

Strijk JS, Bone RE, Thébaud C, Buerki S, Fritsch PW, Hodkinson TR, Strasberg D (2014) Timing and tempo of evolutionary diversification in a biodiversity hotspot: Primulaceae on Indian Ocean islands. Journal of Biogeography 41: 810-822. https://doi.org/10.1111/jbi.12259

Stull GW, Stefano RD de, Soltis DE, Soltis PS (2015) Resolving basal lamiid phylogeny and the circumscription of Icacinaceae with a plastome-scale data set. American Journal of Botany 102: 1794-1813. https://doi.org/10.3732/ajb.1500298

Su H-J, Hu J-M, Anderson FE, Der JP, Nickrent DL (2015) Phylogenetic relationships of Santalales with insights into the origins of holoparasitic Balanophoraceae. Taxon 64: 491-506. https://doi.org/10.12705/643.2

Su Y, Liao W, Wang T, Sun Y, Wei Q, Chang H (2011) Phylogeny and evolutionary divergence times in Apterosperma and Euryodendron: Evidence of a Tertiary origin in south China. Biochemical Systematics and Ecology 39: 769-777. https://doi.org/10.1016/j.bse.2011.07.004

Sugumaran M, Wong KM (2012) Studies in Malesian Gentianaceae I: Fagraea sensu lato complex genus o several genera? A molecular phylogenetic study. The Gardens' Bulletin, Singapore 64: 301-332.

Sun M, Naeem R, Su J-X, Cao Z-Y, Burleigh JG, Soltis PS, Soltis DE, Chen Z-D (2016) Phylogeny of the Rosidae: A dense taxon sampling analysis. Journal of Systematics and Evolution 54: 363-391. https://doi.org/10.1111/jse.12211

Surveswaran S, Wang RJ, Su YCF, Saunders RMK (2010) Generic delimitation and historical biogeography in the early-divergent "ambavioid" lineage of Annonaceae: Cananga, Cyathocalyx and Drepananthus. Taxon 59: 1721-1734. 
Swensen S, Kubitzki K (2010) Datiscaceae. In: Kubitzki K (Ed), Flowering Plants - Eudicots: Sapindales, Cucurbitales, Myrtaceae. The Families and Genera of Vascular Plants, vol. 10. Springer, Berlin, Heidelberg, 175-179. https://doi.org/10.1007/978-3-642-14397-7_11

Swenson U, Nylinder S, Munzinger J (2013) Towards a natural classification of Sapotaceae subfamily Chrysophylloideae in Oceania and Southeast Asia based on nuclear sequence data. Taxon 62: 746-770. https://doi.org/10.12705/624.11

Swenson U, Nylinder S, Munzinger J (2014) Sapotaceae biogeography supports New Caledonia being an old Darwinian island. Journal of Biogeography 41: 797-809. https://doi.org/10.1111/jbi.12246

Sytsma KJ, Litt A, Zjhra ML, Chris Pires J, Nepokroeff M, Conti E, Walker J, Wilson PG (2004) Clades, Clocks, and Continents: Historical and Biogeographical Analysis of Myrtaceae, Vochysiaceae, and Relatives in the Southern Hemisphere. International Journal of Plant Sciences 165: S85-S105. https://doi.org/10.1086/421066

Syzygium Working Group (SYZWG), Ahmad B, Baider C, Bernardini B, Biffin E, Brambach F, Burslem D, Byng JW, Christenhusz MJM, Florens FBV, Lucas EJ, Ray A, Ray R, Smets E, Snow NW, Strijk JS, Wilson PW (2016) Syzygium (Myrtaceae): Monographing a taxonomic giant via 22 coordinated regional revisions. PeerJ Preprints 4:e1930v1. Available from: https://peerj.com/preprints/1930 (April 6, 2016).

Takeuchi WN (2002) Notes and new species in Papuasian Syzygium (Myrtaceae). Edinburgh Journal of Botany 59: 259-272. https://doi.org/10.1017/S0960428602000070

Takeuchi WN (2010) A Floristic Reconnaissance of Montane Environments in the Foja Mts. of Papua Province, Indonesia. Harvard Papers in Botany 15: 11-25. https://doi.org/10.3100/025.015.0104

Takeuchi WN, Pipoly JohnJ III (2009) Nomenclatural transfers in East Malesian Myrsine (Myrsinaceae), and the description of M. warrae, a distinctive new species from ultrabasic environments in Papua New Guinea. Edinburgh Journal of Botany 66: 459-467. https://doi.org/10.1017/S0960428609990102

Takyu M, Aiba S-I, Kitayama K (2002) Beta-diversity and changes in population structure along topographical gradients on different geological substrates in tropical montane forests on Mount Kinabalu, Borneo. Sabah Parks Nature Journal 5: 165-218.

Tantra IGM (1976) A revision of the genus Sterculia L. in Malesia. Forest Research Institute, Bogor, $194 \mathrm{pp}$.

Tchouto MGP, Boer WFD, Wilde JJFED, Maesen LJGVD (2006) Diversity patterns in the flora of the Campo-Ma'an rain forest, Cameroon: do tree species tell it all? In: Hawksworth DL, Bull AT (Eds), Forest Diversity and Management. Topics in Biodiversity and Conservation. Springer Netherlands, 293-314. https://doi.org/10.1007/978-1-4020-5208-8_16

Teijsmann JE (1879) Bekort verslag eener botanische dienstreis naar het Gouvernement van Celebes en Onderhoorigheden, van 12 Juni t. m. 29 December 1877. Natuurkundig Tijdschrift voor Nederlandsch-Indië 38: 54-125.

The Angiosperm Phylogeny Group (2016) An update of the Angiosperm Phylogeny Group classification for the orders and families of flowering plants: APG IV. Botanical Journal of the Linnean Society 181: 1-20. https://doi.org/10.1111/boj.12385

The Malesian Key Group (2004) An Interactive Key to Malesian Seed Plants. Version 1.0. National Herbarium of the Netherlands \& Royal Botanic Gardens, Kew, Leiden, The Netherlands \& Richmond, Surrey, U.K. en. Available from: http://www.kew.org/herbarium/keys/fm/index.html.

The Plant List (2019) Version 1.1. Published on the Internet. Available from: http://www.theplantlist.org (February 12, 2019).

Thiers B (2018) Index Herbariorum: A global directory of public herbaria and associated staff. New York Botanical Garden's Virtual Herbarium. Available from: http://sweetgum.nybg.org/science/ih/ (December 17, 2016). 
Thomas DC, Hughes M (2008) Begonia varipeltata (Begoniaceae): A new peltate species from Sulawesi, Indonesia. Edinburgh Journal of Botany 65: 369. https://doi.org/10.1017/S096042860800509X

Thomas DC, Ardi WH, Hughes M (2009a) Two new species of Begonia (Begoniaceae) from Central Sulawesi, Indonesia. Edinburgh Journal of Botany 66: 103. https://doi.org/10.1017/S0960428609005320

Thomas DC, Ardi WH, Hughes M (2011) Nine new species of Begonia (Begoniaceae) from South and West Sulawesi, Indonesia. Edinburgh Journal of Botany 68: 225-255. https://doi.org/10.1017/S0960428611000072

Thomas DC, Bour A, Ardi WH (2018) Begonia of the Matarombeo karst, Southeast Sulawesi, Indonesia, including two new species. Gardens' Bulletin, Singapore 70: 136-176. https://doi.org/10.26492/gbs70(1).2018-15

Thomas DC, Ardi WH, Hartutiningsih, Hughes M (2009b) Two new species of Begonia (Begoniaceae) from South Sulawesi, Indonesia. Edinburgh Journal of Botany 66: 229-238. https://doi.org/10.1017/S0960428609005484

Thomas DC, Chatrou LW, Stull GW, Johnson DM, Harris DJ, Thongpairoj U, Saunders RMK (2015) The historical origins of palaeotropical intercontinental disjunctions in the pantropical flowering plant family Annonaceae. Perspectives in Plant Ecology, Evolution and Systematics 17: 1-16. https://doi.org/10.1016/j.ppees.2014.11.001

Thomas DC, Hughes M, Phutthai T, Ardi WH, Rajbhandary S, Rubite R, Twyford AD, Richardson JE (2012) West to east dispersal and subsequent rapid diversification of the mega-diverse genus Begonia (Begoniaceae) in the Malesian archipelago. Journal of Biogeography 39: 98-113. https://doi.org/10.1111/j.1365-2699.2011.02596.x

Thomas N, Bruhl JJ, Ford A, Weston PH (2014) Molecular dating of Winteraceae reveals a complex biogeographical history involving both ancient Gondwanan vicariance and long-distance dispersal. Journal of Biogeography 41: 894-904. https://doi.org/10.1111/jbi.12265

Thompson J (1989) A revision of the genus Leptospermum (Myrtaceae). Telopea 3: 301-449. https://doi.org/10.7751/telopea19894902

Thornhill AH, Ho SYW, Külheim C, Crisp MD (2015) Interpreting the modern distribution of Myrtaceae using a dated molecular phylogeny. Molecular Phylogenetics and Evolution 93: 29-43. https://doi.org/10.1016/j.ympev.2015.07.007

Tokuoka T (2007) Molecular phylogenetic analysis of Euphorbiaceae sensu stricto based on plastid and nuclear DNA sequences and ovule and seed character evolution. Journal of Plant Research 120: 511-522. https://doi.org/10.1007/s10265-007-0090-3

Trimanto, Hapsari L (2018) Short communication: A new record of Etlingera megalocheilos (Griff.) A.D. Poulsen (Zingiberaceae) in Sulawesi, Indonesia. Biodiversitas: Journal of Biological Diversity 19: 1227-1235. https://doi.org/10.13057/biodiv/d190407

Tropicos (2015) Missouri Botanical Garden. Available from: http://www.tropicos.org (January 7, 2018).

Tsou C, Li L, Vijayan K (2016) The Intra-familial Relationships of Pentaphylacaceae s.l. as Revealed by DNA Sequence Analysis. Biochemical Genetics 54: 270-282. https://doi.org/10.1007/s10528-016-9717-1

Turner B, Munzinger J, Duangjai S, Temsch EM, Stockenhuber R, Barfuss MHJ, Chase MW, Samuel R (2013) Molecular phylogenetics of New Caledonian Diospyros (Ebenaceae) using plastid and nuclear markers. Molecular Phylogenetics and Evolution 69: 740-763. https://doi.org/10.1016/j.ympev.2013.07.002

Tyukavina A, Hansen MC, Potapov PV, Krylov AM, Goetz SJ (2015) Pan-tropical hinterland forests: mapping minimally disturbed forests. Global Ecology and Biogeography 25: 151-163. https://doi.org/10.1111/geb.12394

Urban MC (2015) Accelerating extinction risk from climate change. Science 348: 571-573. https://doi.org/10.1126/science.aaa4984 
Utteridge TMA (2011) A revision of the genus Medusanthera (Stemonuraceae, Icacinaceae s.I.). Kew Bulletin 66: 49-81. https://doi.org/10.1007/s12225-011-9266-z

Utteridge TMA, Edwards PJ (2009) The subalpine and alpine flora of Mount Jaya (New Guinea): status and threats. Blumea - Biodiversity, Evolution and Biogeography of Plants 54: 280283. https://doi.org/10.3767/000651909X476292

Utteridge TMA, Schori M (2011) Updating Malesian Icacinaceae. The Gardens' Bulletin, Singapore 63: 105-118.

Vadala AJ, Greenwood DR (2001) Australian Paleogene vegetation and environments: evidence for palaeo-Gondwanan elements in the fossil records of Lauraceae. In: Metcalfe I, Smith JMB, Morwood M, Davidson I (Eds), Faunal and Floral Migrations and Evolution in SE AsiaAustralasia. A.A. Balkema Publishers, Lisse, 201-226.

Valcárcel V, Fiz-Palacios O, Wen J (2014) The origin of the early differentiation of Ivies (Hedera L.) and the radiation of the Asian Palmate group (Araliaceae). Molecular Phylogenetics and Evolution 70: 492-503. https://doi.org/10.1016/j.ympev.2013.10.016

Vander Kloet SP (2005) The Taxonomy of Vaccinium Section Rigiolepis (Vaccinieae, Ericaceae). Blumea - Biodiversity, Evolution and Biogeography of Plants 50: 477-497. https://doi.org/10.3767/000651905X622743

Vander Kloet SP, Dickinson TA (2009) A subgeneric classification of the genus Vaccinium and the metamorphosis of $\mathrm{V}$. section Bracteata Nakai: more terrestrial and less epiphytic in habit, more continental and less insular in distribution. Journal of Plant Research 122: 253-268. https://doi.org/10.1007/s10265-008-0211-7

Veranso-Libalah MC, Kadereit G, Stone RD, Couvreur TLP (2018) Multiple shifts to open habitats in Melastomateae (Melastomataceae) congruent with the increase of African Neogene climatic aridity. Journal of Biogeography 45: 1420-1431. https://doi.org/10.1111/jbi.13210

Verdcourt B (1986) Chloranthaceae. Flora Malesiana, Series I 10: 123-144.

Vermeij GJ (1991) When Biotas Meet: Understanding Biotic Interchange. Science 253: 10991104. https://doi.org/10.1126/science.253.5024.1099

Verstraete B, Janssens S, Rønsted N (2017) Non-nodulated bacterial leaf symbiosis promotes the evolutionary success of its host plants in the coffee family (Rubiaceae). Molecular Phylogenetics and Evolution 113: 161-168. https://doi.org/10.1016/j.ympev.2017.05.022

Vidal-Russell R, Nickrent DL (2008) The first mistletoes: Origins of aerial parasitism in Santalales. Molecular Phylogenetics and Evolution 47: 523-537. https://doi.org/10.1016/j.ympev.2008.01.016

Vink W (1955) Hamamelidaceae. Flora Malesiana, Series I 5: 363-379.

Vink W (1970) The Winteraceae of the Old World. I. Pseudowintera and Drimys - Morphology and taxonomy. Blumea - Biodiversity, Evolution and Biogeography of Plants 18: 225-354.

Vogel EF de (1989) Sulawesi (Celebes). In: Campbell DG, Hammond HD (Eds), Floristic inventory of tropical countries: The status of plant systematics, collections, and vegetation, plus recommendations for the future. The New York Botanical Garden, New York, 108-112.

Vomberg M (2004) Zur systematischen Relevanz von Juglandaceen-Blättern unter besonderer Berücksichtigung fossiler Funde aus der Grube Messel und dem Eckfelder Maar. PhD thesis. Johannes-Gutenberg-Universität Mainz Available from: http://ubm.opus.hbznrw.de/volltexte/2005/658/.

de Vos JM, Joppa LN, Gittleman JL, Stephens PR, Pimm SL (2015) Estimating the normal background rate of species extinction. Conservation Biology 29: 452-462. https://doi.org/10.1111/cobi.12380

Wägele H, Klussmann-Kolb A, Kuhlmann M, Haszprunar G, Lindberg D, Koch A, Wägele JW (2011) The taxonomist - an endangered race. A practical proposal for its survival. Frontiers in Zoology 8: 25. https://doi.org/10.1186/1742-9994-8-25

Wagstaff SJ (2004) Evolution and biogeography of the austral genus Phyllocladus (Podocarpaceae). Journal of Biogeography 31: 1569-1577. https://doi.org/10.1111/j.13652699.2004.01066.x 
Wallace AR (1860) On the Zoological Geography of the Malay Archipelago. Journal of the Proceedings of the Linnean Society of London. Zoology 4: 172-184. https://doi.org/10.1111/j.1096-3642.1860.tb00090.x

Wallace AR (1863) On the Physical Geography of the Malay Archipelago. The Journal of the Royal Geographical Society of London 33: 217-234. https://doi.org/10.2307/1798448

Wallace AR (1869) The Malay Archipelago: The land of the Orang-Utan, and the Bird of Paradise. A narrative of travel, with studies of man and nature. Harper \& Bothers, New York, 638 pp. Available from: https://doi.org/10.5962/bhl.title.11170.

Wallace AR (1876a) The geographical distribution of animals, with a study of the relations of living and extinct faunas as elucidating the past changes of the earth's surface. In two volumes. Macmillan and Co., London, Volume 1: xxi, 503; Volume 2: viii, 607 pp. Available from: https://doi.org/10.5962/bhl.title.42326.

Wallace AR (1876b) 1 The geographical distribution of animals, with a study of the relations of living and extinct faunas as elucidating the past changes of the earth's surface. In two volumes - Volume 1. Macmillan and Co., London, xxi, 503 pp. Available from: https://biodiversitylibrary.org/page/30227970.

Wallander E, Albert VA (2000) Phylogeny and classification of Oleaceae based on rps16 and trnLF sequence data. American Journal of Botany 87: 1827-1841.

Wallnöfer B (2001) The Biology and Systematics of Ebenaceae: a Review. Annalen des Naturhistorischen Museums in Wien. Serie B für Botanik und Zoologie 103: 485-512.

Wallnöfer B (2004) Ebenaceae. In: Kubitzki K (Ed), Flowering Plants - Dicotyledons: Celastrales, Oxalidales, Rosales, Cornales, Ericales. The Families and Genera of Vascular Plants, vol. 6. Springer, Berlin, Heidelberg, 125-130. https://doi.org/10.1007/978-3-662-07257-8_16

Wang RJ, Saunders RMK (2006a) A synopsis of Cyathocalyx species (Annonaceae) in Peninsular Malaysia, Sumatra, and Borneo, with descriptions of two new species. Botanical Journal of the Linnean Society 152: 513-532. https://doi.org/10.1111/j.1095-8339.2006.00582.x

Wang RJ, Saunders RMK (2006b) The Genus Cyathocalyx (Annonaceae) in the Philippines. Systematic Botany 31: 285-297. https://doi.org/10.1600/036364406777585793

WCSP (2019) World Checklist of Selected Plant Families. Facilitated by the Royal Botanic Gardens, Kew. Published on the Internet. Available from: http://wcsp.science.kew.org (February 12, 2019).

Webb SD (2006) The Great American Biotic Interchange: Patterns and Processes. Annals of the Missouri Botanical Garden 93: 245-257. https://doi.org/10.3417/00266493(2006)93[245:TGABIP]2.0.CO;2

Weber R (2006) 12 Kulturlandschaftswandel in Zentralsulawesi: Historisch-geographische Analyse einer indonesischen Bergregenwaldregion. Universitätsverlag Göttingen, 243 pp.

Webster GL (1994) Synopsis of the Genera and Suprageneric Taxa of Euphorbiaceae. Annals of the Missouri Botanical Garden 81: 33-144. https://doi.org/10.2307/2399909

Webster GL (2014) Euphorbiaceae. In: Kubitzki K (Ed), Flowering Plants - Eudicots: Malpighiales. The Families and Genera of Vascular Plants, vol. 11. Springer, Berlin, Heidelberg, 51-216. https://doi.org/10.1007/978-3-642-39417-1_10

Weeks A, Zapata F, Pell SK, Daly DC, Mitchell JD, Fine PVA (2014) To move or to evolve: contrasting patterns of intercontinental connectivity and climatic niche evolution in "Terebinthaceae" (Anacardiaceae and Burseraceae). Frontiers in Genetics 5: 409. https://doi.org/10.3389/fgene.2014.00409

Weerasooriya AD, Saunders RMK (2010) Monograph of Mitrephora (Annonaceae). Systematic Botany Monographs 90: 1-167.

Weigelt P, Koenig C, Kreft H (2019) GIFT - A Global Inventory of Floras and Traits for macroecology and biogeography. bioRxiv: 535005. https://doi.org/10.1101/535005

Weitzman AL, Dressler S, Stevens PF (2004) Ternstroemiaceae. In: Kubitzki K (Ed), Flowering Plants - Dicotyledons: Celastrales, Oxalidales, Rosales, Cornales, Ericales. The Families and 
Genera of Vascular Plants, vol. 6. Springer, Berlin, Heidelberg, 450-460. https://doi.org/10.1007/978-3-662-07257-8_47

van Welzen PC (1988) Key to the Malesian genera of Sapindaceae (based on vegetative and fruit characteristics). Blumea - Biodiversity, Evolution and Biogeography of Plants 33: 215-237. van Welzen PC (1991) Gloeocarpus Radlk.(Sapindaceae) revised. Blumea 35: 389-392.

van Welzen PC (1994) Taxonomy, phylogeny, and geography of Neoscortechinia Hook. f. ex Pax (Euphorbiaceae). Blumea - Biodiversity, Evolution and Biogeography of Plants 39: 201320.

van Welzen PC (1995) Taxonomy and phylogeny of the Euphorbiaceae tribe Erismantheae G.L. Webster (Erismanthus, Moultonianthus, and Syndyophyllum). Blumea - Biodiversity, Evolution and Biogeography of Plants 40: 375-396.

van Welzen PC (2016) Bischofia and Hymenocardia (Phyllanthaceae) in Malesia. Blumea Biodiversity, Evolution and Biogeography of Plants 61: 272-279. https://doi.org/10.3767/000651916X694337

van Welzen PC, Slik JWF (2009) Patterns in species richness and composition of plant families in the Malay Archipelago. Blumea - Biodiversity, Evolution and Biogeography of Plants 54: 166-171. https://doi.org/10.3767/000651909X475969

van Welzen PC, Esser H-J (2013) Peraceae. Flora Malesiana, Series I 21: 119-133.

van Welzen PC, Winkel E (2015) A revision of Ostodes (Euphorbiaceae) in Malesia. Blumea Biodiversity, Evolution and Biogeography of Plants 59: 185-190. https://doi.org/10.3767/000651915X687895

van Welzen PC, Bulalacao LJ, an Ôn T (1995) A taxonomic revision of the Malesian genus Trigonopleura Hook.f. (Euphorbiaceae). Blumea - Biodiversity, Evolution and Biogeography of Plants 40: 363-374.

van Welzen PC, Parnell JAN, Slik JWF (2011) Wallace's Line and plant distributions: two or three phytogeographical areas and where to group Java? Biological Journal of the Linnean Society 103: 531-545. https://doi.org/10.1111/j.1095-8312.2011.01647.x

van Welzen PC, Kulju KKM, Sierra SEC, Slik JWF (2010) Key to the Malesian species of Mallotus (Euphorbiaceae). Blumea - Biodiversity, Evolution and Biogeography of Plants 55: 285290. https://doi.org/10.3767/000651910X550909

van Welzen PC, Pruesapan K, Telford IRH, Bruhl JJ (2015) Historical biogeography of Breynia (Phyllanthaceae): what caused speciation? Journal of Biogeography 42: 1493-1502. https://doi.org/10.1111/jbi.12517

van Welzen PC, Strijk JS, Cittert JHA van K, Nucete M, Merckx VSFT (2014) Dated Phylogenies of the Sister Genera Macaranga and Mallotus (Euphorbiaceae): Congruence in Historical Biogeographic Patterns? PLOS ONE 9: e85713. https://doi.org/10.1371/journal.pone.0085713

Wen J (2000) Internal Transcribed Spacer Phylogeny of the Asian and Eastern North American Disjunct Aralia Sect. Dimorphanthus (Araliaceae) and Its Biogeographic Implications. International Journal of Plant Sciences 161: 959-966. https://doi.org/10.1086/317563

van der Werff H (2001) An annotated key to the genera of Lauraceae in the flora Malesiana region. Blumea - Biodiversity, Evolution and Biogeography of Plants 46: 125-140.

Weston PH, Barker NP (2006) A new suprageneric classification of the Proteaceae, with an annotated checklist of genera. Telopea 11: 314-344.

Whitmore TC (1980) A monograph of Agathis. Plant Systematics and Evolution 135: 41-69. https://doi.org/10.1007/BF00983006

Whitmore TC (2008) The genus Macaranga: a prodromus. Royal Botanic Gardens, Kew, Richmond, Surrey, U.K., i-15, 1-293 pp.

Whitmore TC, Sidiyasa K, Whitmore TJ (1987) Tree species enumeration of 0.5 hectare on Halmahera. The Gardens' Bulletin, Singapore 40: 31-34.

Whitten AJ, Muslimin M, Henderson GS (1987) 4 The Ecology of Sulawesi. Gadjah Mada University Press, Yogyakarta, Indonesia, 777 pp. 
Widodo P (2012) New nomenclature in Syzygium (Myrtaceae) from Indonesia and its vicinities. Reinwardtia 13: 235-240. https://doi.org/10.14203/reinwardtia.v13i3.451

Wiens JJ, Ackerly DD, Allen AP, Anacker BL, Buckley LB, Cornell HV, Damschen El, Davies TJ, Grytnes J-A, Harrison SP, Hawkins BA, Holt RD, McCain CM, Stephens PR (2010) Niche conservatism as an emerging principle in ecology and conservation biology. Ecology Letters 13: 1310-1324. https://doi.org/10.1111/j.1461-0248.2010.01515.x

Wieringa J (2015) NHN Herbarium Database. National Herbarium of the Netherlands - NHN. Available from: http://vstbol.leidenuniv.nl/nhn/Explore (December 15, 2015).

de Wilde WJJO (2002) Myristicaceae. Flora Malesiana, Series I 14: 1-634.

Wilkie P, Ahmad B (2011) Sterculiaceae s.I. In: Soepadmo E, Saw LG, Chung RCK, Kiew R (Eds), Tree Flora of Sabah and Sarawak. Forest Research Institute Malaysia (FRIM), Sabah Forestry Department, and Sarawak Forestry Department, Selangor, 331-407.

Willinghöfer S, Cicuzza D, Kessler M (2011) Elevational diversity of terrestrial rainforest herbs: when the whole is less than the sum of its parts. Plant Ecology 213: 407-418. https://doi.org/10.1007/s11258-011-9986-z

Wilson EO (2017) Biodiversity research requires more boots on the ground. Nature Ecology \& Evolution 1: 1590. https://doi.org/10.1038/s41559-017-0360-y

Wilson PG, O'Brien MM, Heslewood MM, Quinn CJ (2005) Relationships within Myrtaceae sensu lato based on a matK phylogeny. Plant Systematics and Evolution 251: 3-19. https://doi.org/10.1007/s00606-004-0162-y

Wiriadinata H (2013) A new species of Begonia (Begoniaceae) from South Sulawesi, Indonesia. Reinwardtia 13: 445-448. https://doi.org/10.14203/reinwardtia.v13i5.428

Won H, Renner SS, Linder P (2006) Dating Dispersal and Radiation in the Gymnosperm Gnetum (Gnetales)—Clock Calibration When Outgroup Relationships Are Uncertain. Systematic Biology 55: 610-622. https://doi.org/10.1080/10635150600812619

Wong KM, Sugumaran M (2012) Studies in Malesian Gentianaceae II: A taxonomic framework for the Fagraea complex, including the new genus Limahlania. The Gardens' Bulletin, Singapore 64: 481-495.

Woodburne MO (2010) The Great American Biotic Interchange: Dispersals, Tectonics, Climate, Sea Level and Holding Pens. Journal of Mammalian Evolution 17: 245-264. https://doi.org/10.1007/s10914-010-9144-8

World Flora Online (2019) An Online Flora of All Known Plants. Available from: http://www.worldfloraonline.org/ (February 12, 2019).

WorldClim (2014) Worldclim version 1.4 (release 3). Bioclim tiles in GeoTIFF format with a resolution of 30 arc-seconds ( 1 km). Available from: http://www.worldclim.org/ (October 10, 2014).

Wu Z-Y, Monro AK, Milne RI, Wang H, Yi T-S, Liu J, Li D-Z (2013) Molecular phylogeny of the nettle family (Urticaceae) inferred from multiple loci of three genomes and extensive generic sampling. Molecular Phylogenetics and Evolution 69: 814-827. https://doi.org/10.1016/j.ympev.2013.06.022

Wündsch M, Biagioni S, Behling H, Reinwarth B, Franz S, Bierbass P, Daut G, Mausbacher R, Haberzettl T (2014) ENSO and monsoon variability during the past $1.5 \mathrm{kyr}$ as reflected in sediments from Lake Kalimpaa, Central Sulawesi (Indonesia). The Holocene. https://doi.org/10.1177/0959683614551217

Wurdack KJ, Hoffmann P, Chase MW (2005) Molecular phylogenetic analysis of uniovulate Euphorbiaceae (Euphorbiaceae sensu stricto) using plastid RBCL and TRNL-F DNA sequences. American Journal of Botany 92: 1397-1420. https://doi.org/10.3732/ajb.92.8.1397

Xi Z, Ruhfel BR, Schaefer H, Amorim AM, Sugumaran M, Wurdack KJ, Endress PK, Matthews ML, Stevens PF, Mathews S, Davis CC (2012) Phylogenomics and a posteriori data partitioning resolve the Cretaceous angiosperm radiation Malpighiales. Proceedings of the National Academy of Sciences 109: 17519-17524. https://doi.org/10.1073/pnas.1205818109 
Xiang Q-Y (Jenny), Thomas DT, Xiang QP (2011) Resolving and dating the phylogeny of Cornales - Effects of taxon sampling, data partitions, and fossil calibrations. Molecular Phylogenetics and Evolution 59: 123-138. https://doi.org/10.1016/j.ympev.2011.01.016

Xie S, Manchester SR, Liu K, Wang Y, Shao Y (2014) Firmiana (Malvaceae: Sterculioideae) fruits from the Upper Miocene of Yunnan, Southwest China. Geobios 47: 271-279. https://doi.org/10.1016/j.geobios.2014.03.005

Xu S, He Z, Zhang Z, Guo Z, Guo W, Lyu H, Li J, Yang M, Du Z, Huang Y, Zhou R, Zhong C, Boufford DE, Lerdau M, Wu C-I, Duke NC, Shi S (2017) The origin, diversification and adaptation of a major mangrove clade (Rhizophoreae) revealed by whole-genome sequencing. National Science Review 4: 721-734. https://doi.org/10.1093/nsr/nwx065

Yamada I (1975) Forest ecological studies of the montane forest of Mt. Pangrango, West Java. I. Stratification and floristic composition of the montane forest near Cibodas. Tonan Ajia Kenkyu (South East Asian Studies) 13: 402-426.

Yamada I (1977) Forest ecological studies of the montane forest of Mt. Pangrango, West Java. IV. Floristic composition along the altitude. Tonan Ajia Kenkyu (South East Asian Studies) 15: 226-254.

Yamada T, Nishida H, Umebayashi M, Uemura K, Kato M (2008) Oldest record of Trimeniaceae from the Early Cretaceous of northern Japan. BMC Evolutionary Biology 8: 135. https://doi.org/10.1186/1471-2148-8-135

Yang L-L, Li H-L, Wei L, Yang T, Kuang D-Y, Li M-H, Liao Y-Y, Chen Z-D, Wu H, Zhang S-Z (2016) A supermatrix approach provides a comprehensive genus-level phylogeny for Gentianales. Journal of Systematics and Evolution 54: 400-415. https://doi.org/10.1111/jse.12192

Yang S-X, Yang J-B, Lei L-G, Li D-Z, Yoshino H, Ikeda T (2004) Reassessing the relationships between Gordonia and Polyspora (Theaceae) based on the combined analyses of molecular data from the nuclear, plastid and mitochondrial genomes. Plant Systematics and Evolution 248: 45-55. https://doi.org/10.1007/s00606-004-0178-3

Yap J-YS, Rossetto M, Costion C, Crayn D, Kooyman RM, Richardson J, Henry R (2018) Filters of floristic exchange: How traits and climate shape the rain forest invasion of Sahul from Sunda. Journal of Biogeography 45: 838-847. https://doi.org/10.1111/jbi.13143

Yesson C, Toomey NH, Culham A (2009) Cyclamen: time, sea and speciation biogeography using a temporally calibrated phylogeny. Journal of Biogeography 36: 1234-1252. https://doi.org/10.1111/j.1365-2699.2008.01971.x

Yesson C, Russell SJ, Parrish T, Dalling JW, Garwood NC (2004) Phylogenetic Framework for Trema (Celtidaceae). Plant Systematics and Evolution 248: 85-109. https://doi.org/10.1007/s00606-004-0186-3

Yuan Y-W, Mabberley DJ, Steane DA, Olmstead RG (2010) Further disintegration and redefinition of Clerodendrum (Lamiaceae): Implications for the understanding of the evolution of an intriguing breeding strategy. Taxon 59: 125-133.

Zahid MS (2004) Nine novelties in Porterandia (Rubiaceae) from Borneo and Sulawesi. Sandakania 15: 55-78.

Zahid MS, Wong KM (2010) The circumscription, taxonomy and biogeography of Porterandia (Rubiaceae - Gardenieae). Edinburgh Journal of Botany 67: 265-342. https://doi.org/10.1017/S096042861000003X

Zalasiewicz J, Waters CN, Summerhayes CP, Wolfe AP, Barnosky AD, Cearreta A, Crutzen P, Ellis E, Fairchild IJ, Gałuszka A, Haff P, Hajdas I, Head MJ, Ivar do Sul JA, Jeandel C, Leinfelder R, McNeill JR, Neal C, Odada E, Oreskes N, Steffen W, Syvitski J, Vidas D, Wagreich M, Williams M (2017) The Working Group on the Anthropocene: Summary of evidence and interim recommendations. Anthropocene 19: 55-60. https://doi.org/10.1016/j.ancene.2017.09.001

Zerega NJC, Clement WL, Datwyler SL, Weiblen GD (2005) Biogeography and divergence times in the mulberry family (Moraceae). Molecular Phylogenetics and Evolution 37: 402-416. https://doi.org/10.1016/j.ympev.2005.07.004 
Zhang L-B, Simmons MP, Renner SS (2007) A phylogeny of Anisophylleaceae based on six nuclear and plastid loci: Ancient disjunctions and recent dispersal between South America, Africa, and Asia. Molecular Phylogenetics and Evolution 44: 1057-1067. https://doi.org/10.1016/j.ympev.2007.03.002

Zhang Q, Feild TS, Antonelli A (2015) Assessing the impact of phylogenetic incongruence on taxonomy, floral evolution, biogeographical history, and phylogenetic diversity. American Journal of Botany 102: 566-580. https://doi.org/10.3732/ajb.1400527

Zhang W, Kan S, Zhao H, Li Z, Wang X (2014) Molecular Phylogeny of Tribe Theeae (Theaceae s.S .) and Its Implications for Generic Delimitation. PLOS ONE 9: e98133. https://doi.org/10.1371/journal.pone.0098133

Zobel M (2016) The species pool concept as a framework for studying patterns of plant diversity. Journal of Vegetation Science 27: 8-18. https://doi.org/10.1111/jvs.12333

Zollinger H (1857) Ueber den Begriff und Umfang einer "Flora Malesiana." Vierteljahresschrift der Naturforschenden Gesellschaft in Zürich 2: 317-349.

Zúñiga JD (2015) Phylogenetics of Sabiaceae with Emphasis on Meliosma Based on Nuclear and $\begin{array}{lllll}\text { Chloroplast } & \text { Data. } & \text { Systematic } & \text { 761-775. }\end{array}$ https://doi.org/10.1600/036364415X689221

Zuo Y-J, Wen J, Zhou S-L (2017) Intercontinental and intracontinental biogeography of the eastern Asian - Eastern North American disjunct Panax (the ginseng genus, Araliaceae), emphasizing its diversification processes in eastern Asia. Molecular Phylogenetics and Evolution 117: 60-74. https://doi.org/10.1016/j.ympev.2017.06.016 


\section{List of Figures}

Figure 1.1 Line drawing of Magnolia sulawesiana 22

Figure 1.2 Map of known occurrences of Magnolia sulawesiana in Sulawesi ..............................23

Figure 2.1 Map of known occurrences of Elaeocarpus firdausii in Sulawesi .................................32

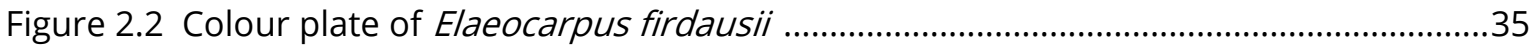

Figure 2.3 Flower details of Elaeocarpus firdausii .........................................................................36

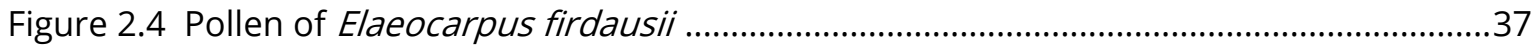

Figure 3.1 Morphological characters of Syzygium balgooyi and S. schumannianum ................48

Figure 3.2 Distribution map of Syzygium balgooyi in Sulawesi......................................................49

Figure 3.3 Line drawing of Syzygium contiguum ...........................................................................5

Figure 3.4 Distribution map of four species of Syzygium in Central Sulawesi .............................55

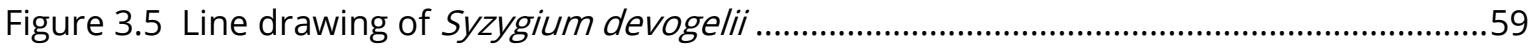

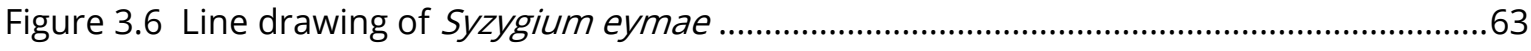

Figure 3.7 Morphological characters of Syzygium galanthum ......................................................66

Figure 3.8 Leaves of all new Syzygium species .............................................................................68

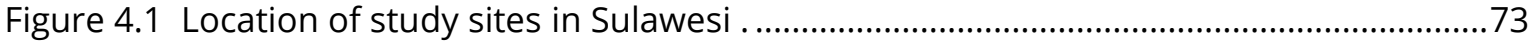

Figure 4.2 Changes in tree diversity and endemism with elevation in LLNP, Sulawesi .............76

Figure 4.3 Species richness in 51 Malesian tree inventory plots in relation to elevation ...........77

Figure 4.4 Floristic turnover of trees with elevation in LLNP, Sulawesi .......................................78

Figure 4.5 Affinities of tree orders in LLNP with altitudinal belts and ecological guilds .............81

Figure 5.1 Diversity and abundance of Australian tree lineages in Malesian forest plots are higher at higher elevations, on ultramafic soils, and east of Wallace's line

Figure 5.2 Elevational tipping points with a 50\%-share of Australian tree species and individuals in forests of the Malesian phytoregions Sundaland, the Philippines, and Wallacea over nonultramafic and ultramafic parent materials 100

Figure 5.3 Four taxa drive the proportion of tree individuals with Australian ancestry in most of 55 Malesian forest plots 101

\section{List of Tables}

Table 4.1 Indicator tree species of three elevational zones in LLNP, Sulawesi ...........................79

Table 4.2 Factors influencing the dominance of important taxonomic orders in LLNP ............80

Table 5.1 Dataset of 55 tree inventory plots from 12 Malesian areas .........................................93

Table 5.2 Elevation, geology, and geographic position determine the proportion of tree species and individuals with Australian ancestry in Malesian forest plots 


\section{Author Contributions and Affiliations}

Chapter 1 - Magnolia sulawesiana described, and a key to the species of Magnolia (Magnoliaceae) occurring in Sulawesi.

Fabian Brambach ${ }^{1,2}$, Hans P. Nooteboom ${ }^{3}$, Heike Culmsee ${ }^{1,4}$

Published in Blumea 58: 271-276 (13 Dec 2013), https://doi.org/10.3767/000651913X676817

FB and HC collected the data, FB analysed the data, and HC produced the line drawing. FB led the writing with major contributions from HPN and HC.

Chapter 2 - Elaeocarpus firdausii (Elaeocarpaceae), a new species from tropical mountain forests of Sulawesi

Fabian Brambach ${ }^{1,2}$, Mark J. E. Coode ${ }^{5}$, Siria Biagionii ${ }^{6}$, Heike Culmse ${ }^{1,4}$

Published in PhytoKeys 62:1-14 (25 Mar 32016, https://doi.org/10.3897/phytokeys.62.7548

FB and HC collected the data. SB conducted the pollen laboratory work and analysed the pollen data. FB analysed all other data and HC produced the line drawing. FB led the writing with major contributions from all authors.

\section{Chapter 3 - Five new species of Syzygium (Myrtaceae) from Sulawesi, Indonesia}

Fabian Brambach ${ }^{1,2}$, James W. Byng 3,7 , Heike Culmsee ${ }^{1,4}$

Published in PhytoKeys 81: 47-78 (15 Jun 2017), https://doi.org/10.3897/phytokeys.81.13488

FB and $\mathrm{HC}$ collected the data, FB analysed the data, and HC produced the line drawing. FB led the writing with major contributions from JWB and HC.

Chapter 4 - Diversity, endemism, and composition of tropical mountain forest communities in Sulawesi, Indonesia, in relation to elevation and soil properties

Fabian Brambach ${ }^{1,2}$, Christoph Leuschner ${ }^{1}$, Aiyen Tjoa ${ }^{8}$, Heike Culmse ${ }^{1,4}$

Published in Perspectives in PPEES 27: 68-79 (Aug 2017), https://doi.org/10.1016/j.ppees.2017.06.003

$\mathrm{CL}$ and $\mathrm{HC}$ conceived the project, $\mathrm{FB}$ and $\mathrm{HC}$ collected the data, and FB performed the data analysis and led the writing with significant contributions from all authors.

\section{Chapter 5 - Predominant colonization of Malesian mountains by Australian tree lineages}

Fabian Brambach ${ }^{1,2}$, Christoph Leuschner ${ }^{1}$, Aiyen Tjoa ${ }^{8}$, Heike Culmsee ${ }^{1,4}$

Published in Journal of Biogeography 46 (2019), https://doi.org/10.1111/JBI.13747

FB and HC conceived the project. FB collected the data, performed the literature review, analysed the data, and led the writing of the manuscript, to which all authors contributed. 
1 Plant Ecology and Ecosystems Research, University of Goettingen, Goettingen, Germany

2 Biodiversity, Macroecology and Biogeography, University of Goettingen, Goettingen, Germany (present address)

3 Naturalis Biodiversity Centre, Botany, Leiden, The Netherlands

${ }^{4}$ DBU Natural Heritage, German Federal Foundation for the Environment, Osnabrück, Germany (present address)

${ }^{5}$ Royal Botanic Garden, Edinburgh, Scotland, United Kingdom

6 Palynology and Climate Dynamics, University of Goettingen, Goettingen, Germany

7 Plant Gateway, Hertford, England, United Kingdom

8 Agricultural Faculty, Tadulako University, Palu, Indonesia 



\section{Appendices}

\section{Appendix 1.1 Examined Magnolia specimens}

Numbers in the list of examined specimens for the construction of the Sulawesi-key refer to the following species:

1. M. angatensis Blanco,

2. M. bintuluensis (A.Agostini) Noot.,

3. M. carsonii Dandy ex Noot. var. carsonii,

4. M. champaca (L.) Baill. ex Pierre var. champaca,

5. M. liliifera (L.) Baill. var. liliifera,

6. M. sulawesiana Brambach, Noot. \& Culmsee

7. M. sumatrana (Miq.) Figlar \& Noot. var. glauca (Blume) Figlar \& Noot.,

8. M. tsiampacca (L.) Figlar. \& Noot. var. tsiampacca,

9. M. utilis (Dandy) V.S.Kumar

10. M. villosa (Miq.) H.Keng and

11. M. vrieseana (Miq.) Baill. ex Pierre.

Afriastini 2112: 11; 2881: 5 - Alston 15937: 11; 16539: 8 - Anonymous s.n. (barcode L 0450378): 8; s.n. (Hort. Bog. IV F 38, Bogor Acc. No. BO-1330147, BO-1330148, BO-1330151): 11; s.n. (Bogor Acc. No. 1324097, BO-1743441, BO 1743443): 8.

Bish 123 (= NIFS bb 18128): 11; 254 (= NIFS bb 21987): 8 - Bloembergen 201 (= NIFS bb 28241): 8; 288 (= NIFS bb 28268): 3 - Brambach et al. 0047: 3; 0086: 5; 0109: 6; 0136: 3; 0145: 5; 0149: 3; 0444: 11; 0632: 11; 0662: 11; 0666: 11; 0892: 5; 1113: 8; 1334: 6; 1512: 3; 1519: 3; 1531: 5; 1554: 5; 1584: 3; 1589: 3 -Bünnemeijer 11567: 5; 12581: 4 - Burki 53 (= NIFS bb 24079): 5; 92 (= NIFS bb 24169): 8; 95 (= NIFS bb 24172): 3; 139 (= NIFS 26276): 3 - Burley et al. 3576: 5; 3618: 11; 3837: 5; 3864: 5; 3930: 11; 4080: 10.

Culmsee 39: 5; 191: 5; 975; 5; 2581: 6; 2945: 6; 3153: 6; 3154: 6; D2-2: 8; r2196: 5.

de Vogel 2531: 5; 5176: 5; 6052: 5 - de Vogel \& Vermeulen 6619: 5, 6726: 5; 6811: 11; 6054: 11; 7054: 11; 7064: 11 - de Vriese \& Teijsmann 131: 4; s.n. (barcode L 0038327): 5; s.n. (barcode L 0038297 ): 11; s.n. (barcode L 0450311): 7; s.n. (barcode L 0450314): 7; s.n. (barcode L 0450327): 11; s.n. (barcode L 0450328): 11; s.n. (barcode L 0450332): 11; s.n. (barcode L 0450333): 11; s.n. (barcode L 0450354): 11; s.n. (barcode L 0450357): 8; s.n. (barcode L 0450358): 8; s.n. (barcode L 0450359): 8; s.n. (barcode L 0450360): 8; s.n. (barcode L 0450367): 8; s.n. (barcode L 0450381): 5; s.n. (barcode L 0450382): 5; s.n. (U Acc. No. 000184): 8; s.n. (U Acc. No. 000185): 8; s.n. (U Acc. No. 000200): 5; s.n. (U Acc. No. 000220); s.n. (BO Acc. No. BO-1364647): 5; s.n. (BO Acc. No. BO1324098): 8.

Forman 202: 11 - Forsten 355: 5; s.n. (barcode L 0038296): 11: 11; s.n. (barcode L 0450299): 5; s.n. (barcode L 0450301): 5; s.n. (barcode L 0450333): 11; s.n. (U Acc. No. 000219): 11; s.n. (BO Acc. No. BO-1364650: 5.

Ganggrijp 21 (= NIFS Cel./ II-420): 5.

Halidjeng 11 H (= NIFS bb 20908): 7 - Hoornstra 54 (= NIFS bb 13487): 11.

Irot 4 (= NIFS bb 26296): 3; 12 (= NIFS bb 26637): 3. 
Kamang 1 (=NIFS bb 31912): 5 - Kessler et al. PK 3008: 11; PK 3009: 5 - Kjellberg 1839: 5; Koorders 17768: 11; 17769: 11; 17770: 8; 17771: 8; 17772: 8; 17773: 8; 17774: 8; 17775: 817776: 8; 17777: 8; 17778: 8; 17779: 11; 17782: 11; 17783: 5; 17784: 5; 17785: 5; 17787: 11; 17788: 11; 17789: 11; 17790: 11; 17791: 5; 17792: 5; 17793: 11; 17794: 5; 17795: 5; 17796: 5; 17797: 11; 24081: 11 .

Lam 2430: 11; 3121: 1 - Linggi 1 (= NIFS bb 32803): 8; Luntungan 1 (= NIFS bb 20000): 8.

McDonald \& Ismail 3874: 5 - Meijer 9360: 5; 9584: 11; 9611: 11; 9628: 11; 9726: 11; 9811: 8; 10010: 9; 10016: 8; 10080: 11; 11006: 8 - Moningka 1 (= NIFS bb 19979): 11; 2 (= NIFS bb 19980): 11.

Netherland Indies Forest Service (NIFS) bb 12385 (= Warouw 1): 5; bb 12386: 11; bb 13487 (= Hoornstra 54): 11; bb 13512 (= Wullur 11): 11; bb 14217 (= Wullur 55): 5; bb 15701 (= Soekarman 12): 11; bb 17121 (Roringpandej 22): 11; bb 18128 (= Bish 123): 11; bb 18195: 3; bb 19581 (= Waturandang E 65): 3; bb 19605 (=Verhoef 121): 5; bb 19703: 7; bb 19726 (= Tumbel 1): 8; bb 19576 (=Waturandang E 60): 8; bb 19979 (= Mongingka 1): 11; bb 19980 (= Moningka 2): 11; bb 20000 (= Luntungan 1): 8; bb 20200 (= von Werner 3): 11; bb 20908 (= Halidjeng $11 \mathrm{H}$ ): 7; bb 21615 (= Waturandang 178): 11; bb 21987 (= Bish 254): 8; bb 21988 (= Patabang 1): 8; bb 21989 (= Patabang 2): 8; bb 23355: 6; bb 24079 (= Burki 53): 5; bb 24169 (= Burki 92): 8; bb 24172 (= Burki 95): 3; bb 24510 (= Rantegaoe E 296): 11; bb 26276: 3; bb 26296 (=Irot 4): 3; bb 28241 (= Bloembergen 201): 8; bb 28295: 3; bb 29194 (= Togas 22): 3; bb 26637 (=Irot 12): 3; bb 28268 (= Bloembergen 228): 3; bb 28295 (=Silo 4): 3; bb 31815 (= Pello 1): 11; bb 31863 (= Politon 38): 11; bb 32323 (= Rantegaoe 19): 11; bb 32459 (= Reppie 19): 11; bb 32472 (= Politon 76): 11; bb 32567 (= Polei 1): 8; bb 32568 (= Polei 2): 5; bb 32803 (= Linggi 1): 8; bb 33115 (= Tangkilisan 1): 8; Cel./ II-201 (= Waturandang 640): 5; Cel./ II-420 (= Ganggrijp 21): 5; Cel./ III-8 (= Waturandang 8, 55, 158): 11; Cel./ III-100 (= Reppie 300): 11; Cel./ III-101 (= Reppie 301: 11; Cel./III-102 (= Reppie 302):11; Cel./ V-308 (= Reppie 527): 11 - Niswan 85: 8 - Noerkas 257: 5; 467: 11.

Patabang 1 (= NIFS bb 21988): 8; 2 (= NIFS bb 21989): 8 - Pello 1 (= NIFS bb 31815): 11; Pitopang et al. RP 347: 7; RP 359: 11; RP 1005: 5 - Polei 1 (= bb 32567): 8; 2 (= bb 32568): 5;bb 24079: 5; bb 31912 (= Kamang 1): 5 - Politon 38 (= NIFS bb 31863): 11; 76 (= NIFS bb 32472): 11 Prawioratmodjo \& Maskuri 1310: 5 - Prawioratmodjo \& Soewoko 1707: 5; 1961: 5;

Rachmat 266: 4 - Ramlanto 227: 5 - Rantegaoe E 296 (= NIFS bb 24510): 11; 19 (= NIFS bb 32323): 11 - Reppie 19 (= NIFS bb 32459): 11;300 (= NIFS Cel./ III-100): 11; 301 (= NIFS Cel./ III-101: 11; 302 (= NIFS Cel./III-102): 11; 527 (= NIFS Cel./ V-308: 11 - Riedel s.n.: 5 - Roringpandej 22 (= NIFS bb 17121): 11.

Sabir et al. 174 N: 5; B2 109: 6 - Silo 4 (= NIFS bb 28295): 3 - Soekarman 12 (= NIFS bb 15701: 11.

Tangkilisan 1 (= NIFS bb 33115): 8 - Tantra 1509: 11; 1546: 5; 1603: 5; 1766: 5 - Teijsmann 5325 HB: 8; 5781 HB: 5 - Togas 22 (= NIFS bb 29194): 3 - Tumbel 1 (= NIFS bb 19726): 8.

van Balgooy 3430: 11 - Verhoef 121 (= NIFS bb 19605): 5 - von Werner 3 (= NIFS bb 20200): 11.

Warouw 1 (= NIFS bb 12385): 5 - Waturandang E 60 (= NIFS bb 19576): 8; E 65 (= NIFS bb 19581): 3; 8 (= NIFS Cel./III-8): 11; 55 (= NIFS Cel./ III-8): 11; 158 (= NIFS Cel./ III-8): 11;178 (= NIFS bb 21615): 11; 640 (= NIFS Cel./ II-201): 5 - Webb et al. s.n. (CEB Acc. No. 0000707): 11 - Weber sn (L Acc. No ): 4 - Wen \& Kartonegoro 10261: 9; 10276: 9; 10288: 11 - Whitmore \& Sidiyasa TCW 2288: 5; Widjaja EAW 182: 8; EAW 9619: 11; Wullur 11 (= NIFS bb 13512): 11; 55 (= NIFS bb 14217): 5.

Yusuf \& Wahyono 166: 11. 


\section{Appendix 4.1 Detailed description of methods}

\section{Study area}

The complex, geologically young mountain region of Central Sulawesi consists of the West Sulawesi plutono-volcanic arc, mostly dominated by granite and other acid plutonic rocks and the Central Sulawesi metamorphic belt (Geological Research and Development Centre 1993, Hall and Wilson 2000, Hall 2013). The wide variety of soil types is due to variation in parent material, topography, elevation and climate; Acrisols, Cambisols, Ferralsols, Gleysols, Lixisols, Luvisols, Nitisols, and Regosols have been reported for LLNP (Dechert 2003, Häring et al. 2005, Culmsee et al. 2010b, Leitner 2010). According to climate data from 12 stations in and around LLNP (period 2002-2008; Kreilein, unpubl.), the climate of the study region is perhumid with most rainfall falling during April-May and November-December and a slightly drier period from July to October. At elevations below $1500 \mathrm{~m}$ in the inter-montane valleys, 1-3 drier months ( $<100$ mm rainfall) do occur (Gunawan 2006). Humid north-westerly winds prevail from November to May and drier south-easterly winds during the rest of the year. ENSO-related droughts occur at irregular intervals (Gunawan 2006, Wündsch et al. 2014). While the populated valleys surrounding the park have a long history of human occupation and land use dating back at least 2.000 years (Henley 2005, Kirleis et al. 2011), most of LLNP itself has only been slightly affected by human activities like swidden agriculture, hunting and small-scale extraction of timber and non-timber forest products (NTFP) until the end of the $19^{\text {th }}$ century. Since then, human impact has steadily increased and conflicts over resources and conservation efforts have appeared (Adiwibowo 2005, Weber 2006, Wündsch et al. 2014, Biagioni et al. 2015a).

\section{Tree inventories}

Criteria for study site selection were the presence of primary forest without major natural and human disturbance on level terrain $\left(<10^{\circ}\right.$ inclination) without groundwater influence. The minimum distance between sites was $1 \mathrm{~km}$ except for sites N1 and N2 (c. $250 \mathrm{~m}$ distance). Five sites (S1050, S1400, S1850, S1900, S2400) had previously been surveyed in 2006/2007 (Culmsee and Pitopang 2009, Culmsee et al. 2010b, 2011) and were here censused a second time. Areas with any signs of logging or rattan-extraction were excluded. However, two NTFP, damar-resin from Agathis dammara (see Appendix 4.5 for full species names) and agarwood from Gyrinops sp., are collected by local inhabitants at elevations of c. $1700-2000$ m throughout the study region and might have a slight, but unknown effect on forest structure and species composition. We established 13 inventory plots (see Table 1, 0.24 ha size, $40 \mathrm{~m} \times 60 \mathrm{~m}$, without slope correction) and divided each plot into a $10 \mathrm{~m} \times 10 \mathrm{~m}$ grid using plastic poles and string. Within the plot, we permanently tagged and pre-identified all trees with dbh (measured at $1.3 \mathrm{~m}$ ) $\geq 10$ $\mathrm{cm}$, recorded their position and collected information relevant for species identification (habit, presence of sap, bark characters, etc.). Tree height was measured with an ultrasound clinometer (Vertex IV with T3-Transponder; Haglöf, Langsele, Sweden) and diameter at breast height (dbh) with a diameter tape. Epiphytes and lianas were removed from the trunk before measuring 
$\mathrm{dbh}$. The diameter of buttressed or stilt-rooted trees was measured above the buttresses (if these were taller than $1.3 \mathrm{~m}$ ) and the measurement height recorded. For the measurement of multi-stemmed trees and strangler-trees, we employed the protocol described in Culmsee et al. (2010b). The same procedure was followed in a $5 \mathrm{~m} \times 5 \mathrm{~m}$ subplot in each of the 24 grid-cells of $10 \mathrm{~m} \times 10 \mathrm{~m}$ (altogether 0.06 ha per plot) for small trees (dbh: $2-9.9 \mathrm{~cm}$ ). The survey data of all plots will be made available through the repository ForestPlots.net (Lopez-Gonzalez et al. 2009).

Table 1 Characteristics of the 13 inventory plots in old-growth mountain rain forests in Lore Lindu National Park, Sulawesi, Indonesia. Temperature and rainfall data modelled for the time period 1950-2000 from WorldClim (2014). Soils according to IUSS Working Group WRB (2014). Data on bedrock material from Geological Research and Development Centre (1993).

\begin{tabular}{|c|c|c|c|c|c|c|c|c|}
\hline Plot & $\begin{array}{l}\text { Elevational } \\
\text { belt }^{1}\end{array}$ & Elev. & Locality & $\begin{array}{l}\text { Latitude/ } \\
\text { longitude }\end{array}$ & Topography & Rain $^{2}$ & $\mathrm{~T}^{3}$ & Soil and bedrock type \\
\hline S0700 & Colline & 700 & Rantena & $\begin{array}{l}1^{\circ} 36.2^{\prime} \mathrm{S} \\
120^{\circ} 04.5^{\prime} \mathrm{E}\end{array}$ & $\begin{array}{l}\text { Gently } \\
\text { sloping ridge }\end{array}$ & 1990 & 23.0 & $\begin{array}{l}\text { Sideralic Cambisol on } \\
\text { acid plutonic rocks }\end{array}$ \\
\hline S0850 & Colline & 850 & Tokepangana & $\begin{array}{l}1^{\circ} 36.9^{\prime} \mathrm{S} \\
120^{\circ} 04.4^{\prime} \mathrm{E}\end{array}$ & Level terrace & 1990 & 23.0 & $\begin{array}{l}\text { Sideralic Cambisol on } \\
\text { acid plutonic rocks }\end{array}$ \\
\hline S1050 & $\begin{array}{l}\text { Sub- } \\
\text { montane }\end{array}$ & 1050 & Pono Valley & $\begin{array}{l}1^{\circ} 29.7^{\prime} \mathrm{S} \\
120^{\circ} 03.4^{\prime} \mathrm{E}\end{array}$ & Level terrace & 1900 & 21.0 & $\begin{array}{l}\text { Sideralic Cambisol on } \\
\text { metamorphic rocks }\end{array}$ \\
\hline S1200 & $\begin{array}{l}\text { Sub- } \\
\text { montane }\end{array}$ & 1200 & Tarara & $\begin{array}{l}1^{\circ} 35.3^{\prime} \mathrm{S} \\
120^{\circ} 17.0^{\prime} \mathrm{E}\end{array}$ & $\begin{array}{l}\text { Up-slope } \\
\text { plateau }\end{array}$ & 1890 & 20.7 & $\begin{array}{l}\text { Stagnic Acrisol / } \\
\text { Mollic Umbrisol on } \\
\text { mixed sedimentary } \\
\text { rocks }\end{array}$ \\
\hline S1400 & $\begin{array}{l}\text { Sub- } \\
\text { montane }\end{array}$ & 1400 & $\begin{array}{l}\text { Bariri Forest } \\
\text { (Baba Haleka) }\end{array}$ & $\begin{array}{l}1^{\circ} 39.4^{\prime} \mathrm{S} \\
120^{\circ} 10.5^{\prime} \mathrm{E}\end{array}$ & $\begin{array}{l}\text { Mid-slope } \\
\text { terrace }\end{array}$ & 1970 & 19.5 & $\begin{array}{l}\text { Rhodic Ferralsol on } \\
\text { acid plutonic rocks }\end{array}$ \\
\hline S1450 & $\begin{array}{l}\text { Sub- } \\
\text { montane }\end{array}$ & 1450 & Torongkilo & $\begin{array}{l}1^{\circ} 24.9^{\prime} \mathrm{S} \\
120^{\circ} 16.7^{\prime} \mathrm{E}\end{array}$ & $\begin{array}{l}\text { Mid-slope } \\
\text { terrace }\end{array}$ & 1870 & 19.1 & $\begin{array}{l}\text { Folic Cambisol on } \\
\text { mixed sedimentary } \\
\text { rocks }\end{array}$ \\
\hline S1650 & $\begin{array}{l}\text { Lower } \\
\text { montane }\end{array}$ & 1650 & Balamba & $\begin{array}{l}1^{\circ} 41.9^{\prime} \mathrm{S} \\
120^{\circ} 09.6^{\prime} \mathrm{E}\end{array}$ & $\begin{array}{l}\text { Lower-slope } \\
\text { terrace }\end{array}$ & 2020 & 17.8 & $\begin{array}{l}\text { Xanthic Ferralsol on } \\
\text { acid plutonic rocks }\end{array}$ \\
\hline S1850 & $\begin{array}{l}\text { Lower } \\
\text { montane }\end{array}$ & 1850 & $\begin{array}{l}\text { Mount } \\
\text { Nokilalaki }\end{array}$ & $\begin{array}{l}1^{\circ} 14.6^{\prime} \mathrm{S} \\
120^{\circ} 09.1^{\prime} \mathrm{E}\end{array}$ & $\begin{array}{l}\text { Mid-slope } \\
\text { terrace }\end{array}$ & 1950 & 16.8 & $\begin{array}{l}\text { Cambic Umbrisol on } \\
\text { acid plutonic rocks }\end{array}$ \\
\hline S1900 & $\begin{array}{l}\text { Lower } \\
\text { montane }\end{array}$ & 1900 & $\begin{array}{l}\text { Mount } \\
\text { Nokilalaki }\end{array}$ & $\begin{array}{l}1^{\circ} 14.7^{\prime} \mathrm{S} \\
120^{\circ} 09.2^{\prime} \mathrm{E}\end{array}$ & $\begin{array}{l}\text { Mid-slope } \\
\text { terrace }\end{array}$ & 1950 & 16.8 & $\begin{array}{l}\text { Cambic Umbrisol on } \\
\text { acid plutonic rocks }\end{array}$ \\
\hline S1950 & $\begin{array}{l}\text { Lower } \\
\text { montane }\end{array}$ & 1950 & Pantakleabae & $\begin{array}{l}1^{\circ} 42.0^{\prime} \mathrm{S} \\
120^{\circ} 09.0^{\prime} \mathrm{E}\end{array}$ & $\begin{array}{l}\text { Gently } \\
\text { sloping ridge }\end{array}$ & 2080 & 16.7 & $\begin{array}{l}\text { Cambic Umbrisol on } \\
\text { acid plutonic rocks }\end{array}$ \\
\hline S2150 & $\begin{array}{l}\text { Upper } \\
\text { montane }\end{array}$ & 2150 & Tutu Malemo & $\begin{array}{l}1^{\circ} 45.9^{\prime} \mathrm{S} \\
120^{\circ} 09.6^{\prime} \mathrm{E}\end{array}$ & $\begin{array}{l}\text { Upslope } \\
\text { plateau }\end{array}$ & 2170 & 15.5 & $\begin{array}{l}\text { Folic Gleysol / Folic } \\
\text { Cambisol on acid } \\
\text { plutonic rocks }\end{array}$ \\
\hline S2350 & $\begin{array}{l}\text { Upper } \\
\text { montane }\end{array}$ & 2350 & Bulu Torenali & $\begin{array}{l}1^{\circ} 17.2^{\prime} \mathrm{S} \\
120^{\circ} 18.7^{\prime} \mathrm{E}\end{array}$ & $\begin{array}{l}\text { Upslope } \\
\text { plateau }\end{array}$ & 2080 & 14.8 & $\begin{array}{l}\text { Folic Histosol on acid } \\
\text { plutonic rocks }\end{array}$ \\
\hline S2400 & $\begin{array}{l}\text { Upper } \\
\text { montane }\end{array}$ & 2400 & $\begin{array}{l}\text { Mount } \\
\text { Rorekautimbu }\end{array}$ & $\begin{array}{l}1^{\circ} 16.7^{\prime} \mathrm{S} \\
120^{\circ} 18.6^{\prime} \mathrm{E}\end{array}$ & $\begin{array}{l}\text { Mid-slope- } \\
\text { terrace }\end{array}$ & 2130 & 14.1 & $\begin{array}{l}\text { Folic Gleysol on acid } \\
\text { plutonic rocks }\end{array}$ \\
\hline
\end{tabular}

1 after van Steenis (1984), modified. ${ }^{2}$ Mean annual rainfall $\left(\mathrm{mm} \mathrm{yr}^{-1}\right) .{ }^{3}$ Mean annual temperature $\left({ }^{\circ} \mathrm{C}\right)$. Elev. = Elevation ( $m$ a.s.I.)

\section{Soil analysis}

To characterise the availability of plant macro-nutrients and the chemical status of the soil, we dug four soil pits of $\geq 50 \mathrm{~cm}$ per plot. In each pit we took $100 \mathrm{~cm} 3$-samples from the mineral soil at 10 and $40 \mathrm{~cm}$ depth and from the lowermost organic layer (OF and $\mathrm{OH}$ horizons) to obtain volume-related nutrient contents. The samples were air-dried and transported to Göttingen for 
nutrient analysis. The $\mathrm{pH}$ of the fresh soil was measured in the lab at Tadulako University, Palu, in a suspension of $10 \mathrm{~g}$ fresh soil in $1 \mathrm{M} \mathrm{KCl}$. The concentrations of total $\mathrm{C}$ and $\mathrm{N}$ were measured by gas chromatography (vario EL, elementar, Hanau, Germany) from samples dried at $70^{\circ} \mathrm{C}(\mathrm{N})$ and corrected for moisture content.

Since no limestone occurs as bedrock in the study region, we assumed that all carbon was of organic origin. The total contents of $\mathrm{Ca}, \mathrm{K}, \mathrm{Mg}$ and $\mathrm{Na}, \mathrm{Al}, \mathrm{Fe}$, and $\mathrm{Mn}$ in the organic layer material was measured by $\mathrm{HNO}_{3}$ digestion and subsequent ICP-OES analysis (Perkin Elmer Optima 5300 $\mathrm{DV}$ ), and the concentrations of exchangeable $\mathrm{Ca}, \mathrm{Mg}, \mathrm{K}, \mathrm{Na}, \mathrm{Al}, \mathrm{Fe}$, and $\mathrm{Mn}$ in the mineral soil by $\mathrm{BaCl}_{2}$ extraction and subsequent element analysis in the percolate by ICP-OES. The observed $\mathrm{pH}$ change during the percolation process was used to calculate the concentration of hydrogen ions at the cation exchangers. Cation exchange capacity (CEC; in $\left.\mu \mathrm{mol}_{\mathrm{c}} \mathrm{g}^{-1}\right)$ was obtained by adding the charge of $\mathrm{K}, \mathrm{Mg}, \mathrm{Ca}, \mathrm{Na}, \mathrm{Al}, \mathrm{Mn}, \mathrm{Fe}$, and $\mathrm{H}$ measured in the percolate; we defined base saturation as the percentage of $\mathrm{K}, \mathrm{Mg}, \mathrm{Ca}$, and $\mathrm{Na}$ ions (expressed as $\mu \mathrm{mol} \mathrm{l}_{\mathrm{c}}$ ) in $\mathrm{CEC}$. One sample from S1200 showed unrealistically high values for $\mathrm{Ca}$ and was excluded from the analysis. In the additional soil pits, we collect soil samples from their main detectable horizons and described the soils according to FAO (2006). We then complemented the soil descriptions with literature information (Dechert 2003, Häring et al. 2005, Culmsee et al. 2010b, Leitner 2010) to identify the soil type according to the WRB system (IUSS Working Group WRB 2014).

\section{Collection of specimens.}

In the plots that were surveyed for the first time, we generally collected herbarium specimens from each individual. From morphospecies that were easily recognized in the field (e.g. palms, Dracaena spp.), we collected at least one specimen per plot. In the plots that had previously been surveyed, we collected only trees that were either in flower or fruit, had not been determined to species level previously (Culmsee and Pitopang 2009, Culmsee et al. 2011), or were recorded for the first time in our survey. In addition, we collected specimens of flowering and/or fruiting trees growing outside all plots. We used a telescopic pruner for smaller trees; for large individuals, we employed a slingshot (Big Shot, Sherrill Tree, Greensboro, USA) and hand chainsaw attached to strings. In a few cases, we used rope-climbing technique to access trees that were difficult to sample otherwise. Specimens were conserved in $70 \%$ denatured alcohol in the field until drying at the facilities of Tadulako University in Palu. In total, 2156 numbers were collected with at least three duplicates each, of which $16 \%$ were fertile, representing $51 \%$ of all morphospecies. Full sets of collections were deposited at CEB and GOET; duplicates of fertile specimens have been sent to $B O$ and will be sent to $K$ and $L$ (Thiers 2018). A small number was sent to the specialists of single families at E, KEP, MO and STU. See Appendix 4.2 for details on species identification.

\section{Data analyses}

All calculations were performed using the software RStudio, Version 0.99.491 (RStudio Team 2015) based on R, Version 3.2.3 (R Core Team 2015). First, we investigated the correlation 
between plot elevation and seven soil parameters with Pearson's $r$ using the rcorr function of the Hmisc library (Harrell Jr. 2015). We did not use precipitation data due to a lack of reliable data with high resolution at different elevations.

The diversity measures observed species richness ( $\left({ }^{0} D_{\text {obs }}\right)$ and effective number of species ( $\left({ }^{1} D_{\text {obs }}\right)$, are expressions of so-called Hill numbers (Hill 1973):, the latter incorporating abundance without favouring common or rare species (Jost 2006). Both measures are sensitive to undersampling, especially in species-rich ecosystems like tropical forests. We therefore also calculated the rarefied/extrapolated values based on a base sample size (BSS) of twice the number of individuals of the plot with the smallest number of individuals (BSS $=210$; see Chao et al. 2014) and used the resulting effective number of species per BSS $\left({ }^{1} D_{210}\right)$ as primary measure of diversity. The same procedure was applied for genera and families. We used the iNEXT package for $\mathrm{R}$ (Hsieh et al. 2014) for the calculation of diversity measures and rarefactionextrapolation curves. The primary diversity measure was then applied as response variable in linear regression models with elevation and seven soil parameters as explaining variables. First, we ran bivariate linear regressions and sorted the environmental variables by their explanatory power $\left(r^{2}\right)$. Then, we excluded all variables, which were significantly $(p \leq 0.05)$ correlated with the most explanatory variable, and repeated the process until only mutually uncorrelated variables remained. The resulting environmental variables were used in multiple linear regression models with the diversity measures as response variable. The models were then simplified by a backward selection procedure using F-tests until obtaining the minimum adequate models. For the relative number of endemic species per plot, we ran logistic regression models (LRM) using the function $g / m$ with binomial error structure and logit link function in $\mathrm{R}$ with plot elevation as explanatory variable.

We conducted a literature search for plot-based tree inventories in Malesia and recorded their locality, elevation, the number of individuals, the number of species and environmental information, where available. We then chose all plots from sources with reliable species identification (incl. deposition of voucher specimens in herbaria), a full list of the recorded species and their abundances and a plot size of 0.1-1.0 ha $(n=38$, see Appendix 4.3) for comparison with our 13 plots. Here again, we used the iNEXT package for R (Hsieh et al. 2014) to produce rarefaction-extrapolation curves. As BSS, we also defined twice the number of individuals of the sampling unit with the smallest number of individuals $(n=90)$.

To search for patterns related to community composition, we also calculated the abundancebased index of Bray-Curtis dissimilarity (Bray and Curtis 1957) for all pairs of plots and used the resulting matrix as dependent variable for a multivariate analysis of variance (MANOVA) using the adonis function in the vegan library for $\mathrm{R}$ (Oksanen et al. 2016) with single environmental parameters (Appendix 4.4, Table 1) as explanatory variables and a Monte-Carlo permutation test with 500 permutations. We then sorted the environmental parameters according to their explanatory power (highest $\mathrm{r}^{2}$ ) and assessed the autocorrelation of these parameters using Pearson's r. All environmental parameters significantly related to elevation, the variable with 
the highest explanatory power, were excluded. The practice was repeated with the most explanatory of the remaining variables. The resulting, mutually independent variables, elevation and $\mathrm{pH}$ of the organic layer $\left(\mathrm{pH}_{\mathrm{O}}\right)$, were both used for a second MANOVA, again with 500 permutations. Furthermore we used non-metric multidimensional scaling (NMDS, function metaMDS in the vegan package) to graphically display the influence of elevation and $\mathrm{pH}_{\circ}$ on tree species composition.

Since the elevational gradient was most pronounced for both diversity and composition, we attempted to define distinct elevational zones based on species composition. We used the matrix of Bray-Curtis dissimilarities for all plot-pairs to conduct a cluster analysis using the hclust function of the vegan package for $R$ (Oksanen et al. 2016) with the average linkage (UPGMA) method and plotted the results in a dendrogram. Subsequently, we performed an indicator species analysis (Dufrêne and Legendre 1997, De Cáceres et al. 2010) using the indicspecies package for $\mathrm{R}$ (De Cáceres and Jansen 2015) and tested the statistical significance of the associations using a permutation test (999 random permutations) to show all species having a significant $(p<0.05)$ association with any elevational zone.

To explore the affiliation of the tree species in the plots with main tree guilds, we pooled all trees with $\mathrm{dbh} \geq 10 \mathrm{~cm}$ and small trees ( $\mathrm{dbh} 2-9.9 \mathrm{~cm}$ ) recorded in the $5 \mathrm{~m} \times 5 \mathrm{~m}$ subplots $(0.06$ ha per plot; small trees were not recorded outside of these subplots) and assigned them to two guilds based on the observed maximum height of the species relative to forest canopy height using our measured tree heights and literature data. The canopy height of a plot was defined as the mean height of the $10 \%$ tallest individuals. All species reaching a maximum height of $\geq$ $2 / 3$ of the respective canopy height in any of the plots were classified as 'canopy species'. Species not reaching this threshold height but which attained heights $>25 \mathrm{~m}$ according to the literature (e.g. van Steenis et al. 1948-2014), were also scored as canopy species. All remaining species were assigned to the guild of understorey species' assuming that they possess special adaptations to the forest understorey environment and are more restricted in their height growth.

We then assigned the species in the two guilds to 35 orders according to APG IV (The Angiosperm Phylogeny Group 2016) , calculated the relative abundance of each order and guild per plot, and took the mean values for each elevational zone. For the 10 families with highest number of tree individuals, we ran logistic regression models (LRM) using the function $g / m$ with binomial error structure and logit link function using plot elevation and guild as explanatory variables and relative abundance of the order as response variable. We simplified the models stepwise by removing first non-significant $(p \geq 0.05)$ interaction effects and then variables until reaching minimum adequate models with only significant terms remaining or further simplification causing a significant $(p<0.05)$ increase in deviance as measured by an F-test. 


\section{Appendix 4.2 Taxonomy and species identification}

We followed Korall et al. (2007) in recognising three separate genera of scaly tree ferns (Alsophila, Cyathea s.s. and Sphaeropteris); for gymnosperms we followed the WCSP (2019). For angiosperms, we generally used the taxonomic concepts of APG IV (The Angiosperm Phylogeny Group 2016) and Stevens (2017) at family and genus levels except for a few taxa, where we chose to take into account recent revisions or phylogenetic studies to accurately reflect systematic relationships: Ehretia (Luebert et al. 2016), Lasjia P.H.Weston \& A.R.Mast (Mast et al. 2008), Machilus Nees (Li et al. 2011), Pleioluma (Swenson et al. 2013), Polyspora (Orel et al. 2013), and Utania (Wong and Sugumaran 2012). For general identification we mainly relied on van Balgooy $(1997,1998,2010)$ and the Interactive Key to Seed Plants of Malesia and Indo-China (The Malesian Key Group 2004). At species level, we used regional floristic accounts like (e.g. Flora Malesiana, The Tree Flora of Sabah and Sarawak, Flora of Jawa) and other taxonomic literature (see Table 1 for details).

Of the total 3852 examined individuals ( 2284 big trees with $\mathrm{dbh} \geq 10 \mathrm{~cm} / 1568$ small trees with dbh $2-9.9 \mathrm{~cm}$ ) we dermined $90.4 \%$ (91.7\% of big trees / 88.6\% of small trees) to species level and a further 5.3\% (4.8\% / 5.9\%) close to published species using "cf." or "aff." qualifiers. The remaining individuals were determined to genus level, but distinguished as separate morphospecies and treated like species in subsequent analyses unless indicated otherwise (Appendix 4.5).

For each species, we assessed whether it naturally occurs in the phytogeographical regions of China, the Indian subcontinent, Indochina, Malesia, Papuasia, Australia, and the Southwestern Pacific. Within the focal regions of Malesia and Papuasia, we further assessed the species' occurrence in the respective subregions (Fig. 1; Brummitt et al. 2001). Morphospecies which could not be assigned to published species names were not assessed. Where possible (79\% of species), we used regional floristic accounts and databases (e.g. Merrill 1923a-1925, van Steenis et al. 1948-2016, Soepadmo et al. 1995-2014, Slik 2009, Pelser et al. 2011, WCSP 2019) and/or other taxonomic literature. Taxa without recent taxonomic revision were assessed searching the online databases of L/U (Wieringa 2015) and those of other major herbaria (mostly A, B, K, MO, NY, P, S, US using GBIF 2015) and species new to science were assumed to occur only in Sulawesi after careful scanning of relevant herbarium specimens. Taxa (i.e. species, subspecies, or varieties) occurring only in Sulawesi were defined as endemic species (Appendix 4.5). For the relative number of endemic species, we compared the number of endemic species to the total number of species occurring in each plot. 
Table 1 Taxonomic literature used for species identification.

\begin{tabular}{|c|c|}
\hline Family & Literature \\
\hline Adoxaceae & (Kern and van Steenis 1951) \\
\hline Anacardiaceae & (Hou 1978) \\
\hline Annonaceae & $\begin{array}{l}\text { (Keßler 1993, 1995, Mols and Keßler 2000, Saunders 2002, 2003, Wang and Saunders } \\
\text { 2006a, 2006b, Surveswaran et al. 2010, Weerasooriya and Saunders 2010, Couvreur et al. } \\
\text { 2012) }\end{array}$ \\
\hline Apocynaceae & (Middleton 2007) \\
\hline Aquifoliaceae & $\begin{array}{l}\text { (Loesener 1901, 1908, 1924, Capitaine 1910, Backer and Bakhuizen van den Brink Jr. } \\
\text { 1965a, Andrews 2002, Hicks 2006) }\end{array}$ \\
\hline Araliaceae & (Philipson 1977, 1978, 1979, Lowry and Plunkett 2010) \\
\hline Araucariaceae & (Whitmore 1980, de Laubenfels 1988, Farjon 2010) \\
\hline Arecaceae & (Dransfield 1988, Mogea 2002, Dransfield et al. 2008, Heatubun et al. 2012) \\
\hline Asparagaceae & (Jankalski 2008) \\
\hline Asteraceae & (Robinson 1999, Robinson et al. 2008) \\
\hline Burseraceae & $\begin{array}{l}\text { (Kalkman 1954, Leenhouts et al. 1956, Leenhouts 1959, Kochummen 1995, Daly et al. } \\
\text { 2010) }\end{array}$ \\
\hline Calophyllaceae & (Stevens 1980) \\
\hline Cannabaceae & (Soepadmo 1977) \\
\hline Cardiopteridaceae & (Howard 1942, Sleumer 1971b, Utteridge and Schori 2011) \\
\hline Celastraceae & (Hou 1962, 1964) \\
\hline Chloranthaceae & (Verdcourt 1986) \\
\hline Chrysobalanaceae & (Prance 1989, 1995) \\
\hline Clethraceae & (Sleumer 1971a, Berhaman 1995) \\
\hline Clusiaceae & $\begin{array}{l}\text { (Lauterbach 1924, Kostermans 1956, Backer and Bakhuizen van den Brink Jr. 1963a, } \\
\text { Stevens 2007) }\end{array}$ \\
\hline Cunoniaceae & (Fortune Hopkins and Hoogland 2002) \\
\hline Cyatheaceae & (Holttum 1963, Hovenkamp and de Joncheere 1988) \\
\hline Dicksoniaceae & (Holttum 1963) \\
\hline Ebenaceae & (Bakhuizen van den Brink 1933, 1936, Kostermans 1977, Wallnöfer 2001, 2004, Ng 2004) \\
\hline Ehretiaceae & (Riedl 1997, Gottschling et al. 2016, Luebert et al. 2016) \\
\hline Elaeocarpaceae & $\begin{array}{l}\text { (Coode 1978, 1995, 1996a, 1996b, 1996c, 1998, 2001b, 2001a, 2001c, 2004, 2007, 2010, } \\
\text { Coode and Weibel 1994) }\end{array}$ \\
\hline Ericaceae & $\begin{array}{l}\text { (Sleumer 1961, 1966, Stevens et al. 2004b, Vander Kloet 2005, Vander Kloet and Dickinson } \\
\text { 2009) }\end{array}$ \\
\hline Escalloniaceae & (Backer and Bakhuizen van den Brink Jr. 1963b) \\
\hline Euphorbiaceae & $\begin{array}{l}\text { (Shaw 1982, van Welzen 1994, Webster 1994, 2014, Esser 1997, Sierra and van Welzen } \\
\text { 2005, Whitmore 2008, van Welzen et al. 2010) }\end{array}$ \\
\hline Fabaceae & (Nielsen et al. 1984, Nielsen 1992) \\
\hline Fagaceae & (Camus 1952, Soepadmo 1970, 2000, Soepadmo and van Steenis 1972) \\
\hline Gentianaceae & (Leenhouts 1962, 1981, Wong and Sugumaran 2012) \\
\hline Gesneriaceae & (Atkins 2003, Mendum and Atkins 2003, Bone and Atkins 2013) \\
\hline Gnetaceae & (Markgraf 1951) \\
\hline Hamamelidaceae & (Vink 1955) \\
\hline Himantandraceae & (Bailey et al. 1943, van Royen 1962) \\
\hline Hydrangeaceae & (Backer and Bakhuizen van den Brink Jr. 1963c, Hufford 2004) \\
\hline Ixonanthaceae & (Kool 1980, 1988, Kubitzki 2014b) \\
\hline Juglandaceae & (Jacobs 1960, Campbell-Gasis 1995, Vomberg 2004) \\
\hline Lamiaceae & (Kok 2008, Bramley 2012) \\
\hline Lauraceae & $\begin{array}{l}\text { (Kostermans 1962, 1968, 1969, 1970, 1973, 1986, 1988, Rohwer 1993, Arifiani 2001, van } \\
\text { der Werff 2001, Julia 2005, Ng 2005b, 2005a, Nishida 2008) }\end{array}$ \\
\hline Loganiaceae & (Leenhouts 1962, Conn 1980) \\
\hline Magnoliaceae & (Nooteboom 1985, 1987, 1988, Kim et al. 2002, Figlar and Nooteboom 2004) \\
\hline Malvaceae & (Tantra 1976, Wilkie and Ahmad 2011) \\
\hline Melastomataceae & (Maxwell and Veldkamp 1990b, 1990a) \\
\hline
\end{tabular}


Table 1 (cont.)

\begin{tabular}{|c|c|}
\hline Family & Literature \\
\hline Meliaceae & (Mabberley 1985, 2010, Pannell 1992, Mabberley et al. 1995, Culmsee 2008) \\
\hline Metteniusaceae & (Sleumer 1971b) \\
\hline Monimiaceae & (Philipson 1980, 1982, 1984, 1985, 1986) \\
\hline Moraceae & (Berg and Corner 2005, Berg et al. 2006, Berg and Culmsee 2011, Berg 2012) \\
\hline Myricaceae & (Backer 1951, Herbert 2005) \\
\hline Myristicaceae & (de Wilde 2002) \\
\hline Myrtaceae & $\begin{array}{l}\text { (Blume 1850, Robinson 1909, Elmer 1914, Merrill 1921, Merrill and Perry 1937, 1939, } \\
\text { Amshoff 1945, 1963, Hartley and Perry 1973, Hartley and Craven 1977, Scott 1979, Hyland } \\
\text { 1983, Thompson 1989, Bean 1992, Craven et al. 2003, 2006, Biffin et al. 2005, Craven and } \\
\text { Biffin 2010, Ashton 2011, Widodo 2012, Soh and Parnell 2015) }\end{array}$ \\
\hline Nyssaceae & (Matthew 1976, 1977) \\
\hline Oleaceae & (Kiew 1978, 1998, 2016) \\
\hline Pandanaceae & (Stone 1983a, 1983b) \\
\hline Paracryphiaceae & (Schlechter 1914, van Steenis 1986) \\
\hline Pentaphylacaceae & (Kobuski 1947, 1953, 1961a, 1961b, 1963, Barker 1980, Weitzman et al. 2004) \\
\hline Peraceae & (van Welzen et al. 1995, van Welzen and Esser 2013) \\
\hline Phyllanthaceae & (Shaw 1972, 1981, 1982, Webster 1994, 2014) \\
\hline Podocarpaceae & (Keng 1978b, de Laubenfels 1988, 2015, Farjon 2010) \\
\hline Primulaceae & (Sleumer 1988b, 1988a, Stone 1989, 1990, Hu 1999, Takeuchi and Pipoly 2009) \\
\hline Proteaceae & (Sleumer 1955, McDonald and Ismail R. 1995, Mast et al. 2008) \\
\hline Putranjivaceae & (Shaw 1982, Webster 1994, Levin 2014) \\
\hline Rosaceae & (Kalkman 1965, 1993) \\
\hline Rubiaceae & $\begin{array}{l}\text { (Bremekamp 1937, 1940a, 1940b, 1940c, Ridsdale 1978, 1989, Sohmer 1988, Ali and } \\
\text { Robbrecht 1991, Davis and Bridson 2004, Zahid 2004, Sohmer and Davis 2007, Darwin } \\
\text { 2010, Zahid and Wong 2010, Barrabé et al. 2012, Low 2013, Chen et al. 2015) }\end{array}$ \\
\hline Rutaceae & (Hartley 1974, 1979, 1981, 2000, Appelhans and Wen 2016) \\
\hline Sabiaceae & (van Beusekom 1971, van Beusekom and van de Water 1984) \\
\hline Salicaceae & (Sleumer 1954) \\
\hline Sapindaceae & $\begin{array}{l}\text { (Bloembergen 1948, van der Ham 1977, van Welzen 1988, Adema et al. 1994, Noorsiha } \\
\text { 1995) }\end{array}$ \\
\hline Sapotaceae & $\begin{array}{l}\text { (Lam 1948, Lam and van Royen 1952, Hermann-Erlee and van Royen 1957, van Royen } \\
\text { 1957, 1960, Chai and Yii 2002, Pennington 2004) }\end{array}$ \\
\hline Simaroubaceae & (Nooteboom 1962, Kulip and Wong 1995) \\
\hline Staphyleaceae & (van der Linden 1960, Pereira 1995) \\
\hline Stemonuraceae & (Sleumer 1971b, Utteridge 2011, Utteridge and Schori 2011) \\
\hline Styracaceae & (van Steenis 1949) \\
\hline Symplocaceae & (Nooteboom 1975, 1977) \\
\hline Theaceae & (Barker 1980, Keng 1984, 1990, Yang et al. 2004) \\
\hline Thymelaeaceae & (Hou 1960) \\
\hline Trimeniaceae & (Rodenburg 1971, Philipson 1986) \\
\hline Winteraceae & (Smith 1969, Vink 1970, Doust and Drinnan 2004) \\
\hline
\end{tabular}





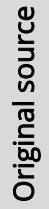

$\stackrel{8}{\circ}$

$\stackrel{8}{\circ}$

$\stackrel{n}{\circ}$

응

흐늠

类

范 을

。

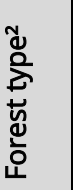




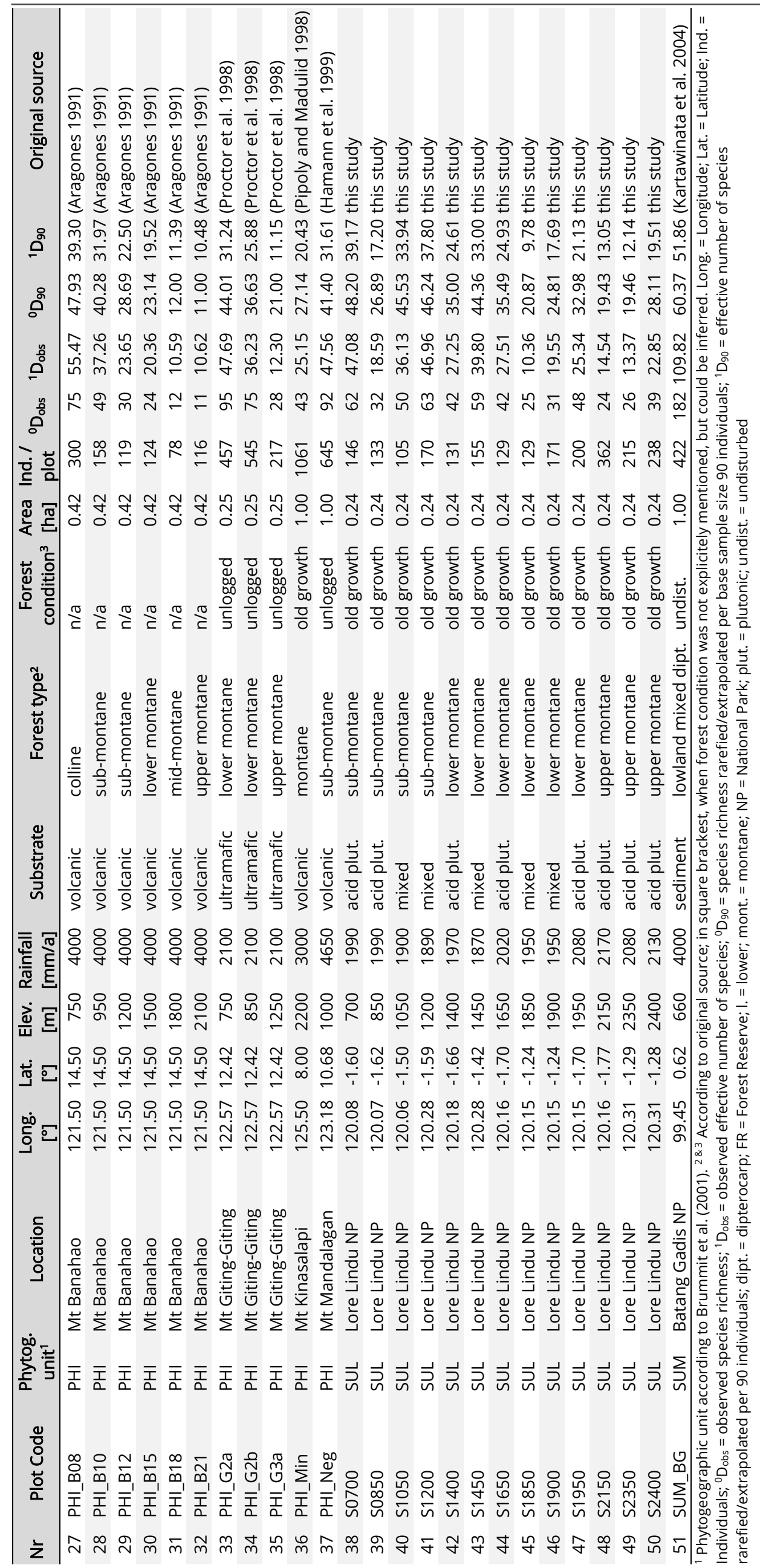




\section{Appendix 4.4 Environmental parameters}

Table 1 Soil parameters characterising 13 inventory plots in Lore Lindu National Park, Sulawesi, Indonesia. Values are means \pm 1SD of four samples per plot (3 in S1200). Different superscript letters indicate significant differences between values within one column based on ANOVA with post-hoc Tukey's HSD test at significance level $p<0.05$.

\begin{tabular}{lccccccc}
\hline Plot & Thicko & BCo & CNo & pHo & BSa & CNa & pHa \\
\hline S0700 & 3 & $76.95 \pm 40.05^{\mathrm{b}}$ & $16.3 \pm 1.05^{\mathrm{c}}$ & $3.20 \pm 0.30^{\mathrm{bcd}}$ & $4.25 \pm 1.36^{\mathrm{c}}$ & $9.11 \pm 0.89^{\mathrm{d}}$ & $3.60 \pm 0.07^{\mathrm{de}}$ \\
S0850 & 5 & $41.13 \pm 9.45^{\mathrm{b}}$ & $17.65 \pm 2.05^{\mathrm{bc}}$ & $3.06 \pm 0.13^{\mathrm{bcde}}$ & $2.72 \pm 0.09^{\mathrm{c}}$ & $10.14 \pm 0.63^{\mathrm{d}}$ & $3.58 \pm 0.08^{\mathrm{e}}$ \\
S1050 & 3 & $122.00 \pm 35.94^{\mathrm{b}}$ & $15.87 \pm 1.92^{\mathrm{c}}$ & $3.48 \pm 0.09^{\mathrm{bc}}$ & $11.31 \pm 4.23^{\mathrm{c}}$ & $11.49 \pm 0.30^{\mathrm{cd}}$ & $3.85 \pm 0.08^{\mathrm{cde}}$ \\
S1200 & 7 & $1061.25 \pm 305.10^{\mathrm{a}}$ & $17.10 \pm 0.62^{\mathrm{bc}}$ & $5.06 \pm 0.60^{\mathrm{a}}$ & $48.76 \pm 22.74^{\mathrm{a}}$ & $9.52 \pm 0.77^{\mathrm{d}}$ & $4.07 \pm 0.22^{\mathrm{bcd}}$ \\
S1400 & 2 & $85.30 \pm 16.82^{\mathrm{b}}$ & $19.50 \pm 5.44^{\mathrm{bc}}$ & $3.45 \pm 0.89^{\mathrm{bc}}$ & $12.14 \pm 2.30^{\mathrm{c}}$ & $9.10 \pm 5.21^{\mathrm{d}}$ & $4.13 \pm 0.09^{\mathrm{abc}}$ \\
S1450 & 9 & $132.62 \pm 21.53^{\mathrm{b}}$ & $17.08 \pm 0.64^{\mathrm{bc}}$ & $3.18 \pm 0.19^{\mathrm{bcd}}$ & $8.21 \pm 3.75^{\mathrm{c}}$ & $13.57 \pm 1.50^{\mathrm{bcd}}$ & $3.94 \pm 0.06^{\mathrm{bcde}}$ \\
S1650 & 8 & $222.22 \pm 49.53^{\mathrm{b}}$ & $18.23 \pm 2.05^{\mathrm{bc}}$ & $3.24 \pm 0.69^{\mathrm{bc}}$ & $11.94 \pm 7.29^{\mathrm{c}}$ & $13.82 \pm 0.77^{\mathrm{bcd}}$ & $4.08 \pm 0.09^{\mathrm{bc}}$ \\
S1850 & 5 & $162.72 \pm 87.31^{\mathrm{b}}$ & $17.74 \pm 2.07^{\mathrm{bc}}$ & $2.98 \pm 0.31^{\mathrm{bcde}}$ & $17.09 \pm 3.89^{\mathrm{bc}}$ & $13.43 \pm 1.41^{\mathrm{bcd}}$ & $4.15 \pm 0.11^{\mathrm{abc}}$ \\
S1900 & 5 & $176.71 \pm 103.56^{\mathrm{b}}$ & $18.18 \pm 2.02^{\mathrm{bc}}$ & $3.74 \pm 0.38^{\mathrm{b}}$ & $32.53 \pm 14.47^{\mathrm{ab}}$ & $13.40 \pm 0.37^{\mathrm{bcd}}$ & $4.30 \pm 0.07^{\mathrm{ab}}$ \\
S1950 & 6 & $80.19 \pm 35.86^{\mathrm{b}}$ & $23.06 \pm 2.17^{\mathrm{ab}}$ & $2.49 \pm 0.35^{\mathrm{cde}}$ & $7.12 \pm 2.71^{\mathrm{c}}$ & $23.46 \pm 2.99^{\mathrm{a}}$ & $4.09 \pm 0.26^{\mathrm{bc}}$ \\
S2150 & 30 & $38.59 \pm 2.10^{\mathrm{b}}$ & $28.38 \pm 3.36^{\mathrm{a}}$ & $2.07 \pm 0.14^{\mathrm{e}}$ & $4.07 \pm 2.34^{\mathrm{c}}$ & $19.81 \pm 5.97^{\mathrm{abc}}$ & $3.62 \pm 0.38^{\mathrm{de}}$ \\
S2350 & 45 & $101.83 \pm 25.83^{\mathrm{b}}$ & $22.87 \pm 1.13^{\mathrm{ab}}$ & $2.20 \pm 0.12^{\mathrm{de}}$ & $14.60 \pm 2.53^{\mathrm{bc}}$ & $26.20 \pm 3.24^{\mathrm{a}}$ & $4.54 \pm 0.16^{\mathrm{a}}$ \\
S2400 & 10 & $79.66 \pm 43.52^{\mathrm{b}}$ & $23.60 \pm 4.15^{\mathrm{ab}}$ & $2.65 \pm 0.29^{\mathrm{cde}}$ & $6.19 \pm 2.91^{\mathrm{c}}$ & $21.39 \pm 7.91^{\mathrm{ab}}$ & $3.54 \pm 0.27^{\mathrm{e}}$ \\
\hline
\end{tabular}

Thick $=$ thickness $(\mathrm{cm}) . \mathrm{BC}=$ Sum of base cations $(\mathrm{Ca}, \mathrm{Mg}, \mathrm{K}) . \mathrm{BS}=$ base saturation (\%). $\mathrm{C}=$ total $\mathrm{C}(\mathrm{g}) . \mathrm{N}=$ total $\mathrm{N}(\mathrm{g}) . \mathrm{C} / \mathrm{N}=$ carbon/nitrogen ratio. $\mathrm{pH}=\mathrm{pH}(\mathrm{KCl})$. Subscript "O" denotes values for organic layer, subscript "A" values for A horizon, measured at $10 \mathrm{~cm}$ depth of mineral soil.

Table 2 Correlation among elevation and seven soil parameters on 13 inventory plots in Lore Lindu National Park, Sulawesi, Indonesia. Correlations, calculated by Pearson's $r$, are shown in upper right triangle matrix, the respective significance values $(p)$ in lower left triangle matrix. Significant correlations $(p<0.05)$ are in bold face.

\begin{tabular}{|c|c|c|c|c|c|c|c|c|c|}
\hline & \multicolumn{8}{|c|}{ Person's r } \\
\hline & & Elev & Thick。 & $\mathrm{BC}_{\mathrm{o}}$ & $\mathrm{C} / \mathrm{N}_{0}$ & $\mathrm{pH}_{\mathrm{o}}$ & $\mathrm{BS}_{\mathrm{A}}$ & $\mathrm{C} / \mathrm{N}_{\mathrm{A}}$ & $\mathrm{pH}_{\mathrm{A}}$ \\
\hline \multirow{8}{*}{$\frac{\frac{0}{\pi}}{\frac{2}{2}}$} & Elev & & 0.60 & -0.20 & 0.76 & -0.55 & -0.02 & 0.85 & 0.35 \\
\hline & Thick。 & 0.031 & & -0.13 & 0.65 & -0.56 & -0.10 & 0.72 & 0.30 \\
\hline & $\mathrm{BC}_{0}$ & 0.518 & 0.677 & & -0.29 & 0.81 & 0.87 & -0.31 & 0.21 \\
\hline & $\mathrm{C} / \mathrm{N}_{\circ}$ & 0.003 & 0.015 & 0.330 & & -0.70 & -0.31 & 0.78 & -0.09 \\
\hline & $\mathrm{pH}_{\mathrm{o}}$ & 0.052 & 0.045 & 0.001 & 0.008 & & 0.79 & -0.73 & 0.13 \\
\hline & $\mathrm{BS}_{\mathrm{A}}$ & 0.958 & 0.748 & 0.000 & 0.308 & 0.001 & & -0.25 & 0.51 \\
\hline & $\mathrm{C} / \mathrm{N}_{\mathrm{A}}$ & 0.000 & 0.006 & 0.306 & 0.002 & 0.005 & 0.402 & & 0.24 \\
\hline & $\mathrm{pH}_{\mathrm{A}}$ & 0.243 & 0.323 & 0.489 & 0.778 & 0.681 & 0.077 & 0.430 & \\
\hline
\end{tabular}




\section{Appendix 4.5 List of all species and their abundances in inventory plots}

See Appendix 4.2 for taxonomic references. Number of individuals of each species per plot are given for big trees (dbh > $10 \mathrm{~cm}$; preceding slash) and small trees (dbh 2-9.9 cm; following slash).

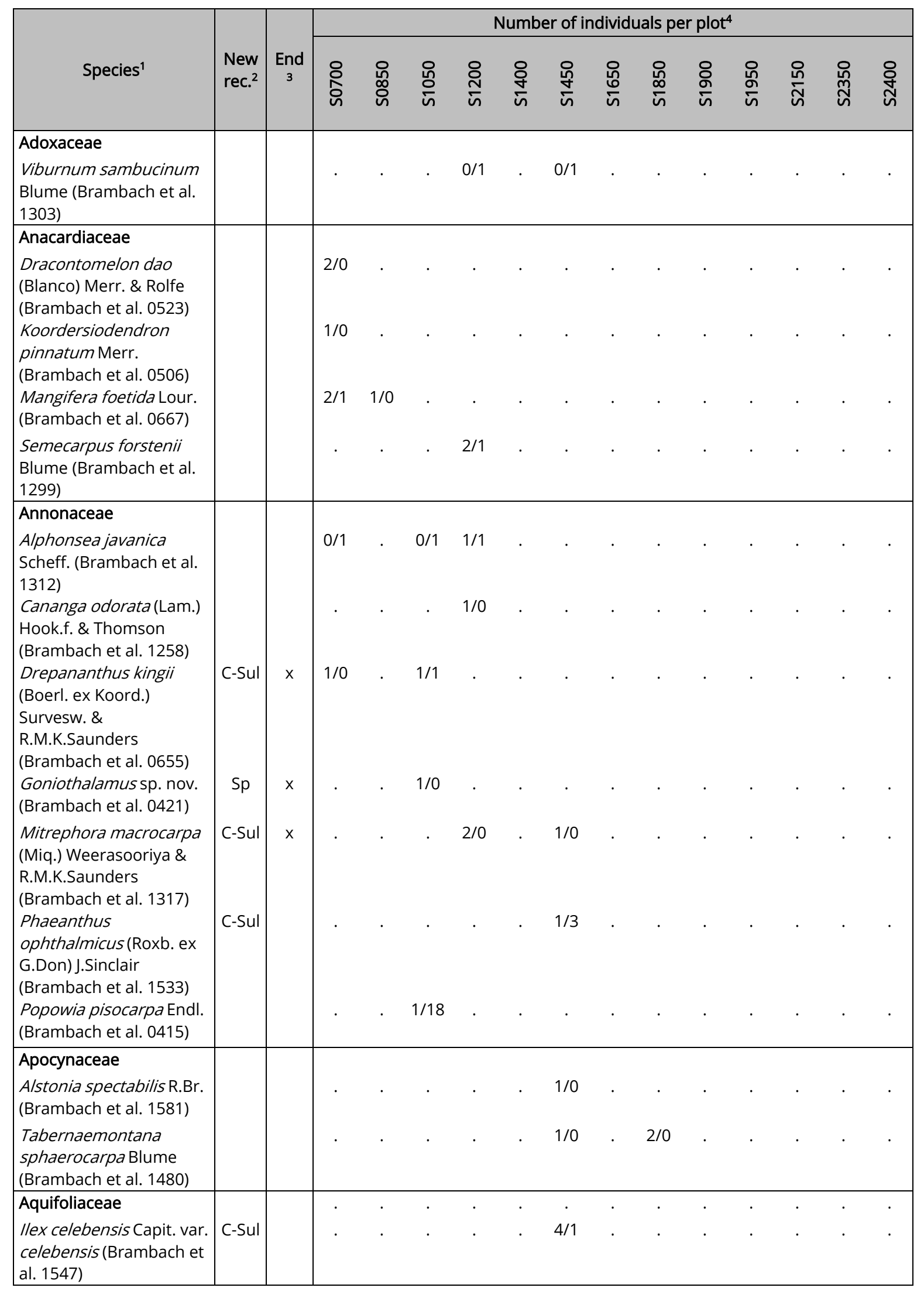




\begin{tabular}{|c|c|c|c|c|c|c|c|c|c|c|c|c|c|c|c|}
\hline \multirow[b]{2}{*}{ Species $^{1}$} & \multirow[b]{2}{*}{$\begin{array}{l}\mathrm{New} \\
\text { rec. }^{2}\end{array}$} & \multirow[b]{2}{*}{$\begin{array}{c}\text { End } \\
3\end{array}$} & \multicolumn{13}{|c|}{ Number of individuals per plot ${ }^{4}$} \\
\hline & & & $\begin{array}{l}8 \\
\text { 요 }\end{array}$ & $\begin{array}{l}\text { 애 } \\
\text { ○ } \\
\text { ํㅐ }\end{array}$ & $\begin{array}{l}\text { 융 } \\
\text { in }\end{array}$ & 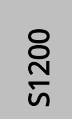 & $\frac{8}{\dot{y}}$ & $\frac{\text { 号 }}{\text { n }}$ & $\begin{array}{l}\text { 음 } \\
\text { in }\end{array}$ & $\begin{array}{l}\text { 웅 } \\
\infty \\
\text { ఓ }\end{array}$ & $\frac{8}{\frac{8}{n}}$ & $\begin{array}{l}\text { 음 } \\
\text { ஸ́ }\end{array}$ & $\stackrel{\text { 음 }}{\text { ஸે }}$ & 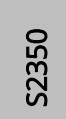 & 䓌 \\
\hline $\begin{array}{l}\text { I/ex odorata Buch.-Ham. } \\
\text { ex D.Don var. teysmannii } \\
\text { Loes. } \\
\text { (Brambach et al. 0780) } \\
\text { /lex sp. nov. (Brambach } \\
\text { et al. 1962) }\end{array}$ & \begin{tabular}{c|} 
C-Sul \\
Sp
\end{tabular} & $x$ & . & . & . & . & . & . & . & . & $0 / 1$ & $0 / 1$ & $2 / 0$ & $2 / 1$ & $1 / 0$ \\
\hline $\begin{array}{l}\text { Araliaceae } \\
\text { Polyscias diversifolia } \\
\text { (Blume) Lowry \& } \\
\text { G.M.Plunkett } \\
\text { (Brambach et al. 1079) } \\
\text { Polyscias nodosa } \\
\text { (Blume) Seem. } \\
\text { (Brambach et al. 1183) }\end{array}$ & $\begin{array}{l}\text { C-Sul } \\
\text { C-Sul }\end{array}$ & & . & . & . & $2 / 1$ & . & $1 / 1$ & . & . & . & . & . & . & . \\
\hline $\begin{array}{l}\text { Araucariaceae } \\
\text { Agathis dammara } \\
\text { (Lamb.) Rich. \& A.Rich } \\
\text { (Culmsee r2182) }\end{array}$ & & & . & . & . & . & . & . & . & . & . & $\begin{array}{c} \\
2 / 1\end{array}$ & . & . & . \\
\hline $\begin{array}{l}\text { Arecaceae } \\
\text { Areca vestiaria Giseke } \\
\text { (Brambach et al. 0291) }\end{array}$ & & & $0 / 1$ & $0 / 1$ & . & . & . & . & . & . & . & . & . & . & . \\
\hline $\begin{array}{l}\text { Areca sp. nov. } \\
\text { (Brambach et al. 0789) } \\
\text { Caryota rumphiana } \\
\text { Zumaidar \& Jeanson } \\
\text { (Brambach et al. 1081) } \\
\text { Oncosperma horridum } \\
\text { (Griff.) Scheff. } \\
\text { (Brambach et al. 0256) } \\
\text { Pinanga caesia Blume } \\
\text { (Brambach et al. 0429) }\end{array}$ & C-Sul & $x$ & . & $\begin{array}{l}3 / 2 \\
0 / 1\end{array}$ & $1 / 0$ & $\cdot$ & . & $1 / 0$ & . & . & . & . & $\begin{array}{c}49 / 9 \\
.\end{array}$ & $\begin{array}{l}2 / 0 \\
.\end{array}$ & . \\
\hline $\begin{array}{l}\text { Asparagaceae } \\
\text { Dracaena angustifolia } \\
\text { (Medik.) Roxb. } \\
\text { (Brambach et al. 1119) } \\
\text { Dracaena borneensis } \\
\text { (Merr.) Jankalski } \\
\text { (Brambach et al. 1124) }\end{array}$ & Sul & & $1 / 1$ & . & $3 / 0$ & $5 / 0$ & . & . & . & . & . & . & . & . & . \\
\hline $\begin{array}{l}\text { Asteraceae } \\
\text { Strobocalyx arborea } \\
\text { (Buch.-Ham.) Sch.Bip. } \\
\text { (Brambach et al. 0384, } \\
\text { 0857) }\end{array}$ & & & $2 / 0$ & . & $1 / 0$ & . & $2 / 1$ & . & $1 / 0$ & $0 / 1$ & $2 / 1$ & . & . & . & . \\
\hline $\begin{array}{l}\text { Burseraceae } \\
\text { Canarium balsamiferum } \\
\text { Willd. (Brambach et al. } \\
\text { 1138) } \\
\text { Canarium hirsutum } \\
\text { Willd. (Brambach et al. } \\
\text { 1136) } \\
\text { Santiria apiculata } \\
\text { A.W.Benn. var. apiculata } \\
\text { (Brambach et al. 0423) }\end{array}$ & & & $7 / 6$ & $\begin{array}{c}17 / 1 \\
2\end{array}$ & $6 / 5$ & $\begin{array}{l}6 / 2 \\
3 / 0\end{array}$ & $7 / 2$ & $1 / 1$ & . & . & . & . & . & . & . \\
\hline $\begin{array}{l}\text { Calophyllaceae } \\
\text { Calophyllum soulattri } \\
\text { Burm.f. (Brambach et al. } \\
\text { 1319) }\end{array}$ & & & . & . & $1 / 0$ & $5 / 1$ & . & $5 / 10$ & $9 / 2$ & . & . & . & . & . & . \\
\hline
\end{tabular}




\begin{tabular}{|c|c|c|c|c|c|c|c|c|c|c|c|c|c|c|c|}
\hline \multirow[b]{2}{*}{ Species $^{1}$} & \multirow[b]{2}{*}{$\begin{array}{l}\text { New } \\
\text { rec. }^{2}\end{array}$} & \multirow[b]{2}{*}{$\begin{array}{c}\text { End } \\
3\end{array}$} & \multicolumn{13}{|c|}{ Number of individuals per plot ${ }^{4}$} \\
\hline & & & $\begin{array}{l}8 \\
\text { 요 }\end{array}$ & $\begin{array}{l}\text { 유 } \\
\text { ᄋ }\end{array}$ & 용 & 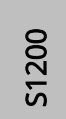 & $\frac{8}{\frac{8}{n}}$ & $\frac{8}{\frac{8}{n}}$ & $\begin{array}{l}\text { 윰 } \\
\text { in }\end{array}$ & $\begin{array}{l}\text { 애 } \\
\infty \\
\text { 苫 }\end{array}$ & $\frac{8}{\frac{8}{n}}$ & $\begin{array}{l}\text { 앵 } \\
\text { Б́ }\end{array}$ & $\stackrel{\text { 은 }}{\text { ஸે }}$ & 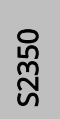 & $\begin{array}{l}\stackrel{8}{\text { N }} \\
\text { ヘ }\end{array}$ \\
\hline $\begin{array}{l}\text { Calophyllum sp. nov. } \\
\text { (Brambach et al. 0881) }\end{array}$ & $\mathrm{Sp}$ & $x$ & . & . & . & . & $2 / 0$ & . & . & . & . & . & . & . & . \\
\hline $\begin{array}{l}\text { Calophyllum sp. } \\
\text { (Brambach et al. 0642) }\end{array}$ & & & $1 / 0$ & . & . & . & . & . & . & . & . & . & . & . & 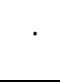 \\
\hline Cannabaceae & & & & & & & & & & & & & & & \\
\hline $\begin{array}{l}\text { Celtis rubrovenia Elmer } \\
\text { (Brambach et al. 1238) }\end{array}$ & Sul & & . & . & . & $4 / 0$ & . & . & . & . & . & . & . & . & . \\
\hline $\begin{array}{l}\text { Gironniera subaequalis } \\
\text { Planch. (Brambach et al. } \\
\text { 0224) }\end{array}$ & & & $3 / 5$ & $15 / 4$ & . & . & . & . & . & . & . & . & . & . & . \\
\hline $\begin{array}{l}\text { Trema orientalis (L.) } \\
\text { Blume (Brambach et al. } \\
\text { 1053) }\end{array}$ & & & . & . & . & $1 / 0$ & . & . & . & . & . & . & . & . & . \\
\hline \begin{tabular}{|l|} 
Cardiopteridaceae \\
Citronella suaveolens \\
(Blume) Howard \\
(Culmsee r2331) \\
\end{tabular} & C-Sul & & . & . & . & . & . & $0 / 1$ & . & . & . & $2 / 0$ & . & . & . \\
\hline $\begin{array}{l}\text { Celastraceae } \\
\text { Lophopetalum } \\
\text { javanicum (Zoll.) Turcz. } \\
\text { (Brambach et al. 1552) } \\
\text { Siphonodon celastrineus } \\
\text { Griff. (Brambach et al. } \\
\text { 1277) } \\
\end{array}$ & C-Sul & & . & . & . & $0 / 1$ & . & $2 / 13$ & . & . & . & . & . & . & . \\
\hline $\begin{array}{l}\text { Chloranthaceae } \\
\text { Ascarina philippinensis } \\
\text { C.B.Rob. (Brambach et } \\
\text { al. 0688) } \\
\end{array}$ & & & . & . & . & . & . & . & . & . & . & . & . & . & $4 / 0$ \\
\hline $\begin{array}{l}\text { Chrysobalanaceae } \\
\text { Maranthes corymbosa } \\
\text { Blume (Brambach et al. } \\
\text { 0584) }\end{array}$ & & & $\dot{\cdot} \cdot 1 / 0$ & . & $\begin{array}{c} \\
0 / 1\end{array}$ & . & . & . & . & . & . & . & . & . & . \\
\hline \begin{tabular}{|l|} 
Clethraceae \\
Clethra canescens \\
Reinw. ex Blume \\
(Brambach et al. 0687) \\
\end{tabular} & & & . & . & . & . & . & . & . & . & $0 / 1$ & . & . & . & $7 / 1$ \\
\hline $\begin{array}{l}\text { Clusiaceae } \\
\text { Garcinia celebica L. } \\
\text { (Brambach et al. 0420) }\end{array}$ & & & . & . & $1 / 0$ & . & . & . & . & . & . & . & . & . & \\
\hline $\begin{array}{l}\text { Garcinia longipedicellata } \\
\text { Kosterm. (Brambach et } \\
\text { al. 1487) }\end{array}$ & C-Sul & $x$ & . & . & . & . & . & $1 / 0$ & . & . & . & . & . & . & . \\
\hline $\begin{array}{l}\text { Garcinia maluensis } \\
\text { Lauterb. (Brambach et } \\
\text { al. 1240) }\end{array}$ & C-Sul & & . & . & . & $5 / 0$ & $0 / 1$ & . & . & . & . & . & . & . & . \\
\hline $\begin{array}{l}\text { Garcinia sp. (Brambach } \\
\text { et al. 1600) }\end{array}$ & & & . & . & . & . & . & $1 / 0$ & . & . & . & . & . & . & ${ }^{\circ}$ \\
\hline Cunoniaceae & & & & & & & & & & & & & & & \\
\hline $\begin{array}{l}\text { Weinmannia aff. } \\
\text { fraxinea (D.Don) Miq. } \\
\text { (Brambach et al. 0761) } \\
\text { Weinmannia furfuracea } \\
\text { H.C.Hopkins (Brambach } \\
\text { et al. 0949) }\end{array}$ & Sul & $x$ & . & . & . & . & . & $1 / 0$ & . & . & . & . & $12 / 1$ & . & $2 / 0$ \\
\hline
\end{tabular}




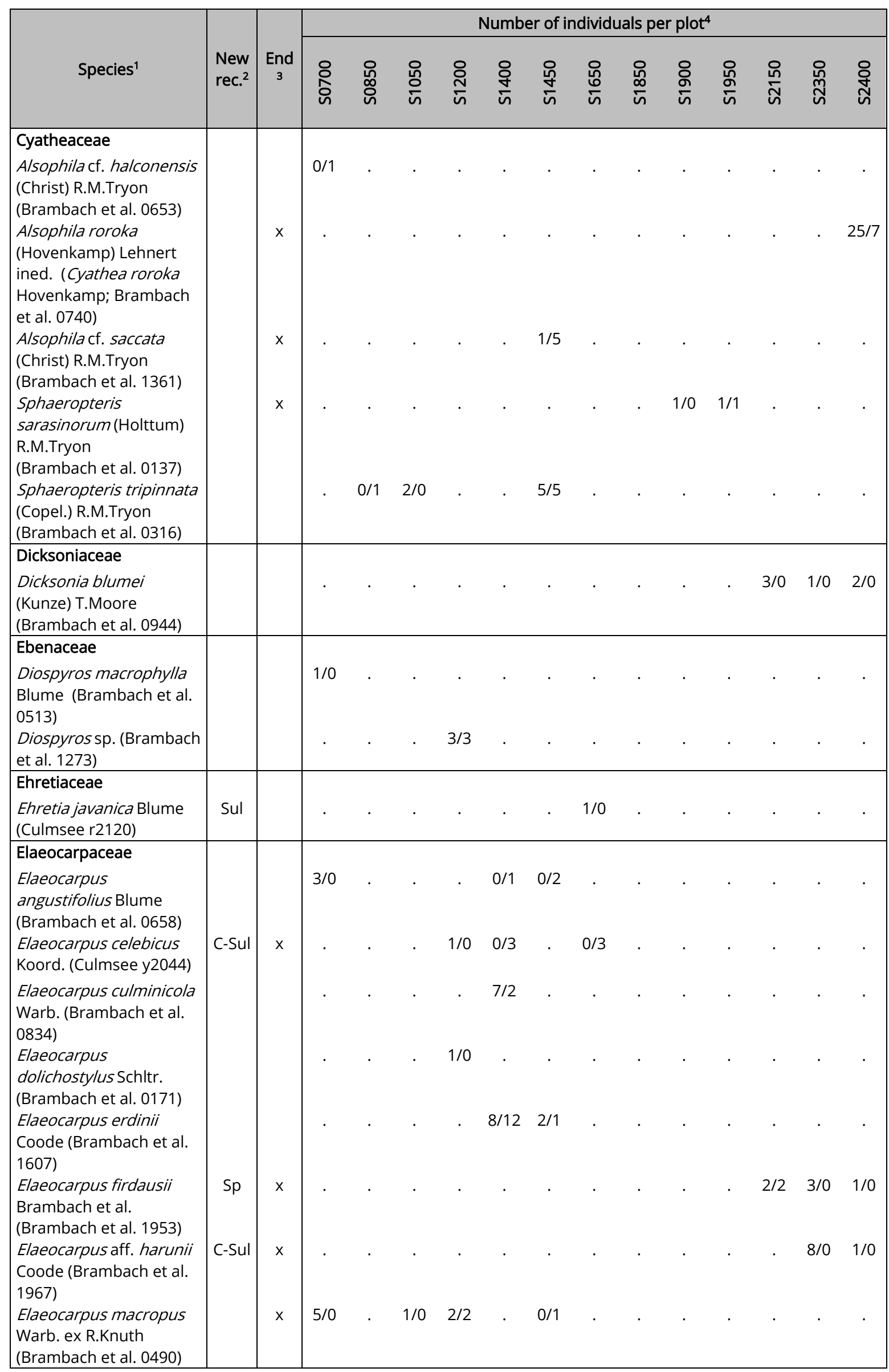




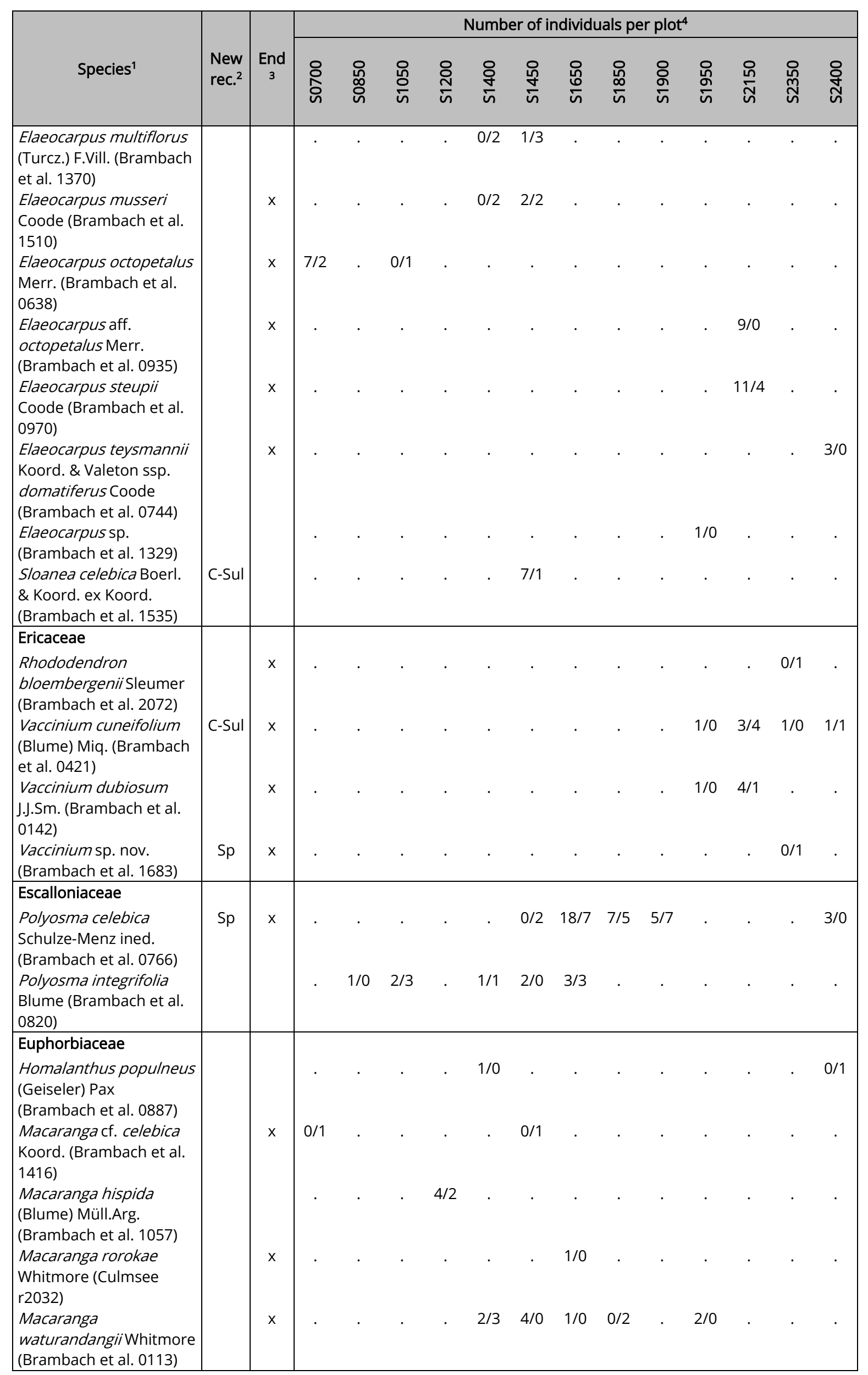




\begin{tabular}{|c|c|c|c|c|c|c|c|c|c|c|c|c|c|c|c|}
\hline \multirow[b]{2}{*}{ Species $^{1}$} & \multirow[b]{2}{*}{$\begin{array}{l}\text { New } \\
\text { rec. }^{2}\end{array}$} & \multirow[b]{2}{*}{$\begin{array}{c}\text { End } \\
3\end{array}$} & \multicolumn{13}{|c|}{ Number of individuals per plot ${ }^{4}$} \\
\hline & & & $\begin{array}{l}\text { 응 } \\
\text { 유 }\end{array}$ & $\begin{array}{l}\text { 유 } \\
\text { ڤ̊ㅇ }\end{array}$ & 응 & 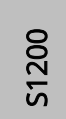 & $\frac{8}{\dot{y}}$ & $\frac{\stackrel{\circ}{\text { \} }}{\text { n }}} &{\begin{array}{l}\text { 유 } \\
\text { ఓ }\end{array}} &{\begin{array}{l}\text { 유 } \\
\infty \\
\text { ఓ }\end{array}} &{\frac{8}{\frac{8}{n}}} &{\frac{\text { 앵 }}{\frac{1}{n}}} &{\frac{\text { 은 }}{\text { Nิ }}} &{\text { 员 }} &{\text { 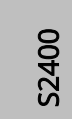 }} \\
{\hline \begin{array}{|l|}\text { Mallotus paniculatus } \\
\text { (Lam.) Müll.Arg. var. } \\
\text { paniculatus } \\
\text { (Brambach et al. 1278) } \\
\text { Neoscortechinia } \\
\text { nicobarica (Hook.f.) Pax } \\
\text { \& K.Hoffm. } \\
\text { (Brambach et al. 0626) } \\
\end{array}} &{\text { C-Sul }} &{ } &{3 / 1} &{\text {. }} &{1 / 0} &{2 / 0} &{\text {. }} &{\text {. }} &{\text {. }} &{\text {. }} &{\text {. }} &{\text {. }} &{\text {. }} &{\text {. }} &{\text {. }} \\
{\hline \begin{array}{|l|}\text { Fabaceae } \\
\text { Archidendron clypearia } \\
\text { (Jack) I.C.Nielsen var. } \\
\text { clypearia } \\
\text { (Culmsee y206) } \\
\text { Archidendron } \\
\text { pauciflorum (Benth.) } \\
\text { I.C.Nielsen var. } \\
\text { pauciflorum (Brambach } \\
\text { et al. 1309) }\end{array}} &{ } &{ } &{\text {. }} &{\text {. }} &{0 / 3} &{0 / 1} &{\text {. }} &{1 / 0} &{\text {. }} &{\text {. }} &{\text {. }} &{\text {. }} &{\text {. }} &{\text {. }} &{\text {. }} \\
{\hline \text { Fagaceae }} &{ } &{ } &{ } &{ } &{ } &{ } &{ } &{ } &{ } &{ } &{ } &{ } &{ } &{ } &{ } \\
{\hline \begin{array}{l}\text { Castanopsis } \\
\text { acuminatissima (Blume) } \\
\text { A.DC. (Culmsee r2289) }\end{array}} &{ } &{ } &{\text {. }} &{\text {. }} &{\text {. }} &{\text {. }} &{6 / 2} &{\text {. }} &{8 / 1} &{\text {. }} &{\text {. }} &{35 / 6} &{\text {. }} &{ } &{\text {. }} \\
{\hline \begin{array}{l}\text { Castanopsis buruana } \\
\text { Miq. (Brambach et al. } \\
\text { 0358) }\end{array}} &{ } &{ } &{5 / 1} &{21 / 1} &{11 / 0} &{\text {. }} &{\text {. }} &{\text {. }} &{\text {. }} &{\text {. }} &{\text {. }} &{\text {. }} &{\text {. }} &{\text {. }} &{\text {. }} \\
{\hline \begin{array}{l}\text { Lithocarpus cf. } \\
\text { bicoloratus (Elmer) } \\
\text { A.Camus (Brambach et } \\
\text { al. 0208) }\end{array}} &{ } &{ } &{\text {. }} &{1 / 1} &{\text {. }} &{\text {. }} &{\text {. }} &{\text {. }} &{\text {. }} &{\text {. }} &{\text {. }} &{\text {. }} &{\text {. }} &{\text {. }} &{\text {. }} \\
{\hline \begin{array}{l}\text { Lithocarpus celebicus } \\
\text { (Miq.) Rehder (Brambach } \\
\text { et al. 0460) }\end{array}} &{ } &{ } &{1 / 0} &{3 / 2} &{3 / 1} &{1 / 0} &{1 / 3} &{4 / 1} &{6 / 1} &{6 / 3} &{14 / 3} &{1 / 0} &{\text {. }} &{\text {. }} &{6 / 2} \\
{\hline \begin{array}{l}\text { Lithocarpus g/utinosus } \\
\text { (Blume) Soepadmo } \\
\text { (Brambach et al. 0170) }\end{array}} &{ } &{ } &{1 / 0} &{1 / 0} &{\text {. }} &{2 / 1} &{1 / 0} &{4 / 0} &{2 / 8} &{1 / 1} &{5 / 0} &{\text {. }} &{\text {. }} &{\text {. }} &{\text {. }} \\
{\hline \begin{array}{l}\text { Lithocarpus havilandii } \\
\text { (Stapf) Barnett } \\
\text { (Brambach et al. 1814) }\end{array}} &{ } &{ } &{\text {. }} &{\text {. }} &{\text {. }} &{\text {. }} &{\text {. }} &{0 / 1} &{2 / 2} &{7 / 1} &{13 / 5} &{1 / 0} &{8 / 3} &{\begin{array}{c}21 / 1 \\
4\end{array}} &{16 / 9} \\
{\hline \begin{array}{l}\text { Lithocarpus indutus } \\
\text { (Blume) Rehder } \\
\text { (Brambach et al. 0382) }\end{array}} &{ } &{ } &{\text {. }} &{\text {. }} &{\text {. }} &{\text {. }} &{1 / 0} &{2 / 0} &{1 / 0} &{3 / 2} &{4 / 1} &{\text {. }} &{\text {. }} &{\text {. }} &{\text {. }} \\
{\hline \begin{array}{l}\text { Lithocarpus } \\
\text { menadoensis (Koord.) } \\
\text { Soepadmo (Culmsee } \\
\text { 3223) }\end{array}} &{ } &{x} &{\text {. }} &{\text {. }} &{\text {. }} &{\text {. }} &{\text {. }} &{\text {. }} &{7 / 6} &{\begin{array}{c}40 / 1 \\
9\end{array}} &{5 / 1} &{\text {. }} &{\text {. }} &{\text {. }} &{\text {. }} \\
{\hline \begin{array}{l}\text { Lithocarpus pusillus } \\
\text { Soepadmo (Brambach et } \\
\text { al. 1332) }\end{array}} &{\text { Sul }} &{ } &{\text {. }} &{\text {. }} &{\text {. }} &{\text {. }} &{1 / 0} &{\text {. }} &{\text {. }} &{\text {. }} &{\text {. }} &{\begin{array}{c}18 / 1 \\
1\end{array}} &{\text {. }} &{ } &{\text {. }} \\
{\hline \begin{array}{l}\text { Trigonobalanus } \\
\text { verticillata Forman } \\
\text { (Brambach et al. 0343) }\end{array}} &{\text { Sul }} &{ } &{\text {. }} &{3 / 0} &{\text {. }} &{\text {. }} &{\text {. }} &{\text {. }} &{\text {. }} &{\text {. }} &{\text {. }} &{\text {. }} &{\text {. }} &{\text {. }} &{\text {. }} \\
{\hline \text { Gentianaceae }} &{ } &{ } &{ } &{ } &{ } &{ } &{ } &{ } &{ } &{ } &{ } &{ } &{ } &{ } &{ } \\
{\hline \begin{array}{l}\text { Fagraea blumeiG.Don } \\
\text { (Brambach et al. 2006) }\end{array}} &{ } &{ } &{\text {. }} &{\text {. }} &{\text {. }} &{\text {. }} &{\text {. }} &{\text {. }} &{\text {. }} &{\text {. }} &{\text {. }} &{\text {. }} &{\text {. }} &{3 / 0} &{\text {. }} \\
{\hline \begin{array}{l}\text { Utania morindifolia } \\
\text { (Blume) G.Don } \\
\text { (Brambach et al. 0326) }\end{array}} &{\text { C-Sul }} &{ } &{\text {. }} &{1 / 0} &{\text {. }} &{\text {. }} &{\text {. }} &{\text {. }} &{\text {. }} &{\text {. }} &{\text {. }} &{\text {. }} &{\text {. }} &{\text {. }} &{\text {. }} \\
$\hline
\end{tabular}




\begin{tabular}{|c|c|c|c|c|c|c|c|c|c|c|c|c|c|c|c|}
\hline \multirow[b]{2}{*}{ Species $^{1}$} & \multirow[b]{2}{*}{$\begin{array}{l}\text { New } \\
\text { rec. }^{2}\end{array}$} & \multirow[b]{2}{*}{$\begin{array}{c}\text { End } \\
3\end{array}$} & \multicolumn{13}{|c|}{ Number of individuals per plot ${ }^{4}$} \\
\hline & & & $\begin{array}{l}\text { 옹 } \\
\text { 요 }\end{array}$ & $\begin{array}{l}\text { 유 } \\
\text { o } \\
\text { 에 }\end{array}$ & 응 & $\frac{\text { 유 }}{\text { i }}$ & $\frac{8}{\frac{8}{4}}$ & 号 & $\begin{array}{l}\text { 음 } \\
\text { in }\end{array}$ & $\begin{array}{l}\text { ధ̊ } \\
\infty \\
\text { in }\end{array}$ & $\frac{8}{\frac{8}{n}}$ & $\begin{array}{l}\text { 음 } \\
\text { ธ }\end{array}$ & $\frac{\stackrel{\Pi}{\pi}}{\text { N }}$ & 윯 & ষ্ণ \\
\hline Gesneriaceae & & & & & & & & & & & & & & & \\
\hline $\begin{array}{l}\text { Cyrtandra sp. nov.1 } \\
\text { (Culmsee y2077) }\end{array}$ & Sp & $x$ & . & . & . & . & . & . & $0 / 1$ & . & . & . & . & . & \\
\hline $\begin{array}{l}\text { Cyrtandrasp. nov.2 } \\
\text { (Culmsee y2033) }\end{array}$ & Sp & $x$ & . & . & . & . & . & . & $0 / 1$ & . & . & . & . & . & \\
\hline $\begin{array}{l}\text { Cyrtandra sp. nov.3 } \\
\text { (Brambach et al. 0485) }\end{array}$ & Sp & $x$ & $0 / 3$ & . & $0 / 1$ & . & . & . & . & . & . & . & . & . & \\
\hline $\begin{array}{l}\text { Gnetaceae } \\
\text { Gnetum gnemon L. } \\
\text { (Brambach et al. 0189) }\end{array}$ & & & $0 / 1$ & $11 / 7$ & . & . & . & . & . & . & $\cdot$ & . & . & . & \\
\hline $\begin{array}{l}\text { Hamamelidaceae } \\
\text { Distyliopsis dunnii } \\
\text { (Hemsl.) P.K.Endress } \\
\text { (Culmsee r2302) } \\
\end{array}$ & & & . & $\cdot$ & . & . & . & . & $0 / 6$ & . & $3 / 2$ & $6 / 5$ & . & . & \\
\hline $\begin{array}{l}\text { Himantandraceae } \\
\text { Galbulimima } \\
\text { belgraveana (F.Muell.) } \\
\text { Sprague (Brambach et } \\
\text { al. 0825) } \\
\end{array}$ & & & . & . & . & . & $2 / 0$ & . & . & . & . & . & . & . & \\
\hline $\begin{array}{l}\text { Hydrangeaceae } \\
\text { Dichroa sp. (Culmsee } \\
\text { y2031) }\end{array}$ & & & . & $\cdot$ & . & . & . & . & $0 / 1$ & . & $\cdot$ & . & . & . & \\
\hline $\begin{array}{l}\text { Ixonanthaceae } \\
\text { Ixonanthes petiolaris } \\
\text { Blume (Brambach et al. } \\
\text { 0335) }\end{array}$ & C-Sul & & $\begin{array}{c}\cdot \\
1 / 0\end{array}$ & $\cdot \dot{6}$ & . & . & . & . & . & . & . & . & . & . & \\
\hline Juglandaceae & & & & & & & & & & & & & & & \\
\hline $\begin{array}{l}\text { Engelhardtia apoensis } \\
\text { Elmer ex Nagel } \\
\text { (Brambach et al. 0856) }\end{array}$ & C-Sul & & . & . & . & . & $1 / 0$ & . & . & . & . & . & . & . & \\
\hline $\begin{array}{l}\text { Engelhardtia rigida } \\
\text { Blume (Culmsee r2297) }\end{array}$ & & & . & . & . & . & . & . & . & . & $11 / 3$ & $1 / 0$ & . & . & \\
\hline $\begin{array}{l}\text { Engelhardtia serrata } \\
\text { Blume (Culmsee r2008) }\end{array}$ & & & . & . & . & . & . & . & $4 / 2$ & . & . & . & . & . & \\
\hline $\begin{array}{l}\text { Engelhardtia spicata } \\
\text { Lechen ex Blume } \\
\text { (Culmsee 990) }\end{array}$ & Sul & & . & . & $1 / 0$ & . & $2 / 3$ & . & . & . & . & . & . & . & \\
\hline Lamiaceae & & & & & & & & & & & & & & & \\
\hline $\begin{array}{l}\text { Callicarpa pentandra } \\
\text { Roxb. (Brambach et al. } \\
\text { 0654) } \\
\text { Vitex quinata (Lour.) } \\
\text { F.N.Williams (Brambach } \\
\text { et al. 1118) }\end{array}$ & & & $1 / 0$ & . & . & $3 / 5$ & . & . & . & . & . & . & . & . & \\
\hline Lauraceae & & & & & & & & & & & & & & & \\
\hline $\begin{array}{l}\text { Actinodaphne cf. } \\
\text { glomerata (Blume) Nees } \\
\text { (Culmsee 3077) }\end{array}$ & & & . & . & . & . & . & . & . & $0 / 1$ & . & . & . & . & \\
\hline $\begin{array}{l}\text { Cinnamomum cf. polderi } \\
\text { Kosterm. (Brambach et } \\
\text { al. 1244) }\end{array}$ & & $x$ & . & . & . & $2 / 2$ & $0 / 2$ & $1 / 1$ & . & . & . & . & . & . & \\
\hline $\begin{array}{l}\text { Cryptocarya cf. albida } \\
\text { Kosterm. (Brambach et } \\
\text { al. 0091) }\end{array}$ & & & . & . & . & . & . & . & . & . & . & $1 / 0$ & . & . & $5 / 0$ \\
\hline $\begin{array}{l}\text { Cryptocarya cf. ampla } \\
\text { Merr. (Brambach et al. } \\
\text { 0530) }\end{array}$ & & & $4 / 1$ & . & . & . & . & . & $1 / 2$ & . & . & . & . & . & \\
\hline
\end{tabular}




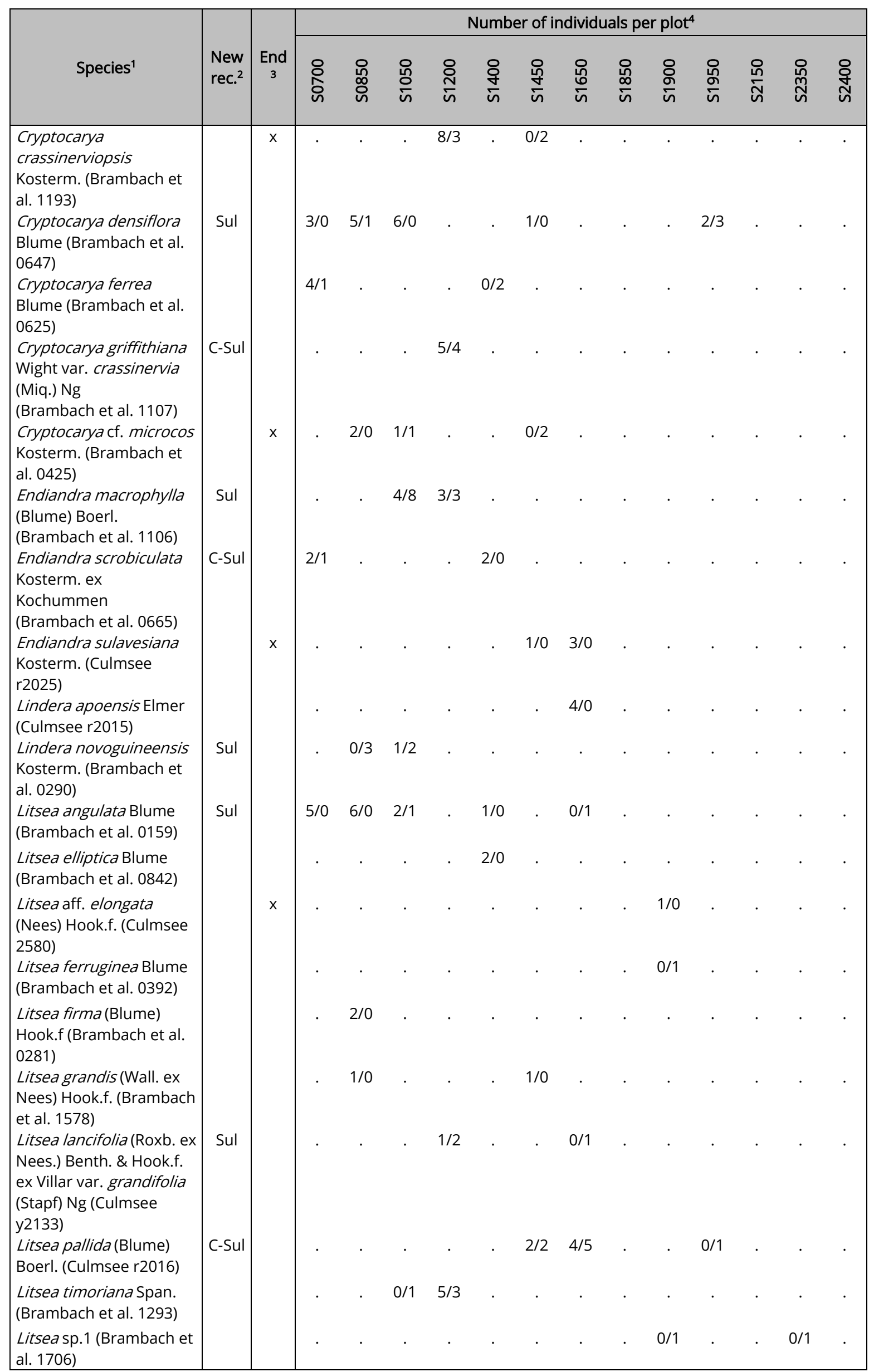




\begin{tabular}{|c|c|c|c|c|c|c|c|c|c|c|c|c|c|c|c|}
\hline \multirow[b]{2}{*}{ Species $^{1}$} & \multirow[b]{2}{*}{$\begin{array}{l}\text { New } \\
\text { rec. }^{2}\end{array}$} & \multirow[b]{2}{*}{$\begin{array}{c}\text { End } \\
3\end{array}$} & \multicolumn{13}{|c|}{ Number of individuals per plot ${ }^{4}$} \\
\hline & & & $\begin{array}{l}\text { ঃ } \\
\text { î }\end{array}$ & $\begin{array}{l}\text { 유 } \\
\text { ᄋ̊ } \\
\text { 인 }\end{array}$ & $\begin{array}{l}\text { 응 } \\
\text { in }\end{array}$ & $\underset{\text { i }}{\stackrel{\text { i }}{n}}$ & $\frac{8}{\frac{8}{4}}$ & $\frac{\text { 운 }}{\text { in }}$ & $\begin{array}{l}\stackrel{\circ}{0} \\
\bar{\sigma}\end{array}$ & $\begin{array}{l}\text { 오 } \\
\infty \\
\text { in }\end{array}$ & $\frac{8}{\frac{8}{n}}$ & $\begin{array}{l}\text { 음 } \\
\text { 亡 }\end{array}$ & $\frac{\text { 은 }}{\text { N }}$ & 员 & 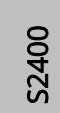 \\
\hline $\begin{array}{l}\text { Litsea sp.2 (Brambach et } \\
\text { al. 1339) }\end{array}$ & & & . & . & . & . & . & $0 / 1$ & . & . & . & . & . & . & \\
\hline $\begin{array}{l}\text { Machilus rimosa (Blume) } \\
\text { Blume (Brambach et al. } \\
\text { 0832) }\end{array}$ & & & . & . & . & . & $1 / 0$ & $2 / 1$ & . & . & . & $1 / 0$ & . & . & . \\
\hline $\begin{array}{l}\text { Neolitsea cassia (L.) } \\
\text { Kosterm. (Brambach et } \\
\text { al. 1576, 1957) }\end{array}$ & C-Sul & & . & . & . & . & . & $1 / 2$ & . & . & . & . & . & $12 / 9$ & $3 / 6$ \\
\hline $\begin{array}{l}\text { Nothaphoebe albipes } \\
\text { Kostermans ined. } \\
\text { (Brambach et al. 0123) }\end{array}$ & $\mathrm{Sp}$ & $x$ & . & . & . & . & $1 / 0$ & . & . & . & . & $1 / 0$ & . & . & \\
\hline $\begin{array}{l}\text { Nothaphoebe sp. nov. } \\
\text { (Brambach et al. 1072) }\end{array}$ & Sp & $x$ & . & . & . & $1 / 0$ & . & . & . & . & . & . & . & . & \\
\hline $\begin{array}{l}\text { Phoebe cf. grandis } \\
\text { (Nees) Merr. (Brambach } \\
\text { et al. 0437) }\end{array}$ & & & $2 / 0$ & . & $2 / 0$ & . & . & . & . & . & . & . & . & . & \\
\hline $\begin{array}{l}\text { Phoebe cf. sterculioides } \\
\text { (Elmer) Merr. (Brambach } \\
\text { et al. 1162) }\end{array}$ & & & . & . & . & $7 / 10$ & . & . & . & . & . & . & . & . & \\
\hline \begin{tabular}{|l} 
Loganiaceae \\
Geniostoma rupestre \\
J.R.Forst \& G.Forst \\
(Brambach et al.1284)
\end{tabular} & C-Sul & & . & . & . & $1 / 0$ & . & . & . & . & $1 / 0$ & . & . & . & \\
\hline $\begin{array}{l}\text { Magnoliaceae } \\
\text { Magnolia carsonii Dandy } \\
\text { ex Noot. var. carsonii } \\
\text { (Brambach et al. 1589) }\end{array}$ & & & . & . & . & . & . & $4 / 0$ & . & . & . & $3 / 1$ & . & . & \\
\hline $\begin{array}{l}\text { Magnolia liliifera(L.) } \\
\text { Baill. var. liliifera } \\
\text { (Brambach et al. 0145) }\end{array}$ & & & . & . & $0 / 3$ & . & $1 / 0$ & $2 / 0$ & . & . & . & $3 / 0$ & . & . & \\
\hline $\begin{array}{l}\text { Magnolia sulawesiana } \\
\text { Brambach et al. } \\
\text { (Brambach et al. 1334) }\end{array}$ & Sp & $x$ & . & . & . & . & . & . & . & . & $4 / 0$ & $1 / 0$ & . & . & \\
\hline $\begin{array}{l}\text { Magnolia tsiampacca (L.) } \\
\text { Figlar \& Noot. var. } \\
\text { tsiampacca } \\
\text { (Brambach et al. 1113) }\end{array}$ & & & . & . & . & $1 / 0$ & . & . & . & . & . & . & . & . & \\
\hline $\begin{array}{l}\text { Magnolia vrieseana } \\
\text { (Miq.) Baill. ex Pierre } \\
\text { (Brambach et al. 0444) }\end{array}$ & & & $2 / 0$ & . & . & . & . & . & . & . & . & . & . & . & \\
\hline $\begin{array}{l}\text { Malvaceae } \\
\text { Sterculia insularis R.Br. } \\
\text { (Brambach et al. 1056) }\end{array}$ & & & . & . & . & $1 / 1$ & . & $1 / 0$ & . & . & . & . & . & . & \\
\hline $\begin{array}{l}\text { Melastomataceae } \\
\text { Astronia atroviridis } \\
\text { Mansf. (Brambach et al. } \\
\text { 0381) }\end{array}$ & Sul & & . & . & . & . & . & . & $0 / 1$ & $1 / 8$ & $6 / 15$ & . & . & . & \\
\hline $\begin{array}{l}\text { Astronia macrophylla } \\
\text { Blume (Brambach et al. } \\
\text { 0543) }\end{array}$ & C-Sul & & $1 / 0$ & . & . & . & . & . & . & . & . & . & . & . & \\
\hline $\begin{array}{l}\text { Memecylon paniculatum } \\
\text { Jack (Brambach et al. } \\
\text { 0302) }\end{array}$ & & & . & $0 / 1$ & . & $0 / 1$ & $0 / 1$ & . & . & . & . & . & . & . & \\
\hline Meliaceae & & & & & & & & & & & & & & & \\
\hline $\begin{array}{l}\text { Aglaia korthalsii Miq. } \\
\text { (Brambach et al. 1305) }\end{array}$ & & & . & . & . & $0 / 3$ & . & $0 / 1$ & . & . & . & . & . & . & \\
\hline
\end{tabular}




\begin{tabular}{|c|c|c|c|c|c|c|c|c|c|c|c|c|c|c|c|}
\hline \multirow[b]{2}{*}{ Species $^{1}$} & \multirow[b]{2}{*}{$\begin{array}{l}\mathrm{New} \\
\text { rec. }^{2}\end{array}$} & \multirow[b]{2}{*}{$\begin{array}{c}\text { End } \\
3\end{array}$} & \multicolumn{13}{|c|}{ Number of individuals per plot ${ }^{4}$} \\
\hline & & & $\begin{array}{l}8 \\
\text { in }\end{array}$ & $\begin{array}{l}\text { 애 } \\
\text { ᄋ్ }\end{array}$ & 융 & 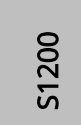 & $\frac{8}{i}$ & $\frac{\text { 号 }}{\text { n }}$ & $\begin{array}{l}\text { 융 } \\
\text { i }\end{array}$ & 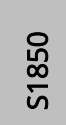 & $\frac{8}{\frac{8}{n}}$ & 앯 & 윣 & 윯 & 온 \\
\hline $\begin{array}{l}\text { Aglaia lancilimba Merr. } \\
\text { (Brambach et al. 0349) }\end{array}$ & & & & $1 / 0$ & . & & . & . & & . & . & & . & . & $\cdot$ \\
\hline $\begin{array}{l}\text { Aglaia silvestris (M. } \\
\text { Roem.) Merr. (Culmsee } \\
\text { r2011) }\end{array}$ & C-Sul & & $\cdot$ & . & . & & . & . & $1 / 0$ & . & . & . & . & . & . \\
\hline $\begin{array}{l}\text { Aglaia spectabilis (Miq.) } \\
\text { S.S.Jain \& Bennet } \\
\text { (Brambach et al. 1149) }\end{array}$ & C-Sul & & $1 / 0$ & . & $0 / 1$ & $2 / 0$ & . & . & . & . & . & . & . & . & $\cdot$ \\
\hline $\begin{array}{l}\text { Aglaia tomentosa Teijsm. } \\
\text { \& Binn. (Brambach et al. } \\
\text { 0438) }\end{array}$ & & & . & . & $1 / 2$ & 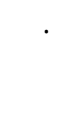 & . & . & . & . & . & . & . & . & · \\
\hline $\begin{array}{l}\text { Chisocheton patens } \\
\text { Blume (Culmsee 213) }\end{array}$ & & & . & . & $2 / 1$ & . & . & . & . & . & . & . & . & . & . \\
\hline $\begin{array}{l}\text { Chisocheton pentandrus } \\
\text { (Blanco) Merr. ssp. } \\
\text { pentandrus } \\
\text { (Brambach et al. 1219) }\end{array}$ & & & . & . & . & $5 / 3$ & . & . & . & . & . & . & . & . & . \\
\hline $\begin{array}{l}\text { Dysoxylum acutangulum } \\
\text { Miq. ssp. foveolatum } \\
\text { (Radlk.) Mabb. (Culmsee } \\
\text { 222) }\end{array}$ & & & . & . & $1 / 0$ & & . & . & . & . & . & . & . & . & . \\
\hline $\begin{array}{l}\text { Dysoxylum alliaceum } \\
\text { (Blume) Blume } \\
\text { (Brambach et al. 1103) }\end{array}$ & & & . & . & . & $1 / 0$ & . & $1 / 0$ & . & . & . & . & . & . & . \\
\hline $\begin{array}{l}\text { Dysoxylum cf. } \\
\text { cyrtobotryum Miq. } \\
\text { (Culmsee y2236) }\end{array}$ & & & . & . & . & . & . & . & . & . & . & $0 / 1$ & . & . & . \\
\hline $\begin{array}{l}\text { Dysoxylum densiflorum } \\
\text { (Blume) Miq. (Brambach } \\
\text { et al. 1208) }\end{array}$ & & & $2 / 0$ & . & $0 / 2$ & $10 / 4$ & . & $1 / 1$ & . & . & . & . & . & . & . \\
\hline $\begin{array}{l}\text { Dysoxylum excelsum } \\
\text { Blume (Culmsee r2106) }\end{array}$ & & & . & $1 / 0$ & . & . & . & . & $1 / 10$ & . & . & . & . & . & . \\
\hline $\begin{array}{l}\text { Dysoxylum nutans } \\
\text { (Blume) Miq. (Brambach } \\
\text { et al. 0527) }\end{array}$ & & & $0 / 1$ & . & . & . & . & . & . & . & . & . & . & . & . \\
\hline $\begin{array}{l}\text { Lansium domesticum } \\
\text { Correa (Brambach et al. } \\
\text { 0462) }\end{array}$ & C-Sul & & $0 / 1$ & . & . & . & . & . & . & . & . & . & . & . & . \\
\hline $\begin{array}{l}\text { Reinwardtiodendronsp. } \\
\text { (Brambach et al. 1509) }\end{array}$ & & & . & . & . & 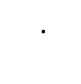 & $1 / 2$ & $1 / 1$ & . & . & . & . & . & . & . \\
\hline $\begin{array}{l}\text { Metteniusaceae } \\
\text { Platea excelsa Blume } \\
\text { var. borneensis (Heine) } \\
\text { Sleumer } \\
\text { (Brambach et al. 1575) } \\
\text { Platea latifolia Blume } \\
\text { (Brambach et al. 1493) }\end{array}$ & & & . & . & $6 / 4$ & . & $\begin{array}{c}12 / 1 \\
1\end{array}$ & $5 / 0$ & $1 / 1$ & $0 / 2$ & . & . & . & . & . \\
\hline Monimiaceae & & & & & & & & & & & & & & & \\
\hline $\begin{array}{l}\text { Kibara coriacea (Blume) } \\
\text { Tul. (Brambach et al. } \\
\text { 0532) }\end{array}$ & & & $1 / 2$ & . & . & & . & . & $0 / 2$ & . & . & . & . & . & . \\
\hline $\begin{array}{l}\text { Levieria montana Becc. } \\
\text { (Brambach et al. 0903) }\end{array}$ & & & . & . & $1 / 1$ & . & $2 / 3$ & . & $2 / 2$ & . & . & . & . & . & . \\
\hline $\begin{array}{l}\text { Matthaea sancta Blume } \\
\text { (Culmsee r536) }\end{array}$ & & & . & . & $1 / 3$ & & . & . & . & . & . & . & . & . & . \\
\hline $\begin{array}{l}\text { Steganthera hirsuta } \\
\text { (Worb.) Perkins } \\
\text { (Brambach et al. 0509) }\end{array}$ & & & $1 / 0$ & . & . & $0 / 2$ & $0 / 1$ & . & $0 / 1$ & . & . & . & . & . & . \\
\hline
\end{tabular}




\begin{tabular}{|c|c|c|c|c|c|c|c|c|c|c|c|c|c|c|c|}
\hline \multirow[b]{2}{*}{ Species $^{1}$} & \multirow[b]{2}{*}{$\begin{array}{l}\text { New } \\
\text { rec. }^{2}\end{array}$} & \multirow[b]{2}{*}{$\begin{array}{c}\text { End } \\
3\end{array}$} & \multicolumn{13}{|c|}{ Number of individuals per plot ${ }^{4}$} \\
\hline & & & 옹 & $\begin{array}{l}\text { 애 } \\
\text { ○ }\end{array}$ & 융 & 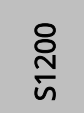 & $\frac{8}{\dot{g}}$ & $\frac{\text { ㅇํํ }}{\text { n }}$ & 员 & 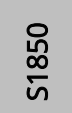 & $\frac{8}{\bar{n}}$ & 앰 & $\frac{\text { ํํㄴ }}{\text { N }}$ & 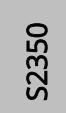 & ণ্ণ \\
\hline Moraceae & & & & & & & & & & & & & & & \\
\hline $\begin{array}{l}\text { Antiaris toxicaria Lesch. } \\
\text { ssp. toxicaria (Brambach } \\
\text { et al. 0505) }\end{array}$ & C-Sul & & $1 / 0$ & . & . & . & . & . & . & . & . & . & . & . & . \\
\hline $\begin{array}{l}\text { Artocarpus lacucha } \\
\text { Roxb. ex Buch.-Ham. } \\
\text { (Brambach et al. 1105) }\end{array}$ & & & . & . & . & $1 / 1$ & . & . & . & . & . & . & . & . & . \\
\hline $\begin{array}{l}\text { Artocarpus teysmannii } \\
\text { Miq. ssp. teysmannii } \\
\text { (Brambach et al. 0366) }\end{array}$ & & & . & $3 / 0$ & . & . & . & . & . & . & . & . & . & . & . \\
\hline $\begin{array}{l}\text { Ficus buntaensis } \\
\text { C.C.Berg (Brambach et } \\
\text { al. 1113) }\end{array}$ & & $x$ & . & . & . & $1 / 4$ & . & . & . & . & . & . & . & . & . \\
\hline $\begin{array}{l}\text { Ficus crassiramea (Miq.) } \\
\text { Miq. ssp. crassiramea } \\
\text { (Brambach et al. 1573) }\end{array}$ & & & . & . & $1 / 0$ & . & . & $2 / 0$ & $1 / 0$ & . & . & $1 / 0$ & . & . & . \\
\hline $\begin{array}{l}\text { Ficus lumutana C.C.Berg } \\
\text { (Brambach et al. 0295) }\end{array}$ & C-Sul & & $2 / 1$ & $1 / 0$ & . & . & . & . & . & . & . & . & . & . & . \\
\hline $\begin{array}{l}\text { Ficus oleifolia King ssp. } \\
\text { oleifolia (Brambach et al. } \\
\text { 1696) }\end{array}$ & & & . & . & . & . & . & . & . & . & . & $0 / 1$ & $0 / 1$ & $0 / 1$ & . \\
\hline $\begin{array}{l}\text { Ficus sulawesiana } \\
\text { C.C.Berg \& Culmsee } \\
\text { (Brambach et al. 0357) }\end{array}$ & & $x$ & . & . & . & . & . & . & . & $0 / 1$ & $0 / 1$ & . & . & . & . \\
\hline $\begin{array}{l}\text { Ficus tinctoria G.Forst. } \\
\text { ssp. gibbosa (Blume) } \\
\text { Corner } \\
\text { (Brambach et al. 1488) }\end{array}$ & & & . & . & . & . & . & $1 / 0$ & . & . & . & . & . & . & . \\
\hline $\begin{array}{l}\text { Ficus variegata Blume } \\
\text { (Brambach et al. 1241) }\end{array}$ & & & . & . & . & $2 / 0$ & . & . & . & . & . & . & . & . & . \\
\hline $\begin{array}{l}\text { Ficus cf. variegata Blume } \\
\text { (Faber et al. y1415) }\end{array}$ & & & . & . & . & . & . & . & . & $0 / 1$ & . & . & . & . & . \\
\hline $\begin{array}{l}\text { Ficus sp. (Brambach et } \\
\text { al. 1408) }\end{array}$ & & & . & . & . & . & . & $0 / 1$ & . & . & . & . & . & . & . \\
\hline $\begin{array}{l}\text { Streblus glaber(Merr.) } \\
\text { Corner ssp. glaber } \\
\text { (Brambach et al. 0905) }\end{array}$ & & & . & . & . & . & $6 / 3$ & . & . & . & . & . & . & . & . \\
\hline $\begin{array}{l}\text { Trophis philippinensis } \\
\text { (Bureau) Corner } \\
\text { (Brambach et al. 1070) }\end{array}$ & & & $1 / 0$ & . & . & $1 / 0$ & . & . & . & . & . & . & . & . & . \\
\hline Myricaceae & & & & & & & & & & & & & & & \\
\hline $\begin{array}{l}\text { Morella javanica (Blume) } \\
\text { I.M.Turner (Brambach et } \\
\text { al. 0737) }\end{array}$ & & & . & . & . & . & . & . & . & . & . & . & . & . & $2 / 0$ \\
\hline Myristicaceae & & & & & & & & & & & & & & & \\
\hline $\begin{array}{l}\text { Gymnacranthera } \\
\text { farquhariana (Wall. ex } \\
\text { Hook.f. \& Thomson) } \\
\text { Warb. var. zippeliana } \\
\text { (Miq.) R.T.A.Schouten } \\
\text { (Brambach et al. 0641) }\end{array}$ & & & $1 / 0$ & . & $1 / 1$ & . & . & . & . & . & . & . & . & . & \\
\hline $\begin{array}{l}\text { Horsfieldia costulata } \\
\text { (Miq.) Warb. (Brambach } \\
\text { et al. 0333) }\end{array}$ & & & $11 / 6$ & $3 / 5$ & $2 / 0$ & $11 / 8$ & $2 / 0$ & . & . & . & . & . & . & . & . \\
\hline $\begin{array}{l}\text { Horsfieldia parviflora } \\
\text { (Roxb.) J.Sinclair } \\
\text { (Brambach et al. 0504) }\end{array}$ & C-Sul & & $2 / 2$ & . & . & . & . & . & . & . & . & . & . & . & . \\
\hline
\end{tabular}




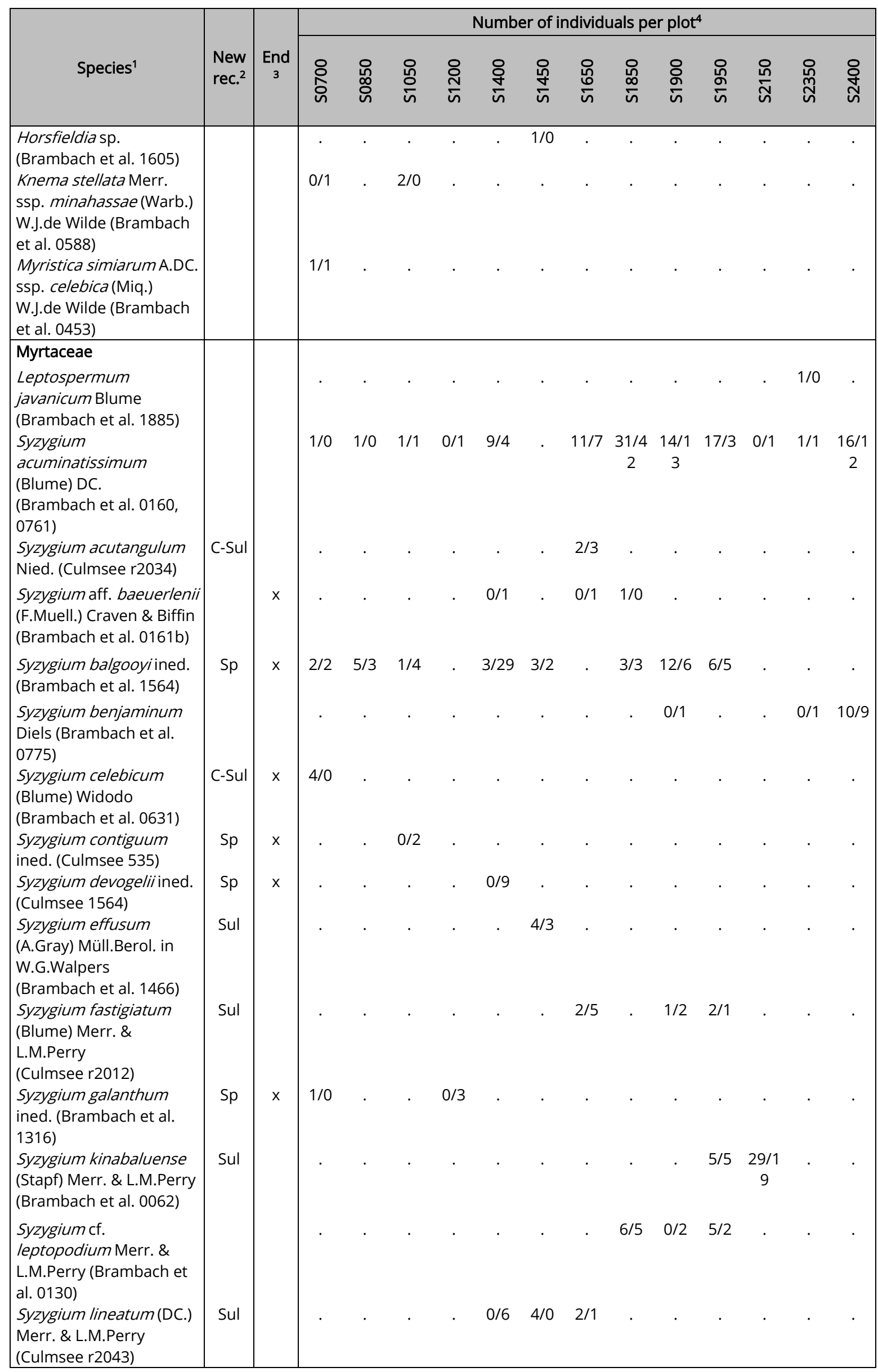




\begin{tabular}{|c|c|c|c|c|c|c|c|c|c|c|c|c|c|c|c|}
\hline \multirow[b]{2}{*}{ Species $^{1}$} & \multirow[b]{2}{*}{$\begin{array}{l}\text { New } \\
\text { rec. }^{2}\end{array}$} & \multirow[b]{2}{*}{$\begin{array}{c}\text { End } \\
3\end{array}$} & \multicolumn{13}{|c|}{ Number of individuals per plot ${ }^{4}$} \\
\hline & & & 응 & $\begin{array}{l}\text { 유 } \\
\text { ᄋ } \\
\text { 이 }\end{array}$ & $\begin{array}{l}\text { 융 } \\
\text { 든 }\end{array}$ & 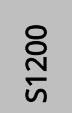 & $\frac{8}{\dot{s}}$ & 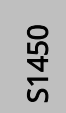 & $\begin{array}{l}\text { 윰 } \\
\text { in }\end{array}$ & $\begin{array}{l}\stackrel{0}{10} \\
\infty \\
\text { i }\end{array}$ & $\frac{8}{\frac{8}{n}}$ & $\begin{array}{l}\text { 음 } \\
\text { ஸ }\end{array}$ & $\stackrel{\text { 은 }}{\text { ஸ̂ }}$ & 윯 & ষ্ণ \\
\hline $\begin{array}{l}\text { Syzygium nigricans } \\
\text { (King) Merr. \& L.M.Perry } \\
\text { (Brambach et al. 0409) }\end{array}$ & C-Sul & & . & $\cdot$ & . & . & . & . & . & $1 / 4$ & $3 / 0$ & . & . & . & . \\
\hline $\begin{array}{l}\text { Syzygium phaeostictum } \\
\text { Merr. \& L.M.Perry } \\
\text { (Brambach et al. 0590) }\end{array}$ & Sul & & $1 / 1$ & . & . & . & . & . & . & . & . & . & . & . & . \\
\hline $\begin{array}{l}\text { Syzygium aff. } \\
\text { rosenbluthii (C.B.Rob.) } \\
\text { Merr. } \\
\text { (Brambach et al. 0985) }\end{array}$ & & $x$ & . & . & . & . & . & . & . & $1 / 0$ & . & $6 / 2$ & $16 / 5$ & . & . \\
\hline $\begin{array}{l}\text { Syzygium tripinnatum } \\
\text { (Blanco) Merr. } \\
\text { (Brambach et al. 0075) }\end{array}$ & Sul & & . & . & . & . & . & . & . & $0 / 3$ & $24 / 5$ & $9 / 7$ & . & . & . \\
\hline $\begin{array}{l}\text { Syzygium zeylanicum (L.) } \\
\text { DC. (Brambach et al. } \\
\text { 0915) }\end{array}$ & C-Sul & & . & . & . & . & $1 / 2$ & . & . & . & . & . & . & . & . \\
\hline $\begin{array}{l}\text { Syzygium sp.1 } \\
\text { (Brambach et al. 0768) }\end{array}$ & & & . & . & . & . & . & . & . & . & . & . & . & . & $6 / 3$ \\
\hline $\begin{array}{l}\text { Syzygium sp.2 } \\
\text { (Brambach et al. 1805) }\end{array}$ & & & . & . & . & . & . & . & . & . & . & . & $15 / 5$ & $12 / 5$ & . \\
\hline $\begin{array}{l}\text { Syzygium sp.3 } \\
\text { (Brambach et al. 0902) }\end{array}$ & & & . & . & . & . & $1 / 1$ & . & $0 / 1$ & . & . & . & . & . & . \\
\hline $\begin{array}{l}\text { Syzygium sp.4 (Culmsee } \\
\text { r2129) }\end{array}$ & & & . & . & . & . & . & . & . & $3 / 2$ & $11 / 4$ & $4 / 5$ & . & . & . \\
\hline $\begin{array}{l}\text { Syzygium sp.5 (Culmsee } \\
\text { r2049) }\end{array}$ & & & . & . & . & . & $1 / 3$ & . & $5 / 9$ & . & $0 / 1$ & $4 / 2$ & $0 / 1$ & . & . \\
\hline $\begin{array}{l}\text { Syzygium sp.6 (Culmsee } \\
\text { 1853) }\end{array}$ & & & . & . & . & . & . & . & . & . & . & . & . & . & $0 / 2$ \\
\hline $\begin{array}{l}\text { Xanthomyrtus } \\
\text { angustifolia A.J.Scott } \\
\text { (Brambach et al. 1907) }\end{array}$ & & & . & . & . & . & . & . & . & . & $1 / 0$ & $1 / 1$ & $\begin{array}{c}22 / 1 \\
1\end{array}$ & $11 / 7$ & $0 / 3$ \\
\hline Nyssaceae & & & & & & & & & & & & & & & \\
\hline $\begin{array}{l}\text { Mastixia pentandra } \\
\text { Blume ssp. scortechinii } \\
\text { (King) K.M.Matthew } \\
\text { (Culmsee r2321) }\end{array}$ & & & . & . & . & . & . & . & $0 / 1$ & $1 / 0$ & $1 / 1$ & $5 / 8$ & . & . & . \\
\hline $\begin{array}{l}\text { Mastixia rostrata Blume } \\
\text { ssp. caudatifolia (Merr.) } \\
\text { K.M.Matthew (Brambach } \\
\text { et al. 0660) }\end{array}$ & C-Sul & & $1 / 0$ & . & . & . & . & . & . & . & . & . & . & . & . \\
\hline \begin{tabular}{|l|} 
Mastixia trichotoma \\
Blume (Culmsee D- \\
260211-01) \\
\end{tabular} & C-Sul & & . & . & . & . & . & . & $2 / 1$ & . & . & . & . & . & . \\
\hline Oleaceae & & & & & & & & & & & & & & & \\
\hline $\begin{array}{l}\text { Chionanthus celebicus } \\
\text { Koord. (Brambach et al. } \\
\text { 1502) }\end{array}$ & & $x$ & . & $0 / 1$ & . & . & . & $1 / 0$ & . & $0 / 2$ & $3 / 1$ & . & . & . & . \\
\hline $\begin{array}{l}\text { Chionanthus polygamus } \\
\text { (Roxb.) Kiew (Brambach } \\
\text { et al. 0317) }\end{array}$ & & & $2 / 0$ & $1 / 0$ & . & . & $17 / 6$ & $2 / 0$ & . & . & . & $1 / 0$ & . & . & . \\
\hline $\begin{array}{l}\text { Chionanthus ramiflorus } \\
\text { Roxb. (Brambach et al. } \\
\text { 1184) }\end{array}$ & & & . & . & . & $1 / 0$ & . & . & . & . & . & . & . & . & \\
\hline $\begin{array}{l}\text { Chionanthus } \\
\text { sulawesicus Kiew } \\
\text { (Culmsee y2052) }\end{array}$ & & $x$ & . & . & . & . & . & . & $1 / 6$ & . & . & . & . & . & . \\
\hline $\begin{array}{l}\text { Ligustrum glomeratum } \\
\text { Blume (Brambach et al. } \\
\text { 1246) }\end{array}$ & C-Sul & & . & . & . & $1 / 0$ & . & . & . & . & . & . & . & . & \\
\hline
\end{tabular}




\begin{tabular}{|c|c|c|c|c|c|c|c|c|c|c|c|c|c|c|c|}
\hline \multirow[b]{2}{*}{ Species $^{1}$} & \multirow[b]{2}{*}{$\begin{array}{l}\text { New } \\
\text { rec. }^{2}\end{array}$} & \multirow[b]{2}{*}{$\begin{array}{c}\text { End } \\
3\end{array}$} & \multicolumn{13}{|c|}{ Number of individuals per plot ${ }^{4}$} \\
\hline & & & $\begin{array}{l}8 \\
\text { 옹 }\end{array}$ & $\begin{array}{l}\text { 애 } \\
\text { ᄋ } \\
\text { ํ }\end{array}$ & 융 & $\frac{8}{\stackrel{8}{n}}$ & $\frac{8}{\frac{8}{4}}$ & $\frac{\text { 装 }}{\text { 亡 }}$ & $\begin{array}{l}\text { 응 } \\
\text { n }\end{array}$ & $\begin{array}{l}\stackrel{0}{h} \\
\infty \\
\text { n }\end{array}$ & $\frac{8}{\frac{8}{n}}$ & $\begin{array}{l}\text { 음 } \\
\text { n }\end{array}$ & 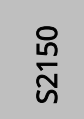 & $\begin{array}{l}\stackrel{\text { ్}}{\text { N }} \\
\text { N }\end{array}$ & ষ্ণ \\
\hline \begin{tabular}{|l|} 
Pandanaceae \\
Pandanus cf. \\
brachyspathus Martelli \\
(Brambach et al. 0596) \\
Pandanus sulawesicus \\
B.C.Stone (Brambach et \\
al. 0111)
\end{tabular} & & $x$ & $0 / 1$ & . & $1 / 0$ & . & . & $6 / 0$ & . & . & . & $1 / 0$ & . & . & . \\
\hline \begin{tabular}{|l|} 
Paracryphiaceae \\
Quintinia apoensis \\
(Elmer) Schltr. \\
(Brambach et al. 1964) \\
Sphenostemon \\
papuanus (Lauterb.) \\
Steenis \& Erdtman \\
(Brambach et al. 0943) \\
\end{tabular} & & & . & . & . & . & . & . & . & $0 / 1$ & $1 / 3$ & . & $\begin{array}{l}17 / 9 \\
2 / 1\end{array}$ & $\begin{array}{c}18 / 1 \\
4 \\
.\end{array}$ & $1 / 0$ \\
\hline \begin{tabular}{|l|} 
Pentaphylacaceae \\
Adinandra celebica \\
Koord. (Brambach et al. \\
0079) \\
Adinandra eymae \\
Kobuski (Brambach et al. \\
0767) \\
Adinandra masambensis \\
Kobuski (Culmsee 2589)
\end{tabular} & C-Sul & $x$ & . & . & . & . & . & . & . & $0 / 1$ & $4 / 1$ & $1 / 3$ & . & $5 / 3$ & $2 / 1$ \\
\hline $\begin{array}{l}\text { Adinandra sp. } \\
\text { (Brambach et al. 0741) } \\
\text { Eurya acuminata DC. } \\
\text { (Brambach et al. 0373) }\end{array}$ & & & . & . & . & . & $\cdot$ & . & . & $\cdot \cdot$ & $2 / 1$ & $\begin{array}{l}1 / 0 \\
\cdot\end{array}$ & . & $1 / 0$ & $\begin{array}{c}1 / 0 \\
.\end{array}$ \\
\hline \begin{tabular}{|l|} 
Eurya chinensis R.Br. \\
ssp. flava (Merr. ex. \\
Melch.) de Wit \\
(Brambach et al. 0784) \\
Ternstroemia \\
philippinensis Merr. \\
(Brambach et al. 0163) \\
Ternstroemia \\
urdanetensis (Elmer) \\
Kobuski var. crassifolia \\
Kobuski (Brambach et al. \\
1938)
\end{tabular} & C-Sul & & . & . & . & . & . & $2 / 1$ & $0 / 2$ & $0 / 5$ & $1 / 2$ & $0 / 1$ & . & $\begin{array}{c}\cdot \\
1 / 1\end{array}$ & $\begin{array}{c}1 / 3 \\
\cdot \\
1 / 0\end{array}$ \\
\hline \begin{tabular}{|l|} 
Peraceae \\
Trigonopleura malayana \\
Hook.f. (Brambach et al. \\
0234)
\end{tabular} & & & . & $10 / 0$ & $1 / 1$ & . & . & . & . & . & . & . & . & . & . \\
\hline $\begin{array}{l}\text { Phyllanthaceae } \\
\text { Antidesma excavatum } \\
\text { Miq. var. excavatum } \\
\text { (Brambach et al. 1282) } \\
\text { Antidesma riparium Airy } \\
\text { Shaw ssp. riparium } \\
\text { (Brambach et al. 0491) } \\
\text { Aporosa frutescens } \\
\text { Blume (Brambach et al. } \\
\text { 0474) } \\
\text { Baccaurea nanihua } \\
\text { Merr. (Brambach et al. } \\
\text { 0642) } \\
\end{array}$ & C-Sul & & $0 / 1$ & $0 / 2$ & $\begin{array}{c}\cdot \\
3 / 1\end{array}$ & $4 / 1$ & . & $\begin{array}{c} \\
0 / 2\end{array}$ & . & . & . & . & . & . & . \\
\hline
\end{tabular}




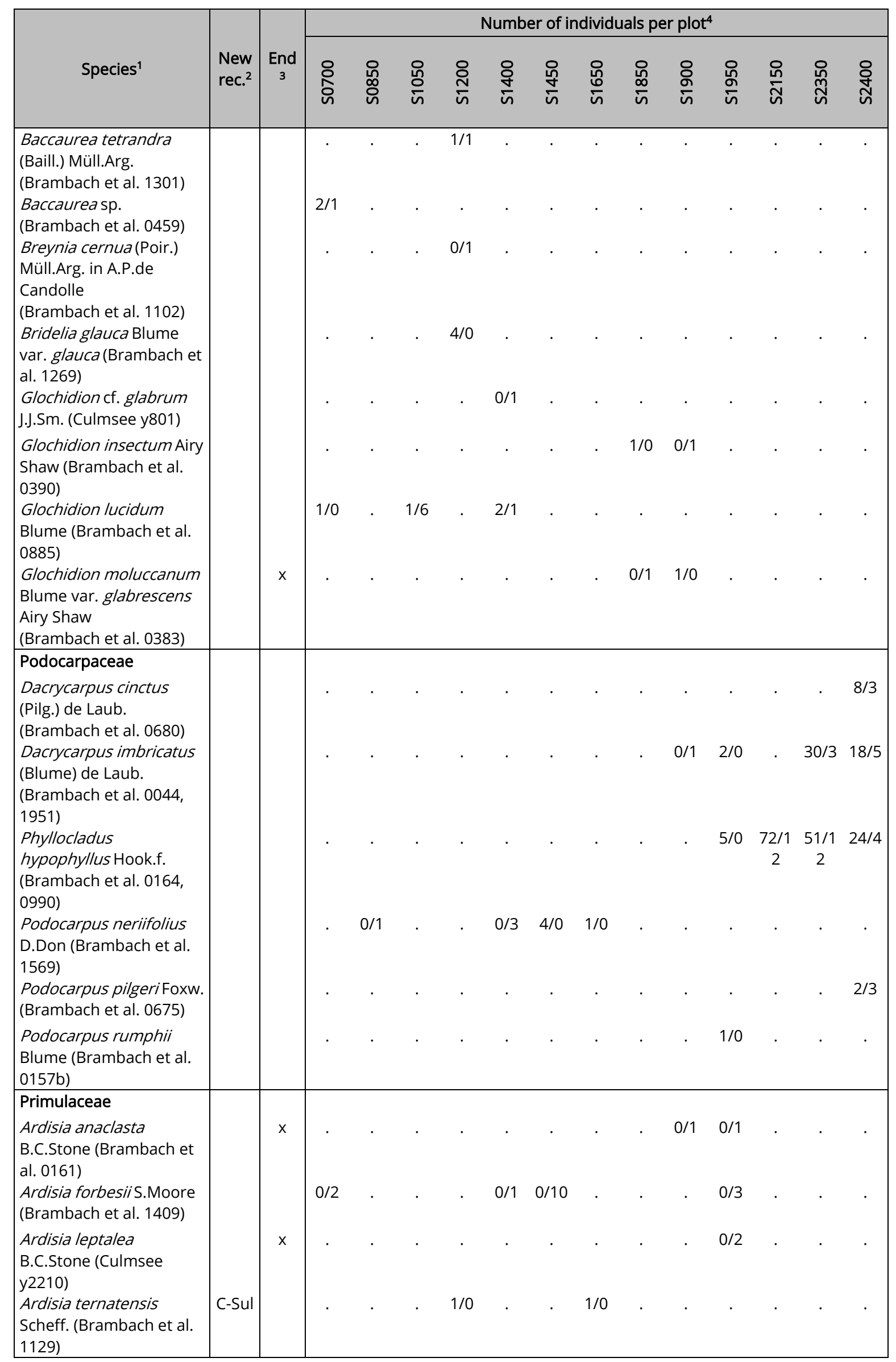




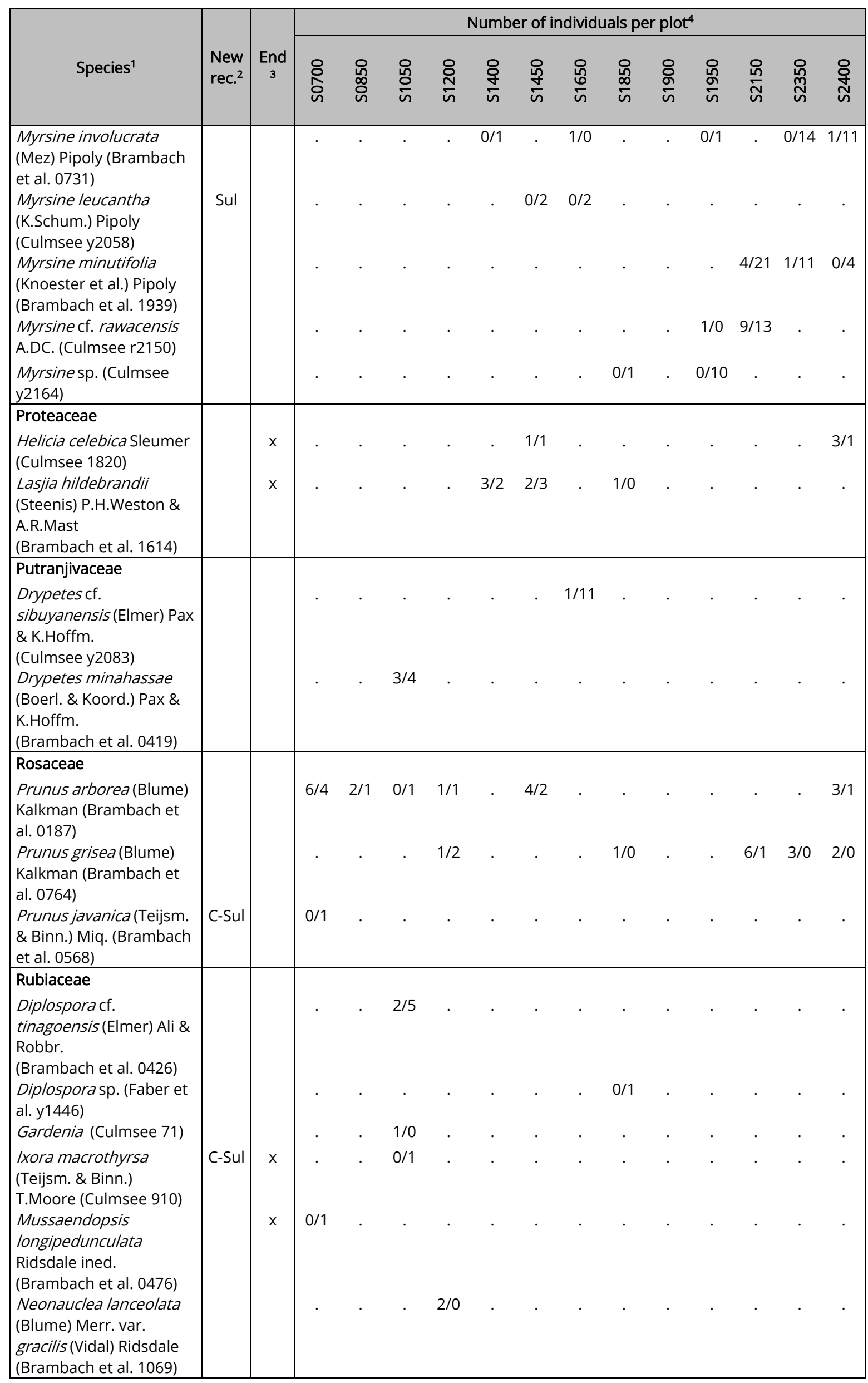




\begin{tabular}{|c|c|c|c|c|c|c|c|c|c|c|c|c|c|c|c|}
\hline \multirow[b]{2}{*}{ Species $^{1}$} & \multirow[b]{2}{*}{$\begin{array}{l}\text { New } \\
\text { rec. }^{2}\end{array}$} & \multirow[b]{2}{*}{$\begin{array}{c}\text { End } \\
3\end{array}$} & \multicolumn{13}{|c|}{ Number of individuals per plot ${ }^{4}$} \\
\hline & & & $\begin{array}{l}8 \\
\text { 우 }\end{array}$ & $\begin{array}{l}\text { 유 } \\
\text { o̊ } \\
\text { ڤn }\end{array}$ & 융 & $\frac{8}{i}$ & $\frac{8}{\dot{4}}$ & 号 & $\begin{array}{l}\text { 유 } \\
\text { in }\end{array}$ & $\begin{array}{l}\text { 유 } \\
\text { 亡 }\end{array}$ & $\frac{8}{\frac{8}{n}}$ & 앵 & $\frac{\text { 은 }}{\text { ஸे }}$ & 윢 & ষ্ণ \\
\hline $\begin{array}{l}\text { Porterandia celebica } \\
\text { M.S.Zahid (Brambach et } \\
\text { al. 0822) }\end{array}$ & & $x$ & . & . & $2 / 0$ & . & $5 / 1$ & . & $2 / 0$ & . & . & . & . & . & . \\
\hline $\begin{array}{l}\text { Praravinia loconensis } \\
\text { Bremek. (Culmsee } \\
\text { y2049) }\end{array}$ & & $x$ & . & . & . & . & . & . & $0 / 4$ & . & . & . & . & . & . \\
\hline $\begin{array}{l}\text { Praravinia sp. nov.1 } \\
\text { (Culmsee 2704) }\end{array}$ & Sp & $x$ & . & . & . & . & . & . & . & $0 / 2$ & . & . & . & . & . \\
\hline $\begin{array}{l}\text { Psychotria viridiflora } \\
\text { Reinw. ex Blume } \\
\text { (Brambach et al. 0416) }\end{array}$ & C-Sul & & $0 / 1$ & $0 / 1$ & $0 / 4$ & . & . & . & . & . & . & . & . & . & . \\
\hline $\begin{array}{l}\text { Psychotria sp. nov.1 } \\
\text { (Culmsee 2601) }\end{array}$ & $\mathrm{Sp}$ & $x$ & . & . & . & . & . & . & . & $0 / 2$ & $0 / 11$ & . & . & . & 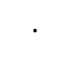 \\
\hline $\begin{array}{l}\text { Psychotria sp. nov.2 } \\
\text { (Brambach et al. 0756) }\end{array}$ & Sp & $x$ & . & . & . & . & . & . & . & . & . & . & . & $1 / 5$ & $3 / 4$ \\
\hline $\begin{array}{l}\text { Timonius minahassae } \\
\text { Koord. (Brambach et al. } \\
\text { 1074) }\end{array}$ & & & . & . & . & $2 / 2$ & . & . & . & . & . & . & . & . & . \\
\hline $\begin{array}{l}\text { Timonius teysmanii } \\
\text { Valeton (Culmsee r2023) }\end{array}$ & C-Sul & $x$ & . & . & . & . & . & . & $2 / 0$ & $1 / 1$ & . & . & . & . & . \\
\hline $\begin{array}{l}\text { Urophyllum strigosum } \\
\text { (Blume) Korth. } \\
\text { (Brambach et al. 0173, } \\
\text { 0330) }\end{array}$ & C-Sul & & . & $0 / 14$ & . & . & . & . & . & . & . & . & . & . & . \\
\hline $\begin{array}{l}\text { Urophyllum sp. } \\
\text { (Brambach et al. 1342) }\end{array}$ & & & . & . & . & . & $0 / 2$ & $0 / 7$ & . & . & . & . & . & . & . \\
\hline Rutaceae & & & & & & & & & & & & & & & \\
\hline $\begin{array}{l}\text { Acronychia pedunculata } \\
\text { (L.) Miq. (Brambach et al. } \\
\text { 1503) }\end{array}$ & & & . & $0 / 1$ & $1 / 2$ & . & $1 / 0$ & $1 / 1$ & . & . & . & . & . & . & . \\
\hline $\begin{array}{l}\text { Melicope denhamii } \\
\text { (Seem.) T.G.Hartley } \\
\text { (Brambach et al. 0890) }\end{array}$ & C-Sul & & . & . & . & . & $1 / 0$ & . & . & . & . & . & . & . & . \\
\hline $\begin{array}{l}\text { Melicope frutescens } \\
\text { (Blanco) Appelhans \& } \\
\text { J.Wen } \\
\text { (Brambach et al. 0424) }\end{array}$ & & & $1 / 0$ & $1 / 1$ & $1 / 0$ & . & $1 / 0$ & . & $2 / 0$ & . & . & . & . & . & . \\
\hline $\begin{array}{l}\text { Melicope maxii } \\
\text { T.G.Hartley (Brambach } \\
\text { et al. 1816) }\end{array}$ & & $x$ & . & . & . & . & . & . & . & $0 / 1$ & . & $1 / 0$ & . & $7 / 1$ & $2 / 1$ \\
\hline $\begin{array}{l}\text { Tetractomia tetrandra } \\
\text { (Roxb.) Merr. } \\
\text { (Brambach et al. 0950, } \\
\text { 1492) }\end{array}$ & & & . & . & . & . & . & $7 / 4$ & . & . & . & . & $13 / 6$ & . & . \\
\hline $\begin{array}{l}\text { Tetradium celebicum } \\
\text { (Koord.) T.G.Hartley } \\
\text { ined. } \\
\text { (Brambach et al. 1158) } \\
\end{array}$ & C-Sul & $x$ & . & . & . & $1 / 0$ & . & . & . & . & . & . & . & . & \\
\hline Sabiaceae & & & & & & & & & & & & & & & \\
\hline $\begin{array}{l}\text { Meliosma pinnata } \\
\text { (Roxb.) Maxim. ssp. } \\
\text { sylvatica (Elmer) Beus. } \\
\text { (Culmsee r2170) } \\
\text { Meliosma sumatrana } \\
\text { (Jack) Walp. (Brambach } \\
\text { et al. 0440) }\end{array}$ & & & $1 / 0$ & . & $1 / 2$ & $1 / 4$ & . & $0 / 1$ & . & $0 / 1$ & . & $1 / 1$ & . & . & . \\
\hline
\end{tabular}




\begin{tabular}{|c|c|c|c|c|c|c|c|c|c|c|c|c|c|c|c|}
\hline \multirow[b]{2}{*}{ Species $^{1}$} & \multirow[b]{2}{*}{$\begin{array}{l}\text { New } \\
\text { rec. }^{2}\end{array}$} & \multirow[b]{2}{*}{$\begin{array}{c}\text { End } \\
3\end{array}$} & \multicolumn{13}{|c|}{ Number of individuals per plot ${ }^{4}$} \\
\hline & & & $\begin{array}{l}8 \\
\text { 요 }\end{array}$ & $\begin{array}{l}\text { 유 } \\
\text { ᄋ̊ }\end{array}$ & $\begin{array}{l}\text { 융 } \\
\text { in }\end{array}$ & $\frac{8}{\frac{8}{n}}$ & $\frac{8}{\frac{8}{n}}$ & $\frac{\text { 운 }}{\text { ń }}$ & $\begin{array}{l}\text { 융 } \\
\text { in }\end{array}$ & $\begin{array}{l}\text { 웅 } \\
\infty \\
\text { ஸ }\end{array}$ & $\frac{8}{\frac{8}{n}}$ & $\frac{\text { 앰 }}{\frac{1}{n}}$ & $\frac{\text { 은 }}{\text { Nิ }}$ & $\begin{array}{l}\text { ํㅠ } \\
\text { N }\end{array}$ & 온 \\
\hline $\begin{array}{l}\text { Salicaceae } \\
\text { Flacourtia rukam Zoll. \& } \\
\text { Moritzi (Brambach et al. } \\
\text { 1209) }\end{array}$ & C-Sul & & $\cdot$ & . & . & $1 / 1$ & . & . & . & . & . & . & . & . & . \\
\hline $\begin{array}{l}\text { Sapindaceae } \\
\text { Acer laurinum Hassk. ex } \\
\text { Miq. (Brambach et al. } \\
\text { 0301) } \\
\text { Arytera littoralis Blume } \\
\text { (Brambach et al. 1152) }\end{array}$ & & & . & $0 / 1$ & $0 / 1$ & $\begin{array}{l}1 / 0 \\
1 / 1\end{array}$ & $3 / 0$ & $1 / 0$ & . & . & . & . & . & . & $\cdot$ \\
\hline $\begin{array}{l}\text { Guioa diplopetala } \\
\text { (Hassk.) Radlk. } \\
\text { (Brambach et al. 0919) } \\
\text { Guioa hirsuta Welzen } \\
\text { (Brambach et al. 0433) }\end{array}$ & C-Sul & $x$ & . & $1 / 1$ & $1 / 0$ & . & $0 / 1$ & . & $0 / 2$ & . & . & $19 / 9$ & $1 / 0$ & . & . \\
\hline $\begin{array}{l}\text { Harpullia cupanioides } \\
\text { Roxb. (Brambach et al. } \\
\text { 1052) } \\
\text { Mischocarpus sundaicus } \\
\text { Blume (Brambach et al. } \\
\text { 0394) } \\
\text { Pometia pinnata } \\
\text { J.R.Forst. \& G.Forst. } \\
\text { (Brambach et al. 0449) }\end{array}$ & C-Sul & & $4 / 2$ & . & $0 / 2$ & $3 / 1$ & . & . & . & . & $0 / 1$ & . & . & . & . \\
\hline $\begin{array}{l}\text { Sapotaceae } \\
\text { Palaquium obovatum } \\
\text { (Griff.) Engl. var. } \\
\text { orientale H.J.Lam } \\
\text { (Brambach et al. 1055) } \\
\text { Planchonella chartacea } \\
\text { (F.Muell. Ex Benth.) } \\
\text { H.J.Lam } \\
\text { (Brambach et al. 0519) } \\
\text { Pleioluma firma (Miq.) } \\
\text { Swenson (Brambach et } \\
\text { al. 0854) } \\
\text { Sarcosperma } \\
\text { paniculatum (King) Stapf } \\
\text { \& King } \\
\text { (Brambach et al. 0497) }\end{array}$ & C-Sul & & $2 / 0$ & $1 / 0$ & $4 / 1$ & $7 / 0$ & . & $\begin{array}{l}\cdot \\
.\end{array}$ & $7 / 1$ & . & . & $2 / 0$ & . & . & . \\
\hline $\begin{array}{l}\text { Simaroubaceae } \\
\text { Ailanthus integrifolia } \\
\text { Lam. ssp. integrifolia } \\
\text { (Brambach et al. 0458) }\end{array}$ & C-Sul & & $1 / 0$ & . & . & & . & $1 / 0$ & . & . & . & . & . & . & . \\
\hline $\begin{array}{l}\text { Staphyleaceae } \\
\text { Turpinia sphaerocarpa } \\
\text { Hassk. (Brambach et al. } \\
\text { 0656) }\end{array}$ & & & $1 / 0$ & . & . & . & . & $0 / 1$ & $1 / 0$ & . & $0 / 1$ & . & . & . & \\
\hline $\begin{array}{l}\text { Stemonuraceae } \\
\text { Gomphandra } \\
\text { mappioides Valeton } \\
\text { (Brambach et al. 0422) } \\
\text { Medusanthera laxiflora } \\
\text { (Miers) R.A. Howard } \\
\text { (Brambach et al. 0659) }\end{array}$ & & & $4 / 1$ & . & $\begin{array}{c}\cdot \\
1 / 0\end{array}$ & . & . & . & $\begin{array}{c}\cdot \\
1 / 0\end{array}$ & . & . & . & . & . & . \\
\hline
\end{tabular}




\begin{tabular}{|c|c|c|c|c|c|c|c|c|c|c|c|c|c|c|c|}
\hline \multirow[b]{2}{*}{ Species $^{1}$} & \multirow[b]{2}{*}{$\begin{array}{l}\text { New } \\
\text { rec. }^{2}\end{array}$} & \multirow[b]{2}{*}{$\begin{array}{c}\text { End } \\
3\end{array}$} & \multicolumn{13}{|c|}{ Number of individuals per plot ${ }^{4}$} \\
\hline & & & 只 & $\begin{array}{l}\text { 유 } \\
\text { o } \\
\text { 인 }\end{array}$ & $\begin{array}{l}\text { 융 } \\
\text { in }\end{array}$ & 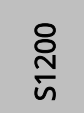 & $\frac{8}{i}$ & $\frac{\text { 운 }}{\text { in }}$ & $\begin{array}{l}\text { 앵 } \\
\text { ज́ }\end{array}$ & $\begin{array}{l}\text { 유 } \\
\text { ஸ } \\
\text { n }\end{array}$ & $\frac{8}{\frac{8}{n}}$ & $\frac{\text { ㅇํㅁ }}{\text { ஸ }}$ & $\frac{\text { 유 }}{\text { ஸ̆ }}$ & 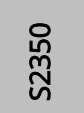 & 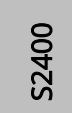 \\
\hline $\begin{array}{l}\text { Styracaceae } \\
\text { Bruinsmia styracoides } \\
\text { Boerl. \& Koord. } \\
\text { (Brambach et al. 0405) }\end{array}$ & & & $\cdot$ & . & . & . & . & $\cdot$ & . & $5 / 0$ & $\cdot$ & $\cdot$ & . & . & \\
\hline $\begin{array}{l}\text { Symplocaceae } \\
\text { Symplocos } \\
\text { cochinchinensis (Lour.) } \\
\text { S.Moore ssp. leptophylla } \\
\text { (Brand) Noot. (Brambach } \\
\text { et al. 0679) } \\
\text { Symplocos cf. } \\
\text { cochinchinensis (Lour.) } \\
\text { S.Moore (Culmsee 2694) } \\
\text { Symplocos fasciculata } \\
\text { Zoll. (Brambach et al. } \\
0150 \text { ) } \\
\text { Symplocos odoratissima } \\
\text { (Blume) Choisy (Culmsee } \\
\text { r2038) } \\
\text { Symplocos ophirensis } \\
\text { Clarke ssp. cumingiana } \\
\text { (Brand) Noot. (Brambach } \\
\text { et al. 0057) }\end{array}$ & & & . & . & . & . & . & . & $\begin{array}{l}0 / 1 \\
0 / 1 \\
2 / 1 \\
0 / 1\end{array}$ & $\begin{array}{l}0 / 1 \\
3 / 2 \\
1 / 1 \\
1 / 5\end{array}$ & $\begin{array}{l}0 / 2 \\
1 / 2 \\
0 / 2 \\
1 / 6\end{array}$ & $\begin{array}{c}0 / 2 \\
0 / 1 \\
\cdot \\
2 / 0\end{array}$ & . & $2 / 0$ & $\begin{array}{l}5 / 3 \\
1 / 2\end{array}$ \\
\hline $\begin{array}{l}\text { Theaceae } \\
\text { Camellia lanceolata } \\
\text { (Blume) Seem. } \\
\text { (Brambach et al. 1399) } \\
\text { Polyspora amboinensis } \\
\text { (Miq.) Orel et al. } \\
\text { (Culmsee r2256, } \\
\text { Brambach et al. 1174) }\end{array}$ & & & $\cdot$ & . & . & $\cdot \cdot$ & . & $0 / 1$ & . & . & $\begin{array}{c}\cdot \\
15 / 6\end{array}$ & $\begin{array}{l}0 / 5 \\
4 / 5\end{array}$ & . & . & $10 / 3$ \\
\hline $\begin{array}{l}\text { Thymelaeaceae } \\
\text { Wikstroemia } \\
\text { androsaemifolia Decne. } \\
\text { (Culmsee y2073) }\end{array}$ & & & . & . & . & . & . & . & $0 / 1$ & . & $0 / 1$ & . & . & . & \\
\hline $\begin{array}{l}\text { Trimeniaceae } \\
\text { Trimenia papuana Ridl. } \\
\text { (Brambach et al. 1866) }\end{array}$ & & & . & . & . & . & . & . & . & . & . & . & $45 / 9$ & $\begin{array}{c}14 / 2 \\
8\end{array}$ & $7 / 7$ \\
\hline $\begin{array}{l}\text { Winteraceae } \\
\text { Tasmannia piperita } \\
\text { (Hook.f.) Miers } \\
\text { (Brambach et al. 0920) }\end{array}$ & & & . & . & . & . & . & $\cdot$ & $\cdot$ & $0 / 2$ & $0 / 2$ & . & $8 / 4$ & $0 / 31$ & $0 / 6$ \\
\hline Total & & 74 & $\begin{array}{c}146 / \\
67\end{array}$ & $\begin{array}{c}133 / \\
69\end{array}$ & $\begin{array}{c}105 / \\
114\end{array}$ & $\begin{array}{c}170 / \\
98\end{array}$ & $\begin{array}{c}131 / \\
147\end{array}$ & $\begin{array}{c}155 / \\
118\end{array}$ & $\begin{array}{c}129 / \\
132\end{array}$ & $\begin{array}{c}129 / \\
144\end{array}$ & $\begin{array}{c}171 / \\
123\end{array}$ & $\begin{array}{c}200 / \\
125\end{array}$ & $\begin{array}{c}362 / \\
143\end{array}$ & $\begin{array}{c}215 / \\
165\end{array}$ & $\begin{array}{r}238 / \\
123\end{array}$ \\
\hline
\end{tabular}

${ }^{1}$ Voucher specimens in parentheses. ${ }^{2}$ Species recorded for the first time in Sulawesi (Sul) or the province of Central Sulawesi (C-Sul). New species found during this study marked as 'Sp'. ${ }^{3}$ Species endemic to Sulawesi. ${ }^{4}$ Plot acronyms contain elevation ( $m$ a.s.I.). 


\section{Appendix 4.6 Tree diversity measures}

Table 1 Diversity measures for all trees: big trees ( $\mathrm{dbh} \geq 10 \mathrm{~cm}$, recorded on 0.24 ha) plus small trees (dbh 2-9.9 cm, recorded on $0.06 \mathrm{ha}$ ).

\begin{tabular}{|l|l|cccc|cccc|cccc|}
\hline \multirow{2}{*}{ Plot } & \multirow{2}{*}{ Ind. } & \multicolumn{5}{|c|}{ Families } & \multicolumn{5}{|c|}{ Genera } & \multicolumn{4}{c|}{ Species } \\
& & ${ }^{0} \mathrm{D}_{\text {obs }}$ & ${ }^{1} \mathrm{D}_{\text {obs }}$ & ${ }^{0} \mathrm{D}_{210}$ & ${ }^{1} \mathrm{D}_{210}$ & ${ }^{0} \mathrm{D}_{\text {obs }}$ & ${ }^{1} \mathrm{D}_{\text {obs }}$ & ${ }^{0} \mathrm{D}_{210}$ & ${ }^{1} \mathrm{D}_{210}$ & ${ }^{0} \mathrm{D}_{\text {obs }}$ & ${ }^{1} \mathrm{D}_{\text {obs }}$ & ${ }^{0} \mathrm{D}_{210}$ & ${ }^{1} \mathrm{D}_{210}$ \\
\hline $\mathrm{S} 0700$ & 213 & 40 & 24.1 & 39.8 & 24.0 & 65 & 38.8 & 64.6 & 38.7 & 78 & 53.5 & 77.5 & 53.3 \\
S0850 & 202 & 25 & 14.8 & 25.2 & 14.8 & 37 & 20.5 & 37.6 & 20.6 & 44 & 23.1 & 44.8 & 23.2 \\
S1050 & 219 & 35 & 20.9 & 34.5 & 20.8 & 59 & 40.5 & 58.2 & 40.1 & 67 & 45.9 & 66.0 & 45.4 \\
S1200 & 268 & 38 & 21.2 & 35.8 & 20.7 & 59 & 39.9 & 54.7 & 38.3 & 72 & 50.5 & 66.5 & 48.0 \\
S1400 & 278 & 29 & 15.0 & 27.8 & 14.7 & 41 & 17.6 & 37.6 & 17.1 & 60 & 33.2 & 54.0 & 31.7 \\
S1450 & 273 & 42 & 26.0 & 38.9 & 25.3 & 56 & 35.3 & 51.5 & 33.9 & 78 & 50.2 & 70.3 & 47.3 \\
S1650 & 261 & 32 & 15.9 & 30.0 & 15.6 & 42 & 20.6 & 39.3 & 20.1 & 63 & 38.6 & 57.4 & 37.0 \\
S1850 & 273 & 24 & 6.7 & 21.6 & 6.5 & 28 & 7.1 & 25.2 & 6.9 & 46 & 16.4 & 41.3 & 15.8 \\
S1900 & 294 & 28 & 10.5 & 24.8 & 10.2 & 30 & 10.9 & 26.5 & 10.7 & 49 & 27.1 & 43.3 & 26.0 \\
S1950 & 325 & 27 & 10.6 & 23.6 & 10.3 & 38 & 15.1 & 32.6 & 14.5 & 61 & 31.4 & 50.7 & 29.3 \\
S2150 & 505 & 17 & 9.9 & 15.3 & 9.6 & 19 & 11.6 & 17.1 & 11.3 & 27 & 16.2 & 23.7 & 15.6 \\
S2350 & 380 & 20 & 11.1 & 18.3 & 10.8 & 26 & 14.7 & 22.7 & 14.2 & 32 & 16.3 & 26.8 & 15.6 \\
S2400 & 361 & 26 & 14.4 & 24.2 & 13.9 & 33 & 18.7 & 30.2 & 18.0 & 44 & 26.8 & 39.4 & 25.5 \\
\hline
\end{tabular}

Plot numbers indicate elevation in $\mathrm{m}$ a.s.l. Ind. $=$ number of individuals. ${ }^{\circ} \mathrm{D}_{\mathrm{obs}}=$ Observed taxon richness. ${ }^{1} D_{\text {obs }}=$ Observed effective number of taxa (Jost 2006). ${ }^{1} D_{210}=$ Taxon richness standardized per 210 individuals.

${ }^{1} \mathrm{D}_{210}=$ Effective number of taxa standardized per 210 individuals.

Table 2 Diversity measures for big trees ( $\mathrm{dbh} \geq 10 \mathrm{~cm}$, recorded on $0.24 \mathrm{ha}$ ).

\begin{tabular}{|c|c|cccc|cccc|cccc|}
\hline \multirow{2}{*}{ Plot } & \multirow{5}{*}{ Ind. } & \multicolumn{5}{|c|}{ Families } & \multicolumn{5}{|c|}{ Genera } & \multicolumn{4}{c|}{ Species } \\
& & ${ }^{0} D_{\text {obs }}$ & ${ }^{1} D_{\text {obs }}$ & ${ }^{0} D_{210}$ & ${ }^{1} D_{210}$ & ${ }^{0} D_{\text {obs }}$ & ${ }^{1} D_{\text {obs }}$ & ${ }^{0} D_{210}$ & ${ }^{1} D_{210}$ & ${ }^{0} D_{\text {obs }}$ & ${ }^{1} D_{\text {obs }}$ & ${ }^{0} D_{210}$ & ${ }^{1} D_{210}$ \\
\hline S0700 & 146 & 34 & 21.4 & 39.0 & 22.5 & 51 & 33.6 & 58.8 & 37.9 & 62 & 47.1 & 72.0 & 54.4 \\
S0850 & 133 & 20 & 12.0 & 22.9 & 12.5 & 26 & 16.1 & 31.2 & 16.7 & 32 & 18.6 & 38.9 & 19.9 \\
S1050 & 105 & 30 & 19.1 & 39.0 & 21.8 & 48 & 34.7 & 67.0 & 44.6 & 50 & 36.1 & 72.5 & 46.7 \\
S1200 & 170 & 33 & 20.4 & 34.0 & 20.8 & 53 & 37.2 & 56.2 & 39.1 & 63 & 47.0 & 68.9 & 50.1 \\
S1400 & 131 & 25 & 17.5 & 26.1 & 19.1 & 31 & 20.3 & 33.6 & 22.6 & 42 & 27.3 & 50.4 & 31.0 \\
S1450 & 155 & 34 & 22.5 & 36.5 & 23.8 & 46 & 28.3 & 52.6 & 30.1 & 59 & 39.8 & 67.9 & 43.8 \\
S1650 & 129 & 24 & 12.4 & 26.8 & 13.5 & 31 & 16.5 & 36.7 & 18.3 & 42 & 27.5 & 49.8 & 31.6 \\
S1850 & 171 & 13 & 4.3 & 17.0 & 4.4 & 13 & 4.3 & 17.0 & 4.4 & 25 & 10.4 & 32.8 & 10.7 \\
S1900 & 171 & 18 & 7.1 & 19.3 & 7.2 & 20 & 7.6 & 21.5 & 7.7 & 31 & 19.5 & 33.4 & 19.8 \\
S1950 & 200 & 25 & 9.3 & 25.4 & 9.3 & 32 & 12.6 & 32.6 & 12.6 & 48 & 25.3 & 49.0 & 25.6 \\
S2150 & 362 & 16 & 9.6 & 15.3 & 9.4 & 18 & 11.1 & 17.1 & 10.9 & 24 & 14.5 & 22.8 & 14.2 \\
S2350 & 215 & 18 & 8.4 & 17.9 & 8.4 & 22 & 12.2 & 21.9 & 12.1 & 25 & 12.9 & 24.8 & 12.9 \\
S2400 & 238 & 24 & 13.1 & 23.6 & 13.0 & 30 & 16.7 & 29.2 & 16.5 & 39 & 22.9 & 37.7 & 22.5 \\
\hline
\end{tabular}

Plot numbers indicate elevation in $\mathrm{m}$ a.s.l. Ind. $=$ number of individuals. ${ }^{0} \mathrm{D}_{\mathrm{obs}}=$ Observed taxon richness. ${ }^{1} D_{\text {obs }}=$ Observed effective number of taxa (Jost 2006). ${ }^{1} D_{210}=$ Taxon richness standardized per 210 individuals.

${ }^{1} D_{210}=$ Effective number of taxa standardized per 210 individuals. 

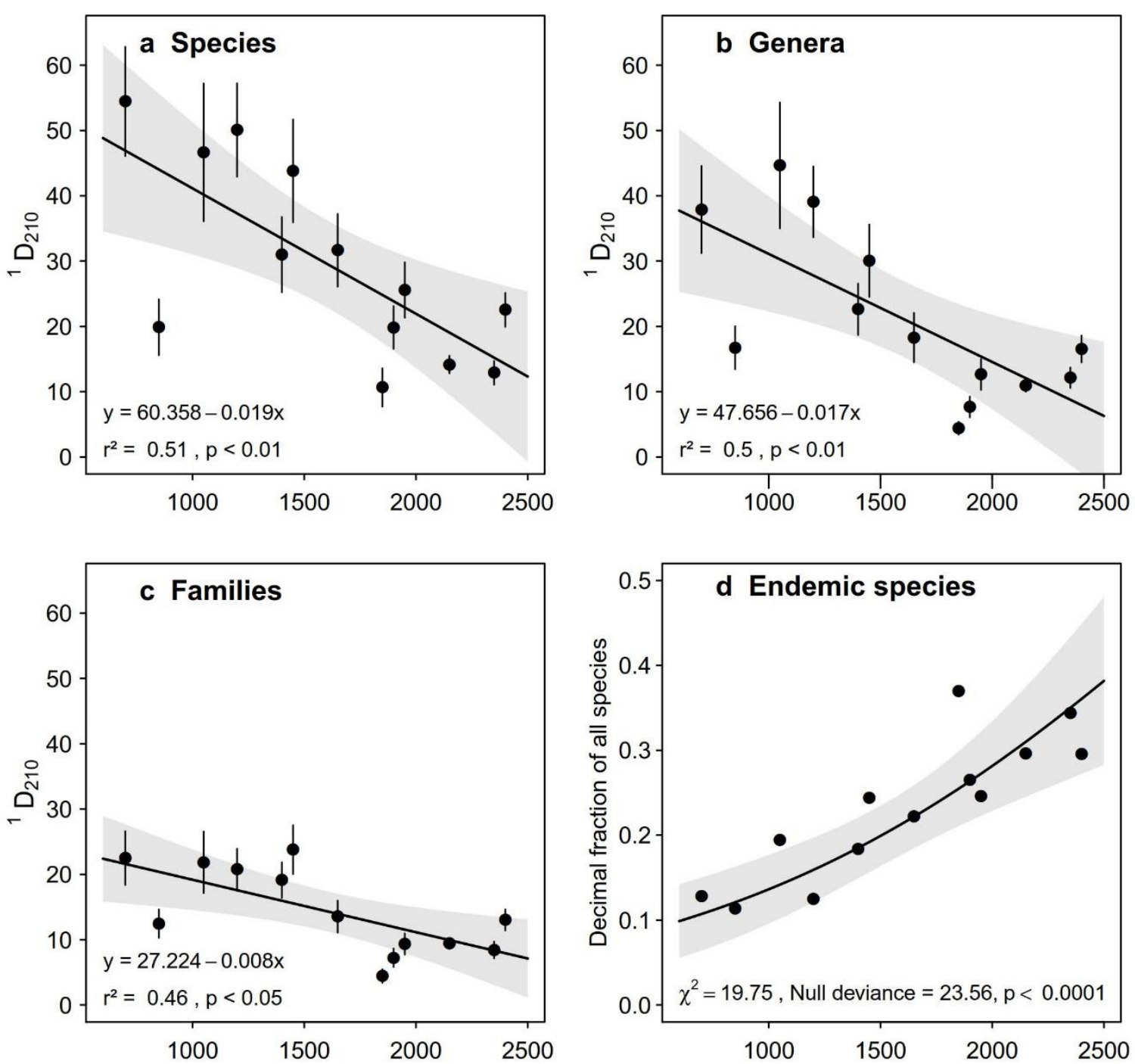

Elevation [m asl]

Figure 1 Changes in tree diversity at different taxonomic levels (a-c) and endemism (d) of big trees (dbh $\geq 10 \mathrm{~cm}$ ) along the elevational gradient in Lore Lindu National Park. Tree diversity per plot $(0.24 \mathrm{ha})$ is standardised number of taxa per 210 individuals $\left({ }^{1} D_{210}\right)$. Black lines are regression curves of linear regression models $(\mathrm{a}-\mathrm{c}$ ) and a logistic regression model with binomial error structure and logit link function (d). Grey areas represent the 95\% confidence intervals of the models. Error bars show 95\% confidence intervals of a rarefaction/extrapolation procedure using a bootstrap method with 500 replications; $n=13$. See Appendix 4.1, Table 1 for plot details. 


\section{Appendix 4.7 Environmental factors influencing community composition}

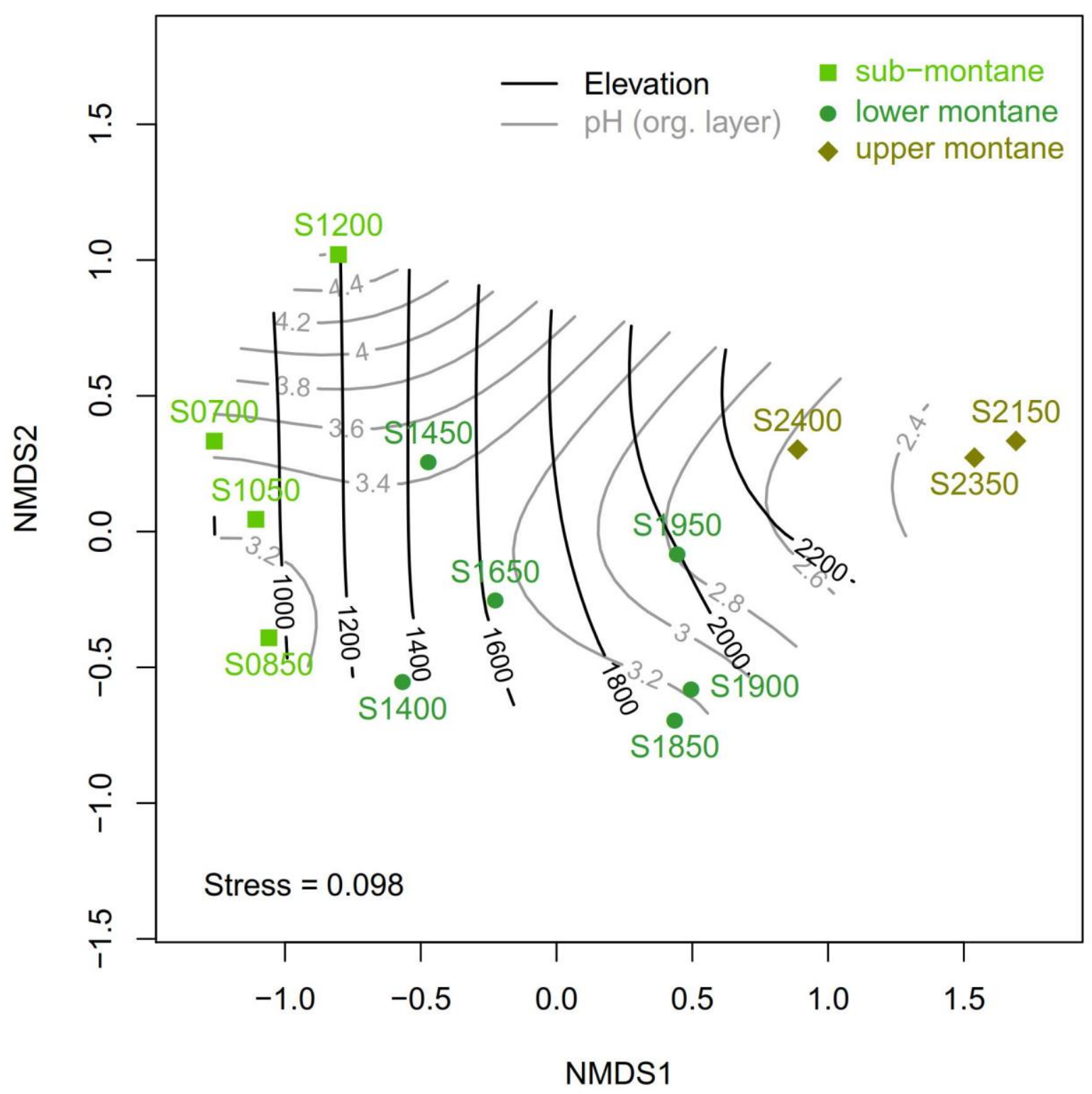

Figure 1 Elevation and the $\mathrm{pH}$ values of the organic layer influence the tree community composition in 13 inventory plots in Lore Lindu National Park. Non-metric multidimensional scaling (NMDS) with Bray-Curtis dissimilarity as distance measure showing differences in floristic composition. Based on abundances of all trees with $\mathrm{dbh} \geq 10 \mathrm{~cm}$. Plots were grouped beforehand by elevation as given in plot labels. 



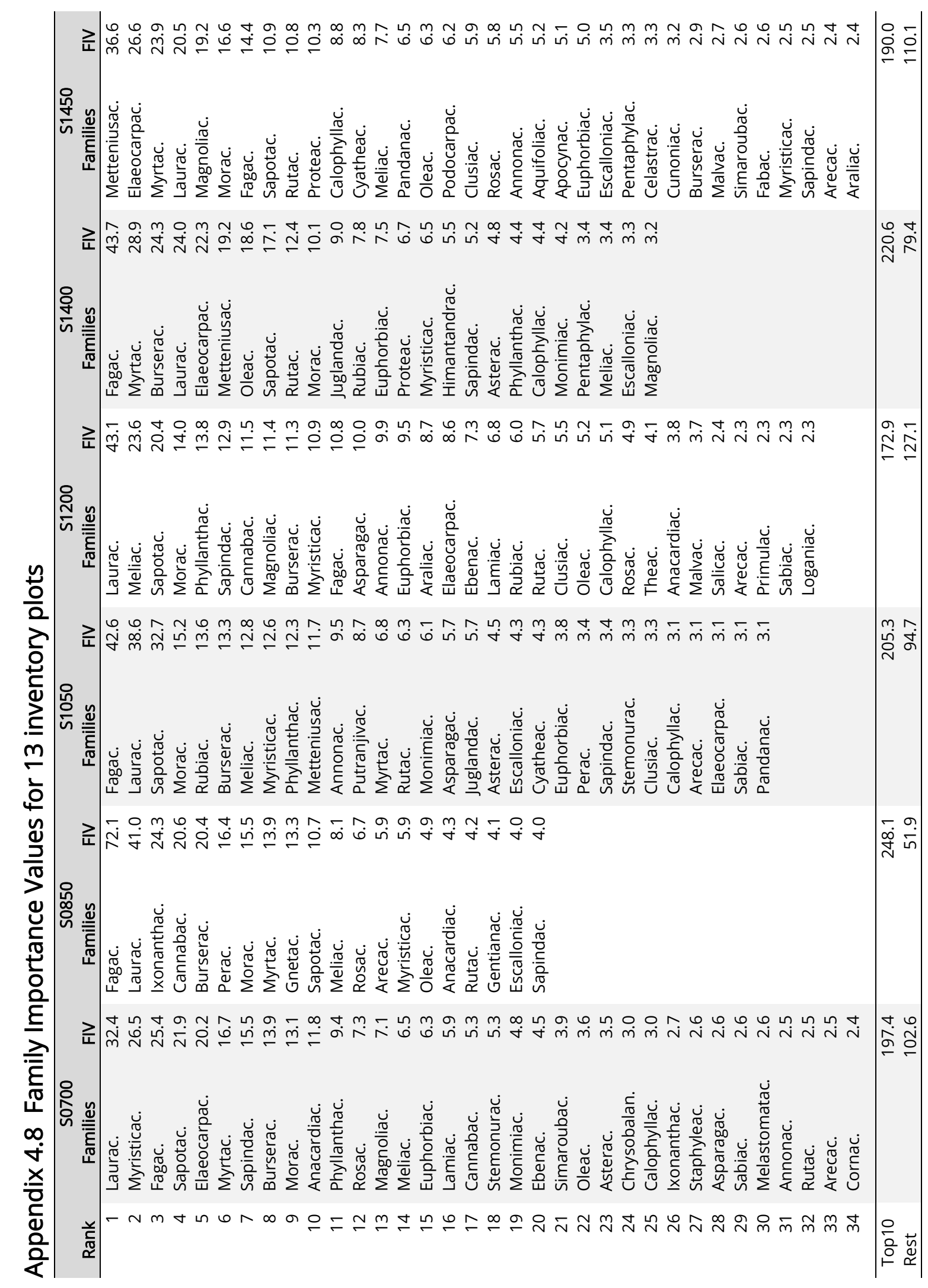




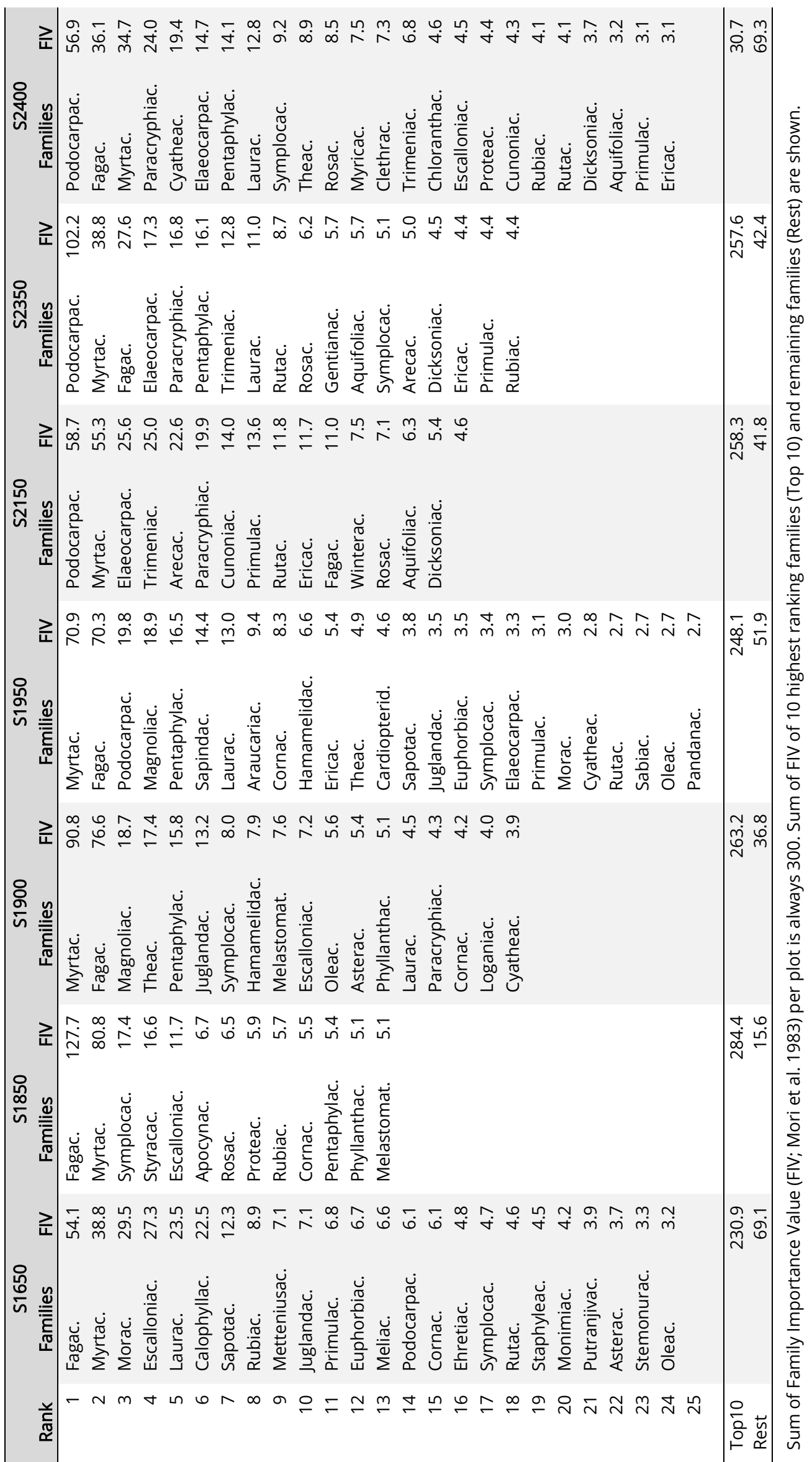




\section{Appendix 5.1 Data sources of tree inventory plots}

Aiba S-I, Kitayama K, Repin R (2002) Species composition and species-area relationships of trees in nine permanent plots in altitudinal sequences on different geological substrates of Mount Kinabalu. Sabah Parks Nature Journal 5: 7-69.

Aragones EG Jr (1991) Vegetation-soil pattern along altitudinal gradient in the western slopes of Mt. Banahaw, Luzon, Philippines: I. The forest communities and changes in forest composition with altitude. Sylvatrop: Technical Journal for Philippine Ecosystems and Natural Ressources 1: 15-45.

Brambach F, Leuschner C, Tjoa A, Culmsee H (2017) Diversity, endemism, and composition of tropical mountain forest communities in Sulawesi, Indonesia, in relation to elevation and soil properties. Perspectives in Plant Ecology, Evolution and Systematics 27: 68-79. https://doi.org/10.1016/j.ppees.2017.06.003

Bratawinata AA (1986) Bestandesgliederung eines Bergregenwaldes in Ostkalimantan / Indonesia nach floristischen und strukturellen Merkmalen. PhD thesis, Georg-AugustUniversität Göttingen, Germany.

Hamann A, Barbon EB, Curio E, Madulid DA (1999) A botanical inventory of a submontane tropical rainforest on Negros Island, Philippines. Biodiversity \& Conservation 8: 10171031. https://doi.org/10.1023/A:1008847704539

Helmi N, Kartawinata K, Samsoedin I (2009) An undescribed lowland natural forest at Bodogol, the Gunung Gede Pangrango National Park, Cibodas Biosphere Reserve, West Jawa, Indonesia. Reinwardtia 13: 33-44.

Kartawinata K, Samsoedin I, Heriyanto M, Afriastini JJ (2004) A tree species inventory in a onehectare plot at the Batang Gadis National Park, North Sumatra, Indonesia. Reinwardtia 12: 145-157.

Kitayama K (1995) Biophysical Conditions of the Montane Cloud Forests of Mount Kinabalu, Sabah, Malaysia. In: Hamilton LS, Juvik JO, Scatena FN (Eds), Tropical Montane Cloud Forests. Ecological Studies. Springer US, New York, 183-197. https://doi.org/10.1007/9781-4612-2500-3_12

Meijer W (1959) Plantsociological Analysis of Montane Rainforest Near Tjibodas, West Java. Acta Botanica Neerlandica 8: 277-291. https://doi.org/10.1111/j.1438-8677.1959.tb00540.x

Pipoly JJ III, Madulid DA (1998) Composition, structure and species richness of a submontane moist forest on Mt Kinasalapi, Mindanao, Philippines. In: Dallmeier F, Comiskey JA (Eds), Forest biodiversity research, monitoring and modelling: Conceptual background and Old World case studies. Man and Biosphere Series. UNESCO and The Parthenon Publishing Group, Paris, New York, 591-599.

Poulsen AD, Nielsen IC, Tan S, Balslev H (1996) A quantitative inventory of trees in one hectare of mixed dipterocarp forest in Temburong, Brunei Darussalam. In: Edwards DS, Booth WE, Choy SC (Eds), Tropical Rainforest Research - Current Issues. Monographiae Biologicae. Springer Netherlands, 139-150. https://doi.org/10.1007/978-94-009-16852_13

Proctor J, Argent GC, Madulid DA (1998) Forests of the ultramafic mount Giting-Giting, Sibuyan Island, the Philippines. Edinburgh Journal of Botany 55: 295-316. https://doi.org/10.1017/S0960428600002201

Purwaningsih, Polosakan R, Yusuf R, Kartawinata K (2017) Phytosociological study of the montane forest on the south slope of Mt. Wilis, East Java, Indonesia. Reinwardtia 16: 31 45. https://doi.org/10.14203/reinwardtia.v16i1.3110

Takyu M, Aiba S-I, Kitayama K (2002) Beta-diversity and changes in population structure along topographical gradients on different geological substrates in tropical montane forests on Mount Kinabalu, Borneo. Sabah Parks Nature Journal 5: 165-218.

Whitmore TC, Sidiyasa K, Whitmore TJ (1987) Tree species enumeration of 0.5 hectare on Halmahera. The Gardens' Bulletin, Singapore 40: 31-34. 
Yamada I (1975) Forest ecological studies of the montane forest of Mt. Pangrango, West Java. I. Stratification and floristic composition of the montane forest near Cibodas. Tonan Ajia Kenkyu (South East Asian Studies) 13: 402-426.

Yamada I (1977) Forest ecological studies of the montane forest of Mt. Pangrango, West Java. IV. Floristic composition along the altitude. Tonan Ajia Kenkyu (South East Asian Studies) 15: $226-254$. 


\section{Appendix 5.2 Supplementary methods}

The bulk of the phylogeographic, phylogenetic, and floristic studies for the assignation of geographic ancestry of species was compiled over the last years by FB. In addition, we conducted Google Scholar searches using the names of families and infrafamilial groups including subfamilies, tribes, genera and informal clades in combination with the terms "phylogeograph*", "biogeograph*", "phylogen*", "revision", "monograph", and "fossil". Of the original 16131 individuals in our dataset, only for 245 (1.5\%) the geographic ancestry remained ambiguous. The percentages of individuals with ambiguous ancestry per plot ranged from $0 \%$ to $11.7 \%$ (median $0 \%$, mean $1.3 \%$ ). We used simple logistic regression models with a quasibinomial error structure to test for significant relationships between environmental parameters and the proportion of individuals with unknown geographic origin per plot. Plots on ultramafic parent material contained a significantly higher portion of those individuals than plots on other substrates ( $\left.D^{2}=0.16, p<0.0001\right)$, possibly highlighting the high number of insufficiently known endemics know to occur there; the other variables did not have any significant effects (Figure 1)
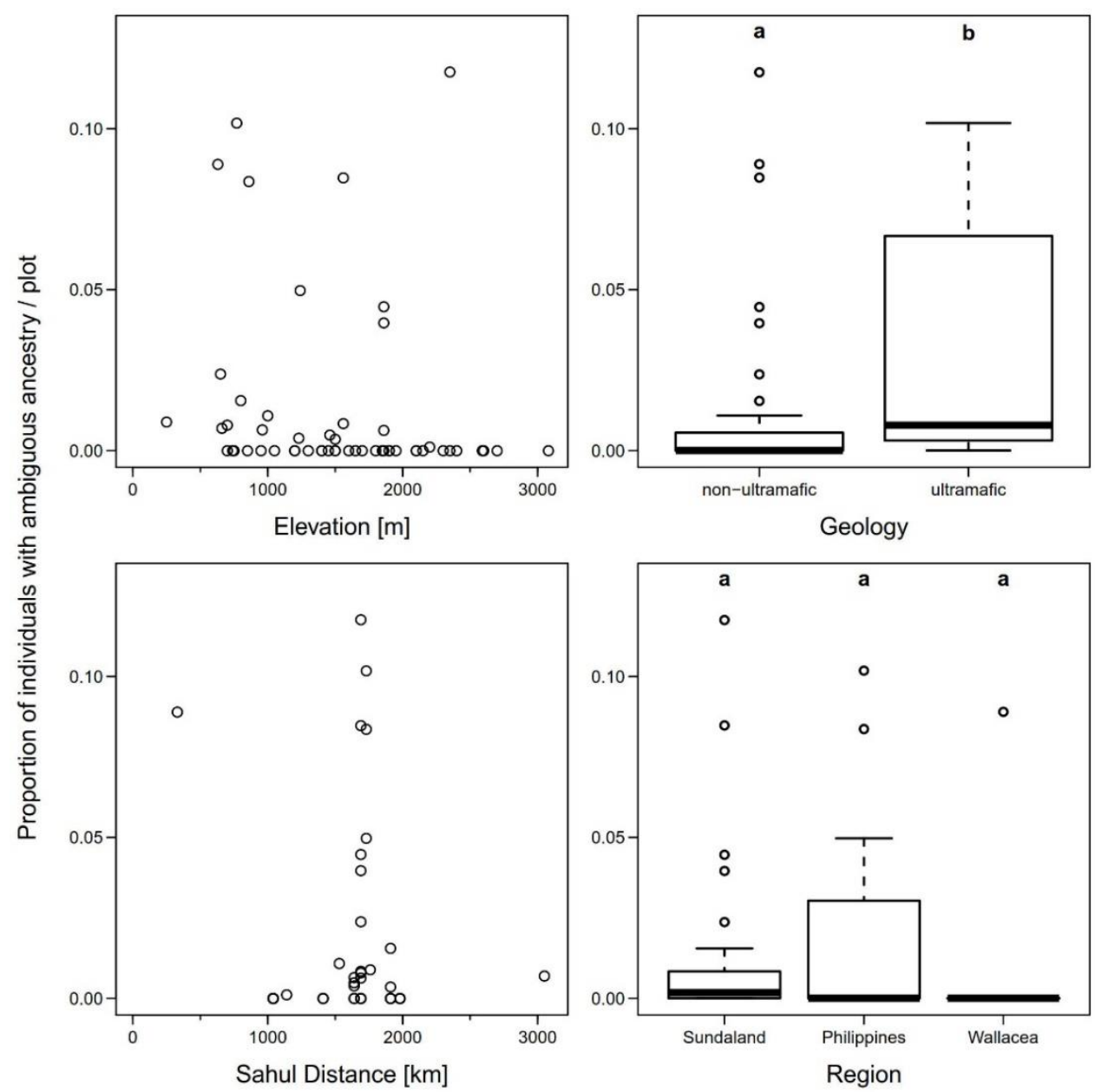

Figure 1. Decimal proportions of tree individuals with ambiguous geographic ancestry per plot and their relation to environmental parameters. Relationships were tested with logistic regression models with quasibinomial error structure. Significant differences were retrieved between ultramafic and nonultramafic substrates but not between geographic regions. Elevation and Sahul Distance did not show any significant linear or quadratic relationships; regression lines are therefore omitted. 
The families are sorted and numbered according to published linear sequences for gymnosperms (Christenhusz et al. 2011), and angiosperms (The Angiosperm Phylogeny Group 2016). Assignment to biogeographic ancestry in parenthesis following the family names only refers to the taxa in our dataset.

\section{Gymnosperms}

\section{Gnetaceae (Asian)}

Gnetum dispersed from Asia into Malesia during the last 20 My in at least two separate events, as inferred by phylogeographic analysis (Won et al. 2006).

\section{Araucariaceae (Australian)}

The only genus in our dataset, Agathis, is sister to the Australian endemic Wollemia; together these two are sister to the Gondwanan-distributed Araucaria. Agathis started to diversify at the Paleogene-Neogene boundary (Kershaw and Wagstaff 2001) and within the genus, Australian and New Caledonian clades are basal with Malesian species in a derived position (Escapa and Catalano 2013). There are no known Agathis fossils from Asia (Fossilworks 2016).

\section{Podocarpaceae (Australian)}

The genera Phyllocladus, Dacrycarpus, Dacrydium, Falcatifolium, and Podocarpus are present in our dataset. Although Phyllocladus diverged from other Podocarpaceae as early as $200 \mathrm{Ma}$, extant species of the genus only began to diversify in the late Miocene (ca $6 \mathrm{Ma}$ ) in Australasia and only P. hypophyllus dispersed into Malesia (Wagstaff 2004).

Dacrycarpus, Dacrydium, and Falcatifolium are part of the Dacrydioid clade for which an Australasian origin (Knopf, Schulz, Little, Stützel, \& Stevenson, 2012) with recent diversification in the Neogene was resolved (Biffin et al. 2011).

Podocarpus is represented in Malesia by species of subgenus Foliolatus. The subgenus is rooted in Australia and New Caledonia (Knopf et al. 2012) and diversified during the Neogene with several lineages spreading northwards to Malesia and beyond to Southeast Asia (Biffin et al. 2011, Quiroga et al. 2016).

\section{Taxaceae (Asian)}

Taxus is widespread in the Northern Hemisphere and practically absent south of the Equator (Farjon 2010). The genus started to diversify at the Oligocene-Miocene boundary, probably in North America, where the early diverging species occur (Leslie et al. 2012). The only Malesian species, Taxus sumatrana, ist most closely related to the T. marei and T. chinensis from East Asia and diverged from the latter in the late Miocene (Liu et al. 2011, Leslie et al. 2012). 


\section{Angiosperms}

\section{Trimeniaceae (Australian)}

Trimeniaceae originated ca $100 \mathrm{Ma}$ as indicated by macrofossils from Japan (Yamada et al. 2008). Relationships within Trimeniaceae have never been analysed with molecular methods, but the present distribution in East Australia (1 sp.), New Caledonia (1) Central and East Malesia (2) and western Pacific islands (2) points to an Australian origin with recent dispersal into Malesia (Philipson 1986).

\section{Winteraceae (Australian)}

The predominantly Australian genus Tasmannia started to diversify in the early Oligocene(ca 30 Ma; Thomas et al. 2014). The Malesian species are poorly sampled in published phylogenies. They belong to a clade in state of active speciation in mountain habitats, most pronounced in New Guinea, but reaching westward to Borneo and the Philippines, indicating young age and recent dispersal (Vink 1970).

\section{Myristicaceae (Asian)}

While the evolutionary history, including crown age, of Myristicaceae is unclear (Doyle et al. 2004), the pre-Neogene fossil record of the family involves only Eurasia and the Americas, with no fossils known from Australia (Fossilworks 2016). The presence of these fossils, together with the low dispersal capability of the large seeds of Myristicaceae is here used to indicate recent dispersal into Malesia from Asia (Doyle et al. 2008).

\section{Magnoliaceae (Asian)}

Magnolia was widespread in Laurasia in the early Eocene and the tropical Asian lineages migrated south in the Neogene, due to climatic cooling, eventually reaching Malesia (Nie et al. 2008, Nooteboom 2011).

\section{Himantandraceae (Australian)}

Extant distribution of the only genus Galbulimima from Sulawesi to N Australia (Endress 1993b) and the sister group relationship with the Fiji endemic Degeneriaceae (Massoni et al. 2014) clearly point to an Australian ancestry of Himantandraceae.

\section{Annonaceae (Asian)}

Annonaceae probably originated in W Gondwana; their present distribution is the result of the complex interplay of vicariance and dispersal events (Thomas et al. 2015). All Malesian taxa belong to clades that diversified in the Neogene. In these clades, splits between Africa and (SE) Asia are common and Australasian taxa are all nested among SE Asian taxa or diverge from them after the onset of the FMI (ca $23 \mathrm{Ma}$ ), indicating recent dispersal into Malesia from SE Asia (Thomas et al. 2015). 


\section{Monimiaceae (Australian)}

All Malesian genera have their origin in Australasia and probably started to migrate no earlier than in the middle Miocene as indicated by the phylogeographic analysis of Renner et al. (2010).

\section{Lauraceae (mixed)}

Tribe Cryptocaryeae, represented in our dataset by Eusideroxylon, Beilschmiedia, Cryptocarya, and Endiandra, is predominantly distributed in the Southern Hemisphere and was inferred to have evolved on Gondwana (Chanderbali et al. 2001). Eusideroxylon, endemic to Sundaland, probably separated from the remaining Cryptocaryeae about 120 Ma so despite its Gondwanan origin, we assume early migration to Asia for the genus. The remaining genera, Cryptocarya and the Beilschmiedia / Endiandra clade, have Australasian taxa in basal positions of their phylogenies indicating Australian ancestry (Rohwer et al. 2014).

Perseeae originated from an Eocene radiation in Laurasia and later moved southward due to global cooling during the Oligocene and Miocene, eventually colonising Malesia. Machilus diversified ca $20 \mathrm{Ma}$, the clade containing the intermingled Alseodaphne, Dehaasia, and Nothaphoebe, 20-30 Ma, and Phoebe ca $25 \mathrm{Ma}$; all consistent with Neogene migration into Malesia from Asia (Li et al. 2011).

The Cinnamomum group probably originated in early Eocene Laurasia, and all clades containing Malesian and Australian species started to radiate in the early Miocene or later, indicating Neogene dispersal into and beyond Malesia from Asia (Huang et al. 2016). Records of preMiocene fossils from Australia attributed to Cinnamomum are doubtful (Vadala and Greenwood 2001).

Likewise, Laureeae, sister to the Cinnamomum group and represented by Actinodaphne, Lindera, Litsea, and Neolitsea in our data, originated in the early Eocene of Laurasia and later moved to lower latitudes due to climatic cooling (Chanderbali et al. 2001, Huang et al. 2016). The exact timing of the arrival in Malesia is not known; Litsea-type macrofossils from the Eocene have been reported from Australia (Vadala and Greenwood 2001), so possibly some longdistance dispersal from Asia to Australia took place before that. Nevertheless, assignation of many Lauraceae fossils is doubtful and the center of diversity in the Litsea group is clearly in $\mathrm{E}$ and SE Asia (Li et al. 2004, 2008), so that we infer an Asian ancestry of this clade with (mostly) recent dispersal into Malesia and to Australia.

\section{Chloranthaceae (Australian)}

Ascarina diverged from its Asian sister group (Sarcandra and Chloranthus) in the midCreataceous, ca $95 \mathrm{Ma}$. However, the extant members of the genus only started to diversify in the Pacific Ocean around $30 \mathrm{Ma}$, forming two clades: one containing Malesian and Pacific Ocean species, which further split up in the Neogene; the other one containing species from Madagascar, New Zealand, and the Pacific Ocean (Zhang et al. 2015). Because of the absence of Ascarina fossils from the Tertiary in Asia, and the presence of Eocene Ascarina pollen in 
Australia (Fossilworks 2016), we consider the most likely explanation to be that Ascarina reached Australia / the Pacific Ocean via long-distance dispersal before the Eocene and spread into Malesia from the southeast in the Neogene.

\section{Pandanaceae (Asian)}

The species in our dataset both belong to Pandanus subgenus Kurzia (Stone 1974), which belonged to the Pandanus subclade I of Gallaher et al. (2015). That study suggests that Pandanaceae originated in Laurasia and Pandanus subclade I originated in SE Asia very recently (ca $11 \mathrm{Ma}$ ) from where it spread eastward to Malesia and the W Pacific.

\section{Asparagaceae (Asian)}

Dracaena originated in E or SE Asia and from there repeatedly dispersed to Africa and the Pacific (Lu and Morden 2014). Although the dating of the dispersal events is not clear, we infer an Asian origin of the genus.

\section{Arecaceae (Asian)}

Oncosperma (stem age ca $20 \mathrm{Ma}$ ), Areca (14 Ma, and Pinanga (12 Ma) belong to a clade in Areceae with SE Asian origin which dispersed into Malesia during the Neogene (Baker and Couvreur 2013). Caryota (Caryoteae) displays the same biogeographic pattern but has a stem age of ca 25 My (Baker and Couvreur 2013).

\section{Sabiaceae (Asian)}

Meliosma has an ample fossil record in Laurasia throughout the Tertiary (van Beusekom 1971). All Old-World species of the genus form one clade (Zúñiga 2015), which has its greatest diversity in E and SE Asia, only one species reaches E Malesia (van Beusekom 1971).

\section{Proteaceae (Australian)}

Lasjia arrived to Central Malesia due to a dispersal event from Australia less than 12 Ma (Mast et al. 2008). Helicia separated from the Australian genus Hollandaea at the beginning of the Pliocene (Barker et al. 2007). The exact divergence time of the remaining genus present in our data, Heliciopsis, is not clear, but it belongs to a clade otherwise consisting of Australian and New Caledonian taxa (Weston and Barker 2006), so we assume Australian ancestry for Heliciopsis as well.

\section{Dilleniaceae (Asian)}

No dated phylogenetic studies have been conducted for Dilleniaceae so far. Dillenia, the only genus in our dataset, is distributed from India to New Guinea and N Australia (Horn 2007). The Malesian species of Dillenia are sister to the Bornean endemic Acrotrema and Dillenia species distributed around the Indian Ocean (Madagascar, Seychelles, Sri Lanka), so we interpret Dillenia as having Asian origin (Horn 2009). 


\section{Altingiaceae (Asian)}

The only species in our dataset belongs to the large E Asian clade of Liquidambar, which is distributed from India to China and Java and can be considered relictual after the widespread occurrence of Liquidambar in Laurasia during the Eocene (Ickert-Bond and Wen 2006).

\section{Hamamelidaceae (Asian)}

Hamamelidaceae have a rich Tertiary fossil record in Laurasia (Endress 1993a) and their centre of diversity in E to SE Asia. Of the Sycopsis-Distylium-Distyliopsis-clade (Li 2008), most diverse in E and SE Asia, only D. dunnii, the species in our dataset, reaches E Malesia.

\section{Daphniphyllaceae (Asian)}

Daphniphyllaceae split from its sister family, the E Asian Cercidiphyllaceae in the late Cretaceous (Jian et al. 2008). Their extant distribution is from E Asia to New Guinea, with the centre of diversity in SW China and a secondary centre in W Malesia (Kubitzki 2007a).

\section{Iteaceae (Asian)}

Itea, centred in E Asia, has a relic distribution due to climatic cooling, having been widespread in Laurasia during the Tertiary (Hermsen 2013). It barely reaches W Malesia with one species (Kubitzki 2007b).

\section{Vitaceae (Asian)}

Leea originated in SE Asia in the late Cretaceous and underwent a rapid radiation in Malesia in the Miocene (Molina et al. 2013).

\section{Fabaceae (mixed)}

Detarioideae: Crudia, distributed in the tropics of America, Africa, and Indo-Malesia, is nested within African taxa and diverged from its African sister group in the Eocene (Bruneau et al. 2008, 2014). Within Malesia, it is strongly centred in Sundaland, with only a few species occurring further east. Eocene fossils attributed to Crudia have been found in North America (Fossilworks 2016). Taken together, this information points to an African origin of Crudia, wide Laurasian distribution during the Eocene and subsequent southward migration due to Neogene cooling, eventually moving into Malesia. Cynometra, another pantropical genus, shows a similar pattern, having diverged from its mainly African relatives in the Eocene (Bruneau et al. 2008, 2014). Sindora is most diverse in SE Asia and Sundaland, only one species crosses Wallace's line. The genus is sister to a clade composed of African taxa and the Bornean endemic Pseudosindora (Fougère-Danezan et al. 2010); the two groups separated at the Oligocene-Miocene boundary (Bruneau et al. 2008) clearly indicating an Asian origin of the Malesian species.

Dialioideae: The widely distributed Dialium is nested in an equally widely distributed clade (Neotropics, Africa, Asia). The clade started to diversify in the early Miocene, with all genera except Dialium becoming restricted to one continental region, possibly as a result of southward movement due to Neogene cooling or long-distance dispersal (Bruneau et al. 2008). The 
absence of Dialium from C and E Malesia and Australia further supports its Asian origin. Koompassia is sister to Mendoravia from Madagscar, the two genera having separated ca 18 $\mathrm{Ma}$, presumably as a result of long-distance dispersal. While the direction of the dispersal event is not clear, the general geographical distribution of the Dialiinae rules out Australia as ancestral area (Bruneau et al. 2008).

Caesalpinioideae: Parkia is pantropical, originated in the Eocene in America and diversified during the Neogene (Bouchenak-Khelladi et al. 2010). The genus is absent from Australia and within Malesia most diverse in Sundaland, indicating Asian ancestry. Ingeae (Archidendron, Albizia) evolved in the early Miocene of America and reached Asia and/or Australia via longdistance dispersal only in the Miocene (Bouchenak-Khelladi et al. 2010). Since Archidendron was resolved as sister to the E Malesian Pararchidendron (Brown et al. 2011) and has its centre of diversity in New Guinea (Nielsen et al. 1984), we assume an Australian origin. Albizia is polyphyletic and with the information currently available, we were not able to assign a geographic ancestry to the species represented in our dataset.

Papilionoideae: The pantropical genus Ormosia is sister to a clade of Amazonian genera (Cardoso et al. 2017); it is most diverse in the Neotropics and in mainland E and SE Asia, with most Malesian species occurring in Sundaland, indicating a probable origin in Asia. Millettia is a polyphyletic genus and the species included in our dataset ( $M$. sericea) has not been included in any molecular phylogenetic analyses so far. However, Adema (2001) suggested a close relationship between that species and mainland Asian taxa. We therefore assume Asian ancestry of Millettia.

\section{Polygalaceae (Australian)}

Xanthophyllum diverged from the rest of Polygalaceae in the Paleocene. In the rest, southern hemisphere clades are successively sister to the more widespread Polygaleae (Forest et al. 2007, Bello et al. 2012), indicating a southern hemisphere origin of the family. While most species of Xanthophyllum occur west of Wallace's line, the greatest diversity at subgeneric level occurs east of that line (van der Meijden 1988) and W Malesian species of Xanthophyllum are nested within their Australian congeners (Persson 2001), so we infer an Australian ancestry for Xanthophyllum. Notably, macrofossils of the genus appear in the Mio-Pliocene fossil record of India (Mehrotra et al. 2014), which is consistent with a scenario of recent immigration from Australia through Malesia to India.

\section{Rosaceae (Asian)}

Prunus appeared ca $60 \mathrm{Ma}$ in E Asia. The tropical species of Malesia belong to different clades which all originated in E Asia and diversified since the late Oligocene (Chin et al. 2014). There was one species of Rosaceae from the Philippines in our dataset with unclear generic identity. The only tree genera occurring in the Philippines besides Prunus are Photinia and Raphiolepis and both have Asian origins (Campbell et al. 2007, Guo et al. 2011). 


\section{Rhamnaceae (mixed)}

Alphitonia separated from the SW Australian endemic Granitites in the early Neogene and started to diversify in Australasia ca $10 \mathrm{Ma}$. From there, some species, including the one in our dataset, entered Malesia in the last 5 My. Ziziphus originated in Asia or Africa in the late Cretaceous but diversified in Asia much later, in the Neogene, when some lineages also spread to Malesia (Hauenschild et al. 2018).

\section{Cannabaceae (Asian)}

Asian species of Celtis group together with African species (Sattarian 2006) and have an extensive fossil record in Laurasia from at least the Eocene (Soepadmo 1977). Asian species of Trema group together with their African congeners, but without good-enough resolution to infer exact patterns of historical biogeography (Yesson et al. 2004). Nevertheless, fossils of Trema appear in the Eocene of Europe, as do those of Gironniera (Yesson et al. 2004). The available information suggests wide Laurasian distribution of Cannabaceae during the Paleogene and later southward migration because of Neogene cooling, eventually reaching the tropical regions of Malesia.

\section{Moraceae (Asian)}

Moraceae probably originated in Gondwana and started to diversify around $90 \mathrm{Ma}$. Phylogeographic patterns of the family are consistent with a wide Laurasian distribution during the Paleo-Eocene and subsequent southward migration since the Miocene (Zerega et al. 2005). All Malesian species of Ficus (except sect. Malvanthera which is not present in our dataset) are nested within Asian clades and diverged from their Asian relatives in the Neogene, consistent with immigration to Malesia from Asia in that period. The Paleogene fossils of Ficus in Australia belong to sect. Malvanthera (Cruaud et al. 2012).

\section{Urticaceae (Asian)}

Leucosyke, together with the morphologically similar Indo-Malesian-Pacific genus Maoutia, is sister to a clade containing taxa formerly included in Cecropiaceae from tropical S America and Africa (Wu et al. 2013). Dendrocnide is sister to the Central American genus Discocnide; their next closest relative is Girardinia from Africa and SE Asia (Wu et al. 2013, Kim et al. 2015). Pipturus (Malesia to Pacific) is sister to the Hawaiian Neraudia; their closest relative is the pantropical and polyphyletic Pouzolzia. Oreocnide (Sri Lanka to Japan) is sister to the rest of Boehmerieae, and Debregeasia is sister to a widespread clade within Boehmeriae. No dated phylogenetic studies for Urticaceae have been published so far and the exact biogeographic relationships are therefore unclear. However, the great diversity at different taxonomic levels in E and SE Asia, the relative scarcity and terminal position of Australian taxa (Wu et al. 2013), and the presence of several Tertiary fossils from Laurasia (Fossilworks 2016) point to an Asian origin of the Malesian members of the family. 


\section{Fagaceae (Asian)}

Fagaceae have a complex biogeographical history centred in Laurasia. While die diversification of Quercus occurred at temperate latitudes, the genera Lithocarpus and Castanopsis have their evolutionary centre in SE Asia. Regardless of the original region of diversification, all Malesian species have a Laurasian, i.e. Asian origin and invaded Malesia E of Sundaland since the Miocene (Manos and Stanford 2001, Cannon and Manos 2003).

\section{Myricaceae (Asian)}

Morella diverged from its sister genus, Myrica in the mid Eocene in Laurasia and diversified in the Neogene. Morella javanica, the species in our dataset, diverged from its Asian relatives ca $16 \mathrm{Ma}$ (Herbert 2005).

\section{Juglandaceae (Asian)}

Juglandaceae subfamily Engelhardtioideae was widespreaed in Laurasia during the Eocene, as indicated by an abundant fossil record (Manchester 1989). There are no phylogenetic studies with adequate taxon sampling to infer details about the evolutionary history of Engelhardtia, but its distribution in Asia and W Malesia together with the fossil record (Manchester 1989) point to an Asian origin of the Malesian species.

\section{Anisophylleaceae (Asian)}

The Asian species of Anisophyllea split from their African sister clade at the beginning of the Miocene. The Sri Langkan A. cinnamomoides is then sister to the Southeast Asian species, suggesting an origin in Africa or Asia (Zhang et al. 2007). Since the genus is neither present in East Malesia nor in Australia or the Pacific Ocean, we assume an Asian origin of the Malesian species.

\section{Tetramelaceae (Asian)}

Tetramelaceae split from Begoniaceae in the Paleocene, probably in Asia (Schaefer et al. 2009) (Schaefer, Heibl, \& Renner, 2009). The only two genera, Octomeles and Tetrameles, split in the Oligocene and Octomeles likely reached its present widespread-Malesian distribution (Swensen and Kubitzki 2010) via eastward dispersal afterward

\section{Celastraceae (mixed)}

Microtropis and two Neotropical genera form a clade that was inferred to have diverged from its large sister clade in the late Cretaceous of Asia (Bacon et al. 2016). The genus is most diverse in E and SE Asia and does not cross Wallace's line (Hou 1962), so we assume an Asian origin.

Siphonodon belongs to another early-diverging (Late Cretaceous) clade of Celastraceae including taxa on former Gondwanan continental areas for which an Australian origin was inferred; the genus diverged from its closest relative, the New Caledonian endemic and monotypic Peripterigya, in the Paleocene (Bacon et al. 2016). S. celastrineaus was resolved as sister to three Australian endemic species of Siphonodon (Simmons et al. 2012a), while the 
other non-Australian species where not sampled. Given the origin of the clade, we assume recent immigration of Siphonodon into Malesia from Australia, although the crown age of the genus is not known.

Euonymus is sister to a clade containing the N American Acanthothamnus and Canotia. The genus is most diverse in Asia with less species occurring in N America, Europe, Malesia, and Australia (Simmons et al. 2012b, Simmons and Cappa 2013) and has a fossil record spanning the Paleocene to Miocene in N America and the Miocene of Eurasia (Bacon et al. 2016) so we infer an Asian origin for the Malesian species.

Kokoona and Lophopetalum are sister to a large Malagasy clade, from which they separated in the Paleocene. An unambiguous ancestral area could be inferred for the common ancestor of these two clades, but it certainly included former fragments of E Gondwana (Bacon et al. 2016). Kokoona has an Indo-W Malesian distribution and Lophopetalum ranges from India to New Guinea, but both are most diverse in Sundaland (Hou 1962). Given the available information, we assume that the genera or their common ancestor rafted on the Indian plate and dispersed into SE Asia and Malesia after contact with the Asian continent.

\section{Connaraceae (Asian)}

No molecular phylogenetic studies with adequate generic sampling exist for Connaraceae. Ellipanthus occurs in E Africa, Madagascar, India, and from SE Asia to Wallacea but not futher east (Lemmens et al. 2004), so we assume an Asian ancestry.

\section{Cunoniaceae (Australian)}

Cunoniaceae have an extensive fossil record in Gondwana dating back to the late Paleocene (Bradford et al. 2004). Many extant clades are disjunct between former Gondwanan landmasses: Schizomeria belongs to tribe Schizomerieae, distributed mainly in Australasia with one species in South Africa. The tribe Caldcluvieae, containing our E Malesian genus Spiraeopsis, has a similar distribution: mostly in Australasia with one species in S America. Cunonieae is distributed in Malesia, Australasia, New Caldedonia, the Indian Ocean, and S Africa, mostly owing to the widespread genus Weinmannia, which is in our dataset (Bradford et al. 2004). The morphological diversity of the genera within tribes combined with the ample Gondwanan fossil record led Bradford and Barnes (Bradford and Barnes 2001) to the obvious conclusion of a Gondwanan vicariant origin for these taxa.

\section{Elaeocarpaceae (mixed)}

Although relatively few Malesian species of Elaeocarpus have been sampled in molecular phylogenies so far, all Malesian, Asian, and Pacific species grouped together in specific clades nested within Australian taxa (Baba 2013) suggesting an Australian origin of the genus. Crayn et al. (2006) retrieved a crown age of 30 My for Elaeocarpus in their dated phylogeny, but the only Malesian species included in their study split from its Australian congeners much later (ca $14 \mathrm{Ma})$. 
No phylogenetic studies have been carried out for Sloanea, but fossil evidence suggests that the genus was a component of Paleo-Oligocene boreotropical forest in N America and Europe (Manchester and Kvaček 2009). The genus is most species-rich the Neotropics. In the Old World, the highest diversity occurs in continental Asia from the Himalayas to the SE Asian peninsula with secondary centres in New Guinea and New Caledonia, while Australia harbours only one species (Coode 1983). Fossil record and species distribution thus suggest an Asian origin of Malesian Sloanea.

\section{Irvingiaceae (Asian)}

Irvingia malayana was retrieved as sister to African species of Irvingia (including the monotypic Desbordesia) with the African Klainedoxia and the Bornean Allantospermam successively sister to that clade (Byng et al. 2016). The split between Klainedoxia and Irvingia occurred in the middle to late Miocene (Xi et al. 2012), suggesting recent long distance dispersal from Africa to SE Asia and Sundaland, where the species occurs at present (Nooteboom 1962).

\section{Ctenolophonaceae (Asian)}

Pollen attributed to the Ctenolophus has been recorded from Africa, where $C$. englerianus exists today, and India since the Paleocene. The appearance of Eocene pollen from SE Asia and W Malesia (Kubitzki 2014a), and Malesian distribution of the only other species of the genus, $C$. parvifolius indicate an Asian origin of the later.

\section{Rhizophoraceae (Asian)}

The two genera from our dataset, Pellacalyx and montypic Gynotroches, belong to tribe Gynotrocheae, which diverged from the mangrove clade Rhizophoreae at the PaleoceneEocene boundary (ca 55 Ma; Xu et al. 2017). All genera of Rhizophoreae have a reliable Eocene fossil record in different areas of Laurasia (Graham 2006). Within Gynotrocheae, Carallia, most diverse in continental Asia and Sundaland (Hou 1958, Kostermans 1982, Qin and Boufford 2007), and Crossostylis from the western Pacific are successively sister to Pellacalyx and Gynotroches (Sun et al. 2016). Pellacalyx is also most diverse in Sundaland, with six of its eight species occurring there (Hou 1958, Qin and Boufford 2007), and the monotypic Gynotroches is widespread from Southeast Asia to Melanesia (Hou 1958). Together, the phylogenetic relationships, fossil record, and diversity patterns of extant species strongly suggest an Asian origin of Gynotrocheae, presumably with long-distance dispersal to and diversification in the western Pacific Ocean by Crossostylis (not present in our dataset).

\section{Ochnaceae (Asian)}

Brackenridgea diverged from the African genus /dertia in the middle Miocene and further split into an African and an Asian clade in the Pliocene (Bissiengou 2014).

\section{Clusiaceae (Asian)}

Garcinia likely originated in Africa and diversified in the Neogene spreading over India to SE Asia and further to Malesia and Australia (Ruhfel et al. 2016). 


\section{Calophyllaceae (Asian)}

Calophyllaceae were present in boreotropical forests of the Holarctic during the Eocene and migrated south to tropical latitudes in response to global climatic cooling starting at the EoceneOligocene boundary (Meseguer et al. 2018). The clade containing the genera in our dataset (Calophyllum, Kayea, and Mesua) contains pantropical genera as well as those with a more restricted Old-World distribution. It started to diversify in the early Oligocene; an Indian origin with subsequent eastward migration was inferred for Kayea, while the ancestral areas for Mesua and Calophyllum were ambiguous (Ruhfel et al. 2016). Mesua is distributed from India, where most species occur, to West Malesia (Stevens 2007). Calophyllum is pantropical, but has its centre of diversity in the Paleotropics and fossils indicate it was present and diversified in South Asia during the Miocene (Khan et al. 2017). These distribution patterns as well as the recent time of divergence of the two genera in the middle Miocene and presence in South Asia at that time strongly suggest an Asian origin for both and later dispersal into Malesia.

\section{Hypericacae (Asian)}

Cratoxylon separated from the Malagasy genus Eliea in the middle Eocene and dispersed from India into SE Asia, Sundaland, and Wallacea afterwards (Ruhfel et al. 2016).

\section{Putranjivaceae (Asian)}

The pantropical Drypetes is sister to Putranjiva, which has an Indo-Chinese-Malesian distribution. The former is most diverse in Africa and Indo-Malesia, but diversity declines sharply east of Wallace's line (Levin 2014). The crown age of Putranjivaceae is not known but the family diverged from the African monotypic Lophopyxidaceae in the late Eocene to early Pliocene (Xi et al. 2012) and pollen associated with Drypetes has been found in the late Eocene in Europe (Davis et al. 2005), suggesting an African or Eurasian origin. Together with the patterns of extant diversity of Drypetes, we consider the information most compatible with a Neogene migration from SE Asia to Malesia and further to the Pacific and Australia.

\section{Centroplacaceae (Asian)}

Bhesa diverged from the African Centroplacum, the only other genus of the family, in the late Cretaceous (ca $69 \mathrm{Ma}$ ), but it is not sure whether this split was due to vicariance involving Africa and Indo-Madagascar or Australia, or whether a dispersal event best explained the split (Cai et al. 2016). Bhesa is absent from Australia but most species rich in the region spanning from India to W Malesia (Hou 1962), which makes rafting on the Indian plate and later dispersal onto Asia and further into Malesia the most likely scenario.

\section{Trigoniaceae (Asian)}

Trigoniaceae separated from their closest relative, the Dichapetalaceae, in the Eocene but the extant members of the family started to diversify only in the late Oligocene (Xi et al. 2012). While generic sampling of the family in molecular phylogenetic studies has been sparse, Trigoniastrum is morphologically most similar to the Malagasy genus Humbertiodendron, with 
the Neotropical taxa of the family more distant (Bittrich 2014). With the limited information available, the relatively young crown age and extant distribution pattern of the family seem to suggest a wider past distribution in boreotropical forests and southward migration due to climatic cooling in the Neogene. Humbertiodendron could have arrived in Madagascar by windfacilitated long-distance dispersal. Furthermore, since Trigoniastrum only occurs in Sundaland, an origin in Australia is less likely than one in Asia.

\section{Dichapetalaceae (Asian)}

Dichapetalaceae separated from Trigoniaceae ca $60 \mathrm{Ma}$ and diversified in the early Miocene (Xi et al. 2012). The evolutionary history of Dichapetalum has not been tested with molecular methods, but the Malesian members of the genus are centred in Sundaland (Leenhouts 1957), so we consider an Asian origin more likely.

\section{Chrysobalanaceae (mixed)}

Kostermanthus was retrieved as sister to the rest of Chrysobalanaceae (Bardon et al. 2016) with an ancestral area in SE Asia / Oceania (the study did not discriminate between the two). Since the genus is centred in W Malesia, reaching the Philippines and Sulawesi, and one species is endemic to the Malay peninsula (Prance 1989) and the rest of the family originated in Africa (Bardon et al., 2016), we consider an Asian origin of Kostermanthus far more likely than one in Australia.

Parinari originated in Africa in the early Miocene; all sampled Indo-Malesian species formed a monophyletic clade together with Neotropical species in derived positions. Hence, in the early to middle Miocene this clade originated in SE Asia or W Malesia, subsequently diversified in Malesia, and reached the Neotropics via long-distance dispersal (Bardon et al. 2016).

The clade containing the genera Atuna, Maranthes, and Parastemon, originated in Africa in the late Oligocene and involved repeated dispersal to SE Asia / Oceania (Bardon et al. 2016). Atuna and Parastemon are most diverse in Sundaland and/or continental SE Asia with few species occurring there and the only species of Maranthes in the region is widespread all over Malesia (Prance 1989). We consider that original dispersal from Africa to SE Asia / Sundaland and subsequent further eastward expansion, partly coupled with diversification is the most likely scenario for these groups.

The lineage of Angelesia and Hunga reached SE Asia / Oceania via long-distance dispersal in the middle Miocene and the two genera later separated the Miocene-Pliocene boundary (Bardon et al. 2016). Hunga is now confined to New Caledonia and New Guinea while Angelesia has a wider distribution from SE Asia to New Guinea (Sothers and Prance 2014), suggesting that the common ancestor of the two genera arrived in Australasia from S America and then spread westward into Malesia. 


\section{Achariaceae (Asian)}

Trichadenia and Ryparosa belong to a clade including the Sundaland-centred genera Pangium and Gynocardia, as well as several nested S African genera. Likewise, Hydnocarpus is sister to a clade containing the widespread Erythrospermum and several African taxa. The exact phylogenetic relationships in both clades are unclear (Chase et al. 2002, Groppo et al. 2013), but the complete absence of Achariaceae in Australia and the fact that all three genera included in our dataset are limited to Sundaland or most diverse there (Sleumer 1954), make an Australian origin very unlikely.

\section{Salicaceae (mixed)}

Casearia belongs to the sister clade to the rest of Salicaceae, sometimes treated as a separate family, Samydaceae. The genus is polyphyletic, but its paleotropical species apparently form a monophyletic lineage, which diverged from Neotropical species of Samyda in the early Miocene and subsequently diversified and spread in the Paleotropics (Samarakoon 2015). Although taxon sampling of Paleotropical species was sparse, the basal position of species from New Guinea and Malesia and more nested clades of African and Malagasy taxa together with the recent divergence time suggests initial long-distance dispersal from the Neotropics to Australasia and subsequent further spread westward, including the colonisation of Malesia.

Ahernia is closely related to three small Neotropical genera (Alford 2005) but the crown age of that clade is not known. Since the genus only occurs in the N Philippines and Hainan, we assume a Laurasian, i.e. Asian origin. Homalium is most closely related to the Malagasy endemic Bembicia, pointing to a likely African origin of the genus (Alford 2005). It has a pantropical distribution, but in the Asian-Australian tropics its diversity is highest in Sundaland and the Philippines with a sharp decline further east (Sleumer 1954), so we also assume an Asian origin of Malesian Homalium. The widespread Paleotropical Flacourtia and the pantropical Xylosma together are sister to Hemiscolopia (Alford, 2005), which is distributed in continental SE Asia and Sundaland (Sleumer 1954), indicating an SE Asian origin of all three genera.

\section{Peraceae (Asian)}

Peraceae started to diversify in the Eocene (Xi et al. 2012) and their present distribution in the tropics of America, Africa, and Asia can probably be seen as a relict due to Neogene climatic cooling. Trigonopleura is distributed in Sundaland with one species reaching Sulawesi (van Welzen and Esser 2013), so an Asian origin is assumed.

\section{Euphorbiaceae (mixed)}

Neoscortechinia is sister to the monotypic Cheilosa, distributed in Sundaland and the Philippines (Tokuoka 2007). The morphological phylogenetic study by van Welzen (1994) found a Sundaland (i.e. Asian) origin of the genus, with the only E Malesian species nested among others distributed in W and C Malesia. 
Moultonianthus is sister to Erismanthus and Syndiophyllum; the combined clade is mainly distributed in SE Asia and Sundaland, with only one nested species of Syndiophyllum occurring in New Guinea (van Welzen 1995, Wurdack et al. 2005), suggesting an Asian origin.

Elateriospermum is the only Paleotropical genus in the 'articulated crotonoids' subclade of Crotonoideae (Wurdack et al. 2005). Its restricted distribution in Sundaland (Webster, 2014) suggests an origin in that area.

Ostodes is placed in a clade with other genera that are centred in SE Asia (Tokuoka 2007). The genus contains only two species: one from China and SE Asia and another from India to Sundaland (van Welzen and Winkel 2015), making an Australian origin unlikely.

The widespread genus Acalypha originated in Africa in the Paleocene and started to diversify in the early Miocene (Cervantes et al. 2016). The sister relationship of a Malesian / Pacific clade with a clade from Africa and Asia (Sagun et al. 2010, 201) suggests recent colonisation of the former areas since the Miocene, possible as a result of climate-driven southward movement.

The clade containing Blumeodendron, Hancea, Mallotus, and Macaranga originated in Asia in the middle Paleocene (Cervantes et al. 2016). Blumeodendron diverged from the other genera in the early Eocene and today is most diverse in Sundaland, with only two species occurring in E Malesia, presumably due to recent invasion from Sundaland (Ottens-Treurniet and van Welzen 2016). Hancea split off the Macaranga-Mallotus-clade in Sundaland in the late Eocene (Cervantes et al. 2016) and the only species in our dataset, widespread H. penangiana, is nested in species which occur in SE Asia and Sundaland (Kulju et al. 2007). Finally, Macaranga and Mallotus both originated in Sundaland in the Oligocene and single lineages of both genera reached Australasia via long-distance dispersal soon afterwards, before the onset of the MFI (van Welzen et al. 2014). All species of Mallotus in our dataset belong to clades that spread eastwards through Malesia more recently in the Mio-Pliocene and the genus is therefore scored as having an Asian origin. The situation in Macaranga is more complex, with one clade having reached Australasia at the Oligocene-Miocene boundary, diversified there, and later dispersed westward reaching Sundaland again. Two other clades diversified in SE Asia / Sundaland and later, in the Mio-Pliocene several species migrated eastwards (van Welzen et al. 2014). We therefore placed our species of Macaranga in one of these three clades according to the phylogeny of Welzen et al. (2014) where possible, otherwise based on the morphologically defined species groups of Whitmore (2008), and assigned them to Asian or Australian ancestry accordingly.

Ptychopyxis presumably also belongs to the clade of the preceding paragraph, but to date has not been included in any molecular phylogenetic study. The genus is most diverse in Sundaland with single species occurring in SE Asia and New Guinea, indicating an Asian origin (Stoops and van Welzen 2013). 
Claoxylon belongs to a clade with the African Erythrococca and Micrococca, distributed from Africa to Malesia, which separated from the African Discoclaoxylon in the middle Eocene (Cervantes et al. 2016). Later, in the Oligocene, Claox/on separated from its nearest relatives (Erythrococca and Micrococca) and diversified reaching its present wide distribution from Madagascar through Asia to Australasia. The genus is most diverse in Sundaland, with secondary centres of diversity in the Malagasy region, Papuasia, and the Pacific Ocean (WCSP 2019). Taken together, the phylogeny and the distribution pattern, suggest an African origin and later dispersal to Asia and further east into and through Malesia.

Melanolepis belongs to the Chrozophorinae, a mainly Asian clade, with single taxa spreading into Africa, Europe, and (our species Melanolepis multiglandulosus) throughout Malesia to the Pacific (Webster 2014). Not all genera of the Chrozophorinae have been included in molecular phylogenetic studies, but Sumbaviopsis (SE Asia and Sundaland) has repeatedly been resolved as the sister genus of Melanolepis (Wurdack et al. 2005, Tokuoka 2007) and the two probably split in the early Miocene (Cervantes et al. 2016). As the whole clade is centred in Asia, despite the lack of resolution in the published phylogenies, we assume an Asian origin.

Koilodepas belongs to the tribe Epiprineae (Webster 2014) which, albeit with rather sparse taxon sampling, was resolved as monophyletic when Cephalomappa was included (Wurdack et al. 2005). Cephalomappa, the closest of all sampled genera, and Koilodepas separated in the early Miocene (Cervantes et al. 2016). Both genera are strongly centred in Sundaland and all other genera of the tribe have their greatest diversity in Asia or Africa (Cephalocroton; Webster 2014), making an Australian origin of Koilodepas very unlikely.

Pimelodendron belongs to the pantropical tribe Stomatocalyceae, a monophyletic clade sister to the rest of Euphorbioideae (Wurdack et al., 2005) which probably originated in the late Cretaceous (Xi et al. 2012). Pimelodendron is most diverse in Sundaland with only one species crossing Wallace's line (Djarwaningsih 2004). Taken together, we consider a scenario of wide Laurasian distribution in the Paleogene and subsequent migration to SE Asia and Malesia most likely.

Balakata, a member of tribe Hippomaneae, has not been included in molecular phylogenetic studies so far, but morphology suggests a close relationship with Anomostachys from Africa and Madagascar (Webster 2014). The genus only includes two species, one from India to the Philippines, the other in C and E Malesia (Esser 1999); it is absent from Australia and the Pacific Ocean. Based on the limited information, we consider an origin of the genus in Africa or Asia most likely.

Homalanthus is sister to a pantropical (predominantly S American) clade of several genera (Wurdack et al. 2005), but the timing of the divergence is not known, although it must have occurred less than $40 \mathrm{Ma}$ (Xi et al. 2012). Long-distance dispersal from S America to SE Asia / Australia or a former Laurasian distribution and subsequent southward migration are two possible scenarios consistent with the temporal information available. Because Homalanthus is 
most species- and endemism-rich in New Guinea and the W Pacific Ocean, we here assume a recent long-distance dispersal event from S America to New Guinea and subsequent colonisation of Malesia from there.

\section{Ixonanthaceae (Asian)}

Ixonanthes diverged from the rest of Ixonanthaceae, distributed in tropical Africa and northern S America near the Paleocene-Eocene boundary (Xi et al. 2012, Byng et al. 2016). The phylogeny and divergence times, together with the present distribution of Ixonanthes (SE Asia to the Maluku Islands), suggest a former Laurasian distribution of the family and southward migration to the present relic areas due to Neogene cooling, meaning an Asian origin for our purpose.

\section{Phyllanthaceae (Asian)}

Breynia originated in the late Oligocene to early Miocene in continental SE Asia and subsequently spread in various directions, including eastward into Malesia and Australia (van Welzen et al. 2015). Glochidion diverged from Breynia and Synostemon in the Oligocene (Li et al. 2009). Although the question of the genus' origin was not specifically addressed in the study of Hembry et al. (2013), their results showed all Malesian, Australian, and Pacific species of Glochidion to be derived from continental Asian clades.

Bridelia originated in SE Asia and started to diversify ca $10 \mathrm{Ma}$. The genus reached Australia at least twice independently ca $2 \mathrm{Ma}$ (Li et al. 2009). The non-African species of Cleistanthus form the sister group of Bridelia. Most species occur in Southeast Asia and Sundaland, and the only Australian species tested so far diverged from its Malesian counterparts ca $13 \mathrm{Ma}$ (Li et al. 2009) suggesting recent (Miocene) dispersal from Asia into Malesia and further to Australia and the Pacific Ocean.

Bischofia, together with the African Spondianthus, is sister to the rest of subfamily Antidesmatoideae; the two genera already diverged in the Late Cretaceous (Li et al. 2009). Bischofia contains one species endemic to China and another widespread from India to the Pacific Ocean (van Welzen 2016). Given the relationship with African Spondianthus and the endemic Chinese species, we consider an Australian origin of the genus to be unlikely.

Antidesma has a wide paleotropical distribution, with half of its ca 100 species occurring in continental Southeast Asia and Sundaland but also spreading to tropical Africa, India, and China as well as eastward to Papuasia, Australia and the Pacific Ocean (WCSP 2019). The genus diverged from its closest relative, Thecacoris from tropical Africa and Madagascar, in the early Miocene (Li et al. 2009). Given the high species diversity in Southeast Asia and Sundaland and the sister relationship to the African genus, we consider an Asian, or at least Laurasian origin of Antidesma to be most likely.

Aporosa and Baccaurea belong to a pantropical clade that started to diversify in the early Eocene (Li et al. 2009). Eocene leaf fossils of Aporosa have been found in India (Shukla et al. 2016) and the genus colonised the rest of Malesia from Sundaland (Schot 1998). Baccaurea has 
its centre of diversity in Sundaland and phylogeographic analysis using morphological characters inferred that it originated in Southeast Asia (Haegens 2000).

\section{Combretaceae (Asian)}

The pantropical genus Terminalia started to diversify in South America in the early Miocene. Most of the Old-World species, including the two species in our dataset, belong to a clade that originated in Africa in the Mid-Miocene and spread through Asia to Australia from there (Berger et al. 2016).

\section{Lythraceae (Asian)}

Duabanga and Lagerstroemia are sister taxa which separated the beginning of the Tertiary. Although their origin was inferred to be Australian in the phylogeographic analysis of Berger et al. (2016), this is unlikely considering the fossil record: Both genera have an extensive record in Eurasia, especially in India and Sundaland, from at least the Miocene onwards while there are no known fossils from Australia (Graham 2013). Lythraceae originated in South America in the Late Cretaceous and shortly afterwards spread through North America to Eurasia and Africa (Berger et al. 2016). In light of that information, we believe that an Asian origin of the species in our dataset is most likely.

\section{Myrtaceae (Australian)}

All species in our dataset (including genus indets) belong to subfamily Myrtoideae, which originated at the Cretaceous-Paleogene boundary in Australia. All relevant lineages in Myrtoideae diversified in Australasia and only recently, since the Miocene, spread to other regions, including the expansion to Central- and West-Malesia and into Asia (Sytsma et al. 2004, Thornhill et al. 2015, Berger et al. 2016).

\section{Melastomataceae (mixed)}

Melastomataceae likely started to diversify in South America in the early Paleocene and LDD by volant animals has played a prominent role in the family's evolutionary history (Berger et al. 2016). Pternandra was the earliest diverging lineage of the Melastomataceae crown. The genus is now distributed from Thailand throughout Malesia and likely diversified from the MidMiocene onwards (Renner 2004). While from the available data, it cannot be unambiguously concluded whether the ancestors of extant Pternandra came from Asia or Australia, the genus' centre of diversity in Sundaland and absence of Australian species points to Asia.

Memecylon, another early diverging lineage split from its Neotropical sister genus Mouriri in the early Miocene, probably through LDD (Berger et al. 2016). Most extant species as well as the basal groups occur in Africa, from which the genus diversified and spread several times to Asia and Malesia among other areas (Stone 2014).

The tribe Astronieae, containing our genera Astronia and Astrocalyx, diverged from the Neotropical Henrietteeae in the early Miocene (ca $18 \mathrm{Ma}$ ) probably also via LDD (Berger et al. 
2016). The basal position of the New-Guinea-centred genera Astronidium and Beccarianthus within Astronieae (Penneys, 2013) points to New Guinea as the starting point for further dispersal to Malesia and into Southeast Asia.

In the Eocene (ca $38 \mathrm{Ma}$ ), the Medinilla lineage split from Neotropical ancestors (Berger et al. 2016). The genus diversified much later, in the Miocene and is now widespread from Africa through Madagascar, India, Southeast Asia, and Australia. It has centres of diversity in Madagascar and Malesia, while in Australia only one species occurs (Bodegom and Veldkamp 2001). Therefore, we infer a Southeast Asian origin for the Malesian members of the genus.

The common ancestor of Melastoma and its sister genus Osbeckia reached SE Asia via LDD from Africa during the Mid-Miocene (ca $16 \mathrm{Ma}$ ) and Melastoma presumably spread further east into Malesia afterwards (Veranso-Libalah et al. 2018).

\section{Crypteroniaceae (Asian)}

Crypteroniaceae split from a clade containing the Neotropical Alzateaceae and Pennaeaceae from southern Africa in the early Eocene. The ancestors of extant species likely rafted on the Indian plate and spread into SE Asia and Malesia after the collision of the Indian plate with Asia (Rutschmann et al. 2004, Berger et al. 2016).

\section{Staphyleaceae (Asian)}

Turpinia as presently described is not monophyletic. However, the Old-World species of Turpinia seem to form a monophyletic group and although results of different markers provided contradictory results, the Malesian species always were nested among mainland Asian taxa, so that an Asian origin is most likely (Harris et al. 2017b).

\section{Burseraceae (Asian)}

Our species all belong to tribe Canarieae, which after evolving in Eurasia partly moved to Southeast Asia due to Oligocene cooling (Federman et al. 2015). Within Canarieae, several large genera are not monophyletic, but the species in our dataset belong to clades of Santiria, Dacryodes, and Canarium as well as the monophyletic genera Scutinanthe and Triomma that all originated in Southeast Asia and underwent recent (Miocene) diversification with some species spreading east through Malesia (Weeks et al. 2014, Federman et al. 2015).

Haplolobus has not been included in phylogenetic analyses so far, so its placement is unclear. However, since all Malesian clades of the family present a uniform pattern of recent diversification in Southeast Asia (Federman et al. 2015), we also attribute an Asian origin to Haplolobus.

\section{Anacardiaceae (Asian)}

Anacardiaceae started to diversify in Southeast Asia in the Upper Cretaceous. Members of the family in our dataset belong to three clades, according to the phylogeographic study of Weeks et al. (2014): Dracontomelon is part of the 'Spondioideae 2', an early branching lineage that 
originated in the Upper Cretaceous and started to diversify at the Eocene-Oligocene boundary in Southeast Asia. Dracontomelon split from its sister genus Pseudospondias at the beginning of the Miocene in Southeast Asia and later, probably only during the Pliocene spread into Central and East Malesia (Weeks et al. 2014).

Buchanania separated from the 'Spondioideae 1' in the Mid-Paleocene in Southeast Asia. The genus underwent recent diversification and eastward expansion in the late Miocene and Pliocene (Weeks et al. 2014).

Koordersiodendron has not been sampled in phylogenetic studies. Based on morphology, it belongs to subfamily Spondioideae (Pell et al. 2010, 201), a polyphyletic assemblage of the two clades 'Spondioideae 1' and 'Spondioideae 2'. Since both of them originated in Southeast Asia and all their Malesian genera arrived in the region from Asia (Weeks et al. 2014), we assume that Koordersiodendron also has a Southeast Asian origin.

Gluta, Mangifera, Swintonia, Melanochyla, and Semecarpus all belong to 'Anacardioideae 4', a clade which originated in Southeast Asia or Oceania at the Cretaceous-Paleogene boundary and started to diversify in Southeast Asia shortly afterwards. All lineages containing Malesian genera in 'Anacardioideae 4' were present in Southeast Asia in the Oligocene and - if occurring there today - only moved to eastern Malesia and Oceania since the Miocene or later (Weeks et al. 2014).

Since all clades of Malesian Anacardiaceae were retrieved to have Southeast Asian origins and recent expansion into (and sometimes) beyond Malesia (Weeks et al. 2014), we also score Parishia, which has not been sampled for phylogenetic studies and several genus indets as originally Asian taxa.

\section{Sapindaceae (mixed)}

Sapindaceae originated in Eurasia in the early Cretaceous but SE Asia has been a centre of diversification and dispersal throughout much of the family's evolutionary history, which involved several LDD events (Buerki et al. 2011).

Acerbelongs to an early-diverging clade, the Hippocastanoideae, and originated in Eurasia. The genus has diversified since the early Miocene from there, giving rise to the Malesian species Acer laurinum, among others (Buerki et al. 2011, Harris et al. 2017a).

Harpullia is part of another early branching lineage, the Dodonaeoideae. The genus is nested among Australasian taxa (Buerki et al. 2011) and has most extant species occurring in Australia and New Guinea. The only two widespread Indo-Malesian species form a clade nested among the Australasian species (Buerki et al. 2012), so we infer an Australian origin of the genus.

All remaining taxa in our dataset belong to subfamily Sapindoideae. Dimocarpus, Lepisanthes, Litchi, Nephelium, Pometia, and Xerospermum are part of a clade that originated in Southeast Asia in the Eocene and diversified and spread to different areas since then. The mentioned 
genera started to diversify in the late Oligocene to early Miocene and partly expanded their ranges to Eastern Malesia and further East (Buerki et al. 2011).

Another group of genera (Arytera, Guioa, and Mischocarpus) are part of a recent radiation starting in the Early Miocene from Australasia (Buerki et al. 2011). Although the Philippine endemic Gloeocarpus patentivalvis has not been sampled for phylogenetic studies so far, its morphology suggests a placement within this group (van Welzen 1991). It is therefore assumed to have an Australian origin as well.

\section{Rutaceae (mixed)}

Achronychia, and Melicope form part of the Acronychia-Melicope clade of Rutaceae which has its origin in Australasia (Appelhans et al. 2014). Acronychia was inferred to have its geographic origin in Australia, from where five of its species colonised Malesia (Holzmeyer et al. 2015), probably in the late Miocene to Pliocene (Appelhans et al. 2012). The species of Melicope in our dataset belong to the sections Lepta and Pelea (Hartley 2000), corresponding to the sister clade of Acronychia which has its origin in Australasia and started to diversify in the late Miocene as well (Appelhans et al. 2014). Tetractomia is sister to the Acronychia-Melicope clade and together they are nested among Australasian taxa (Appelhans et al., 2014). Hence, Tetractomia, which is widespread in Malesia today, also has an Australian origin.

Tetradium diverged from its closest relative, the East Asian Phellodendron, in the Paleocene and started to diversify ca $20 \mathrm{Ma}$ in continental Asia (Appelhans et al. 2018). Most species of Tetradium still occur in that region; only three species have reached Sundaland and one Sulawesi (Hartley 1981).

\section{Simaroubaceae (Asian)}

Ailanthus started to diversify in the Oligocene of Asia (including Southeast Asia) and colonised Malesia from there in the Early to Mid-Miocene (Clayton et al. 2009). Eurycoma split from its sister, Odyendea from tropical Africa in the Early Miocene and only diversified in the Pliocene of Sundaland (Clayton et al. 2009). Since all tree-genera of Simaroubaceae occurring in Malesia were inferred to have originated in Asia by the phylogeographic study of Clayton et al. (2009), we also scored one genus indet as Asian.

\section{Meliaceae (Asian)}

Meliaceae originated in Africa in the Upper Cretaceous (Muellner-Riehl et al. 2016) and soon spread to Laurasia where they were present and widespread during the Eocene (Muellner et al. 2006).

Toona and its sister genus Cedrela were present and widespread in Laurasian boreotropical forest of the Eocene and presumably moved to lower latitudes due to climatic cooling in the Oligocene (Muellner et al. 2006). While Cedrela became confined to the Americas, Toona established in Asia including Sundaland and later, in the Early Miocene, crossed Wallace's line spreading to New Guinea and Australia (Koecke et al. 2013). 
Also in the Mid-Eocene (ca $45 \mathrm{Ma}$ ), Sandoricum split from the African and Malagasy clade Ekebergia + Quivisianthe (Muellner-Riehl et al. 2016) presumably from a Laurasian ancestor. Sandoricum diversified in the Miocene (Koenen 2011) and is now strongly centred in Sundaland with only one species widespread in Malesia.

The clade containing Aglaia, Dysoxylum, Chisocheton, and Cabralea separated from its sister clade containing mostly Neotropical and African species in the Mid Oligocene and started to diversify shortly afterwards, most likely in Sundaland and/or mainland Southeast Asia (Koenen et al. 2015). Aglaia, including the nested Reinwardtiodendron, originated in Sundaland and started to diversify at the Oligocene-Miocene boundary. The genus repeatedly dispersed into and through Malesia starting from the Mid-Miocene (ca 14 Ma; Grudinski et al. 2014). Aphanamixis is sister to Aglaia and originated in Sundaland as well, with subsequent diversification and expansion into eastern Malesia from the late Miocene onwards (Grudinski et al. 2014). The genera Dysoxylum, Chisocheton, and the Neotrpical Cabralea form a grade basal to Aglaia. Dysoxylum is strongly polyphyletic, with species of the genus spread over at least four clades (Koenen 2011, Koenen et al. 2015). The monophyletic Chisocheton is nested within one of these clades.

Since all relevant lineages of Meliaceae have a Laurasian origin and are inferred to have colonised Malesia from Asia (Muellner et al. 2006, Koenen 2011, Koecke et al. 2013, Grudinski et al. 2014, Muellner-Riehl et al. 2016), we also score the Meliaceae records with uncertain generic identity as Asian.

\section{Malvaceae (Asian)}

Malvaceae have an extensive fossil record in Laurasia from the Cretaceous throughout the Cenozoic (Xie et al. 2014) pointing to a presence in Laurasian boreotropic forest during the Eocene, when all major clades had already evolved (Richardson et al. 2015).

The Sterculioideae evolved in Africa or Asia in the Mid Eocene (ca $40 \mathrm{Ma}$ ) and diversified mostly in Asia where the major lineages were present by the Mid-Oligocene (Carter 2011). The genera of our dataset belong to three clades: The Cola clade (Firmiana, Pterocymbium, Scaphium), Sterculia clade (Sterculia), and Heritiera clade (Heritiera). The exact relationships between these clades are not clear, but all originated in Asia and diversified from the Miocene onwards (Carter 2011, Richardson et al. 2015).

Helicteroideae originated in the Mid Eocene and started do diversify in the Mid-Oligocene, splitting into a clade of mainland Asian taxa and a mostly Malesian clade. The latter diversified in Sundaland - where most species occur today - since the Mid-Miocene (Richardson et al. 2015) and contains the genera Coelostegia, Durio, and Neesia of our dataset.

Brownlowioideae separated from the mostly Laurasian subfamilies Tilioideae and Dombeyoideae in the late Eocene (Richardson et al. 2015), presumably from an ancestor which also occurred in Laurasia. Most species of the subfamily now occur in tropical Asia, especially in 
Sundaland. Diplodiscus and Pentace from our dataset are both strongly centred in Sundaland as well (Bayer and Kubitzki 2003). The latter and another Sunda-centred genus, Brownlowia, split only in the Pliocene (Richardson et al. 2015).

Grewioideae also originated in the late Eocene and the Grewia clade containing our genera, Grewia, and Microcos started to diversify in the Mid-Oligocene (Richardson et al. 2015). The paleotropical Microcos and Colona split from Neotropical ancestors at some point during the Miocene or Pliocene, suggesting recent transoceanic LDD (Brunken and Muellner 2012, Richardson et al. 2015). The current diversity centres in Sundaland and absence from Australia of both genera (Bayer and Kubitzki 2003) point to an initial colonization of Sundaland and later spread into Malesia from there. The pantropical Grewia is sister to the tropical African genus Desplatsia, indicating an African origin of Grewia in the Miocene and later dispersal to Asia and into Malesia (Richardson et al. 2015).

Pterospermum split from other genera occurring in Asia and the western Indian Ocean in the Miocene (Richardson et al. 2015). Together with the genus' extant distribution from India and China to Central Malesia (Bayer and Kubitzki 2003) this suggests recent diversification in Asia and dispersal into Malesia from there.

\section{Thymelaeaceae (Asian)}

Thymelaeaceae originated in the Eocene, but the area of origin is not known. The earliest diverging clade contains the monotypic Synandrodaphne from Africa and Octolepidoideae (Gonystyloideae) with one subclade in Africa and Madagascar as well. The remainder of Octolepidoideae is distributed in Malesia, northern Australia, and the western Pacific Ocean with centres of diversity in Sundaland and New Caledonia (Herber 2003) and split from the African species in the Mid-Miocene (Motsi 2009). The presence of fossils of the Octolepioideae in Eocene India and Oligocene to Miocene of Borneo (Herber 2003) indicates that this clade has its origin in tropical Asia. It diversified in the Mid-Miocene, apparently reaching Africa via LDD first and later (ca $8 \mathrm{Ma}$ ) spreading from Sundaland eastwards with a secondary radiation in New Caledonia (Motsi 2009).

Subfamily Aquilarioideae split from Thymelaeoideae in the Eocene (ca $40 \mathrm{Ma}$ ). It contains two genera, Aquilaria and Gyrinops, started to diversify only in the Miocene, and now together encompass ca 25 species distributed from India to New Guinea with most species in Malesia (Motsi 2009). Aquilaria and Gyrinops are mutually paraphyletic, but the combined lineage has early diverging clades in India and Sundaland with Eastern Malesian members generally nested between more western congeners (Eurlings and Gravendeel 2005), which indicates recent colonisation of Malesia from Southeast Asia.

Thymelaeoideae contain the bulk of the family's species. They started to diversify in the Early Oligocene. Wikstroemia, widespread from Asia to Hawaii, belongs to a fundamentally Eurasian clade (Herber 2003) and split from other Eurasian genera in the Mid-Miocene (Motsi 2009). 
Since all tree-genera of Thymelaeaceae which occur in the Philippines have Asian origins (Herber 2003, Eurlings and Gravendeel 2005, Motsi 2009), we also scored to genus indets from the Philippines as Asian.

\section{Dipterocarpaceae (Asian)}

Dipterocarpaceae started to diversify in the Paleocene (Heckenhauer et al. 2017). Fossils of the family from the Eocene have been found in India (Dutta et al. 2011, 20) and South China (Feng et al. 2013). Later, in the Oligocene, they also appear in Sundaland, where the overwhelming diversity of extant species occurs. The family is much less diverse east of Wallace's line (Ashton 2003a) and the species there belong to several lineages which all evolved in the Neogene and are nested among clades from mainland Asia and/or Sundaland (Heckenhauer et al. 2017).

\section{3 'Olacaceae' (Asian)}

'Olacaceae' as defined by APG IV are a paraphyletic grade at the base of the order Santalales (The Angiosperm Phylogeny Group 2016). They contain three families with species from our dataset (Nickrent et al. 2010), all rather old with origins dating back to the Cretaceous (VidalRussell and Nickrent 2008):

Strombosiaceae arose in the Early Cretaceous (ca 105 Ma; Vidal-Russell and Nickrent 2008) and are likely sister to all other Santalales. The small family is pantropical and the earliest diverging clade, monotypic Scorodocarpus, is distributed in Sundaland. The rest of the family is composed of Strombosia, which contains species from tropical Africa, India, and Sundaland plus an African clade including the nested Neotropical Tetrastylidium (Nickrent et al. 2010, Su et al. 2015). Due to the basal position of Sundaland taxa in the family and because none of the clades occurs east of Wallace's line, we assume an Asian origin of Strombosia and Scorodocarpus.

Aptandraceae originated in the early Cretaceous and started to split into two clades in the Late Cretaceous (ca $82 \mathrm{Ma}$; Vidal-Russell and Nickrent 2008). One of these clades, the Anacoloseae, later split into the South American genus Cathedra and a Paleotropical group: Phanerodiscus from Madagascar and Anacolosa, widely distributed from Africa and Madagascar to Australia and the Pacific Ocean. Most species of Anacolosa today occur in continental Southeast Asia, but there are also a number of species in East Malesia and the Western Pacific Ocean (Sleumer 1980). Given the present distribution of the genus, its close relationship to Phanerodiscus and the extensive fossil record of Anacoloseae throughout the Tertiary in Laurasia (Malécot and Lobreau-Callen 2005), we assume an Asian origin of Anacolosa.

Coulaceae originated in the early Cretaceous (ca 104 Ma; Magallón et al. 2015) and consist of three monotypic genera. Minquartia from the Neotropics is sister to the tropical African Coula and the Sundaland endemic Ochanostachys (Nickrent et al. 2010). The timing of diversification in the family is not known, but the absence of the family from Australasia and the distribution of Ochanostachys suggests that the latter originated in Asia. 


\section{6 'Santalaceae' (mixed)}

Santalaceae, as currently circumscribed are a paraphyletic assemblage including Balanophoraceae (The Angiosperm Phylogeny Group 2016).

Dendrotrophe belongs to the Amphorogynaceae, a family that originated in the late Cretaceous (ca $73 \mathrm{Ma}$ ) and started to diversify in the early Eocene (ca $42 \mathrm{Ma}$; Vidal-Russell and Nickrent 2008). The origin of Amphorogynaceae must be Australasian, since the early diverging lineages of the family have extant members in New Caledonia and Australia, whereas the Malesian genera, including Dendrotrophe, belong to one nested clade (Su et al. 2015) which diversified only in the Neogene (Vidal-Russell and Nickrent 2008).

Cervantesiaceae originated in the late Cretaceous (ca 79 Ma) as it split from Thesiaceae (VidalRussell and Nickrent 2008). The topology of the family tree, with the South American Cervantesia-clade sister to the mainly Paleotropic Pyrularia-clade and nested position of the Indo-Malesian Scleropyrum within African taxa (Su et al. 2015) suggests that the family originated in Laurasia and split apart because of climate-induced southward.

\section{Nyctaginaceae (Australian)}

The pantropical genus Pisonia originated in the Neotropics, as indicated by its position among the Neotropical genera Pisoniella, Neea, and Guapira (Douglas and Spellenberg 2010). Apparently, the other three genera are nested within a paraphyletic Pisonia and the whole clade (Pisonieae) is quite young, having diversified in the Neogene only with several LDD events from the Americas to the Indo-Pacific (Hayward and Horton 2014). Species sampling has been too sparse so far to infer the exact timing and patterns of the genus' biogeographical history. Nevertheless, the relative paucity of species in the Indian Ocean and hence Africa/Asia as compared to the richness in the Pacific Ocean (Stemmerik 1964) indicates predominant dispersal from the Neotropics to the Pacific Ocean and from there into Malesia.

\section{Nyssaceae (Asian)}

Mastixia split from the small East and Southeast Asian genus Diplopanax in the Late Cretaceous to Paleocene and started to diversify in the Late Eocene of Eurasia (Xiang et al. 2011) as indicated by a rich fossil record (Matthew 1976). Today the genus has an Indo-Malesian distribution with most species occurring in Sundaland (Matthew 1976).

\section{Hydrangeaceae (Asian)}

Dichroa forms a clade with mostly Asian species within the large, overwhelmingly Asian clade Hydrangea II of the paraphyletic genus Hydrangea (Samain et al. 2010). The clade containing Dichroa split from its Asian ancestors in the Miocene (Xiang et al. 2011) and most extant species occur in China, Southeast Asia, and Sundaland (Hufford 2004). 


\section{Cornaceae (Asian)}

Alangium originated in the Late Cretaceous of East to Southeast Asia. The species in our dataset belong to sections Conostigma, Alangium, and/or Marlea, all of which have their origins in Southeast Asia with only recent, if any, dispersal to Central and East Malesia in the Neogene (Feng et al. 2009).

\section{Lecythidaceae (Asian)}

Lecythidaceae originated in the Cretaceous (ca 100 Ma; Magallón et al. 2015) and started to diversify in the Mid-Eocene (ca 47 Ma; Bell et al. 2010), presumably in Africa, as indicated by the two early-diverging lineages Napoleonaeoideae and Scytopetaloideae which both exclusively or overwhelmingly occur on that continent today (Mori et al. 2007). Barringtonia is nested in clades from Africa (Foetidia, Petersianthus) and Indo-Malesia (Chydenanthus, Petersianthus) but the timing of that divergence is not known (Mori et al. 2007). Barringtonia itself is fundamentally a Malesian genus with centres of diversity in Sundaland and New Guinea, although a few widespread species reach from Madagascar to the Pacific Ocean (Payens 1967). Given the nested position among African and Asian genera, the primary centre of diversity in Sundaland, and the presence of Eocene macrofossils from India, we conclude that the genus has an Asian rather than Australian origin. The relatively high diversity in East Malesia and the Western Pacific is probably due to recent speciation (Payens 1967).

Only three genera (Barringtonia, Chydenanthus, and Planchonia) of Lecythidaceae, all of subfamily Barringtonioideae occur in Borneo. The discussion for Barringtonia (see above) applies also to the subfamily. We therefore scored one genus indet from Borneo as Asian as well.

\section{Pentaphylacaceae (Asian)}

The genera in our dataset ( Ternstroemia, Eurya, and Adinandra) belong to three different clades in the family but have in common that they occur - often with many members - in East and Southeast Asia and/or have close relatives there and have started to diversify in the Miocene (Su et al. 2011, Tsou et al. 2016).

Ternstroemia is a pantropical genus most diverse in the Neotropics and Malesia (Weitzman et al. 2004). While no Neotropical species have been included in phylogenetic studies of the family, the Asian and Malesian species are nested among Anneslea and Sladenia, both from China and Southeast Asia, and started to diversify in the Early Miocene (Su et al. 2011, Tsou et al. 2016).

The closest relative of Eurya is the Neotropical Freziera. Together, they diverged from another pair with an amphipacific distribution, monotypic Euryodendron from China and Symplococarpon from the Neotropics in the Early Miocene (Su et al. 2011, Tsou et al. 2016). Disjunctions between temperate East Asia and North America have been found in many families and have been attributed to the split up of arcto-Tertiary forests due to climatic cooling in the Mid-Miocene. Pentaphylacaceae today are most species rich in subtropical areas of East Asia as 
well as in tropical mountains, so their ecological niche and timing match the disjunction with subsequent southward movement of Eurya into East Asia, where the genus is by far most species-rich today. The dispersal to Malesia - mostly to mountainous areas - occurred then in the course of the diversification of the genus.

Adinandra and Cleyera are probably both not monophyletic; together they form a monophyletic lineage sister to the clade mentioned in the preceding paragraph (Tsou et al. 2016). They are distributed from China and India to Malesia and in the Neotropics; most species occur in Sundaland and the diversity sharply declines towards the east with no species in Australia (Kobuski 1947). The diversity pattern suggests an evolutionary origin in arcto-Tertiary forests (see above) with subsequent southward movement in the Miocene (Su et al. 2011), eventually reaching Sundaland, where the genus diversified and then moved further into Central and East Malesia.

\section{Sapotaceae (mixed)}

Sapotaceae probably originated in Asia as indicated by the two fundamentally Indo-Chinese genera Sarcosperma and Eberhardtia, which successively split from the rest of the family in the Cretaceous (Richardson et al. 2014). Sarcosperma paniculatum is the only member of the genus occurring on both sides of Wallace's line while the remaining ten species are distributed in India, China, and Sundaland (WCSP 2019).

Madhuca, Palaquium, and Payena belong to a clade of subfamily Sapotoideae, which originated in Sundaland at the Eocene-Oligocene boundary. The genera have diversified during the Neogene in Sundaland with some species dispersing to Papuasia and - in the case of Palaquium - undergoing extensive radiation there (Richardson et al. 2014).

In subfamily Chrysophylloideae, Pleioluma and Planchonella belong to a clade which started to diversify with the split of Pleioluma from the rest during the Early Eocene (ca $50 \mathrm{Ma}$ ) in the then isolated Australia. The extant members of Pleioluma diversified much later, in the Mid-Miocene of New Guinea and/or Australia and from there dispersed to New Caledonia and westward. However, only the two species from our dataset crossed Wallace's line (Swenson et al. 2014). Planchonella, including several formerly segregated genera, is much older (Late Eocene). It also originated in Australia and repeatedly spread to New Caledonia and the Western Pacific Ocean. The few species disjunctions between Papuasian and Sundaland-species occurred since the Mid-Miocene, indicating recent dispersal from east to west(Swenson et al. 2014).

Donella, also of subfamily Chrysophylloideae, has a different biogeographic history: The genus split from the monotypic African Breviea in the Paleocene and is confined to Africa and Madagascar except for the species in our dataset, Donella lanceolata. D. lanceolata has a wide Indo-Pacific distribution and diverged from its Madagascan congeners in the Late Miocene $(<10$ $\mathrm{Ma})$, indicating recent long-distance dispersal from Madagascar to West Malesia and further east from there (Bartish et al. 2011). 


\section{Ebenaceae (Asian)}

Diospyros likely originated in Africa / Eurasia in the Mid-Eocene (41 Ma; Turner et al. 2013). In the Late Eocene one clade reached Australia, while the rest of the genus continued to strive in Africa and Eurasia with later occasional vicariance or dispersal events to other areas. All species occurring in Malesia belong to clades that originated in Eurasia and mostly diversified since the late Oligocene, so the genus probably colonised Malesia from Asia (Duangjai et al. 2009, Turner et al. 2013).

\section{Primulaceae (mixed)}

The genera in our dataset (Ardisia, Embelia, and Myrsine) all belong to the tropical woody clade sister to the north-temperate Lysimachieae and traditionally circumscribed as Myrsinaceae. The tropical woody clade split from its herbaceous relatives in the Early Oligocene (ca $30 \mathrm{Ma}$; Yesson et al. 2009), but its internal structure is poorly known due to insufficient taxon sampling in published phylogenies. Ardisia is distributed worldwide in the tropics, but best represented in Mesoamerica and Malesia, especially Sundaland (Stone 1989, Ricketson and Pipoly 2003). The genus belongs to a clade which - apart from the pantropical Ardisia - is restricted to IndoMalesia and the Pacific Ocean and split from its Neotropical sister clade, including Parathesis, Stylogyne and Geissanthus, in the Early Miocene (14-17 Ma; Yesson et al. 2009, Strijk et al. 2014) indicating a boreotropical origin. Ardisia has not been sampled sufficiently in phylogenies to infer its phylogeography, but the patterns of species richness of the genus suggest an origin in Asia and/or North America and subsequent southward migration and extensive speciation in Sundaland during the Neogene. The genus is furthermore species-poor in Australia (6 species; Jackes 2009), so we assume an Asian origin.

Embelia and Myrsine, together with the paleotropical mangrove genus Aegiceras and the Neotropical Cybianthus, form another poorly resolved clade within the tropical woody Primulaceae-Myrsinoideae (Yesson et al. 2009, Chen et al. 2016). The clade originated in the Early to Mid-Miocene (15-22 Ma), but it is not known whether the New Zealand endemic Elingamita, or the two clades mentioned in the preceding paragraph are its sister group (Yesson et al. 2009, Strijk et al. 2014). Embelia is widely distributed from Africa and Madagascar through tropical Asia and Malesia to the Pacific Ocean (Ståhl and Anderberg 2004), but has its center of diversity in Southeast Asia and West Malesia, so we place it as an Asian genus.

Myrsine, on the other hand, has a pantropical distribution with most species occurring in the Pacific Ocean and surrounding areas like Australia, New Guinea, the Philippines, the Andes, and Mesoamerica, while Sundaland and continental Asia harbour relatively few species (Ståhl and Anderberg 2004). The genus has probably only diversified within the last 10 My (Strijk et al. 2014) and we propose an Eastern (Papuasian) origin for the Malesian species based on the distribution pattern. 


\section{Theaceae (Asian)}

Theaceae likely originated in Laurasia in the Late Cretaceous and started to diversify in the MidEocene of the same area. Schima is nested in the North American genera Franklinia and Gordonia and its ancestors probably moved to East Asia via the Bering land bridge in the Late Miocene (Li et al. 2013). Today, most species of Schima occur in China and Southeast Asia (Stevens et al. 2004a) and the genus colonised Malesia from there.

The remaining genera in our dataset belong to Tribe Theeae, where Polyspora diverged from the remaining lineages in the late Oligocene of Asia (Li et al. 2013) and started to diversify only in the last 10 My (Zhang et al. 2014) with some clades spreading into Malesia, where it shows the highest diversity in Sundaland today (Keng 1984). Pyrenaria is nested in the paraphyletic Camellia, the lineage started to diversify at the beginning of the Neogene in Asia and spread from there (Li et al. 2013, Zhang et al. 2014).

\section{Symplocaceae (Asian)}

Symplocos originated in Eurasia ca $52 \mathrm{Ma}$, from where they dispersed to the Americas, and later moved to lower latitudes on both continents due to climatic cooling since the Oligocene, thus colonising South America and Malesia (Fritsch et al. 2015).

\section{Styracaceae (Asian)}

Styracaceae originated in Eurasia and formed part of the boreotropical flora before becoming disjunct on both sides of the Pacific Ocean due to climatic deterioration. Both Styrax and Bruinsmia therefore have Asian origin (Fritsch et al. 2001).

\section{Actinidiaceae (Asian)}

Actinidiaceae is composed of only three genera, two of which are confined to Asia and most species-rich in China, and the amphipacific Saurauia, which is present in our data (Dressler and Bayer 2004). The distribution pattern of Saurauia in the Neotropics and Tropical Asia (India and China to Fiji), together with the presence of Saurauia fossils from the Tertiary in Europe has been attributed to a former boreotropical distribution and later southward migration due to climatic cooling in the Oligocene (Soejarto 1980), an interpretation we follow here.

\section{Clethraceae (Asian)}

Most species of Clethra belong to a recently evolved Neotropical clade, which is sister to the remainder of the species (Fior et al. 2003). The latter are distributed in Macaronesia (C. arborea), North America (two species) and Asia including Malesia (Dressler and Bayer 2004). More specifically, the Malesian species of Clethra, including the species in our dataset, are sister to a clade of mainly East Asian (plus C. acuminata from North America) species (Fior et al. 2003). Although divergence times have not been assessed for the genus, the phylogenetic topology strongly suggests a former boreotropical distribution and recent colonization of Malesia after the ancestors of extant species had moved towards the equator in the course of Mid-Tertiary climatic cooling. 


\section{Ericaceae (Asian)}

Our dataset only contains one indeterminate record of Rhododendron from Mount Banahaw in Luzon. It most likely belongs to section Vireya, since all species of Rhododendron occurring in the Philippines, with the exception of two species from extreme northern Luzon belong to that section (Sleumer 1966). Vireya rhododendrons originated in Asia and later moved into Sundaland, from where since the Late Eocene (ca $40 \mathrm{Ma}$ ) they repeatedly crossed Wallace's line, and once also Lydekker's line to New Guinea (Landis et al. 2013). However, there seem to have been no back-dispersals, so we score Rhododendron as an Asian genus (although Rhododendron apparently belongs to the few taxa that started to disperse from Asia to Australasia before the onset of the Malesian floristic exchange).

Diplycosia, a fundamentally Malesian genus with two outlying species in Assam and SE Asia, is sister to Gaultheria series Gymnobotrys, a clade which is distributed from the Himalayas to New Guinea. Together, these two are sister to G. series Hispidula from the East Asia and North America (Fritsch et al. 2011). The topology is thus consistent with a scenario of colonisation of Malesia from Asian ancestors.

Malesian species of Vaccinium, although sparsely sampled so far, are apparently sister to the Agapetes-clade from continental Asia, and these two are nested among Asian and American taxa (Powell and Kron 2002), so we assume an Asian origin.

\section{Metteniusaceae (Asian)}

Metteniusaceae are a mostly Neotropical family, with only four genera occurring in the Old World tropics (Potgieter and Duno 2016, Stevens 2017). Platea, from our dataset, and the Neotropical Calatola are together sister to the remaining Metteniusaceae, which then split into a clade of Apodytes from the Paleotropics, Raphiostylis from Africa, and Dendrobangia from the Neotropics and another clade with mostly Neotropical genera plus the Southeast Asian Pittosporopsis (Stull et al. 2015). The Malesian members of the family are thus not closely related, but their placement in the phylogeny suggests a Tertiary boreotropical distribution of the family with later movement to areas near the equator. The presence of Platea in Laurasia is also indicated by pollen records from the Paleocene in North America (Manchester et al. 2015).

\section{Rubiaceae (mixed)}

The ancestor of subfamilies Ixoroideae and Cinchonoideae originated in the Neotropics during the late Cretaceous (Manns et al. 2012). Cinchonoideae today are predominantly Neotropical, but there have been several dispersal events to the Old World in different periods: One clade (tribes Naucleeae and Hymanodictyeae) dispersed to the Old World at the latest in the Eocene, where it had a wide distribution in boreotropical forests. As the boreotropical forest belt disintegrated due to climatic cooling in the Late Eocene to Oligocene, members of Naucleeae (Nauclea, Adina, and Neonauclea in our data) moved south to tropical areas of Asia (Manns et al. 2012). There, the lineages diversified in the Miocene, giving rise among others to the subtribe Naucleinae (Nauclea from our data) which later dispersed to Africa and into Malesia and to the 
Adidinae (Adina and Neonauclea in our dataset) which also spread into Malesia (Löfstrand et al. 2014).

Guettardeae, on the other hand, remained in the Neotropics, from where in the Miocene several lineages, among them Timonius from our dataset, dispersed westward over the Pacific Ocean to Australia, Malesia and the Indian Ocean (Manns and Bremer 2010, Manns et al. 2012). Timonius thus has a different biogeographic history and entered Malesia from the east

In subfamily Ixoroideae, Augusteae diverged from the remainder of the Coffeeae alliance (except the earlier-diverging Airospermeae) during the Oligocene and split into the two genera Augusta (two species in Melanesia, two in the Neotropics) and Wendlandia (Kainulainen et al. 2017). Wendlandia is widely distributed in the Paleotropics from Ethiopia to Australia and most of its species occur in China and continental Southeast Asia, while there are only three species in New Guinea, five in Australia, and none in the Pacific (WCSP 2019). In addition, species occurring in Malesia appear nested between those from continental Asia (Kainulainen et al. 2013), so we assume a Miocene colonisation of Malesia from Southeast Asia.

The remaining genera of our dataset in the Coffeeae alliance belong to different tribes but their ancestors all diversified in Southeast Asia during the Late Miocene to Pliocene after having diverged from African ancestors in the (Mid- to) Late Miocene (Kainulainen et al. 2017). They are Discospermum and Diplospora in Coffeeae, Hypobathrum in Octotropidae, Tarenna in Pavetteae, and Aidia, Gardenia, Porderandia, Randia, and Rothmannia in Gardenieae. The species from Borneo and the Philippines originally determined as Randia are also placed here. Asian and Malesian members of 'Randia' have been transferred to a number of other genera, which, however, all fall into the Coffeeae alliance.

Generic limits in Vanguerieae have been in constant flux over the last decades, with a major trend being the disintegration of large, paraphyletic Canthium, and placement of Malesian members of Vanguerieae in Canthium subgenus Canthium (including Meyna), Psydrax, Cyclophyllum and Pyrostria (WCSP 2019). Specifically, the Bornean specimens originally determined as Canthium sp. could belong to Psydrax (Bridson 1985), Cyclophyllum (Bridson 1987, Razafimandimbison et al. 2009), or Pyrostria (Alejandro et al. 2014). Psydrax and the dioecious group of Vanguerieae (including Cyclophyllum and Pyrostria) diverged from an African clade (Keetia and Afrocanthium) in the Mid- to Late Miocene, and have a mainly African and Malagasy distribution. The Asian taxa all appear in derived positions, indicating recent (Late Miocene or later) dispersal from Africa to Asia and Malesia with subsequent diversification (Verstraete et al. 2017).

Lasiantheae originated in the Neotropics and reached Eurasia by boreotropical migration or transatlantic long-distance dispersal in the Eocene. After the split-off of African and Neotropical species, Lasianthus quickly diversified in tropical Asia from the beginning of the Neogene (Smedmark et al. 2014). Likewise, Urophyllum split from its African sister group in the early Oligocene, as the Eurasian boreotropical forest belt broke up into an African and East Asian 
portion. In the early Miocene, the genus diversified and spread into Malesia (Smedmark et al. 2010).

The Psychotria species from our dataset belong to the Afro-Asian-WIOR Psychotria lineage, which originated in Africa in the Early Miocene. It is not clear, whether there were two independent colonisations of Asia from Africa in this clade, or only one with later back-dispersal to Africa. Regardless, the ancestral lineage of our Psychotria species reached tropical Asia from Africa in the Mid-Miocene and further diversified from there (Razafimandimbison et al. 2017).

\section{Gentianaceae (Asian)}

The genera in our dataset all belong to a clade (Fagraea s.l.) which diverged from its closest relatives, Neotropical Potalia and African-Malagasy Anthocleista in the Early Miocene and started to diversify in the Mid-Miocene (ca $10 \mathrm{Ma}$; Merckx et al. 2013). A former boreotropical connection between the genera has been suggested, but long-distance dispersal is also an option (Frasier 2008). In any case, the clade is most species rich in Sundaland and all species occurring east of Wallace's line are nested among congeners from further west (Sugumaran and Wong 2012), indicating recent colonisation of Malesia from Southeast Asia.

\section{Loganiaceae (mixed)}

Geniostoma diverged ca $20 \mathrm{Ma}$ from its sister clade, comprising the Australian Orianthera and cosmopolitan Mitreola (Foster et al. 2014). Geniostoma apparently underwent a rapid radiation in the Pacific Ocean, especially in New Caledonia and Melanesia in the last 10 My (Foster et al. 2014) and one species spread further westward into Malesia (Conn 1980).

Norrisia belongs to Antonieae, a small pantropical tribe of four genera that split from the rest of Loganiaceae $>40 \mathrm{Ma}$ (Frasier 2008, Foster et al. 2014). The other genera of Antonieae occur in the Neotropics (Antonia, Bonyunia) and tropical Africa (Tropicos 2015). Relationships within the tribe are not entirely clear, but one or both of the Old World genera (Norrisia, Usteria) are sister to the Neotropical members (Frasier 2008, Yang et al. 2016). Although there are no age estimates for the internal phylogeny of Antonieae, the distribution pattern suggests a former boreotropical distribution of the clade. Furthermore, Norrisia only occurs in Sundaland and the Philippines, so it is reasonable to assume an Asian origin of the genus.

\section{Apocynaceae (mixed)}

Alstonia and Dyera together form the tribe Alstonieae, after the Neotropical Aspidospermateae sister to all remaining Apocynaceae (Simões et al. 2007). Dyera is restricted to Sundaland, while Alstonia has a wide paleotropical distribution from tropical Africa to the Pacific, with centres of diversity in continental Southeast Asia and Sundaland and on New Caledonia (WCSP 2019). Based on the sister relationship with Dyera from Sundaland and the geographic diversity pattern of Alstonia, we assume an Asian origin of both genera.

Ochrosia split from the remainder of tribe Vinceae (except Kopsia) in the Late Eocene, ca $37 \mathrm{Ma}$, and started to diversify in the Late Oligocene (ca 25 Ma; Morokawa 2014). The genus is most 
species rich in Papuasia and the tropical West Pacific, has no endemic species in continental Asia or Sundaland (WCSP 2019), and the species occurring in other regions are nested among those from Papuasia and the West Pacific (Morokawa 2014), clearly indicating an Australasian origin of Ochrosia.

Tabernaemontana is a large, pantropical genus that diverged from its mostly African sister clade in the Mid Oligocene (ca $26 \mathrm{Ma}$ ) and started to diversify shortly afterwards (Early Miocene, 22 Ma; Morokawa 2014). First, the genus split into a Neotropical and a Paleotropical clade. From the latter, the Malagasy members separated ca 14 Ma followed by a divergence of African and Asian populations (ca $13 \mathrm{Ma}$ ). The topology and divergence times suggest an Asian origin of Paleotropical Tabernaemontana or an African origin and later dispersal to Malesia via Asia. They rule out an Australian origin and the latter is also unlikely because only one widely distributed member of the genus occurs in Australia (WCSP 2019).

Kibatalia belongs to the pantropical tribe Malouetieae and its successive sister groups are African Funtumia and Malouetia from tropical Africa and tropical South America (Livshultz et al. 2007). The genus itself is distributed from continental Southeast Asia to Sulawesi and most species occur in Sundaland and the Philippines (WCSP 2019). Since the whole tribe includes no Australian taxa and because of Kibatalia's distribution pattern, we assume an Asian origin.

\section{Boraginaceae (Ehretiaceae, Asian)}

Ehretia javanica, the only Malesian member of the otherwise Asian Ehretia III-clade of was inferred to have colonised Malesia from Asia (Gottschling and Hilger 2004).

\section{Oleaceae (Asian)}

Most species of Ligustrum occur in Asia, with only seven spreading into Malesia and one barely reaching North Australia (WCSP 2019). The genus is nested within Syringa (Li et al. 2002) and diverged from East Asian lineages of Syringa in the middle Miocene, ca 12 Ma (Li et al. 2012).

Neither Chionanthus nor Olea are monophyletic, but rather intermingled together with several other genera (e.g. Osmanthus, Olea, Noronhia, Nestegis, Notelaea, Phillyraea) in the subtribe Oleinae. The subtribe has a near worldwide distribution (WCSP 2019) but most species occur in Eurasia. The only Australian / Pacific genera, Nestegis and Notelaea, split from Eurasian sister lineages less than $15 \mathrm{Ma}$ (Wallander and Albert 2000, Hong-Wa and Besnard 2013), so despite the unsettled taxonomy, species of Chionanthus and Olea are here considered to be of Asian origin. More specifically, the species of Olea in our dataset belong to subgen. Tetrapilus, a monophyletic group present in Asia to central Malesia (Green 2002) which diverged from other Eurasian taxa ca $25 \mathrm{Ma}$ (Besnard et al. 2009). The Asian and Malesian members of Chionanthus, though sparsely sampled, were resolved as sister to a clade of North American congeners, diverging ca $25 \mathrm{Ma}$ (Hong-Wa and Besnard 2013). 


\section{Bignoniaceae (Asian)}

Radermachera belongs to the Paleotropical clade of Bignoniaceae, which diverged from the Neotropical Tabebuia alliance. Its closest relatives are the monotypic Tecomella from dry areas in India and Pakistan and then a group of African taxa from dry habitats (Olmstead et al. 2009). The genus occurs from India to Wallacea and is most species-rich in continental Southeast Asia, with only two species crossing Wallace's line (van Steenis 1977). The phylogenetic topology suggests an origin of the clade in Asia or Africa and recent colonisation of Malesia from Southeast Asia.

\section{Lamiaceae (Asian)}

Callicarpa, together with the Australian endemic subfamily Prosteranthoideae forms the sister clade to all remaining Lamiaceae (Li et al. 2016). However, species from East Malesia and Australia appear in derived positions in the phylogeny of Callicarpa (Li et al. 2016) and the genus is most species rich in Sundaland and continental Asia with much fewer species in Papuasia and Australia (WCSP 2019), so we assume an Asian origin.

The Malesian forest species of Clerodendrum (subfamily Ajugoideae) belong to the 'Asian' clade, which is sister to the rest of the genus from tropical Africa (Yuan et al. 2010). Within the 'Asian' clade, most species occur in Sundaland and continental Asia with a sharp decline in species richness towards the east (WCSP 2019) and fossils of Ajugoideae have been found from the Oligocene of Europe (Harley et al. 2004), so we assume an Asian origin of Clerodendrum.

Teijsmanniodendron is probably nested within Vitex (together with the Caribbean Petitia and Pseudocarpidium), forming the pantropical subfamily Viticoideae, sister to Symphoremoideae (Li et al. 2016). Vitex s.l. is most species rich in tropical Africa, followed by the Neotropics and tropical Asia (WCSP 2019). Within tropical Asia, the genus is most diverse in continental Southeast Asia and Sundaland with only a few species occurring east of Wallace's line (WCSP 2019) suggesting a boreotropical origin of the genus and colonisation of Malesia by Asian lineages.

\section{Stemonuraceae (Australian)}

Stemonuraceae, represented in our dataset by Gomphandra, Medusanthera, and Stemonurus, is of Australasian origin and diversified ca $20 \mathrm{Ma}$ (Beaulieu et al. 2013). Medusanthera and Stemonurus, although not sampled by Beaulieu et al. (2013), must have arisen from Australian ancestors due to the overall young age of the family.

\section{Cardiopteridaceae (Australian)}

According to the phylogeographic study of Beaulieu et al. (2013), Cardiopteridaceae originated around $55 \mathrm{Ma}$ in Australasia. All genera were resolved to have Australasian descent: Citronella diverged first, Gonocaryum and Cardiopteris split later (ca $40 \mathrm{Ma}$ ). 


\section{Aquifoliaceae (Asian)}

Extant species of /lex stem from a Miocene radiation starting in East Asia ca $15 \mathrm{Ma}$, and all Malesian species, as well as those occurring further east (Australia, New Caledonia), represent derived Asian lineages. /lex pollen records from the Oligocene of Australia (Martin 1977) are doubtful (Manen et al. 2002).

\section{Asteraceae (Asian)}

Strobocalyx, together with Tarlmounia, probably arrived in the region via long-distance dispersal from America less than ca $15 \mathrm{Ma}$, as indicated by the pair's closest relatives, which are all American (Keeley et al. 2007). Although from the phylogeny it is not clear, where exactly it first established, we take the occurrence of the monotypic sister genus Tarlmounia, endemic to continental S and SE Asia, as indication that Strobocalyx colonised Malesia from Asia.

\section{Escalloniaceae (Australian)}

Polyosma, the only genus of Escalloniaceae in our data, is an old genus (ca 70 My stem age) and, as the rest of the family has an Australasian origin (Beaulieu et al. 2013).

\section{Paracryphiaceae (Australian)}

Paracryphiaceae, present in our dataset with Quintinia and Sphenostemon, are an old family (ca 95 My) with Australasian origin (Beaulieu et al. 2013) and a present distribution from New Caledonia and Australia to Central Malesia (Sulawesi and the Philippines). Since in Malesia it is only present in mountain habitats, and since Central and East Malesian mountains only started to form recently ( $\leq 10 \mathrm{Ma}$; Hall 2012), we consider this family a recent immigrant from Australia.

\section{Adoxaceae (Asian)}

The family is centred in Laurasia; only Viburnum occurs in our dataset. Viburnum originated in tropical lowland forests of SE-Asia in the Oligocene and the Malesian species belong to several distinct lineages (Spriggs et al. 2015).

\section{Pittosporaceae (Australian)}

Pittosporaceae originated in the Mid Miocene of Australasia (Beaulieu et al. 2013), and six of its nine genera are endemic to Australia today (Bakker and van Steenis 1957). Within Pittosporum, which is present in our data, many basal lineages are Australian indicating multiple dispersal out of Australia into the adjacent regions Indian Ocean, Malesia, and SW Pacific (Chandler et al. 2007).

\section{Araliaceae (mixed)}

Araliaceae originated in Australia or Southeast Asia, probably in the Mid Eocene (Beaulieu et al. 2013). The genera of our dataset belong to two different groups, all in subfamily Aralioideae:

Aralia bipinnata belongs to Aralia section Dimorphanthus, which originated in Laurasia where it was present in Early Tertiary boreotropical forests (Wen 2000). The Asian and North American members of the section split in the Late Eocene to Late Oligocene (Valcárcel et al. 2014, Zuo et 
al. 2017) probably due to climatic cooling and the Malesian members are derived from continental Asian lineages.

The Asian Palmatae group of Araliaceae, containing the genera Macropanax, Trevesia, and Schefflera (the latter wildly polyphyletic, but the Asian members belong here) from our dataset, originated in Southeast Asia in the Late Cretaceous or Paleocene (Li and Wen 2014, Valcárcel et al. 2014). Temporal estimates for the diversification of the genera vary between studies, but all retrieve Southeast Asia as area of origin and dispersal of single lineages to East Malesia since the Miocene (Li and Wen 2014, Valcárcel et al. 2014, Zuo et al. 2017).

Polyscias is a large genus, which originated in Australasia (Nicolas and Plunkett 2014). All but one of our species belong to subgenus Arthrophyllum, distributed from continental Southeast Asia to Australia and Caledonia. Within the subgenus, the Malesian species all appear in derived positions and the basal clades are all Australian (Plunkett and Lowry 2010), indicating that Polyscias subgenus Arthrophyllum originated in Australia. P. nodosa, the sole member of subgenus Eupteron, is distributed from Java to the Solomon Islands (Philipson 1979). It diverged from a large clade distributed from Africa to Polynesia in the late Eocene (ca $39 \mathrm{Ma}$; Plunkett and Lowry 2010, Zuo et al. 2017). Together, they are sister to subgenus Tieghemopanax, which is centred in Melanesia, especially New Caledonia (Plunkett and Lowry 2010). The wide distribution of the sister group of $P$. nodosa makes the biogeographic interpretation difficult, but the fact that the large sister group does not include a single species from continental Asia, as well as the nested position among Melanesian taxa points to an Australian origin of $P$. nodosa. 


\section{Appendix 5.3 Tree species with assigned geographic origin}

Tree species used for the analysis with their geographic origin, applied classification methods, and references (see Appendix 5.1). distr. = geographic distribution, phyl. = phylogenetic analysis, phylogeogr. $=$ phylogeographic analysis.

\begin{tabular}{|c|c|c|c|c|c|}
\hline No & Family & Species & Origin & $\begin{array}{l}\text { Classification } \\
\text { method }\end{array}$ & References \\
\hline \multicolumn{6}{|c|}{ Gymnosperms } \\
\hline 11 & Gnetaceae & $\begin{array}{l}\text { Gnetum cuspidatum } \\
\text { Blume }\end{array}$ & Asian & phylogeogr. & Won et al. 2006 \\
\hline 12 & & Gnetum gnemon L. & Asian & phylogeogr. & Won et al. 2006 \\
\hline 13 & Araucariaceae & Agathis borneensis Warb. & Austr. & $\begin{array}{l}\text { dated phyl., } \\
\text { distr./fossils }\end{array}$ & $\begin{array}{l}\text { Escapa \& Catalano 2013, } \\
\text { Kershaw \& Wagstaff } 2001\end{array}$ \\
\hline 14 & & $\begin{array}{l}\text { Agathis dammara (Lamb.) } \\
\text { Rich. \& A.Rich. }\end{array}$ & Austr. & $\begin{array}{l}\text { dated phyl., } \\
\text { distr./fossils }\end{array}$ & $\begin{array}{l}\text { Escapa \& Catalano 2013, } \\
\text { Kershaw \& Wagstaff } 2001\end{array}$ \\
\hline 15 & & $\begin{array}{l}\text { Agathis kinabaluensis de } \\
\text { Laub. }\end{array}$ & Austr. & $\begin{array}{l}\text { dated phyl., } \\
\text { distr./fossils }\end{array}$ & $\begin{array}{l}\text { Escapa \& Catalano 2013, } \\
\text { Kershaw \& Wagstaff } 2001\end{array}$ \\
\hline 16 & Podocarpaceae & $\begin{array}{l}\text { Dacrycarpus cinctus (Pilg.) } \\
\text { de Laub. }\end{array}$ & Austr. & phylogeogr. & $\begin{array}{l}\text { Biffin et al. 2011, Knopf } \\
\text { et al. } 2012\end{array}$ \\
\hline 17 & & $\begin{array}{l}\text { Dacrycarpus cumingii } \\
\text { (Parl.) de Laub. }\end{array}$ & Austr. & phylogeogr. & $\begin{array}{l}\text { Biffin et al. 2011, Knopf } \\
\text { et al. } 2012\end{array}$ \\
\hline 18 & & Dacrydium gibbsiae Stapf & Austr. & phylogeogr. & $\begin{array}{l}\text { Biffin et al. 2011, Knopf } \\
\text { et al. } 2012\end{array}$ \\
\hline 19 & & $\begin{array}{l}\text { Dacrycarpus imbricatus } \\
\text { (Blume) de Laub. }\end{array}$ & Austr. & phylogeogr. & $\begin{array}{l}\text { Biffin et al. 2011, Knopf } \\
\text { et al. } 2012\end{array}$ \\
\hline 20 & & $\begin{array}{l}\text { Dacrycarpus } \\
\text { kinabaluensis (Wasscher) } \\
\text { de Laub. }\end{array}$ & Austr. & phylogeogr. & $\begin{array}{l}\text { Biffin et al. 2011, Knopf } \\
\text { et al. } 2012\end{array}$ \\
\hline 21 & & $\begin{array}{l}\text { Dacrydium pectinatum de } \\
\text { Laub. }\end{array}$ & Austr. & phylogeogr. & $\begin{array}{l}\text { Biffin et al. 2011, Knopf } \\
\text { et al. } 2012\end{array}$ \\
\hline 22 & & $\begin{array}{l}\text { Falcatifolium falciforme } \\
\text { (Parl.) de Laub. }\end{array}$ & Austr. & phylogeogr. & $\begin{array}{l}\text { Biffin et al. 2011, Knopf } \\
\text { et al. } 2012\end{array}$ \\
\hline 23 & & $\begin{array}{l}\text { Phyllocladus hypophyllus } \\
\text { Hook.f. }\end{array}$ & Austr. & phylogeogr. & Wagstaff 2004 \\
\hline 24 & & $\begin{array}{l}\text { Podocarpus gibbsii } \\
\text { N.E.Gray }\end{array}$ & Austr. & phylogeogr. & $\begin{array}{l}\text { Knopf et al. 2012, } \\
\text { Quiroga et al. } 2016\end{array}$ \\
\hline 25 & & $\begin{array}{l}\text { Podocarpus neriifolius } \\
\text { D.Don }\end{array}$ & Austr. & phylogeogr. & $\begin{array}{l}\text { Knopf et al. 2012, } \\
\text { Quiroga et al. } 2016\end{array}$ \\
\hline 26 & & Podocarpus pilgeri Foxw. & Austr. & phylogeogr. & $\begin{array}{l}\text { Knopf et al. 2012, } \\
\text { Quiroga et al. } 2016\end{array}$ \\
\hline 27 & & $\begin{array}{l}\text { Podocarpus ramosii } \\
\text { R.R.Mill }\end{array}$ & Austr. & phylogeogr. & $\begin{array}{l}\text { Knopf et al. 2012, } \\
\text { Quiroga et al. } 2016\end{array}$ \\
\hline 28 & & $\begin{array}{l}\text { Podocarpus rumphii } \\
\text { Blume }\end{array}$ & Austr. & phylogeogr. & $\begin{array}{l}\text { Knopf et al. 2012, } \\
\text { Quiroga et al. } 2016\end{array}$ \\
\hline 29 & & Podocarpus sp. & Austr. & phylogeogr. & $\begin{array}{l}\text { Knopf et al. 2012, } \\
\text { Quiroga et al. } 2016\end{array}$ \\
\hline 30 & Taxaceae & $\begin{array}{l}\text { Taxus sumatrana (Miq.) } \\
\text { de Laub. }\end{array}$ & Asian & $\begin{array}{l}\text { dated phyl., } \\
\text { distr./fossils }\end{array}$ & $\begin{array}{l}\text { Farjon 2010, Leslie et al. } \\
\text { 2012, Liu et al. } 2011\end{array}$ \\
\hline
\end{tabular}




\begin{tabular}{|c|c|c|c|c|c|}
\hline No & Family & Species & Origin & $\begin{array}{l}\text { Classification } \\
\text { method }\end{array}$ & References \\
\hline \multicolumn{6}{|c|}{ Angiosperms } \\
\hline 31 & Achariaceae & $\begin{array}{l}\text { Hydnocarpus borneensis } \\
\text { Sleumer }\end{array}$ & Asian & $\begin{array}{l}\text { undated phyl., } \\
\text { distr./fossils }\end{array}$ & $\begin{array}{l}\text { Chase et al. } 2002, \\
\text { Sleumer } 1954\end{array}$ \\
\hline 32 & & $\begin{array}{l}\text { Hydnocarpus pinguis } \\
\text { Sleumer }\end{array}$ & Asian & $\begin{array}{l}\text { undated phyl., } \\
\text { distr./fossils }\end{array}$ & $\begin{array}{l}\text { Chase et al. 2002, } \\
\text { Sleumer } 1954\end{array}$ \\
\hline 33 & & Hydnocarpus sp.1 & Asian & $\begin{array}{l}\text { undated phyl., } \\
\text { distr./fossils }\end{array}$ & $\begin{array}{l}\text { Chase et al. 2002, } \\
\text { Sleumer } 1954\end{array}$ \\
\hline 34 & & Hydnocarpus sp.2 & Asian & $\begin{array}{l}\text { undated phyl., } \\
\text { distr./fossils }\end{array}$ & $\begin{array}{l}\text { Chase et al. } 2002, \\
\text { Sleumer } 1954\end{array}$ \\
\hline 35 & & Hydnocarpus sp.3 & Asian & $\begin{array}{l}\text { undated phyl., } \\
\text { distr./fossils }\end{array}$ & $\begin{array}{l}\text { Chase et al. } 2002, \\
\text { Sleumer } 1954\end{array}$ \\
\hline 36 & & $\begin{array}{l}\text { Hydnocarpus sumatranus } \\
\text { (Miq.) Koord. }\end{array}$ & Asian & $\begin{array}{l}\text { undated phyl., } \\
\text { distr./fossils }\end{array}$ & $\begin{array}{l}\text { Chase et al. 2002, } \\
\text { Sleumer } 1954\end{array}$ \\
\hline 37 & & $\begin{array}{l}\text { Hydnocarpus tenuipetalus } \\
\text { Sleumer }\end{array}$ & Asian & $\begin{array}{l}\text { undated phyl., } \\
\text { distr./fossils }\end{array}$ & $\begin{array}{l}\text { Chase et al. } 2002, \\
\text { Sleumer } 1954\end{array}$ \\
\hline 38 & & $\begin{array}{l}\text { Hydnocarpus woodii } \\
\text { Merr. }\end{array}$ & Asian & $\begin{array}{l}\text { undated phyl., } \\
\text { distr./fossils }\end{array}$ & $\begin{array}{l}\text { Chase et al. } 2002, \\
\text { Sleumer } 1954\end{array}$ \\
\hline 39 & & $\begin{array}{l}\text { Ryparosa baccaureoides } \\
\text { Sleumer }\end{array}$ & Asian & $\begin{array}{l}\text { undated phyl., } \\
\text { distr./fossils }\end{array}$ & $\begin{array}{l}\text { Chase et al. } 2002, \\
\text { Sleumer } 1954\end{array}$ \\
\hline 40 & & Ryparosa caesia Blume & Asian & $\begin{array}{l}\text { undated phyl., } \\
\text { distr./fossils }\end{array}$ & $\begin{array}{l}\text { Chase et al. } 2002, \\
\text { Sleumer } 1954\end{array}$ \\
\hline 41 & & $\begin{array}{l}\text { Ryparosa kostermansii } \\
\text { Sleumer }\end{array}$ & Asian & $\begin{array}{l}\text { undated phyl., } \\
\text { distr./fossils }\end{array}$ & $\begin{array}{l}\text { Chase et al. } 2002, \\
\text { Sleumer } 1954\end{array}$ \\
\hline 42 & & $\begin{array}{l}\text { Trichadenia philippinensis } \\
\text { Merr. }\end{array}$ & Asian & $\begin{array}{l}\text { undated phyl., } \\
\text { distr./fossils }\end{array}$ & $\begin{array}{l}\text { Chase et al. } 2002, \\
\text { Sleumer } 1954\end{array}$ \\
\hline 43 & Actinidiaceae & Saurauia bracteosa DC. & Asian & distr./fossils & $\begin{array}{l}\text { Dressler \& Bayer 2004, } \\
\text { Soejarto } 1980\end{array}$ \\
\hline 44 & & $\begin{array}{l}\text { Saurauia javanica (Nees) } \\
\text { Hoogland }\end{array}$ & Asian & distr./fossils & $\begin{array}{l}\text { Dressler \& Bayer 2004, } \\
\text { Soejarto } 1980\end{array}$ \\
\hline 45 & & $\begin{array}{l}\text { Saurauia latibractea } \\
\text { Choisy }\end{array}$ & Asian & distr./fossils & $\begin{array}{l}\text { Dressler \& Bayer 2004, } \\
\text { Soejarto } 1980\end{array}$ \\
\hline 46 & & $\begin{array}{l}\text { Saurauia microphylla de } \\
\text { Vriese }\end{array}$ & Asian & distr./fossils & $\begin{array}{l}\text { Dressler \& Bayer 2004, } \\
\text { Soejarto } 1980\end{array}$ \\
\hline 47 & & Saurauia nudiflora DC. & Asian & distr./fossils & $\begin{array}{l}\text { Dressler \& Bayer 2004, } \\
\text { Soejarto } 1980\end{array}$ \\
\hline 48 & & Saurauia pendula Blume & Asian & distr./fossils & $\begin{array}{l}\text { Dressler \& Bayer 2004, } \\
\text { Soejarto } 1980\end{array}$ \\
\hline 49 & & $\begin{array}{l}\text { Saurauia polysperma } \\
\text { (Blanco) Merr. }\end{array}$ & Asian & distr./fossils & $\begin{array}{l}\text { Dressler \& Bayer 2004, } \\
\text { Soejarto } 1980\end{array}$ \\
\hline 50 & & Saurauia sp. & Asian & distr./fossils & $\begin{array}{l}\text { Dressler \& Bayer 2004, } \\
\text { Soejarto } 1980\end{array}$ \\
\hline 51 & & $\begin{array}{l}\text { Saurauia subcordata } \\
\text { Korth. }\end{array}$ & Asian & distr./fossils & $\begin{array}{l}\text { Dressler \& Bayer 2004, } \\
\text { Soejarto } 1980\end{array}$ \\
\hline 52 & Adoxaceae & $\begin{array}{l}\text { Viburnum coriaceum } \\
\text { Blume }\end{array}$ & Asian & phylogeogr. & Spriggs et al. 2015 \\
\hline 53 & & $\begin{array}{l}\text { Viburnum hispidulum } \\
\text { J.Kern }\end{array}$ & Asian & phylogeogr. & Spriggs et al. 2015 \\
\hline
\end{tabular}




\begin{tabular}{|c|c|c|c|c|c|}
\hline No & Family & Species & Origin & $\begin{array}{l}\text { Classification } \\
\text { method }\end{array}$ & References \\
\hline 54 & & $\begin{array}{l}\text { Viburnum lutescens } \\
\text { Blume }\end{array}$ & Asian & phylogeogr. & Spriggs et al. 2015 \\
\hline 55 & & $\begin{array}{l}\text { Viburnum sambucinum } \\
\text { Blume }\end{array}$ & Asian & phylogeogr. & Spriggs et al. 2015 \\
\hline 56 & Altingiaceae & $\begin{array}{l}\text { Liquidambar excelsa } \\
\text { (Noronha) Oken }\end{array}$ & Asian & phylogeogr. & Ickert-Bond \& Wen 2006 \\
\hline 57 & Anacardiaceae & Anacardiaceae sp.1 & Asian & phylogeogr. & Weeks et al. 2014 \\
\hline 58 & & Anacardiaceae sp.2 & Asian & phylogeogr. & Weeks et al. 2014 \\
\hline 59 & & $\begin{array}{l}\text { Buchanania arborescens } \\
\text { (Blume) Blume }\end{array}$ & Asian & phylogeogr. & Weeks et al. 2014 \\
\hline 60 & & $\begin{array}{l}\text { Buchanania insignis } \\
\text { Blume }\end{array}$ & Asian & phylogeogr. & Weeks et al. 2014 \\
\hline 61 & & $\begin{array}{l}\text { Buchanania aff. sessilifolia } \\
\text { Blume }\end{array}$ & Asian & phylogeogr. & Weeks et al. 2014 \\
\hline 62 & & $\begin{array}{l}\text { Dracontomelon dao } \\
\text { (Blanco) Merr. \& Rolfe }\end{array}$ & Asian & phylogeogr. & Weeks et al. 2014 \\
\hline 63 & & Gluta laxiflora Ridl. & Asian & phylogeogr. & Weeks et al. 2014 \\
\hline 64 & & $\begin{array}{l}\text { Gluta oba (Merr.) Ding } \\
\text { Hou }\end{array}$ & Asian & phylogeogr. & Weeks et al. 2014 \\
\hline 65 & & Gluta sabahana Ding Hou & Asian & phylogeogr. & Weeks et al. 2014 \\
\hline 66 & & Gluta sp.1 & Asian & phylogeogr. & Weeks et al. 2014 \\
\hline 67 & & Gluta sp.2 & Asian & phylogeogr. & Weeks et al. 2014 \\
\hline 68 & & $\begin{array}{l}\text { Gluta wallichii (Hook.f.) } \\
\text { Ding Hou }\end{array}$ & Asian & phylogeogr. & Weeks et al. 2014 \\
\hline 69 & & $\begin{array}{l}\text { Koordersiodendron } \\
\text { pinnatum Merr. }\end{array}$ & Asian & phylogeogr. & Weeks et al. 2014 \\
\hline 70 & & Mangifera foetida Lour. & Asian & phylogeogr. & Weeks et al. 2014 \\
\hline 71 & & Mangifera laurina Blume & Asian & phylogeogr. & Weeks et al. 2014 \\
\hline 72 & & $\begin{array}{l}\text { Mangifera swintoniodes } \\
\text { Kosterm. }\end{array}$ & Asian & phylogeogr. & Weeks et al. 2014 \\
\hline 73 & & $\begin{array}{l}\text { Melanochyla beccariana } \\
\text { Oliv. }\end{array}$ & Asian & phylogeogr. & Weeks et al. 2014 \\
\hline 74 & & $\begin{array}{l}\text { Melanochyla bracteata } \\
\text { King }\end{array}$ & Asian & phylogeogr. & Weeks et al. 2014 \\
\hline 75 & & $\begin{array}{l}\text { Melanochyla caesia } \\
\text { (Blume) Ding Hou }\end{array}$ & Asian & phylogeogr. & Weeks et al. 2014 \\
\hline 76 & & Melanochyla elmeri Merr. & Asian & phylogeogr. & Weeks et al. 2014 \\
\hline 77 & & Parishia maingayi Hook.f. & Asian & phylogeogr. & Weeks et al. 2014 \\
\hline 78 & & $\begin{array}{l}\text { Semecarpus forstenii } \\
\text { Blume }\end{array}$ & Asian & phylogeogr. & Weeks et al. 2014 \\
\hline 79 & & $\begin{array}{l}\text { Semecarpus glauciphylla } \\
\text { Elmer }\end{array}$ & Asian & phylogeogr. & Weeks et al. 2014 \\
\hline 80 & & $\begin{array}{l}\text { Semecarpus heterophylla } \\
\text { Blume }\end{array}$ & Asian & phylogeogr. & Weeks et al. 2014 \\
\hline 81 & & $\begin{array}{l}\text { Semecarpus rufovelutina } \\
\text { Ridl. }\end{array}$ & Asian & phylogeogr. & Weeks et al. 2014 \\
\hline 82 & & Semecarpus sp.1 & Asian & phylogeogr. & Weeks et al. 2014 \\
\hline 83 & & Semecarpus sp.2 & Asian & phylogeogr. & Weeks et al. 2014 \\
\hline
\end{tabular}




\begin{tabular}{|c|c|c|c|c|c|}
\hline No & Family & Species & Origin & $\begin{array}{l}\text { Classification } \\
\text { method }\end{array}$ & References \\
\hline 84 & & $\begin{array}{l}\text { Swintonia foxworthyi } \\
\text { Elmer }\end{array}$ & Asian & phylogeogr. & Weeks et al. 2014 \\
\hline 85 & & Swintonia glauca Engl. & Asian & phylogeogr. & Weeks et al. 2014 \\
\hline 86 & & Swintonia sp. & Asian & phylogeogr. & Weeks et al. 2014 \\
\hline 87 & Anisophylleaceae & Anisophyllea sp. & Asian & phylogeogr. & Zhang et al. 2007 \\
\hline 88 & Annonaceae & $\begin{array}{l}\text { Alphonsea elliptica } \\
\text { Hook.f. \& Thomson }\end{array}$ & Asian & phylogeogr. & Thomas et al. 2015 \\
\hline 89 & & Alphonsea javanica Scheff. & Asian & phylogeogr. & Thomas et al. 2015 \\
\hline 90 & & $\begin{array}{l}\text { Cananga odorata (Lam.) } \\
\text { Hook.f. \& Thomson }\end{array}$ & Asian & phylogeogr. & Thomas et al. 2015 \\
\hline 91 & & Cyathocalyx sp. & Asian & phylogeogr. & Thomas et al. 2015 \\
\hline 92 & & $\begin{array}{l}\text { Drepananthus hexagynus } \\
\text { (Miq.) Survesw. \& } \\
\text { R.M.K.Saunders }\end{array}$ & Asian & phylogeogr. & Thomas et al. 2015 \\
\hline 93 & & $\begin{array}{l}\text { Drepananthus kingii } \\
\text { (Boerl. ex Koord.) } \\
\text { Survesw. \& } \\
\text { R.M.K.Saunders }\end{array}$ & Asian & phylogeogr. & Thomas et al. 2015 \\
\hline 94 & & $\begin{array}{l}\text { Drepananthus magnificus } \\
\text { (Diels) Survesw. \& } \\
\text { R.M.K.Saunders }\end{array}$ & Asian & phylogeogr. & Thomas et al. 2015 \\
\hline 95 & & $\begin{array}{l}\text { Fissistigma manubriatum } \\
\text { (Hook.f. \& Thomson) } \\
\text { Merr. }\end{array}$ & Asian & phylogeogr. & Thomas et al. 2015 \\
\hline 96 & & Annonaceae sp.1 & Asian & phylogeogr. & Thomas et al. 2015 \\
\hline 97 & & Annonaceae sp.2 & Asian & phylogeogr. & Thomas et al. 2015 \\
\hline 98 & & Annonaceae sp.3 & Asian & phylogeogr. & Thomas et al. 2015 \\
\hline 99 & & Annonaceae sp.4 & Asian & phylogeogr. & Thomas et al. 2015 \\
\hline 100 & & Annonaceae sp.5 & Asian & phylogeogr. & Thomas et al. 2015 \\
\hline 101 & & Annonaceae sp.6 & Asian & phylogeogr. & Thomas et al. 2015 \\
\hline 102 & & Annonaceae sp.7 & Asian & phylogeogr. & Thomas et al. 2015 \\
\hline 103 & & Annonaceae sp.8 & Asian & phylogeogr. & Thomas et al. 2015 \\
\hline 104 & & Annonaceae sp.9 & Asian & phylogeogr. & Thomas et al. 2015 \\
\hline 105 & & $\begin{array}{l}\text { Goniothalamus amuyon } \\
\text { (Blanco) Merr. }\end{array}$ & Asian & phylogeogr. & Thomas et al. 2015 \\
\hline 106 & & $\begin{array}{l}\text { Goniothalamus } \\
\text { fasciculatus Boerl. }\end{array}$ & Asian & phylogeogr. & Thomas et al. 2015 \\
\hline 107 & & $\begin{array}{l}\text { Goniothalamus } \\
\text { macrophyllus (Blume) } \\
\text { Hook.f \& Thomson }\end{array}$ & Asian & phylogeogr. & Thomas et al. 2015 \\
\hline 108 & & $\begin{array}{l}\text { Goniothalamus ridleyi } \\
\text { King }\end{array}$ & Asian & phylogeogr. & Thomas et al. 2015 \\
\hline 109 & & Goniothalamus sp.1 & Asian & phylogeogr. & Thomas et al. 2015 \\
\hline 110 & & Goniothalamus sp.nov. & Asian & phylogeogr. & Thomas et al. 2015 \\
\hline 111 & & $\begin{array}{l}\text { Haplostichanthus } \\
\text { lanceolata (S. Vidal) } \\
\text { Heusden }\end{array}$ & Asian & phylogeogr. & Thomas et al. 2015 \\
\hline
\end{tabular}




\begin{tabular}{|c|c|c|c|c|c|}
\hline No & Family & Species & Origin & $\begin{array}{l}\text { Classification } \\
\text { method }\end{array}$ & References \\
\hline 112 & & $\begin{array}{l}\text { Huberantha rumphii } \\
\text { (Blume ex Hensch.) } \\
\text { Chaowasku }\end{array}$ & Asian & phylogeogr. & Thomas et al. 2015 \\
\hline 113 & & $\begin{array}{l}\text { Maasia hypoleuca (Hook.f. } \\
\text { \& Thomson) Mols, Kessler } \\
\text { \& Rogstad }\end{array}$ & Asian & phylogeogr. & Thomas et al. 2015 \\
\hline 114 & & $\begin{array}{l}\text { Maasia sumatrana (Miq.) } \\
\text { Mols, Kessler \& Rogstad }\end{array}$ & Asian & phylogeogr. & Thomas et al. 2015 \\
\hline 115 & & $\begin{array}{l}\text { Mezzettia havilandi } \\
\text { (Boerl.) Ridl. }\end{array}$ & Asian & phylogeogr. & Thomas et al. 2015 \\
\hline 116 & & Mezzettia parviflora Becc. & Asian & phylogeogr. & Thomas et al. 2015 \\
\hline 117 & & $\begin{array}{l}\text { Mitrella kentii (Blume) } \\
\text { Miq. }\end{array}$ & Asian & phylogeogr. & Thomas et al. 2015 \\
\hline 118 & & $\begin{array}{l}\text { Mitrephora macrocarpa } \\
\text { (Miq.) Weerasooriya \& } \\
\text { R.M.K.Saunders }\end{array}$ & Asian & phylogeogr. & Thomas et al. 2015 \\
\hline 119 & & $\begin{array}{l}\text { Monocarpia } \\
\text { kalimantanensis Kessler }\end{array}$ & Asian & phylogeogr. & Thomas et al. 2015 \\
\hline 120 & & $\begin{array}{l}\text { Monoon lateriflorum } \\
\text { (Blume) Miq. }\end{array}$ & Asian & phylogeogr. & Thomas et al. 2015 \\
\hline 121 & & $\begin{array}{l}\text { Neo-uvaria } \\
\text { acuminatissima (Miq.) Airy } \\
\text { Shaw }\end{array}$ & Asian & phylogeogr. & Thomas et al. 2015 \\
\hline 122 & & Orophea hexandra Blume & Asian & phylogeogr. & Thomas et al. 2015 \\
\hline 123 & & $\begin{array}{l}\text { Phaeanthus ophthalmicus } \\
\text { (Roxb. ex G.Don) J.Sinclair }\end{array}$ & Asian & phylogeogr. & Thomas et al. 2015 \\
\hline 124 & & $\begin{array}{l}\text { Polyalthia cauliflora } \\
\text { Hook.f. \& Thomson }\end{array}$ & Asian & phylogeogr. & Thomas et al. 2015 \\
\hline 125 & & Polyalthia sp.1 & Asian & phylogeogr. & Thomas et al. 2015 \\
\hline 126 & & Polyalthia sp.2 & Asian & phylogeogr. & Thomas et al. 2015 \\
\hline 127 & & Polyalthia sp.3 & Asian & phylogeogr. & Thomas et al. 2015 \\
\hline 128 & & Polyalthia sp.4 & Asian & phylogeogr. & Thomas et al. 2015 \\
\hline 129 & & Popowia pisocarpa Endl. & Asian & phylogeogr. & Thomas et al. 2015 \\
\hline 130 & & Popowia sp. & Asian & phylogeogr. & Thomas et al. 2015 \\
\hline 131 & & Sageraea lanceolata Miq. & Asian & phylogeogr. & Thomas et al. 2015 \\
\hline 132 & & $\begin{array}{l}\text { Xylopia elliptica Maingay } \\
\text { ex Hook.f. \& Thomson }\end{array}$ & Asian & phylogeogr. & Thomas et al. 2015 \\
\hline 133 & & $\begin{array}{l}\text { Xylopia malayana Hook.f. } \\
\text { \& Thomson }\end{array}$ & Asian & phylogeogr. & Thomas et al. 2015 \\
\hline 134 & & Xylopia sp.1 & Asian & phylogeogr. & Thomas et al. 2015 \\
\hline 135 & & Xylopia sp.2 & Asian & phylogeogr. & Thomas et al. 2015 \\
\hline 136 & Apocynaceae & $\begin{array}{l}\text { Alstonia macrophylla Wall. } \\
\text { ex G.Don }\end{array}$ & Asian & $\begin{array}{l}\text { undated phyl., } \\
\text { distr./fossils }\end{array}$ & $\begin{array}{l}\text { Simões et al. 2007, WCSP } \\
2017\end{array}$ \\
\hline 137 & & Alstonia parvifolia Merr. & Asian & $\begin{array}{l}\text { undated phyl., } \\
\text { distr./fossils }\end{array}$ & $\begin{array}{l}\text { Simões et al. 2007, WCSP } \\
2017\end{array}$ \\
\hline 138 & & $\begin{array}{l}\text { Alstonia scholaris (L.) R. } \\
\mathrm{Br} \text {. }\end{array}$ & Asian & $\begin{array}{l}\text { undated phyl., } \\
\text { distr./fossils }\end{array}$ & $\begin{array}{l}\text { Simões et al. 2007, WCSP } \\
2017\end{array}$ \\
\hline
\end{tabular}




\begin{tabular}{|c|c|c|c|c|c|}
\hline No & Family & Species & Origin & $\begin{array}{l}\text { Classification } \\
\text { method }\end{array}$ & References \\
\hline 139 & & Alstonia sp.1 & Asian & $\begin{array}{l}\text { undated phyl., } \\
\text { distr./fossils }\end{array}$ & $\begin{array}{l}\text { Simões et al. 2007, WCSP } \\
2017\end{array}$ \\
\hline 140 & & Alstonia sp.2 & Asian & $\begin{array}{l}\text { undated phyl., } \\
\text { distr./fossils }\end{array}$ & $\begin{array}{l}\text { Simões et al. 2007, WCSP } \\
2017\end{array}$ \\
\hline 141 & & Alstonia sp.3 & Asian & $\begin{array}{l}\text { undated phyl., } \\
\text { distr./fossils }\end{array}$ & $\begin{array}{l}\text { Simões et al. 2007, WCSP } \\
2017\end{array}$ \\
\hline 142 & & Alstonia spectabilis R.Br. & Asian & $\begin{array}{l}\text { undated phyl., } \\
\text { distr./fossils }\end{array}$ & $\begin{array}{l}\text { Simões et al. 2007, WCSP } \\
2017\end{array}$ \\
\hline 143 & & $\begin{array}{l}\text { Dyera costulata (Miq.) } \\
\text { Hook.f. }\end{array}$ & Asian & $\begin{array}{l}\text { undated phyl., } \\
\text { distr./fossils }\end{array}$ & $\begin{array}{l}\text { Simões et al. 2007, WCSP } \\
2017\end{array}$ \\
\hline 144 & & Kibatalia sp. & Asian & $\begin{array}{l}\text { undated phyl., } \\
\text { distr./fossils }\end{array}$ & $\begin{array}{l}\text { Livshultz et al. 2007, } \\
\text { WCSP } 2017\end{array}$ \\
\hline 145 & & Ochrosia apoensis Elmer & Austr. & $\begin{array}{l}\text { phylogeogr., } \\
\text { distr./fossils }\end{array}$ & $\begin{array}{l}\text { Morokawa 2014, WCSP } \\
2017\end{array}$ \\
\hline 146 & & $\begin{array}{l}\text { Tabernaemontana } \\
\text { corymbosa Roxb. ex Wall. }\end{array}$ & Asian & $\begin{array}{l}\text { phylogeogr., } \\
\text { distr./fossils }\end{array}$ & $\begin{array}{l}\text { Morokawa 2014, WCSP } \\
2017\end{array}$ \\
\hline 147 & & $\begin{array}{l}\text { Tabernaemontana } \\
\text { macrocarpa Jack }\end{array}$ & Asian & $\begin{array}{l}\text { phylogeogr., } \\
\text { distr./fossils }\end{array}$ & $\begin{array}{l}\text { Morokawa 2014, WCSP } \\
2017\end{array}$ \\
\hline 148 & & Tabernaemontana sp. & Asian & $\begin{array}{l}\text { phylogeogr., } \\
\text { distr./fossils }\end{array}$ & $\begin{array}{l}\text { Morokawa 2014, WCSP } \\
2017\end{array}$ \\
\hline 149 & & $\begin{array}{l}\text { Tabernaemontana } \\
\text { sphaerocarpa Blume }\end{array}$ & Asian & $\begin{array}{l}\text { phylogeogr., } \\
\text { distr./fossils }\end{array}$ & $\begin{array}{l}\text { Morokawa 2014, WCSP } \\
2017\end{array}$ \\
\hline 150 & Aquifoliaceae & Ilex apoensis Elmer & Asian & phylogeogr. & Manen et al. 2010 \\
\hline 151 & & Ilex celebensis Capit. & Asian & phylogeogr. & Manen et al. 2010 \\
\hline 152 & & Ilex crenata Thunb. & Asian & phylogeogr. & Manen et al. 2010 \\
\hline 153 & & Ilex cymosa Blume & Asian & phylogeogr. & Manen et al. 2010 \\
\hline 154 & & Ilex odorata Buch.-Ham. & Asian & phylogeogr. & Manen et al. 2010 \\
\hline 155 & & Ilex oppositifolia Merr. & Asian & phylogeogr. & Manen et al. 2010 \\
\hline 156 & & Ilex sp. & Asian & phylogeogr. & Manen et al. 2010 \\
\hline 157 & & Ilex sp. nov. & Asian & phylogeogr. & Manen et al. 2010 \\
\hline 158 & & Ilex zygophylla Merr. & Asian & phylogeogr. & Manen et al. 2010 \\
\hline 159 & Araliaceae & Aralia bipinnata Blanco & Asian & phylogeogr. & $\begin{array}{l}\text { Valcárcel et al. 2014, Wen } \\
2000\end{array}$ \\
\hline 160 & & $\begin{array}{l}\text { Macropanax concinnus } \\
\text { Miq. }\end{array}$ & Asian & phylogeogr. & $\begin{array}{l}\text { Li \& Wen 2014, Valcárcel } \\
\text { et al. 2014, Zuo et al. } \\
2017\end{array}$ \\
\hline 161 & & $\begin{array}{l}\text { Macropanax dispermus } \\
\text { (Blume) Kuntze }\end{array}$ & Asian & phylogeogr. & $\begin{array}{l}\text { Li \& Wen 2014, Valcárcel } \\
\text { et al. 2014, Zuo et al. } \\
2017\end{array}$ \\
\hline 162 & & $\begin{array}{l}\text { Polyscias aherniana } \\
\text { (Merr.) Lowry \& } \\
\text { G.M.Plunkett }\end{array}$ & Austr. & $\begin{array}{l}\text { dated phyl., } \\
\text { distr./fossils }\end{array}$ & $\begin{array}{l}\text { Lowry \& Plunkett 2010, } \\
\text { Plunkett \& Lowry } 2010\end{array}$ \\
\hline 163 & & $\begin{array}{l}\text { Polyscias collina } \\
\text { (Philipson) Lowry \& } \\
\text { G.M.Plunkett }\end{array}$ & Austr. & $\begin{array}{l}\text { dated phyl., } \\
\text { distr./fossils }\end{array}$ & $\begin{array}{l}\text { Lowry \& Plunkett 2010, } \\
\text { Plunkett \& Lowry } 2010\end{array}$ \\
\hline 164 & & $\begin{array}{l}\text { Polyscias diversifolia } \\
\text { (Blume) Lowry \& } \\
\text { G.M.Plunkett }\end{array}$ & Austr. & $\begin{array}{l}\text { dated phyl., } \\
\text { distr./fossils }\end{array}$ & $\begin{array}{l}\text { Lowry \& Plunkett 2010, } \\
\text { Plunkett \& Lowry } 2010\end{array}$ \\
\hline
\end{tabular}




\begin{tabular}{|c|c|c|c|c|c|}
\hline No & Family & Species & Origin & $\begin{array}{l}\text { Classification } \\
\text { method }\end{array}$ & References \\
\hline 165 & & $\begin{array}{l}\text { Polyscias nodosa (Blume) } \\
\text { Seem. }\end{array}$ & Austr. & $\begin{array}{l}\text { dated phyl., } \\
\text { distr./fossils }\end{array}$ & $\begin{array}{l}\text { Philipson 1979, Plunkett } \\
\text { \& Lowry 2010, Zuo et al. } \\
2017\end{array}$ \\
\hline 166 & & $\begin{array}{l}\text { Schefflera divaricata } \\
\text { (Blume) Koord. }\end{array}$ & Asian & phylogeogr. & $\begin{array}{l}\text { Li \& Wen 2014, Valcárcel } \\
\text { et al. 2014, Zuo et al. } \\
2017\end{array}$ \\
\hline 167 & & $\begin{array}{l}\text { Schefflera heptaphylla (L.) } \\
\text { Frodin }\end{array}$ & Asian & phylogeogr. & $\begin{array}{l}\text { Li \& Wen 2014, Valcárcel } \\
\text { et al. 2014, Zuo et al. } \\
2017\end{array}$ \\
\hline 168 & & Trevesia sundaica Miq. & Asian & phylogeogr. & $\begin{array}{l}\text { Li \& Wen 2014, Valcárcel } \\
\text { et al. 2014, Zuo et al. } \\
2017\end{array}$ \\
\hline 169 & Araucariaceae & Agathis borneensis Warb. & Austr. & $\begin{array}{l}\text { dated phyl., } \\
\text { distr./fossils }\end{array}$ & $\begin{array}{l}\text { Escapa \& Catalano 2013, } \\
\text { Kershaw \& Wagstaff } 2001\end{array}$ \\
\hline 170 & & $\begin{array}{l}\text { Agathis dammara (Lamb.) } \\
\text { Rich. \& A.Rich. }\end{array}$ & Austr. & $\begin{array}{l}\text { dated phyl., } \\
\text { distr./fossils }\end{array}$ & $\begin{array}{l}\text { Escapa \& Catalano 2013, } \\
\text { Kershaw \& Wagstaff } 2001\end{array}$ \\
\hline 171 & & $\begin{array}{l}\text { Agathis kinabaluensis de } \\
\text { Laub. }\end{array}$ & Austr. & $\begin{array}{l}\text { dated phyl., } \\
\text { distr./fossils }\end{array}$ & $\begin{array}{l}\text { Escapa \& Catalano 2013, } \\
\text { Kershaw \& Wagstaff } 2001\end{array}$ \\
\hline 172 & Arecaceae & Areca sp.nov. & Asian & phylogeogr. & Baker \& Couvreur 2013 \\
\hline 173 & & Caryota rumphiana Mart. & Asian & phylogeogr. & Baker \& Couvreur 2013 \\
\hline 174 & & $\begin{array}{l}\text { Oncosperma horridum } \\
\text { (Griff.) Scheff. }\end{array}$ & Asian & phylogeogr. & Baker \& Couvreur 2013 \\
\hline 175 & & Pinanga caesia Blume & Asian & phylogeogr. & Baker \& Couvreur 2013 \\
\hline 176 & & $\begin{array}{l}\text { Pinanga rumphiana } \\
\text { (Mart.) J.Dransf. \& } \\
\text { Govaerts }\end{array}$ & Asian & phylogeogr. & Baker \& Couvreur 2013 \\
\hline 177 & Asparagaceae & $\begin{array}{l}\text { Dracaena angustifolia } \\
\text { (Medik.) Roxb. }\end{array}$ & Asian & phylogeogr. & Lu \& Morden 2014 \\
\hline 178 & & $\begin{array}{l}\text { Dracaena borneensis } \\
\text { (Merr.) Jankalski }\end{array}$ & Asian & phylogeogr. & Lu \& Morden 2014 \\
\hline 179 & Asteraceae & $\begin{array}{l}\text { Strobocalyx arborea } \\
\text { (Buch.-Ham.) Sch.Bip. }\end{array}$ & Asian & dated phyl. & Keeley et al. 2007 \\
\hline 180 & Bignoniaceae & $\begin{array}{l}\text { Radermachera gigantea } \\
\text { (BI.) Miq. }\end{array}$ & Asian & $\begin{array}{l}\text { undated phyl., } \\
\text { distr./fossils }\end{array}$ & $\begin{array}{l}\text { Olmstead 2013, van } \\
\text { Steenis } 1977\end{array}$ \\
\hline 181 & Burseraceae & Burseraceae sp.1 & Asian & phylogeogr. & $\begin{array}{l}\text { Federman et al. 2015, } \\
\text { Weeks et al. } 2014\end{array}$ \\
\hline 182 & & Burseraceae sp.2 & Asian & phylogeogr. & $\begin{array}{l}\text { Federman et al. } 2015 \text {, } \\
\text { Weeks et al. } 2014\end{array}$ \\
\hline 183 & & Burseraceae sp.3 & Asian & phylogeogr. & $\begin{array}{l}\text { Federman et al. } 2015 \text {, } \\
\text { Weeks et al. } 2014\end{array}$ \\
\hline 184 & & Canarium asperum Benth. & Asian & phylogeogr. & $\begin{array}{l}\text { Federman et al. 2015, } \\
\text { Weeks et al. } 2014\end{array}$ \\
\hline 185 & & $\begin{array}{l}\text { Canarium balsamiferum } \\
\text { Willd. }\end{array}$ & Asian & phylogeogr. & $\begin{array}{l}\text { Federman et al. } 2015 \text {, } \\
\text { Weeks et al. } 2014\end{array}$ \\
\hline 186 & & $\begin{array}{l}\text { Canarium denticulatum } \\
\text { Blume }\end{array}$ & Asian & phylogeogr. & $\begin{array}{l}\text { Federman et al. } 2015 \text {, } \\
\text { Weeks et al. } 2014\end{array}$ \\
\hline 187 & & Canarium hirsutum Willd. & Asian & phylogeogr. & $\begin{array}{l}\text { Federman et al. } 2015 \text {, } \\
\text { Weeks et al. } 2014\end{array}$ \\
\hline
\end{tabular}




\begin{tabular}{|c|c|c|c|c|c|}
\hline No & Family & Species & Origin & $\begin{array}{l}\text { Classification } \\
\text { method }\end{array}$ & References \\
\hline 188 & & Canarium littorale Blume & Asian & phylogeogr. & $\begin{array}{l}\text { Federman et al. } 2015 \text {, } \\
\text { Weeks et al. } 2014\end{array}$ \\
\hline 189 & & $\begin{array}{l}\text { Canarium megalanthum } \\
\text { Merr. }\end{array}$ & Asian & phylogeogr. & $\begin{array}{l}\text { Federman et al. } 2015 \text {, } \\
\text { Weeks et al. } 2014\end{array}$ \\
\hline 190 & & Canarium merrillii H.J.Lam & Asian & phylogeogr. & $\begin{array}{l}\text { Federman et al. } 2015 \text {, } \\
\text { Weeks et al. } 2014\end{array}$ \\
\hline 191 & & $\begin{array}{l}\text { Canarium patentinervium } \\
\text { Miq. }\end{array}$ & Asian & phylogeogr. & $\begin{array}{l}\text { Federman et al. } 2015 \text {, } \\
\text { Weeks et al. } 2014\end{array}$ \\
\hline 192 & & Canarium sp.1 & Asian & phylogeogr. & $\begin{array}{l}\text { Federman et al. } 2015 \text {, } \\
\text { Weeks et al. } 2014\end{array}$ \\
\hline 193 & & Canarium sp.2 & Asian & phylogeogr. & $\begin{array}{l}\text { Federman et al. } 2015 \text {, } \\
\text { Weeks et al. } 2014\end{array}$ \\
\hline 194 & & Canarium sp.3 & Asian & phylogeogr. & $\begin{array}{l}\text { Federman et al. } 2015 \text {, } \\
\text { Weeks et al. } 2014\end{array}$ \\
\hline 195 & & Canarium sp.4 & Asian & phylogeogr. & $\begin{array}{l}\text { Federman et al. } 2015 \text {, } \\
\text { Weeks et al. } 2014\end{array}$ \\
\hline 196 & & Canarium sp.5 & Asian & phylogeogr. & $\begin{array}{l}\text { Federman et al. } 2015, \\
\text { Weeks et al. } 2014\end{array}$ \\
\hline 197 & & Canarium vulgare Leenh. & Asian & phylogeogr. & $\begin{array}{l}\text { Federman et al. } 2015, \\
\text { Weeks et al. } 2014\end{array}$ \\
\hline 198 & & $\begin{array}{l}\text { Dacryodes costata } \\
\text { (A.W.Benn.) H.J.Lam }\end{array}$ & Asian & phylogeogr. & $\begin{array}{l}\text { Federman et al. } 2015 \text {, } \\
\text { Weeks et al. } 2014\end{array}$ \\
\hline 199 & & $\begin{array}{l}\text { Dacryodes laxa } \\
\text { (A.W.Benn.) H.J.Lam }\end{array}$ & Asian & phylogeogr. & $\begin{array}{l}\text { Federman et al. } 2015 \text {, } \\
\text { Weeks et al. } 2014\end{array}$ \\
\hline 200 & & $\begin{array}{l}\text { Dacryodes rostrata } \\
\text { (Blume) H.J.Lam }\end{array}$ & Asian & phylogeogr. & $\begin{array}{l}\text { Federman et al. } 2015, \\
\text { Weeks et al. } 2014\end{array}$ \\
\hline 201 & & $\begin{array}{l}\text { Dacryodes rugosa (Blume) } \\
\text { H.J.Lam }\end{array}$ & Asian & phylogeogr. & $\begin{array}{l}\text { Federman et al. } 2015 \text {, } \\
\text { Weeks et al. } 2014\end{array}$ \\
\hline 202 & & Dacryodes sp.1 & Asian & phylogeogr. & $\begin{array}{l}\text { Federman et al. } 2015 \text {, } \\
\text { Weeks et al. } 2014\end{array}$ \\
\hline 203 & & Dacryodes sp.2 & Asian & phylogeogr. & $\begin{array}{l}\text { Federman et al. } 2015 \text {, } \\
\text { Weeks et al. } 2014\end{array}$ \\
\hline 204 & & Dacryodes sp.3 & Asian & phylogeogr. & $\begin{array}{l}\text { Federman et al. } 2015, \\
\text { Weeks et al. } 2014\end{array}$ \\
\hline 205 & & Dacryodes sp.4 & Asian & phylogeogr. & $\begin{array}{l}\text { Federman et al. } 2015, \\
\text { Weeks et al. } 2014\end{array}$ \\
\hline 206 & & Dacryodes sp.5 & Asian & phylogeogr. & $\begin{array}{l}\text { Federman et al. } 2015 \text {, } \\
\text { Weeks et al. } 2014\end{array}$ \\
\hline 207 & & Dacryodes sp.6 & Asian & phylogeogr. & $\begin{array}{l}\text { Federman et al. } 2015 \text {, } \\
\text { Weeks et al. } 2014\end{array}$ \\
\hline 208 & & Dacryodes sp.7 & Asian & phylogeogr. & $\begin{array}{l}\text { Federman et al. } 2015, \\
\text { Weeks et al. } 2014\end{array}$ \\
\hline 209 & & Dacryodes sp.8 & Asian & phylogeogr. & $\begin{array}{l}\text { Federman et al. } 2015 \text {, } \\
\text { Weeks et al. } 2014\end{array}$ \\
\hline 210 & & Dacryodes sp.9 & Asian & phylogeogr. & $\begin{array}{l}\text { Federman et al. } 2015 \text {, } \\
\text { Weeks et al. } 2014\end{array}$ \\
\hline 211 & & $\begin{array}{l}\text { Haplolobus floribundus } \\
\text { (K.Schum.) H.J.Lam }\end{array}$ & Asian & phylogeogr. & $\begin{array}{l}\text { Federman et al. } 2015 \text {, } \\
\text { Weeks et al. } 2014\end{array}$ \\
\hline
\end{tabular}




\begin{tabular}{|c|c|c|c|c|c|}
\hline No & Family & Species & Origin & $\begin{array}{l}\text { Classification } \\
\text { method }\end{array}$ & References \\
\hline 212 & & $\begin{array}{l}\text { Santiria apiculata } \\
\text { A.W.Benn. }\end{array}$ & Asian & phylogeogr. & $\begin{array}{l}\text { Federman et al. } 2015, \\
\text { Weeks et al. } 2014\end{array}$ \\
\hline 213 & & Santiria laevigata Blume & Asian & phylogeogr. & $\begin{array}{l}\text { Federman et al. } 2015, \\
\text { Weeks et al. } 2014\end{array}$ \\
\hline 214 & & $\begin{array}{l}\text { Santiria megaphylla } \\
\text { Kalkman }\end{array}$ & Asian & phylogeogr. & $\begin{array}{l}\text { Federman et al. } 2015 \text {, } \\
\text { Weeks et al. } 2014\end{array}$ \\
\hline 215 & & Santiria mollis Engl. & Asian & phylogeogr. & $\begin{array}{l}\text { Federman et al. } 2015, \\
\text { Weeks et al. } 2014\end{array}$ \\
\hline 216 & & $\begin{array}{l}\text { Santiria oblongifolia } \\
\text { Blume }\end{array}$ & Asian & phylogeogr. & $\begin{array}{l}\text { Federman et al. } 2015, \\
\text { Weeks et al. } 2014\end{array}$ \\
\hline 217 & & Santiria sp. & Asian & phylogeogr. & $\begin{array}{l}\text { Federman et al. } 2015 \text {, } \\
\text { Weeks et al. } 2014\end{array}$ \\
\hline 218 & & Santiria tomentosa Blume & Asian & phylogeogr. & $\begin{array}{l}\text { Federman et al. } 2015, \\
\text { Weeks et al. } 2014\end{array}$ \\
\hline 219 & & $\begin{array}{l}\text { Triomma malaccensis } \\
\text { Hook.f. }\end{array}$ & Asian & phylogeogr. & $\begin{array}{l}\text { Federman et al. } 2015, \\
\text { Weeks et al. } 2014\end{array}$ \\
\hline 220 & Calophyllaceae & $\begin{array}{l}\text { Calophyllum blancoi } \\
\text { Planch. \& Triana }\end{array}$ & Asian & $\begin{array}{l}\text { phylogeogr., } \\
\text { distr./fossils }\end{array}$ & $\begin{array}{l}\text { Khan et al. 2017, } \\
\text { Meseguer et al. 2018, } \\
\text { Ruhfel et al. 2016, } \\
\text { Stevens } 2007\end{array}$ \\
\hline 221 & & Calophyllum calaba L. & Asian & $\begin{array}{l}\text { phylogeogr., } \\
\text { distr./fossils }\end{array}$ & $\begin{array}{l}\text { Khan et al. 2017, } \\
\text { Meseguer et al. 2018, } \\
\text { Ruhfel et al. 2016, } \\
\text { Stevens } 2007\end{array}$ \\
\hline 222 & & $\begin{array}{l}\text { Calophyllum dasypodium } \\
\text { Miq. }\end{array}$ & Asian & $\begin{array}{l}\text { phylogeogr., } \\
\text { distr./fossils }\end{array}$ & $\begin{array}{l}\text { Khan et al. 2017, } \\
\text { Meseguer et al. 2018, } \\
\text { Ruhfel et al. 2016, } \\
\text { Stevens } 2007\end{array}$ \\
\hline 223 & & $\begin{array}{l}\text { Calophyllum } \\
\text { depressinervosum } \\
\text { M.R.Hend. \& Wyatt-Sm. }\end{array}$ & Asian & $\begin{array}{l}\text { phylogeogr., } \\
\text { distr./fossils }\end{array}$ & $\begin{array}{l}\text { Khan et al. 2017, } \\
\text { Meseguer et al. 2018, } \\
\text { Ruhfel et al. 2016, } \\
\text { Stevens } 2007\end{array}$ \\
\hline 224 & & $\begin{array}{l}\text { Calophyllum garcinioides } \\
\text { P.F.Stevens }\end{array}$ & Asian & $\begin{array}{l}\text { phylogeogr., } \\
\text { distr./fossils }\end{array}$ & $\begin{array}{l}\text { Khan et al. 2017, } \\
\text { Meseguer et al. 2018, } \\
\text { Ruhfel et al. 2016, } \\
\text { Stevens } 2007\end{array}$ \\
\hline 225 & & $\begin{array}{l}\text { Calophyllum gracilipes } \\
\text { Merr. }\end{array}$ & Asian & $\begin{array}{l}\text { phylogeogr., } \\
\text { distr./fossils }\end{array}$ & $\begin{array}{l}\text { Khan et al. 2017, } \\
\text { Meseguer et al. 2018, } \\
\text { Ruhfel et al. 2016, } \\
\text { Stevens } 2007\end{array}$ \\
\hline 226 & & $\begin{array}{l}\text { Calophyllum } \\
\text { macrocarpum Hook.f. }\end{array}$ & Asian & $\begin{array}{l}\text { phylogeogr., } \\
\text { distr./fossils }\end{array}$ & $\begin{array}{l}\text { Khan et al. 2017, } \\
\text { Meseguer et al. 2018, } \\
\text { Ruhfel et al. 2016, } \\
\text { Stevens } 2007\end{array}$ \\
\hline 227 & & $\begin{array}{l}\text { Calophyllum nodosum } \\
\text { Vesque }\end{array}$ & Asian & $\begin{array}{l}\text { phylogeogr., } \\
\text { distr./fossils }\end{array}$ & $\begin{array}{l}\text { Khan et al. 2017, } \\
\text { Meseguer et al. 2018, } \\
\text { Ruhfel et al. 2016, } \\
\text { Stevens } 2007\end{array}$ \\
\hline
\end{tabular}




\begin{tabular}{|c|c|c|c|c|c|}
\hline No & Family & Species & Origin & $\begin{array}{l}\text { Classification } \\
\text { method }\end{array}$ & References \\
\hline 228 & & $\begin{array}{l}\text { Calophyllum } \\
\text { pentapetalum (Blanco) } \\
\text { Merr. }\end{array}$ & Asian & $\begin{array}{l}\text { phylogeogr., } \\
\text { distr./fossils }\end{array}$ & $\begin{array}{l}\text { Khan et al. 2017, } \\
\text { Meseguer et al. 2018, } \\
\text { Ruhfel et al. 2016, } \\
\text { Stevens } 2007\end{array}$ \\
\hline 229 & & Calophyllum rigidum Miq. & Asian & $\begin{array}{l}\text { phylogeogr., } \\
\text { distr./fossils }\end{array}$ & $\begin{array}{l}\text { Khan et al. 2017, } \\
\text { Meseguer et al. 2018, } \\
\text { Ruhfel et al. 2016, } \\
\text { Stevens } 2007\end{array}$ \\
\hline 230 & & $\begin{array}{l}\text { Calophyllum soulattri } \\
\text { Burm.f. }\end{array}$ & Asian & $\begin{array}{l}\text { phylogeogr., } \\
\text { distr./fossils }\end{array}$ & $\begin{array}{l}\text { Khan et al. 2017, } \\
\text { Meseguer et al. 2018, } \\
\text { Ruhfel et al. 2016, } \\
\text { Stevens } 2007\end{array}$ \\
\hline 231 & & Calophyllum sp.1 & Asian & $\begin{array}{l}\text { phylogeogr., } \\
\text { distr./fossils }\end{array}$ & $\begin{array}{l}\text { Khan et al. 2017, } \\
\text { Meseguer et al. 2018, } \\
\text { Ruhfel et al. 2016, } \\
\text { Stevens } 2007\end{array}$ \\
\hline 232 & & Calophyllum sp.2 & Asian & $\begin{array}{l}\text { phylogeogr., } \\
\text { distr./fossils }\end{array}$ & $\begin{array}{l}\text { Khan et al. 2017, } \\
\text { Meseguer et al. 2018, } \\
\text { Ruhfel et al. 2016, } \\
\text { Stevens } 2007\end{array}$ \\
\hline 233 & & Calophyllum sp.3 & Asian & $\begin{array}{l}\text { phylogeogr., } \\
\text { distr./fossils }\end{array}$ & $\begin{array}{l}\text { Khan et al. 2017, } \\
\text { Meseguer et al. 2018, } \\
\text { Ruhfel et al. 2016, } \\
\text { Stevens } 2007\end{array}$ \\
\hline 234 & & Calophyllum sp.4 & Asian & $\begin{array}{l}\text { phylogeogr., } \\
\text { distr./fossils }\end{array}$ & $\begin{array}{l}\text { Khan et al. 2017, } \\
\text { Meseguer et al. 2018, } \\
\text { Ruhfel et al. 2016, } \\
\text { Stevens } 2007\end{array}$ \\
\hline 235 & & Calophyllum sp.5 & Asian & $\begin{array}{l}\text { phylogeogr., } \\
\text { distr./fossils }\end{array}$ & $\begin{array}{l}\text { Khan et al. 2017, } \\
\text { Meseguer et al. 2018, } \\
\text { Ruhfel et al. 2016, } \\
\text { Stevens } 2007\end{array}$ \\
\hline 236 & & Calophyllum sp.6 & Asian & $\begin{array}{l}\text { phylogeogr., } \\
\text { distr./fossils }\end{array}$ & $\begin{array}{l}\text { Khan et al. 2017, } \\
\text { Meseguer et al. 2018, } \\
\text { Ruhfel et al. 2016, } \\
\text { Stevens } 2007\end{array}$ \\
\hline 237 & & Calophyllum sp.nov. & Asian & $\begin{array}{l}\text { phylogeogr., } \\
\text { distr./fossils }\end{array}$ & $\begin{array}{l}\text { Khan et al. 2017, } \\
\text { Meseguer et al. 2018, } \\
\text { Ruhfel et al. 2016, } \\
\text { Stevens } 2007\end{array}$ \\
\hline 238 & & $\begin{array}{l}\text { Calophyllum tetrapterum } \\
\text { Miq. }\end{array}$ & Asian & $\begin{array}{l}\text { phylogeogr., } \\
\text { distr./fossils }\end{array}$ & $\begin{array}{l}\text { Khan et al. 2017, } \\
\text { Meseguer et al. 2018, } \\
\text { Ruhfel et al. 2016, } \\
\text { Stevens } 2007\end{array}$ \\
\hline 239 & & $\begin{array}{l}\text { Calophyllum venulosum } \\
\text { Zoll. }\end{array}$ & Asian & $\begin{array}{l}\text { phylogeogr., } \\
\text { distr./fossils }\end{array}$ & $\begin{array}{l}\text { Khan et al. 2017, } \\
\text { Meseguer et al. 2018, } \\
\text { Ruhfel et al. 2016, } \\
\text { Stevens } 2007\end{array}$ \\
\hline
\end{tabular}




\begin{tabular}{|c|c|c|c|c|c|}
\hline No & Family & Species & Origin & $\begin{array}{l}\text { Classification } \\
\text { method }\end{array}$ & References \\
\hline 240 & & Kayea beccariana Baill. & Asian & phylogeogr. & Ruhfel et al. 2016 \\
\hline 241 & & Kayea elmeri Merr. & Asian & phylogeogr. & Ruhfel et al. 2016 \\
\hline 242 & & Kayea grandis King & Asian & phylogeogr. & Ruhfel et al. 2016 \\
\hline 243 & & Kayea oblongifolia Ridl. & Asian & phylogeogr. & Ruhfel et al. 2016 \\
\hline 244 & & Kayea sp.1 & Asian & phylogeogr. & Ruhfel et al. 2016 \\
\hline 245 & & Kayea sp.2 & Asian & phylogeogr. & Ruhfel et al. 2016 \\
\hline 246 & & Kayea sp.3 & Asian & phylogeogr. & Ruhfel et al. 2016 \\
\hline 247 & & Mesua ferrea L. & Asian & $\begin{array}{l}\text { phylogeogr., } \\
\text { distr./fossils }\end{array}$ & $\begin{array}{l}\text { Meseguer et al. 2018, } \\
\text { Ruhfel et al. 2016, } \\
\text { Stevens } 2007\end{array}$ \\
\hline 248 & Cannabaceae & Celtis luzonica Warb. & Asian & $\begin{array}{l}\text { undated phyl., } \\
\text { distr./fossils }\end{array}$ & $\begin{array}{l}\text { Sattarian 2006, } \\
\text { Soepadmo } 1977\end{array}$ \\
\hline 249 & & Celtis rubrovenia Elmer & Asian & $\begin{array}{l}\text { undated phyl., } \\
\text { distr./fossils }\end{array}$ & $\begin{array}{l}\text { Sattarian 2006, } \\
\text { Soepadmo } 1977\end{array}$ \\
\hline 250 & & $\begin{array}{l}\text { Gironniera celtidifolia } \\
\text { Gaudich. }\end{array}$ & Asian & $\begin{array}{l}\text { undated phyl., } \\
\text { distr./fossils }\end{array}$ & Yesson et al. 2004 \\
\hline 251 & & $\begin{array}{l}\text { Gironniera nervosa } \\
\text { Planch. }\end{array}$ & Asian & $\begin{array}{l}\text { undated phyl., } \\
\text { distr./fossils }\end{array}$ & Yesson et al. 2004 \\
\hline 252 & & $\begin{array}{l}\text { Gironniera subaequalis } \\
\text { Planch. }\end{array}$ & Asian & $\begin{array}{l}\text { undated phyl., } \\
\text { distr./fossils }\end{array}$ & Yesson et al. 2004 \\
\hline 253 & & $\begin{array}{l}\text { Trema orientalis (L.) } \\
\text { Blume }\end{array}$ & Asian & phylogeogr. & Yesson et al. 2004 \\
\hline 254 & Cardiopteridaceae & $\begin{array}{l}\text { Citronella suaveolens } \\
\text { (Blume) Howard }\end{array}$ & Austr. & phylogeogr. & Beaulieu et al. 2013 \\
\hline 255 & & $\begin{array}{l}\text { Gonocaryum minus } \\
\text { Sleumer }\end{array}$ & Austr. & phylogeogr. & Beaulieu et al. 2013 \\
\hline 256 & Celastraceae & $\begin{array}{l}\text { Euonymus glandulosus } \\
\text { (Merr.) Ding Hou }\end{array}$ & Asian & $\begin{array}{l}\text { dated phyl., } \\
\text { distr./fossils }\end{array}$ & $\begin{array}{l}\text { Bacon et al. 2016, } \\
\text { Simmons et al. 2012b, } \\
\text { Simmons \& Cappa } 2013\end{array}$ \\
\hline 257 & & $\begin{array}{l}\text { Kokoona littoralis } \\
\text { M.A.Lawson }\end{array}$ & Asian & $\begin{array}{l}\text { phylogeogr., } \\
\text { distr./fossils }\end{array}$ & $\begin{array}{l}\text { Bacon et al. 2016, Hou } \\
1962\end{array}$ \\
\hline 258 & & $\begin{array}{l}\text { Lophopetalum } \\
\text { beccarianum Pierre }\end{array}$ & Asian & $\begin{array}{l}\text { phylogeogr., } \\
\text { distr./fossils }\end{array}$ & $\begin{array}{l}\text { Bacon et al. 2016, Hou } \\
1962\end{array}$ \\
\hline 259 & & $\begin{array}{l}\text { Lophopetalum javanicum } \\
\text { (Zoll.) Turcz. }\end{array}$ & Asian & $\begin{array}{l}\text { phylogeogr., } \\
\text { distr./fossils }\end{array}$ & $\begin{array}{l}\text { Bacon et al. 2016, Hou } \\
1962\end{array}$ \\
\hline 260 & & Lophopetalum sp.1 & Asian & $\begin{array}{l}\text { phylogeogr., } \\
\text { distr./fossils }\end{array}$ & $\begin{array}{l}\text { Bacon et al. 2016, Hou } \\
1962\end{array}$ \\
\hline 261 & & Lophopetalum sp.2 & Asian & $\begin{array}{l}\text { phylogeogr., } \\
\text { distr./fossils }\end{array}$ & $\begin{array}{l}\text { Bacon et al. 2016, Hou } \\
1962\end{array}$ \\
\hline 262 & & Microtropis rigida Ridl. & Asian & $\begin{array}{l}\text { phylogeogr., } \\
\text { distr./fossils }\end{array}$ & $\begin{array}{l}\text { Bacon et al. 2016, Hou } \\
1962\end{array}$ \\
\hline 263 & & $\begin{array}{l}\text { Microtropis wallichiana } \\
\text { Wight ex Thwaites }\end{array}$ & Asian & $\begin{array}{l}\text { phylogeogr., } \\
\text { distr./fossils }\end{array}$ & $\begin{array}{l}\text { Bacon et al. 2016, Hou } \\
1962\end{array}$ \\
\hline 264 & & $\begin{array}{l}\text { Siphonodon celastrineus } \\
\text { Griff. }\end{array}$ & Austr. & phylogeogr. & $\begin{array}{l}\text { Bacon et al. 2016, } \\
\text { Simmons et al. 2012a }\end{array}$ \\
\hline 265 & Centroplacaceae & Bhesa paniculata Arn. & Asian & phylogeogr. & Cai et al. 2016, Hou 1962 \\
\hline 266 & & Bhesa sp. & Asian & phylogeogr. & Cai et al. 2016, Hou 1962 \\
\hline
\end{tabular}




\begin{tabular}{|c|c|c|c|c|c|}
\hline No & Family & Species & Origin & $\begin{array}{l}\text { Classification } \\
\text { method }\end{array}$ & References \\
\hline 267 & Chloranthaceae & $\begin{array}{l}\text { Ascarina philippinensis } \\
\text { C.B.Rob. }\end{array}$ & Austr. & phylogeogr. & Zhang et al. 2015 \\
\hline 268 & Chrysobalanaceae & $\begin{array}{l}\text { Angelesia splendens } \\
\text { Korth. }\end{array}$ & Austr. & $\begin{array}{l}\text { phylogeogr., } \\
\text { distr./fossils }\end{array}$ & $\begin{array}{l}\text { Bardon et al. 2016, } \\
\text { Sothers \& Prance } 2014\end{array}$ \\
\hline 269 & & Atuna racemosa Raf. & Asian & $\begin{array}{l}\text { phylogeogr., } \\
\text { distr./fossils }\end{array}$ & $\begin{array}{l}\text { Bardon et al. 2016, } \\
\text { Prance } 1989\end{array}$ \\
\hline 270 & & $\begin{array}{l}\text { Kostermanthus } \\
\text { heteropetalus (Scort. ex } \\
\text { King) Prance }\end{array}$ & Asian & $\begin{array}{l}\text { phylogeogr., } \\
\text { distr./fossils }\end{array}$ & $\begin{array}{l}\text { Bardon et al. 2016, } \\
\text { Prance } 1989\end{array}$ \\
\hline 271 & & $\begin{array}{l}\text { Maranthes corymbosa } \\
\text { Blume }\end{array}$ & Asian & $\begin{array}{l}\text { phylogeogr., } \\
\text { distr./fossils }\end{array}$ & $\begin{array}{l}\text { Bardon et al. 2016, } \\
\text { Prance } 1989\end{array}$ \\
\hline 272 & & $\begin{array}{l}\text { Parastemon grandifructus } \\
\text { Prance }\end{array}$ & Asian & $\begin{array}{l}\text { phylogeogr., } \\
\text { distr./fossils }\end{array}$ & $\begin{array}{l}\text { Bardon et al. 2016, } \\
\text { Prance } 1989\end{array}$ \\
\hline 273 & & $\begin{array}{l}\text { Parinari canarioides } \\
\text { Kosterm. }\end{array}$ & Asian & phylogeogr. & Bardon et al. 2016 \\
\hline 274 & & $\begin{array}{l}\text { Parinari costata (Korth.) } \\
\text { Blume }\end{array}$ & Asian & phylogeogr. & Bardon et al. 2016 \\
\hline 275 & & Parinari elmeri Merr. & Asian & phylogeogr. & Bardon et al. 2016 \\
\hline 276 & & $\begin{array}{l}\text { Parinari oblongifolia } \\
\text { Hook.f. }\end{array}$ & Asian & phylogeogr. & Bardon et al. 2016 \\
\hline 277 & Clethraceae & $\begin{array}{l}\text { Clethra canescens Reinw. } \\
\text { ex Blume }\end{array}$ & Asian & $\begin{array}{l}\text { undated phyl., } \\
\text { distr./fossils }\end{array}$ & $\begin{array}{l}\text { Dressler \& Bayer 2004, } \\
\text { Fior et al. } 2003\end{array}$ \\
\hline 278 & & Clethra pachyphylla Merr. & Asian & $\begin{array}{l}\text { undated phyl., } \\
\text { distr./fossils }\end{array}$ & $\begin{array}{l}\text { Dressler \& Bayer 2004, } \\
\text { Fior et al. } 2003\end{array}$ \\
\hline 279 & Clusiaceae & Garcinia beccarii Pierre & Asian & phylogeogr. & Ruhfel et al. 2016 \\
\hline 280 & & $\begin{array}{l}\text { Garcinia binucao (Blanco) } \\
\text { Choisy }\end{array}$ & Asian & phylogeogr. & Ruhfel et al. 2016 \\
\hline 281 & & Garcinia blumei Pierre & Asian & phylogeogr. & Ruhfel et al. 2016 \\
\hline 282 & & $\begin{array}{l}\text { Garcinia brevirostris } \\
\text { Scheff. }\end{array}$ & Asian & phylogeogr. & Ruhfel et al. 2016 \\
\hline 283 & & Garcinia caudiculata Ridl. & Asian & phylogeogr. & Ruhfel et al. 2016 \\
\hline 284 & & Garcinia celebica L. & Asian & phylogeogr. & Ruhfel et al. 2016 \\
\hline 285 & & Garcinia dioica Blume & Asian & phylogeogr. & Ruhfel et al. 2016 \\
\hline 286 & & $\begin{array}{l}\text { Garcinia dulcis (Roxb.) } \\
\text { Kurz }\end{array}$ & Asian & phylogeogr. & Ruhfel et al. 2016 \\
\hline 287 & & $\begin{array}{l}\text { Garcinia gaudichaudii } \\
\text { Planch. \& Triana }\end{array}$ & Asian & phylogeogr. & Ruhfel et al. 2016 \\
\hline 288 & & Garcinia havilandii Stapf & Asian & phylogeogr. & Ruhfel et al. 2016 \\
\hline 289 & & Garcinia lateriflora Blume & Asian & phylogeogr. & Ruhfel et al. 2016 \\
\hline 290 & & $\begin{array}{l}\text { Garcinia longipedicellata } \\
\text { Kosterm. }\end{array}$ & Asian & phylogeogr. & Ruhfel et al. 2016 \\
\hline 291 & & $\begin{array}{l}\text { Garcinia maingayi Hook.f. } \\
\text { ex T.Anderson }\end{array}$ & Asian & phylogeogr. & Ruhfel et al. 2016 \\
\hline 292 & & $\begin{array}{l}\text { Garcinia maluensis } \\
\text { Lauterb. }\end{array}$ & Asian & phylogeogr. & Ruhfel et al. 2016 \\
\hline 293 & & $\begin{array}{l}\text { Garcinia merguensis } \\
\text { Wight }\end{array}$ & Asian & phylogeogr. & Ruhfel et al. 2016 \\
\hline
\end{tabular}




\begin{tabular}{|c|c|c|c|c|c|}
\hline No & Family & Species & Origin & $\begin{array}{l}\text { Classification } \\
\text { method }\end{array}$ & References \\
\hline 294 & & $\begin{array}{l}\text { Garcinia parvifolia (Miq.) } \\
\text { Miq. }\end{array}$ & Asian & phylogeogr. & Ruhfel et al. 2016 \\
\hline 295 & & $\begin{array}{l}\text { Garcinia penangiana } \\
\text { Pierre }\end{array}$ & Asian & phylogeogr. & Ruhfel et al. 2016 \\
\hline 296 & & $\begin{array}{l}\text { Garcinia rhizophoroides } \\
\text { Elmer }\end{array}$ & Asian & phylogeogr. & Ruhfel et al. 2016 \\
\hline 297 & & $\begin{array}{l}\text { Garcinia rostrata (Hassk.) } \\
\text { Miq. }\end{array}$ & Asian & phylogeogr. & Ruhfel et al. 2016 \\
\hline 298 & & Garcinia sp.01 & Asian & phylogeogr. & Ruhfel et al. 2016 \\
\hline 299 & & Garcinia sp.02 & Asian & phylogeogr. & Ruhfel et al. 2016 \\
\hline 300 & & Garcinia sp.03 & Asian & phylogeogr. & Ruhfel et al. 2016 \\
\hline 301 & & Garcinia sp.04 & Asian & phylogeogr. & Ruhfel et al. 2016 \\
\hline 302 & & Garcinia sp.05 & Asian & phylogeogr. & Ruhfel et al. 2016 \\
\hline 303 & & Garcinia sp.06 & Asian & phylogeogr. & Ruhfel et al. 2016 \\
\hline 304 & & Garcinia sp.07 & Asian & phylogeogr. & Ruhfel et al. 2016 \\
\hline 305 & & Garcinia sp.08 & Asian & phylogeogr. & Ruhfel et al. 2016 \\
\hline 306 & & Garcinia sp.09 & Asian & phylogeogr. & Ruhfel et al. 2016 \\
\hline 307 & & Garcinia sp.10 & Asian & phylogeogr. & Ruhfel et al. 2016 \\
\hline 308 & & Garcinia sp.11 & Asian & phylogeogr. & Ruhfel et al. 2016 \\
\hline 309 & & Garcinia sp.12 & Asian & phylogeogr. & Ruhfel et al. 2016 \\
\hline 310 & & Garcinia sp.13 & Asian & phylogeogr. & Ruhfel et al. 2016 \\
\hline 311 & & Garcinia sp.14 & Asian & phylogeogr. & Ruhfel et al. 2016 \\
\hline 312 & & Garcinia sp.15 & Asian & phylogeogr. & Ruhfel et al. 2016 \\
\hline 313 & & Garcinia sp.16 & Asian & phylogeogr. & Ruhfel et al. 2016 \\
\hline 314 & & Garcinia sp.17 & Asian & phylogeogr. & Ruhfel et al. 2016 \\
\hline 315 & & Garcinia sp.18 & Asian & phylogeogr. & Ruhfel et al. 2016 \\
\hline 316 & & Garcinia sp.19 & Asian & phylogeogr. & Ruhfel et al. 2016 \\
\hline 317 & & Garcinia sp.20 & Asian & phylogeogr. & Ruhfel et al. 2016 \\
\hline 318 & & Garcinia sp.21 & Asian & phylogeogr. & Ruhfel et al. 2016 \\
\hline 319 & & Garcinia sp.22 & Asian & phylogeogr. & Ruhfel et al. 2016 \\
\hline 320 & & Garcinia sp.23 & Asian & phylogeogr. & Ruhfel et al. 2016 \\
\hline 321 & & $\begin{array}{l}\text { Garcinia urophylla Scort. } \\
\text { ex King }\end{array}$ & Asian & phylogeogr. & Ruhfel et al. 2016 \\
\hline 322 & Combretaceae & $\begin{array}{l}\text { Terminalia foetidissima } \\
\text { Griff. }\end{array}$ & Asian & phylogeogr. & Berger et al. 2016 \\
\hline 323 & & Terminalia nitens C.Presl & Asian & phylogeogr. & Berger et al. 2016 \\
\hline 324 & Connaraceae & Ellipanthus beccarii Pierre & Asian & distr./fossils & Lemmens et al. 2004 \\
\hline 325 & Cornaceae & $\begin{array}{l}\text { Alangium javanicum } \\
\text { (Blume) Wangerin }\end{array}$ & Asian & phylogeogr. & Feng et al. 2009 \\
\hline 326 & & Alangium sp. & Asian & phylogeogr. & Feng et al. 2009 \\
\hline 327 & Crypteroniaceae & Axinandra coriacea Baill. & Asian & phylogeogr. & $\begin{array}{l}\text { Berger et al. 2016, } \\
\text { Rutschmann et al. } 2004\end{array}$ \\
\hline 328 & & $\begin{array}{l}\text { Crypteronia cumingii } \\
\text { (Planch.) Endl. }\end{array}$ & Asian & phylogeogr. & $\begin{array}{l}\text { Berger et al. 2016, } \\
\text { Rutschmann et al. } 2004\end{array}$ \\
\hline 329 & & $\begin{array}{l}\text { Crypteronia paniculata } \\
\text { Blume }\end{array}$ & Asian & phylogeogr. & $\begin{array}{l}\text { Berger et al. 2016, } \\
\text { Rutschmann et al. } 2004\end{array}$ \\
\hline 330 & & Crypteronia sp. & Asian & phylogeogr. & $\begin{array}{l}\text { Berger et al. 2016, } \\
\text { Rutschmann et al. } 2004\end{array}$ \\
\hline
\end{tabular}




\begin{tabular}{|c|c|c|c|c|c|}
\hline No & Family & Species & Origin & $\begin{array}{l}\text { Classification } \\
\text { method }\end{array}$ & References \\
\hline 331 & Ctenolophonaceae & $\begin{array}{l}\text { Ctenolophon parvifolius } \\
\text { Oliv. }\end{array}$ & Asian & distr./fossils & Kubitzki 2014 \\
\hline 332 & Cunoniaceae & $\begin{array}{l}\text { Schizomeria serrata } \\
\text { (Hochr.) Hochr. }\end{array}$ & Austr. & $\begin{array}{l}\text { undated phyl., } \\
\text { distr./fossils }\end{array}$ & $\begin{array}{l}\text { Bradford \& Barnes 2001, } \\
\text { Bradford et al. } 2004\end{array}$ \\
\hline 333 & & $\begin{array}{l}\text { Spiraeopsis celebica } \\
\text { (Blume) Miq. }\end{array}$ & Austr. & $\begin{array}{l}\text { undated phyl., } \\
\text { distr./fossils }\end{array}$ & $\begin{array}{l}\text { Bradford \& Barnes 2001, } \\
\text { Bradford et al. } 2004\end{array}$ \\
\hline 334 & & $\begin{array}{l}\text { Weinmannia clemensiae } \\
\text { Steenis }\end{array}$ & Austr. & $\begin{array}{l}\text { undated phyl., } \\
\text { distr./fossils }\end{array}$ & $\begin{array}{l}\text { Bradford \& Barnes 2001, } \\
\text { Bradford et al. } 2004\end{array}$ \\
\hline 335 & & $\begin{array}{l}\text { Weinmannia aff. fraxinea } \\
\text { (D.Don) Miq. }\end{array}$ & Austr. & $\begin{array}{l}\text { undated phyl., } \\
\text { distr./fossils }\end{array}$ & $\begin{array}{l}\text { Bradford \& Barnes 2001, } \\
\text { Bradford et al. } 2004\end{array}$ \\
\hline 336 & & $\begin{array}{l}\text { Weinmannia furfuracea } \\
\text { H.C.Hopkins }\end{array}$ & Austr. & $\begin{array}{l}\text { undated phyl., } \\
\text { distr./fossils }\end{array}$ & $\begin{array}{l}\text { Bradford \& Barnes 2001, } \\
\text { Bradford et al. } 2004\end{array}$ \\
\hline 337 & & $\begin{array}{l}\text { Weinmannia hutchinsonii } \\
\text { Merr. }\end{array}$ & Austr. & $\begin{array}{l}\text { undated phyl., } \\
\text { distr./fossils }\end{array}$ & $\begin{array}{l}\text { Bradford \& Barnes 2001, } \\
\text { Bradford et al. } 2004\end{array}$ \\
\hline 338 & & $\begin{array}{l}\text { Weinmannia negrosensis } \\
\text { Elmer }\end{array}$ & Austr. & $\begin{array}{l}\text { undated phyl., } \\
\text { distr./fossils }\end{array}$ & $\begin{array}{l}\text { Bradford \& Barnes 2001, } \\
\text { Bradford et al. } 2004\end{array}$ \\
\hline 339 & & Weinmannia sp. & Austr. & $\begin{array}{l}\text { undated phyl., } \\
\text { distr./fossils }\end{array}$ & $\begin{array}{l}\text { Bradford \& Barnes 2001, } \\
\text { Bradford et al. } 2004\end{array}$ \\
\hline 340 & Daphniphyllaceae & $\begin{array}{l}\text { Daphniphyllum } \\
\text { borneense Stapf }\end{array}$ & Asian & $\begin{array}{l}\text { dated phyl., } \\
\text { distr./fossils }\end{array}$ & $\begin{array}{l}\text { Jian et al. 2008, Kubitzki } \\
2007\end{array}$ \\
\hline 341 & & $\begin{array}{l}\text { Daphniphyllum } \\
\text { buchananiifolium Hallier } \mathrm{f} \text {. }\end{array}$ & Asian & distr./fossils & $\begin{array}{l}\text { Jian et al. 2008, Kubitzki } \\
2007\end{array}$ \\
\hline 342 & Dichapetalaceae & Dichapetalum sp. & Asian & $\begin{array}{l}\text { dated phyl., } \\
\text { distr./fossils }\end{array}$ & $\begin{array}{l}\text { Leenhouts 1957, Xi et al. } \\
2012\end{array}$ \\
\hline 343 & Dilleniaceae & $\begin{array}{l}\text { Dillenia beccariana } \\
\text { Martelli }\end{array}$ & Asian & undated phyl. & Hoorn 2007, 2009 \\
\hline 344 & & Dillenia indica L. & Asian & undated phyl. & Hoorn 2007, 2009 \\
\hline 345 & & $\begin{array}{l}\text { Dillenia ovalifolia } \\
\text { Hoogland }\end{array}$ & Asian & undated phyl. & Hoorn 2007, 2009 \\
\hline 346 & & $\begin{array}{l}\text { Dillenia philippinensis } \\
\text { Rolfe }\end{array}$ & Asian & undated phyl. & Hoorn 2007, 2009 \\
\hline 347 & & $\begin{array}{l}\text { Dillenia reifferscheidia } \\
\text { Fern.-Vill. }\end{array}$ & Asian & undated phyl. & Hoorn 2007, 2009 \\
\hline 348 & & Dillenia sp.1 & Asian & undated phyl. & Hoorn 2007, 2009 \\
\hline 349 & & Dillenia sp.2 & Asian & undated phyl. & Hoorn 2007, 2009 \\
\hline 350 & & Dillenia sp.3 & Asian & undated phyl. & Hoorn 2007, 2009 \\
\hline 351 & Dipterocarpaceae & Anisoptera costata Korth. & Asian & $\begin{array}{l}\text { dated phyl., } \\
\text { distr./fossils }\end{array}$ & $\begin{array}{l}\text { Ashton 2008, Dutta et al. } \\
\text { 2011, Feng et al. 2013, } \\
\text { Heckenhauer et al. } 2017\end{array}$ \\
\hline 352 & & Anisoptera laevis Ridl. & Asian & $\begin{array}{l}\text { dated phyl., } \\
\text { distr./fossils }\end{array}$ & $\begin{array}{l}\text { Ashton 2008, Dutta et al. } \\
\text { 2011, Feng et al. 2013, } \\
\text { Heckenhauer et al. } 2017\end{array}$ \\
\hline 353 & & $\begin{array}{l}\text { Anisoptera thurifera } \\
\text { (Blanco) Blume }\end{array}$ & Asian & $\begin{array}{l}\text { dated phyl., } \\
\text { distr./fossils }\end{array}$ & $\begin{array}{l}\text { Ashton 2008, Dutta et al. } \\
\text { 2011, Feng et al. 2013, } \\
\text { Heckenhauer et al. } 2017\end{array}$ \\
\hline 354 & & $\begin{array}{l}\text { Dipterocarpus caudatus } \\
\text { Foxw. }\end{array}$ & Asian & $\begin{array}{l}\text { dated phyl., } \\
\text { distr./fossils }\end{array}$ & $\begin{array}{l}\text { Ashton 2008, Dutta et al. } \\
\text { 2011, Feng et al. 2013, } \\
\text { Heckenhauer et al. } 2017\end{array}$ \\
\hline
\end{tabular}




\begin{tabular}{|c|c|c|c|c|c|}
\hline No & Family & Species & Origin & $\begin{array}{l}\text { Classification } \\
\text { method }\end{array}$ & References \\
\hline 355 & & $\begin{array}{l}\text { Dipterocarpus } \\
\text { palembanicus Slooten }\end{array}$ & Asian & $\begin{array}{l}\text { dated phyl., } \\
\text { distr./fossils }\end{array}$ & $\begin{array}{l}\text { Ashton 2008, Dutta et al. } \\
\text { 2011, Feng et al. 2013, } \\
\text { Heckenhauer et al. } 2017\end{array}$ \\
\hline 356 & & $\begin{array}{l}\text { Dryobalanops beccarii } \\
\text { Dyer }\end{array}$ & Asian & $\begin{array}{l}\text { dated phyl., } \\
\text { distr./fossils }\end{array}$ & $\begin{array}{l}\text { Ashton 2008, Dutta et al. } \\
\text { 2011, Feng et al. 2013, } \\
\text { Heckenhauer et al. } 2017\end{array}$ \\
\hline 357 & & $\begin{array}{l}\text { Dryobalanops lanceolata } \\
\text { Burck }\end{array}$ & Asian & $\begin{array}{l}\text { dated phyl., } \\
\text { distr./fossils }\end{array}$ & $\begin{array}{l}\text { Ashton 2008, Dutta et al. } \\
\text { 2011, Feng et al. 2013, } \\
\text { Heckenhauer et al. } 2017\end{array}$ \\
\hline 358 & & Hopea beccariana Burck & Asian & $\begin{array}{l}\text { dated phyl., } \\
\text { distr./fossils }\end{array}$ & $\begin{array}{l}\text { Ashton 2008, Dutta et al. } \\
\text { 2011, Feng et al. 2013, } \\
\text { Heckenhauer et al. } 2017\end{array}$ \\
\hline 359 & & $\begin{array}{l}\text { Hopea dryobalanoides } \\
\text { Miq. }\end{array}$ & Asian & $\begin{array}{l}\text { dated phyl., } \\
\text { distr./fossils }\end{array}$ & $\begin{array}{l}\text { Ashton 2008, Dutta et al. } \\
\text { 2011, Feng et al. 2013, } \\
\text { Heckenhauer et al. } 2017\end{array}$ \\
\hline 360 & & Hopea dyeri F.Heim & Asian & $\begin{array}{l}\text { dated phyl., } \\
\text { distr./fossils }\end{array}$ & $\begin{array}{l}\text { Ashton 2008, Dutta et al. } \\
\text { 2011, Feng et al. 2013, } \\
\text { Heckenhauer et al. } 2017\end{array}$ \\
\hline 361 & & Hopea foxworthyi Elmer & Asian & $\begin{array}{l}\text { dated phyl., } \\
\text { distr./fossils }\end{array}$ & $\begin{array}{l}\text { Ashton 2008, Dutta et al. } \\
\text { 2011, Feng et al. 2013, } \\
\text { Heckenhauer et al. } 2017\end{array}$ \\
\hline 362 & & Hopea nigra Burck & Asian & $\begin{array}{l}\text { dated phyl., } \\
\text { distr./fossils }\end{array}$ & $\begin{array}{l}\text { Ashton 2008, Dutta et al. } \\
\text { 2011, Feng et al. 2013, } \\
\text { Heckenhauer et al. } 2017\end{array}$ \\
\hline 363 & & $\begin{array}{l}\text { Hopea pentanervia } \\
\text { Symington ex G.H.S.Wood }\end{array}$ & Asian & $\begin{array}{l}\text { dated phyl., } \\
\text { distr./fossils }\end{array}$ & $\begin{array}{l}\text { Ashton 2008, Dutta et al. } \\
\text { 2011, Feng et al. 2013, } \\
\text { Heckenhauer et al. } 2017\end{array}$ \\
\hline 364 & & Hopea sangal Korth. & Asian & $\begin{array}{l}\text { dated phyl., } \\
\text { distr./fossils }\end{array}$ & $\begin{array}{l}\text { Ashton 2008, Dutta et al. } \\
\text { 2011, Feng et al. 2013, } \\
\text { Heckenhauer et al. } 2017\end{array}$ \\
\hline 365 & & Hopea sp.1 & Asian & $\begin{array}{l}\text { dated phyl., } \\
\text { distr./fossils }\end{array}$ & $\begin{array}{l}\text { Ashton 2008, Dutta et al. } \\
\text { 2011, Feng et al. 2013, } \\
\text { Heckenhauer et al. } 2017\end{array}$ \\
\hline 366 & & $\begin{array}{l}\text { Parashorea malaanonan } \\
\text { (Blanco) Merr. }\end{array}$ & Asian & $\begin{array}{l}\text { dated phyl., } \\
\text { distr./fossils }\end{array}$ & $\begin{array}{l}\text { Ashton 2008, Dutta et al. } \\
\text { 2011, Feng et al. 2013, } \\
\text { Heckenhauer et al. } 2017\end{array}$ \\
\hline 367 & & $\begin{array}{l}\text { Parashorea smythiesii } \\
\text { Wyatt-Sm. ex P.S.Ashton }\end{array}$ & Asian & $\begin{array}{l}\text { dated phyl., } \\
\text { distr./fossils }\end{array}$ & $\begin{array}{l}\text { Ashton 2008, Dutta et al. } \\
\text { 2011, Feng et al. 2013, } \\
\text { Heckenhauer et al. } 2017\end{array}$ \\
\hline 368 & & Shorea acuminata Dyer & Asian & $\begin{array}{l}\text { dated phyl., } \\
\text { distr./fossils }\end{array}$ & $\begin{array}{l}\text { Ashton 2008, Dutta et al. } \\
\text { 2011, Feng et al. 2013, } \\
\text { Heckenhauer et al. } 2017\end{array}$ \\
\hline 369 & & Shorea almon Foxw. & Asian & $\begin{array}{l}\text { dated phyl., } \\
\text { distr./fossils }\end{array}$ & $\begin{array}{l}\text { Ashton 2008, Dutta et al. } \\
\text { 2011, Feng et al. 2013, } \\
\text { Heckenhauer et al. } 2017\end{array}$ \\
\hline 370 & & $\begin{array}{l}\text { Shorea amplexicaulis } \\
\text { P.S.Ashton }\end{array}$ & Asian & $\begin{array}{l}\text { dated phyl., } \\
\text { distr./fossils }\end{array}$ & $\begin{array}{l}\text { Ashton 2008, Dutta et al. } \\
\text { 2011, Feng et al. 2013, } \\
\text { Heckenhauer et al. } 2017\end{array}$ \\
\hline
\end{tabular}




\begin{tabular}{|c|c|c|c|c|c|}
\hline No & Family & Species & Origin & $\begin{array}{l}\text { Classification } \\
\text { method }\end{array}$ & References \\
\hline 371 & & $\begin{array}{l}\text { Shorea argentifolia } \\
\text { Symington }\end{array}$ & Asian & $\begin{array}{l}\text { dated phyl., } \\
\text { distr./fossils }\end{array}$ & $\begin{array}{l}\text { Ashton 2008, Dutta et al. } \\
\text { 2011, Feng et al. 2013, } \\
\text { Heckenhauer et al. } 2017\end{array}$ \\
\hline 372 & & $\begin{array}{l}\text { Shorea confusa } \\
\text { P.S.Ashton }\end{array}$ & Asian & $\begin{array}{l}\text { dated phyl., } \\
\text { distr./fossils }\end{array}$ & $\begin{array}{l}\text { Ashton 2008, Dutta et al. } \\
\text { 2011, Feng et al. 2013, } \\
\text { Heckenhauer et al. } 2017\end{array}$ \\
\hline 373 & & $\begin{array}{l}\text { Shorea domatiosa } \\
\text { P.S.Ashton }\end{array}$ & Asian & $\begin{array}{l}\text { dated phyl., } \\
\text { distr./fossils }\end{array}$ & $\begin{array}{l}\text { Ashton 2008, Dutta et al. } \\
\text { 2011, Feng et al. 2013, } \\
\text { Heckenhauer et al. } 2017\end{array}$ \\
\hline 374 & & Shorea exelliptica Meijer & Asian & $\begin{array}{l}\text { dated phyl., } \\
\text { distr./fossils }\end{array}$ & $\begin{array}{l}\text { Ashton 2008, Dutta et al. } \\
\text { 2011, Feng et al. 2013, } \\
\text { Heckenhauer et al. } 2017\end{array}$ \\
\hline 375 & & Shorea faguetiana F.Heim & Asian & $\begin{array}{l}\text { dated phyl., } \\
\text { distr./fossils }\end{array}$ & $\begin{array}{l}\text { Ashton 2008, Dutta et al. } \\
\text { 2011, Feng et al. 2013, } \\
\text { Heckenhauer et al. } 2017\end{array}$ \\
\hline 376 & & Shorea fallax Meijer & Asian & $\begin{array}{l}\text { dated phyl., } \\
\text { distr./fossils }\end{array}$ & $\begin{array}{l}\text { Ashton 2008, Dutta et al. } \\
\text { 2011, Feng et al. 2013, } \\
\text { Heckenhauer et al. } 2017\end{array}$ \\
\hline 377 & & $\begin{array}{l}\text { Shorea ferruginea Dyer ex } \\
\text { Brandis }\end{array}$ & Asian & $\begin{array}{l}\text { dated phyl., } \\
\text { distr./fossils }\end{array}$ & $\begin{array}{l}\text { Ashton 2008, Dutta et al. } \\
\text { 2011, Feng et al. 2013, } \\
\text { Heckenhauer et al. } 2017\end{array}$ \\
\hline 378 & & $\begin{array}{l}\text { Shorea foxworthyi } \\
\text { Symington }\end{array}$ & Asian & $\begin{array}{l}\text { dated phyl., } \\
\text { distr./fossils }\end{array}$ & $\begin{array}{l}\text { Ashton 2008, Dutta et al. } \\
\text { 2011, Feng et al. 2013, } \\
\text { Heckenhauer et al. } 2017\end{array}$ \\
\hline 379 & & Shorea gibbosa Brandis & Asian & $\begin{array}{l}\text { dated phyl., } \\
\text { distr./fossils }\end{array}$ & $\begin{array}{l}\text { Ashton 2008, Dutta et al. } \\
\text { 2011, Feng et al. 2013, } \\
\text { Heckenhauer et al. } 2017\end{array}$ \\
\hline 380 & & Shorea hypoleuca Meijer & Asian & $\begin{array}{l}\text { dated phyl., } \\
\text { distr./fossils }\end{array}$ & $\begin{array}{l}\text { Ashton 2008, Dutta et al. } \\
\text { 2011, Feng et al. 2013, } \\
\text { Heckenhauer et al. } 2017\end{array}$ \\
\hline 381 & & Shorea laevis Ridl. & Asian & $\begin{array}{l}\text { dated phyl., } \\
\text { distr./fossils }\end{array}$ & $\begin{array}{l}\text { Ashton 2008, Dutta et al. } \\
\text { 2011, Feng et al. 2013, } \\
\text { Heckenhauer et al. } 2017\end{array}$ \\
\hline 382 & & Shorea leprosula Miq. & Asian & $\begin{array}{l}\text { dated phyl., } \\
\text { distr./fossils }\end{array}$ & $\begin{array}{l}\text { Ashton 2008, Dutta et al. } \\
\text { 2011, Feng et al. 2013, } \\
\text { Heckenhauer et al. } 2017\end{array}$ \\
\hline 383 & & Shorea macroptera Dyer & Asian & $\begin{array}{l}\text { dated phyl., } \\
\text { distr./fossils }\end{array}$ & $\begin{array}{l}\text { Ashton 2008, Dutta et al. } \\
\text { 2011, Feng et al. 2013, } \\
\text { Heckenhauer et al. } 2017\end{array}$ \\
\hline 384 & & Shorea maxwelliana King & Asian & $\begin{array}{l}\text { dated phyl., } \\
\text { distr./fossils }\end{array}$ & $\begin{array}{l}\text { Ashton 2008, Dutta et al. } \\
\text { 2011, Feng et al. 2013, } \\
\text { Heckenhauer et al. } 2017\end{array}$ \\
\hline 385 & & $\begin{array}{l}\text { Shorea monticola } \\
\text { P.S.Ashton }\end{array}$ & Asian & $\begin{array}{l}\text { dated phyl., } \\
\text { distr./fossils }\end{array}$ & $\begin{array}{l}\text { Ashton 2008, Dutta et al. } \\
\text { 2011, Feng et al. 2013, } \\
\text { Heckenhauer et al. } 2017\end{array}$ \\
\hline 386 & & Shorea obscura Meijer & Asian & $\begin{array}{l}\text { dated phyl., } \\
\text { distr./fossils }\end{array}$ & $\begin{array}{l}\text { Ashton 2008, Dutta et al. } \\
\text { 2011, Feng et al. 2013, } \\
\text { Heckenhauer et al. } 2017\end{array}$ \\
\hline
\end{tabular}




\begin{tabular}{|c|c|c|c|c|c|}
\hline No & Family & Species & Origin & $\begin{array}{l}\text { Classification } \\
\text { method }\end{array}$ & References \\
\hline 387 & & Shorea parvifolia Dyer & Asian & $\begin{array}{l}\text { dated phyl., } \\
\text { distr./fossils }\end{array}$ & $\begin{array}{l}\text { Ashton 2008, Dutta et al. } \\
\text { 2011, Feng et al. 2013, } \\
\text { Heckenhauer et al. } 2017\end{array}$ \\
\hline 388 & & Shorea pauciflora King & Asian & $\begin{array}{l}\text { dated phyl., } \\
\text { distr./fossils }\end{array}$ & $\begin{array}{l}\text { Ashton 2008, Dutta et al. } \\
\text { 2011, Feng et al. 2013, } \\
\text { Heckenhauer et al. } 2017\end{array}$ \\
\hline 389 & & $\begin{array}{l}\text { Shorea platyclados } \\
\text { Slooten ex Endert }\end{array}$ & Asian & $\begin{array}{l}\text { dated phyl., } \\
\text { distr./fossils }\end{array}$ & $\begin{array}{l}\text { Ashton 2008, Dutta et al. } \\
\text { 2011, Feng et al. 2013, } \\
\text { Heckenhauer et al. } 2017\end{array}$ \\
\hline 390 & & $\begin{array}{l}\text { Shorea polysperma } \\
\text { (Blanco) Merr. }\end{array}$ & Asian & $\begin{array}{l}\text { dated phyl., } \\
\text { distr./fossils }\end{array}$ & $\begin{array}{l}\text { Ashton 2008, Dutta et al. } \\
\text { 2011, Feng et al. 2013, } \\
\text { Heckenhauer et al. } 2017\end{array}$ \\
\hline 391 & & Shorea scaberrima Burck & Asian & $\begin{array}{l}\text { dated phyl., } \\
\text { distr./fossils }\end{array}$ & $\begin{array}{l}\text { Ashton 2008, Dutta et al. } \\
\text { 2011, Feng et al. 2013, } \\
\text { Heckenhauer et al. } 2017\end{array}$ \\
\hline 392 & & Shorea scrobiculata Burck & Asian & $\begin{array}{l}\text { dated phyl., } \\
\text { distr./fossils }\end{array}$ & $\begin{array}{l}\text { Ashton 2008, Dutta et al. } \\
\text { 2011, Feng et al. 2013, } \\
\text { Heckenhauer et al. } 2017\end{array}$ \\
\hline 393 & & Shorea sp.1 & Asian & $\begin{array}{l}\text { dated phyl., } \\
\text { distr./fossils }\end{array}$ & $\begin{array}{l}\text { Ashton 2008, Dutta et al. } \\
\text { 2011, Feng et al. 2013, } \\
\text { Heckenhauer et al. } 2017\end{array}$ \\
\hline 394 & & Shorea sp.2 & Asian & $\begin{array}{l}\text { dated phyl., } \\
\text { distr./fossils }\end{array}$ & $\begin{array}{l}\text { Ashton 2008, Dutta et al. } \\
\text { 2011, Feng et al. 2013, } \\
\text { Heckenhauer et al. } 2017\end{array}$ \\
\hline 395 & & Shorea sp.3 & Asian & $\begin{array}{l}\text { dated phyl., } \\
\text { distr./fossils }\end{array}$ & $\begin{array}{l}\text { Ashton 2008, Dutta et al. } \\
\text { 2011, Feng et al. 2013, } \\
\text { Heckenhauer et al. } 2017\end{array}$ \\
\hline 396 & & Shorea sp.4 & Asian & $\begin{array}{l}\text { dated phyl., } \\
\text { distr./fossils }\end{array}$ & $\begin{array}{l}\text { Ashton 2008, Dutta et al. } \\
\text { 2011, Feng et al. 2013, } \\
\text { Heckenhauer et al. } 2017\end{array}$ \\
\hline 397 & & Shorea sp.5 & Asian & $\begin{array}{l}\text { dated phyl., } \\
\text { distr./fossils }\end{array}$ & $\begin{array}{l}\text { Ashton 2008, Dutta et al. } \\
\text { 2011, Feng et al. 2013, } \\
\text { Heckenhauer et al. } 2017\end{array}$ \\
\hline 398 & & Vatica endertii Slooten & Asian & $\begin{array}{l}\text { dated phyl., } \\
\text { distr./fossils }\end{array}$ & $\begin{array}{l}\text { Ashton 2008, Dutta et al. } \\
\text { 2011, Feng et al. 2013, } \\
\text { Heckenhauer et al. } 2017\end{array}$ \\
\hline 399 & & Vatica granulata Slooten & Asian & $\begin{array}{l}\text { dated phyl., } \\
\text { distr./fossils }\end{array}$ & $\begin{array}{l}\text { Ashton 2008, Dutta et al. } \\
\text { 2011, Feng et al. 2013, } \\
\text { Heckenhauer et al. } 2017\end{array}$ \\
\hline 400 & & $\begin{array}{l}\text { Vatica mangachapoi } \\
\text { Blanco }\end{array}$ & Asian & $\begin{array}{l}\text { dated phyl., } \\
\text { distr./fossils }\end{array}$ & $\begin{array}{l}\text { Ashton 2008, Dutta et al. } \\
\text { 2011, Feng et al. 2013, } \\
\text { Heckenhauer et al. } 2017\end{array}$ \\
\hline 401 & & Vatica micrantha Slooten & Asian & $\begin{array}{l}\text { dated phyl., } \\
\text { distr./fossils }\end{array}$ & $\begin{array}{l}\text { Ashton 2008, Dutta et al. } \\
\text { 2011, Feng et al. 2013, } \\
\text { Heckenhauer et al. } 2017\end{array}$ \\
\hline 402 & & $\begin{array}{l}\text { Vatica odorata (Griff.) } \\
\text { Symington }\end{array}$ & Asian & $\begin{array}{l}\text { dated phyl., } \\
\text { distr./fossils }\end{array}$ & $\begin{array}{l}\text { Ashton 2008, Dutta et al. } \\
\text { 2011, Feng et al. 2013, } \\
\text { Heckenhauer et al. } 2017\end{array}$ \\
\hline
\end{tabular}




\begin{tabular}{|c|c|c|c|c|c|}
\hline No & Family & Species & Origin & $\begin{array}{l}\text { Classification } \\
\text { method }\end{array}$ & References \\
\hline 403 & & Vatica perakensis King & Asian & $\begin{array}{l}\text { dated phyl., } \\
\text { distr./fossils }\end{array}$ & $\begin{array}{l}\text { Ashton 2008, Dutta et al. } \\
\text { 2011, Feng et al. 2013, } \\
\text { Heckenhauer et al. } 2017\end{array}$ \\
\hline 404 & & Vatica sp. & Asian & $\begin{array}{l}\text { dated phyl., } \\
\text { distr./fossils }\end{array}$ & $\begin{array}{l}\text { Ashton 2008, Dutta et al. } \\
\text { 2011, Feng et al. 2013, } \\
\text { Heckenhauer et al. } 2017\end{array}$ \\
\hline 405 & Ebenaceae & $\begin{array}{l}\text { Diospyros bangkana } \\
\text { Bakh. }\end{array}$ & Asian & phylogeogr. & $\begin{array}{l}\text { Duangjai et al. 2009, } \\
\text { Turner et al. } 2013\end{array}$ \\
\hline 406 & & $\begin{array}{l}\text { Diospyros borneensis } \\
\text { Hiern }\end{array}$ & Asian & phylogeogr. & $\begin{array}{l}\text { Duangjai et al. 2009, } \\
\text { Turner et al. } 2013\end{array}$ \\
\hline 407 & & $\begin{array}{l}\text { Diospyros buxifolia } \\
\text { (Blume) Hiern }\end{array}$ & Asian & phylogeogr. & $\begin{array}{l}\text { Duangjai et al. 2009, } \\
\text { Turner et al. } 2013\end{array}$ \\
\hline 408 & & $\begin{array}{l}\text { Diospyros castanea } \\
\text { (Craib) Fletcher }\end{array}$ & Asian & phylogeogr. & $\begin{array}{l}\text { Duangjai et al. 2009, } \\
\text { Turner et al. } 2013\end{array}$ \\
\hline 409 & & $\begin{array}{l}\text { Diospyros caudisepala } \\
\text { Bakh. }\end{array}$ & Asian & phylogeogr. & $\begin{array}{l}\text { Duangjai et al. 2009, } \\
\text { Turner et al. } 2013\end{array}$ \\
\hline 410 & & $\begin{array}{l}\text { Diospyros confertiflora } \\
\text { (Hiern) Bakh. }\end{array}$ & Asian & phylogeogr. & $\begin{array}{l}\text { Duangjai et al. 2009, } \\
\text { Turner et al. } 2013\end{array}$ \\
\hline 411 & & Diospyros curranii Merr. & Asian & phylogeogr. & $\begin{array}{l}\text { Duangjai et al. 2009, } \\
\text { Turner et al. } 2013\end{array}$ \\
\hline 412 & & $\begin{array}{l}\text { Diospyros diepenhorstii } \\
\text { Miq. }\end{array}$ & Asian & phylogeogr. & $\begin{array}{l}\text { Duangjai et al. 2009, } \\
\text { Turner et al. } 2013\end{array}$ \\
\hline 413 & & Diospyros discolor Willd. & Asian & phylogeogr. & $\begin{array}{l}\text { Duangjai et al. 2009, } \\
\text { Turner et al. } 2013\end{array}$ \\
\hline 414 & & Diospyros elliptifolia Merr. & Asian & phylogeogr. & $\begin{array}{l}\text { Duangjai et al. 2009, } \\
\text { Turner et al. } 2013\end{array}$ \\
\hline 415 & & $\begin{array}{l}\text { Diospyros frutescens } \\
\text { Blume }\end{array}$ & Asian & phylogeogr. & $\begin{array}{l}\text { Duangjai et al. 2009, } \\
\text { Turner et al. } 2013\end{array}$ \\
\hline 416 & & Diospyros javanica Bakh. & Asian & phylogeogr. & $\begin{array}{l}\text { Duangjai et al. 2009, } \\
\text { Turner et al. } 2013\end{array}$ \\
\hline 417 & & $\begin{array}{l}\text { Diospyros macrophylla } \\
\text { Blume }\end{array}$ & Asian & phylogeogr. & $\begin{array}{l}\text { Duangjai et al. 2009, } \\
\text { Turner et al. } 2013\end{array}$ \\
\hline 418 & & Diospyros piscicapa Ridl. & Asian & phylogeogr. & $\begin{array}{l}\text { Duangjai et al. 2009, } \\
\text { Turner et al. } 2013\end{array}$ \\
\hline 419 & & $\begin{array}{l}\text { Diospyros } \\
\text { pseudomalabarica Bakh. }\end{array}$ & Asian & phylogeogr. & $\begin{array}{l}\text { Duangjai et al. 2009, } \\
\text { Turner et al. } 2013\end{array}$ \\
\hline 420 & & Diospyros sp.01 & Asian & phylogeogr. & $\begin{array}{l}\text { Duangjai et al. 2009, } \\
\text { Turner et al. } 2013\end{array}$ \\
\hline 421 & & Diospyros sp.02 & Asian & phylogeogr. & $\begin{array}{l}\text { Duangjai et al. 2009, } \\
\text { Turner et al. } 2013\end{array}$ \\
\hline 422 & & Diospyros sp.03 & Asian & phylogeogr. & $\begin{array}{l}\text { Duangjai et al. 2009, } \\
\text { Turner et al. } 2013\end{array}$ \\
\hline 423 & & Diospyros sp.04 & Asian & phylogeogr. & $\begin{array}{l}\text { Duangjai et al. 2009, } \\
\text { Turner et al. } 2013\end{array}$ \\
\hline 424 & & Diospyros sp.05 & Asian & phylogeogr. & $\begin{array}{l}\text { Duangjai et al. 2009, } \\
\text { Turner et al. } 2013\end{array}$ \\
\hline 425 & & Diospyros sp.06 & Asian & phylogeogr. & $\begin{array}{l}\text { Duangjai et al. 2009, } \\
\text { Turner et al. } 2013\end{array}$ \\
\hline
\end{tabular}




\begin{tabular}{|c|c|c|c|c|c|}
\hline No & Family & Species & Origin & $\begin{array}{l}\text { Classification } \\
\text { method }\end{array}$ & References \\
\hline 426 & & Diospyros sp.07 & Asian & phylogeogr. & $\begin{array}{l}\text { Duangjai et al. 2009, } \\
\text { Turner et al. } 2013\end{array}$ \\
\hline 427 & & Diospyros sp.08 & Asian & phylogeogr. & $\begin{array}{l}\text { Duangjai et al. 2009, } \\
\text { Turner et al. } 2013\end{array}$ \\
\hline 428 & & Diospyros sp.09 & Asian & phylogeogr. & $\begin{array}{l}\text { Duangjai et al. 2009, } \\
\text { Turner et al. } 2013\end{array}$ \\
\hline 429 & & Diospyros sp.10 & Asian & phylogeogr. & $\begin{array}{l}\text { Duangjai et al. 2009, } \\
\text { Turner et al. } 2013\end{array}$ \\
\hline 430 & & Diospyros sp.11 & Asian & phylogeogr. & $\begin{array}{l}\text { Duangjai et al. 2009, } \\
\text { Turner et al. } 2013\end{array}$ \\
\hline 431 & & Diospyros sp.12 & Asian & phylogeogr. & $\begin{array}{l}\text { Duangjai et al. 2009, } \\
\text { Turner et al. } 2013\end{array}$ \\
\hline 432 & & Diospyros sp.13 & Asian & phylogeogr. & $\begin{array}{l}\text { Duangjai et al. 2009, } \\
\text { Turner et al. } 2013\end{array}$ \\
\hline 433 & & Diospyros sp.14 & Asian & phylogeogr. & $\begin{array}{l}\text { Duangjai et al. 2009, } \\
\text { Turner et al. } 2013\end{array}$ \\
\hline 434 & & Diospyros sp.15 & Asian & phylogeogr. & $\begin{array}{l}\text { Duangjai et al. 2009, } \\
\text { Turner et al. } 2013\end{array}$ \\
\hline 435 & & Diospyros sp.16 & Asian & phylogeogr. & $\begin{array}{l}\text { Duangjai et al. 2009, } \\
\text { Turner et al. } 2013\end{array}$ \\
\hline 436 & & Diospyros sp.17 & Asian & phylogeogr. & $\begin{array}{l}\text { Duangjai et al. 2009, } \\
\text { Turner et al. } 2013\end{array}$ \\
\hline 437 & & Diospyros sumatrana Miq. & Asian & phylogeogr. & $\begin{array}{l}\text { Duangjai et al. 2009, } \\
\text { Turner et al. } 2013\end{array}$ \\
\hline 438 & & $\begin{array}{l}\text { Diospyros venosa Wall. ex } \\
\text { A.DC. }\end{array}$ & Asian & phylogeogr. & $\begin{array}{l}\text { Duangjai et al. 2009, } \\
\text { Turner et al. } 2013\end{array}$ \\
\hline 439 & Ehretiaceae & Ehretia javanica Blume & Asian & phylogeogr. & Gottschling \& Hilger 2004 \\
\hline 440 & Elaeocarpaceae & $\begin{array}{l}\text { Elaeocarpus acronodia } \\
\text { Mast. }\end{array}$ & Austr. & phylogeogr. & $\begin{array}{l}\text { Baba 2013, Crayn et al. } \\
2006\end{array}$ \\
\hline 441 & & $\begin{array}{l}\text { Elaeocarpus angustifolius } \\
\text { Blume }\end{array}$ & Austr. & phylogeogr. & $\begin{array}{l}\text { Baba 2013, Crayn et al. } \\
2006\end{array}$ \\
\hline 442 & & $\begin{array}{l}\text { Elaeocarpus calomala } \\
\text { (Blanco) Merr. }\end{array}$ & Austr. & phylogeogr. & $\begin{array}{l}\text { Baba 2013, Crayn et al. } \\
2006\end{array}$ \\
\hline 443 & & $\begin{array}{l}\text { Elaeocarpus celebicus } \\
\text { Koord. }\end{array}$ & Austr. & phylogeogr. & $\begin{array}{l}\text { Baba 2013, Crayn et al. } \\
2006\end{array}$ \\
\hline 444 & & $\begin{array}{l}\text { Elaeocarpus corneri } \\
\text { Weibel }\end{array}$ & Austr. & phylogeogr. & $\begin{array}{l}\text { Baba 2013, Crayn et al. } \\
2006\end{array}$ \\
\hline 445 & & $\begin{array}{l}\text { Elaeocarpus culminicola } \\
\text { Warb. }\end{array}$ & Austr. & phylogeogr. & $\begin{array}{l}\text { Baba 2013, Crayn et al. } \\
2006\end{array}$ \\
\hline 446 & & $\begin{array}{l}\text { Elaeocarpus cumingii } \\
\text { Turcz. }\end{array}$ & Austr. & phylogeogr. & $\begin{array}{l}\text { Baba 2013, Crayn et al. } \\
2006\end{array}$ \\
\hline 447 & & $\begin{array}{l}\text { Elaeocarpus dolichostylus } \\
\text { Schltr. }\end{array}$ & Austr. & phylogeogr. & $\begin{array}{l}\text { Baba 2013, Crayn et al. } \\
2006\end{array}$ \\
\hline 448 & & Elaeocarpus erdinii Coode & Austr. & phylogeogr. & $\begin{array}{l}\text { Baba 2013, Crayn et al. } \\
2006\end{array}$ \\
\hline 449 & & $\begin{array}{l}\text { Elaeocarpus firdausii } \\
\text { Brambach, Coode, } \\
\text { Biagioni \& Culmsee }\end{array}$ & Austr. & phylogeogr. & $\begin{array}{l}\text { Baba 2013, Crayn et al. } \\
2006\end{array}$ \\
\hline
\end{tabular}




\begin{tabular}{|c|c|c|c|c|c|}
\hline No & Family & Species & Origin & $\begin{array}{l}\text { Classification } \\
\text { method }\end{array}$ & References \\
\hline 450 & & Elaeocarpus glaber Blume & Austr. & phylogeogr. & $\begin{array}{l}\text { Baba 2013, Crayn et al. } \\
2006\end{array}$ \\
\hline 451 & & $\begin{array}{l}\text { Elaeocarpus gustaviifolius } \\
\text { Knuth }\end{array}$ & Austr. & phylogeogr. & $\begin{array}{l}\text { Baba 2013, Crayn et al. } \\
2006\end{array}$ \\
\hline 452 & & $\begin{array}{l}\text { Elaeocarpus aff. harunii } \\
\text { Coode }\end{array}$ & Austr. & phylogeogr. & $\begin{array}{l}\text { Baba 2013, Crayn et al. } \\
2006\end{array}$ \\
\hline 453 & & $\begin{array}{l}\text { Elaeocarpus hochreutineri } \\
\text { Weibel }\end{array}$ & Austr. & phylogeogr. & $\begin{array}{l}\text { Baba 2013, Crayn et al. } \\
2006\end{array}$ \\
\hline 454 & & Elaeocarpus knuthii Merr. & Austr. & phylogeogr. & $\begin{array}{l}\text { Baba 2013, Crayn et al. } \\
2006\end{array}$ \\
\hline 455 & & $\begin{array}{l}\text { Elaeocarpus macrophyllus } \\
\text { Blume }\end{array}$ & Austr. & phylogeogr. & $\begin{array}{l}\text { Baba 2013, Crayn et al. } \\
2006\end{array}$ \\
\hline 456 & & $\begin{array}{l}\text { Elaeocarpus mastersii } \\
\text { King }\end{array}$ & Austr. & phylogeogr. & $\begin{array}{l}\text { Baba 2013, Crayn et al. } \\
2006\end{array}$ \\
\hline 457 & & $\begin{array}{l}\text { Elaeocarpus multiflorus } \\
\text { (Turcz.) Fern.-Vill. }\end{array}$ & Austr. & phylogeogr. & $\begin{array}{l}\text { Baba 2013, Crayn et al. } \\
2006\end{array}$ \\
\hline 458 & & $\begin{array}{l}\text { Elaeocarpus musseri } \\
\text { Coode }\end{array}$ & Austr. & phylogeogr. & $\begin{array}{l}\text { Baba 2013, Crayn et al. } \\
2006\end{array}$ \\
\hline 459 & & Elaeocarpus nitidus Jack & Austr. & phylogeogr. & $\begin{array}{l}\text { Baba 2013, Crayn et al. } \\
2006\end{array}$ \\
\hline 460 & & $\begin{array}{l}\text { Elaeocarpus aff. } \\
\text { octopetalus Merr. }\end{array}$ & Austr. & phylogeogr. & $\begin{array}{l}\text { Baba 2013, Crayn et al. } \\
2006\end{array}$ \\
\hline 461 & & $\begin{array}{l}\text { Elaeocarpus } \\
\text { palembanicus (Miq.) } \\
\text { Corner }\end{array}$ & Austr. & phylogeogr. & $\begin{array}{l}\text { Baba 2013, Crayn et al. } \\
2006\end{array}$ \\
\hline 462 & & $\begin{array}{l}\text { Elaeocarpus pierrei } \\
\text { Koord. \& Valeton }\end{array}$ & Austr. & phylogeogr. & $\begin{array}{l}\text { Baba 2013, Crayn et al. } \\
2006\end{array}$ \\
\hline 463 & & $\begin{array}{l}\text { Elaeocarpus sarcanthus } \\
\text { Schltr. }\end{array}$ & Austr. & phylogeogr. & $\begin{array}{l}\text { Baba 2013, Crayn et al. } \\
2006\end{array}$ \\
\hline 464 & & Elaeocarpus sp.02 & Austr. & phylogeogr. & $\begin{array}{l}\text { Baba 2013, Crayn et al. } \\
2006\end{array}$ \\
\hline 465 & & Elaeocarpus sp.03 & Austr. & phylogeogr. & $\begin{array}{l}\text { Baba 2013, Crayn et al. } \\
2006\end{array}$ \\
\hline 466 & & Elaeocarpus sp.04 & Austr. & phylogeogr. & $\begin{array}{l}\text { Baba 2013, Crayn et al. } \\
2006\end{array}$ \\
\hline 467 & & Elaeocarpus sp.05 & Austr. & phylogeogr. & $\begin{array}{l}\text { Baba 2013, Crayn et al. } \\
2006\end{array}$ \\
\hline 468 & & Elaeocarpus sp.06 & Austr. & phylogeogr. & $\begin{array}{l}\text { Baba 2013, Crayn et al. } \\
2006\end{array}$ \\
\hline 469 & & Elaeocarpus sp.07 & Austr. & phylogeogr. & $\begin{array}{l}\text { Baba 2013, Crayn et al. } \\
2006\end{array}$ \\
\hline 470 & & Elaeocarpus sp.08 & Austr. & phylogeogr. & $\begin{array}{l}\text { Baba 2013, Crayn et al. } \\
2006\end{array}$ \\
\hline 471 & & Elaeocarpus sp.09 & Austr. & phylogeogr. & $\begin{array}{l}\text { Baba 2013, Crayn et al. } \\
2006\end{array}$ \\
\hline 472 & & Elaeocarpus sp.10 & Austr. & phylogeogr. & $\begin{array}{l}\text { Baba 2013, Crayn et al. } \\
2006\end{array}$ \\
\hline
\end{tabular}




\begin{tabular}{|c|c|c|c|c|c|}
\hline No & Family & Species & Origin & $\begin{array}{l}\text { Classification } \\
\text { method }\end{array}$ & References \\
\hline 473 & & Elaeocarpus sp.11 & Austr. & phylogeogr. & $\begin{array}{l}\text { Baba 2013, Crayn et al. } \\
2006\end{array}$ \\
\hline 474 & & Elaeocarpus sp.12 & Austr. & phylogeogr. & $\begin{array}{l}\text { Baba 2013, Crayn et al. } \\
2006\end{array}$ \\
\hline 475 & & Elaeocarpus sp.13 & Austr. & phylogeogr. & $\begin{array}{l}\text { Baba 2013, Crayn et al. } \\
2006\end{array}$ \\
\hline 476 & & Elaeocarpus steupii Coode & Austr. & phylogeogr. & $\begin{array}{l}\text { Baba 2013, Crayn et al. } \\
2006\end{array}$ \\
\hline 477 & & $\begin{array}{l}\text { Elaeocarpus stipularis } \\
\text { Blume }\end{array}$ & Austr. & phylogeogr. & $\begin{array}{l}\text { Baba 2013, Crayn et al. } \\
2006\end{array}$ \\
\hline 478 & & $\begin{array}{l}\text { Elaeocarpus } \\
\text { submonoceras Miq. }\end{array}$ & Austr. & phylogeogr. & $\begin{array}{l}\text { Baba 2013, Crayn et al. } \\
2006\end{array}$ \\
\hline 479 & & $\begin{array}{l}\text { Elaeocarpus teysmannii } \\
\text { Koord. \& Valeton }\end{array}$ & Austr. & phylogeogr. & $\begin{array}{l}\text { Baba 2013, Crayn et al. } \\
2006\end{array}$ \\
\hline 480 & & $\begin{array}{l}\text { Sloanea celebica Boerl. \& } \\
\text { Koord. ex Koord. }\end{array}$ & Asian & distr./fossils & $\begin{array}{l}\text { Coode 1983, Manchester } \\
\text { \& Kvaček } 2009\end{array}$ \\
\hline 481 & Ericaceae & Diplycosia sp. & Asian & undated phyl. & Fritsch et al. 2011 \\
\hline 482 & & Rhododendron sp. & Asian & phylogeogr. & Landis et al. 2013 \\
\hline 483 & & Vaccinium bancanum Miq. & Asian & undated phyl. & Powell \& Kron 2002 \\
\hline 484 & & $\begin{array}{l}\text { Vaccinium cuneifolium } \\
\text { (Blume) Miq. }\end{array}$ & Asian & undated phyl. & Powell \& Kron 2002 \\
\hline 485 & & $\begin{array}{l}\text { Vaccinium dubiosum } \\
\text { J.J.Sm. }\end{array}$ & Asian & undated phyl. & Powell \& Kron 2002 \\
\hline 486 & & $\begin{array}{l}\text { Vaccinium laurifolium } \\
\text { (Blume) Miq. }\end{array}$ & Asian & undated phyl. & Powell \& Kron 2002 \\
\hline 487 & & $\begin{array}{l}\text { Vaccinium simulans } \\
\text { Sleumer }\end{array}$ & Asian & undated phyl. & Powell \& Kron 2002 \\
\hline 488 & & Vaccinium sp.1 & Asian & undated phyl. & Powell \& Kron 2002 \\
\hline 489 & Escalloniaceae & $\begin{array}{l}\text { Polyosma celebica } \\
\text { Schulze-Menz ined. }\end{array}$ & Austr. & phylogeogr. & Beaulieu et al. 2013 \\
\hline 490 & & Polyosma cyanea Elmer & Austr. & phylogeogr. & Beaulieu et al. 2013 \\
\hline 491 & & Polyosma hookeri Stapf & Austr. & phylogeogr. & Beaulieu et al. 2013 \\
\hline 492 & & Polyosma illicifolia Blume & Austr. & phylogeogr. & Beaulieu et al. 2013 \\
\hline 493 & & $\begin{array}{l}\text { Polyosma integrifolia } \\
\text { Blume }\end{array}$ & Austr. & phylogeogr. & Beaulieu et al. 2013 \\
\hline 494 & & Polyosma kingiana Schltr. & Austr. & phylogeogr. & Beaulieu et al. 2013 \\
\hline 495 & & $\begin{array}{l}\text { Polyosma sorsogonensis } \\
\text { Elmer }\end{array}$ & Austr. & phylogeogr. & Beaulieu et al. 2013 \\
\hline 496 & & Polyosma sp.1 & Austr. & phylogeogr. & Beaulieu et al. 2013 \\
\hline 497 & & Polyosma sp.2 & Austr. & phylogeogr. & Beaulieu et al. 2013 \\
\hline 498 & & Polyosma sp.3 & Austr. & phylogeogr. & Beaulieu et al. 2013 \\
\hline 499 & & $\begin{array}{l}\text { Polyosma verticillata } \\
\text { Merr. }\end{array}$ & Austr. & phylogeogr. & Beaulieu et al. 2013 \\
\hline 500 & Euphorbiaceae & $\begin{array}{l}\text { Acalypha amentacea } \\
\text { Roxb. }\end{array}$ & Asian & $\begin{array}{l}\text { phylogeogr., } \\
\text { distr./fossils }\end{array}$ & $\begin{array}{l}\text { Cervantes et al. 2016, } \\
\text { Sagun et al. } 2010\end{array}$ \\
\hline 501 & & $\begin{array}{l}\text { Balakata baccata (Roxb.) } \\
\text { Esser }\end{array}$ & Asian & distr./fossils & $\begin{array}{l}\text { Esser 1999, Webster } \\
2014\end{array}$ \\
\hline
\end{tabular}




\begin{tabular}{|c|c|c|c|c|c|}
\hline No & Family & Species & Origin & $\begin{array}{l}\text { Classification } \\
\text { method }\end{array}$ & References \\
\hline 502 & & $\begin{array}{l}\text { Blumeodendron kurzii } \\
\text { (Hook.f.) J.J.Sm. ex Koord. } \\
\text { \& Valeton }\end{array}$ & Asian & $\begin{array}{l}\text { phylogeogr., } \\
\text { distr./fossils }\end{array}$ & $\begin{array}{l}\text { Cervantes et al. 2016, } \\
\text { Ottens-Treurniet \& van } \\
\text { Welzen } 2016\end{array}$ \\
\hline 503 & & Blumeodendron sp.1 & Asian & $\begin{array}{l}\text { phylogeogr., } \\
\text { distr./fossils }\end{array}$ & $\begin{array}{l}\text { Cervantes et al. 2016, } \\
\text { Ottens-Treurniet \& van } \\
\text { Welzen } 2016\end{array}$ \\
\hline 504 & & $\begin{array}{l}\text { Blumeodendron } \\
\text { subrotundifolium (Elmer) } \\
\text { Merr. }\end{array}$ & Asian & $\begin{array}{l}\text { phylogeogr., } \\
\text { distr./fossils }\end{array}$ & $\begin{array}{l}\text { Cervantes et al. 2016, } \\
\text { Ottens-Treurniet \& van } \\
\text { Welzen } 2016\end{array}$ \\
\hline 505 & & $\begin{array}{l}\text { Blumeodendron tokbrai } \\
\text { (Blume) Kurz }\end{array}$ & Asian & $\begin{array}{l}\text { phylogeogr., } \\
\text { distr./fossils }\end{array}$ & $\begin{array}{l}\text { Cervantes et al. 2016, } \\
\text { Ottens-Treurniet \& van } \\
\text { Welzen } 2016\end{array}$ \\
\hline 506 & & $\begin{array}{l}\text { Claoxylon brachyandrum } \\
\text { Pax \& K.Hoffm. }\end{array}$ & Asian & $\begin{array}{l}\text { phylogeogr., } \\
\text { distr./fossils }\end{array}$ & $\begin{array}{l}\text { Cervantes et al. 2016, } \\
\text { WCSP } 2017\end{array}$ \\
\hline 507 & & Claoxylon sp.1 & Asian & $\begin{array}{l}\text { phylogeogr., } \\
\text { distr./fossils }\end{array}$ & $\begin{array}{l}\text { Cervantes et al. 2016, } \\
\text { WCSP } 2017\end{array}$ \\
\hline 508 & & $\begin{array}{l}\text { Elateriospermum tapos } \\
\text { Blume }\end{array}$ & Asian & $\begin{array}{l}\text { undated phyl., } \\
\text { distr./fossils }\end{array}$ & $\begin{array}{l}\text { Webster 2014, Wurdack } \\
\text { et al. } 2005\end{array}$ \\
\hline 509 & & $\begin{array}{l}\text { Hancea penangensis } \\
\text { (Müll.Arg.) S.E.C.Sierra }\end{array}$ & Asian & phylogeogr. & $\begin{array}{l}\text { Cervantes et al. } 2016 \text {, } \\
\text { Kulju et al. } 2007\end{array}$ \\
\hline 510 & & $\begin{array}{l}\text { Homalanthus fastuosus } \\
\text { (Linden) Fern.-Vill. }\end{array}$ & Austr. & $\begin{array}{l}\text { dated phyl., } \\
\text { distr./fossils }\end{array}$ & $\begin{array}{l}\text { Esser 1997, Wurdack et } \\
\text { al. 2005, Xi et al. } 2012\end{array}$ \\
\hline 511 & & $\begin{array}{l}\text { Homalanthus } \\
\text { macradenius Pax \& } \\
\text { K.Hoffm. }\end{array}$ & Austr. & $\begin{array}{l}\text { dated phyl., } \\
\text { distr./fossils }\end{array}$ & $\begin{array}{l}\text { Esser 1997, Wurdack et } \\
\text { al. 2005, Xi et al. } 2012\end{array}$ \\
\hline 512 & & $\begin{array}{l}\text { Homalanthus populneus } \\
\text { (Geiseler) Pax }\end{array}$ & Austr. & $\begin{array}{l}\text { dated phyl., } \\
\text { distr./fossils }\end{array}$ & $\begin{array}{l}\text { Esser 1997, Wurdack et } \\
\text { al. 2005, Xi et al. } 2012\end{array}$ \\
\hline 513 & & Homalanthus sp.1 & Austr. & $\begin{array}{l}\text { dated phyl., } \\
\text { distr./fossils }\end{array}$ & $\begin{array}{l}\text { Esser 1997, Wurdack et } \\
\text { al. 2005, Xi et al. } 2012\end{array}$ \\
\hline 514 & & Homalanthus sp.2 & Austr. & $\begin{array}{l}\text { dated phyl., } \\
\text { distr./fossils }\end{array}$ & $\begin{array}{l}\text { Esser 1997, Wurdack et } \\
\text { al. 2005, Xi et al. } 2012\end{array}$ \\
\hline 515 & & $\begin{array}{l}\text { Koilodepas longifolium } \\
\text { Hook.f. }\end{array}$ & Asian & $\begin{array}{l}\text { phylogeogr., } \\
\text { distr./fossils }\end{array}$ & $\begin{array}{l}\text { Cervantes et al. 2016, } \\
\text { Webster } 2014\end{array}$ \\
\hline 516 & & $\begin{array}{l}\text { Macaranga bicolor } \\
\text { Müll.Arg. }\end{array}$ & Asian & phylogeogr. & van Welzen et al. 2014 \\
\hline 517 & & $\begin{array}{l}\text { Macaranga costulata Pax } \\
\text { \& K.Hoffm. }\end{array}$ & Asian & phylogeogr. & van Welzen et al. 2014 \\
\hline 518 & & $\begin{array}{l}\text { Macaranga denticulata } \\
\text { (Blume) Müll.Arg. }\end{array}$ & Asian & phylogeogr. & van Welzen et al. 2014 \\
\hline 519 & & $\begin{array}{l}\text { Macaranga gigantea } \\
\text { (Rchb.f. \& Zoll.) Müll.Arg. }\end{array}$ & Asian & phylogeogr. & van Welzen et al. 2014 \\
\hline 520 & & $\begin{array}{l}\text { Macaranga hispida } \\
\text { (Blume) Müll.Arg. }\end{array}$ & Austr. & phylogeogr. & van Welzen et al. 2014 \\
\hline 521 & & $\begin{array}{l}\text { Macaranga hosei King ex } \\
\text { Hook.f. }\end{array}$ & Asian & phylogeogr. & van Welzen et al. 2014 \\
\hline 522 & & $\begin{array}{l}\text { Macaranga hypoleuca } \\
\text { (Rchb.f. \& Zoll.) Müll.Arg. }\end{array}$ & Asian & phylogeogr. & van Welzen et al. 2014 \\
\hline
\end{tabular}




\begin{tabular}{|c|c|c|c|c|c|}
\hline No & Family & Species & Origin & $\begin{array}{l}\text { Classification } \\
\text { method }\end{array}$ & References \\
\hline 523 & & $\begin{array}{l}\text { Macaranga lowii King ex } \\
\text { Hook.f. }\end{array}$ & Asian & phylogeogr. & van Welzen et al. 2014 \\
\hline 524 & & $\begin{array}{l}\text { Macaranga pachyphylla } \\
\text { Müll.Arg. }\end{array}$ & Asian & phylogeogr. & van Welzen et al. 2014 \\
\hline 525 & & $\begin{array}{l}\text { Macaranga rhizinoides } \\
\text { (Blume) Müll.Arg. }\end{array}$ & Asian & phylogeogr. & van Welzen et al. 2014 \\
\hline 526 & & $\begin{array}{l}\text { Macaranga rorokae } \\
\text { Whitmore }\end{array}$ & Austr. & phylogeogr. & van Welzen et al. 2014 \\
\hline 527 & & $\begin{array}{l}\text { Macaranga sarcocarpa } \\
\text { Müll.Arg. }\end{array}$ & Asian & phylogeogr. & van Welzen et al. 2014 \\
\hline 528 & & $\begin{array}{l}\text { Macaranga strigosissima } \\
\text { Airy Shaw }\end{array}$ & Asian & phylogeogr. & van Welzen et al. 2014 \\
\hline 529 & & $\begin{array}{l}\text { Macaranga tanarius (L.) } \\
\text { Müll.Arg. }\end{array}$ & Austr. & phylogeogr. & van Welzen et al. 2014 \\
\hline 530 & & $\begin{array}{l}\text { Macaranga thomasii } \\
\text { Whitmore }\end{array}$ & Austr. & phylogeogr. & van Welzen et al. 2014 \\
\hline 531 & & $\begin{array}{l}\text { Macaranga trachyphylla } \\
\text { Airy Shaw }\end{array}$ & Asian & phylogeogr. & van Welzen et al. 2014 \\
\hline 532 & & $\begin{array}{l}\text { Macaranga triloba } \\
\text { (Thunb.) Müll.Arg. }\end{array}$ & Asian & phylogeogr. & van Welzen et al. 2014 \\
\hline 533 & & $\begin{array}{l}\text { Macaranga umbrosa } \\
\text { S.J.Davies }\end{array}$ & Asian & phylogeogr. & van Welzen et al. 2014 \\
\hline 534 & & $\begin{array}{l}\text { Macaranga waturandangii } \\
\text { Whitmore }\end{array}$ & Asian & phylogeogr. & van Welzen et al. 2014 \\
\hline 535 & & $\begin{array}{l}\text { Mallotus cumingii } \\
\text { Müll.Arg. }\end{array}$ & Asian & phylogeogr. & van Welzen et al. 2014 \\
\hline 536 & & $\begin{array}{l}\text { Mallotus mollissimus } \\
\text { (Geiseler) Airy Shaw }\end{array}$ & Asian & phylogeogr. & van Welzen et al. 2014 \\
\hline 537 & & $\begin{array}{l}\text { Mallotus paniculatus } \\
\text { (Lam.) Müll.Arg. }\end{array}$ & Asian & phylogeogr. & van Welzen et al. 2014 \\
\hline 538 & & $\begin{array}{l}\text { Mallotus philippensis } \\
\text { (Lam.) Müll.Arg. }\end{array}$ & Asian & phylogeogr. & van Welzen et al. 2014 \\
\hline 539 & & Mallotus sp. & Asian & phylogeogr. & van Welzen et al. 2014 \\
\hline 540 & & $\begin{array}{l}\text { Melanolepis } \\
\text { multiglandulosa (Reinw. } \\
\text { ex Blume) Rchb. \& Zoll. }\end{array}$ & Asian & $\begin{array}{l}\text { phylogeogr., } \\
\text { distr./fossils }\end{array}$ & $\begin{array}{l}\text { Cervantes et al. 2016, } \\
\text { Webster } 2014\end{array}$ \\
\hline 541 & & $\begin{array}{l}\text { Moultonianthus } \\
\text { leembruggianus (Boerl. \& } \\
\text { Koord.) Steenis }\end{array}$ & Asian & $\begin{array}{l}\text { undated phyl., } \\
\text { distr./fossils }\end{array}$ & $\begin{array}{l}\text { van Welzen 1995, } \\
\text { Wurdack et al. } 2005\end{array}$ \\
\hline 542 & & $\begin{array}{l}\text { Neoscortechinia kingii } \\
\text { (Hook.f.) Pax \& K.Hoffm. }\end{array}$ & Asian & phylogeogr. & $\begin{array}{l}\text { Tokuoka 2007, van } \\
\text { Welzen } 1994\end{array}$ \\
\hline 543 & & $\begin{array}{l}\text { Neoscortechinia } \\
\text { nicobarica (Hook.f.) Pax \& } \\
\text { K.Hoffm. }\end{array}$ & Asian & phylogeogr. & $\begin{array}{l}\text { Tokuoka 2007, van } \\
\text { Welzen } 1994\end{array}$ \\
\hline 544 & & $\begin{array}{l}\text { Neoscortechinia } \\
\text { philippinensis (Merr.) }\end{array}$ & Asian & phylogeogr. & $\begin{array}{l}\text { Tokuoka 2007, van } \\
\text { Welzen } 1994\end{array}$ \\
\hline
\end{tabular}




\begin{tabular}{|c|c|c|c|c|c|}
\hline No & Family & Species & Origin & $\begin{array}{l}\text { Classification } \\
\text { method }\end{array}$ & References \\
\hline 545 & & Ostodes paniculata Blume & Asian & $\begin{array}{l}\text { undated phyl., } \\
\text { distr./fossils }\end{array}$ & $\begin{array}{l}\text { Tokuoka 2007, van } \\
\text { Welzen \& Winkel } 2015\end{array}$ \\
\hline 546 & & $\begin{array}{l}\text { Pimelodendron } \\
\text { griffithianum (Müll.Arg.) } \\
\text { Benth. ex Hook.f. }\end{array}$ & Asian & $\begin{array}{l}\text { dated phyl., } \\
\text { distr./fossils }\end{array}$ & $\begin{array}{l}\text { Djawarningsih 2004, Xi et } \\
\text { al. } 2012\end{array}$ \\
\hline 547 & & $\begin{array}{l}\text { Ptychopyxis javanica } \\
\text { (J.J.Sm.) Croizat }\end{array}$ & Asian & distr./fossils & $\begin{array}{l}\text { Stoops \& van Welzen } \\
2013\end{array}$ \\
\hline 548 & & Ptychopyxis kingii Ridl. & Asian & distr./fossils & $\begin{array}{l}\text { Stoops \& van Welzen } \\
2013\end{array}$ \\
\hline 549 & & Ptychopyxis sp. & Asian & distr./fossils & $\begin{array}{l}\text { Stoops \& van Welzen } \\
2013\end{array}$ \\
\hline 550 & Fabaceae & $\begin{array}{l}\text { Archidendron bubalinum } \\
\text { (Jack) I.C.Nielsen }\end{array}$ & Austr. & $\begin{array}{l}\text { dated phyl., } \\
\text { distr./fossils }\end{array}$ & $\begin{array}{l}\text { Bouchenak-Khelladi et al. } \\
\text { 2010, Brown et al. } 2011\end{array}$ \\
\hline 551 & & $\begin{array}{l}\text { Archidendron clypearia } \\
\text { (Jack) I.C.Nielsen }\end{array}$ & Austr. & $\begin{array}{l}\text { dated phyl., } \\
\text { distr./fossils }\end{array}$ & $\begin{array}{l}\text { Bouchenak-Khelladi et al. } \\
\text { 2010, Brown et al. } 2011\end{array}$ \\
\hline 552 & & $\begin{array}{l}\text { Archidendron ellipticum } \\
\text { (Blanco) I.C.Nielsen }\end{array}$ & Austr. & $\begin{array}{l}\text { dated phyl., } \\
\text { distr./fossils }\end{array}$ & $\begin{array}{l}\text { Bouchenak-Khelladi et al. } \\
\text { 2010, Brown et al. } 2011\end{array}$ \\
\hline 553 & & $\begin{array}{l}\text { Archidendron havilandii } \\
\text { (Ridl.) I.C.Nielsen }\end{array}$ & Austr. & $\begin{array}{l}\text { dated phyl., } \\
\text { distr./fossils }\end{array}$ & $\begin{array}{l}\text { Bouchenak-Khelladi et al. } \\
\text { 2010, Brown et al. } 2011\end{array}$ \\
\hline 554 & & $\begin{array}{l}\text { Archidendron } \\
\text { microcarpum (Benth.) } \\
\text { I.C.Nielsen }\end{array}$ & Austr. & $\begin{array}{l}\text { dated phyl., } \\
\text { distr./fossils }\end{array}$ & $\begin{array}{l}\text { Bouchenak-Khelladi et al. } \\
\text { 2010, Brown et al. } 2011\end{array}$ \\
\hline 555 & & $\begin{array}{l}\text { Archidendron nervosum } \\
\text { de Wit }\end{array}$ & Austr. & $\begin{array}{l}\text { dated phyl., } \\
\text { distr./fossils }\end{array}$ & $\begin{array}{l}\text { Bouchenak-Khelladi et al. } \\
\text { 2010, Brown et al. } 2011\end{array}$ \\
\hline 556 & & $\begin{array}{l}\text { Archidendron pauciflorum } \\
\text { (Benth.) I.C.Nielsen }\end{array}$ & Austr. & $\begin{array}{l}\text { dated phyl., } \\
\text { distr./fossils }\end{array}$ & $\begin{array}{l}\text { Bouchenak-Khelladi et al. } \\
\text { 2010, Brown et al. } 2011\end{array}$ \\
\hline 557 & & Archidendron sp. & Austr. & $\begin{array}{l}\text { dated phyl., } \\
\text { distr./fossils }\end{array}$ & $\begin{array}{l}\text { Bouchenak-Khelladi et al. } \\
\text { 2010, Brown et al. } 2011\end{array}$ \\
\hline 558 & & Archidendron sp.1 & Austr. & $\begin{array}{l}\text { dated phyl., } \\
\text { distr./fossils }\end{array}$ & $\begin{array}{l}\text { Bouchenak-Khelladi et al. } \\
\text { 2010, Brown et al. } 2011\end{array}$ \\
\hline 559 & & Crudia sp. & Asian & $\begin{array}{l}\text { dated phyl., } \\
\text { distr./fossils }\end{array}$ & Bruneau et al. 2008, 2014 \\
\hline 560 & & Crudia tenuipes Merr. & Asian & $\begin{array}{l}\text { dated phyl., } \\
\text { distr./fossils }\end{array}$ & Bruneau et al. 2008, 2014 \\
\hline 561 & & Cynometra ramiflora L. & Asian & $\begin{array}{l}\text { dated phyl., } \\
\text { distr./fossils }\end{array}$ & Bruneau et al. 2008, 2014 \\
\hline 562 & & Dialium indum L. & Asian & $\begin{array}{l}\text { dated phyl., } \\
\text { distr./fossils }\end{array}$ & Bruneau et al. 2008 \\
\hline 563 & & Dialium kunstleri Prain & Asian & $\begin{array}{l}\text { dated phyl., } \\
\text { distr./fossils }\end{array}$ & Bruneau et al. 2008 \\
\hline 564 & & Dialium sp.1 & Asian & $\begin{array}{l}\text { dated phyl., } \\
\text { distr./fossils }\end{array}$ & Bruneau et al. 2008 \\
\hline 565 & & $\begin{array}{l}\text { Koompassia excelsa } \\
\text { (Becc.) Taub. }\end{array}$ & Asian & $\begin{array}{l}\text { dated phyl., } \\
\text { distr./fossils }\end{array}$ & Bruneau et al. 2008 \\
\hline 566 & & $\begin{array}{l}\text { Koompassia malaccensis } \\
\text { Benth. }\end{array}$ & Asian & $\begin{array}{l}\text { dated phyl., } \\
\text { distr./fossils }\end{array}$ & Bruneau et al. 2008 \\
\hline 567 & & $\begin{array}{l}\text { Millettia sericea (Vent.) } \\
\text { Wight \& Arn. ex Hassk. }\end{array}$ & Asian & $\begin{array}{l}\text { undated phyl., } \\
\text { distr./fossils }\end{array}$ & $\begin{array}{l}\text { Adema 2001, Cardoso et } \\
\text { al. } 2012\end{array}$ \\
\hline
\end{tabular}




\begin{tabular}{|c|c|c|c|c|c|}
\hline No & Family & Species & Origin & $\begin{array}{l}\text { Classification } \\
\text { method }\end{array}$ & References \\
\hline 568 & & $\begin{array}{l}\text { Ormosia sumatrana (Miq.) } \\
\text { Prain }\end{array}$ & Asian & $\begin{array}{l}\text { undated phyl., } \\
\text { distr./fossils }\end{array}$ & Cardoso et al. 2012 \\
\hline 569 & & Parkia speciosa Hassk. & Asian & phylogeogr. & $\begin{array}{l}\text { Bouchenak-Khelladi et al. } \\
2010\end{array}$ \\
\hline 570 & & $\begin{array}{l}\text { Sindora coriacea (Baker) } \\
\text { Prain }\end{array}$ & Asian & $\begin{array}{l}\text { dated phyl., } \\
\text { distr./fossils }\end{array}$ & $\begin{array}{l}\text { Bruneau et al. } 2008, \\
\text { Fougère-Danezan et al. } \\
2010\end{array}$ \\
\hline 571 & Fagaceae & $\begin{array}{l}\text { Castanopsis } \\
\text { acuminatissima (Blume) } \\
\text { A.DC. }\end{array}$ & Asian & phylogeogr. & Manos \& Stanford 2001 \\
\hline 572 & & $\begin{array}{l}\text { Castanopsis argentea } \\
\text { (Blume) A.DC. }\end{array}$ & Asian & phylogeogr. & Manos \& Stanford 2001 \\
\hline 573 & & Castanopsis buruana Miq. & Asian & phylogeogr. & Manos \& Stanford 2001 \\
\hline 574 & & $\begin{array}{l}\text { Castanopsis clemensii } \\
\text { Soepadmo }\end{array}$ & Asian & phylogeogr. & Manos \& Stanford 2001 \\
\hline 575 & & $\begin{array}{l}\text { Castanopsis costata } \\
\text { (Blume) A.DC. }\end{array}$ & Asian & phylogeogr. & Manos \& Stanford 2001 \\
\hline 576 & & $\begin{array}{l}\text { Castanopsis javanica } \\
\text { (Blume) A.DC. }\end{array}$ & Asian & phylogeogr. & Manos \& Stanford 2001 \\
\hline 577 & & $\begin{array}{l}\text { Castanopsis megacarpa } \\
\text { Gamble }\end{array}$ & Asian & phylogeogr. & Manos \& Stanford 2001 \\
\hline 578 & & $\begin{array}{l}\text { Castanopsis motleyana } \\
\text { King }\end{array}$ & Asian & phylogeogr. & Manos \& Stanford 2001 \\
\hline 579 & & $\begin{array}{l}\text { Castanopsis paucispina } \\
\text { Soepadmo }\end{array}$ & Asian & phylogeogr. & Manos \& Stanford 2001 \\
\hline 580 & & $\begin{array}{l}\text { Castanopsis philipensis } \\
\text { (Blanco) Vidal }\end{array}$ & Asian & phylogeogr. & Manos \& Stanford 2001 \\
\hline 581 & & Castanopsis sp.01 & Asian & phylogeogr. & Manos \& Stanford 2001 \\
\hline 582 & & Castanopsis sp.02 & Asian & phylogeogr. & Manos \& Stanford 2001 \\
\hline 583 & & Castanopsis sp.03 & Asian & phylogeogr. & Manos \& Stanford 2001 \\
\hline 584 & & Castanopsis sp.04 & Asian & phylogeogr. & Manos \& Stanford 2001 \\
\hline 585 & & Castanopsis sp.05 & Asian & phylogeogr. & Manos \& Stanford 2001 \\
\hline 586 & & Castanopsis sp.06 & Asian & phylogeogr. & Manos \& Stanford 2001 \\
\hline 587 & & Castanopsis sp.07 & Asian & phylogeogr. & Manos \& Stanford 2001 \\
\hline 588 & & Castanopsis sp.08 & Asian & phylogeogr. & Manos \& Stanford 2001 \\
\hline 589 & & $\begin{array}{l}\text { Castanopsis tungurrut } \\
\text { (Blume) A.DC. }\end{array}$ & Asian & phylogeogr. & Manos \& Stanford 2001 \\
\hline 590 & & Fagaceae sp. & Asian & phylogeogr. & Manos \& Stanford 2001 \\
\hline 591 & & $\begin{array}{l}\text { Lithocarpus beccarianus } \\
\text { (Benth.) A.Camus }\end{array}$ & Asian & phylogeogr. & $\begin{array}{l}\text { Cannon \& Manos 2003, } \\
\text { Manos \& Stanford } 2001\end{array}$ \\
\hline 592 & & $\begin{array}{l}\text { Lithocarpus bennettii } \\
\text { (Miq.) Rehder }\end{array}$ & Asian & phylogeogr. & $\begin{array}{l}\text { Cannon \& Manos 2003, } \\
\text { Manos \& Stanford } 2001\end{array}$ \\
\hline 593 & & $\begin{array}{l}\text { Lithocarpus cf. bicoloratus } \\
\text { (Elmer) A.Camus }\end{array}$ & Asian & phylogeogr. & $\begin{array}{l}\text { Cannon \& Manos 2003, } \\
\text { Manos \& Stanford } 2001\end{array}$ \\
\hline 594 & & $\begin{array}{l}\text { Lithocarpus blumeanus } \\
\text { (Korth.) Rehder }\end{array}$ & Asian & phylogeogr. & $\begin{array}{l}\text { Cannon \& Manos 2003, } \\
\text { Manos \& Stanford } 2001\end{array}$ \\
\hline 595 & & $\begin{array}{l}\text { Lithocarpus bullatus } \\
\text { Hatus. ex Soepadmo }\end{array}$ & Asian & phylogeogr. & $\begin{array}{l}\text { Cannon \& Manos 2003, } \\
\text { Manos \& Stanford } 2001\end{array}$ \\
\hline
\end{tabular}




\begin{tabular}{|c|c|c|c|c|c|}
\hline No & Family & Species & Origin & $\begin{array}{l}\text { Classification } \\
\text { method }\end{array}$ & References \\
\hline 596 & & $\begin{array}{l}\text { Lithocarpus caudatifolius } \\
\text { (Merr.) Rehder }\end{array}$ & Asian & phylogeogr. & $\begin{array}{l}\text { Cannon \& Manos 2003, } \\
\text { Manos \& Stanford } 2001\end{array}$ \\
\hline 597 & & $\begin{array}{l}\text { Lithocarpus celebicus } \\
\text { (Miq.) Rehder }\end{array}$ & Asian & phylogeogr. & $\begin{array}{l}\text { Cannon \& Manos 2003, } \\
\text { Manos \& Stanford } 2001\end{array}$ \\
\hline 598 & & $\begin{array}{l}\text { Lithocarpus clementianus } \\
\text { (King ex Hook.f.) A.Camus }\end{array}$ & Asian & phylogeogr. & $\begin{array}{l}\text { Cannon \& Manos 2003, } \\
\text { Manos \& Stanford } 2001\end{array}$ \\
\hline 599 & & $\begin{array}{l}\text { Lithocarpus confertus } \\
\text { Soepadmo }\end{array}$ & Asian & phylogeogr. & $\begin{array}{l}\text { Cannon \& Manos 2003, } \\
\text { Manos \& Stanford } 2001\end{array}$ \\
\hline 600 & & $\begin{array}{l}\text { Lithocarpus cyclophorus } \\
\text { (Endl.) A.Camus }\end{array}$ & Asian & phylogeogr. & $\begin{array}{l}\text { Cannon \& Manos 2003, } \\
\text { Manos \& Stanford } 2001\end{array}$ \\
\hline 601 & & $\begin{array}{l}\text { Lithocarpus daphnoideus } \\
\text { (Blume) A.Camus }\end{array}$ & Asian & phylogeogr. & $\begin{array}{l}\text { Cannon \& Manos 2003, } \\
\text { Manos \& Stanford } 2001\end{array}$ \\
\hline 602 & & $\begin{array}{l}\text { Lithocarpus elegans } \\
\text { (Blume) Hatus. ex } \\
\text { Soepadmo }\end{array}$ & Asian & phylogeogr. & $\begin{array}{l}\text { Cannon \& Manos 2003, } \\
\text { Manos \& Stanford } 2001\end{array}$ \\
\hline 603 & & $\begin{array}{l}\text { Lithocarpus } \\
\text { encleisocarpus (Korth.) } \\
\text { A.Camus }\end{array}$ & Asian & phylogeogr. & $\begin{array}{l}\text { Cannon \& Manos 2003, } \\
\text { Manos \& Stanford } 2001\end{array}$ \\
\hline 604 & & $\begin{array}{l}\text { Lithocarpus glutinosus } \\
\text { (Blume) Soepadmo }\end{array}$ & Asian & phylogeogr. & $\begin{array}{l}\text { Cannon \& Manos 2003, } \\
\text { Manos \& Stanford } 2001\end{array}$ \\
\hline 605 & & $\begin{array}{l}\text { Lithocarpus hallieri } \\
\text { (Seemen) A.Camus }\end{array}$ & Asian & phylogeogr. & $\begin{array}{l}\text { Cannon \& Manos 2003, } \\
\text { Manos \& Stanford } 2001\end{array}$ \\
\hline 606 & & $\begin{array}{l}\text { Lithocarpus hatusimae } \\
\text { Soepadmo }\end{array}$ & Asian & phylogeogr. & $\begin{array}{l}\text { Cannon \& Manos 2003, } \\
\text { Manos \& Stanford } 2001\end{array}$ \\
\hline 607 & & $\begin{array}{l}\text { Lithocarpus havilandii } \\
\text { (Stapf) Barnett }\end{array}$ & Asian & phylogeogr. & $\begin{array}{l}\text { Cannon \& Manos 2003, } \\
\text { Manos \& Stanford } 2001\end{array}$ \\
\hline 608 & & $\begin{array}{l}\text { Lithocarpus hystrix } \\
\text { (Korth.) Rehder }\end{array}$ & Asian & phylogeogr. & $\begin{array}{l}\text { Cannon \& Manos 2003, } \\
\text { Manos \& Stanford } 2001\end{array}$ \\
\hline 609 & & $\begin{array}{l}\text { Lithocarpus cf. indutus } \\
\text { (Blume) Rehder }\end{array}$ & Asian & phylogeogr. & $\begin{array}{l}\text { Cannon \& Manos 2003, } \\
\text { Manos \& Stanford } 2001\end{array}$ \\
\hline 610 & & $\begin{array}{l}\text { Lithocarpus korthalsii } \\
\text { (Endl.) Soepadmo }\end{array}$ & Asian & phylogeogr. & $\begin{array}{l}\text { Cannon \& Manos 2003, } \\
\text { Manos \& Stanford } 2001\end{array}$ \\
\hline 611 & & $\begin{array}{l}\text { Lithocarpus lampadarius } \\
\text { (Gamble) A.Camus }\end{array}$ & Asian & phylogeogr. & $\begin{array}{l}\text { Cannon \& Manos 2003, } \\
\text { Manos \& Stanford } 2001\end{array}$ \\
\hline 612 & & $\begin{array}{l}\text { Lithocarpus leptogyne } \\
\text { (Korth.) Soepadmo }\end{array}$ & Asian & phylogeogr. & $\begin{array}{l}\text { Cannon \& Manos 2003, } \\
\text { Manos \& Stanford } 2001\end{array}$ \\
\hline 613 & & $\begin{array}{l}\text { Lithocarpus lucidus } \\
\text { (Roxb.) Rehder }\end{array}$ & Asian & phylogeogr. & $\begin{array}{l}\text { Cannon \& Manos 2003, } \\
\text { Manos \& Stanford } 2001\end{array}$ \\
\hline 614 & & $\begin{array}{l}\text { Lithocarpus luteus } \\
\text { Soepadmo }\end{array}$ & Asian & phylogeogr. & $\begin{array}{l}\text { Cannon \& Manos 2003, } \\
\text { Manos \& Stanford } 2001\end{array}$ \\
\hline 615 & & $\begin{array}{l}\text { Lithocarpus maingayi } \\
\text { (Benth.) Rehder }\end{array}$ & Asian & phylogeogr. & $\begin{array}{l}\text { Cannon \& Manos 2003, } \\
\text { Manos \& Stanford } 2001\end{array}$ \\
\hline 616 & & $\begin{array}{l}\text { Lithocarpus menadoensis } \\
\text { (Koord.) Soepadmo }\end{array}$ & Asian & phylogeogr. & $\begin{array}{l}\text { Cannon \& Manos 2003, } \\
\text { Manos \& Stanford } 2001\end{array}$ \\
\hline 617 & & $\begin{array}{l}\text { Lithocarpus nieuwenhuisii } \\
\text { (Seemen) A.Camus }\end{array}$ & Asian & phylogeogr. & $\begin{array}{l}\text { Cannon \& Manos 2003, } \\
\text { Manos \& Stanford } 2001\end{array}$ \\
\hline 618 & & $\begin{array}{l}\text { Lithocarpus nodosus } \\
\text { Soepadmo }\end{array}$ & Asian & phylogeogr. & $\begin{array}{l}\text { Cannon \& Manos 2003, } \\
\text { Manos \& Stanford } 2001\end{array}$ \\
\hline
\end{tabular}




\begin{tabular}{|c|c|c|c|c|c|}
\hline No & Family & Species & Origin & $\begin{array}{l}\text { Classification } \\
\text { method }\end{array}$ & References \\
\hline 619 & & $\begin{array}{l}\text { Lithocarpus papillifer } \\
\text { Hatus. ex Soepadmo }\end{array}$ & Asian & phylogeogr. & $\begin{array}{l}\text { Cannon \& Manos 2003, } \\
\text { Manos \& Stanford } 2001\end{array}$ \\
\hline 620 & & $\begin{array}{l}\text { Lithocarpus philippinensis } \\
\text { (A.DC.) Rehder }\end{array}$ & Asian & phylogeogr. & $\begin{array}{l}\text { Cannon \& Manos 2003, } \\
\text { Manos \& Stanford } 2001\end{array}$ \\
\hline 621 & & $\begin{array}{l}\text { Lithocarpus } \\
\text { pseudomoluccus (Blume) } \\
\text { Rehder }\end{array}$ & Asian & phylogeogr. & $\begin{array}{l}\text { Cannon \& Manos 2003, } \\
\text { Manos \& Stanford } 2001\end{array}$ \\
\hline 622 & & $\begin{array}{l}\text { Lithocarpus pusillus } \\
\text { Soepadmo }\end{array}$ & Asian & phylogeogr. & $\begin{array}{l}\text { Cannon \& Manos 2003, } \\
\text { Manos \& Stanford } 2001\end{array}$ \\
\hline 623 & & $\begin{array}{l}\text { Lithocarpus rigidus } \\
\text { Soepadmo }\end{array}$ & Asian & phylogeogr. & $\begin{array}{l}\text { Cannon \& Manos 2003, } \\
\text { Manos \& Stanford } 2001\end{array}$ \\
\hline 624 & & $\begin{array}{l}\text { Lithocarpus rotundatus } \\
\text { (Blume) A.Camus }\end{array}$ & Asian & phylogeogr. & $\begin{array}{l}\text { Cannon \& Manos 2003, } \\
\text { Manos \& Stanford } 2001\end{array}$ \\
\hline 625 & & Lithocarpus sp.01 & Asian & phylogeogr. & $\begin{array}{l}\text { Cannon \& Manos 2003, } \\
\text { Manos \& Stanford } 2001\end{array}$ \\
\hline 626 & & Lithocarpus sp.02 & Asian & phylogeogr. & $\begin{array}{l}\text { Cannon \& Manos 2003, } \\
\text { Manos \& Stanford } 2001\end{array}$ \\
\hline 627 & & Lithocarpus sp.03 & Asian & phylogeogr. & $\begin{array}{l}\text { Cannon \& Manos 2003, } \\
\text { Manos \& Stanford } 2001\end{array}$ \\
\hline 628 & & Lithocarpus sp.04 & Asian & phylogeogr. & $\begin{array}{l}\text { Cannon \& Manos 2003, } \\
\text { Manos \& Stanford } 2001\end{array}$ \\
\hline 629 & & Lithocarpus sp.05 & Asian & phylogeogr. & $\begin{array}{l}\text { Cannon \& Manos 2003, } \\
\text { Manos \& Stanford } 2001\end{array}$ \\
\hline 630 & & Lithocarpus sp.06 & Asian & phylogeogr. & $\begin{array}{l}\text { Cannon \& Manos 2003, } \\
\text { Manos \& Stanford } 2001\end{array}$ \\
\hline 631 & & Lithocarpus sp.07 & Asian & phylogeogr. & $\begin{array}{l}\text { Cannon \& Manos 2003, } \\
\text { Manos \& Stanford } 2001\end{array}$ \\
\hline 632 & & Lithocarpus sp.08 & Asian & phylogeogr. & $\begin{array}{l}\text { Cannon \& Manos 2003, } \\
\text { Manos \& Stanford } 2001\end{array}$ \\
\hline 633 & & Lithocarpus sp.09 & Asian & phylogeogr. & $\begin{array}{l}\text { Cannon \& Manos 2003, } \\
\text { Manos \& Stanford } 2001\end{array}$ \\
\hline 634 & & Lithocarpus sp.10 & Asian & phylogeogr. & $\begin{array}{l}\text { Cannon \& Manos 2003, } \\
\text { Manos \& Stanford } 2001\end{array}$ \\
\hline 635 & & Lithocarpus sp.11 & Asian & phylogeogr. & $\begin{array}{l}\text { Cannon \& Manos 2003, } \\
\text { Manos \& Stanford } 2001\end{array}$ \\
\hline 636 & & Lithocarpus sp.12 & Asian & phylogeogr. & $\begin{array}{l}\text { Cannon \& Manos 2003, } \\
\text { Manos \& Stanford } 2001\end{array}$ \\
\hline 637 & & Lithocarpus sp.13 & Asian & phylogeogr. & $\begin{array}{l}\text { Cannon \& Manos 2003, } \\
\text { Manos \& Stanford } 2001\end{array}$ \\
\hline 638 & & Lithocarpus sp.14 & Asian & phylogeogr. & $\begin{array}{l}\text { Cannon \& Manos 2003, } \\
\text { Manos \& Stanford } 2001\end{array}$ \\
\hline 639 & & Lithocarpus sp.15 & Asian & phylogeogr. & $\begin{array}{l}\text { Cannon \& Manos 2003, } \\
\text { Manos \& Stanford } 2001\end{array}$ \\
\hline 640 & & Lithocarpus sp.16 & Asian & phylogeogr. & $\begin{array}{l}\text { Cannon \& Manos 2003, } \\
\text { Manos \& Stanford } 2001\end{array}$ \\
\hline 641 & & $\begin{array}{l}\text { Lithocarpus sundaicus } \\
\text { (Blume) Rehder }\end{array}$ & Asian & phylogeogr. & $\begin{array}{l}\text { Cannon \& Manos 2003, } \\
\text { Manos \& Stanford } 2001\end{array}$ \\
\hline
\end{tabular}




\begin{tabular}{|c|c|c|c|c|c|}
\hline No & Family & Species & Origin & $\begin{array}{l}\text { Classification } \\
\text { method }\end{array}$ & References \\
\hline 642 & & $\begin{array}{l}\text { Lithocarpus turbinatus } \\
\text { (Stapf) Forman }\end{array}$ & Asian & phylogeogr. & $\begin{array}{l}\text { Cannon \& Manos 2003, } \\
\text { Manos \& Stanford } 2001\end{array}$ \\
\hline 643 & & $\begin{array}{l}\text { Lithocarpus woodii } \\
\text { (Hance) A.Camus }\end{array}$ & Asian & phylogeogr. & $\begin{array}{l}\text { Cannon \& Manos 2003, } \\
\text { Manos \& Stanford } 2001\end{array}$ \\
\hline 644 & & Quercus argentata Korth. & Asian & phylogeogr. & Manos \& Stanford 2001 \\
\hline 645 & & $\begin{array}{l}\text { Quercus chrysotricha } \\
\text { A.Camus }\end{array}$ & Asian & phylogeogr. & Manos \& Stanford 2001 \\
\hline 646 & & Quercus elmeri Merr. & Asian & phylogeogr. & Manos \& Stanford 2001 \\
\hline 647 & & $\begin{array}{l}\text { Quercus gemelliflora } \\
\text { Blume }\end{array}$ & Asian & phylogeogr. & Manos \& Stanford 2001 \\
\hline 648 & & Quercus lowii King & Asian & phylogeogr. & Manos \& Stanford 2001 \\
\hline 649 & & $\begin{array}{l}\text { Quercus } \\
\text { pseudoverticillata } \\
\text { Soepadmo }\end{array}$ & Asian & phylogeogr. & Manos \& Stanford 2001 \\
\hline 650 & & Quercus sp.1 & Asian & phylogeogr. & Manos \& Stanford 2001 \\
\hline 651 & & Quercus sp.2 & Asian & phylogeogr. & Manos \& Stanford 2001 \\
\hline 652 & & $\begin{array}{l}\text { Quercus subsericea } \\
\text { A.Camus }\end{array}$ & Asian & phylogeogr. & Manos \& Stanford 2001 \\
\hline 653 & & $\begin{array}{l}\text { Quercus sumatrana } \\
\text { Soepadmo }\end{array}$ & Asian & phylogeogr. & Manos \& Stanford 2001 \\
\hline 654 & & $\begin{array}{l}\text { Quercus treubiana } \\
\text { Seemen }\end{array}$ & Asian & phylogeogr. & Manos \& Stanford 2001 \\
\hline 655 & & $\begin{array}{l}\text { Quercus valdinervosa } \\
\text { Soepadmo }\end{array}$ & Asian & phylogeogr. & Manos \& Stanford 2001 \\
\hline 656 & & $\begin{array}{l}\text { Trigonobalanus verticillata } \\
\text { Forman }\end{array}$ & Asian & phylogeogr. & Manos \& Stanford 2001 \\
\hline 657 & Gentianaceae & Fagraea auriculata Jack & Asian & dated phyl. & $\begin{array}{l}\text { Frasier et al. 2008, } \\
\text { Merckx et al. 2013, } \\
\text { Sugumaran \& Wong } 2012\end{array}$ \\
\hline 658 & & Fagraea blumei G.Don & Asian & dated phyl. & $\begin{array}{l}\text { Frasier et al. 2008, } \\
\text { Merckx et al. 2013, } \\
\text { Sugumaran \& Wong } 2012\end{array}$ \\
\hline 659 & & Fagraea ceilanica Thunb. & Asian & dated phyl. & $\begin{array}{l}\text { Frasier et al. 2008, } \\
\text { Merckx et al. 2013, } \\
\text { Sugumaran \& Wong } 2012\end{array}$ \\
\hline 660 & & Fagraea sp.1 & Asian & dated phyl. & $\begin{array}{l}\text { Frasier et al. 2008, } \\
\text { Merckx et al. 2013, } \\
\text { Sugumaran \& Wong } 2012\end{array}$ \\
\hline 661 & & $\begin{array}{l}\text { Picrophloeus collinus } \\
\text { (K.M.Wong \& Sugau) } \\
\text { K.M.Wong }\end{array}$ & Asian & dated phyl. & $\begin{array}{l}\text { Frasier et al. 2008, } \\
\text { Merckx et al. 2013, } \\
\text { Sugumaran \& Wong } 2012\end{array}$ \\
\hline 662 & & $\begin{array}{l}\text { Utania morindifolia } \\
\text { (Blume) G.Don }\end{array}$ & Asian & dated phyl. & $\begin{array}{l}\text { Frasier et al. 2008, } \\
\text { Merckx et al. 2013, } \\
\text { Sugumaran \& Wong } 2012\end{array}$ \\
\hline 663 & Hamamelidaceae & $\begin{array}{l}\text { Distyliopsis dunnii } \\
\text { (Hemsl.) P.K.Endress }\end{array}$ & Asian & $\begin{array}{l}\text { undated phyl., } \\
\text { distr./fossils }\end{array}$ & Endress 1993, Li 2008 \\
\hline 664 & Himantandraceae & $\begin{array}{l}\text { Galbulimima belgraveana } \\
\text { (F.Muell.) Sprague }\end{array}$ & Austr. & $\begin{array}{l}\text { undated phyl., } \\
\text { distr./fossils }\end{array}$ & $\begin{array}{l}\text { Endress 1993, Massoni et } \\
\text { al. } 2014\end{array}$ \\
\hline
\end{tabular}




\begin{tabular}{|c|c|c|c|c|c|}
\hline No & Family & Species & Origin & $\begin{array}{l}\text { Classification } \\
\text { method }\end{array}$ & References \\
\hline 665 & Hydrangeaceae & $\begin{array}{l}\text { Dichroa sylvatica (Reinw. } \\
\text { ex Bl.) Merr. }\end{array}$ & Asian & $\begin{array}{l}\text { dated phyl., } \\
\text { distr./fossils }\end{array}$ & $\begin{array}{l}\text { Hufford 2004, Samain et } \\
\text { al. 2010, Xiang et al. } 2011\end{array}$ \\
\hline 666 & Hypericaceae & $\begin{array}{l}\text { Cratoxylum arborescens } \\
\text { (Vahl) Blume }\end{array}$ & Asian & phylogeogr. & Ruhfel et al. 2016 \\
\hline 667 & & $\begin{array}{l}\text { Cratoxylum formosum } \\
\text { (Jacq.) Benth. \& Hook.f. ex } \\
\text { Dyer }\end{array}$ & Asian & phylogeogr. & Ruhfel et al. 2016 \\
\hline 668 & & $\begin{array}{l}\text { Cratoxylum sumatranum } \\
\text { (Jack) Blume }\end{array}$ & Asian & phylogeogr. & Ruhfel et al. 2016 \\
\hline 669 & Irvingiaceae & $\begin{array}{l}\text { Irvingia malayana Oliv. ex } \\
\text { A.W.Benn. }\end{array}$ & Asian & $\begin{array}{l}\text { phylogeogr., } \\
\text { distr./fossils }\end{array}$ & $\begin{array}{l}\text { Byng et al. 2016, } \\
\text { Nooteboom 1962, Xi et } \\
\text { al. } 2012\end{array}$ \\
\hline 670 & Iteaceae & Itea macrophylla Wall. & Asian & distr./fossils & Hermsen 2013 \\
\hline 671 & Ixonanthaceae & $\begin{array}{l}\text { Ixonanthes petiolaris } \\
\text { Blume }\end{array}$ & Asian & $\begin{array}{l}\text { phylogeogr., } \\
\text { distr./fossils }\end{array}$ & $\begin{array}{l}\text { Byng et al. 2016, Xi et al. } \\
2012\end{array}$ \\
\hline 672 & & Ixonanthes reticulata Jack & Asian & $\begin{array}{l}\text { phylogeogr., } \\
\text { distr./fossils }\end{array}$ & $\begin{array}{l}\text { Byng et al. 2016, Xi et al. } \\
2012\end{array}$ \\
\hline 673 & Juglandaceae & $\begin{array}{l}\text { Engelhardtia apoensis } \\
\text { Elmer ex Nagel }\end{array}$ & Asian & distr./fossils & Manchester 1989 \\
\hline 674 & & Engelhardtia rigida Blume & Asian & distr./fossils & Manchester 1989 \\
\hline 675 & & $\begin{array}{l}\text { Engelhardtia serrata } \\
\text { Blume }\end{array}$ & Asian & distr./fossils & Manchester 1989 \\
\hline 676 & & Engelhardtia sp.1 & Asian & distr./fossils & Manchester 1989 \\
\hline 677 & & $\begin{array}{l}\text { Engelhardtia spicata } \\
\text { Lechen ex Blume }\end{array}$ & Asian & distr./fossils & Manchester 1989 \\
\hline 678 & Lamiaceae & $\begin{array}{l}\text { Callicarpa pentandra } \\
\text { Roxb. }\end{array}$ & Asian & $\begin{array}{l}\text { undated phyl., } \\
\text { distr./fossils }\end{array}$ & Li et al. 2016, WCSP 2017 \\
\hline 679 & & $\begin{array}{l}\text { Clerodendrum } \\
\text { brachyanthum Schauer }\end{array}$ & Asian & $\begin{array}{l}\text { undated phyl., } \\
\text { distr./fossils }\end{array}$ & $\begin{array}{l}\text { Harley et al. 2004, WCSP } \\
\text { 2017, Yuan et al. } 2010\end{array}$ \\
\hline 680 & & $\begin{array}{l}\text { Clerodendrum } \\
\text { phyllomega Steud. }\end{array}$ & Asian & $\begin{array}{l}\text { undated phyl., } \\
\text { distr./fossils }\end{array}$ & $\begin{array}{l}\text { Harley et al. 2004, WCSP } \\
\text { 2017, Yuan et al. } 2010\end{array}$ \\
\hline 681 & & $\begin{array}{l}\text { Teijsmanniodendron } \\
\text { holophyllum (Baker) } \\
\text { Kosterm. }\end{array}$ & Asian & $\begin{array}{l}\text { undated phyl., } \\
\text { distr./fossils }\end{array}$ & Li et al. 2016, WCSP 2017 \\
\hline 682 & & $\begin{array}{l}\text { Teijsmanniodendron } \\
\text { pteropodum (Miq.) Bakh. }\end{array}$ & Asian & $\begin{array}{l}\text { undated phyl., } \\
\text { distr./fossils }\end{array}$ & Li et al. 2016, WCSP 2017 \\
\hline 683 & & $\begin{array}{l}\text { Teijsmanniodendron } \\
\text { sarawakanum (H.Pearson) } \\
\text { Kosterm. }\end{array}$ & Asian & $\begin{array}{l}\text { undated phyl., } \\
\text { distr./fossils }\end{array}$ & Li et al. 2016, WCSP 2017 \\
\hline 684 & & Teijsmanniodendron sp. & Asian & $\begin{array}{l}\text { undated phyl., } \\
\text { distr./fossils }\end{array}$ & Li et al. 2016, WCSP 2017 \\
\hline 685 & & $\begin{array}{l}\text { Vitex quinata (Lour.) } \\
\text { F.N.Williams }\end{array}$ & Asian & $\begin{array}{l}\text { undated phyl., } \\
\text { distr./fossils }\end{array}$ & Li et al. 2016, WCSP 2017 \\
\hline 686 & Lauraceae & $\begin{array}{l}\text { Actinodaphne angustifolia } \\
\text { (Blume) Nees }\end{array}$ & Asian & $\begin{array}{l}\text { dated phyl., } \\
\text { undated phyl. }\end{array}$ & $\begin{array}{l}\text { Chanderbali et al. 2001, } \\
\text { Li et al. 2004, } 2008\end{array}$ \\
\hline 687 & & $\begin{array}{l}\text { Actinodaphne glabra } \\
\text { Blume }\end{array}$ & Asian & $\begin{array}{l}\text { dated phyl., } \\
\text { undated phyl. }\end{array}$ & $\begin{array}{l}\text { Chanderbali et al. 2001, } \\
\text { Li et al. 2004, } 2008\end{array}$ \\
\hline
\end{tabular}




\begin{tabular}{|c|c|c|c|c|c|}
\hline No & Family & Species & Origin & $\begin{array}{l}\text { Classification } \\
\text { method }\end{array}$ & References \\
\hline 688 & & $\begin{array}{l}\text { Actinodaphne glomerata } \\
\text { (Blume) Nees }\end{array}$ & Asian & $\begin{array}{l}\text { dated phyl., } \\
\text { undated phyl. }\end{array}$ & $\begin{array}{l}\text { Chanderbali et al. 2001, } \\
\text { Li et al. 2004, } 2008\end{array}$ \\
\hline 689 & & Actinodaphne sp.1 & Asian & $\begin{array}{l}\text { dated phyl., } \\
\text { undated phyl. }\end{array}$ & $\begin{array}{l}\text { Chanderbali et al. 2001, } \\
\text { Li et al. 2004, } 2008\end{array}$ \\
\hline 690 & & Actinodaphne sp.2 & Asian & $\begin{array}{l}\text { dated phyl., } \\
\text { undated phyl. }\end{array}$ & $\begin{array}{l}\text { Chanderbali et al. 2001, } \\
\text { Li et al. 2004, } 2008\end{array}$ \\
\hline 691 & & $\begin{array}{l}\text { Alseodaphne longipes } \\
\text { Quisumb. \& Merr. }\end{array}$ & Asian & phylogeogr. & Li et al. 2011 \\
\hline 692 & & $\begin{array}{l}\text { Alseodaphne } \\
\text { oblanceolata (Merr.) } \\
\text { Kosterm. }\end{array}$ & Asian & phylogeogr. & Li et al. 2011 \\
\hline 693 & & $\begin{array}{l}\text { Alseodaphne } \\
\text { peduncularis (Wall. ex } \\
\text { Nees) Meisn. }\end{array}$ & Asian & phylogeogr. & Li et al. 2011 \\
\hline 694 & & Alseodaphne sp.1 & Asian & phylogeogr. & Li et al. 2011 \\
\hline 695 & & Alseodaphne sp.2 & Asian & phylogeogr. & Li et al. 2011 \\
\hline 696 & & $\begin{array}{l}\text { Beilschmiedia dictyoneura } \\
\text { Kosterm. }\end{array}$ & Austr. & dated phyl. & $\begin{array}{l}\text { Chanderbali et al 2001, } \\
\text { Rohwer et al. } 2014\end{array}$ \\
\hline 697 & & $\begin{array}{l}\text { Beilschmiedia glabra } \\
\text { Kosterm. }\end{array}$ & Austr. & dated phyl. & $\begin{array}{l}\text { Chanderbali et al 2001, } \\
\text { Rohwer et al. } 2014\end{array}$ \\
\hline 698 & & $\begin{array}{l}\text { Beilschmiedia } \\
\text { gynotrochioides Kosterm. }\end{array}$ & Austr. & dated phyl. & $\begin{array}{l}\text { Chanderbali et al 2001, } \\
\text { Rohwer et al. } 2014\end{array}$ \\
\hline 699 & & $\begin{array}{l}\text { Beilschmiedia madang } \\
\text { Blume }\end{array}$ & Austr. & dated phyl. & $\begin{array}{l}\text { Chanderbali et al 2001, } \\
\text { Rohwer et al. } 2014\end{array}$ \\
\hline 700 & & $\begin{array}{l}\text { Beilschmiedia perakensis } \\
\text { Gamble }\end{array}$ & Austr. & dated phyl. & $\begin{array}{l}\text { Chanderbali et al 2001, } \\
\text { Rohwer et al. } 2014\end{array}$ \\
\hline 701 & & $\begin{array}{l}\text { Beilschmiedia rivularis } \\
\text { Kosterm. }\end{array}$ & Austr. & dated phyl. & $\begin{array}{l}\text { Chanderbali et al 2001, } \\
\text { Rohwer et al. } 2014\end{array}$ \\
\hline 702 & & Beilschmiedia sp.1 & Austr. & dated phyl. & $\begin{array}{l}\text { Chanderbali et al 2001, } \\
\text { Rohwer et al. } 2014\end{array}$ \\
\hline 703 & & Beilschmiedia sp.2 & Austr. & dated phyl. & $\begin{array}{l}\text { Chanderbali et al 2001, } \\
\text { Rohwer et al. } 2014\end{array}$ \\
\hline 704 & & Beilschmiedia sp.3 & Austr. & dated phyl. & $\begin{array}{l}\text { Chanderbali et al 2001, } \\
\text { Rohwer et al. } 2014\end{array}$ \\
\hline 705 & & Beilschmiedia sp.4 & Austr. & dated phyl. & $\begin{array}{l}\text { Chanderbali et al 2001, } \\
\text { Rohwer et al. } 2014\end{array}$ \\
\hline 706 & & Beilschmiedia sp.5 & Austr. & dated phyl. & $\begin{array}{l}\text { Chanderbali et al 2001, } \\
\text { Rohwer et al. } 2014\end{array}$ \\
\hline 707 & & Beilschmiedia sp.6 & Austr. & dated phyl. & $\begin{array}{l}\text { Chanderbali et al 2001, } \\
\text { Rohwer et al. } 2014\end{array}$ \\
\hline 708 & & $\begin{array}{l}\text { Cinnamomum mercadoi } \\
\text { S.Vidal }\end{array}$ & Asian & phylogeogr. & Huang et al. 2016 \\
\hline 709 & & $\begin{array}{l}\text { Cinnamomum polderi } \\
\text { Kosterm. }\end{array}$ & Asian & phylogeogr. & Huang et al. 2016 \\
\hline 710 & & $\begin{array}{l}\text { Cinnamomum porrectum } \\
\text { (Roxb.) Kosterm }\end{array}$ & Asian & phylogeogr. & Huang et al. 2016 \\
\hline 711 & & $\begin{array}{l}\text { Cinnamomum sintoc } \\
\text { Blume }\end{array}$ & Asian & phylogeogr. & Huang et al. 2016 \\
\hline
\end{tabular}




\begin{tabular}{|c|c|c|c|c|c|}
\hline No & Family & Species & Origin & $\begin{array}{l}\text { Classification } \\
\text { method }\end{array}$ & References \\
\hline 712 & & Cinnamomum sp.1 & Asian & phylogeogr. & Huang et al. 2016 \\
\hline 713 & & Cinnamomum sp.2 & Asian & phylogeogr. & Huang et al. 2016 \\
\hline 714 & & Cinnamomum sp.3 & Asian & phylogeogr. & Huang et al. 2016 \\
\hline 715 & & Cinnamomum sp.4 & Asian & phylogeogr. & Huang et al. 2016 \\
\hline 716 & & $\begin{array}{l}\text { Cinnamomum } \\
\text { subcuneatum Miq. }\end{array}$ & Asian & phylogeogr. & Huang et al. 2016 \\
\hline 717 & & $\begin{array}{l}\text { Cryptocarya acutifolia } \\
\text { H.W.Li }\end{array}$ & Austr. & dated phyl. & $\begin{array}{l}\text { Chanderbali et al 2001, } \\
\text { Rohwer et al. } 2014\end{array}$ \\
\hline 718 & & $\begin{array}{l}\text { Cryptocarya albida } \\
\text { Kosterm. }\end{array}$ & Austr. & dated phyl. & $\begin{array}{l}\text { Chanderbali et al 2001, } \\
\text { Rohwer et al. } 2014\end{array}$ \\
\hline 719 & & Cryptocarya ampla Merr. & Austr. & dated phyl. & $\begin{array}{l}\text { Chanderbali et al 2001, } \\
\text { Rohwer et al. } 2014\end{array}$ \\
\hline 720 & & $\begin{array}{l}\text { Cryptocarya } \\
\text { crassinerviopsis Kosterm. }\end{array}$ & Austr. & dated phyl. & $\begin{array}{l}\text { Chanderbali et al 2001, } \\
\text { Rohwer et al. } 2014\end{array}$ \\
\hline 721 & & $\begin{array}{l}\text { Cryptocarya densiflora } \\
\text { Blume }\end{array}$ & Austr. & dated phyl. & $\begin{array}{l}\text { Chanderbali et al 2001, } \\
\text { Rohwer et al. } 2014\end{array}$ \\
\hline 722 & & Cryptocarya ferrea Blume & Austr. & dated phyl. & $\begin{array}{l}\text { Chanderbali et al 2001, } \\
\text { Rohwer et al. } 2014\end{array}$ \\
\hline 723 & & $\begin{array}{l}\text { Cryptocarya griffithiana } \\
\text { Wight }\end{array}$ & Austr. & dated phyl. & $\begin{array}{l}\text { Chanderbali et al 2001, } \\
\text { Rohwer et al. } 2014\end{array}$ \\
\hline 724 & & $\begin{array}{l}\text { Cryptocarya microcos } \\
\text { Kosterm. }\end{array}$ & Austr. & dated phyl. & $\begin{array}{l}\text { Chanderbali et al 2001, } \\
\text { Rohwer et al. } 2014\end{array}$ \\
\hline 725 & & $\begin{array}{l}\text { Cryptocarya palawanensis } \\
\text { Merr. }\end{array}$ & Austr. & dated phyl. & $\begin{array}{l}\text { Chanderbali et al 2001, } \\
\text { Rohwer et al. } 2014\end{array}$ \\
\hline 726 & & Cryptocarya sp.1 & Austr. & dated phyl. & $\begin{array}{l}\text { Chanderbali et al 2001, } \\
\text { Rohwer et al. } 2014\end{array}$ \\
\hline 727 & & Cryptocarya sp.2 & Austr. & dated phyl. & $\begin{array}{l}\text { Chanderbali et al 2001, } \\
\text { Rohwer et al. } 2014\end{array}$ \\
\hline 728 & & Cryptocarya sp.3 & Austr. & dated phyl. & $\begin{array}{l}\text { Chanderbali et al 2001, } \\
\text { Rohwer et al. } 2014\end{array}$ \\
\hline 729 & & Dehaasia firma Blume & Asian & phylogeogr. & Li et al. 2011 \\
\hline 730 & & $\begin{array}{l}\text { Dehaasia incrassata (Jack) } \\
\text { Kosterm. }\end{array}$ & Asian & phylogeogr. & Li et al. 2011 \\
\hline 731 & & $\begin{array}{l}\text { Dehaasia membranacea } \\
\text { Kosterm. }\end{array}$ & Asian & phylogeogr. & Li et al. 2011 \\
\hline 732 & & Dehaasia sp.1 & Asian & phylogeogr. & Li et al. 2011 \\
\hline 733 & & $\begin{array}{l}\text { Endiandra clavigera } \\
\text { Kosterm. }\end{array}$ & Austr. & dated phyl. & $\begin{array}{l}\text { Chanderbali et al 2001, } \\
\text { Rohwer et al. } 2014\end{array}$ \\
\hline 734 & & $\begin{array}{l}\text { Endiandra macrophylla } \\
\text { (Blume) Boerl. }\end{array}$ & Austr. & dated phyl. & $\begin{array}{l}\text { Chanderbali et al 2001, } \\
\text { Rohwer et al. } 2014\end{array}$ \\
\hline 735 & & $\begin{array}{l}\text { Endiandra rubescens } \\
\text { (Blume) Miq. }\end{array}$ & Austr. & dated phyl. & $\begin{array}{l}\text { Chanderbali et al 2001, } \\
\text { Rohwer et al. } 2014\end{array}$ \\
\hline 736 & & $\begin{array}{l}\text { Endiandra scrobiculata } \\
\text { Kosterm. ex Kochummen }\end{array}$ & Austr. & dated phyl. & $\begin{array}{l}\text { Chanderbali et al 2001, } \\
\text { Rohwer et al. } 2014\end{array}$ \\
\hline 737 & & Endiandra sp.1 & Austr. & dated phyl. & $\begin{array}{l}\text { Chanderbali et al 2001, } \\
\text { Rohwer et al. } 2014\end{array}$ \\
\hline 738 & & Endiandra sp.2 & Austr. & dated phyl. & $\begin{array}{l}\text { Chanderbali et al 2001, } \\
\text { Rohwer et al. } 2014\end{array}$ \\
\hline
\end{tabular}




\begin{tabular}{|c|c|c|c|c|c|}
\hline No & Family & Species & Origin & $\begin{array}{l}\text { Classification } \\
\text { method }\end{array}$ & References \\
\hline 739 & & Endiandra sp.3 & Austr. & dated phyl. & $\begin{array}{l}\text { Chanderbali et al 2001, } \\
\text { Rohwer et al. } 2014\end{array}$ \\
\hline 740 & & Endiandra sp.4 & Austr. & dated phyl. & $\begin{array}{l}\text { Chanderbali et al 2001, } \\
\text { Rohwer et al. } 2014\end{array}$ \\
\hline 741 & & $\begin{array}{l}\text { Endiandra sulavesiana } \\
\text { Kosterm. }\end{array}$ & Austr. & dated phyl. & $\begin{array}{l}\text { Chanderbali et al 2001, } \\
\text { Rohwer et al. } 2014\end{array}$ \\
\hline 742 & & $\begin{array}{l}\text { Eusideroxylon zwageri } \\
\text { Teijsm. \& Binn. }\end{array}$ & Asian & dated phyl. & $\begin{array}{l}\text { Chanderbali et al 2001, } \\
\text { Rohwer et al. } 2014\end{array}$ \\
\hline 743 & & Lindera apoensis Elmer & Asian & $\begin{array}{l}\text { dated phyl., } \\
\text { undated phyl. }\end{array}$ & $\begin{array}{l}\text { Chanderbali et al. 2001, } \\
\text { Li et al. 2004, } 2008\end{array}$ \\
\hline 744 & & $\begin{array}{l}\text { Lindera novoguineensis } \\
\text { Kosterm. }\end{array}$ & Asian & $\begin{array}{l}\text { dated phyl., } \\
\text { undated phyl. }\end{array}$ & $\begin{array}{l}\text { Chanderbali et al. 2001, } \\
\text { Li et al. 2004, } 2008\end{array}$ \\
\hline 745 & & $\begin{array}{l}\text { Lindera polyantha (Blume) } \\
\text { Boerl. }\end{array}$ & Asian & $\begin{array}{l}\text { dated phyl., } \\
\text { undated phyl. }\end{array}$ & $\begin{array}{l}\text { Chanderbali et al. 2001, } \\
\text { Li et al. 2004, } 2008\end{array}$ \\
\hline 746 & & $\begin{array}{l}\text { Litsea accedens (Blume) } \\
\text { Boerl. }\end{array}$ & Asian & $\begin{array}{l}\text { dated phyl., } \\
\text { undated phyl. }\end{array}$ & $\begin{array}{l}\text { Chanderbali et al. 2001, } \\
\text { Li et al. 2004, } 2008\end{array}$ \\
\hline 747 & & Litsea angulata Blume & Asian & $\begin{array}{l}\text { dated phyl., } \\
\text { undated phyl. }\end{array}$ & $\begin{array}{l}\text { Chanderbali et al. 2001, } \\
\text { Li et al. 2004, } 2008\end{array}$ \\
\hline 748 & & $\begin{array}{l}\text { Litsea brachystachya } \\
\text { Fern.-Vill. }\end{array}$ & Asian & $\begin{array}{l}\text { dated phyl., } \\
\text { undated phyl. }\end{array}$ & $\begin{array}{l}\text { Chanderbali et al. 2001, } \\
\text { Li et al. 2004, } 2008\end{array}$ \\
\hline 749 & & Litsea caulocarpa Merr. & Asian & $\begin{array}{l}\text { dated phyl., } \\
\text { undated phyl. }\end{array}$ & $\begin{array}{l}\text { Chanderbali et al. 2001, } \\
\text { Li et al. 2004, } 2008\end{array}$ \\
\hline 750 & & $\begin{array}{l}\text { Litsea cordata (Jack) } \\
\text { Hook.f. }\end{array}$ & Asian & $\begin{array}{l}\text { dated phyl., } \\
\text { undated phyl. }\end{array}$ & $\begin{array}{l}\text { Chanderbali et al. 2001, } \\
\text { Li et al. 2004, } 2008\end{array}$ \\
\hline 751 & & Litsea costata Boerl. & Asian & $\begin{array}{l}\text { dated phyl., } \\
\text { undated phyl. }\end{array}$ & $\begin{array}{l}\text { Chanderbali et al. 2001, } \\
\text { Li et al. 2004, } 2008\end{array}$ \\
\hline 752 & & Litsea cubeba (Lour.) Pers. & Asian & $\begin{array}{l}\text { dated phyl., } \\
\text { undated phyl. }\end{array}$ & $\begin{array}{l}\text { Chanderbali et al. 2001, } \\
\text { Li et al. 2004, } 2008\end{array}$ \\
\hline 753 & & Litsea cuprea Merr. & Asian & $\begin{array}{l}\text { dated phyl., } \\
\text { undated phyl. }\end{array}$ & $\begin{array}{l}\text { Chanderbali et al. 2001, } \\
\text { Li et al. 2004, } 2008\end{array}$ \\
\hline 754 & & Litsea diversifolia Blume & Asian & $\begin{array}{l}\text { dated phyl., } \\
\text { undated phyl. }\end{array}$ & $\begin{array}{l}\text { Chanderbali et al. 2001, } \\
\text { Li et al. 2004, } 2008\end{array}$ \\
\hline 755 & & Litsea elliptica Blume & Asian & $\begin{array}{l}\text { dated phyl., } \\
\text { undated phyl. }\end{array}$ & $\begin{array}{l}\text { Chanderbali et al. 2001, } \\
\text { Li et al. 2004, } 2008\end{array}$ \\
\hline 756 & & $\begin{array}{l}\text { Litsea elongata (Nees) } \\
\text { Hook.f. }\end{array}$ & Asian & $\begin{array}{l}\text { dated phyl., } \\
\text { undated phyl. }\end{array}$ & $\begin{array}{l}\text { Chanderbali et al. 2001, } \\
\text { Li et al. 2004, } 2008\end{array}$ \\
\hline 757 & & $\begin{array}{l}\text { Litsea erectinervia } \\
\text { Kosterm. }\end{array}$ & Asian & $\begin{array}{l}\text { dated phyl., } \\
\text { undated phyl. }\end{array}$ & $\begin{array}{l}\text { Chanderbali et al. 2001, } \\
\text { Li et al. 2004, } 2008\end{array}$ \\
\hline 758 & & $\begin{array}{l}\text { Litsea firma (Blume) } \\
\text { Hook.f. }\end{array}$ & Asian & $\begin{array}{l}\text { dated phyl., } \\
\text { undated phyl. }\end{array}$ & $\begin{array}{l}\text { Chanderbali et al. 2001, } \\
\text { Li et al. 2004, } 2008\end{array}$ \\
\hline 759 & & Litsea formanii Kosterm. & Asian & $\begin{array}{l}\text { dated phyl., } \\
\text { undated phyl. }\end{array}$ & $\begin{array}{l}\text { Chanderbali et al. 2001, } \\
\text { Li et al. 2004, } 2008\end{array}$ \\
\hline 760 & & $\begin{array}{l}\text { Litsea grandis (Wall. ex } \\
\text { Nees) Hook.f. }\end{array}$ & Asian & $\begin{array}{l}\text { dated phyl., } \\
\text { undated phyl. }\end{array}$ & $\begin{array}{l}\text { Chanderbali et al. 2001, } \\
\text { Li et al. 2004, } 2008\end{array}$ \\
\hline 761 & & $\begin{array}{l}\text { Litsea guppyi (F. Muell.) F. } \\
\text { Muell. ex Forman }\end{array}$ & Asian & $\begin{array}{l}\text { dated phyl., } \\
\text { undated phyl. }\end{array}$ & $\begin{array}{l}\text { Chanderbali et al. 2001, } \\
\text { Li et al. 2004, } 2008\end{array}$ \\
\hline 762 & & $\begin{array}{l}\text { Litsea lanceolata (Blume) } \\
\text { Kosterm. }\end{array}$ & Asian & $\begin{array}{l}\text { dated phyl., } \\
\text { undated phyl. }\end{array}$ & $\begin{array}{l}\text { Chanderbali et al. 2001, } \\
\text { Li et al. 2004, } 2008\end{array}$ \\
\hline
\end{tabular}




\begin{tabular}{|c|c|c|c|c|c|}
\hline No & Family & Species & Origin & $\begin{array}{l}\text { Classification } \\
\text { method }\end{array}$ & References \\
\hline 763 & & $\begin{array}{l}\text { Litsea longipes (Meisn.) } \\
\text { Hook. f. }\end{array}$ & Asian & $\begin{array}{l}\text { dated phyl., } \\
\text { undated phyl. }\end{array}$ & $\begin{array}{l}\text { Chanderbali et al. 2001, } \\
\text { Li et al. 2004, } 2008\end{array}$ \\
\hline 764 & & $\begin{array}{l}\text { Litsea luzonica (Blume) } \\
\text { Fern.-Vill. }\end{array}$ & Asian & $\begin{array}{l}\text { dated phyl., } \\
\text { undated phyl. }\end{array}$ & $\begin{array}{l}\text { Chanderbali et al. 2001, } \\
\text { Li et al. 2004, } 2008\end{array}$ \\
\hline 765 & & $\begin{array}{l}\text { Litsea mappacea (Blume) } \\
\text { Boerl. }\end{array}$ & Asian & $\begin{array}{l}\text { dated phyl., } \\
\text { undated phyl. }\end{array}$ & $\begin{array}{l}\text { Chanderbali et al. 2001, } \\
\text { Li et al. 2004, } 2008\end{array}$ \\
\hline 766 & & Litsea noronhae (Blume) & Asian & $\begin{array}{l}\text { dated phyl., } \\
\text { undated phyl. }\end{array}$ & $\begin{array}{l}\text { Chanderbali et al. 2001, } \\
\text { Li et al. 2004, } 2008\end{array}$ \\
\hline 767 & & $\begin{array}{l}\text { Litsea ochracea (Blume) } \\
\text { Boerl. }\end{array}$ & Asian & $\begin{array}{l}\text { dated phyl., } \\
\text { undated phyl. }\end{array}$ & $\begin{array}{l}\text { Chanderbali et al. 2001, } \\
\text { Li et al. 2004, } 2008\end{array}$ \\
\hline 768 & & $\begin{array}{l}\text { Litsea pallida (Blume) } \\
\text { Boerl. }\end{array}$ & Asian & $\begin{array}{l}\text { dated phyl., } \\
\text { undated phyl. }\end{array}$ & $\begin{array}{l}\text { Chanderbali et al. 2001, } \\
\text { Li et al. 2004, } 2008\end{array}$ \\
\hline 769 & & $\begin{array}{l}\text { Litsea perrottetii (Blume) } \\
\text { Fern.-Vill. }\end{array}$ & Asian & $\begin{array}{l}\text { dated phyl., } \\
\text { undated phyl. }\end{array}$ & $\begin{array}{l}\text { Chanderbali et al. 2001, } \\
\text { Li et al. 2004, } 2008\end{array}$ \\
\hline 770 & & Litsea quercoides Elmer & Asian & $\begin{array}{l}\text { dated phyl., } \\
\text { undated phyl. }\end{array}$ & $\begin{array}{l}\text { Chanderbali et al. 2001, } \\
\text { Li et al. 2004, } 2008\end{array}$ \\
\hline 771 & & Litsea resinosa Blume & Asian & $\begin{array}{l}\text { dated phyl., } \\
\text { undated phyl. }\end{array}$ & $\begin{array}{l}\text { Chanderbali et al. 2001, } \\
\text { Li et al. 2004, } 2008\end{array}$ \\
\hline 772 & & $\begin{array}{l}\text { Litsea sarawacensis } \\
\text { Gamble }\end{array}$ & Asian & $\begin{array}{l}\text { dated phyl., } \\
\text { undated phyl. }\end{array}$ & $\begin{array}{l}\text { Chanderbali et al. 2001, } \\
\text { Li et al. 2004, } 2008\end{array}$ \\
\hline 773 & & Litsea sp.01 & Asian & $\begin{array}{l}\text { dated phyl., } \\
\text { undated phyl. }\end{array}$ & $\begin{array}{l}\text { Chanderbali et al. 2001, } \\
\text { Li et al. 2004, } 2008\end{array}$ \\
\hline 774 & & Litsea sp.02 & Asian & $\begin{array}{l}\text { dated phyl., } \\
\text { undated phyl. }\end{array}$ & $\begin{array}{l}\text { Chanderbali et al. 2001, } \\
\text { Li et al. 2004, } 2008\end{array}$ \\
\hline 775 & & Litsea sp.03 & Asian & $\begin{array}{l}\text { dated phyl., } \\
\text { undated phyl. }\end{array}$ & $\begin{array}{l}\text { Chanderbali et al. 2001, } \\
\text { Li et al. 2004, } 2008\end{array}$ \\
\hline 776 & & Litsea sp.04 & Asian & $\begin{array}{l}\text { dated phyl., } \\
\text { undated phyl. }\end{array}$ & $\begin{array}{l}\text { Chanderbali et al. 2001, } \\
\text { Li et al. 2004, } 2008\end{array}$ \\
\hline 777 & & Litsea sp.05 & Asian & $\begin{array}{l}\text { dated phyl., } \\
\text { undated phyl. }\end{array}$ & $\begin{array}{l}\text { Chanderbali et al. 2001, } \\
\text { Li et al. 2004, } 2008\end{array}$ \\
\hline 778 & & Litsea sp.06 & Asian & $\begin{array}{l}\text { dated phyl., } \\
\text { undated phyl. }\end{array}$ & $\begin{array}{l}\text { Chanderbali et al. 2001, } \\
\text { Li et al. 2004, } 2008\end{array}$ \\
\hline 779 & & Litsea sp.07 & Asian & $\begin{array}{l}\text { dated phyl., } \\
\text { undated phyl. }\end{array}$ & $\begin{array}{l}\text { Chanderbali et al. 2001, } \\
\text { Li et al. 2004, } 2008\end{array}$ \\
\hline 780 & & Litsea sp.09 & Asian & $\begin{array}{l}\text { dated phyl., } \\
\text { undated phyl. }\end{array}$ & $\begin{array}{l}\text { Chanderbali et al. 2001, } \\
\text { Li et al. 2004, } 2008\end{array}$ \\
\hline 781 & & Litsea sp.10 & Asian & $\begin{array}{l}\text { dated phyl., } \\
\text { undated phyl. }\end{array}$ & $\begin{array}{l}\text { Chanderbali et al. 2001, } \\
\text { Li et al. 2004, } 2008\end{array}$ \\
\hline 782 & & Litsea sp.11 & Asian & $\begin{array}{l}\text { dated phyl., } \\
\text { undated phyl. }\end{array}$ & $\begin{array}{l}\text { Chanderbali et al. 2001, } \\
\text { Li et al. 2004, } 2008\end{array}$ \\
\hline 783 & & Litsea sp.12 & Asian & $\begin{array}{l}\text { dated phyl., } \\
\text { undated phyl. }\end{array}$ & $\begin{array}{l}\text { Chanderbali et al. 2001, } \\
\text { Li et al. 2004, } 2008\end{array}$ \\
\hline 784 & & Litsea sp.13 & Asian & $\begin{array}{l}\text { dated phyl., } \\
\text { undated phyl. }\end{array}$ & $\begin{array}{l}\text { Chanderbali et al. 2001, } \\
\text { Li et al. 2004, } 2008\end{array}$ \\
\hline 785 & & Litsea sp.14 & Asian & $\begin{array}{l}\text { dated phyl., } \\
\text { undated phyl. }\end{array}$ & $\begin{array}{l}\text { Chanderbali et al. 2001, } \\
\text { Li et al. 2004, } 2008\end{array}$ \\
\hline 786 & & Litsea sp.15 & Asian & $\begin{array}{l}\text { dated phyl., } \\
\text { undated phyl. }\end{array}$ & $\begin{array}{l}\text { Chanderbali et al. 2001, } \\
\text { Li et al. 2004, } 2008\end{array}$ \\
\hline
\end{tabular}




\begin{tabular}{|c|c|c|c|c|c|}
\hline No & Family & Species & Origin & $\begin{array}{l}\text { Classification } \\
\text { method }\end{array}$ & References \\
\hline 787 & & Litsea sp.16 & Asian & $\begin{array}{l}\text { dated phyl., } \\
\text { undated phyl. }\end{array}$ & $\begin{array}{l}\text { Chanderbali et al. 2001, } \\
\text { Li et al. 2004, } 2008\end{array}$ \\
\hline 788 & & Litsea sp.17 & Asian & $\begin{array}{l}\text { dated phyl., } \\
\text { undated phyl. }\end{array}$ & $\begin{array}{l}\text { Chanderbali et al. 2001, } \\
\text { Li et al. 2004, } 2008\end{array}$ \\
\hline 789 & & Litsea sp.18 & Asian & $\begin{array}{l}\text { dated phyl., } \\
\text { undated phyl. }\end{array}$ & $\begin{array}{l}\text { Chanderbali et al. 2001, } \\
\text { Li et al. 2004, } 2008\end{array}$ \\
\hline 790 & & Litsea sp.19 & Asian & $\begin{array}{l}\text { dated phyl., } \\
\text { undated phyl. }\end{array}$ & $\begin{array}{l}\text { Chanderbali et al. 2001, } \\
\text { Li et al. 2004, } 2008\end{array}$ \\
\hline 791 & & Litsea sp.20 & Asian & $\begin{array}{l}\text { dated phyl., } \\
\text { undated phyl. }\end{array}$ & $\begin{array}{l}\text { Chanderbali et al. 2001, } \\
\text { Li et al. 2004, } 2008\end{array}$ \\
\hline 792 & & Litsea staintonii Kosterm. & Asian & $\begin{array}{l}\text { dated phyl., } \\
\text { undated phyl. }\end{array}$ & $\begin{array}{l}\text { Chanderbali et al. 2001, } \\
\text { Li et al. 2004, } 2008\end{array}$ \\
\hline 793 & & $\begin{array}{l}\text { Litsea subumbelliflora } \\
\text { (Blume) } \mathrm{Ng}\end{array}$ & Asian & $\begin{array}{l}\text { dated phyl., } \\
\text { undated phyl. }\end{array}$ & $\begin{array}{l}\text { Chanderbali et al. 2001, } \\
\text { Li et al. 2004, } 2008\end{array}$ \\
\hline 794 & & Litsea timoriana Span. & Asian & $\begin{array}{l}\text { dated phyl., } \\
\text { undated phyl. }\end{array}$ & $\begin{array}{l}\text { Chanderbali et al. 2001, } \\
\text { Li et al. 2004, } 2008\end{array}$ \\
\hline 795 & & Litsea tomentosa Blume & Asian & $\begin{array}{l}\text { dated phyl., } \\
\text { undated phyl. }\end{array}$ & $\begin{array}{l}\text { Chanderbali et al. 2001, } \\
\text { Li et al. 2004, } 2008\end{array}$ \\
\hline 796 & & $\begin{array}{l}\text { Machilus philippinensis } \\
\text { Merr. }\end{array}$ & Asian & phylogeogr. & Li et al. 2011 \\
\hline 797 & & $\begin{array}{l}\text { Machilus rimosa (Blume) } \\
\text { Blume }\end{array}$ & Asian & phylogeogr. & Li et al. 2011 \\
\hline 798 & & $\begin{array}{l}\text { Neolitsea cassia (L.) } \\
\text { Kosterm. }\end{array}$ & Asian & $\begin{array}{l}\text { dated phyl., } \\
\text { undated phyl. }\end{array}$ & $\begin{array}{l}\text { Chanderbali et al. 2001, } \\
\text { Li et al. 2004, } 2008\end{array}$ \\
\hline 799 & & $\begin{array}{l}\text { Neolitsea javanica (Blume) } \\
\text { Backer }\end{array}$ & Asian & $\begin{array}{l}\text { dated phyl., } \\
\text { undated phyl. }\end{array}$ & $\begin{array}{l}\text { Chanderbali et al. 2001, } \\
\text { Li et al. 2004, } 2008\end{array}$ \\
\hline 800 & & Neolitsea sp.1 & Asian & $\begin{array}{l}\text { dated phyl., } \\
\text { undated phyl. }\end{array}$ & $\begin{array}{l}\text { Chanderbali et al. 2001, } \\
\text { Li et al. 2004, } 2008\end{array}$ \\
\hline 801 & & Neolitsea sp.2 & Asian & $\begin{array}{l}\text { dated phyl., } \\
\text { undated phyl. }\end{array}$ & $\begin{array}{l}\text { Chanderbali et al. 2001, } \\
\text { Li et al. 2004, } 2008\end{array}$ \\
\hline 802 & & $\begin{array}{l}\text { Actinodaphne multiflora } \\
\text { Benth. }\end{array}$ & Asian & $\begin{array}{l}\text { dated phyl., } \\
\text { undated phyl. }\end{array}$ & $\begin{array}{l}\text { Chanderbali et al. 2001, } \\
\text { Li et al. 2004, } 2008\end{array}$ \\
\hline 803 & & $\begin{array}{l}\text { Neolitsea villosa (Blume) } \\
\text { Merr. }\end{array}$ & Asian & $\begin{array}{l}\text { dated phyl., } \\
\text { undated phyl. }\end{array}$ & $\begin{array}{l}\text { Chanderbali et al. 2001, } \\
\text { Li et al. 2004, } 2008\end{array}$ \\
\hline 804 & & $\begin{array}{l}\text { Nothaphoebe albipes } \\
\text { Kosterm. ined }\end{array}$ & Asian & phylogeogr. & Li et al. 2011 \\
\hline 805 & & $\begin{array}{l}\text { Nothaphoebe } \\
\text { heterophylla Merr. }\end{array}$ & Asian & phylogeogr. & Li et al. 2011 \\
\hline 806 & & $\begin{array}{l}\text { Nothaphoebe kingiana } \\
\text { Gamble }\end{array}$ & Asian & phylogeogr. & Li et al. 2011 \\
\hline 807 & & $\begin{array}{l}\text { Nothaphoebe } \\
\text { sarawacensis Gamble }\end{array}$ & Asian & phylogeogr. & Li et al. 2011 \\
\hline 808 & & Nothaphoebe sp.1 & Asian & phylogeogr. & Li et al. 2011 \\
\hline 809 & & Nothaphoebe sp.nov. & Asian & phylogeogr. & Li et al. 2011 \\
\hline 810 & & $\begin{array}{l}\text { Phoebe cf. grandis (Nees) } \\
\text { Merr. }\end{array}$ & Asian & phylogeogr. & Li et al. 2011 \\
\hline 811 & & Phoebe sp.1 & Asian & phylogeogr. & Li et al. 2011 \\
\hline 812 & & Phoebe sp.2 & Asian & phylogeogr. & Li et al. 2011 \\
\hline
\end{tabular}




\begin{tabular}{|c|c|c|c|c|c|}
\hline No & Family & Species & Origin & $\begin{array}{l}\text { Classification } \\
\text { method }\end{array}$ & References \\
\hline 813 & & $\begin{array}{l}\text { Phoebe cf. sterculioides } \\
\text { (Elmer) Merr. }\end{array}$ & Asian & phylogeogr. & Li et al. 2011 \\
\hline 814 & Lecythidaceae & $\begin{array}{l}\text { Barringtonia calyptrocalyx } \\
\text { K.Schum. }\end{array}$ & Asian & $\begin{array}{l}\text { undated phyl., } \\
\text { distr./fossils }\end{array}$ & $\begin{array}{l}\text { Mori et al. 2007, Payens } \\
1967\end{array}$ \\
\hline 815 & & $\begin{array}{l}\text { Barringtonia lanceolata } \\
\text { (Ridl.) Payens }\end{array}$ & Asian & $\begin{array}{l}\text { undated phyl., } \\
\text { distr./fossils }\end{array}$ & $\begin{array}{l}\text { Mori et al. 2007, Payens } \\
1967\end{array}$ \\
\hline 816 & & $\begin{array}{l}\text { Barringtonia longisepala } \\
\text { Payens }\end{array}$ & Asian & $\begin{array}{l}\text { undated phyl., } \\
\text { distr./fossils }\end{array}$ & $\begin{array}{l}\text { Mori et al. 2007, Payens } \\
1967\end{array}$ \\
\hline 817 & & Barringtonia sp.1 & Asian & $\begin{array}{l}\text { undated phyl., } \\
\text { distr./fossils }\end{array}$ & $\begin{array}{l}\text { Mori et al. 2007, Payens } \\
1967\end{array}$ \\
\hline 818 & & Barringtonia sp.2 & Asian & $\begin{array}{l}\text { undated phyl., } \\
\text { distr./fossils }\end{array}$ & $\begin{array}{l}\text { Mori et al. 2007, Payens } \\
1967\end{array}$ \\
\hline 819 & & Barringtonia sp.3 & Asian & $\begin{array}{l}\text { undated phyl., } \\
\text { distr./fossils }\end{array}$ & $\begin{array}{l}\text { Mori et al. 2007, Payens } \\
1967\end{array}$ \\
\hline 820 & & Lecythidaceae sp. & Asian & $\begin{array}{l}\text { undated phyl., } \\
\text { distr./fossils }\end{array}$ & $\begin{array}{l}\text { Mori et al. 2007, Payens } \\
1967\end{array}$ \\
\hline 821 & Loganiaceae & $\begin{array}{l}\text { Geniostoma rupestre } \\
\text { J.R.Forst. \& G.Forst. }\end{array}$ & Austr. & $\begin{array}{l}\text { dated phyl., } \\
\text { distr./fossils }\end{array}$ & $\begin{array}{l}\text { Conn 1980, Foster et al. } \\
2014\end{array}$ \\
\hline 822 & & Norrisia major Soler. & Austr. & $\begin{array}{l}\text { undated phyl., } \\
\text { distr./fossils }\end{array}$ & $\begin{array}{l}\text { Frasier 2008, Tropicos } \\
\text { 2015, Yang et al. } 2016\end{array}$ \\
\hline 823 & Lythraceae & $\begin{array}{l}\text { Duabanga moluccana } \\
\text { Blume }\end{array}$ & Asian & $\begin{array}{l}\text { phylogeogr., } \\
\text { distr./fossils }\end{array}$ & $\begin{array}{l}\text { Berger et al. 2017, } \\
\text { Graham } 2013\end{array}$ \\
\hline 824 & & $\begin{array}{l}\text { Lagerstroemia piriformis } \\
\text { Koehne }\end{array}$ & Asian & $\begin{array}{l}\text { phylogeogr., } \\
\text { distr./fossils }\end{array}$ & $\begin{array}{l}\text { Berger et al. 2017, } \\
\text { Graham } 2013\end{array}$ \\
\hline 825 & & Lagerstroemia sp. & Asian & $\begin{array}{l}\text { phylogeogr., } \\
\text { distr./fossils }\end{array}$ & $\begin{array}{l}\text { Berger et al. 2017, } \\
\text { Graham } 2013\end{array}$ \\
\hline 826 & Magnoliaceae & $\begin{array}{l}\text { Magnolia beccarii (Ridl.) } \\
\text { ined. }\end{array}$ & Asian & phylogeogr. & $\begin{array}{l}\text { Noteboom 2011, Nie et } \\
\text { al. } 2008\end{array}$ \\
\hline 827 & & $\begin{array}{l}\text { Magnolia borneensis } \\
\text { Noot. }\end{array}$ & Asian & phylogeogr. & $\begin{array}{l}\text { Noteboom 2011, Nie et } \\
\text { al. } 2008\end{array}$ \\
\hline 828 & & $\begin{array}{l}\text { Magnolia carsonii Dandy } \\
\text { ex Noot. }\end{array}$ & Asian & phylogeogr. & $\begin{array}{l}\text { Noteboom 2011, Nie et } \\
\text { al. } 2008\end{array}$ \\
\hline 829 & & $\begin{array}{l}\text { Magnolia elegans (Blume) } \\
\text { H.Keng }\end{array}$ & Asian & phylogeogr. & $\begin{array}{l}\text { Noteboom 2011, Nie et } \\
\text { al. } 2008\end{array}$ \\
\hline 830 & & Magnolia liliifera (L.) Baill. & Asian & phylogeogr. & $\begin{array}{l}\text { Noteboom 2011, Nie et } \\
\text { al. } 2008\end{array}$ \\
\hline 831 & & $\begin{array}{l}\text { Magnolia macklottii } \\
\text { (Korth.) Dandy }\end{array}$ & Asian & phylogeogr. & $\begin{array}{l}\text { Noteboom 2011, Nie et } \\
\text { al. } 2008\end{array}$ \\
\hline 832 & & $\begin{array}{l}\text { Magnolia montana } \\
\text { (Blume) Figlar }\end{array}$ & Asian & phylogeogr. & $\begin{array}{l}\text { Noteboom 2011, Nie et } \\
\text { al. } 2008\end{array}$ \\
\hline 833 & & $\begin{array}{l}\text { Magnolia persuaveolens } \\
\text { Dandy }\end{array}$ & Asian & phylogeogr. & $\begin{array}{l}\text { Noteboom 2011, Nie et } \\
\text { al. } 2008\end{array}$ \\
\hline 834 & & Magnolia sp.1 & Asian & phylogeogr. & $\begin{array}{l}\text { Noteboom 2011, Nie et } \\
\text { al. } 2008\end{array}$ \\
\hline 835 & & Magnolia sp.2 & Asian & phylogeogr. & $\begin{array}{l}\text { Noteboom 2011, Nie et } \\
\text { al. } 2008\end{array}$ \\
\hline 836 & & Magnolia sp.3 & Asian & phylogeogr. & Noteboom 2011, Nie et \\
\hline
\end{tabular}




\begin{tabular}{|c|c|c|c|c|c|}
\hline No & Family & Species & Origin & $\begin{array}{l}\text { Classification } \\
\text { method }\end{array}$ & References \\
\hline 837 & & Magnolia sp.4 & Asian & phylogeogr. & $\begin{array}{l}\text { Noteboom 2011, Nie et } \\
\text { al. } 2008\end{array}$ \\
\hline 838 & & Magnolia sp.5 & Asian & phylogeogr. & $\begin{array}{l}\text { Noteboom 2011, Nie et } \\
\text { al. } 2008\end{array}$ \\
\hline 839 & & $\begin{array}{l}\text { Magnolia sulawesiana } \\
\text { Brambach et al. }\end{array}$ & Asian & phylogeogr. & $\begin{array}{l}\text { Noteboom 2011, Nie et } \\
\text { al. } 2008\end{array}$ \\
\hline 840 & & $\begin{array}{l}\text { Magnolia sumatrana } \\
\text { (Miq.) Figlar \& Noot. }\end{array}$ & Asian & phylogeogr. & $\begin{array}{l}\text { Noteboom 2011, Nie et } \\
\text { al. } 2008\end{array}$ \\
\hline 841 & & $\begin{array}{l}\text { Magnolia tsiampacca (L.) } \\
\text { Figlar \& Noot. }\end{array}$ & Asian & phylogeogr. & $\begin{array}{l}\text { Noteboom 2011, Nie et } \\
\text { al. } 2008\end{array}$ \\
\hline 842 & & $\begin{array}{l}\text { Magnolia utilis (Dandy) } \\
\text { V.S.Kumar }\end{array}$ & Asian & phylogeogr. & $\begin{array}{l}\text { Noteboom 2011, Nie et } \\
\text { al. } 2008\end{array}$ \\
\hline 843 & & $\begin{array}{l}\text { Magnolia vrieseana (Miq.) } \\
\text { Baill. ex Pierre }\end{array}$ & Asian & phylogeogr. & $\begin{array}{l}\text { Noteboom 2011, Nie et } \\
\text { al. } 2008\end{array}$ \\
\hline 844 & Malvaceae & $\begin{array}{l}\text { Coelostegia griffithii } \\
\text { Benth. }\end{array}$ & Asian & phylogeogr. & Richardson et al. 2015 \\
\hline 845 & & $\begin{array}{l}\text { Diplodiscus paniculatus } \\
\text { Turcz. }\end{array}$ & Asian & $\begin{array}{l}\text { phylogeogr., } \\
\text { distr./fossils }\end{array}$ & $\begin{array}{l}\text { Bayer \& Kubitzki 2003, } \\
\text { Richardson et al. } 2015\end{array}$ \\
\hline 846 & & $\begin{array}{l}\text { Durio acutifolius (Mast.) } \\
\text { Kosterm. }\end{array}$ & Asian & phylogeogr. & Richardson et al. 2015 \\
\hline 847 & & $\begin{array}{l}\text { Durio excelsus (Korth.) } \\
\text { Bakh. }\end{array}$ & Asian & phylogeogr. & Richardson et al. 2015 \\
\hline 848 & & $\begin{array}{l}\text { Durio kutejensis (Hassk.) } \\
\text { Becc. }\end{array}$ & Asian & phylogeogr. & Richardson et al. 2015 \\
\hline 849 & & $\begin{array}{l}\text { Durio malaccensis Planch. } \\
\text { ex Mast. }\end{array}$ & Asian & phylogeogr. & Richardson et al. 2015 \\
\hline 850 & & Durio oxleyanus Griff. & Asian & phylogeogr. & Richardson et al. 2015 \\
\hline 851 & & Durio sp.1 & Asian & phylogeogr. & Richardson et al. 2015 \\
\hline 852 & & Durio sp.2 & Asian & phylogeogr. & Richardson et al. 2015 \\
\hline 853 & & Durio zibethinus L. & Asian & phylogeogr. & Richardson et al. 2015 \\
\hline 854 & & $\begin{array}{l}\text { Firmiana malayana } \\
\text { Kosterm. }\end{array}$ & Asian & phylogeogr. & $\begin{array}{l}\text { Carter 2011, Richardson } \\
\text { et al. } 2015\end{array}$ \\
\hline 855 & & $\begin{array}{l}\text { Grewia cinnamomifolia } \\
\text { (Burret) Stapf ex } \\
\text { P.S.Ashton }\end{array}$ & Asian & phylogeogr. & Richardson et al. 2015 \\
\hline 856 & & Grewia multiflora Juss. & Asian & phylogeogr. & Richardson et al. 2015 \\
\hline 857 & & $\begin{array}{l}\text { Heritiera simplicifolia } \\
\text { (Mast.) Kosterm. }\end{array}$ & Asian & phylogeogr. & $\begin{array}{l}\text { Carter 2011, Richardson } \\
\text { et al. } 2015\end{array}$ \\
\hline 858 & & $\begin{array}{l}\text { Heritiera sumatrana (Miq.) } \\
\text { Kosterm. }\end{array}$ & Asian & phylogeogr. & $\begin{array}{l}\text { Carter 2011, Richardson } \\
\text { et al. } 2015\end{array}$ \\
\hline 859 & & $\begin{array}{l}\text { Microcos antidesmifolia } \\
\text { (King) Burret }\end{array}$ & Asian & $\begin{array}{l}\text { phylogeogr., } \\
\text { distr./fossils }\end{array}$ & $\begin{array}{l}\text { Bayer \& Kubitzki 2003, } \\
\text { Richardson et al. } 2015\end{array}$ \\
\hline 860 & & $\begin{array}{l}\text { Microcos hirsuta (Korth.) } \\
\text { Burret }\end{array}$ & Asian & $\begin{array}{l}\text { phylogeogr., } \\
\text { distr./fossils }\end{array}$ & $\begin{array}{l}\text { Bayer \& Kubitzki 2003, } \\
\text { Richardson et al. } 2015\end{array}$ \\
\hline 861 & & Microcos sp.1 & Asian & $\begin{array}{l}\text { phylogeogr., } \\
\text { distr./fossils }\end{array}$ & $\begin{array}{l}\text { Bayer \& Kubitzki 2003, } \\
\text { Richardson et al. } 2015\end{array}$ \\
\hline 862 & & Microcos sp. 2 & Asian & $\begin{array}{l}\text { phylogeogr., } \\
\text { distr./fossils }\end{array}$ & $\begin{array}{l}\text { Bayer \& Kubitzki 2003, } \\
\text { Richardson et al. } 2015\end{array}$ \\
\hline
\end{tabular}




\begin{tabular}{|c|c|c|c|c|c|}
\hline No & Family & Species & Origin & $\begin{array}{l}\text { Classification } \\
\text { method }\end{array}$ & References \\
\hline 863 & & Microcos sp.3 & Asian & $\begin{array}{l}\text { phylogeogr., } \\
\text { distr./fossils }\end{array}$ & $\begin{array}{l}\text { Bayer \& Kubitzki 2003, } \\
\text { Richardson et al. } 2015\end{array}$ \\
\hline 864 & & $\begin{array}{l}\text { Microcos triflora (Blanco) } \\
\text { R.C.K.Chung }\end{array}$ & Asian & $\begin{array}{l}\text { phylogeogr., } \\
\text { distr./fossils }\end{array}$ & $\begin{array}{l}\text { Bayer \& Kubitzki 2003, } \\
\text { Richardson et al. } 2015\end{array}$ \\
\hline 865 & & $\begin{array}{l}\text { Neesia altissima (Blume) } \\
\text { Blume }\end{array}$ & Asian & phylogeogr. & Richardson et al. 2015 \\
\hline 866 & & Pentace laxiflora Merr. & Asian & $\begin{array}{l}\text { phylogeogr., } \\
\text { distr./fossils }\end{array}$ & $\begin{array}{l}\text { Bayer \& Kubitzki 2003, } \\
\text { Richardson et al. } 2015\end{array}$ \\
\hline 867 & & $\begin{array}{l}\text { Pterospermum niveum } \\
\text { S.Vidal }\end{array}$ & Asian & $\begin{array}{l}\text { phylogeogr., } \\
\text { distr./fossils }\end{array}$ & $\begin{array}{l}\text { Bayer \& Kubitzki 2003, } \\
\text { Richardson et al. } 2015\end{array}$ \\
\hline 868 & & Pterospermum sp. & Asian & $\begin{array}{l}\text { phylogeogr., } \\
\text { distr./fossils }\end{array}$ & $\begin{array}{l}\text { Bayer \& Kubitzki 2003, } \\
\text { Richardson et al. } 2015\end{array}$ \\
\hline 869 & & Pterospermum sp.1 & Asian & $\begin{array}{l}\text { phylogeogr., } \\
\text { distr./fossils }\end{array}$ & $\begin{array}{l}\text { Bayer \& Kubitzki 2003, } \\
\text { Richardson et al. } 2015\end{array}$ \\
\hline 870 & & $\begin{array}{l}\text { Pterocymbium tinctorium } \\
\text { (Blanco) Merr. }\end{array}$ & Asian & phylogeogr. & $\begin{array}{l}\text { Carter 2011, Richardson } \\
\text { et al. } 2015\end{array}$ \\
\hline 871 & & $\begin{array}{l}\text { Scaphium macropodum } \\
\text { (Miq.) Beumée ex K.Heyne }\end{array}$ & Asian & phylogeogr. & $\begin{array}{l}\text { Carter 2011, Richardson } \\
\text { et al. } 2015\end{array}$ \\
\hline 872 & & Scaphium sp. & Asian & phylogeogr. & $\begin{array}{l}\text { Carter 2011, Richardson } \\
\text { et al. } 2015\end{array}$ \\
\hline 873 & & Sterculia coccinea Jack & Asian & phylogeogr. & $\begin{array}{l}\text { Carter 2011, Richardson } \\
\text { et al. } 2015\end{array}$ \\
\hline 874 & & Sterculia insularis R.Br. & Asian & phylogeogr. & $\begin{array}{l}\text { Carter 2011, Richardson } \\
\text { et al. } 2015\end{array}$ \\
\hline 875 & & Sterculia longifolia Vent. & Asian & phylogeogr. & $\begin{array}{l}\text { Carter 2011, Richardson } \\
\text { et al. } 2015\end{array}$ \\
\hline 876 & & Sterculia oblongata R.Br. & Asian & phylogeogr. & $\begin{array}{l}\text { Carter 2011, Richardson } \\
\text { et al. } 2015\end{array}$ \\
\hline 877 & & Sterculia rubiginosa Vent. & Asian & phylogeogr. & $\begin{array}{l}\text { Carter 2011, Richardson } \\
\text { et al. } 2015\end{array}$ \\
\hline 878 & & Sterculia scortechinii King & Asian & phylogeogr. & $\begin{array}{l}\text { Carter 2011, Richardson } \\
\text { et al. } 2015\end{array}$ \\
\hline 879 & & Sterculia sp.1 & Asian & phylogeogr. & $\begin{array}{l}\text { Carter 2011, Richardson } \\
\text { et al. } 2015\end{array}$ \\
\hline 880 & & Sterculia sp.2 & Asian & phylogeogr. & $\begin{array}{l}\text { Carter 2011, Richardson } \\
\text { et al. } 2015\end{array}$ \\
\hline 881 & & Sterculia urceolata Sm. & Asian & phylogeogr. & $\begin{array}{l}\text { Carter 2011, Richardson } \\
\text { et al. } 2015\end{array}$ \\
\hline 882 & Melastomataceae & $\begin{array}{l}\text { Astronia acuminatissima } \\
\text { Merr. }\end{array}$ & Austr. & phylogeogr. & $\begin{array}{l}\text { Berger et al. 2016, } \\
\text { Penneys } 2013\end{array}$ \\
\hline 883 & & Astronia atroviridis Mansf. & Austr. & phylogeogr. & $\begin{array}{l}\text { Berger et al. 2016, } \\
\text { Penneys } 2013\end{array}$ \\
\hline 884 & & Astrocalyx calycina Merr. & Austr. & phylogeogr. & $\begin{array}{l}\text { Berger et al. 2016, } \\
\text { Penneys } 2013\end{array}$ \\
\hline 885 & & Astronia gitingensis Elmer & Austr. & phylogeogr. & $\begin{array}{l}\text { Berger et al. 2016, } \\
\text { Penneys } 2013\end{array}$ \\
\hline 886 & & $\begin{array}{l}\text { Astronia macrophylla } \\
\text { Blume }\end{array}$ & Austr. & phylogeogr. & $\begin{array}{l}\text { Berger et al. 2016, } \\
\text { Penneys } 2013\end{array}$ \\
\hline
\end{tabular}




\begin{tabular}{|c|c|c|c|c|c|}
\hline No & Family & Species & Origin & $\begin{array}{l}\text { Classification } \\
\text { method }\end{array}$ & References \\
\hline 887 & & Astronia sp.1 & Austr. & phylogeogr. & $\begin{array}{l}\text { Berger et al. 2016, } \\
\text { Penneys } 2013\end{array}$ \\
\hline 888 & & Astronia sp.2 & Austr. & phylogeogr. & $\begin{array}{l}\text { Berger et al. 2016, } \\
\text { Penneys } 2013\end{array}$ \\
\hline 889 & & Astronia spectabilis Blume & Austr. & phylogeogr. & $\begin{array}{l}\text { Berger et al. 2016, } \\
\text { Penneys } 2013\end{array}$ \\
\hline 890 & & Astronia stapfii Koord. & Austr. & phylogeogr. & $\begin{array}{l}\text { Berger et al. 2016, } \\
\text { Penneys } 2013\end{array}$ \\
\hline 891 & & Astronia viridifolia Elmer & Austr. & phylogeogr. & $\begin{array}{l}\text { Berger et al. 2016, } \\
\text { Penneys } 2013\end{array}$ \\
\hline 892 & & Medinilla sp.1 & Asian & $\begin{array}{l}\text { phylogeogr., } \\
\text { distr./fossils }\end{array}$ & $\begin{array}{l}\text { Berger et al. 2016, } \\
\text { Bodegom \& Veldkamp } \\
2001\end{array}$ \\
\hline 893 & & $\begin{array}{l}\text { Melastoma sanguineum } \\
\text { Sims }\end{array}$ & Asian & phylogeogr. & $\begin{array}{l}\text { Veranso-Libalah et al. } \\
2018\end{array}$ \\
\hline 894 & & $\begin{array}{l}\text { Memecylon brachybotrys } \\
\text { Merr }\end{array}$ & Asian & phylogeogr. & $\begin{array}{l}\text { Berger et al. 2016, Stone } \\
2014\end{array}$ \\
\hline 895 & & $\begin{array}{l}\text { Memecylon cumingii } \\
\text { Naudin }\end{array}$ & Asian & phylogeogr. & $\begin{array}{l}\text { Berger et al. 2016, Stone } \\
2014\end{array}$ \\
\hline 896 & & $\begin{array}{l}\text { Memecylon excelsum } \\
\text { Blume }\end{array}$ & Asian & phylogeogr. & $\begin{array}{l}\text { Berger et al. 2016, Stone } \\
2014\end{array}$ \\
\hline 897 & & Memecylon lanceolatum & Asian & phylogeogr. & $\begin{array}{l}\text { Berger et al. 2016, Stone } \\
2014\end{array}$ \\
\hline 898 & & $\begin{array}{l}\text { Memecylon minutiflorum } \\
\text { Miq. }\end{array}$ & Asian & phylogeogr. & $\begin{array}{l}\text { Berger et al. 2016, Stone } \\
2014\end{array}$ \\
\hline 899 & & $\begin{array}{l}\text { Memecylon oligoneurum } \\
\text { Blume }\end{array}$ & Asian & phylogeogr. & $\begin{array}{l}\text { Berger et al. 2016, Stone } \\
2014\end{array}$ \\
\hline 900 & & Memecylon sp.1 & Asian & phylogeogr. & $\begin{array}{l}\text { Berger et al. 2016, Stone } \\
2014\end{array}$ \\
\hline 901 & & Memecylon sp.2 & Asian & phylogeogr. & $\begin{array}{l}\text { Berger et al. 2016, Stone } \\
2014\end{array}$ \\
\hline 902 & & Memecylon sp.3 & Asian & phylogeogr. & $\begin{array}{l}\text { Berger et al. 2016, Stone } \\
2014\end{array}$ \\
\hline 903 & & Memecylon sp.4 & Asian & phylogeogr. & $\begin{array}{l}\text { Berger et al. 2016, Stone } \\
2014\end{array}$ \\
\hline 904 & & Memecylon sp.5 & Asian & phylogeogr. & $\begin{array}{l}\text { Berger et al. 2016, Stone } \\
2014\end{array}$ \\
\hline 905 & & Memecylon sp.6 & Asian & phylogeogr. & $\begin{array}{l}\text { Berger et al. 2016, Stone } \\
2014\end{array}$ \\
\hline 906 & & Memecylon sp.7 & Asian & phylogeogr. & $\begin{array}{l}\text { Berger et al. 2016, Stone } \\
2014\end{array}$ \\
\hline 907 & & Memecylon sp.8 & Asian & phylogeogr. & $\begin{array}{l}\text { Berger et al. 2016, Stone } \\
2014\end{array}$ \\
\hline 908 & & $\begin{array}{l}\text { Pternandra azurea (DC.) } \\
\text { Burkill }\end{array}$ & Asian & phylogeogr. & $\begin{array}{l}\text { Berger et al. 2016, } \\
\text { Renner } 2004\end{array}$ \\
\hline 909 & & $\begin{array}{l}\text { Pternandra caerulescens } \\
\text { Jack }\end{array}$ & Asian & phylogeogr. & $\begin{array}{l}\text { Berger et al. 2016, } \\
\text { Renner } 2004\end{array}$ \\
\hline
\end{tabular}




\begin{tabular}{|c|c|c|c|c|c|}
\hline No & Family & Species & Origin & $\begin{array}{l}\text { Classification } \\
\text { method }\end{array}$ & References \\
\hline 910 & & Pternandra cordata Baill. & Asian & phylogeogr. & $\begin{array}{l}\text { Berger et al. 2016, } \\
\text { Renner } 2004\end{array}$ \\
\hline 911 & & Pternandra jackiana Ridl. & Asian & phylogeogr. & $\begin{array}{l}\text { Berger et al. 2016, } \\
\text { Renner } 2004\end{array}$ \\
\hline 912 & & $\begin{array}{l}\text { Pternandra rostrata } \\
\text { M.P.Nayar }\end{array}$ & Asian & phylogeogr. & $\begin{array}{l}\text { Berger et al. 2016, } \\
\text { Renner } 2004\end{array}$ \\
\hline 913 & & Pternandra sp.1 & Asian & phylogeogr. & $\begin{array}{l}\text { Berger et al. 2016, } \\
\text { Renner } 2004\end{array}$ \\
\hline 914 & & Pternandra sp.2 & Asian & phylogeogr. & $\begin{array}{l}\text { Berger et al. 2016, } \\
\text { Renner } 2004\end{array}$ \\
\hline 915 & & Pternandra sp.3 & Asian & phylogeogr. & $\begin{array}{l}\text { Berger et al. 2016, } \\
\text { Renner } 2004\end{array}$ \\
\hline 916 & & Pternandra sp.4 & Asian & phylogeogr. & $\begin{array}{l}\text { Berger et al. 2016, } \\
\text { Renner } 2004\end{array}$ \\
\hline 917 & & $\begin{array}{l}\text { Pternandra tesellata } \\
\text { M.P.Nayar }\end{array}$ & Asian & phylogeogr. & $\begin{array}{l}\text { Berger et al. 2016, } \\
\text { Renner } 2004\end{array}$ \\
\hline 918 & Meliaceae & Aglaia argentea Blume & Asian & phylogeogr. & Grudinski et al. 2014 \\
\hline 919 & & Aglaia edulis (Roxb.) Wall. & Asian & phylogeogr. & Grudinski et al. 2014 \\
\hline 920 & & $\begin{array}{l}\text { Aglaia elliptica (C.DC.) } \\
\text { Blume }\end{array}$ & Asian & phylogeogr. & Grudinski et al. 2014 \\
\hline 921 & & $\begin{array}{l}\text { Aglaia grandis Korth. ex } \\
\text { Miq. }\end{array}$ & Asian & phylogeogr. & Grudinski et al. 2014 \\
\hline 922 & & Aglaia lancilimba Merr. & Asian & phylogeogr. & Grudinski et al. 2014 \\
\hline 923 & & Aglaia leptantha Miq. & Asian & phylogeogr. & Grudinski et al. 2014 \\
\hline 924 & & Aglaia leucophylla King & Asian & phylogeogr. & Grudinski et al. 2014 \\
\hline 925 & & $\begin{array}{l}\text { Aglaia luzoniensis (Vidal) } \\
\text { Merr. \& Rolfe }\end{array}$ & Asian & phylogeogr. & Grudinski et al. 2014 \\
\hline 926 & & $\begin{array}{l}\text { Aglaia malaccensis (Ridl.) } \\
\text { Pannell }\end{array}$ & Asian & phylogeogr. & Grudinski et al. 2014 \\
\hline 927 & & $\begin{array}{l}\text { Aglaia odoratissima } \\
\text { Blume }\end{array}$ & Asian & phylogeogr. & Grudinski et al. 2014 \\
\hline 928 & & Aglaia oligophylla Miq. & Asian & phylogeogr. & Grudinski et al. 2014 \\
\hline 929 & & Aglaia palembanica Miq. & Asian & phylogeogr. & Grudinski et al. 2014 \\
\hline 930 & & $\begin{array}{l}\text { Aglaia rimosa (Blanco) } \\
\text { Merr. }\end{array}$ & Asian & phylogeogr. & Grudinski et al. 2014 \\
\hline 931 & & $\begin{array}{l}\text { Aglaia silvestris (M.Roem.) } \\
\text { Merr. }\end{array}$ & Asian & phylogeogr. & Grudinski et al. 2014 \\
\hline 932 & & Aglaia sp.01 & Asian & phylogeogr. & Grudinski et al. 2014 \\
\hline 933 & & Aglaia sp.02 & Asian & phylogeogr. & Grudinski et al. 2014 \\
\hline 934 & & Aglaia sp.03 & Asian & phylogeogr. & Grudinski et al. 2014 \\
\hline 935 & & Aglaia sp.04 & Asian & phylogeogr. & Grudinski et al. 2014 \\
\hline 936 & & Aglaia sp.05 & Asian & phylogeogr. & Grudinski et al. 2014 \\
\hline 937 & & Aglaia sp.06 & Asian & phylogeogr. & Grudinski et al. 2014 \\
\hline 938 & & Aglaia sp.07 & Asian & phylogeogr. & Grudinski et al. 2014 \\
\hline 939 & & Aglaia sp.08 & Asian & phylogeogr. & Grudinski et al. 2014 \\
\hline 940 & & Aglaia sp.09 & Asian & phylogeogr. & Grudinski et al. 2014 \\
\hline 941 & & Aglaia sp.10 & Asian & phylogeogr. & Grudinski et al. 2014 \\
\hline 942 & & Aglaia sp.11 & Asian & phylogeogr. & Grudinski et al. 2014 \\
\hline
\end{tabular}




\begin{tabular}{|c|c|c|c|c|c|}
\hline No & Family & Species & Origin & $\begin{array}{l}\text { Classification } \\
\text { method }\end{array}$ & References \\
\hline 943 & & Aglaia sp.13 & Asian & phylogeogr. & Grudinski et al. 2014 \\
\hline 944 & & $\begin{array}{l}\text { Aglaia spectabilis (Miq.) } \\
\text { S.S.Jain \& Bennet }\end{array}$ & Asian & phylogeogr. & Grudinski et al. 2014 \\
\hline 945 & & Aglaia squamulosa King & Asian & phylogeogr. & Grudinski et al. 2014 \\
\hline 946 & & $\begin{array}{l}\text { Aglaia tomentosa Teijsm. } \\
\text { \& Binn. }\end{array}$ & Asian & phylogeogr. & Grudinski et al. 2014 \\
\hline 947 & & $\begin{array}{l}\text { Aphanamixis borneensis } \\
\text { (Miq.) Merr. }\end{array}$ & Asian & phylogeogr. & Grudinski et al. 2014 \\
\hline 948 & & $\begin{array}{l}\text { Aphanamixis polystachya } \\
\text { (Wall.) R.Parker }\end{array}$ & Asian & phylogeogr. & Grudinski et al. 2014 \\
\hline 949 & & $\begin{array}{l}\text { Azadirachta excelsa (Jack) } \\
\text { Jacobs }\end{array}$ & Asian & phylogeogr. & Grudinski et al. 2014 \\
\hline 950 & & $\begin{array}{l}\text { Chisocheton cumingianus } \\
\text { (C.DC.) Harms }\end{array}$ & Asian & phylogeogr. & $\begin{array}{l}\text { Koenen 2011, Koenen et } \\
\text { al. } 2015\end{array}$ \\
\hline 951 & & $\begin{array}{l}\text { Chisocheton medusae } \\
\text { Airy Shaw }\end{array}$ & Asian & phylogeogr. & $\begin{array}{l}\text { Koenen 2011, Koenen et } \\
\text { al. } 2015\end{array}$ \\
\hline 952 & & $\begin{array}{l}\text { Chisocheton patens } \\
\text { Blume }\end{array}$ & Asian & phylogeogr. & $\begin{array}{l}\text { Koenen 2011, Koenen et } \\
\text { al. } 2015\end{array}$ \\
\hline 953 & & $\begin{array}{l}\text { Chisocheton pentandrus } \\
\text { (Blanco) Merr. }\end{array}$ & Asian & phylogeogr. & $\begin{array}{l}\text { Koenen 2011, Koenen et } \\
\text { al. } 2015\end{array}$ \\
\hline 954 & & Chisocheton sp. & Asian & phylogeogr. & $\begin{array}{l}\text { Koenen 2011, Koenen et } \\
\text { al. } 2015\end{array}$ \\
\hline 955 & & $\begin{array}{l}\text { Dysoxylum acutangulum } \\
\text { Miq. }\end{array}$ & Asian & phylogeogr. & $\begin{array}{l}\text { Koenen 2011, Koenen et } \\
\text { al. } 2015\end{array}$ \\
\hline 956 & & $\begin{array}{l}\text { Dysoxylum alliaceum } \\
\text { (Blume) Blume }\end{array}$ & Asian & phylogeogr. & $\begin{array}{l}\text { Koenen 2011, Koenen et } \\
\text { al. } 2015\end{array}$ \\
\hline 957 & & $\begin{array}{l}\text { Dysoxylum arborescens } \\
\text { (Blume) Miq. }\end{array}$ & Asian & phylogeogr. & $\begin{array}{l}\text { Koenen 2011, Koenen et } \\
\text { al. } 2015\end{array}$ \\
\hline 958 & & $\begin{array}{l}\text { Dysoxylum cauliflorum } \\
\text { Hiern }\end{array}$ & Asian & phylogeogr. & $\begin{array}{l}\text { Koenen 2011, Koenen et } \\
\text { al. } 2015\end{array}$ \\
\hline 959 & & $\begin{array}{l}\text { Dysoxylum cumingianum } \\
\text { C.DC. }\end{array}$ & Asian & phylogeogr. & $\begin{array}{l}\text { Koenen 2011, Koenen et } \\
\text { al. } 2015\end{array}$ \\
\hline 960 & & $\begin{array}{l}\text { Dysoxylum cyrtobotryum } \\
\text { Miq. }\end{array}$ & Asian & phylogeogr. & $\begin{array}{l}\text { Koenen 2011, Koenen et } \\
\text { al. } 2015\end{array}$ \\
\hline 961 & & $\begin{array}{l}\text { Dysoxylum densiflorum } \\
\text { (Blume) Miq. }\end{array}$ & Asian & phylogeogr. & $\begin{array}{l}\text { Koenen 2011, Koenen et } \\
\text { al. } 2015\end{array}$ \\
\hline 962 & & $\begin{array}{l}\text { Dysoxylum excelsum } \\
\text { Blume }\end{array}$ & Asian & phylogeogr. & $\begin{array}{l}\text { Koenen 2011, Koenen et } \\
\text { al. } 2015\end{array}$ \\
\hline 963 & & $\begin{array}{l}\text { Dysoxylum macrocarpum } \\
\text { Blume }\end{array}$ & Asian & phylogeogr. & $\begin{array}{l}\text { Koenen 2011, Koenen et } \\
\text { al. } 2015\end{array}$ \\
\hline 964 & & $\begin{array}{l}\text { Dysoxylum nutans } \\
\text { (Blume) Miq. }\end{array}$ & Asian & phylogeogr. & $\begin{array}{l}\text { Koenen 2011, Koenen et } \\
\text { al. } 2015\end{array}$ \\
\hline 965 & & $\begin{array}{l}\text { Dysoxylum parasiticum } \\
\text { (Osbeck) Kosterm. }\end{array}$ & Asian & phylogeogr. & $\begin{array}{l}\text { Koenen 2011, Koenen et } \\
\text { al. } 2015\end{array}$ \\
\hline 966 & & $\begin{array}{l}\text { Dysoxylum rugulosum } \\
\text { King }\end{array}$ & Asian & phylogeogr. & $\begin{array}{l}\text { Koenen 2011, Koenen et } \\
\text { al. } 2015\end{array}$ \\
\hline 967 & & Dysoxylum sp.1 & Asian & phylogeogr. & $\begin{array}{l}\text { Koenen 2011, Koenen et } \\
\text { al. } 2015\end{array}$ \\
\hline
\end{tabular}




\begin{tabular}{|c|c|c|c|c|c|}
\hline No & Family & Species & Origin & $\begin{array}{l}\text { Classification } \\
\text { method }\end{array}$ & References \\
\hline 968 & & Dysoxylum sp.2 & Asian & phylogeogr. & $\begin{array}{l}\text { Koenen 2011, Koenen et } \\
\text { al. } 2015\end{array}$ \\
\hline 969 & & Meliaceae sp.1 & Asian & phylogeogr. & $\begin{array}{l}\text { Koenen 2011, Koenen et } \\
\text { al. 2015, Muellner-Riehl } \\
\text { et al. } 2016\end{array}$ \\
\hline 970 & & Meliaceae sp.2 & Asian & phylogeogr. & $\begin{array}{l}\text { Koenen 2011, Koenen et } \\
\text { al. 2015, Muellner-Riehl } \\
\text { et al. } 2016\end{array}$ \\
\hline 971 & & Meliaceae sp.3 & Asian & phylogeogr. & $\begin{array}{l}\text { Koenen 2011, Koenen et } \\
\text { al. 2015, Muellner-Riehl } \\
\text { et al. } 2016\end{array}$ \\
\hline 972 & & $\begin{array}{l}\text { Reinwardtiodendron } \\
\text { humile (Hassk.) Mabb. }\end{array}$ & Asian & phylogeogr. & Grudinski et al. 2014 \\
\hline 973 & & Reinwardtiodendron sp.1 & Asian & phylogeogr. & Grudinski et al. 2014 \\
\hline 974 & & $\begin{array}{l}\text { Sandoricum borneense } \\
\text { Miq. }\end{array}$ & Asian & phylogeogr. & $\begin{array}{l}\text { Koenen 2011, Muellner- } \\
\text { Riehl et al. } 2016\end{array}$ \\
\hline 975 & & $\begin{array}{l}\text { Sandoricum koetjape } \\
\text { (Burm.f.) Merr. }\end{array}$ & Asian & phylogeogr. & $\begin{array}{l}\text { Koenen 2011, Muellner- } \\
\text { Riehl et al. } 2016\end{array}$ \\
\hline 976 & & $\begin{array}{l}\text { Toona calantas Merr. \& } \\
\text { Rolfe }\end{array}$ & Asian & phylogeogr. & $\begin{array}{l}\text { Koecke et al. 2013, } \\
\text { Muellner et al. } 2006\end{array}$ \\
\hline 977 & & $\begin{array}{l}\text { Toona sureni (Blume) } \\
\text { Merr. }\end{array}$ & Asian & phylogeogr. & $\begin{array}{l}\text { Koecke et al. 2013, } \\
\text { Muellner et al. } 2006\end{array}$ \\
\hline 978 & Metteniusaceae & Platea excelsa Blume & Asian & $\begin{array}{l}\text { undated phyl., } \\
\text { distr./fossils }\end{array}$ & $\begin{array}{l}\text { Manchester et al. 2015, } \\
\text { Potgieter + Duno 2016, } \\
\text { Stull et al. } 2015\end{array}$ \\
\hline 979 & & Platea latifolia Blume & Asian & $\begin{array}{l}\text { undated phyl., } \\
\text { distr./fossils }\end{array}$ & $\begin{array}{l}\text { Manchester et al. 2015, } \\
\text { Potgieter + Duno 2016, } \\
\text { Stull et al. } 2015\end{array}$ \\
\hline 980 & Monimiaceae & $\begin{array}{l}\text { Kibara coriacea (Blume) } \\
\text { Tul. }\end{array}$ & Austr. & phylogeogr. & Renner et al. 2010 \\
\hline 981 & & Levieria montana Becc. & Austr. & phylogeogr. & Renner et al. 2010 \\
\hline 982 & & Matthaea sancta Blume & Austr. & phylogeogr. & Renner et al. 2010 \\
\hline 983 & & $\begin{array}{l}\text { Steganthera hirsuta } \\
\text { (Warb.) Perkins }\end{array}$ & Austr. & phylogeogr. & Renner et al. 2010 \\
\hline 984 & Moraceae & Antiaris toxicaria Lesch. & Asian & phylogeogr. & Zerega et al. 2005 \\
\hline 985 & & $\begin{array}{l}\text { Artocarpus chama Buch.- } \\
\text { Ham. }\end{array}$ & Asian & phylogeogr. & Zerega et al. 2005 \\
\hline 986 & & Artocarpus dadah Miq. & Asian & phylogeogr. & Zerega et al. 2005 \\
\hline 987 & & $\begin{array}{l}\text { Artocarpus elasticus } \\
\text { Reinw. ex Blume }\end{array}$ & Asian & phylogeogr. & Zerega et al. 2005 \\
\hline 988 & & $\begin{array}{l}\text { Artocarpus gomezianus } \\
\text { Wall. ex Trécul }\end{array}$ & Asian & phylogeogr. & Zerega et al. 2005 \\
\hline 989 & & $\begin{array}{l}\text { Artocarpus integer } \\
\text { (Thunb.) Merr. }\end{array}$ & Asian & phylogeogr. & Zerega et al. 2005 \\
\hline 990 & & Artocarpus kemando Miq. & Asian & phylogeogr. & Zerega et al. 2005 \\
\hline 991 & & $\begin{array}{l}\text { Artocarpus lacucha Roxb. } \\
\text { ex Buch.-Ham. }\end{array}$ & Asian & phylogeogr. & Zerega et al. 2005 \\
\hline
\end{tabular}




\begin{tabular}{|c|c|c|c|c|c|}
\hline No & Family & Species & Origin & $\begin{array}{l}\text { Classification } \\
\text { method }\end{array}$ & References \\
\hline 992 & & $\begin{array}{l}\text { Artocarpus lanceifolius } \\
\text { Roxb. }\end{array}$ & Asian & phylogeogr. & Zerega et al. 2005 \\
\hline 993 & & Artocarpus nitidus Trécul & Asian & phylogeogr. & Zerega et al. 2005 \\
\hline 994 & & $\begin{array}{l}\text { Artocarpus odoratissimus } \\
\text { Blanco }\end{array}$ & Asian & phylogeogr. & Zerega et al. 2005 \\
\hline 995 & & Artocarpus ovatus Blanco & Asian & phylogeogr. & Zerega et al. 2005 \\
\hline 996 & & Artocarpus rigidus Blume & Asian & phylogeogr. & Zerega et al. 2005 \\
\hline 997 & & Artocarpus sp.1 & Asian & phylogeogr. & Zerega et al. 2005 \\
\hline 998 & & Artocarpus sp.2 & Asian & phylogeogr. & Zerega et al. 2005 \\
\hline 999 & & Artocarpus sp.3 & Asian & phylogeogr. & Zerega et al. 2005 \\
\hline 1000 & & Artocarpus tamaran Becc. & Asian & phylogeogr. & Zerega et al. 2005 \\
\hline 1001 & & $\begin{array}{l}\text { Artocarpus teysmannii } \\
\text { Miq. }\end{array}$ & Asian & phylogeogr. & Zerega et al. 2005 \\
\hline 1002 & & $\begin{array}{l}\text { Artocarpus tomentosulus } \\
\text { F.M.Jarrett }\end{array}$ & Asian & phylogeogr. & Zerega et al. 2005 \\
\hline 1003 & & Ficus ampelas Burm.f. & Asian & phylogeogr. & Cruaud et al. 2012 \\
\hline 1004 & & Ficus annulata Blume & Asian & phylogeogr. & Cruaud et al. 2012 \\
\hline 1005 & & Ficus balete Merr. & Asian & phylogeogr. & Cruaud et al. 2012 \\
\hline 1006 & & Ficus beccarii King & Asian & phylogeogr. & Cruaud et al. 2012 \\
\hline 1007 & & Ficus benjamina L. & Asian & phylogeogr. & Cruaud et al. 2012 \\
\hline 1008 & & Ficus botryocarpa Miq. & Asian & phylogeogr. & Cruaud et al. 2012 \\
\hline 1009 & & Ficus buntaensis C.C.Berg & Asian & phylogeogr. & Cruaud et al. 2012 \\
\hline 1010 & & Ficus callosa Willd. & Asian & phylogeogr. & Cruaud et al. 2012 \\
\hline 1011 & & Ficus chrysolepis Miq. & Asian & phylogeogr. & Cruaud et al. 2012 \\
\hline 1012 & & Ficus congesta Roxb. & Asian & phylogeogr. & Cruaud et al. 2012 \\
\hline 1013 & & $\begin{array}{l}\text { Ficus crassiramea (Miq.) } \\
\text { Miq. }\end{array}$ & Asian & phylogeogr. & Cruaud et al. 2012 \\
\hline 1014 & & Ficus drupacea Thunb. & Asian & phylogeogr. & Cruaud et al. 2012 \\
\hline 1015 & & $\begin{array}{l}\text { Ficus fistulosa Reinw. ex } \\
\text { Blume }\end{array}$ & Asian & phylogeogr. & Cruaud et al. 2012 \\
\hline 1016 & & $\begin{array}{l}\text { Ficus grossularioides } \\
\text { Burm.f. }\end{array}$ & Asian & phylogeogr. & Cruaud et al. 2012 \\
\hline 1017 & & $\begin{array}{l}\text { Ficus gul K.Schum. \& } \\
\text { Lauterb. }\end{array}$ & Asian & phylogeogr. & Cruaud et al. 2012 \\
\hline 1018 & & Ficus heteropleura Blume & Asian & phylogeogr. & Cruaud et al. 2012 \\
\hline 1019 & & Ficus lumutana C.C.Berg & Asian & phylogeogr. & Cruaud et al. 2012 \\
\hline 1020 & & $\begin{array}{l}\text { Ficus minahassae (Teijsm. } \\
\text { \& Vriese) Miq. }\end{array}$ & Asian & phylogeogr. & Cruaud et al. 2012 \\
\hline 1021 & & Ficus montana Burm.f. & Asian & phylogeogr. & Cruaud et al. 2012 \\
\hline 1022 & & $\begin{array}{l}\text { Ficus nervosa B.Heyne ex } \\
\text { Roth }\end{array}$ & Asian & phylogeogr. & Cruaud et al. 2012 \\
\hline 1023 & & Ficus nota (Blanco) Merr. & Asian & phylogeogr. & Cruaud et al. 2012 \\
\hline 1024 & & Ficus punctata Thunb. & Asian & phylogeogr. & Cruaud et al. 2012 \\
\hline 1025 & & $\begin{array}{l}\text { Ficus ribes Reinw. ex } \\
\text { Blume }\end{array}$ & Asian & phylogeogr. & Cruaud et al. 2012 \\
\hline 1026 & & Ficus septica Burm.f. & Asian & phylogeogr. & Cruaud et al. 2012 \\
\hline 1027 & & Ficus sp.1 & Asian & phylogeogr. & Cruaud et al. 2012 \\
\hline 1028 & & Ficus sp.2 & Asian & phylogeogr. & Cruaud et al. 2012 \\
\hline
\end{tabular}




\begin{tabular}{|c|c|c|c|c|c|}
\hline No & Family & Species & Origin & $\begin{array}{l}\text { Classification } \\
\text { method }\end{array}$ & References \\
\hline 1029 & & Ficus sp.3 & Asian & phylogeogr. & Cruaud et al. 2012 \\
\hline 1030 & & Ficus sp.4 & Asian & phylogeogr. & Cruaud et al. 2012 \\
\hline 1031 & & Ficus sp.5 & Asian & phylogeogr. & Cruaud et al. 2012 \\
\hline 1032 & & Ficus sp.6 & Asian & phylogeogr. & Cruaud et al. 2012 \\
\hline 1033 & & Ficus sp.7 & Asian & phylogeogr. & Cruaud et al. 2012 \\
\hline 1034 & & Ficus sp.8 & Asian & phylogeogr. & Cruaud et al. 2012 \\
\hline 1035 & & Ficus sp.9 & Asian & phylogeogr. & Cruaud et al. 2012 \\
\hline 1036 & & Ficus tinctoria G.Forst. & Asian & phylogeogr. & Cruaud et al. 2012 \\
\hline 1037 & & Ficus ulmifolia Lam. & Asian & phylogeogr. & Cruaud et al. 2012 \\
\hline 1038 & & Ficus variegata Blume & Asian & phylogeogr. & Cruaud et al. 2012 \\
\hline 1039 & & Ficus villosa Blume & Asian & phylogeogr. & Cruaud et al. 2012 \\
\hline 1040 & & $\begin{array}{l}\text { Parartocarpus venenosus } \\
\text { (Zoll. \& Moritzi) Becc. }\end{array}$ & Asian & phylogeogr. & Zerega et al. 2005 \\
\hline 1041 & & $\begin{array}{l}\text { Streblus glaber (Merr.) } \\
\text { Corner }\end{array}$ & Asian & phylogeogr. & Zerega et al. 2005 \\
\hline 1042 & & $\begin{array}{l}\text { Streblus ilicifolius (Vidal) } \\
\text { Corner }\end{array}$ & Asian & phylogeogr. & Zerega et al. 2005 \\
\hline 1043 & & $\begin{array}{l}\text { Trophis philippinensis } \\
\text { (Bureau) Corner }\end{array}$ & Asian & phylogeogr. & Zerega et al. 2005 \\
\hline 1044 & Myricaceae & $\begin{array}{l}\text { Morella javanica (Blume) } \\
\text { I.M.Turner }\end{array}$ & Asian & phylogeogr. & Herbert 2005 \\
\hline 1045 & Myristicaceae & $\begin{array}{l}\text { Gymnacranthera } \\
\text { contracta Warb. }\end{array}$ & Asian & $\begin{array}{l}\text { phylogeogr., } \\
\text { distr./fossils }\end{array}$ & Doyle et al. 2004, 2008 \\
\hline 1046 & & $\begin{array}{l}\text { Gymnacranthera } \\
\text { farquhariana (Wall. ex } \\
\text { Hook.f. \& Thomson) Warb. }\end{array}$ & Asian & $\begin{array}{l}\text { phylogeogr., } \\
\text { distr./fossils }\end{array}$ & Doyle et al. 2004, 2008 \\
\hline 1047 & & $\begin{array}{l}\text { Gymnacranthera forbesii } \\
\text { (King) Warb. }\end{array}$ & Asian & $\begin{array}{l}\text { phylogeogr., } \\
\text { distr./fossils }\end{array}$ & Doyle et al. 2004, 2008 \\
\hline 1048 & & Gymnacranthera sp. & Asian & $\begin{array}{l}\text { phylogeogr., } \\
\text { distr./fossils }\end{array}$ & Doyle et al. 2004, 2008 \\
\hline 1049 & & $\begin{array}{l}\text { Horsfieldia borneensis } \\
\text { W.J.de Wilde }\end{array}$ & Asian & $\begin{array}{l}\text { phylogeogr., } \\
\text { distr./fossils }\end{array}$ & Doyle et al. 2004, 2008 \\
\hline 1050 & & $\begin{array}{l}\text { Horsfieldia costulata } \\
\text { (Miq.) Warb. }\end{array}$ & Asian & $\begin{array}{l}\text { phylogeogr., } \\
\text { distr./fossils }\end{array}$ & Doyle et al. 2004, 2008 \\
\hline 1051 & & $\begin{array}{l}\text { Horsfieldia crassifolia } \\
\text { (Hook.f. \& Thomson) } \\
\text { Warb. }\end{array}$ & Asian & $\begin{array}{l}\text { phylogeogr., } \\
\text { distr./fossils }\end{array}$ & Doyle et al. 2004, 2008 \\
\hline 1052 & & $\begin{array}{l}\text { Horsfieldia glabra (Blume) } \\
\text { Warb. }\end{array}$ & Asian & $\begin{array}{l}\text { phylogeogr., } \\
\text { distr./fossils }\end{array}$ & Doyle et al. 2004, 2008 \\
\hline 1053 & & $\begin{array}{l}\text { Horsfieldia irya (Gaertn.) } \\
\text { Warb. }\end{array}$ & Asian & $\begin{array}{l}\text { phylogeogr., } \\
\text { distr./fossils }\end{array}$ & Doyle et al. 2004, 2008 \\
\hline 1054 & & $\begin{array}{l}\text { Horsfieldia parviflora } \\
\text { (Roxb.) J.Sinclair }\end{array}$ & Asian & $\begin{array}{l}\text { phylogeogr., } \\
\text { distr./fossils }\end{array}$ & Doyle et al. 2004, 2008 \\
\hline 1055 & & $\begin{array}{l}\text { Horsfieldia polyspherula } \\
\text { (Hook.f. ex King) J.Sinclair }\end{array}$ & Asian & $\begin{array}{l}\text { phylogeogr., } \\
\text { distr./fossils }\end{array}$ & Doyle et al. 2004, 2008 \\
\hline 1056 & & $\begin{array}{l}\text { Horsfieldia punctatifolia } \\
\text { J.Sinclair }\end{array}$ & Asian & $\begin{array}{l}\text { phylogeogr., } \\
\text { distr./fossils }\end{array}$ & Doyle et al. 2004, 2008 \\
\hline
\end{tabular}




\begin{tabular}{|c|c|c|c|c|c|}
\hline No & Family & Species & Origin & $\begin{array}{l}\text { Classification } \\
\text { method }\end{array}$ & References \\
\hline 1057 & & $\begin{array}{l}\text { Horsfieldia reticulata } \\
\text { Warb. }\end{array}$ & Asian & $\begin{array}{l}\text { phylogeogr., } \\
\text { distr./fossils }\end{array}$ & Doyle et al. 2004, 2008 \\
\hline 1058 & & Horsfieldia sp.1 & Asian & $\begin{array}{l}\text { phylogeogr., } \\
\text { distr./fossils }\end{array}$ & Doyle et al. 2004, 2008 \\
\hline 1059 & & Horsfieldia sp.2 & Asian & $\begin{array}{l}\text { phylogeogr., } \\
\text { distr./fossils }\end{array}$ & Doyle et al. 2004, 2008 \\
\hline 1060 & & Horsfieldia sp.3 & Asian & $\begin{array}{l}\text { phylogeogr., } \\
\text { distr./fossils }\end{array}$ & Doyle et al. 2004, 2008 \\
\hline 1061 & & $\begin{array}{l}\text { Horsfieldia spicata (Roxb.) } \\
\text { J.Sinclair }\end{array}$ & Asian & $\begin{array}{l}\text { phylogeogr., } \\
\text { distr./fossils }\end{array}$ & Doyle et al. 2004, 2008 \\
\hline 1062 & & $\begin{array}{l}\text { Horsfieldia subalpina } \\
\text { J.Sinclair }\end{array}$ & Asian & $\begin{array}{l}\text { phylogeogr., } \\
\text { distr./fossils }\end{array}$ & Doyle et al. 2004, 2008 \\
\hline 1063 & & $\begin{array}{l}\text { Horsfieldia tomentosa } \\
\text { Warb. }\end{array}$ & Asian & $\begin{array}{l}\text { phylogeogr., } \\
\text { distr./fossils }\end{array}$ & Doyle et al. 2004, 2008 \\
\hline 1064 & & $\begin{array}{l}\text { Horsfieldia wallichii } \\
\text { (Hook.f. \& Thomson) } \\
\text { Warb. }\end{array}$ & Asian & $\begin{array}{l}\text { phylogeogr., } \\
\text { distr./fossils }\end{array}$ & Doyle et al. 2004, 2008 \\
\hline 1065 & & $\begin{array}{l}\text { Knema cinerea (Poir.) } \\
\text { Warb. }\end{array}$ & Asian & $\begin{array}{l}\text { phylogeogr., } \\
\text { distr./fossils }\end{array}$ & Doyle et al. 2004, 2008 \\
\hline 1066 & & $\begin{array}{l}\text { Knema conferta (King) } \\
\text { Warb. }\end{array}$ & Asian & $\begin{array}{l}\text { phylogeogr., } \\
\text { distr./fossils }\end{array}$ & Doyle et al. 2004, 2008 \\
\hline 1067 & & $\begin{array}{l}\text { Knema intermedia } \\
\text { (Blume) Warb. }\end{array}$ & Asian & $\begin{array}{l}\text { phylogeogr., } \\
\text { distr./fossils }\end{array}$ & Doyle et al. 2004, 2008 \\
\hline 1068 & & $\begin{array}{l}\text { Knema kinabaluensis } \\
\text { J.Sinclair }\end{array}$ & Asian & $\begin{array}{l}\text { phylogeogr., } \\
\text { distr./fossils }\end{array}$ & Doyle et al. 2004, 2008 \\
\hline 1069 & & Knema korthalsii Warb. & Asian & $\begin{array}{l}\text { phylogeogr., } \\
\text { distr./fossils }\end{array}$ & Doyle et al. 2004, 2008 \\
\hline 1070 & & Knema latericia Elmer & Asian & $\begin{array}{l}\text { phylogeogr., } \\
\text { distr./fossils }\end{array}$ & Doyle et al. 2004, 2008 \\
\hline 1071 & & $\begin{array}{l}\text { Knema laurina (Blume) } \\
\text { Warb. }\end{array}$ & Asian & $\begin{array}{l}\text { phylogeogr., } \\
\text { distr./fossils }\end{array}$ & Doyle et al. 2004, 2008 \\
\hline 1072 & & $\begin{array}{l}\text { Knema linguiformis } \\
\text { (J.Sinclair) W.J.de Wilde }\end{array}$ & Asian & $\begin{array}{l}\text { phylogeogr., } \\
\text { distr./fossils }\end{array}$ & Doyle et al. 2004, 2008 \\
\hline 1073 & & $\begin{array}{l}\text { Knema membranifolia } \\
\text { H.J.P.Winkl. }\end{array}$ & Asian & $\begin{array}{l}\text { phylogeogr., } \\
\text { distr./fossils }\end{array}$ & Doyle et al. 2004, 2008 \\
\hline 1074 & & Knema oblongata Merr. & Asian & $\begin{array}{l}\text { phylogeogr., } \\
\text { distr./fossils }\end{array}$ & Doyle et al. 2004, 2008 \\
\hline 1075 & & $\begin{array}{l}\text { Knema percoriacea } \\
\text { Sinclair }\end{array}$ & Asian & $\begin{array}{l}\text { phylogeogr., } \\
\text { distr./fossils }\end{array}$ & Doyle et al. 2004, 2008 \\
\hline 1076 & & Knema sp.1 & Asian & $\begin{array}{l}\text { phylogeogr., } \\
\text { distr./fossils }\end{array}$ & Doyle et al. 2004, 2008 \\
\hline 1077 & & Knema sp.2 & Asian & $\begin{array}{l}\text { phylogeogr., } \\
\text { distr./fossils }\end{array}$ & Doyle et al. 2004, 2008 \\
\hline 1078 & & Knema sp.3 & Asian & $\begin{array}{l}\text { phylogeogr., } \\
\text { distr./fossils }\end{array}$ & Doyle et al. 2004, 2008 \\
\hline 1079 & & Knema sp.4 & Asian & $\begin{array}{l}\text { phylogeogr., } \\
\text { distr./fossils }\end{array}$ & Doyle et al. 2004, 2008 \\
\hline
\end{tabular}




\begin{tabular}{|c|c|c|c|c|c|}
\hline No & Family & Species & Origin & $\begin{array}{l}\text { Classification } \\
\text { method }\end{array}$ & References \\
\hline 1080 & & Knema stellata Merr. & Asian & $\begin{array}{l}\text { phylogeogr., } \\
\text { distr./fossils }\end{array}$ & Doyle et al. 2004, 2008 \\
\hline 1081 & & $\begin{array}{l}\text { Myristica borneensis } \\
\text { Warb. }\end{array}$ & Asian & $\begin{array}{l}\text { phylogeogr., } \\
\text { distr./fossils }\end{array}$ & Doyle et al. 2004, 2008 \\
\hline 1082 & & Myristica cumingii Warb. & Asian & $\begin{array}{l}\text { phylogeogr., } \\
\text { distr./fossils }\end{array}$ & Doyle et al. 2004, 2008 \\
\hline 1083 & & $\begin{array}{l}\text { Myristica elliptica Wall. ex } \\
\text { Hook.f. \& Thomson }\end{array}$ & Asian & $\begin{array}{l}\text { phylogeogr., } \\
\text { distr./fossils }\end{array}$ & Doyle et al. 2004, 2008 \\
\hline 1084 & & Myristica iners Blume & Asian & $\begin{array}{l}\text { phylogeogr., } \\
\text { distr./fossils }\end{array}$ & Doyle et al. 2004, 2008 \\
\hline 1085 & & Myristica maxima Warb. & Asian & $\begin{array}{l}\text { phylogeogr., } \\
\text { distr./fossils }\end{array}$ & Doyle et al. 2004, 2008 \\
\hline 1086 & & $\begin{array}{l}\text { Myristica mindanaensis } \\
\text { Warb. }\end{array}$ & Asian & $\begin{array}{l}\text { phylogeogr., } \\
\text { distr./fossils }\end{array}$ & Doyle et al. 2004, 2008 \\
\hline 1087 & & $\begin{array}{l}\text { Myristica philippensis } \\
\text { Lam. }\end{array}$ & Asian & $\begin{array}{l}\text { phylogeogr., } \\
\text { distr./fossils }\end{array}$ & Doyle et al. 2004, 2008 \\
\hline 1088 & & Myristica simiarum A.DC. & Asian & $\begin{array}{l}\text { phylogeogr., } \\
\text { distr./fossils }\end{array}$ & Doyle et al. 2004, 2008 \\
\hline 1089 & & Myristicaceae sp.1 & Asian & $\begin{array}{l}\text { phylogeogr., } \\
\text { distr./fossils }\end{array}$ & Doyle et al. 2004, 2008 \\
\hline 1090 & & Myristicaceae sp.2 & Asian & $\begin{array}{l}\text { phylogeogr., } \\
\text { distr./fossils }\end{array}$ & Doyle et al. 2004, 2008 \\
\hline 1091 & Myrtaceae & $\begin{array}{l}\text { Decaspermum fruticosum } \\
\text { J.R.Forst. \& G.Forst. }\end{array}$ & Austr. & phylogeogr. & $\begin{array}{l}\text { Berger et al. 2016, } \\
\text { Sytsma et al. 2004, } \\
\text { Thornhill et al. } 2015\end{array}$ \\
\hline 1092 & & $\begin{array}{l}\text { Leptospermum javanicum } \\
\text { Blume }\end{array}$ & Austr. & phylogeogr. & $\begin{array}{l}\text { Berger et al. 2016, } \\
\text { Sytsma et al. 2004, } \\
\text { Thornhill et al. } 2015\end{array}$ \\
\hline 1093 & & $\begin{array}{l}\text { Leptospermum recurvum } \\
\text { Hook.f. }\end{array}$ & Austr. & phylogeogr. & $\begin{array}{l}\text { Berger et al. 2016, } \\
\text { Sytsma et al. 2004, } \\
\text { Thornhill et al. } 2015\end{array}$ \\
\hline 1094 & & Myrtaceae sp.1 & Austr. & phylogeogr. & $\begin{array}{l}\text { Berger et al. 2016, } \\
\text { Sytsma et al. 2004, } \\
\text { Thornhill et al. } 2015\end{array}$ \\
\hline 1095 & & Myrtaceae sp.2 & Austr. & phylogeogr. & $\begin{array}{l}\text { Berger et al. 2016, } \\
\text { Sytsma et al. 2004, } \\
\text { Thornhill et al. } 2015\end{array}$ \\
\hline 1096 & & Myrtaceae sp.3 & Austr. & phylogeogr. & $\begin{array}{l}\text { Berger et al. 2016, } \\
\text { Sytsma et al. 2004, } \\
\text { Thornhill et al. } 2015\end{array}$ \\
\hline 1097 & & Rhodamnia cinerea Jack & Austr. & phylogeogr. & $\begin{array}{l}\text { Berger et al. 2016, } \\
\text { Sytsma et al. 2004, } \\
\text { Thornhill et al. } 2015\end{array}$ \\
\hline 1098 & & $\begin{array}{l}\text { Syzygium } \\
\text { acuminatissimum (Blume) } \\
\text { DC. }\end{array}$ & Austr. & phylogeogr. & $\begin{array}{l}\text { Berger et al. 2016, } \\
\text { Sytsma et al. 2004, } \\
\text { Thornhill et al. } 2015\end{array}$ \\
\hline
\end{tabular}




\begin{tabular}{|c|c|c|c|c|c|}
\hline No & Family & Species & Origin & $\begin{array}{l}\text { Classification } \\
\text { method }\end{array}$ & References \\
\hline 1099 & & $\begin{array}{l}\text { Syzygium antisepticum } \\
\text { (Blume) Merr. \& L.M.Perry }\end{array}$ & Austr. & phylogeogr. & $\begin{array}{l}\text { Berger et al. 2016, } \\
\text { Sytsma et al. 2004, } \\
\text { Thornhill et al. } 2015\end{array}$ \\
\hline 1100 & & $\begin{array}{l}\text { Syzygium } \\
\text { aphanomyrtoides Merr. \& } \\
\text { L.M.Perry }\end{array}$ & Austr. & phylogeogr. & $\begin{array}{l}\text { Berger et al. 2016, } \\
\text { Sytsma et al. 2004, } \\
\text { Thornhill et al. } 2015\end{array}$ \\
\hline 1101 & & $\begin{array}{l}\text { Syzygium arcuatinervium } \\
\text { (Merr.) Craven \& Biffin }\end{array}$ & Austr. & phylogeogr. & $\begin{array}{l}\text { Berger et al. 2016, } \\
\text { Sytsma et al. 2004, } \\
\text { Thornhill et al. } 2015\end{array}$ \\
\hline 1102 & & $\begin{array}{l}\text { Syzygium aff. baeuerlenii } \\
\text { (F.Muell.) Craven \& Biffin }\end{array}$ & Austr. & phylogeogr. & $\begin{array}{l}\text { Berger et al. 2016, } \\
\text { Sytsma et al. 2004, } \\
\text { Thornhill et al. } 2015\end{array}$ \\
\hline 1103 & & Syzygium sp. nov.3 & Austr. & phylogeogr. & $\begin{array}{l}\text { Berger et al. 2016, } \\
\text { Sytsma et al. 2004, } \\
\text { Thornhill et al. } 2015\end{array}$ \\
\hline 1104 & & $\begin{array}{l}\text { Syzygium bankense } \\
\text { (Hassk.) Merr. \& L.M.Perry }\end{array}$ & Austr. & phylogeogr. & $\begin{array}{l}\text { Berger et al. 2016, } \\
\text { Sytsma et al. 2004, } \\
\text { Thornhill et al. } 2015\end{array}$ \\
\hline 1105 & & $\begin{array}{l}\text { Syzygium benjaminum } \\
\text { Diels }\end{array}$ & Austr. & phylogeogr. & $\begin{array}{l}\text { Berger et al. 2016, } \\
\text { Sytsma et al. 2004, } \\
\text { Thornhill et al. } 2015\end{array}$ \\
\hline 1106 & & $\begin{array}{l}\text { Syzygium castaneum } \\
\text { (Merr.) Merr. \& L.M.Perry }\end{array}$ & Austr. & phylogeogr. & $\begin{array}{l}\text { Berger et al. 2016, } \\
\text { Sytsma et al. 2004, } \\
\text { Thornhill et al. } 2015\end{array}$ \\
\hline 1107 & & $\begin{array}{l}\text { Syzygium caudatilimbum } \\
\text { (Merr.) Merr. \& L.M.Perry }\end{array}$ & Austr. & phylogeogr. & $\begin{array}{l}\text { Berger et al. 2016, } \\
\text { Sytsma et al. 2004, } \\
\text { Thornhill et al. } 2015\end{array}$ \\
\hline 1108 & & $\begin{array}{l}\text { Syzygium celebicum } \\
\text { (Blume) Widodo }\end{array}$ & Austr. & phylogeogr. & $\begin{array}{l}\text { Berger et al. 2016, } \\
\text { Sytsma et al. 2004, } \\
\text { Thornhill et al. } 2015\end{array}$ \\
\hline 1109 & & $\begin{array}{l}\text { Syzygium chloranthum } \\
\text { (Duthie) Merr. \& L.M.Perry }\end{array}$ & Austr. & phylogeogr. & $\begin{array}{l}\text { Berger et al. 2016, } \\
\text { Sytsma et al. 2004, } \\
\text { Thornhill et al. } 2015\end{array}$ \\
\hline 1110 & & $\begin{array}{l}\text { Syzygium clavellatum } \\
\text { (Merr.) Merr. }\end{array}$ & Austr. & phylogeogr. & $\begin{array}{l}\text { Berger et al. 2016, } \\
\text { Sytsma et al. 2004, } \\
\text { Thornhill et al. } 2015\end{array}$ \\
\hline 1111 & & $\begin{array}{l}\text { Syzygium confertum } \\
\text { (Korth.) Merr. \& L.M.Perry }\end{array}$ & Austr. & phylogeogr. & $\begin{array}{l}\text { Berger et al. 2016, } \\
\text { Sytsma et al. 2004, } \\
\text { Thornhill et al. } 2015\end{array}$ \\
\hline 1112 & & $\begin{array}{l}\text { Syzygium corymbosum } \\
\text { (Blume) DC. }\end{array}$ & Austr. & phylogeogr. & $\begin{array}{l}\text { Berger et al. 2016, } \\
\text { Sytsma et al. 2004, } \\
\text { Thornhill et al. } 2015\end{array}$ \\
\hline 1113 & & $\begin{array}{l}\text { Syzygium cuneiforme } \\
\text { Merr. \& L.M.Perry }\end{array}$ & Austr. & phylogeogr. & $\begin{array}{l}\text { Berger et al. 2016, } \\
\text { Sytsma et al. 2004, } \\
\text { Thornhill et al. } 2015\end{array}$ \\
\hline 1114 & & $\begin{array}{l}\text { Syzygium decipiens } \\
\text { (Koord. \& Valeton) Merr. \& } \\
\text { L.M.Perry }\end{array}$ & Austr. & phylogeogr. & $\begin{array}{l}\text { Berger et al. 2016, } \\
\text { Sytsma et al. 2004, } \\
\text { Thornhill et al. } 2015\end{array}$ \\
\hline
\end{tabular}




\begin{tabular}{|c|c|c|c|c|c|}
\hline No & Family & Species & Origin & $\begin{array}{l}\text { Classification } \\
\text { method }\end{array}$ & References \\
\hline 1115 & & $\begin{array}{l}\text { Syzygium effusum } \\
\text { (A.Gray) Müll.Berol. }\end{array}$ & Austr. & phylogeogr. & $\begin{array}{l}\text { Berger et al. 2016, } \\
\text { Sytsma et al. 2004, } \\
\text { Thornhill et al. } 2015\end{array}$ \\
\hline 1116 & & $\begin{array}{l}\text { Syzygium elliptilimbum } \\
\text { (Merr.) Merr. \& L.M.Perry }\end{array}$ & Austr. & phylogeogr. & $\begin{array}{l}\text { Berger et al. 2016, } \\
\text { Sytsma et al. 2004, } \\
\text { Thornhill et al. } 2015\end{array}$ \\
\hline 1117 & & $\begin{array}{l}\text { Syzygium fastigiatum } \\
\text { (Blume) Merr. \& L.M.Perry }\end{array}$ & Austr. & phylogeogr. & $\begin{array}{l}\text { Berger et al. 2016, } \\
\text { Sytsma et al. 2004, } \\
\text { Thornhill et al. } 2015\end{array}$ \\
\hline 1118 & & $\begin{array}{l}\text { Syzygium filiforme } \\
\text { Chantar. \& J.Parn. }\end{array}$ & Austr. & phylogeogr. & $\begin{array}{l}\text { Berger et al. 2016, } \\
\text { Sytsma et al. 2004, } \\
\text { Thornhill et al. } 2015\end{array}$ \\
\hline 1119 & & $\begin{array}{l}\text { Syzygium flosculiferum } \\
\text { (M.R.Hend.) Sreek. }\end{array}$ & Austr. & phylogeogr. & $\begin{array}{l}\text { Berger et al. 2016, } \\
\text { Sytsma et al. 2004, } \\
\text { Thornhill et al. } 2015\end{array}$ \\
\hline 1120 & & Syzygium sp. nov.4 & Austr. & phylogeogr. & $\begin{array}{l}\text { Berger et al. 2016, } \\
\text { Sytsma et al. 2004, } \\
\text { Thornhill et al. } 2015\end{array}$ \\
\hline 1121 & & $\begin{array}{l}\text { Syzygium garciae (Merr.) } \\
\text { Merr. }\end{array}$ & Austr. & phylogeogr. & $\begin{array}{l}\text { Berger et al. 2016, } \\
\text { Sytsma et al. 2004, } \\
\text { Thornhill et al. } 2015\end{array}$ \\
\hline 1122 & & $\begin{array}{l}\text { Syzygium glabratum (DC.) } \\
\text { Veldkamp }\end{array}$ & Austr. & phylogeogr. & $\begin{array}{l}\text { Berger et al. 2016, } \\
\text { Sytsma et al. 2004, } \\
\text { Thornhill et al. } 2015\end{array}$ \\
\hline 1123 & & $\begin{array}{l}\text { Syzygium grande (Wight) } \\
\text { Walp. }\end{array}$ & Austr. & phylogeogr. & $\begin{array}{l}\text { Berger et al. 2016, } \\
\text { Sytsma et al. 2004, } \\
\text { Thornhill et al. } 2015\end{array}$ \\
\hline 1124 & & $\begin{array}{l}\text { Syzygium griffithii (Duthie) } \\
\text { Merr. \& L.M.Perry }\end{array}$ & Austr. & phylogeogr. & $\begin{array}{l}\text { Berger et al. 2016, } \\
\text { Sytsma et al. 2004, } \\
\text { Thornhill et al. } 2015\end{array}$ \\
\hline 1125 & & $\begin{array}{l}\text { Syzygium havilandii } \\
\text { (Merr.) Merr. \& L.M.Perry }\end{array}$ & Austr. & phylogeogr. & $\begin{array}{l}\text { Berger et al. 2016, } \\
\text { Sytsma et al. 2004, } \\
\text { Thornhill et al. } 2015\end{array}$ \\
\hline 1126 & & $\begin{array}{l}\text { Syzygium hirtum (Korth.) } \\
\text { Merr. \& L.M.Perry }\end{array}$ & Austr. & phylogeogr. & $\begin{array}{l}\text { Berger et al. 2016, } \\
\text { Sytsma et al. 2004, } \\
\text { Thornhill et al. } 2015\end{array}$ \\
\hline 1127 & & $\begin{array}{l}\text { Syzygium houttuynii Merr. } \\
\text { \& L.M.Perry }\end{array}$ & Austr. & phylogeogr. & $\begin{array}{l}\text { Berger et al. 2016, } \\
\text { Sytsma et al. 2004, } \\
\text { Thornhill et al. } 2015\end{array}$ \\
\hline 1128 & & $\begin{array}{l}\text { Syzygium kinabaluense } \\
\text { (Stapf) Merr. \& L.M.Perry }\end{array}$ & Austr. & phylogeogr. & $\begin{array}{l}\text { Berger et al. 2016, } \\
\text { Sytsma et al. 2004, } \\
\text { Thornhill et al. } 2015\end{array}$ \\
\hline 1129 & & $\begin{array}{l}\text { Syzygium kunstleri (King) } \\
\text { Bahadur \& R.C.Gaur }\end{array}$ & Austr. & phylogeogr. & $\begin{array}{l}\text { Berger et al. 2016, } \\
\text { Sytsma et al. 2004, } \\
\text { Thornhill et al. } 2015\end{array}$ \\
\hline 1130 & & $\begin{array}{l}\text { Syzygium laxiflorum } \\
\text { (Blume) DC. }\end{array}$ & Austr. & phylogeogr. & $\begin{array}{l}\text { Berger et al. 2016, } \\
\text { Sytsma et al. 2004, } \\
\text { Thornhill et al. } 2015\end{array}$ \\
\hline
\end{tabular}




\begin{tabular}{|c|c|c|c|c|c|}
\hline No & Family & Species & Origin & $\begin{array}{l}\text { Classification } \\
\text { method }\end{array}$ & References \\
\hline 1131 & & $\begin{array}{l}\text { Syzygium cf. leptopodium } \\
\text { Merr. \& L.M.Perry }\end{array}$ & Austr. & phylogeogr. & $\begin{array}{l}\text { Berger et al. 2016, } \\
\text { Sytsma et al. 2004, } \\
\text { Thornhill et al. } 2015\end{array}$ \\
\hline 1132 & & $\begin{array}{l}\text { Syzygium leucocladum } \\
\text { Merr. \& L.M.Perry }\end{array}$ & Austr. & phylogeogr. & $\begin{array}{l}\text { Berger et al. 2016, } \\
\text { Sytsma et al. 2004, } \\
\text { Thornhill et al. } 2015\end{array}$ \\
\hline 1133 & & $\begin{array}{l}\text { Syzygium lineatum (DC.) } \\
\text { Merr. \& L.M.Perry }\end{array}$ & Austr. & phylogeogr. & $\begin{array}{l}\text { Berger et al. 2016, } \\
\text { Sytsma et al. 2004, } \\
\text { Thornhill et al. } 2015\end{array}$ \\
\hline 1134 & & $\begin{array}{l}\text { Syzygium magnoliifolium } \\
\text { (Blume) DC. }\end{array}$ & Austr. & phylogeogr. & $\begin{array}{l}\text { Berger et al. 2016, } \\
\text { Sytsma et al. 2004, } \\
\text { Thornhill et al. } 2015\end{array}$ \\
\hline 1135 & & $\begin{array}{l}\text { Syzygium mainitense } \\
\text { (Elmer) Merr. }\end{array}$ & Austr. & phylogeogr. & $\begin{array}{l}\text { Berger et al. 2016, } \\
\text { Sytsma et al. 2004, } \\
\text { Thornhill et al. } 2015\end{array}$ \\
\hline 1136 & & $\begin{array}{l}\text { Syzygium medium (Korth.) } \\
\text { Merr. \& L.M.Perry }\end{array}$ & Austr. & phylogeogr. & $\begin{array}{l}\text { Berger et al. 2016, } \\
\text { Sytsma et al. 2004, } \\
\text { Thornhill et al. } 2015\end{array}$ \\
\hline 1137 & & $\begin{array}{l}\text { Syzygium myrtilloides } \\
\text { Merr. \& L.M.Perry }\end{array}$ & Austr. & phylogeogr. & $\begin{array}{l}\text { Berger et al. 2016, } \\
\text { Sytsma et al. 2004, } \\
\text { Thornhill et al. } 2015\end{array}$ \\
\hline 1138 & & $\begin{array}{l}\text { Syzygium napiforme } \\
\text { (Koord. \& Valeton) Merr. \& } \\
\text { L.M.Perry }\end{array}$ & Austr. & phylogeogr. & $\begin{array}{l}\text { Berger et al. 2016, } \\
\text { Sytsma et al. 2004, } \\
\text { Thornhill et al. } 2015\end{array}$ \\
\hline 1139 & & $\begin{array}{l}\text { Syzygium nervosum } \\
\text { A.Cunn. ex DC. }\end{array}$ & Austr. & phylogeogr. & $\begin{array}{l}\text { Berger et al. 2016, } \\
\text { Sytsma et al. 2004, } \\
\text { Thornhill et al. } 2015\end{array}$ \\
\hline 1140 & & $\begin{array}{l}\text { Syzygium nigricans (King) } \\
\text { Merr. \& L.M.Perry }\end{array}$ & Austr. & phylogeogr. & $\begin{array}{l}\text { Berger et al. 2016, } \\
\text { Sytsma et al. 2004, } \\
\text { Thornhill et al. } 2015\end{array}$ \\
\hline 1141 & & Syzygium nitidum Benth. & Austr. & phylogeogr. & $\begin{array}{l}\text { Berger et al. 2016, } \\
\text { Sytsma et al. 2004, } \\
\text { Thornhill et al. } 2015\end{array}$ \\
\hline 1142 & & $\begin{array}{l}\text { Syzygium oligomyrum } \\
\text { Diels }\end{array}$ & Austr. & phylogeogr. & $\begin{array}{l}\text { Berger et al. 2016, } \\
\text { Sytsma et al. 2004, } \\
\text { Thornhill et al. } 2015\end{array}$ \\
\hline 1143 & & $\begin{array}{l}\text { Syzygium pachysepalum } \\
\text { Merr. \& L.M.Perry }\end{array}$ & Austr. & phylogeogr. & $\begin{array}{l}\text { Berger et al. 2016, } \\
\text { Sytsma et al. 2004, } \\
\text { Thornhill et al. } 2015\end{array}$ \\
\hline 1144 & & $\begin{array}{l}\text { Syzygium palawanense } \\
\text { (C.B.Rob.) Merr. \& } \\
\text { L.M.Perry }\end{array}$ & Austr. & phylogeogr. & $\begin{array}{l}\text { Berger et al. 2016, } \\
\text { Sytsma et al. 2004, } \\
\text { Thornhill et al. } 2015\end{array}$ \\
\hline 1145 & & $\begin{array}{l}\text { Syzygium paraiense Merr. } \\
\text { \& L.M.Perry }\end{array}$ & Austr. & phylogeogr. & $\begin{array}{l}\text { Berger et al. 2016, } \\
\text { Sytsma et al. 2004, } \\
\text { Thornhill et al. } 2015\end{array}$ \\
\hline 1146 & & $\begin{array}{l}\text { Syzygium paucipunctatum } \\
\text { (Koord. \& Valeton) Merr. \& } \\
\text { L.M.Perry }\end{array}$ & Austr. & phylogeogr. & $\begin{array}{l}\text { Berger et al. 2016, } \\
\text { Sytsma et al. 2004, } \\
\text { Thornhill et al. } 2015\end{array}$ \\
\hline
\end{tabular}




\begin{tabular}{|c|c|c|c|c|c|}
\hline No & Family & Species & Origin & $\begin{array}{l}\text { Classification } \\
\text { method }\end{array}$ & References \\
\hline 1147 & & $\begin{array}{l}\text { Syzygium } \\
\text { perspicuinervium (Merr.) } \\
\text { Masam. }\end{array}$ & Austr. & phylogeogr. & $\begin{array}{l}\text { Berger et al. 2016, } \\
\text { Sytsma et al. 2004, } \\
\text { Thornhill et al. } 2015\end{array}$ \\
\hline 1148 & & $\begin{array}{l}\text { Syzygium petakense Merr. } \\
\text { \& L.M.Perry }\end{array}$ & Austr. & phylogeogr. & $\begin{array}{l}\text { Berger et al. 2016, } \\
\text { Sytsma et al. 2004, } \\
\text { Thornhill et al. } 2015\end{array}$ \\
\hline 1149 & & $\begin{array}{l}\text { Syzygium phaeostictum } \\
\text { Merr. \& L.M.Perry }\end{array}$ & Austr. & phylogeogr. & $\begin{array}{l}\text { Berger et al. 2016, } \\
\text { Sytsma et al. 2004, } \\
\text { Thornhill et al. } 2015\end{array}$ \\
\hline 1150 & & $\begin{array}{l}\text { Syzygium polyanthum } \\
\text { (Wight) Walp. }\end{array}$ & Austr. & phylogeogr. & $\begin{array}{l}\text { Berger et al. 2016, } \\
\text { Sytsma et al. 2004, } \\
\text { Thornhill et al. } 2015\end{array}$ \\
\hline 1151 & & $\begin{array}{l}\text { Syzygium pterophorum } \\
\text { Merr. \& L.M.Perry }\end{array}$ & Austr. & phylogeogr. & $\begin{array}{l}\text { Berger et al. 2016, } \\
\text { Sytsma et al. 2004, } \\
\text { Thornhill et al. } 2015\end{array}$ \\
\hline 1152 & & $\begin{array}{l}\text { Syzygium punctilimbum } \\
\text { (Merr.) Merr. \& L.M.Perry }\end{array}$ & Austr. & phylogeogr. & $\begin{array}{l}\text { Berger et al. 2016, } \\
\text { Sytsma et al. 2004, } \\
\text { Thornhill et al. } 2015\end{array}$ \\
\hline 1153 & & $\begin{array}{l}\text { Syzygium pycnanthum } \\
\text { Merr. \& L.M.Perr }\end{array}$ & Austr. & phylogeogr. & $\begin{array}{l}\text { Berger et al. 2016, } \\
\text { Sytsma et al. 2004, } \\
\text { Thornhill et al. } 2015\end{array}$ \\
\hline 1154 & & $\begin{array}{l}\text { Syzygium racemosum } \\
\text { (Blume) DC. }\end{array}$ & Austr. & phylogeogr. & $\begin{array}{l}\text { Berger et al. 2016, } \\
\text { Sytsma et al. 2004, } \\
\text { Thornhill et al. } 2015\end{array}$ \\
\hline 1155 & & $\begin{array}{l}\text { Syzygium aff. rosenbluthii } \\
\text { (C.B.Rob.) Merr. }\end{array}$ & Austr. & phylogeogr. & $\begin{array}{l}\text { Berger et al. 2016, } \\
\text { Sytsma et al. 2004, } \\
\text { Thornhill et al. } 2015\end{array}$ \\
\hline 1156 & & $\begin{array}{l}\text { Syzygium scortechinii } \\
\text { (King) Chantar. \&J.Parn. }\end{array}$ & Austr. & phylogeogr. & $\begin{array}{l}\text { Berger et al. 2016, } \\
\text { Sytsma et al. 2004, } \\
\text { Thornhill et al. } 2015\end{array}$ \\
\hline 1157 & & Syzygium sp.01 & Austr. & phylogeogr. & $\begin{array}{l}\text { Berger et al. 2016, } \\
\text { Sytsma et al. 2004, } \\
\text { Thornhill et al. } 2015\end{array}$ \\
\hline 1158 & & Syzygium sp.02 & Austr. & phylogeogr. & $\begin{array}{l}\text { Berger et al. 2016, } \\
\text { Sytsma et al. 2004, } \\
\text { Thornhill et al. } 2015\end{array}$ \\
\hline 1159 & & Syzygium sp.03 & Austr. & phylogeogr. & $\begin{array}{l}\text { Berger et al. 2016, } \\
\text { Sytsma et al. 2004, } \\
\text { Thornhill et al. } 2015\end{array}$ \\
\hline 1160 & & Syzygium sp.04 & Austr. & phylogeogr. & $\begin{array}{l}\text { Berger et al. 2016, } \\
\text { Sytsma et al. 2004, } \\
\text { Thornhill et al. } 2015\end{array}$ \\
\hline 1161 & & Syzygium sp.05 & Austr. & phylogeogr. & $\begin{array}{l}\text { Berger et al. 2016, } \\
\text { Sytsma et al. 2004, } \\
\text { Thornhill et al. } 2015\end{array}$ \\
\hline 1162 & & Syzygium sp.06 & Austr. & phylogeogr. & $\begin{array}{l}\text { Berger et al. 2016, } \\
\text { Sytsma et al. 2004, } \\
\text { Thornhill et al. } 2015\end{array}$ \\
\hline
\end{tabular}




\begin{tabular}{|c|c|c|c|c|c|}
\hline No & Family & Species & Origin & $\begin{array}{l}\text { Classification } \\
\text { method }\end{array}$ & References \\
\hline 1163 & & Syzygium sp.07 & Austr. & phylogeogr. & $\begin{array}{l}\text { Berger et al. 2016, } \\
\text { Sytsma et al. } 2004, \\
\text { Thornhill et al. } 2015\end{array}$ \\
\hline 1164 & & Syzygium sp.08 & Austr. & phylogeogr. & $\begin{array}{l}\text { Berger et al. 2016, } \\
\text { Sytsma et al. 2004, } \\
\text { Thornhill et al. } 2015\end{array}$ \\
\hline 1165 & & Syzygium sp.09 & Austr. & phylogeogr. & $\begin{array}{l}\text { Berger et al. 2016, } \\
\text { Sytsma et al. 2004, } \\
\text { Thornhill et al. } 2015\end{array}$ \\
\hline 1166 & & Syzygium sp.10 & Austr. & phylogeogr. & $\begin{array}{l}\text { Berger et al. 2016, } \\
\text { Sytsma et al. 2004, } \\
\text { Thornhill et al. } 2015\end{array}$ \\
\hline 1167 & & Syzygium sp.11 & Austr. & phylogeogr. & $\begin{array}{l}\text { Berger et al. 2016, } \\
\text { Sytsma et al. 2004, } \\
\text { Thornhill et al. } 2015\end{array}$ \\
\hline 1168 & & Syzygium sp.12 & Austr. & phylogeogr. & $\begin{array}{l}\text { Berger et al. 2016, } \\
\text { Sytsma et al. 2004, } \\
\text { Thornhill et al. } 2015\end{array}$ \\
\hline 1169 & & Syzygium sp.13 & Austr. & phylogeogr. & $\begin{array}{l}\text { Berger et al. 2016, } \\
\text { Sytsma et al. 2004, } \\
\text { Thornhill et al. } 2015\end{array}$ \\
\hline 1170 & & Syzygium sp.14 & Austr. & phylogeogr. & $\begin{array}{l}\text { Berger et al. 2016, } \\
\text { Sytsma et al. 2004, } \\
\text { Thornhill et al. } 2015\end{array}$ \\
\hline 1171 & & Syzygium sp.15 & Austr. & phylogeogr. & $\begin{array}{l}\text { Berger et al. 2016, } \\
\text { Sytsma et al. 2004, } \\
\text { Thornhill et al. } 2015\end{array}$ \\
\hline 1172 & & Syzygium sp.16 & Austr. & phylogeogr. & $\begin{array}{l}\text { Berger et al. 2016, } \\
\text { Sytsma et al. 2004, } \\
\text { Thornhill et al. } 2015\end{array}$ \\
\hline 1173 & & Syzygium sp.17 & Austr. & phylogeogr. & $\begin{array}{l}\text { Berger et al. 2016, } \\
\text { Sytsma et al. 2004, } \\
\text { Thornhill et al. } 2015\end{array}$ \\
\hline 1174 & & Syzygium sp.18 & Austr. & phylogeogr. & $\begin{array}{l}\text { Berger et al. 2016, } \\
\text { Sytsma et al. 2004, } \\
\text { Thornhill et al. } 2015\end{array}$ \\
\hline 1175 & & Syzygium sp.19 & Austr. & phylogeogr. & $\begin{array}{l}\text { Berger et al. 2016, } \\
\text { Sytsma et al. 2004, } \\
\text { Thornhill et al. } 2015\end{array}$ \\
\hline 1176 & & Syzygium sp.20 & Austr. & phylogeogr. & $\begin{array}{l}\text { Berger et al. 2016, } \\
\text { Sytsma et al. 2004, } \\
\text { Thornhill et al. } 2015\end{array}$ \\
\hline 1177 & & Syzygium sp.21 & Austr. & phylogeogr. & $\begin{array}{l}\text { Berger et al. 2016, } \\
\text { Sytsma et al. 2004, } \\
\text { Thornhill et al. } 2015\end{array}$ \\
\hline 1178 & & Syzygium sp.22 & Austr. & phylogeogr. & $\begin{array}{l}\text { Berger et al. 2016, } \\
\text { Sytsma et al. 2004, } \\
\text { Thornhill et al. } 2015\end{array}$ \\
\hline
\end{tabular}




\begin{tabular}{|c|c|c|c|c|c|}
\hline No & Family & Species & Origin & $\begin{array}{l}\text { Classification } \\
\text { method }\end{array}$ & References \\
\hline 1179 & & Syzygium sp.23 & Austr. & phylogeogr. & $\begin{array}{l}\text { Berger et al. 2016, } \\
\text { Sytsma et al. 2004, } \\
\text { Thornhill et al. } 2015\end{array}$ \\
\hline 1180 & & Syzygium sp.24 & Austr. & phylogeogr. & $\begin{array}{l}\text { Berger et al. 2016, } \\
\text { Sytsma et al. 2004, } \\
\text { Thornhill et al. } 2015\end{array}$ \\
\hline 1181 & & Syzygium sp.25 & Austr. & phylogeogr. & $\begin{array}{l}\text { Berger et al. 2016, } \\
\text { Sytsma et al. 2004, } \\
\text { Thornhill et al. } 2015\end{array}$ \\
\hline 1182 & & Syzygium sp.26 & Austr. & phylogeogr. & $\begin{array}{l}\text { Berger et al. 2016, } \\
\text { Sytsma et al. 2004, } \\
\text { Thornhill et al. } 2015\end{array}$ \\
\hline 1183 & & Syzygium sp.27 & Austr. & phylogeogr. & $\begin{array}{l}\text { Berger et al. 2016, } \\
\text { Sytsma et al. 2004, } \\
\text { Thornhill et al. } 2015\end{array}$ \\
\hline 1184 & & Syzygium sp.28 & Austr. & phylogeogr. & $\begin{array}{l}\text { Berger et al. 2016, } \\
\text { Sytsma et al. 2004, } \\
\text { Thornhill et al. } 2015\end{array}$ \\
\hline 1185 & & Syzygium sp.29 & Austr. & phylogeogr. & $\begin{array}{l}\text { Berger et al. 2016, } \\
\text { Sytsma et al. 2004, } \\
\text { Thornhill et al. } 2015\end{array}$ \\
\hline 1186 & & Syzygium sp.30 & Austr. & phylogeogr. & $\begin{array}{l}\text { Berger et al. 2016, } \\
\text { Sytsma et al. 2004, } \\
\text { Thornhill et al. } 2015\end{array}$ \\
\hline 1187 & & Syzygium sp.31 & Austr. & phylogeogr. & $\begin{array}{l}\text { Berger et al. 2016, } \\
\text { Sytsma et al. 2004, } \\
\text { Thornhill et al. } 2015\end{array}$ \\
\hline 1188 & & Syzygium sp.32 & Austr. & phylogeogr. & $\begin{array}{l}\text { Berger et al. 2016, } \\
\text { Sytsma et al. 2004, } \\
\text { Thornhill et al. } 2015\end{array}$ \\
\hline 1189 & & Syzygium sp.33 & Austr. & phylogeogr. & $\begin{array}{l}\text { Berger et al. 2016, } \\
\text { Sytsma et al. 2004, } \\
\text { Thornhill et al. } 2015\end{array}$ \\
\hline 1190 & & Syzygium sp.34 & Austr. & phylogeogr. & $\begin{array}{l}\text { Berger et al. 2016, } \\
\text { Sytsma et al. 2004, } \\
\text { Thornhill et al. } 2015\end{array}$ \\
\hline 1191 & & Syzygium sp.35 & Austr. & phylogeogr. & $\begin{array}{l}\text { Berger et al. 2016, } \\
\text { Sytsma et al. 2004, } \\
\text { Thornhill et al. } 2015\end{array}$ \\
\hline 1192 & & Syzygium sp.36 & Austr. & phylogeogr. & $\begin{array}{l}\text { Berger et al. 2016, } \\
\text { Sytsma et al. 2004, } \\
\text { Thornhill et al. } 2015\end{array}$ \\
\hline 1193 & & Syzygium sp.37 & Austr. & phylogeogr. & $\begin{array}{l}\text { Berger et al. 2016, } \\
\text { Sytsma et al. 2004, } \\
\text { Thornhill et al. } 2015\end{array}$ \\
\hline 1194 & & Syzygium sp.38 & Austr. & phylogeogr. & $\begin{array}{l}\text { Berger et al. 2016, } \\
\text { Sytsma et al. 2004, } \\
\text { Thornhill et al. } 2015\end{array}$ \\
\hline
\end{tabular}




\begin{tabular}{|c|c|c|c|c|c|}
\hline No & Family & Species & Origin & $\begin{array}{l}\text { Classification } \\
\text { method }\end{array}$ & References \\
\hline 1195 & & Syzygium sp.39 & Austr. & phylogeogr. & $\begin{array}{l}\text { Berger et al. 2016, } \\
\text { Sytsma et al. } 2004, \\
\text { Thornhill et al. } 2015\end{array}$ \\
\hline 1196 & & Syzygium sp.40 & Austr. & phylogeogr. & $\begin{array}{l}\text { Berger et al. 2016, } \\
\text { Sytsma et al. 2004, } \\
\text { Thornhill et al. } 2015\end{array}$ \\
\hline 1197 & & Syzygium sp.41 & Austr. & phylogeogr. & $\begin{array}{l}\text { Berger et al. 2016, } \\
\text { Sytsma et al. 2004, } \\
\text { Thornhill et al. } 2015\end{array}$ \\
\hline 1198 & & Syzygium sp.42 & Austr. & phylogeogr. & $\begin{array}{l}\text { Berger et al. 2016, } \\
\text { Sytsma et al. 2004, } \\
\text { Thornhill et al. } 2015\end{array}$ \\
\hline 1199 & & Syzygium sp.43 & Austr. & phylogeogr. & $\begin{array}{l}\text { Berger et al. 2016, } \\
\text { Sytsma et al. 2004, } \\
\text { Thornhill et al. } 2015\end{array}$ \\
\hline 1200 & & Syzygium sp.44 & Austr. & phylogeogr. & $\begin{array}{l}\text { Berger et al. 2016, } \\
\text { Sytsma et al. 2004, } \\
\text { Thornhill et al. } 2015\end{array}$ \\
\hline 1201 & & Syzygium sp.45 & Austr. & phylogeogr. & $\begin{array}{l}\text { Berger et al. 2016, } \\
\text { Sytsma et al. 2004, } \\
\text { Thornhill et al. } 2015\end{array}$ \\
\hline 1202 & & Syzygium sp.46 & Austr. & phylogeogr. & $\begin{array}{l}\text { Berger et al. 2016, } \\
\text { Sytsma et al. 2004, } \\
\text { Thornhill et al. } 2015\end{array}$ \\
\hline 1203 & & Syzygium sp.48 & Austr. & phylogeogr. & $\begin{array}{l}\text { Berger et al. 2016, } \\
\text { Sytsma et al. 2004, } \\
\text { Thornhill et al. } 2015\end{array}$ \\
\hline 1204 & & Syzygium sp.49 & Austr. & phylogeogr. & $\begin{array}{l}\text { Berger et al. 2016, } \\
\text { Sytsma et al. 2004, } \\
\text { Thornhill et al. } 2015\end{array}$ \\
\hline 1205 & & Syzygium sp.50 & Austr. & phylogeogr. & $\begin{array}{l}\text { Berger et al. 2016, } \\
\text { Sytsma et al. 2004, } \\
\text { Thornhill et al. } 2015\end{array}$ \\
\hline 1206 & & Syzygium sp.51 & Austr. & phylogeogr. & $\begin{array}{l}\text { Berger et al. 2016, } \\
\text { Sytsma et al. 2004, } \\
\text { Thornhill et al. } 2015\end{array}$ \\
\hline 1207 & & Syzygium sp.52 & Austr. & phylogeogr. & $\begin{array}{l}\text { Berger et al. 2016, } \\
\text { Sytsma et al. 2004, } \\
\text { Thornhill et al. } 2015\end{array}$ \\
\hline 1208 & & Syzygium sp.53 & Austr. & phylogeogr. & $\begin{array}{l}\text { Berger et al. 2016, } \\
\text { Sytsma et al. 2004, } \\
\text { Thornhill et al. } 2015\end{array}$ \\
\hline 1209 & & Syzygium sp.54 & Austr. & phylogeogr. & $\begin{array}{l}\text { Berger et al. 2016, } \\
\text { Sytsma et al. 2004, } \\
\text { Thornhill et al. } 2015\end{array}$ \\
\hline 1210 & & Syzygium sp.55 & Austr. & phylogeogr. & $\begin{array}{l}\text { Berger et al. 2016, } \\
\text { Sytsma et al. 2004, } \\
\text { Thornhill et al. } 2015\end{array}$ \\
\hline
\end{tabular}




\begin{tabular}{|c|c|c|c|c|c|}
\hline No & Family & Species & Origin & $\begin{array}{l}\text { Classification } \\
\text { method }\end{array}$ & References \\
\hline 1211 & & Syzygium sp.56 & Austr. & phylogeogr. & $\begin{array}{l}\text { Berger et al. 2016, } \\
\text { Sytsma et al. 2004, } \\
\text { Thornhill et al. } 2015\end{array}$ \\
\hline 1212 & & Syzygium sp.57 & Austr. & phylogeogr. & $\begin{array}{l}\text { Berger et al. 2016, } \\
\text { Sytsma et al. 2004, } \\
\text { Thornhill et al. } 2015\end{array}$ \\
\hline 1213 & & Syzygium sp.58 & Austr. & phylogeogr. & $\begin{array}{l}\text { Berger et al. 2016, } \\
\text { Sytsma et al. 2004, } \\
\text { Thornhill et al. } 2015\end{array}$ \\
\hline 1214 & & Syzygium sp.59 & Austr. & phylogeogr. & $\begin{array}{l}\text { Berger et al. 2016, } \\
\text { Sytsma et al. 2004, } \\
\text { Thornhill et al. } 2015\end{array}$ \\
\hline 1215 & & Syzygium sp.60 & Austr. & phylogeogr. & $\begin{array}{l}\text { Berger et al. 2016, } \\
\text { Sytsma et al. 2004, } \\
\text { Thornhill et al. } 2015\end{array}$ \\
\hline 1216 & & Syzygium sp.61 & Austr. & phylogeogr. & $\begin{array}{l}\text { Berger et al. 2016, } \\
\text { Sytsma et al. 2004, } \\
\text { Thornhill et al. } 2015\end{array}$ \\
\hline 1217 & & Syzygium sp.62 & Austr. & phylogeogr. & $\begin{array}{l}\text { Berger et al. 2016, } \\
\text { Sytsma et al. 2004, } \\
\text { Thornhill et al. } 2015\end{array}$ \\
\hline 1218 & & $\begin{array}{l}\text { Syzygium steenisii Merr. \& } \\
\text { L.M.Perry }\end{array}$ & Austr. & phylogeogr. & $\begin{array}{l}\text { Berger et al. 2016, } \\
\text { Sytsma et al. 2004, } \\
\text { Thornhill et al. } 2015\end{array}$ \\
\hline 1219 & & $\begin{array}{l}\text { Syzygium stipulare } \\
\text { (Blume) Craven \& } \\
\text { T.G.Hartley }\end{array}$ & Austr. & phylogeogr. & $\begin{array}{l}\text { Berger et al. 2016, } \\
\text { Sytsma et al. 2004, } \\
\text { Thornhill et al. } 2015\end{array}$ \\
\hline 1220 & & $\begin{array}{l}\text { Syzygium subcrenatum } \\
\text { Merr. \& L.M.Perry }\end{array}$ & Austr. & phylogeogr. & $\begin{array}{l}\text { Berger et al. 2016, } \\
\text { Sytsma et al. 2004, } \\
\text { Thornhill et al. } 2015\end{array}$ \\
\hline 1221 & & $\begin{array}{l}\text { Syzygium suringarianum } \\
\text { (Koord. \& Valeton) } \\
\text { Amshoff }\end{array}$ & Austr. & phylogeogr. & $\begin{array}{l}\text { Berger et al. 2016, } \\
\text { Sytsma et al. 2004, } \\
\text { Thornhill et al. } 2015\end{array}$ \\
\hline 1222 & & $\begin{array}{l}\text { Syzygium tawahense } \\
\text { (Korth.) Merr. \& L.M.Perry }\end{array}$ & Austr. & phylogeogr. & $\begin{array}{l}\text { Berger et al. 2016, } \\
\text { Sytsma et al. 2004, } \\
\text { Thornhill et al. } 2015\end{array}$ \\
\hline 1223 & & $\begin{array}{l}\text { Syzygium tripinnatum } \\
\text { (Blanco) Merr. }\end{array}$ & Austr. & phylogeogr. & $\begin{array}{l}\text { Berger et al. 2016, } \\
\text { Sytsma et al. 2004, } \\
\text { Thornhill et al. } 2015\end{array}$ \\
\hline 1224 & & $\begin{array}{l}\text { Syzygium valdevenosum } \\
\text { (Duthie) Merr. \& L.M.Perry }\end{array}$ & Austr. & phylogeogr. & $\begin{array}{l}\text { Berger et al. 2016, } \\
\text { Sytsma et al. 2004, } \\
\text { Thornhill et al. } 2015\end{array}$ \\
\hline 1225 & & $\begin{array}{l}\text { Syzygium viridifolium } \\
\text { (Elmer) Merr. \& L.M.Perry }\end{array}$ & Austr. & phylogeogr. & $\begin{array}{l}\text { Berger et al. 2016, } \\
\text { Sytsma et al. 2004, } \\
\text { Thornhill et al. } 2015\end{array}$ \\
\hline 1226 & & $\begin{array}{l}\text { Syzygium zeylanicum (L.) } \\
\text { DC. }\end{array}$ & Austr. & phylogeogr. & $\begin{array}{l}\text { Berger et al. 2016, } \\
\text { Sytsma et al. 2004, } \\
\text { Thornhill et al. } 2015\end{array}$ \\
\hline
\end{tabular}




\begin{tabular}{|c|c|c|c|c|c|}
\hline No & Family & Species & Origin & $\begin{array}{l}\text { Classification } \\
\text { method }\end{array}$ & References \\
\hline 1227 & & $\begin{array}{l}\text { Tristaniopsis elliptica } \\
\text { (Stapf) Peter G.Wilson \& } \\
\text { J.T.Waterh. }\end{array}$ & Austr. & phylogeogr. & $\begin{array}{l}\text { Berger et al. 2016, } \\
\text { Sytsma et al. 2004, } \\
\text { Thornhill et al. } 2015\end{array}$ \\
\hline 1228 & & $\begin{array}{l}\text { Tristaniopsis obovata } \\
\text { (Benn.) Peter G.Wilson \& } \\
\text { J.T.Waterh. }\end{array}$ & Austr. & phylogeogr. & $\begin{array}{l}\text { Berger et al. 2016, } \\
\text { Sytsma et al. 2004, } \\
\text { Thornhill et al. } 2015\end{array}$ \\
\hline 1229 & & Tristaniopsis sp.1 & Austr. & phylogeogr. & $\begin{array}{l}\text { Berger et al. 2016, } \\
\text { Sytsma et al. 2004, } \\
\text { Thornhill et al. } 2015\end{array}$ \\
\hline 1230 & & Tristaniopsis sp.2 & Austr. & phylogeogr. & $\begin{array}{l}\text { Berger et al. 2016, } \\
\text { Sytsma et al. 2004, } \\
\text { Thornhill et al. } 2015\end{array}$ \\
\hline 1231 & & Tristaniopsis sp.3 & Austr. & phylogeogr. & $\begin{array}{l}\text { Berger et al. 2016, } \\
\text { Sytsma et al. 2004, } \\
\text { Thornhill et al. } 2015\end{array}$ \\
\hline 1232 & & $\begin{array}{l}\text { Tristaniopsis whiteana } \\
\text { (Griff.) Peter G.Wilson \& } \\
\text { J.T.Waterh. }\end{array}$ & Austr. & phylogeogr. & $\begin{array}{l}\text { Berger et al. 2016, } \\
\text { Sytsma et al. 2004, } \\
\text { Thornhill et al. } 2015\end{array}$ \\
\hline 1233 & & $\begin{array}{l}\text { Xanthomyrtus angustifolia } \\
\text { A.J.Scott }\end{array}$ & Austr. & phylogeogr. & $\begin{array}{l}\text { Berger et al. 2016, } \\
\text { Sytsma et al. 2004, } \\
\text { Thornhill et al. } 2015\end{array}$ \\
\hline 1234 & & $\begin{array}{l}\text { Xanthomyrtus } \\
\text { diplycosiifolia (C.B.Rob.) } \\
\text { Merr. }\end{array}$ & Austr. & phylogeogr. & $\begin{array}{l}\text { Berger et al. 2016, } \\
\text { Sytsma et al. 2004, } \\
\text { Thornhill et al. } 2015\end{array}$ \\
\hline 1235 & Nyctaginaceae & $\begin{array}{l}\text { Pisonia umbellifera (J.R. } \\
\text { Forst. \& G. Forst.) Seem. }\end{array}$ & Austr. & $\begin{array}{l}\text { dated phyl., } \\
\text { distr./fossils }\end{array}$ & $\begin{array}{l}\text { Douglas \& Spellenberg } \\
\text { 2010, Hayward \& Horton, } \\
\text { 2014, Stemmerik } 1964\end{array}$ \\
\hline 1236 & Nyssaceae & Mastixia pentandra Blume & Asian & $\begin{array}{l}\text { dated phyl., } \\
\text { distr./fossils }\end{array}$ & $\begin{array}{l}\text { Matthew 1976, Xiang et } \\
\text { al. } 2011\end{array}$ \\
\hline 1237 & & Mastixia rostrata Blume & Asian & $\begin{array}{l}\text { dated phyl., } \\
\text { distr./fossils }\end{array}$ & $\begin{array}{l}\text { Matthew 1976, Xiang et } \\
\text { al. } 2011\end{array}$ \\
\hline 1238 & & Mastixia sp.1 & Asian & $\begin{array}{l}\text { dated phyl., } \\
\text { distr./fossils }\end{array}$ & $\begin{array}{l}\text { Matthew 1976, Xiang et } \\
\text { al. } 2011\end{array}$ \\
\hline 1239 & & Mastixia sp.2 & Asian & $\begin{array}{l}\text { dated phyl., } \\
\text { distr./fossils }\end{array}$ & $\begin{array}{l}\text { Matthew 1976, Xiang et } \\
\text { al. } 2011\end{array}$ \\
\hline 1240 & & $\begin{array}{l}\text { Mastixia trichotoma } \\
\text { Blume }\end{array}$ & Asian & $\begin{array}{l}\text { dated phyl., } \\
\text { distr./fossils }\end{array}$ & $\begin{array}{l}\text { Matthew 1976, Xiang et } \\
\text { al. } 2011\end{array}$ \\
\hline 1241 & Ochnaceae & $\begin{array}{l}\text { Brackenridgea palustris } \\
\text { Bartell. }\end{array}$ & Asian & phylogeogr. & Bissiengou 2014 \\
\hline 1242 & & Brackenridgea sp. & Asian & phylogeogr. & Bissiengou 2014 \\
\hline 1243 & Olacaceae & $\begin{array}{l}\text { Anacolosa frutescens } \\
\text { (Blume) Blume }\end{array}$ & Asian & $\begin{array}{l}\text { dated phyl., } \\
\text { distr./fossils }\end{array}$ & $\begin{array}{l}\text { Malécot \& Lobreau- } \\
\text { Callen 2005, Sleumer } \\
\text { 1980, Vidal-Russell \& } \\
\text { Nickrent } 2008\end{array}$ \\
\hline 1244 & & $\begin{array}{l}\text { Ochanostachys } \\
\text { amentacea Mast. }\end{array}$ & Asian & $\begin{array}{l}\text { dated phyl., } \\
\text { distr./fossils }\end{array}$ & $\begin{array}{l}\text { Magallón et al. 2015, } \\
\text { Nickrent et al. } 2010\end{array}$ \\
\hline
\end{tabular}




\begin{tabular}{|c|c|c|c|c|c|}
\hline No & Family & Species & Origin & $\begin{array}{l}\text { Classification } \\
\text { method }\end{array}$ & References \\
\hline 1245 & & $\begin{array}{l}\text { Scorodocarpus } \\
\text { borneensis (Baill.) Becc. }\end{array}$ & Asian & $\begin{array}{l}\text { dated phyl., } \\
\text { distr./fossils }\end{array}$ & $\begin{array}{l}\text { Nickrent et al. 2010, Su et } \\
\text { al. 2015, Vidal-Russell \& } \\
\text { Nickrent } 2008\end{array}$ \\
\hline 1246 & & $\begin{array}{l}\text { Strombosia ceylanica } \\
\text { Gardner }\end{array}$ & Asian & $\begin{array}{l}\text { dated phyl., } \\
\text { distr./fossils }\end{array}$ & $\begin{array}{l}\text { Nickrent et al. 2010, Su et } \\
\text { al. 2015, Vidal-Russell \& } \\
\text { Nickrent } 2008\end{array}$ \\
\hline 1247 & Oleaceae & $\begin{array}{l}\text { Chionanthus celebicus } \\
\text { Koord. }\end{array}$ & Asian & dated phyl. & $\begin{array}{l}\text { Hong-Wa \& Besnard } \\
2013\end{array}$ \\
\hline 1248 & & Chionanthus crispus Kiew & Asian & dated phyl. & $\begin{array}{l}\text { Hong-Wa \& Besnard } \\
2013\end{array}$ \\
\hline 1249 & & $\begin{array}{l}\text { Chionanthus nitens } \\
\text { Koord. \& Valeton }\end{array}$ & Asian & dated phyl. & $\begin{array}{l}\text { Hong-Wa \& Besnard } \\
2013\end{array}$ \\
\hline 1250 & & $\begin{array}{l}\text { Chionanthus polygamus } \\
\text { (Roxb.) Kiew }\end{array}$ & Asian & dated phyl. & $\begin{array}{l}\text { Hong-Wa \& Besnard } \\
2013\end{array}$ \\
\hline 1251 & & $\begin{array}{l}\text { Chionanthus ramiflorus } \\
\text { Roxb. }\end{array}$ & Asian & dated phyl. & $\begin{array}{l}\text { Hong-Wa \& Besnard } \\
2013\end{array}$ \\
\hline 1252 & & Chionanthus sp. & Asian & dated phyl. & $\begin{array}{l}\text { Hong-Wa \& Besnard } \\
2013\end{array}$ \\
\hline 1253 & & Chionanthus sp.1 & Asian & dated phyl. & $\begin{array}{l}\text { Hong-Wa \& Besnard } \\
2013\end{array}$ \\
\hline 1254 & & Chionanthus sp.2 & Asian & dated phyl. & $\begin{array}{l}\text { Hong-Wa \& Besnard } \\
2013\end{array}$ \\
\hline 1255 & & $\begin{array}{l}\text { Chionanthus spicatus } \\
\text { Blume }\end{array}$ & Asian & dated phyl. & $\begin{array}{l}\text { Hong-Wa \& Besnard } \\
2013\end{array}$ \\
\hline 1256 & & $\begin{array}{l}\text { Chionanthus sulawesicus } \\
\text { Kiew }\end{array}$ & Asian & dated phyl. & $\begin{array}{l}\text { Hong-Wa \& Besnard } \\
2013\end{array}$ \\
\hline 1257 & & $\begin{array}{l}\text { Ligustrum glomeratum } \\
\text { Blume }\end{array}$ & Asian & dated phyl. & Li et al. 2002, 2012 \\
\hline 1258 & & $\begin{array}{l}\text { Olea javanica (Blume) } \\
\text { Knobl. }\end{array}$ & Asian & dated phyl. & Besnard et al. 2009 \\
\hline 1259 & & $\begin{array}{l}\text { Olea rubrovenia (Elmer) } \\
\text { Kiew }\end{array}$ & Asian & dated phyl. & Besnard et al. 2009 \\
\hline 1260 & Pandanaceae & $\begin{array}{l}\text { Pandanus cf. } \\
\text { brachyspathus Martelli }\end{array}$ & Asian & phylogeogr. & Gallaher et al. 2015 \\
\hline 1261 & & $\begin{array}{l}\text { Pandanus sulawesicus } \\
\text { B.C.Stone }\end{array}$ & Asian & phylogeogr. & Gallaher et al. 2015 \\
\hline 1262 & Paracryphiaceae & $\begin{array}{l}\text { Quintinia apoensis (Elmer) } \\
\text { Schltr. }\end{array}$ & Austr. & phylogeogr. & Beaulieu et al. 2013 \\
\hline 1263 & & $\begin{array}{l}\text { Sphenostemon papuanus } \\
\text { (Lauterb.) Steenis \& } \\
\text { Erdtman }\end{array}$ & Austr. & phylogeogr. & Beaulieu et al. 2013 \\
\hline 1264 & Pentaphylacaceae & $\begin{array}{l}\text { Adinandra acuminata } \\
\text { Korth. }\end{array}$ & Asian & $\begin{array}{l}\text { undated phyl., } \\
\text { distr./fossils }\end{array}$ & $\begin{array}{l}\text { Kobuski 1947, Tsou et al. } \\
2016\end{array}$ \\
\hline 1265 & & $\begin{array}{l}\text { Adinandra borneensis } \\
\text { Kobuski }\end{array}$ & Asian & $\begin{array}{l}\text { undated phyl., } \\
\text { distr./fossils }\end{array}$ & $\begin{array}{l}\text { Kobuski 1947, Tsou et al. } \\
2016\end{array}$ \\
\hline 1266 & & Adinandra celebica Koord. & Asian & $\begin{array}{l}\text { undated phyl., } \\
\text { distr./fossils }\end{array}$ & $\begin{array}{l}\text { Kobuski 1947, Tsou et al. } \\
2016\end{array}$ \\
\hline
\end{tabular}




\begin{tabular}{|c|c|c|c|c|c|}
\hline No & Family & Species & Origin & $\begin{array}{l}\text { Classification } \\
\text { method }\end{array}$ & References \\
\hline 1267 & & $\begin{array}{l}\text { Adinandra clemensiae } \\
\text { Kobuski }\end{array}$ & Asian & $\begin{array}{l}\text { undated phyl., } \\
\text { distr./fossils }\end{array}$ & $\begin{array}{l}\text { Kobuski 1947, Tsou et al. } \\
2016\end{array}$ \\
\hline 1268 & & Adinandra cordifolia Ridl. & Asian & $\begin{array}{l}\text { undated phyl., } \\
\text { distr./fossils }\end{array}$ & $\begin{array}{l}\text { Kobuski 1947, Tsou et al. } \\
2016\end{array}$ \\
\hline 1269 & & Adinandra dumosa Jack & Asian & $\begin{array}{l}\text { undated phyl., } \\
\text { distr./fossils }\end{array}$ & $\begin{array}{l}\text { Kobuski 1947, Tsou et al. } \\
2016\end{array}$ \\
\hline 1270 & & $\begin{array}{l}\text { Adinandra elliptica } \\
\text { C.B.Rob. }\end{array}$ & Asian & $\begin{array}{l}\text { undated phyl., } \\
\text { distr./fossils }\end{array}$ & $\begin{array}{l}\text { Kobuski 1947, Tsou et al. } \\
2016\end{array}$ \\
\hline 1271 & & Adinandra excelsa Korth. & Asian & $\begin{array}{l}\text { undated phyl., } \\
\text { distr./fossils }\end{array}$ & $\begin{array}{l}\text { Kobuski 1947, Tsou et al. } \\
2016\end{array}$ \\
\hline 1272 & & Adinandra eymae Kobuski & Asian & $\begin{array}{l}\text { undated phyl., } \\
\text { distr./fossils }\end{array}$ & $\begin{array}{l}\text { Kobuski 1947, Tsou et al. } \\
2016\end{array}$ \\
\hline 1273 & & Adinandra luzonica Merr. & Asian & $\begin{array}{l}\text { undated phyl., } \\
\text { distr./fossils }\end{array}$ & $\begin{array}{l}\text { Kobuski 1947, Tsou et al. } \\
2016\end{array}$ \\
\hline 1274 & & $\begin{array}{l}\text { Adinandra masambensis } \\
\text { Kobuski }\end{array}$ & Asian & $\begin{array}{l}\text { undated phyl., } \\
\text { distr./fossils }\end{array}$ & $\begin{array}{l}\text { Kobuski 1947, Tsou et al. } \\
2016\end{array}$ \\
\hline 1275 & & Adinandra sp.1 & Asian & $\begin{array}{l}\text { undated phyl., } \\
\text { distr./fossils }\end{array}$ & $\begin{array}{l}\text { Kobuski 1947, Tsou et al. } \\
2016\end{array}$ \\
\hline 1276 & & Adinandra sp.2 & Asian & $\begin{array}{l}\text { undated phyl., } \\
\text { distr./fossils }\end{array}$ & $\begin{array}{l}\text { Kobuski 1947, Tsou et al. } \\
2016\end{array}$ \\
\hline 1277 & & Adinandra sp.3 & Asian & $\begin{array}{l}\text { undated phyl., } \\
\text { distr./fossils }\end{array}$ & $\begin{array}{l}\text { Kobuski 1947, Tsou et al. } \\
2016\end{array}$ \\
\hline 1278 & & Eurya acuminata DC. & Asian & $\begin{array}{l}\text { undated phyl., } \\
\text { distr./fossils }\end{array}$ & $\begin{array}{l}\text { de Wit 1947, Tsou et al. } \\
2016\end{array}$ \\
\hline 1279 & & Eurya chinensis R.Br. & Asian & $\begin{array}{l}\text { undated phyl., } \\
\text { distr./fossils }\end{array}$ & $\begin{array}{l}\text { de Wit 1947, Tsou et al. } \\
2016\end{array}$ \\
\hline 1280 & & Eurya coriacea Merr. & Asian & $\begin{array}{l}\text { undated phyl., } \\
\text { distr./fossils }\end{array}$ & $\begin{array}{l}\text { de Wit 1947, Tsou et al. } \\
2016\end{array}$ \\
\hline 1281 & & $\begin{array}{l}\text { Eurya glabra (Blume) } \\
\text { Korth. }\end{array}$ & Asian & $\begin{array}{l}\text { undated phyl., } \\
\text { distr./fossils }\end{array}$ & $\begin{array}{l}\text { de Wit 1947, Tsou et al. } \\
2016\end{array}$ \\
\hline 1282 & & $\begin{array}{l}\text { Eurya obovata (Blume) } \\
\text { Korth. }\end{array}$ & Asian & $\begin{array}{l}\text { undated phyl., } \\
\text { distr./fossils }\end{array}$ & $\begin{array}{l}\text { de Wit 1947, Tsou et al. } \\
2016\end{array}$ \\
\hline 1283 & & Eurya sp. & Asian & $\begin{array}{l}\text { undated phyl., } \\
\text { distr./fossils }\end{array}$ & $\begin{array}{l}\text { de Wit 1947, Tsou et al. } \\
2016\end{array}$ \\
\hline 1284 & & Eurya trichocarpa Korth. & Asian & $\begin{array}{l}\text { undated phyl., } \\
\text { distr./fossils }\end{array}$ & $\begin{array}{l}\text { de Wit 1947, Tsou et al. } \\
2016\end{array}$ \\
\hline 1285 & & $\begin{array}{l}\text { Ternstroemia coriacea } \\
\text { Scheff. }\end{array}$ & Asian & $\begin{array}{l}\text { undated phyl., } \\
\text { distr./fossils }\end{array}$ & $\begin{array}{l}\text { Tsou et al. 2016, } \\
\text { Weitzman et al. } 2004\end{array}$ \\
\hline 1286 & & $\begin{array}{l}\text { Ternstroemia elongata } \\
\text { (Korth.) Koord. }\end{array}$ & Asian & $\begin{array}{l}\text { undated phyl., } \\
\text { distr./fossils }\end{array}$ & $\begin{array}{l}\text { Tsou et al. 2016, } \\
\text { Weitzman et al. } 2004\end{array}$ \\
\hline 1287 & & Ternstroemia lowii Stapf & Asian & $\begin{array}{l}\text { undated phyl., } \\
\text { distr./fossils }\end{array}$ & $\begin{array}{l}\text { Tsou et al. 2016, } \\
\text { Weitzman et al. } 2004\end{array}$ \\
\hline 1288 & & $\begin{array}{l}\text { Ternstroemia } \\
\text { philippinensis Merr. }\end{array}$ & Asian & $\begin{array}{l}\text { undated phyl., } \\
\text { distr./fossils }\end{array}$ & $\begin{array}{l}\text { Tsou et al. 2016, } \\
\text { Weitzman et al. } 2004\end{array}$ \\
\hline 1289 & & Ternstroemia sp. & Asian & $\begin{array}{l}\text { undated phyl., } \\
\text { distr./fossils }\end{array}$ & $\begin{array}{l}\text { Tsou et al. 2016, } \\
\text { Weitzman et al. } 2004\end{array}$ \\
\hline 1290 & & $\begin{array}{l}\text { Ternstroemia toquian } \\
\text { Fern.-Vill. }\end{array}$ & Asian & $\begin{array}{l}\text { undated phyl., } \\
\text { distr./fossils }\end{array}$ & $\begin{array}{l}\text { Tsou et al. 2016, } \\
\text { Weitzman et al. } 2004\end{array}$ \\
\hline
\end{tabular}




\begin{tabular}{|c|c|c|c|c|c|}
\hline No & Family & Species & Origin & $\begin{array}{l}\text { Classification } \\
\text { method }\end{array}$ & References \\
\hline 1291 & & $\begin{array}{l}\text { Ternstroemia } \\
\text { urdanetensis (Elmer) } \\
\text { Kobuski }\end{array}$ & Asian & $\begin{array}{l}\text { undated phyl., } \\
\text { distr./fossils }\end{array}$ & $\begin{array}{l}\text { Tsou et al. 2016, } \\
\text { Weitzman et al. } 2004\end{array}$ \\
\hline 1292 & Peraceae & $\begin{array}{l}\text { Trigonopleura malayana } \\
\text { Hook.f. }\end{array}$ & Asian & $\begin{array}{l}\text { dated phyl., } \\
\text { distr./fossils }\end{array}$ & $\begin{array}{l}\text { van Welzen \& Esser 2013, } \\
\text { Xi et al. } 2012\end{array}$ \\
\hline 1293 & Phyllanthaceae & $\begin{array}{l}\text { Antidesma excavatum } \\
\text { Miq. }\end{array}$ & Asian & $\begin{array}{l}\text { dated phyl., } \\
\text { distr./fossils }\end{array}$ & Li et al. 2009, WCSP 2017 \\
\hline 1294 & & $\begin{array}{l}\text { Antidesma neurocarpum } \\
\text { Miq. }\end{array}$ & Asian & $\begin{array}{l}\text { dated phyl., } \\
\text { distr./fossils }\end{array}$ & Li et al. 2009, WCSP 2017 \\
\hline 1295 & & $\begin{array}{l}\text { Antidesma tetrandrum } \\
\text { Blume }\end{array}$ & Asian & $\begin{array}{l}\text { dated phyl., } \\
\text { distr./fossils }\end{array}$ & Li et al. 2009, WCSP 2017 \\
\hline 1296 & & $\begin{array}{l}\text { Antidesma velutinosum } \\
\text { Blume }\end{array}$ & Asian & $\begin{array}{l}\text { dated phyl., } \\
\text { distr./fossils }\end{array}$ & Li et al. 2009, WCSP 2017 \\
\hline 1297 & & $\begin{array}{l}\text { Aporosa antennifera (Airy } \\
\text { Shaw) Airy Shaw }\end{array}$ & Asian & phylogeogr. & Li et al. 2009, Schot 1998 \\
\hline 1298 & & $\begin{array}{l}\text { Aporosa arborea (Blume) } \\
\text { Müll.Arg. }\end{array}$ & Asian & phylogeogr. & Li et al. 2009, Schot 1998 \\
\hline 1299 & & Aporosa elmeri Merr. & Asian & phylogeogr. & Li et al. 2009, Schot 1998 \\
\hline 1300 & & Aporosa falcifera Hook.f. & Asian & phylogeogr. & Li et al. 2009, Schot 1998 \\
\hline 1301 & & Aporosa frutescens Blume & Asian & phylogeogr. & Li et al. 2009, Schot 1998 \\
\hline 1302 & & $\begin{array}{l}\text { Aporosa grandistipula } \\
\text { Merr. }\end{array}$ & Asian & phylogeogr. & Li et al. 2009, Schot 1998 \\
\hline 1303 & & $\begin{array}{l}\text { Aporosa lagenocarpa Airy } \\
\text { Shaw }\end{array}$ & Asian & phylogeogr. & Li et al. 2009, Schot 1998 \\
\hline 1304 & & $\begin{array}{l}\text { Aporosa lucida (Miq.) Airy } \\
\text { Shaw }\end{array}$ & Asian & phylogeogr. & Li et al. 2009, Schot 1998 \\
\hline 1305 & & Aporosa lunata (Miq.) Kurz & Asian & phylogeogr. & Li et al. 2009, Schot 1998 \\
\hline 1306 & & Aporosa maingayi Hook.f. & Asian & phylogeogr. & Li et al. 2009, Schot 1998 \\
\hline 1307 & & Aporosa sp. & Asian & phylogeogr. & Li et al. 2009, Schot 1998 \\
\hline 1308 & & Aporosa sp.1 & Asian & phylogeogr. & Li et al. 2009, Schot 1998 \\
\hline 1309 & & Aporosa sp.2 & Asian & phylogeogr. & Li et al. 2009, Schot 1998 \\
\hline 1310 & & Aporosa sp.3 & Asian & phylogeogr. & Li et al. 2009, Schot 1998 \\
\hline 1311 & & $\begin{array}{l}\text { Aporosa sphaeridiophora } \\
\text { Merr. }\end{array}$ & Asian & phylogeogr. & Li et al. 2009, Schot 1998 \\
\hline 1312 & & Aporosa stellifera Hook.f. & Asian & phylogeogr. & Li et al. 2009, Schot 1998 \\
\hline 1313 & & $\begin{array}{l}\text { Aporosa subcaudata } \\
\text { Merr. }\end{array}$ & Asian & phylogeogr. & Li et al. 2009, Schot 1998 \\
\hline 1314 & & $\begin{array}{l}\text { Aporosa symplocoides } \\
\text { (Hook.f.) Gage }\end{array}$ & Asian & phylogeogr. & Li et al. 2009, Schot 1998 \\
\hline 1315 & & $\begin{array}{l}\text { Baccaurea brevipes } \\
\text { Hook.f. }\end{array}$ & Asian & $\begin{array}{l}\text { phylogeogr., } \\
\text { dated phyl. }\end{array}$ & $\begin{array}{l}\text { Haegens 2000, Li et al. } \\
2009\end{array}$ \\
\hline 1316 & & $\begin{array}{l}\text { Baccaurea deflexa } \\
\text { Müll.Arg. }\end{array}$ & Asian & $\begin{array}{l}\text { phylogeogr., } \\
\text { dated phyl. }\end{array}$ & $\begin{array}{l}\text { Haegens 2000, Li et al. } \\
2009\end{array}$ \\
\hline 1317 & & $\begin{array}{l}\text { Baccaurea dulcis (Jack) } \\
\text { Müll.Arg. }\end{array}$ & Asian & $\begin{array}{l}\text { phylogeogr., } \\
\text { dated phyl. }\end{array}$ & $\begin{array}{l}\text { Haegens 2000, Li et al. } \\
2009\end{array}$ \\
\hline 1318 & & $\begin{array}{l}\text { Baccaurea lanceolata } \\
\text { (Miq.) Müll.Arg. }\end{array}$ & Asian & $\begin{array}{l}\text { phylogeogr., } \\
\text { dated phyl. }\end{array}$ & $\begin{array}{l}\text { Haegens 2000, Li et al. } \\
2009\end{array}$ \\
\hline
\end{tabular}




\begin{tabular}{|c|c|c|c|c|c|}
\hline No & Family & Species & Origin & $\begin{array}{l}\text { Classification } \\
\text { method }\end{array}$ & References \\
\hline 1319 & & $\begin{array}{l}\text { Baccaurea macrocarpa } \\
\text { (Miq.) Müll.Arg. }\end{array}$ & Asian & $\begin{array}{l}\text { phylogeogr., } \\
\text { dated phyl. }\end{array}$ & $\begin{array}{l}\text { Haegens 2000, Li et al. } \\
2009\end{array}$ \\
\hline 1320 & & $\begin{array}{l}\text { Baccaurea multiflora } \\
\text { Burck ex J.J.Sm. }\end{array}$ & Asian & $\begin{array}{l}\text { phylogeogr., } \\
\text { dated phyl. }\end{array}$ & $\begin{array}{l}\text { Haegens 2000, Li et al. } \\
2009\end{array}$ \\
\hline 1321 & & Baccaurea nanihua Merr. & Asian & $\begin{array}{l}\text { phylogeogr., } \\
\text { dated phyl. }\end{array}$ & $\begin{array}{l}\text { Haegens 2000, Li et al. } \\
2009\end{array}$ \\
\hline 1322 & & $\begin{array}{l}\text { Baccaurea odoratissima } \\
\text { Elmer }\end{array}$ & Asian & $\begin{array}{l}\text { phylogeogr., } \\
\text { dated phyl. }\end{array}$ & $\begin{array}{l}\text { Haegens 2000, Li et al. } \\
2009\end{array}$ \\
\hline 1323 & & $\begin{array}{l}\text { Baccaurea pubera (Miq.) } \\
\text { Müll.Arg. }\end{array}$ & Asian & $\begin{array}{l}\text { phylogeogr., } \\
\text { dated phyl. }\end{array}$ & $\begin{array}{l}\text { Haegens 2000, Li et al. } \\
2009\end{array}$ \\
\hline 1324 & & $\begin{array}{l}\text { Baccaurea racemosa } \\
\text { (Reinw. ex Blume) } \\
\text { Müll.Arg. }\end{array}$ & Asian & $\begin{array}{l}\text { phylogeogr., } \\
\text { dated phyl. }\end{array}$ & $\begin{array}{l}\text { Haegens 2000, Li et al. } \\
2009\end{array}$ \\
\hline 1325 & & Baccaurea sp.1 & Asian & $\begin{array}{l}\text { phylogeogr., } \\
\text { dated phyl. }\end{array}$ & $\begin{array}{l}\text { Haegens 2000, Li et al. } \\
2009\end{array}$ \\
\hline 1326 & & Baccaurea sp.2 & Asian & $\begin{array}{l}\text { phylogeogr., } \\
\text { dated phyl. }\end{array}$ & $\begin{array}{l}\text { Haegens 2000, Li et al. } \\
2009\end{array}$ \\
\hline 1327 & & Baccaurea sp.3 & Asian & $\begin{array}{l}\text { phylogeogr., } \\
\text { dated phyl. }\end{array}$ & $\begin{array}{l}\text { Haegens 2000, Li et al. } \\
2009\end{array}$ \\
\hline 1328 & & Baccaurea sp.4 & Asian & $\begin{array}{l}\text { phylogeogr., } \\
\text { dated phyl. }\end{array}$ & $\begin{array}{l}\text { Haegens 2000, Li et al. } \\
2009\end{array}$ \\
\hline 1329 & & $\begin{array}{l}\text { Baccaurea tetrandra } \\
\text { (Baill.) Müll.Arg. }\end{array}$ & Asian & $\begin{array}{l}\text { phylogeogr., } \\
\text { dated phyl. }\end{array}$ & $\begin{array}{l}\text { Haegens 2000, Li et al. } \\
2009\end{array}$ \\
\hline 1330 & & Bischofia javanica Blume & Asian & $\begin{array}{l}\text { dated phyl., } \\
\text { distr./fossils }\end{array}$ & $\begin{array}{l}\text { Li et al. 2009, van Welzen } \\
2016\end{array}$ \\
\hline 1331 & & Breynia sp. & Asian & phylogeogr. & van Welzen et al. 2015 \\
\hline 1332 & & Bridelia glauca Blume & Asian & phylogeogr. & Li et al. 2009 \\
\hline 1333 & & Bridelia insulana Hance & Asian & phylogeogr. & Li et al. 2009 \\
\hline 1334 & & Bridelia sp. & Asian & phylogeogr. & Li et al. 2009 \\
\hline 1335 & & Cleistanthus sp. & Asian & phylogeogr. & Li et al. 2009 \\
\hline 1336 & & $\begin{array}{l}\text { Glochidion cyrtostylum } \\
\text { Miq. }\end{array}$ & Asian & phylogeogr. & $\begin{array}{l}\text { Hembry et al. 2013, Li et } \\
\text { al. } 2009\end{array}$ \\
\hline 1337 & & $\begin{array}{l}\text { Glochidion insectum Airy } \\
\text { Shaw }\end{array}$ & Asian & phylogeogr. & $\begin{array}{l}\text { Hembry et al. 2013, Li et } \\
\text { al. } 2009\end{array}$ \\
\hline 1338 & & Glochidion lucidum Blume & Asian & phylogeogr. & $\begin{array}{l}\text { Hembry et al. 2013, Li et } \\
\text { al. } 2009\end{array}$ \\
\hline 1339 & & $\begin{array}{l}\text { Glochidion macrocarpum } \\
\text { Blume }\end{array}$ & Asian & phylogeogr. & $\begin{array}{l}\text { Hembry et al. 2013, Li et } \\
\text { al. } 2009\end{array}$ \\
\hline 1340 & & $\begin{array}{l}\text { Glochidion moluccanum } \\
\text { Blume }\end{array}$ & Asian & phylogeogr. & $\begin{array}{l}\text { Hembry et al. 2013, Li et } \\
\text { al. } 2009\end{array}$ \\
\hline 1341 & & Glochidion rubrum Blume & Asian & phylogeogr. & $\begin{array}{l}\text { Hembry et al. 2013, Li et } \\
\text { al. } 2009\end{array}$ \\
\hline 1342 & & Glochidion sp.1 & Asian & phylogeogr. & $\begin{array}{l}\text { Hembry et al. 2013, Li et } \\
\text { al. } 2009\end{array}$ \\
\hline 1343 & & Glochidion sp.2 & Asian & phylogeogr. & $\begin{array}{l}\text { Hembry et al. 2013, Li et } \\
\text { al. } 2009\end{array}$ \\
\hline 1344 & & Glochidion sp.3 & Asian & phylogeogr. & Hembry et al. 2013, Li et \\
\hline
\end{tabular}




\begin{tabular}{|c|c|c|c|c|c|}
\hline No & Family & Species & Origin & $\begin{array}{l}\text { Classification } \\
\text { method }\end{array}$ & References \\
\hline 1345 & Pittosporaceae & $\begin{array}{l}\text { Pittosporum pentandrum } \\
\text { (Blanco) Merr. }\end{array}$ & Austr. & phylogeogr. & $\begin{array}{l}\text { Beaulieu et al. 2013, } \\
\text { Chandler et al. } 2007\end{array}$ \\
\hline 1346 & Polygalaceae & $\begin{array}{l}\text { Xanthophyllum adenotus } \\
\text { Miq. }\end{array}$ & Austr. & $\begin{array}{l}\text { dated phyl., } \\
\text { distr./fossils }\end{array}$ & $\begin{array}{l}\text { Forest et al. 2007, van } \\
\text { der Meijden 1988, } \\
\text { Persson } 2001\end{array}$ \\
\hline 1347 & & $\begin{array}{l}\text { Xanthophyllum discolor } \\
\text { Chodat }\end{array}$ & Austr. & $\begin{array}{l}\text { dated phyl., } \\
\text { distr./fossils }\end{array}$ & $\begin{array}{l}\text { Forest et al. 2007, van } \\
\text { der Meijden 1988, } \\
\text { Persson } 2001\end{array}$ \\
\hline 1348 & & $\begin{array}{l}\text { Xanthophyllum flavescens } \\
\text { Roxb. }\end{array}$ & Austr. & $\begin{array}{l}\text { dated phyl., } \\
\text { distr./fossils }\end{array}$ & $\begin{array}{l}\text { Forest et al. 2007, van } \\
\text { der Meijden 1988, } \\
\text { Persson } 2001\end{array}$ \\
\hline 1349 & & $\begin{array}{l}\text { Xanthophyllum } \\
\text { montanum Meijden }\end{array}$ & Austr. & $\begin{array}{l}\text { dated phyl., } \\
\text { distr./fossils }\end{array}$ & $\begin{array}{l}\text { Forest et al. 2007, van } \\
\text { der Meijden 1988, } \\
\text { Persson } 2001\end{array}$ \\
\hline 1350 & & $\begin{array}{l}\text { Xanthophyllum obscurum } \\
\text { A.W.Benn. }\end{array}$ & Austr. & $\begin{array}{l}\text { dated phyl., } \\
\text { distr./fossils }\end{array}$ & $\begin{array}{l}\text { Forest et al. 2007, van } \\
\text { der Meijden 1988, } \\
\text { Persson } 2001\end{array}$ \\
\hline 1351 & & $\begin{array}{l}\text { Xanthophyllum parvum } \\
\text { Chodat }\end{array}$ & Austr. & $\begin{array}{l}\text { dated phyl., } \\
\text { distr./fossils }\end{array}$ & $\begin{array}{l}\text { Forest et al. 2007, van } \\
\text { der Meijden 1988, } \\
\text { Persson } 2001\end{array}$ \\
\hline 1352 & & $\begin{array}{l}\text { Xanthophyllum } \\
\text { penibukanense Heine }\end{array}$ & Austr. & $\begin{array}{l}\text { dated phyl., } \\
\text { distr./fossils }\end{array}$ & $\begin{array}{l}\text { Forest et al. 2007, van } \\
\text { der Meijden 1988, } \\
\text { Persson } 2001\end{array}$ \\
\hline 1353 & & $\begin{array}{l}\text { Xanthophyllum } \\
\text { purpureum Ridl. }\end{array}$ & Austr. & $\begin{array}{l}\text { dated phyl., } \\
\text { distr./fossils }\end{array}$ & $\begin{array}{l}\text { Forest et al. 2007, van } \\
\text { der Meijden 1988, } \\
\text { Persson } 2001\end{array}$ \\
\hline 1354 & & $\begin{array}{l}\text { Xanthophyllum rufum } \\
\text { A.W.Benn. }\end{array}$ & Austr. & $\begin{array}{l}\text { dated phyl., } \\
\text { distr./fossils }\end{array}$ & $\begin{array}{l}\text { Forest et al. 2007, van } \\
\text { der Meijden 1988, } \\
\text { Persson } 2001\end{array}$ \\
\hline 1355 & & Xanthophyllum sp.1 & Austr. & $\begin{array}{l}\text { dated phyl., } \\
\text { distr./fossils }\end{array}$ & $\begin{array}{l}\text { Forest et al. 2007, van } \\
\text { der Meijden 1988, } \\
\text { Persson } 2001\end{array}$ \\
\hline 1356 & & Xanthophyllum sp.2 & Austr. & $\begin{array}{l}\text { dated phyl., } \\
\text { distr./fossils }\end{array}$ & $\begin{array}{l}\text { Forest et al. 2007, van } \\
\text { der Meijden 1988, } \\
\text { Persson } 2001\end{array}$ \\
\hline 1357 & & Xanthophyllum sp.3 & Austr. & $\begin{array}{l}\text { dated phyl., } \\
\text { distr./fossils }\end{array}$ & $\begin{array}{l}\text { Forest et al. 2007, van } \\
\text { der Meijden 1988, } \\
\text { Persson } 2001\end{array}$ \\
\hline 1358 & & Xanthophyllum sp.4 & Austr. & $\begin{array}{l}\text { dated phyl., } \\
\text { distr./fossils }\end{array}$ & $\begin{array}{l}\text { Forest et al. 2007, van } \\
\text { der Meijden 1988, } \\
\text { Persson } 2001\end{array}$ \\
\hline 1359 & & Xanthophyllum sp.5 & Austr. & $\begin{array}{l}\text { dated phyl., } \\
\text { distr./fossils }\end{array}$ & $\begin{array}{l}\text { Forest et al. 2007, van } \\
\text { der Meijden 1988, } \\
\text { Persson } 2001\end{array}$ \\
\hline 1360 & & $\begin{array}{l}\text { Xanthophyllum stipitatum } \\
\text { A.W.Benn. }\end{array}$ & Austr. & $\begin{array}{l}\text { dated phyl., } \\
\text { distr./fossils }\end{array}$ & $\begin{array}{l}\text { Forest et al. 2007, van } \\
\text { der Meijden 1988, } \\
\text { Persson } 2001\end{array}$ \\
\hline
\end{tabular}




\begin{tabular}{|c|c|c|c|c|c|}
\hline No & Family & Species & Origin & $\begin{array}{l}\text { Classification } \\
\text { method }\end{array}$ & References \\
\hline 1361 & & $\begin{array}{l}\text { Xanthophyllum tenue } \\
\text { Chodat }\end{array}$ & Austr. & $\begin{array}{l}\text { dated phyl., } \\
\text { distr./fossils }\end{array}$ & $\begin{array}{l}\text { Forest et al. 2007, van } \\
\text { der Meijden 1988, } \\
\text { Persson } 2001\end{array}$ \\
\hline 1362 & & $\begin{array}{l}\text { Xanthophyllum velutinum } \\
\text { Chodat }\end{array}$ & Austr. & $\begin{array}{l}\text { dated phyl., } \\
\text { distr./fossils }\end{array}$ & $\begin{array}{l}\text { Forest et al. 2007, van } \\
\text { der Meijden 1988, } \\
\text { Persson } 2001\end{array}$ \\
\hline 1363 & & $\begin{array}{l}\text { Xanthophyllum vitellinum } \\
\text { (Blume) D.Dietr. }\end{array}$ & Austr. & $\begin{array}{l}\text { dated phyl., } \\
\text { distr./fossils }\end{array}$ & $\begin{array}{l}\text { Forest et al. 2007, van } \\
\text { der Meijden 1988, } \\
\text { Persson } 2001\end{array}$ \\
\hline 1364 & Primulaceae & Ardisia copelandii Mez & Asian & $\begin{array}{l}\text { dated phyl., } \\
\text { distr./fossils }\end{array}$ & $\begin{array}{l}\text { Ståhl \& Anderberg 2004, } \\
\text { Strijk et al. 2014, Yesson } \\
\text { et al. } 2009\end{array}$ \\
\hline 1365 & & Ardisia darlingii Merr. & Asian & $\begin{array}{l}\text { dated phyl., } \\
\text { distr./fossils }\end{array}$ & $\begin{array}{l}\text { Ståhl \& Anderberg 2004, } \\
\text { Strijk et al. 2014, Yesson } \\
\text { et al. } 2009\end{array}$ \\
\hline 1366 & & Ardisia elliptica Thunb. & Asian & $\begin{array}{l}\text { dated phyl., } \\
\text { distr./fossils }\end{array}$ & $\begin{array}{l}\text { Ståhl \& Anderberg 2004, } \\
\text { Strijk et al. 2014, Yesson } \\
\text { et al. } 2009\end{array}$ \\
\hline 1367 & & Ardisia javanica A.DC. & Asian & $\begin{array}{l}\text { dated phyl., } \\
\text { distr./fossils }\end{array}$ & $\begin{array}{l}\text { Ståhl \& Anderberg 2004, } \\
\text { Strijk et al. 2014, Yesson } \\
\text { et al. } 2009\end{array}$ \\
\hline 1368 & & $\begin{array}{l}\text { Ardisia macrophylla } \\
\text { Reinw. ex Blume }\end{array}$ & Asian & $\begin{array}{l}\text { dated phyl., } \\
\text { distr./fossils }\end{array}$ & $\begin{array}{l}\text { Ståhl \& Anderberg 2004, } \\
\text { Strijk et al. 2014, Yesson } \\
\text { et al. } 2009\end{array}$ \\
\hline 1369 & & Ardisia paniculata Roxb. & Asian & $\begin{array}{l}\text { dated phyl., } \\
\text { distr./fossils }\end{array}$ & $\begin{array}{l}\text { Ståhl \& Anderberg 2004, } \\
\text { Strijk et al. 2014, Yesson } \\
\text { et al. } 2009\end{array}$ \\
\hline 1370 & & Ardisia pterocaulis Miq. & Asian & $\begin{array}{l}\text { dated phyl., } \\
\text { distr./fossils }\end{array}$ & $\begin{array}{l}\text { Ståhl \& Anderberg 2004, } \\
\text { Strijk et al. 2014, Yesson } \\
\text { et al. } 2009\end{array}$ \\
\hline 1371 & & $\begin{array}{l}\text { Ardisia sanguinolenta } \\
\text { Blume }\end{array}$ & Asian & $\begin{array}{l}\text { dated phyl., } \\
\text { distr./fossils }\end{array}$ & $\begin{array}{l}\text { Ståhl \& Anderberg 2004, } \\
\text { Strijk et al. 2014, Yesson } \\
\text { et al. } 2009\end{array}$ \\
\hline 1372 & & Ardisia sp.1 & Asian & $\begin{array}{l}\text { dated phyl., } \\
\text { distr./fossils }\end{array}$ & $\begin{array}{l}\text { Ståhl \& Anderberg 2004, } \\
\text { Strijk et al. 2014, Yesson } \\
\text { et al. } 2009\end{array}$ \\
\hline 1373 & & Ardisia sp.2 & Asian & $\begin{array}{l}\text { dated phyl., } \\
\text { distr./fossils }\end{array}$ & $\begin{array}{l}\text { Ståhl \& Anderberg 2004, } \\
\text { Strijk et al. 2014, Yesson } \\
\text { et al. } 2009\end{array}$ \\
\hline 1374 & & Ardisia sp.3 & Asian & $\begin{array}{l}\text { dated phyl., } \\
\text { distr./fossils }\end{array}$ & $\begin{array}{l}\text { Ståhl \& Anderberg 2004, } \\
\text { Strijk et al. 2014, Yesson } \\
\text { et al. } 2009\end{array}$ \\
\hline 1375 & & Ardisia sp.4 & Asian & $\begin{array}{l}\text { dated phyl., } \\
\text { distr./fossils }\end{array}$ & $\begin{array}{l}\text { Ståhl \& Anderberg 2004, } \\
\text { Strijk et al. 2014, Yesson } \\
\text { et al. } 2009\end{array}$ \\
\hline 1376 & & Ardisia tayabensis Merr. & Asian & $\begin{array}{l}\text { dated phyl., } \\
\text { distr./fossils }\end{array}$ & $\begin{array}{l}\text { Ståhl \& Anderberg 2004, } \\
\text { Strijk et al. 2014, Yesson } \\
\text { et al. } 2009\end{array}$ \\
\hline
\end{tabular}




\begin{tabular}{|c|c|c|c|c|c|}
\hline No & Family & Species & Origin & $\begin{array}{l}\text { Classification } \\
\text { method }\end{array}$ & References \\
\hline 1377 & & Ardisia ternatensis Scheff. & Asian & $\begin{array}{l}\text { dated phyl., } \\
\text { distr./fossils }\end{array}$ & $\begin{array}{l}\text { Ståhl \& Anderberg 2004, } \\
\text { Strijk et al. 2014, Yesson } \\
\text { et al. } 2009\end{array}$ \\
\hline 1378 & & $\begin{array}{l}\text { Ardisia tuberculata Wall. } \\
\text { ex A.DC. }\end{array}$ & Asian & $\begin{array}{l}\text { dated phyl., } \\
\text { distr./fossils }\end{array}$ & $\begin{array}{l}\text { Ståhl \& Anderberg 2004, } \\
\text { Strijk et al. 2014, Yesson } \\
\text { et al. } 2009\end{array}$ \\
\hline 1379 & & Embelia sp. & Asian & $\begin{array}{l}\text { dated phyl., } \\
\text { distr./fossils }\end{array}$ & $\begin{array}{l}\text { Ståhl \& Anderberg 2004, } \\
\text { Strijk et al. 2014, Yesson } \\
\text { et al. } 2009\end{array}$ \\
\hline 1380 & & Myrsine affinis A.DC. & Austr. & $\begin{array}{l}\text { dated phyl., } \\
\text { distr./fossils }\end{array}$ & $\begin{array}{l}\text { Ståhl \& Anderberg 2004, } \\
\text { Strijk et al. 2014, Yesson } \\
\text { et al. } 2009\end{array}$ \\
\hline 1381 & & $\begin{array}{l}\text { Myrsine amorosoana } \\
\text { Pipoly }\end{array}$ & Austr. & $\begin{array}{l}\text { dated phyl., } \\
\text { distr./fossils }\end{array}$ & $\begin{array}{l}\text { Ståhl \& Anderberg 2004, } \\
\text { Strijk et al. 2014, Yesson } \\
\text { et al. } 2009\end{array}$ \\
\hline 1382 & & $\begin{array}{l}\text { Myrsine avenis (Blume) } \\
\text { A.DC. }\end{array}$ & Austr. & $\begin{array}{l}\text { dated phyl., } \\
\text { distr./fossils }\end{array}$ & $\begin{array}{l}\text { Ståhl \& Anderberg 2004, } \\
\text { Strijk et al. 2014, Yesson } \\
\text { et al. } 2009\end{array}$ \\
\hline 1383 & & $\begin{array}{l}\text { Myrsine forbesii (Mez) } \\
\text { Pipoly }\end{array}$ & Austr. & $\begin{array}{l}\text { dated phyl., } \\
\text { distr./fossils }\end{array}$ & $\begin{array}{l}\text { Ståhl \& Anderberg 2004, } \\
\text { Strijk et al. 2014, Yesson } \\
\text { et al. } 2009\end{array}$ \\
\hline 1384 & & $\begin{array}{l}\text { Myrsine hasseltii Blume } \\
\text { ex Scheff. }\end{array}$ & Austr. & $\begin{array}{l}\text { dated phyl., } \\
\text { distr./fossils }\end{array}$ & $\begin{array}{l}\text { Ståhl \& Anderberg 2004, } \\
\text { Strijk et al. 2014, Yesson } \\
\text { et al. } 2009\end{array}$ \\
\hline 1385 & & $\begin{array}{l}\text { Myrsine involucrata (Mez) } \\
\text { Pipoly }\end{array}$ & Austr. & $\begin{array}{l}\text { dated phyl., } \\
\text { distr./fossils }\end{array}$ & $\begin{array}{l}\text { Ståhl \& Anderberg 2004, } \\
\text { Strijk et al. 2014, Yesson } \\
\text { et al. } 2009\end{array}$ \\
\hline 1386 & & $\begin{array}{l}\text { Myrsine minutifolia } \\
\text { (Knoester et al.) Pipoly }\end{array}$ & Austr. & $\begin{array}{l}\text { dated phyl., } \\
\text { distr./fossils }\end{array}$ & $\begin{array}{l}\text { Ståhl \& Anderberg 2004, } \\
\text { Strijk et al. 2014, Yesson } \\
\text { et al. } 2009\end{array}$ \\
\hline 1387 & & $\begin{array}{l}\text { Myrsine cf. rawacensis } \\
\text { A.DC. }\end{array}$ & Austr. & $\begin{array}{l}\text { dated phyl., } \\
\text { distr./fossils }\end{array}$ & $\begin{array}{l}\text { Ståhl \& Anderberg 2004, } \\
\text { Strijk et al. 2014, Yesson } \\
\text { et al. } 2009\end{array}$ \\
\hline 1388 & & Myrsine sp. & Austr. & $\begin{array}{l}\text { dated phyl., } \\
\text { distr./fossils }\end{array}$ & $\begin{array}{l}\text { Ståhl \& Anderberg 2004, } \\
\text { Strijk et al. 2014, Yesson } \\
\text { et al. } 2009\end{array}$ \\
\hline 1389 & Proteaceae & $\begin{array}{l}\text { Heliciopsis artocarpoides } \\
\text { (Elmer) Sleumer }\end{array}$ & Austr. & undated phyl. & Weston \& Barker 2006 \\
\hline 1390 & & $\begin{array}{l}\text { Helicia attenuata (Jack) } \\
\text { Blume }\end{array}$ & Austr. & phylogeogr. & Barker et al. 2007 \\
\hline 1391 & & Helicia celebica Sleumer & Austr. & phylogeogr. & Barker et al. 2007 \\
\hline 1392 & & $\begin{array}{l}\text { Helicia excelsa (Roxb.) } \\
\text { Blume }\end{array}$ & Austr. & phylogeogr. & Barker et al. 2007 \\
\hline 1393 & & Helicia petiolaris Benn. & Austr. & phylogeogr. & Barker et al. 2007 \\
\hline 1394 & & $\begin{array}{l}\text { Helicia robusta (Roxb.) } \\
\text { R.Br. ex Blume }\end{array}$ & Austr. & phylogeogr. & Barker et al. 2007 \\
\hline 1395 & & $\begin{array}{l}\text { Helicia serrata (R.Br.) } \\
\text { Blume }\end{array}$ & Austr. & phylogeogr. & Barker et al. 2007 \\
\hline
\end{tabular}




\begin{tabular}{|c|c|c|c|c|c|}
\hline No & Family & Species & Origin & $\begin{array}{l}\text { Classification } \\
\text { method }\end{array}$ & References \\
\hline 1396 & & Helicia sp.1 & Austr. & phylogeogr. & Barker et al. 2007 \\
\hline 1397 & & Helicia sp.2 & Austr. & phylogeogr. & Barker et al. 2007 \\
\hline 1398 & & Helicia sp.3 & Austr. & phylogeogr. & Barker et al. 2007 \\
\hline 1399 & & $\begin{array}{l}\text { Lasjia hildebrandii } \\
\text { (Steenis) P.H.Weston \& } \\
\text { A.R.Mast }\end{array}$ & Austr. & phylogeogr. & Mast et al. 2008 \\
\hline 1400 & Putranjivaceae & Drypetes kikir Airy Shaw & Asian & $\begin{array}{l}\text { phylogeogr., } \\
\text { distr./fossils }\end{array}$ & $\begin{array}{l}\text { Davis et al. 2005, Levin } \\
\text { 2014, Xi et al. } 2012\end{array}$ \\
\hline 1401 & & $\begin{array}{l}\text { Drypetes longifolia } \\
\text { (Blume) Pax \& K.Hoffm. }\end{array}$ & Asian & $\begin{array}{l}\text { phylogeogr., } \\
\text { distr./fossils }\end{array}$ & $\begin{array}{l}\text { Davis et al. 2005, Levin } \\
\text { 2014, Xi et al. } 2012\end{array}$ \\
\hline 1402 & & $\begin{array}{l}\text { Drypetes microphylla } \\
\text { (Merr.) Pax \& K.Hoffm. }\end{array}$ & Asian & $\begin{array}{l}\text { phylogeogr., } \\
\text { distr./fossils }\end{array}$ & $\begin{array}{l}\text { Davis et al. 2005, Levin } \\
\text { 2014, Xi et al. } 2012\end{array}$ \\
\hline 1403 & & $\begin{array}{l}\text { Drypetes minahassae } \\
\text { (Boerl. \& Koord.) Pax \& } \\
\text { K.Hoffm. }\end{array}$ & Asian & $\begin{array}{l}\text { phylogeogr., } \\
\text { distr./fossils }\end{array}$ & $\begin{array}{l}\text { Davis et al. 2005, Levin } \\
2014 \text {, Xi et al. } 2012\end{array}$ \\
\hline 1404 & & Drypetes pendula Ridl. & Asian & $\begin{array}{l}\text { phylogeogr., } \\
\text { distr./fossils }\end{array}$ & $\begin{array}{l}\text { Davis et al. 2005, Levin } \\
\text { 2014, Xi et al. } 2012\end{array}$ \\
\hline 1405 & & $\begin{array}{l}\text { Drypetes polyneura Airy } \\
\text { Shaw }\end{array}$ & Asian & $\begin{array}{l}\text { phylogeogr., } \\
\text { distr./fossils }\end{array}$ & $\begin{array}{l}\text { Davis et al. 2005, Levin } \\
\text { 2014, Xi et al. } 2012\end{array}$ \\
\hline 1406 & & $\begin{array}{l}\text { Drypetes sibuyanensis } \\
\text { (Elmer) Pax \& K.Hoffm. }\end{array}$ & Asian & $\begin{array}{l}\text { phylogeogr., } \\
\text { distr./fossils }\end{array}$ & $\begin{array}{l}\text { Davis et al. 2005, Levin } \\
\text { 2014, Xi et al. } 2012\end{array}$ \\
\hline 1407 & & Drypetes sp.1 & Asian & $\begin{array}{l}\text { phylogeogr., } \\
\text { distr./fossils }\end{array}$ & $\begin{array}{l}\text { Davis et al. 2005, Levin } \\
\text { 2014, Xi et al. } 2012\end{array}$ \\
\hline 1408 & & Drypetes sp.2 & Asian & $\begin{array}{l}\text { phylogeogr., } \\
\text { distr./fossils }\end{array}$ & $\begin{array}{l}\text { Davis et al. 2005, Levin } \\
2014 \text {, Xi et al. } 2012\end{array}$ \\
\hline 1409 & Rhamnaceae & $\begin{array}{l}\text { Alphitonia excelsa (Fenzl) } \\
\text { Reissek ex Benth. }\end{array}$ & Austr. & phylogeogr. & Hauenschild et al. 2018 \\
\hline 1410 & & $\begin{array}{l}\text { Ziziphus angustifolia } \\
\text { (Miq.) Hatus. ex Steenis }\end{array}$ & Asian & phylogeogr. & Hauenschild et al. 2018 \\
\hline 1411 & & Ziziphus suluensis Merr. & Asian & phylogeogr. & Hauenschild et al. 2018 \\
\hline 1412 & & Zizyphus sp. & Asian & phylogeogr. & Hauenschild et al. 2018 \\
\hline 1413 & Rhizophoraceae & $\begin{array}{l}\text { Gynotroches axillaris } \\
\text { Blume }\end{array}$ & Asian & $\begin{array}{l}\text { dated phyl., } \\
\text { distr./fossils }\end{array}$ & $\begin{array}{l}\text { Graham 2006, Hou 1958, } \\
\text { Sun et al. 2016, Xu et al. } \\
2017\end{array}$ \\
\hline 1414 & & $\begin{array}{l}\text { Pellacalyx pustulatus } \\
\text { Merr. }\end{array}$ & Asian & $\begin{array}{l}\text { dated phyl., } \\
\text { distr./fossils }\end{array}$ & $\begin{array}{l}\text { Graham 2006, Hou 1958, } \\
\text { Sun et al. 2016, Xu et al. } \\
2017\end{array}$ \\
\hline 1415 & Rosaceae & $\begin{array}{l}\text { Prunus arborea (Blume) } \\
\text { Kalkman }\end{array}$ & Asian & phylogeogr. & Chin et al. 2014 \\
\hline 1416 & & $\begin{array}{l}\text { Prunus beccarii (Ridl.) } \\
\text { Kalkman }\end{array}$ & Asian & phylogeogr. & Chin et al. 2014 \\
\hline 1417 & & $\begin{array}{l}\text { Prunus fragrans (Elmer) } \\
\text { Kalkman }\end{array}$ & Asian & phylogeogr. & Chin et al. 2014 \\
\hline 1418 & & $\begin{array}{l}\text { Prunus grisea (Blume ex } \\
\text { Müll.Berol.) Kalkman }\end{array}$ & Asian & phylogeogr. & Chin et al. 2014 \\
\hline 1419 & & Prunus mirabilis Kalkman & Asian & phylogeogr. & Chin et al. 2014 \\
\hline 1420 & & $\begin{array}{l}\text { Prunus oocarpa (Stapf) } \\
\text { Kalkman }\end{array}$ & Asian & phylogeogr. & Chin et al. 2014 \\
\hline
\end{tabular}




\begin{tabular}{|c|c|c|c|c|c|}
\hline No & Family & Species & Origin & $\begin{array}{l}\text { Classification } \\
\text { method }\end{array}$ & References \\
\hline 1421 & & $\begin{array}{l}\text { Prunus rubiginosa (Elmer) } \\
\text { Kalkman }\end{array}$ & Asian & phylogeogr. & Chin et al. 2014 \\
\hline 1422 & & Prunus sp.1 & Asian & phylogeogr. & Chin et al. 2014 \\
\hline 1423 & & Prunus sp. 2 & Asian & phylogeogr. & Chin et al. 2014 \\
\hline 1424 & & Prunus sp.3 & Asian & phylogeogr. & Chin et al. 2014 \\
\hline 1425 & & Prunus sp.4 & Asian & phylogeogr. & Chin et al. 2014 \\
\hline 1426 & & Rosaceae sp. & Asian & phylogeogr. & $\begin{array}{l}\text { Campbell et al. 2007, } \\
\text { Chin et al. 2014, Guo et } \\
\text { al. } 2011\end{array}$ \\
\hline 1427 & Rubiaceae & Adina multifolia Havil. & Asian & phylogeogr. & $\begin{array}{l}\text { Manns \& Bremer 2010, } \\
\text { Manns et al. } 2012\end{array}$ \\
\hline 1428 & & Adina sp. & Asian & phylogeogr. & $\begin{array}{l}\text { Manns \& Bremer 2010, } \\
\text { Manns et al. } 2012\end{array}$ \\
\hline 1429 & & $\begin{array}{l}\text { Aidia corymbosa (Blume) } \\
\text { K.M.Wong }\end{array}$ & Asian & phylogeogr. & Kainulainen et al. 2017 \\
\hline 1430 & & $\begin{array}{l}\text { Aidia racemosa (Cav.) } \\
\text { Tirveng. }\end{array}$ & Asian & phylogeogr. & Kainulainen et al. 2017 \\
\hline 1431 & & $\begin{array}{l}\text { Canthium confertum } \\
\text { Korth. }\end{array}$ & Asian & $\begin{array}{l}\text { dated phyl., } \\
\text { distr./fossils }\end{array}$ & $\begin{array}{l}\text { Verstraete et al. 2017, } \\
\text { WCSP } 2017\end{array}$ \\
\hline 1432 & & Canthium sp.1 & Asian & $\begin{array}{l}\text { dated phyl., } \\
\text { distr./fossils }\end{array}$ & $\begin{array}{l}\text { Verstraete et al. 2017, } \\
\text { WCSP } 2017\end{array}$ \\
\hline 1433 & & Canthium sp.2 & Asian & $\begin{array}{l}\text { dated phyl., } \\
\text { distr./fossils }\end{array}$ & $\begin{array}{l}\text { Verstraete et al. 2017, } \\
\text { WCSP } 2017\end{array}$ \\
\hline 1434 & & $\begin{array}{l}\text { Diplospora tinagoensis } \\
\text { (Elmer) Ali \& Robbr. }\end{array}$ & Asian & phylogeogr. & Kainulainen et al. 2017 \\
\hline 1435 & & $\begin{array}{l}\text { Discospermum abnorme } \\
\text { (Korth.) Ali \& Robbr. }\end{array}$ & Asian & phylogeogr. & Kainulainen et al. 2017 \\
\hline 1436 & & Gardenia forsteniana Miq. & Asian & phylogeogr. & Kainulainen et al. 2017 \\
\hline 1437 & & $\begin{array}{l}\text { Gardenia jasminoides } \\
\text { J.Ellis }\end{array}$ & Asian & phylogeogr. & Kainulainen et al. 2017 \\
\hline 1438 & & Gardenia sp.1 & Asian & phylogeogr. & Kainulainen et al. 2017 \\
\hline 1439 & & Gardenia sp.2 & Asian & phylogeogr. & Kainulainen et al. 2017 \\
\hline 1440 & & Gardenia sp.3 & Asian & phylogeogr. & Kainulainen et al. 2017 \\
\hline 1441 & & $\begin{array}{l}\text { Gardenia tubifera Wall. ex } \\
\text { Roxb. }\end{array}$ & Asian & phylogeogr. & Kainulainen et al. 2017 \\
\hline 1442 & & Randia sp. & Asian & phylogeogr. & Kainulainen et al. 2017 \\
\hline 1443 & & Randia sp. & Asian & phylogeogr. & Kainulainen et al. 2017 \\
\hline 1444 & & $\begin{array}{l}\text { Hypobathrum frutescens } \\
\text { Blume }\end{array}$ & Asian & phylogeogr. & Kainulainen et al. 2017 \\
\hline 1445 & & $\begin{array}{l}\text { Lasianthus laevigatus } \\
\text { Blume }\end{array}$ & Asian & phylogeogr. & Smedmark et al. 2014 \\
\hline 1446 & & $\begin{array}{l}\text { Lasianthus latifolius } \\
\text { Blume ex Miq. }\end{array}$ & Asian & phylogeogr. & Smedmark et al. 2014 \\
\hline 1447 & & Lasianthus sp. & Asian & phylogeogr. & Smedmark et al. 2014 \\
\hline 1448 & & Lasianthus sp.1 & Asian & phylogeogr. & Smedmark et al. 2014 \\
\hline 1449 & & Lasianthus sp.2 & Asian & phylogeogr. & Smedmark et al. 2014 \\
\hline 1450 & & Nauclea sp.1 & Asian & phylogeogr. & $\begin{array}{l}\text { Manns \& Bremer 2010, } \\
\text { Manns et al. } 2012\end{array}$ \\
\hline
\end{tabular}




\begin{tabular}{|c|c|c|c|c|c|}
\hline No & Family & Species & Origin & $\begin{array}{l}\text { Classification } \\
\text { method }\end{array}$ & References \\
\hline 1451 & & Nauclea sp.2 & Asian & phylogeogr. & $\begin{array}{l}\text { Manns \& Bremer 2010, } \\
\text { Manns et al. } 2012\end{array}$ \\
\hline 1452 & & $\begin{array}{l}\text { Nauclea subdita (Korth.) } \\
\text { Steud. }\end{array}$ & Asian & phylogeogr. & $\begin{array}{l}\text { Manns \& Bremer 2010, } \\
\text { Manns et al. } 2012\end{array}$ \\
\hline 1453 & & $\begin{array}{l}\text { Neonauclea calycina } \\
\text { (Bartl. ex DC.) Merr. }\end{array}$ & Asian & phylogeogr. & $\begin{array}{l}\text { Manns \& Bremer 2010, } \\
\text { Manns et al. } 2012\end{array}$ \\
\hline 1454 & & $\begin{array}{l}\text { Neonauclea excelsa } \\
\text { (Blume) Merr. }\end{array}$ & Asian & phylogeogr. & $\begin{array}{l}\text { Manns \& Bremer 2010, } \\
\text { Manns et al. } 2012\end{array}$ \\
\hline 1455 & & $\begin{array}{l}\text { Neonauclea lanceolata } \\
\text { (Blume) Merr. }\end{array}$ & Asian & phylogeogr. & $\begin{array}{l}\text { Manns \& Bremer 2010, } \\
\text { Manns et al. } 2012\end{array}$ \\
\hline 1456 & & $\begin{array}{l}\text { Neonauclea media (Havil.) } \\
\text { Merr. }\end{array}$ & Asian & phylogeogr. & $\begin{array}{l}\text { Manns \& Bremer 2010, } \\
\text { Manns et al. } 2012\end{array}$ \\
\hline 1457 & & Neonauclea sp. & Asian & phylogeogr. & $\begin{array}{l}\text { Manns \& Bremer 2010, } \\
\text { Manns et al. } 2012\end{array}$ \\
\hline 1458 & & Neonauclea sp.1 & Asian & phylogeogr. & $\begin{array}{l}\text { Manns \& Bremer 2010, } \\
\text { Manns et al. } 2012\end{array}$ \\
\hline 1459 & & Neonauclea sp.2 & Asian & phylogeogr. & $\begin{array}{l}\text { Manns \& Bremer 2010, } \\
\text { Manns et al. } 2012\end{array}$ \\
\hline 1460 & & $\begin{array}{l}\text { Porterandia anisophylla } \\
\text { (Jack ex Roxb.) Ridl. }\end{array}$ & Asian & phylogeogr. & Kainulainen et al. 2017 \\
\hline 1461 & & $\begin{array}{l}\text { Porterandia celebica } \\
\text { M.S.Zahid }\end{array}$ & Asian & phylogeogr. & Kainulainen et al. 2017 \\
\hline 1462 & & Psychotria sp.1 & Asian & phylogeogr. & $\begin{array}{l}\text { Razafimandimbison et al. } \\
2017\end{array}$ \\
\hline 1463 & & Psychotria sp.2 & Asian & phylogeogr. & $\begin{array}{l}\text { Razafimandimbison et al. } \\
2017\end{array}$ \\
\hline 1464 & & Psychotria sp.nov.2 & Asian & phylogeogr. & $\begin{array}{l}\text { Razafimandimbison et al. } \\
2017\end{array}$ \\
\hline 1465 & & $\begin{array}{l}\text { Psydrax glabra (Blume) } \\
\text { Deb \& M.Gangop. }\end{array}$ & Asian & $\begin{array}{l}\text { dated phyl., } \\
\text { distr./fossils }\end{array}$ & $\begin{array}{l}\text { Verstraete et al. 2017, } \\
\text { WCSP } 2017\end{array}$ \\
\hline 1466 & & Psydrax dicoccos Gaertn. & Asian & $\begin{array}{l}\text { dated phyl., } \\
\text { distr./fossils }\end{array}$ & $\begin{array}{l}\text { Verstraete et al. 2017, } \\
\text { WCSP } 2017\end{array}$ \\
\hline 1467 & & Psydrax sp.1 & Asian & $\begin{array}{l}\text { dated phyl., } \\
\text { distr./fossils }\end{array}$ & $\begin{array}{l}\text { Verstraete et al. 2017, } \\
\text { WCSP } 2017\end{array}$ \\
\hline 1468 & & Psydrax sp.2 & Asian & $\begin{array}{l}\text { dated phyl., } \\
\text { distr./fossils }\end{array}$ & $\begin{array}{l}\text { Verstraete et al. 2017, } \\
\text { WCSP } 2017\end{array}$ \\
\hline 1469 & & $\begin{array}{l}\text { Rothmannia merrillii } \\
\text { (Elmer) J.T.Pereira \& } \\
\text { Ridsdale }\end{array}$ & Asian & phylogeogr. & Kainulainen et al. 2017 \\
\hline 1470 & & $\begin{array}{l}\text { Tarenna arborea (Elmer) } \\
\text { Elmer }\end{array}$ & Asian & phylogeogr. & Kainulainen et al. 2017 \\
\hline 1471 & & $\begin{array}{l}\text { Tarenna confusa (Blume) } \\
\text { Valeton }\end{array}$ & Asian & phylogeogr. & Kainulainen et al. 2017 \\
\hline 1472 & & Tarenna sp. & Asian & phylogeogr. & Kainulainen et al. 2017 \\
\hline 1473 & & $\begin{array}{l}\text { Timonius borneensis } \\
\text { Valeton }\end{array}$ & Austr. & phylogeogr. & $\begin{array}{l}\text { Manns \& Bremer 2010, } \\
\text { Manns et al. } 2012\end{array}$ \\
\hline 1474 & & $\begin{array}{l}\text { Timonius flavescens } \\
\text { (Jacq.) Baker }\end{array}$ & Austr. & phylogeogr. & $\begin{array}{l}\text { Manns \& Bremer 2010, } \\
\text { Manns et al. } 2012\end{array}$ \\
\hline
\end{tabular}




\begin{tabular}{|c|c|c|c|c|c|}
\hline No & Family & Species & Origin & $\begin{array}{l}\text { Classification } \\
\text { method }\end{array}$ & References \\
\hline 1475 & & $\begin{array}{l}\text { Timonius minahassae } \\
\text { Koord. }\end{array}$ & Austr. & phylogeogr. & $\begin{array}{l}\text { Manns \& Bremer 2010, } \\
\text { Manns et al. } 2012\end{array}$ \\
\hline 1476 & & Timonius sp. & Austr. & phylogeogr. & $\begin{array}{l}\text { Manns \& Bremer 2010, } \\
\text { Manns et al. } 2012\end{array}$ \\
\hline 1477 & & $\begin{array}{l}\text { Timonius teysmanii } \\
\text { Valeton }\end{array}$ & Austr. & phylogeogr. & $\begin{array}{l}\text { Manns \& Bremer 2010, } \\
\text { Manns et al. } 2012\end{array}$ \\
\hline 1478 & & $\begin{array}{l}\text { Urophyllum arboreum } \\
\text { (Reinw. ex Blume) Korth. }\end{array}$ & Asian & phylogeogr. & Smedmark et al. 2010 \\
\hline 1479 & & $\begin{array}{l}\text { Urophyllum } \\
\text { macrophyllum (Blume) } \\
\text { Korth. }\end{array}$ & Asian & phylogeogr. & Smedmark et al. 2010 \\
\hline 1480 & & Urophyllum sp. & Asian & phylogeogr. & Smedmark et al. 2010 \\
\hline 1481 & & $\begin{array}{l}\text { Wendlandia dasythyrsa } \\
\text { Miq. }\end{array}$ & Asian & $\begin{array}{l}\text { phylogeogr., } \\
\text { distr./fossils }\end{array}$ & $\begin{array}{l}\text { Kainulainen et al. 2013, } \\
\text { 2017, WCSP } 2017\end{array}$ \\
\hline 1482 & & Wendlandia glabrata DC. & Asian & $\begin{array}{l}\text { phylogeogr., } \\
\text { distr./fossils }\end{array}$ & $\begin{array}{l}\text { Kainulainen et al. 2013, } \\
\text { 2017, WCSP } 2017\end{array}$ \\
\hline 1483 & Rutaceae & $\begin{array}{l}\text { Acronychia pedunculata } \\
\text { (L.) Miq. }\end{array}$ & Austr. & phylogeogr. & $\begin{array}{l}\text { Appelhans et al. 2012, } \\
\text { Holzmeyer et al. } 2015\end{array}$ \\
\hline 1484 & & $\begin{array}{l}\text { Melicope clemensiae } \\
\text { T.G.Hartley }\end{array}$ & Austr. & phylogeogr. & $\begin{array}{l}\text { Appelhans et al. 2012, } \\
2014\end{array}$ \\
\hline 1485 & & $\begin{array}{l}\text { Melicope denhamii } \\
\text { (Seem.) T.G.Hartley }\end{array}$ & Austr. & phylogeogr. & $\begin{array}{l}\text { Appelhans et al. 2012, } \\
2014\end{array}$ \\
\hline 1486 & & $\begin{array}{l}\text { Melicope frutescens } \\
\text { (Blanco) Appelhans \& } \\
\text { J.Wen }\end{array}$ & Austr. & phylogeogr. & $\begin{array}{l}\text { Appelhans et al. 2012, } \\
2014\end{array}$ \\
\hline 1487 & & $\begin{array}{l}\text { Melicope glabella } \\
\text { T.G.Hartley }\end{array}$ & Austr. & phylogeogr. & $\begin{array}{l}\text { Appelhans et al. 2012, } \\
2014\end{array}$ \\
\hline 1488 & & $\begin{array}{l}\text { Melicope latifolia (DC.) } \\
\text { T.G. Hartley }\end{array}$ & Austr. & phylogeogr. & $\begin{array}{l}\text { Appelhans et al. 2012, } \\
2014\end{array}$ \\
\hline 1489 & & $\begin{array}{l}\text { Melicope maxii } \\
\text { T.G.Hartley }\end{array}$ & Austr. & phylogeogr. & $\begin{array}{l}\text { Appelhans et al. 2012, } \\
2014\end{array}$ \\
\hline 1490 & & $\begin{array}{l}\text { Melicope triphylla (Lam.) } \\
\text { Merr. }\end{array}$ & Austr. & phylogeogr. & $\begin{array}{l}\text { Appelhans et al. 2012, } \\
2014\end{array}$ \\
\hline 1491 & & $\begin{array}{l}\text { Tetradium celebicum } \\
\text { (Koord.) T.G.Hartley ined. }\end{array}$ & Asian & phylogeogr. & Appelhans et al. 2018 \\
\hline 1492 & & $\begin{array}{l}\text { Tetractomia tetrandra } \\
\text { (Roxb.) Merr. }\end{array}$ & Austr. & phylogeogr. & $\begin{array}{l}\text { Appelhans et al. 2012, } \\
2014\end{array}$ \\
\hline 1493 & Sabiaceae & $\begin{array}{l}\text { Meliosma lanceolata } \\
\text { Blume }\end{array}$ & Asian & $\begin{array}{l}\text { undated phyl., } \\
\text { distr./fossils }\end{array}$ & $\begin{array}{l}\text { van Beusekom 1971, } \\
\text { Zúñiga } 2015\end{array}$ \\
\hline 1494 & & $\begin{array}{l}\text { Meliosma pinnata (Roxb.) } \\
\text { Maxim. }\end{array}$ & Asian & $\begin{array}{l}\text { undated phyl., } \\
\text { distr./fossils }\end{array}$ & $\begin{array}{l}\text { van Beusekom 1971, } \\
\text { Zúñiga } 2015\end{array}$ \\
\hline 1495 & & $\begin{array}{l}\text { Meliosma rufopilosa } \\
\text { M.R.Hend. }\end{array}$ & Asian & $\begin{array}{l}\text { undated phyl., } \\
\text { distr./fossils }\end{array}$ & $\begin{array}{l}\text { van Beusekom 1971, } \\
\text { Zúñiga } 2015\end{array}$ \\
\hline 1496 & & Meliosma sp. & Asian & $\begin{array}{l}\text { undated phyl., } \\
\text { distr./fossils }\end{array}$ & $\begin{array}{l}\text { van Beusekom 1971, } \\
\text { Zúñiga } 2015\end{array}$ \\
\hline 1497 & & $\begin{array}{l}\text { Meliosma sumatrana } \\
\text { (Jack) Walp. }\end{array}$ & Asian & $\begin{array}{l}\text { undated phyl., } \\
\text { distr./fossils }\end{array}$ & $\begin{array}{l}\text { van Beusekom 1971, } \\
\text { Zúñiga } 2015\end{array}$ \\
\hline
\end{tabular}




\begin{tabular}{|c|c|c|c|c|c|}
\hline No & Family & Species & Origin & $\begin{array}{l}\text { Classification } \\
\text { method }\end{array}$ & References \\
\hline 1498 & Salicaceae & Ahernia glandulosa Merr. & Asian & $\begin{array}{l}\text { undated phyl., } \\
\text { distr./fossils }\end{array}$ & Alford 2005 \\
\hline 1499 & & $\begin{array}{l}\text { Casearia fuliginosa } \\
\text { (Blanco) Blanco }\end{array}$ & Austr. & phylogeogr. & Samarakoon 2015 \\
\hline 1500 & & Casearia hosei Merr. & Austr. & phylogeogr. & Samarakoon 2015 \\
\hline 1501 & & Casearia rugulosa Blume & Austr. & phylogeogr. & Samarakoon 2015 \\
\hline 1502 & & $\begin{array}{l}\text { Casearia tuberculata } \\
\text { Blume }\end{array}$ & Austr. & phylogeogr. & Samarakoon 2015 \\
\hline 1503 & & $\begin{array}{l}\text { Flacourtia kinabaluensis } \\
\text { Sleumer }\end{array}$ & Asian & $\begin{array}{l}\text { undated phyl., } \\
\text { distr./fossils }\end{array}$ & $\begin{array}{l}\text { Alford 2005, Sleumer } \\
1954\end{array}$ \\
\hline 1504 & & $\begin{array}{l}\text { Flacourtia rukam Zoll. \& } \\
\text { Moritzi }\end{array}$ & Asian & $\begin{array}{l}\text { undated phyl., } \\
\text { distr./fossils }\end{array}$ & $\begin{array}{l}\text { Alford 2005, Sleumer } \\
1954\end{array}$ \\
\hline 1505 & & Homalium sp. & Asian & $\begin{array}{l}\text { undated phyl., } \\
\text { distr./fossils }\end{array}$ & Alford 2005 \\
\hline 1506 & Santalaceae & Dendrotrophe sp. & Austr. & $\begin{array}{l}\text { dated phyl., } \\
\text { distr./fossils }\end{array}$ & $\begin{array}{l}\text { Su et al. 2015, Vidal- } \\
\text { Russell \& Nickrent } 2008\end{array}$ \\
\hline 1507 & & $\begin{array}{l}\text { Scleropyrum pentandrum } \\
\text { (Dennst.) Mabb. }\end{array}$ & Asian & $\begin{array}{l}\text { dated phyl., } \\
\text { distr./fossils }\end{array}$ & $\begin{array}{l}\text { Su et al. 2015, Vidal- } \\
\text { Russell \& Nickrent } 2008\end{array}$ \\
\hline 1508 & Sapindaceae & Acer laurinum Hassk. & Asian & phylogeogr. & $\begin{array}{l}\text { Buerki et al. 2011, Harris } \\
\text { et al. 2017b }\end{array}$ \\
\hline 1509 & & Arytera littoralis Blume & Austr. & phylogeogr. & Buerki et al. 2011 \\
\hline 1510 & & Dimocarpus longan Lour. & Asian & phylogeogr. & Buerki et al. 2011 \\
\hline 1511 & & Dimocarpus sp. & Asian & phylogeogr. & Buerki et al. 2011 \\
\hline 1512 & & $\begin{array}{l}\text { Gloeocarpus patentivalvis } \\
\text { (Radlk.) Radlk. }\end{array}$ & Austr. & phylogeogr. & Buerki et al. 2011 \\
\hline 1513 & & $\begin{array}{l}\text { Guioa diplopetala (Hassk.) } \\
\text { Radlk. }\end{array}$ & Austr. & phylogeogr. & Buerki et al. 2011 \\
\hline 1514 & & Guioa hirsuta Welzen & Austr. & phylogeogr. & Buerki et al. 2011 \\
\hline 1515 & & $\begin{array}{l}\text { Guioa pleuropteris } \\
\text { (Blume) Radlk. }\end{array}$ & Austr. & phylogeogr. & Buerki et al. 2011 \\
\hline 1516 & & $\begin{array}{l}\text { Guioa pterorhachis } \\
\text { Welzen }\end{array}$ & Austr. & phylogeogr. & Buerki et al. 2011 \\
\hline 1517 & & $\begin{array}{l}\text { Harpullia cupanioides } \\
\text { Roxb. }\end{array}$ & Austr. & phylogeogr. & Buerki et al. 2011 \\
\hline 1518 & & $\begin{array}{l}\text { Lepisanthes fruticosa } \\
\text { (Roxb.) Leenh. }\end{array}$ & Asian & phylogeogr. & Buerki et al. 2011 \\
\hline 1519 & & $\begin{array}{l}\text { Lepisanthes kinabaluensis } \\
\text { Leenh. }\end{array}$ & Asian & phylogeogr. & Buerki et al. 2011 \\
\hline 1520 & & $\begin{array}{l}\text { Lepisanthes schizolepis } \\
\text { Radlk. }\end{array}$ & Asian & phylogeogr. & Buerki et al. 2011 \\
\hline 1521 & & $\begin{array}{l}\text { Lepisanthes tetraphylla } \\
\text { Radlk. }\end{array}$ & Asian & phylogeogr. & Buerki et al. 2011 \\
\hline 1522 & & Litchi chinensis Sonn. & Asian & phylogeogr. & Buerki et al. 2011 \\
\hline 1523 & & $\begin{array}{l}\text { Mischocarpus } \\
\text { pentapetalus (Roxb.) } \\
\text { Radlk. }\end{array}$ & Austr. & phylogeogr. & Buerki et al. 2011 \\
\hline 1524 & & $\begin{array}{l}\text { Nephelium cuspidatum } \\
\text { Blume }\end{array}$ & Asian & phylogeogr. & Buerki et al. 2011 \\
\hline
\end{tabular}




\begin{tabular}{|c|c|c|c|c|c|}
\hline No & Family & Species & Origin & $\begin{array}{l}\text { Classification } \\
\text { method }\end{array}$ & References \\
\hline 1525 & & Nephelium lappaceum L. & Asian & phylogeogr. & Buerki et al. 2011 \\
\hline 1526 & & Nephelium mangayi Hiern & Asian & phylogeogr. & Buerki et al. 2011 \\
\hline 1527 & & $\begin{array}{l}\text { Nephelium ramboutan- } \\
\text { ake (Labill.) Leenh. }\end{array}$ & Asian & phylogeogr. & Buerki et al. 2011 \\
\hline 1528 & & Nephelium sp.1 & Asian & phylogeogr. & Buerki et al. 2011 \\
\hline 1529 & & Nephelium sp.2 & Asian & phylogeogr. & Buerki et al. 2011 \\
\hline 1530 & & Nephelium sp.3 & Asian & phylogeogr. & Buerki et al. 2011 \\
\hline 1531 & & $\begin{array}{l}\text { Pometia pinnata J.R.Forst. } \\
\text { \& G.Forst. }\end{array}$ & Asian & phylogeogr. & Buerki et al. 2011 \\
\hline 1532 & & $\begin{array}{l}\text { Xerospermum laevigatum } \\
\text { Radlk. }\end{array}$ & Asian & phylogeogr. & Buerki et al. 2011 \\
\hline 1533 & & $\begin{array}{l}\text { Xerospermum } \\
\text { noronhianum (Blume) } \\
\text { Blume }\end{array}$ & Asian & phylogeogr. & Buerki et al. 2011 \\
\hline 1534 & Sapotaceae & $\begin{array}{l}\text { Donella lanceolata } \\
\text { (Blume) Aubrév. }\end{array}$ & Asian & phylogeogr. & Bartish et al. 2011 \\
\hline 1535 & & Madhuca endertii H.J.Lam & Asian & phylogeogr. & Richardson et al. 2014 \\
\hline 1536 & & $\begin{array}{l}\text { Madhuca glabrescens } \\
\text { H.J.Lam }\end{array}$ & Asian & phylogeogr. & Richardson et al. 2014 \\
\hline 1537 & & $\begin{array}{l}\text { Madhuca kingiana (Brace } \\
\text { ex King \& Gamble) } \\
\text { H.J.Lam }\end{array}$ & Asian & phylogeogr. & Richardson et al. 2014 \\
\hline 1538 & & $\begin{array}{l}\text { Madhuca sericea (Miq.) } \\
\text { S.Moore }\end{array}$ & Asian & phylogeogr. & Richardson et al. 2014 \\
\hline 1539 & & Madhuca sp.1 & Asian & phylogeogr. & Richardson et al. 2014 \\
\hline 1540 & & Madhuca sp.2 & Asian & phylogeogr. & Richardson et al. 2014 \\
\hline 1541 & & $\begin{array}{l}\text { Palaquium foxworthyi } \\
\text { Merr. }\end{array}$ & Asian & phylogeogr. & Richardson et al. 2014 \\
\hline 1542 & & $\begin{array}{l}\text { Palaquium gutta (Hook.) } \\
\text { Baill. }\end{array}$ & Asian & phylogeogr. & Richardson et al. 2014 \\
\hline 1543 & & $\begin{array}{l}\text { Palaquium herveyi King \& } \\
\text { Gamble }\end{array}$ & Asian & phylogeogr. & Richardson et al. 2014 \\
\hline 1544 & & $\begin{array}{l}\text { Palaquium hexandrum } \\
\text { (Griff.) Baill. }\end{array}$ & Asian & phylogeogr. & Richardson et al. 2014 \\
\hline 1545 & & $\begin{array}{l}\text { Palaquium lanceolatum } \\
\text { Blanco }\end{array}$ & Asian & phylogeogr. & Richardson et al. 2014 \\
\hline 1546 & & $\begin{array}{l}\text { Palaquium luzoniense } \\
\text { (Fern.-Vill.) Vidal, }\end{array}$ & Asian & phylogeogr. & Richardson et al. 2014 \\
\hline 1547 & & $\begin{array}{l}\text { Palaquium merrillii } \\
\text { Dubard }\end{array}$ & Asian & phylogeogr. & Richardson et al. 2014 \\
\hline 1548 & & $\begin{array}{l}\text { Palaquium obovatum } \\
\text { (Griff.) Engl. }\end{array}$ & Asian & phylogeogr. & Richardson et al. 2014 \\
\hline 1549 & & $\begin{array}{l}\text { Palaquium philippense } \\
\text { (Perr.) C.B.Rob. }\end{array}$ & Asian & phylogeogr. & Richardson et al. 2014 \\
\hline 1550 & & $\begin{array}{l}\text { Palaquium quercifolium } \\
\text { (de Vriese) Burck }\end{array}$ & Asian & phylogeogr. & Richardson et al. 2014 \\
\hline 1551 & & $\begin{array}{l}\text { Palaquium rostratum } \\
\text { (Miq.) Burck }\end{array}$ & Asian & phylogeogr. & Richardson et al. 2014 \\
\hline
\end{tabular}




\begin{tabular}{|c|c|c|c|c|c|}
\hline No & Family & Species & Origin & $\begin{array}{l}\text { Classification } \\
\text { method }\end{array}$ & References \\
\hline 1552 & & Palaquium sp.1 & Asian & phylogeogr. & Richardson et al. 2014 \\
\hline 1553 & & Palaquium sp.2 & Asian & phylogeogr. & Richardson et al. 2014 \\
\hline 1554 & & Palaquium sp.3 & Asian & phylogeogr. & Richardson et al. 2014 \\
\hline 1555 & & $\begin{array}{l}\text { Payena acuminata } \\
\text { (Blume) Pierre }\end{array}$ & Asian & phylogeogr. & Richardson et al. 2014 \\
\hline 1556 & & Payena gigas A.Bruggen & Asian & phylogeogr. & Richardson et al. 2014 \\
\hline 1557 & & $\begin{array}{l}\text { Payena leerii (Teijsm. \& } \\
\text { Binn.) Kurz }\end{array}$ & Asian & phylogeogr. & Richardson et al. 2014 \\
\hline 1558 & & $\begin{array}{l}\text { Payena microphylla (de } \\
\text { Vriese) Burck }\end{array}$ & Asian & phylogeogr. & Richardson et al. 2014 \\
\hline 1559 & & Payena sp.1 & Asian & phylogeogr. & Richardson et al. 2014 \\
\hline 1560 & & Payena sp.2 & Asian & phylogeogr. & Richardson et al. 2014 \\
\hline 1561 & & $\begin{array}{l}\text { Planchonella chartacea } \\
\text { (F.Muell. ex Benth.) } \\
\text { H.J.Lam }\end{array}$ & Austr. & phylogeogr. & Swenson et al. 2014 \\
\hline 1562 & & $\begin{array}{l}\text { Planchonella duclitan } \\
\text { (Blanco) Bakh.f. }\end{array}$ & Austr. & phylogeogr. & Swenson et al. 2014 \\
\hline 1563 & & $\begin{array}{l}\text { Planchonella maingayi } \\
\text { (C.B.Clarke) P.Royen }\end{array}$ & Austr. & phylogeogr. & Swenson et al. 2014 \\
\hline 1564 & & $\begin{array}{l}\text { Planchonella malaccensis } \\
\text { (C.B.Clarke) Swenson) }\end{array}$ & Austr. & phylogeogr. & Swenson et al. 2014 \\
\hline 1565 & & Planchonella sp.1 & Austr. & phylogeogr. & Swenson et al. 2014 \\
\hline 1566 & & Planchonella sp.2 & Austr. & phylogeogr. & Swenson et al. 2014 \\
\hline 1567 & & Planchonella sp.3 & Austr. & phylogeogr. & Swenson et al. 2014 \\
\hline 1568 & & Planchonella sp.4 & Austr. & phylogeogr. & Swenson et al. 2014 \\
\hline 1569 & & $\begin{array}{l}\text { Pleioluma firma (Miq.) } \\
\text { Swenson }\end{array}$ & Austr. & phylogeogr. & Swenson et al. 2014 \\
\hline 1570 & & $\begin{array}{l}\text { Pleioluma moluccana } \\
\text { (Burck) Swenson }\end{array}$ & Austr. & phylogeogr. & Swenson et al. 2014 \\
\hline 1571 & & $\begin{array}{l}\text { Sarcosperma paniculatum } \\
\text { (King) Stapf \& King }\end{array}$ & Asian & $\begin{array}{l}\text { phylogeogr., } \\
\text { distr./fossils }\end{array}$ & $\begin{array}{l}\text { Richardson et al. 2014, } \\
\text { WCSP } 2017\end{array}$ \\
\hline 1572 & Schisandraceae & $\begin{array}{l}\text { Illicium kinabaluense } \\
\text { A.C.Sm. }\end{array}$ & Asian & phylogeogr. & Clayton et al. 2009 \\
\hline 1573 & Simaroubaceae & Ailanthus integrifolia Lam. & Asian & phylogeogr. & Clayton et al. 2009 \\
\hline 1574 & & $\begin{array}{l}\text { Eurycoma apiculata } \\
\text { A.W.Benn. }\end{array}$ & Asian & phylogeogr. & Clayton et al. 2009 \\
\hline 1575 & & Eurycoma longifolia Jack & Asian & phylogeogr. & Clayton et al. 2009 \\
\hline 1576 & & Eurycoma sp. & Asian & phylogeogr. & Clayton et al. 2009 \\
\hline 1577 & & Simaroubaceae sp. & Asian & phylogeogr. & Clayton et al. 2009 \\
\hline 1578 & Staphyleaceae & Turpinia ovalifolia Elmer & Asian & $\begin{array}{l}\text { undated phyl., } \\
\text { distr./fossils }\end{array}$ & Harris et al. 2017a \\
\hline 1579 & & Turpinia sp.1 & Asian & $\begin{array}{l}\text { undated phyl., } \\
\text { distr./fossils }\end{array}$ & Harris et al. 2017a \\
\hline 1580 & & Turpinia sp.2 & Asian & $\begin{array}{l}\text { undated phyl., } \\
\text { distr./fossils }\end{array}$ & Harris et al. 2017a \\
\hline 1581 & & Turpinia sp.3 & Asian & $\begin{array}{l}\text { undated phyl., } \\
\text { distr./fossils }\end{array}$ & Harris et al. 2017a \\
\hline
\end{tabular}




\begin{tabular}{|c|c|c|c|c|c|}
\hline No & Family & Species & Origin & $\begin{array}{l}\text { Classification } \\
\text { method }\end{array}$ & References \\
\hline 1582 & & $\begin{array}{l}\text { Turpinia sphaerocarpa } \\
\text { Hassk. }\end{array}$ & Asian & $\begin{array}{l}\text { undated phyl., } \\
\text { distr./fossils }\end{array}$ & Harris et al. $2017 a$ \\
\hline 1583 & Stemonuraceae & $\begin{array}{l}\text { Gomphandra mappioides } \\
\text { Valeton }\end{array}$ & Austr. & phylogeogr. & Beaulieu et al. 2013 \\
\hline 1584 & & $\begin{array}{l}\text { Medusanthera laxiflora } \\
\text { (Miers) R.A.Howard }\end{array}$ & Austr. & phylogeogr. & Beaulieu et al. 2013 \\
\hline 1585 & & $\begin{array}{l}\text { Stemonurus malaccensis } \\
\text { (Mast.) Sleumer }\end{array}$ & Austr. & phylogeogr. & Beaulieu et al. 2013 \\
\hline 1586 & & Stemonurus sp. & Austr. & phylogeogr. & Beaulieu et al. 2013 \\
\hline 1587 & & $\begin{array}{l}\text { Stemonurus umbellatus } \\
\text { Becc. }\end{array}$ & Austr. & phylogeogr. & Beaulieu et al. 2013 \\
\hline 1588 & Styracaceae & $\begin{array}{l}\text { Bruinsmia styracoides } \\
\text { Boerl. \& Koord. }\end{array}$ & Asian & phylogeogr. & Fritsch et al. 2001 \\
\hline 1589 & & $\begin{array}{l}\text { Styrax paralleloneurus } \\
\text { Perkins }\end{array}$ & Asian & phylogeogr. & Fritsch et al. 2001 \\
\hline 1590 & Symplocaceae & $\begin{array}{l}\text { Symplocos adenophylla } \\
\text { Wall. ex G.Don }\end{array}$ & Asian & phylogeogr. & Fritsch et al. 2015 \\
\hline 1591 & & $\begin{array}{l}\text { Symplocos anomala } \\
\text { Brand }\end{array}$ & Asian & phylogeogr. & Fritsch et al. 2015 \\
\hline 1592 & & Symplocos buxifolia Stapf & Asian & phylogeogr. & Fritsch et al. 2015 \\
\hline 1593 & & $\begin{array}{l}\text { Symplocos cf. } \\
\text { cochinchinensis (Lour.) } \\
\text { S.Moore }\end{array}$ & Asian & phylogeogr. & Fritsch et al. 2015 \\
\hline 1594 & & $\begin{array}{l}\text { Symplocos costata Choisy } \\
\text { ex Zoll. }\end{array}$ & Asian & phylogeogr. & Fritsch et al. 2015 \\
\hline 1595 & & Symplocos deflexa Stapf & Asian & phylogeogr. & Fritsch et al. 2015 \\
\hline 1596 & & $\begin{array}{l}\text { Symplocos fasciculata } \\
\text { Zoll. }\end{array}$ & Asian & phylogeogr. & Fritsch et al. 2015 \\
\hline 1597 & & $\begin{array}{l}\text { Symplocos lancifolia } \\
\text { Siebold \& Zucc. }\end{array}$ & Asian & phylogeogr. & Fritsch et al. 2015 \\
\hline 1598 & & $\begin{array}{l}\text { Symplocos odoratissima } \\
\text { (Blume) Choisy }\end{array}$ & Asian & phylogeogr. & Fritsch et al. 2015 \\
\hline 1599 & & $\begin{array}{l}\text { Symplocos ophirensis } \\
\text { Clarke }\end{array}$ & Asian & phylogeogr. & Fritsch et al. 2015 \\
\hline 1600 & & Symplocos pendula Wight & Asian & phylogeogr. & Fritsch et al. 2015 \\
\hline 1601 & & Symplocos sp.1 & Asian & phylogeogr. & Fritsch et al. 2015 \\
\hline 1602 & & Symplocos sp.2 & Asian & phylogeogr. & Fritsch et al. 2015 \\
\hline 1603 & & Symplocos sp.3 & Asian & phylogeogr. & Fritsch et al. 2015 \\
\hline 1604 & & Symplocos sp.4 & Asian & phylogeogr. & Fritsch et al. 2015 \\
\hline 1605 & & Symplocos vidalii Rolfe & Asian & phylogeogr. & Fritsch et al. 2015 \\
\hline 1606 & & $\begin{array}{l}\text { Symplocos whitfordii } \\
\text { Brand }\end{array}$ & Asian & phylogeogr. & Fritsch et al. 2015 \\
\hline 1607 & Tetramelaceae & $\begin{array}{l}\text { Octomeles sumatrana } \\
\text { Miq. }\end{array}$ & Asian & $\begin{array}{l}\text { dated phyl., } \\
\text { distr./fossils }\end{array}$ & $\begin{array}{l}\text { Farjon 2010, Leslie et al. } \\
\text { 2012, Liu et al. } 2011\end{array}$ \\
\hline 1608 & Theaceae & Camellia sp. & Asian & phylogeogr. & $\begin{array}{l}\text { Li et al. 2013, Zhang et al. } \\
2014\end{array}$ \\
\hline 1609 & & $\begin{array}{l}\text { Polyspora amboinensis } \\
\text { (Miq.) Orel et al. }\end{array}$ & Asian & phylogeogr. & $\begin{array}{l}\text { Li et al. 2013, Zhang et al. } \\
2014\end{array}$ \\
\hline
\end{tabular}




\begin{tabular}{|c|c|c|c|c|c|}
\hline No & Family & Species & Origin & $\begin{array}{l}\text { Classification } \\
\text { method }\end{array}$ & References \\
\hline 1610 & & $\begin{array}{l}\text { Polyspora excelsa (Blume) } \\
\text { Orel et al. }\end{array}$ & Asian & phylogeogr. & $\begin{array}{l}\text { Li et al. 2013, Zhang et al. } \\
2014\end{array}$ \\
\hline 1611 & & $\begin{array}{l}\text { Polyspora grandiflora } \\
\text { (Merr.) Orel et al. }\end{array}$ & Asian & phylogeogr. & $\begin{array}{l}\text { Li et al. 2013, Zhang et al. } \\
2014\end{array}$ \\
\hline 1612 & & $\begin{array}{l}\text { Polyspora havilandii } \\
\text { (Burkill) Orel et al. }\end{array}$ & Asian & phylogeogr. & $\begin{array}{l}\text { Li et al. 2013, Zhang et al. } \\
2014\end{array}$ \\
\hline 1613 & & $\begin{array}{l}\text { Polyspora integerrima } \\
\text { (Miq.) Orel et al. }\end{array}$ & Asian & phylogeogr. & $\begin{array}{l}\text { Li et al. 2013, Zhang et al. } \\
2014\end{array}$ \\
\hline 1614 & & $\begin{array}{l}\text { Polyspora luzonica (S. } \\
\text { Vidal) Orel et al. }\end{array}$ & Asian & phylogeogr. & $\begin{array}{l}\text { Li et al. 2013, Zhang et al. } \\
2014\end{array}$ \\
\hline 1615 & & Polyspora sp.1 & Asian & phylogeogr. & $\begin{array}{l}\text { Li et al. 2013, Zhang et al. } \\
2014\end{array}$ \\
\hline 1616 & & Polyspora sp.2 & Asian & phylogeogr. & $\begin{array}{l}\text { Li et al. 2013, Zhang et al. } \\
2014\end{array}$ \\
\hline 1617 & & Polyspora sp.3 & Asian & phylogeogr. & $\begin{array}{l}\text { Li et al. 2013, Zhang et al. } \\
2014\end{array}$ \\
\hline 1618 & & Polyspora sp.4 & Asian & phylogeogr. & $\begin{array}{l}\text { Li et al. 2013, Zhang et al. } \\
2014\end{array}$ \\
\hline 1619 & & Polyspora sp.5 & Asian & phylogeogr. & $\begin{array}{l}\text { Li et al. 2013, Zhang et al. } \\
2014\end{array}$ \\
\hline 1620 & & Polyspora sp.6 & Asian & phylogeogr. & $\begin{array}{l}\text { Li et al. 2013, Zhang et al. } \\
2014\end{array}$ \\
\hline 1621 & & Pyrenaria serrata Blume & Asian & phylogeogr. & $\begin{array}{l}\text { Li et al. 2013, Zhang et al. } \\
2014\end{array}$ \\
\hline 1622 & & $\begin{array}{l}\text { Schima brevifolia (Hook.f.) } \\
\text { Baill. ex Stapf }\end{array}$ & Asian & phylogeogr. & Li et al. 2013 \\
\hline 1623 & & Schima sp. & Asian & phylogeogr. & Li et al. 2013 \\
\hline 1624 & & $\begin{array}{l}\text { Schima wallichii (DC.) } \\
\text { Korth. }\end{array}$ & Asian & phylogeogr. & Li et al. 2013 \\
\hline 1625 & & Theaceae sp.1 & Asian & phylogeogr. & $\begin{array}{l}\text { Li et al. 2013, Zhang et al. } \\
2014\end{array}$ \\
\hline 1626 & & Theaceae sp.2 & Asian & phylogeogr. & $\begin{array}{l}\text { Li et al. 2013, Zhang et al. } \\
2014\end{array}$ \\
\hline 1627 & Thymelaeaceae & $\begin{array}{l}\text { Aquilaria malaccensis } \\
\text { Lam. }\end{array}$ & Asian & dated phyl. & $\begin{array}{l}\text { Eurlings \& Gravendeel } \\
\text { 2005, Motsi } 2009\end{array}$ \\
\hline 1628 & & Aquilaria sp. & Asian & dated phyl. & $\begin{array}{l}\text { Eurlings \& Gravendeel } \\
\text { 2005, Motsi } 2009\end{array}$ \\
\hline 1629 & & Thymelaeaceae sp. & Asian & dated phyl. & $\begin{array}{l}\text { Eurlings \& Gravendeel } \\
\text { 2005, Herber 2003, Motsi } \\
2009\end{array}$ \\
\hline 1630 & & $\begin{array}{l}\text { Gonystylus acuminatus } \\
\text { Airy Shaw }\end{array}$ & Asian & $\begin{array}{l}\text { dated phyl., } \\
\text { distr./fossils }\end{array}$ & Herber 2003, Motsi 2009 \\
\hline 1631 & & $\begin{array}{l}\text { Gonystylus } \\
\text { consanguineus Airy Shaw }\end{array}$ & Asian & $\begin{array}{l}\text { dated phyl., } \\
\text { distr./fossils }\end{array}$ & Herber 2003, Motsi 2009 \\
\hline 1632 & & Gonystylus forbesii Gilg & Asian & $\begin{array}{l}\text { dated phyl., } \\
\text { distr./fossils }\end{array}$ & Herber 2003, Motsi 2009 \\
\hline 1633 & & $\begin{array}{l}\text { Gonystylus macrophyllus } \\
\text { (Miq.) Airy Shaw }\end{array}$ & Asian & $\begin{array}{l}\text { dated phyl., } \\
\text { distr./fossils }\end{array}$ & Herber 2003, Motsi 2009 \\
\hline
\end{tabular}




\begin{tabular}{|c|c|c|c|c|c|}
\hline No & Family & Species & Origin & $\begin{array}{l}\text { Classification } \\
\text { method }\end{array}$ & References \\
\hline 1634 & & Gonostylus sp. & Asian & $\begin{array}{l}\text { dated phyl., } \\
\text { distr./fossils }\end{array}$ & Herber 2003, Motsi 2009 \\
\hline 1635 & & $\begin{array}{l}\text { Wikstroemia polyantha } \\
\text { Merr. }\end{array}$ & Asian & $\begin{array}{l}\text { dated phyl., } \\
\text { distr./fossils }\end{array}$ & Herber 2003, Motsi 2009 \\
\hline 1636 & Trigoniaceae & $\begin{array}{l}\text { Trigoniastrum } \\
\text { hypoleucum Miq. }\end{array}$ & Asian & $\begin{array}{l}\text { dated phyl., } \\
\text { distr./fossils }\end{array}$ & $\begin{array}{l}\text { Bittrich 2014, Xi et al. } \\
2012\end{array}$ \\
\hline 1637 & Trimeniaceae & Trimenia papuana Ridl. & Austr. & distr./fossils & Philipson 1993 \\
\hline 1638 & Urticaceae & $\begin{array}{l}\text { Debregeasia longifolia } \\
\text { (Burm.f.) Wedd. }\end{array}$ & Asian & $\begin{array}{l}\text { undated phyl., } \\
\text { distr./fossils }\end{array}$ & Wu et al. 2013 \\
\hline 1639 & & $\begin{array}{l}\text { Dendrocnide luzonensis } \\
\text { (Wedd.) Chew }\end{array}$ & Asian & $\begin{array}{l}\text { undated phyl., } \\
\text { distr./fossils }\end{array}$ & Wu et al. 2013 \\
\hline 1640 & & $\begin{array}{l}\text { Dendrocnide luzonensis } \\
\text { (Wedd.) Chew }\end{array}$ & Asian & $\begin{array}{l}\text { undated phyl., } \\
\text { distr./fossils }\end{array}$ & Wu et al. 2013 \\
\hline 1641 & & $\begin{array}{l}\text { Dendrocnide stimulans } \\
\text { (L.f.) Chew }\end{array}$ & Asian & $\begin{array}{l}\text { undated phyl., } \\
\text { distr./fossils }\end{array}$ & Wu et al. 2013 \\
\hline 1642 & & $\begin{array}{l}\text { Leucosyke capitellana } \\
\text { (Poir.) Wedd. }\end{array}$ & Asian & $\begin{array}{l}\text { undated phyl., } \\
\text { distr./fossils }\end{array}$ & Wu et al. 2013 \\
\hline 1643 & & $\begin{array}{l}\text { Oreocnide rubescens } \\
\text { (Blume) Miq. }\end{array}$ & Asian & $\begin{array}{l}\text { undated phyl., } \\
\text { distr./fossils }\end{array}$ & Wu et al. 2013 \\
\hline 1644 & & $\begin{array}{l}\text { Pipturus arborescens } \\
\text { (Link) C.B. Rob. }\end{array}$ & Asian & $\begin{array}{l}\text { undated phyl., } \\
\text { distr./fossils }\end{array}$ & Wu et al. 2013 \\
\hline 1645 & Vitaceae & Leea sp. & Asian & phylogeogr. & Molina et al. 2013 \\
\hline 1646 & Winteraceae & $\begin{array}{l}\text { Tasmannia piperita } \\
\text { (Hook.f.) Miers }\end{array}$ & Austr. & phylogeogr. & Thomas et al. 2014 \\
\hline
\end{tabular}

